Tatiane Furlaneto de Souza

\title{
DRENAGEM URBANA SOB CENÁRIOS DE LONGO PRAZO VISANDO INCENTIVOS AMBIENTAIS
}

\author{
Dissertação apresentada à Escola de \\ Engenharia de São Carlos da Universidade \\ de São Paulo, como parte dos requisitos para \\ obtenção do título de Mestre em Engenharia \\ (Hidráulica e Saneamento).
}

ORIENTADOR: Prof. Dr. Eduardo Mario Mendiondo

São Carlos 
AUTORIZO A REPRODUÇÃO E DIVULGAÇÃO TOTAL OU PARCIAL DESTE TRABALHO, POR QUALQUER MEIO CONVENCIONAL OU ELETRÔNICO, PARA FINS DE ESTUDO E PESQUISA, DESDE QUE CITADA A FONTE.

Ficha catalográfica preparada pela Seção de Tratamento da Informação do Serviço de Biblioteca - EESC/USP

S729d

Souza, Tatiane Furlaneto de

Drenagem urbana sob cenários de longo prazo visando incentivos ambientais / Tatiane Furlaneto de Souza; orientador Eduardo Mario Mendiondo. -- São Carlos, 2008.

Dissertação (Mestrado-Programa de Pós-Graduação e Área de Concentração em Hidráulica e Saneamento) -- Escola de Engenharia de São Carlos da Universidade de São Paulo, 2008 .

1. Hidrologia hidráulica. 2. Cenários de longo prazo. 3. Drenagem urbana. 4. Incentivos ambientais. I. Titulo. 
FOLHA DE JULGAMENTO

Candidata: Engenheira TATIANE FURLANETO DE SOUZA

Dissertação defendida e julgada em 04/07/2008 perante a Comissão Julgadora:

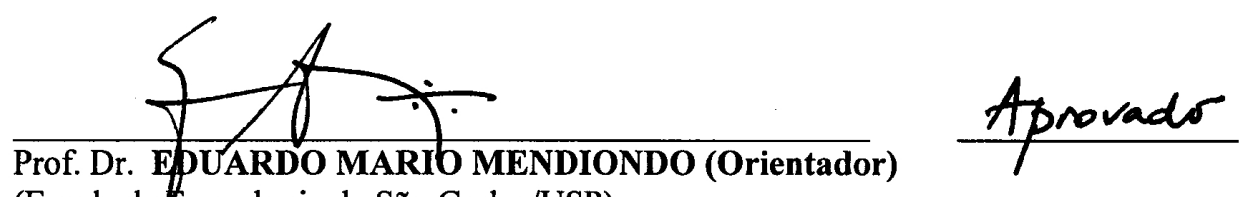
(Escola de Engenharia de São Carlos/USP)
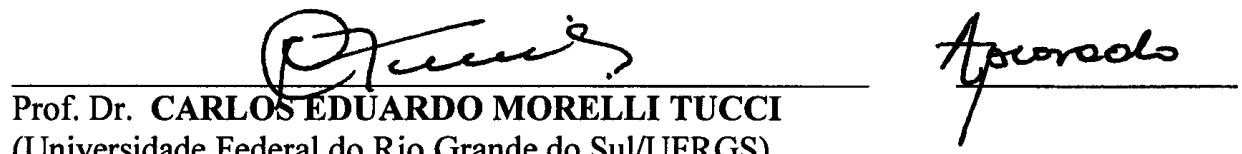

(Universidade Federal do Rio Grande do Sul/UFRGS)
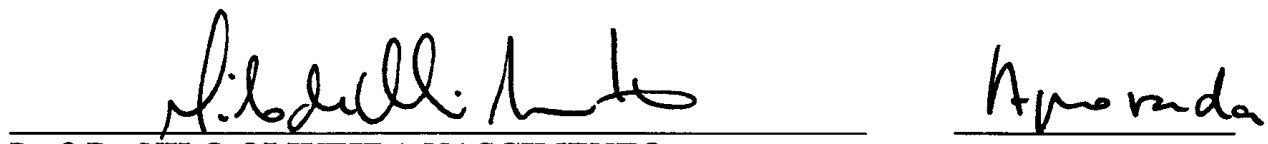

Prof. Dr. NILO OLIVEIRA NASCIMENTO

(Universidade Federal de Minas Gerais/UFMG)
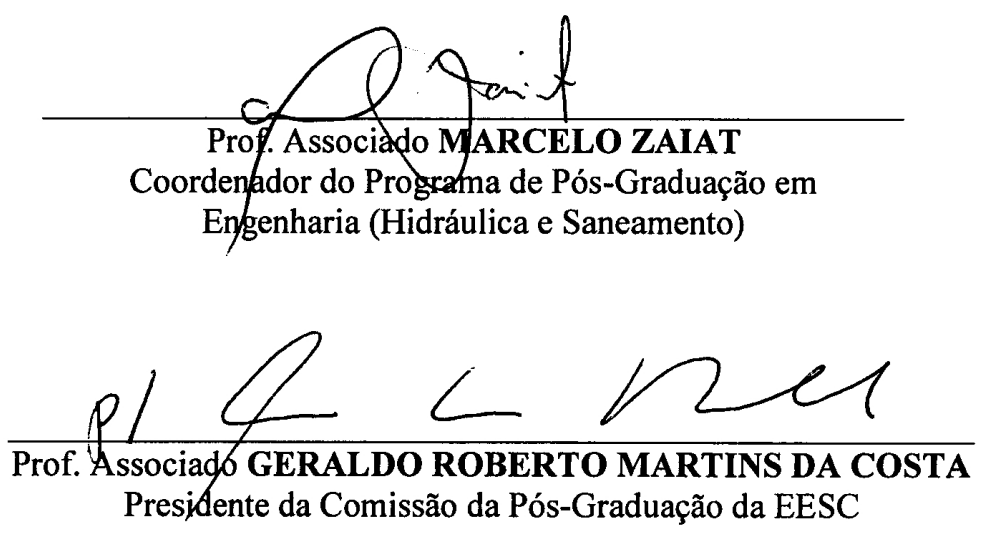
À minha mãe. 


\section{AGRADECIMENTOS}

Agradeço ao Professor Mario (Eduardo Mario Mendiondo), pela orientação, incentivo e, sobretudo pela confiança depositada nesse trabalho.

Agradeço aos professores Rodrigo de Melo Porto e Luisa Fernanda Ribeiro Reis pela leitura apurada do texto, bem como pelos questionamentos e pelas sugestões dadas.

Agradeço aos pesquisadores do NIBH (Núcleo Integrado de Bacias Hidrográficas): Alfredo A. Ohnuma Júnior, Anaí F. Vasconcelos, Cristiane A. G. Ribeiro, Diogo M. F. Almeida, Fernando Simão e Silva, Melissa C. P. Graciosa, Paulino de Almeida Neto, Pedro F. Caballero Campos, Ricardo C. Galavoti, e, de maneira especial à Micheli F. Gonçalves e a Valter C. G. R. Lima pelo intenso auxílio concedido durante a fase final da pesquisa.

Agradeço aos meus grandes amigos: Flavia Bottino e Ignazio Giuntoli pelas conversas, pelas brincadeiras, pelas risadas, pelos conselhos e, por todo apoio concedido para conclusão deste trabalho. Especialmente à Flavita por ceder seu 'ombro amigo' nos momentos mais difíceis e ao Ig por me estender a mão amiga e também sua casa quando mais precisei, me "agüentando" diariamente durante dois meses. E, sobretudo, por transformar esse período de grande dificuldade em momentos divertidos em que pude conhecer "La Piovra" e aprender umas receitinhas maravilhosas de "Terra Nostra".

Agradeço à Juliana P. M. de Andrade e à Daniela B. B. Trivella por me acolherem carinhosamente em sua casa e por tornarem divertida minha estada em São Carlos. De maneira especial agradeço à Jujuba ainda pelas inúmeras discussões e conselhos a respeito da minha pesquisa.

Agradeço aos técnicos José Roberto Maramarque (Betão) e Waldomiro Antônio Filho (Miro) pelo profissionalismo e dedicação. De forma mais especial, ao Betão, por todo seu conhecimento prático compartilhado durante muitas conversas. 
Agradeço a todos os funcionários do Departamento de Hidráulica e Saneamento (SHS), principalmente à Rose, Sá e Pavi.

Agradeço ao SAAE (Serviço Autônomo de Água e Esgoto) de São Carlos, em especial ao diretor geral Eduardo Cotrim, pelo fornecimento e permissão de utilização dos dados de monitoramento hidrométrico.

Agradeço ao $\mathrm{CNPq}$ pelo auxílio à pesquisa por intermédio da bolsa de estudos.

Agradeço de forma muito especial àqueles que me incentivaram a ingressar no mestrado em hidráulica e saneamento do PPG-SHS: professor Masato Kobiyama, Mariana Bin e Luana Ronconi.

Agradeço à Renata Bovo Peres pela atenciosa acolhida em São Carlos durante o processo de seleção do mestrado.

Agradeço as amigas Ana Lara Lessa e Carla Gonçalves pelo apoio, amizade e carinho principalmente durante o primeiro ano do mestrado.

Agradeço aos amigos: Carolina Decker, Carlos Daniel Mendes, Deise Paludo e Heloise Schatzmann que, embora distantes, sempre estiveram muito presentes durante mais essa etapa.

Agradeço a todos meus familiares: mãe, pai, irmãos, cunhada, sobrinho, vó, tios, tias, primos e prima. Família da qual tenho o maior orgulho de pertencer.

Agradeço de maneira muito especial à Ricardo Figueira Bidone, pelo apoio, carinho, orientação, amizade, cumplicidade, e sobretudo por estar sempre presente, apesar da distância.

Por fim, agradeço à Deus por todo conhecimento adquirido e compartilhado, por ter possibilitado o encontro com muitas pessoas algumas das quais ficarão guardadas na minha memória e no meu coração e, além disso, por me dar muita força, sempre. 
“O Futuro é múltiplo e incerto...não está escrito em parte alguma, está por fazer"

(Michel Godet)

“A melhor forma de apostar no futuro é fazê-lo brotar no presente" (Juscelino Kubitschek de Oliveira) 


\section{RESUMO}

SOUZA, T.F. (2008). Drenagem urbana sob cenários de longo prazo visando incentivos ambientais. Dissertação de Mestrado. Escola de Engenharia de São Carlos, Universidade de São Paulo.

A presente pesquisa trata do estudo de cenários regionais de drenagem urbana das principais sub-bacias pertencentes à área urbana de São Carlos/SP e da aplicação de incentivos ambientais em escala de lote. As projeções temporais realizadas dizem respeito às mudanças do uso e ocupação do solo para os anos de 2025, 2050, 2075 e 2100. Os cenários de uso e ocupação do solo têm como base os estudos referentes ao Millennium Ecosystem Assessment (Global Orchestration, Order from Strength, Adapting Mosaic e TechnoGarden) e sua adequação na escala local, para macrodrenagem urbana, proposta por Mendiondo (2005). Os eventos pluviométricos utilizados nas simulações dos cenários, por sua vez, foram selecionados em função das condições de umidade antecedente. Para os cenários propostos, foram avaliadas variações dos regimes hidrológico e hidráulico através de curvas de permanência em alguns pontos ao longo da parte de montante da sub-bacia do Monjolinho. Ainda, em escala de lote, é proposta uma metodologia de incentivos ambientais com base no armazenamento potencial de água no lote e na vazão máxima instantânea, para cada cenário estudado. A metodologia proposta de incentivo ambiental revela-se de simples aplicação por parte de órgãos públicos e de rápida obtenção dos resultados. Embora os cenários propostos sejam fictícios, os custos estimados $\left(\mathrm{R} \$ / \mathrm{m}^{2}\right)$ são aplicáveis para condições atuais.

Palavras-chave: cenários de longo prazo, drenagem urbana, incentivos ambientais. 


\begin{abstract}
SOUZA, T.F. (2008).Urban drainage in long term scenarios subsidizing environmental incentives. M.Sc. Dissertation. School of Engineering at San Carlos, University of Sao Paulo, San Carlos, Brazil.
\end{abstract}

This research discussed the study of regional scenarios of urban drainage of the main sub-basins belonging to the urban area of San Carlos / SP and the application of environmental incentives in lot scale. The projections of time made are related to changes of use and occupation of land for the years of 2025, 2050, 2075 and 2100. The scenarios of use and occupation of land are based on the studies concerning the Millennium Ecosystem Assessment (Global Orchestration, Order from Strength, Adapting Mosaic and TechnoGarden) and its appropriateness in the local scale, to urban macrodrainage, proposed by Mendiondo (2005). The rainfall events used in the simulations of scenarios were selected for the conditions of background humidity. For the proposed scenarios have been evaluated changes in the hydrological and hydraulic systems through remain curves in some points along the top part of sub-basin of Monjolinho. Still, in scale of lot, is proposed a methodology for environmental incentives based on the potential for water storage in the lot and the maximum instantaneous flow for each scenario studied. The proposed methodology of environmental incentive appears to be the simple application by public agencies and quickly get the results. Although the proposed scenarios are fictitious, the estimated costs $\left(\mathrm{R} \$ / \mathrm{m}^{2}\right)$ are applicable to current conditions.

Palavras-chave: long term scenarios, urban drainage, environmental incentives. 


\section{SUMÁRIO}

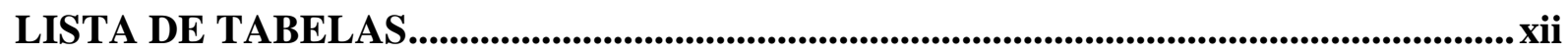

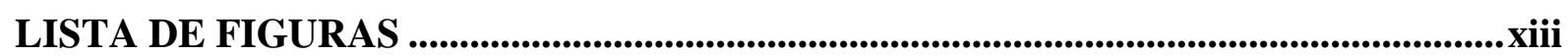

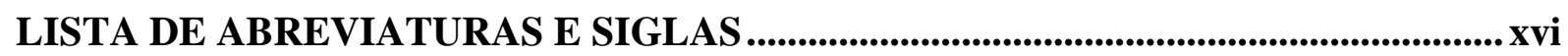

LISTA DE SÍMBOLOS .......................................................................................................xviii

1. INTRODUÇÃO E JUSTIFICATIVA ........................................................................ 1

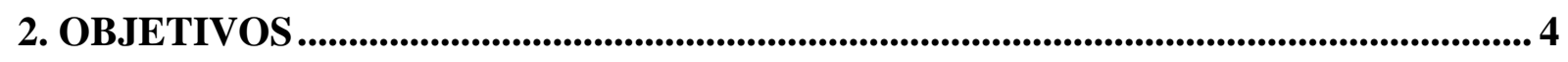

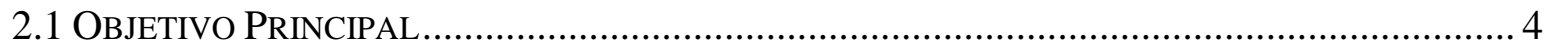

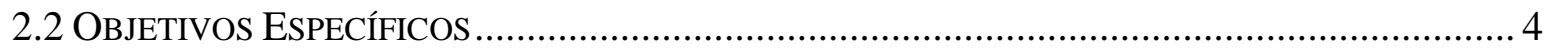

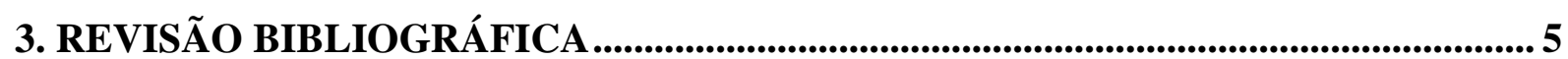

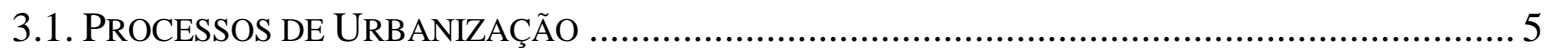

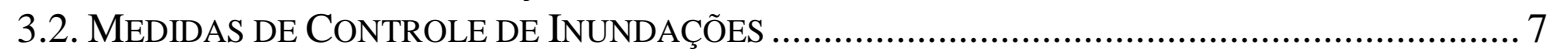

3.3. CENÁRIOS COMO FERRAMENTA DE PLANEJAMENTO ...................................................... 9

3.3.1 Histórico e metodologias de construção de cenários ............................................. 10

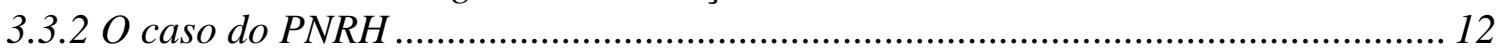

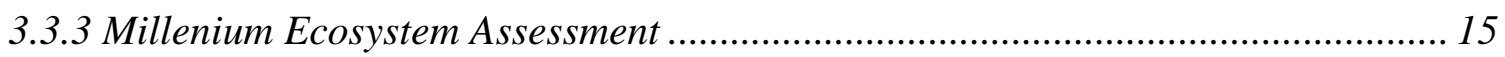

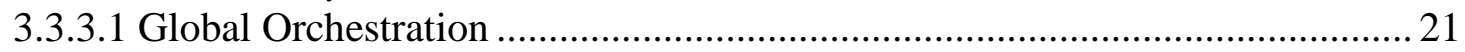

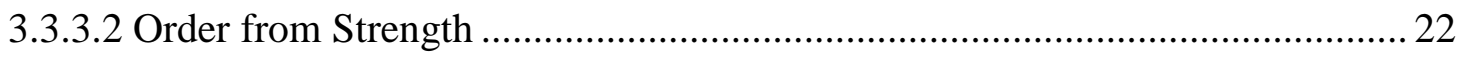

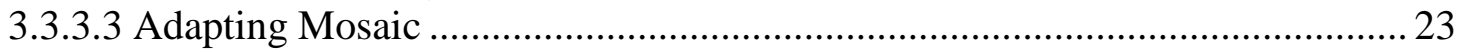

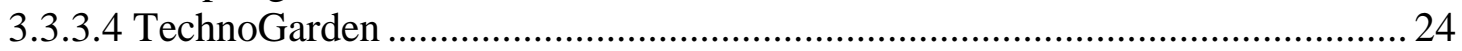

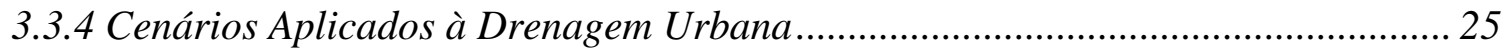

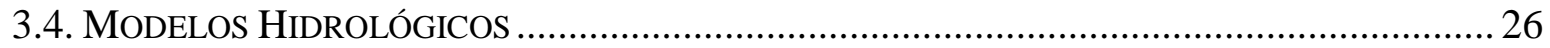

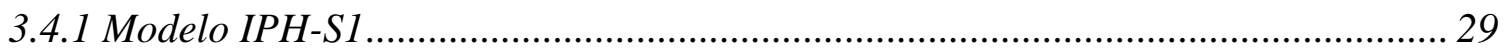

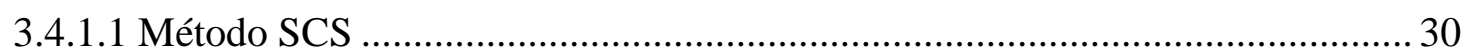

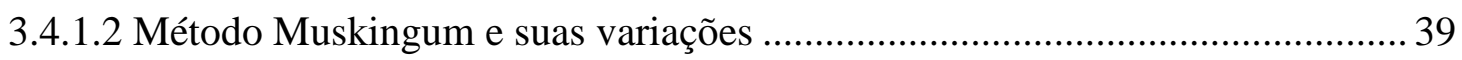

3.4.1.3 Curvas de Permanência na interpretação cenários ........................................ 45

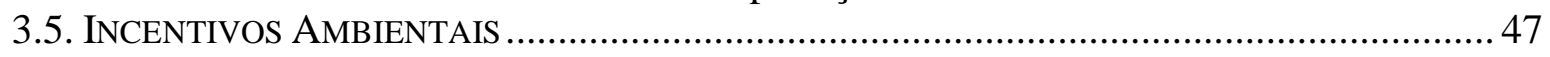

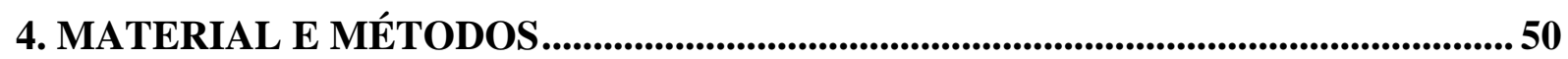

4.1 NARRATIVA dos CENÁRIOS REGIONAIS DE DRENAGEM URBANA ...................................50

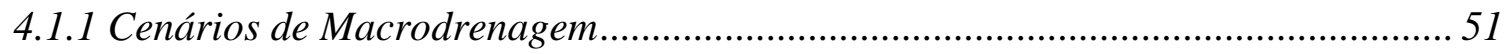

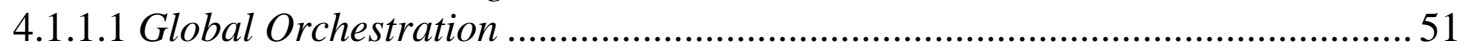

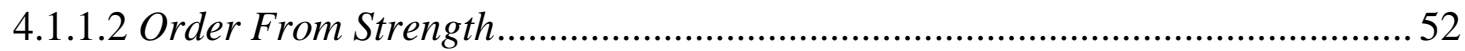

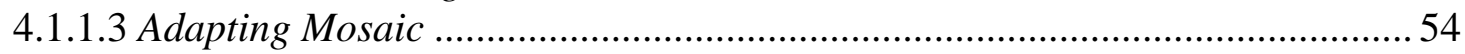

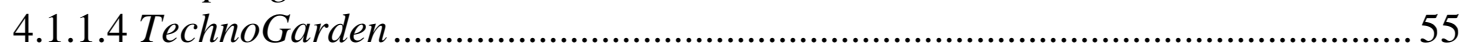

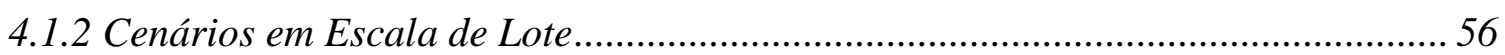

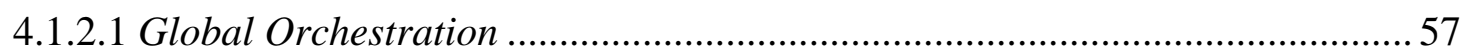

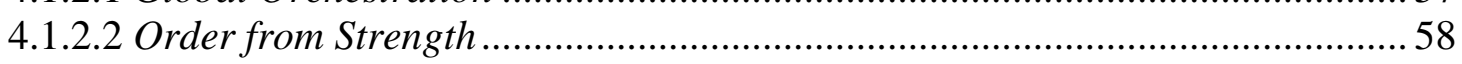

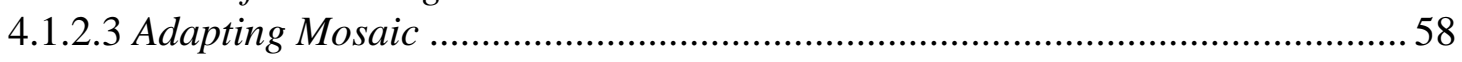

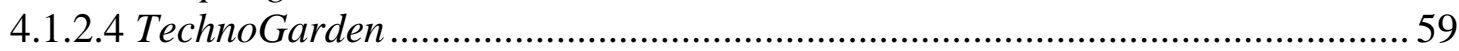

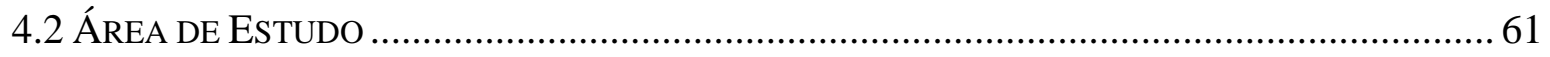

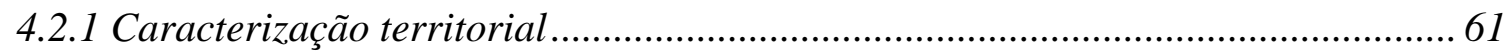

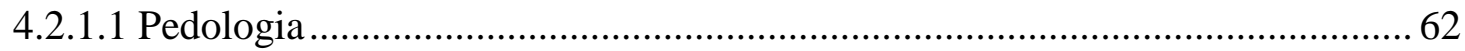

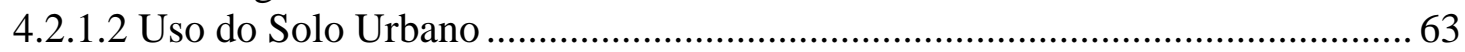

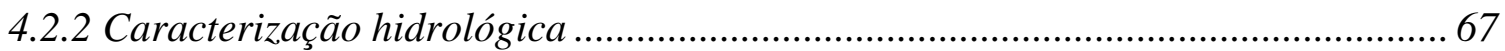

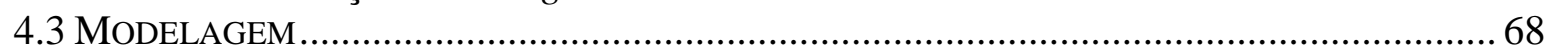




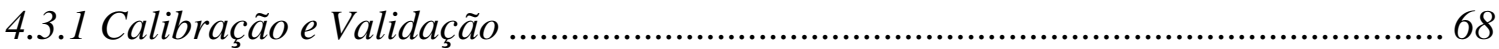

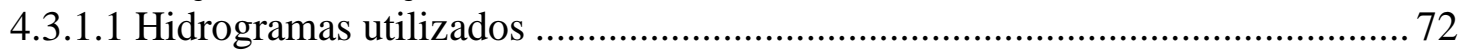

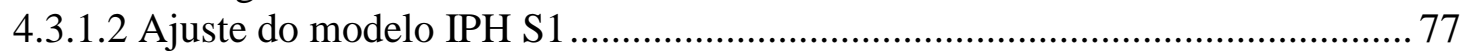

4.3.2 Caracterização e seleção dos eventos para simulação............................................ 82

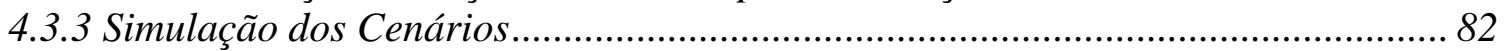

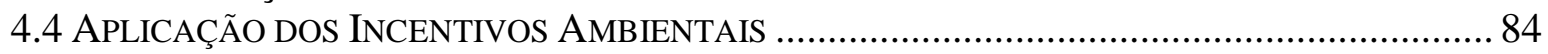

4.4.1 Definição da Expressão do Incentivo Ambiental ....................................................... 85

4.4.2 Armazenamento e vazão como variáveis de decisão na proposição de incentivos

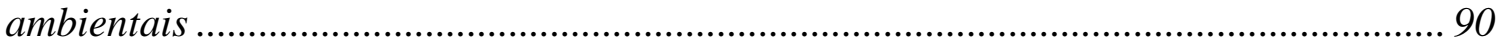

4.4.3 Simulação dos Cenários em Escala de Lote ........................................................... 94

5. RESULTADOS E DISCUSSÕES ...........................................................................................96

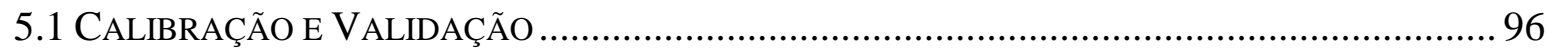

5.2 CARACTERIZAÇÃO E SELEÇÃO DOS EVENTOS A SEREM SIMULADOS NOS CENÁRIOS ........ 109

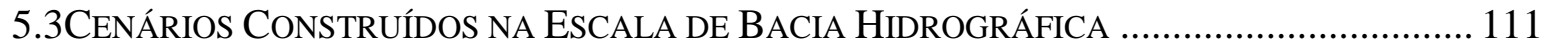

5.4 CENÁRIOS CONSTRUÍdOS NA ESCALA DE LOTE URBANO............................................... 121

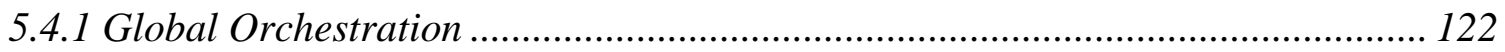

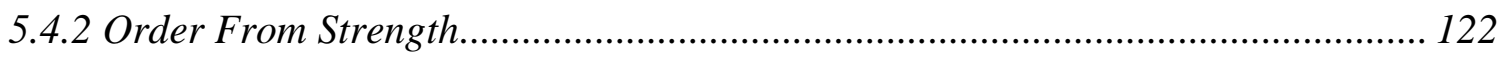

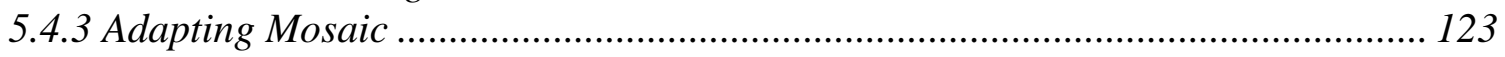

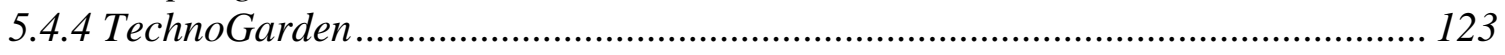

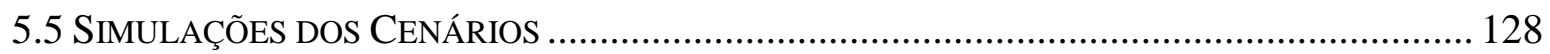

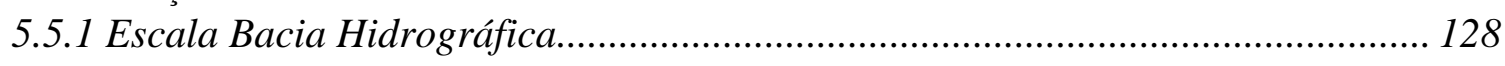

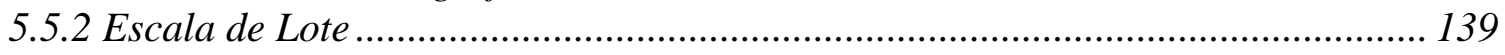

6. CONCLUSÕES E RECOMENDAÇÕES ................................................................... 144

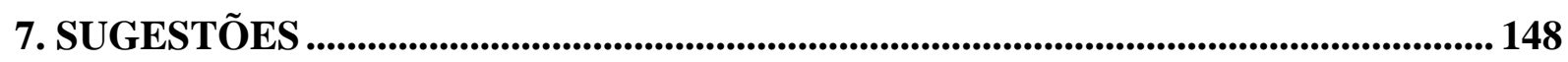

8. REFERÊNCIAS BIBLIOGRÁFICAS ................................................................................... 149

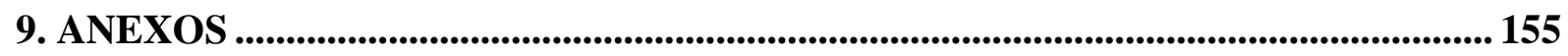

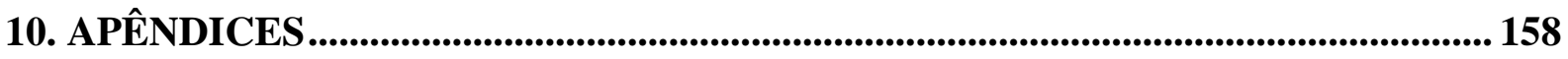




\section{LISTA DE TABELAS}

Tabela 1: Exemplos de estudos de cenários ao longo do século.......................................... 11

Tabela 2: Estimativa dos valores de $\mathrm{CN}$ para bacias rurais. ................................................. 33

Tabela 3: Estimativa dos valores de CN para bacias urbanas e suburbanas. ........................... 34

Tabela 4: Correção de CN para outras condições iniciais de umidade. .................................... 35

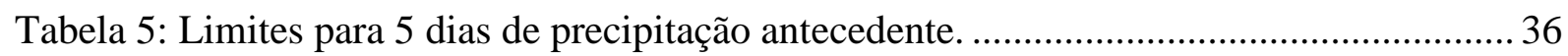

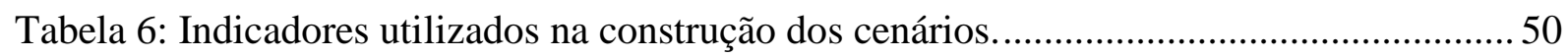

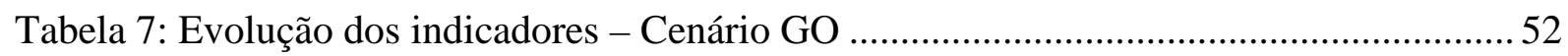

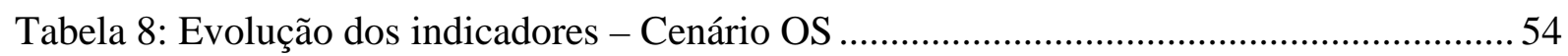

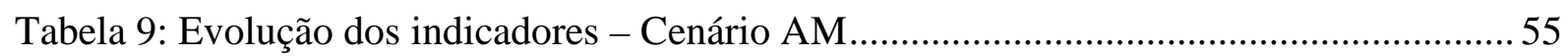

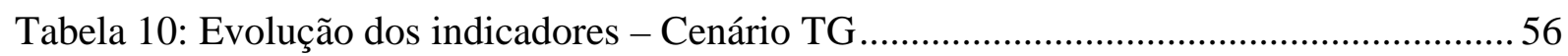

Tabela 11: Evolução dos Indicadores para o Lote Típico - Cenário GO ................................57

Tabela 12: Evolução dos Indicadores para o Lote Típico - Cenário OS ................................. 58

Tabela 13: Evolução dos Indicadores para o Lote Típico - Cenário AM................................ 59

Tabela 14: Evolução dos Indicadores para o Lote Típico - Cenário TG ................................. 60

Tabela 15: Classificação Climática de acordo com Köeppen. ............................................... 67

Tabela 16: Caracterização dos eventos utilizados nas fases de calibração e validação. .......... 73

Tabela 17:Caracterização dos eventos utilizados nas fases de calibração e validação. Cont. . 73

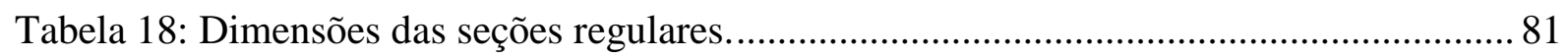

Tabela 19: Erros dos volumes escoados e simulados, dados em percentuais. .......................... 97

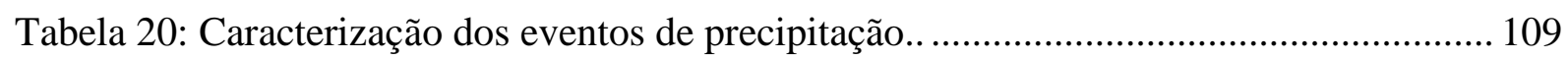

Tabela 21: Características dos eventos utilizados na simulação dos cenários. ....................... 111

Tabela 22: Taxa de crescimento populacional para São Carlos............................................ 111

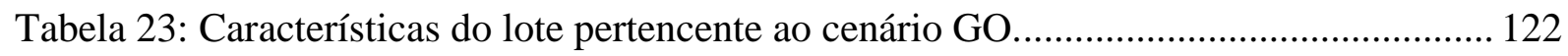

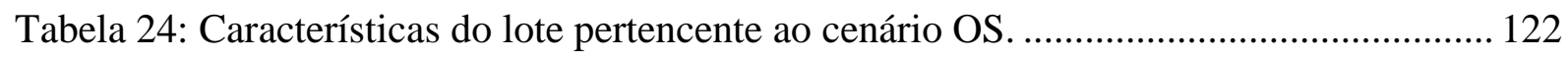

Tabela 25: Características do lote pertencente ao cenário AM........................................... 123

Tabela 26: Características do lote pertencente ao cenário TG............................................ 123

Tabela 27: Parâmetros utilizados na estimativa do IPTU com incentivo ambiental.............. 141 


\section{LISTA DE FIGURAS}

Figura 1: Quadro síntese de integração entre objetivos e metodologias. ................................. 3

Figura 2: Representação lógica do processo de construção de cenários. ................................. 13

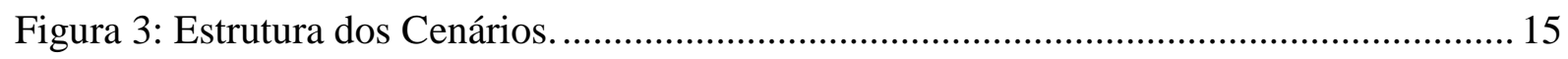

Figura 4: Projeção de mudanças na renda da população em cada cenário em 1995 e 2050 .... 18

Figura 5: Projeção das mudanças na economia para os quatro cenários.................................. 18

Figura 6: Avaliação dos vetores de mudança na biodiversidade e nos ecossistemas. ............. 19

Figura 7: Estimativa dos serviços de provisão, regulação e culturais ..................................... 20

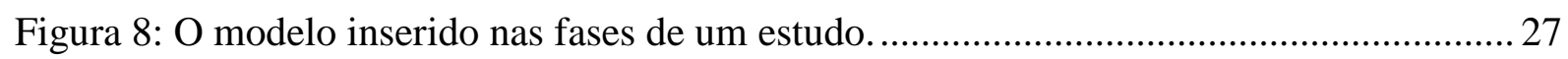

Figura 9: Configuração detalhada dos módulos bacia e rio com os métodos adotados........... 30

Figura 10: Hidrograma Unitário Triangular do SCS............................................................ 37

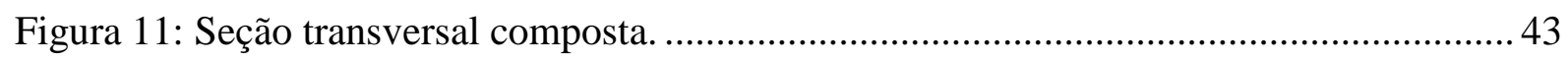

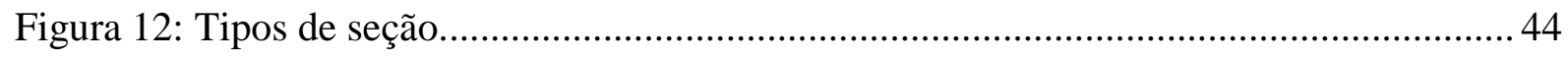

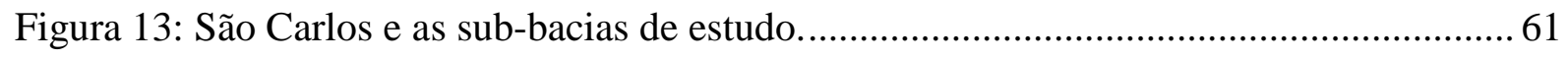

Figura 14: São Carlos e suas sub-bacias, com destaque para sub-bacia do Monjolinho. ........ 63

Figura 15: Tipos de solo das sub-bacia, onde a área cinza representa a ocupação urbana. ..... 64

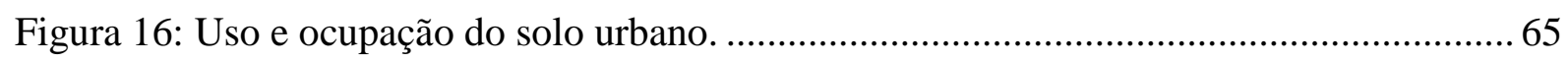

Figura 17: Sub-bacias pertencentes à área urbana de São Carlos. ......................................... 66

Figura 18: Seções de calibração e validação........................................................................ 68

Figura 19: Posto pluvio-fluviométrico - Estação Fórum....................................................... 69

Figura 20: Detalhe do posto - Estação Fórum. ..................................................................... 69

Figura 21: Posto hidrométrico monitorado pelo SAAE - Córrego Monjolinho ....................... 69

Figura 22: Detalhe do posto (Monjolinho - Casa Branca), hoje desativado............................ 69

Figura 23: Posto hidrométrico monitorado pelo SAAE - Próximo ao Shopping Iguatemi..... 70

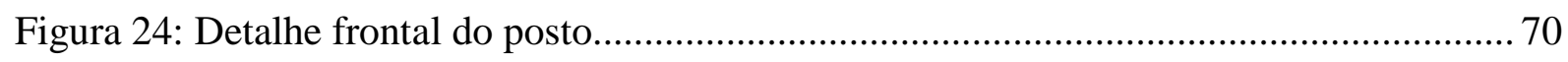

Figura 25: Posto hidrométrico monitorado pelo SAAE - Próximo ao Shopping Iguatemi..... 70

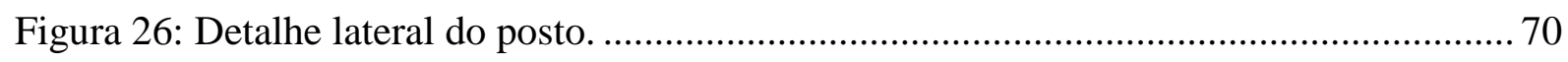

Figura 27: Precipitação observada $(41,8 \mathrm{~mm})$ e hidrogramas observados dados em função das vazões e utilizados na fase de calibração. Dia: 30/01/2004, evento (c)............................ 74

Figura 28: Precipitação observada $(41,8 \mathrm{~mm})$ e hidrogramas observados dados em função das vazões específicas e utilizados na fase de calibração. Dia: 30/01/2004, evento (c).......... 74

Figura 29: Precipitação observada $(15,5 \mathrm{~mm})$ e hidrogramas observados em função das vazões específicas e utilizados na fase de calibração. Dia: 09/01/2004, evento (a). ............... 75

Figura 30: Precipitação observada $(22,5 \mathrm{~mm})$ e hidrogramas observados em função das vazões específicas e utilizados na fase de calibração. Dia: 09/01/2004, evento (b). 
Figura 31: Precipitação observada $(13,6 \mathrm{~mm})$ e hidrogramas observados em função das vazões específicas e utilizados na fase de validação. Dia: 01/11/2003, evento (d).

Figura 32: Precipitação observada $(15,2 \mathrm{~mm})$ e hidrogramas observados em função das vazões específicas e utilizados na fase de validação. Dia: 27/12/2003, evento (e).

Figura 33: Precipitação observada $(16,5 \mathrm{~mm})$ e hidrogramas observados em função das vazões específicas e utilizados na fase de validação. Dia: 31/12/2003, evento (f).

Figura 34: Seção transversal, rotatória na Rua Miguel Petroni.

Figura 35: Seção transversal do ponto de controle 1 (PC 1), bacia do Córrego Gregório....... 79

Figura 36: Seção transversal do ponto de controle 2 (PC 2), bacia do Córrego Monjolinho. . 79

Figura 37: Seção transversal do ponto de controle 3 (PC 3), bacia do Córrego Monjolinho. . 79

Figura 38: Estimativa da seção fictícia a partir da seção real da Rua Miguel Petroni............. 80

Figura 39: Estimativa da seção fictícia a partir da seção real do PC 1. .................................. 80

Figura 40: Estimativa da seção fictícia a partir da seção real do PC 2. .................................. 81

Figura 41: Estimativa da seção fictícia a partir da seção real, Bacia Monjolinho .................... 81

Figura 42: Seções de avaliação dos resultados das simulações. ............................................. 83

Figura 43: Analogia entre cenários "Global/Local” e "Espacial/Pontual”. ............................. 84

Figura 44: Evolução dos pesos relativos a valoração para os cenários GO e OS. ................... 88

Figura 45: Evolução do somatório dos pesos relativos à valoração para o cenário AM.......... 89

Figura 46: Evolução do somatório dos pesos relativos à valoração para o cenário TG........... 90

Figura 47: Gráfico das vazões simuladas e observadas nos três pontos de controle para efeitos de calibração do modelo de simulação, relativo ao evento "a".

Figura 48: Gráfico das vazões simuladas e observadas nos três pontos de controle para efeitos de calibração do modelo de simulação, relativo ao evento " $b$ ".

Figura 49 Gráfico das vazões simuladas e observadas nos três pontos de controle para

efeitos de calibração do modelo de simulação, relativo ao evento "c".

Figura 50: Gráfico das vazões simuladas e observadas nos três pontos de controle para efeitos de validação do modelo de simulação, relativo ao evento "d".

Figura 51: Gráfico das vazões simuladas e observadas nos três pontos de controle para efeitos de validação do modelo de simulação, relativo ao evento "e".

Figura 52: Gráfico das vazões simuladas e observadas nos três pontos de controle para efeitos de validação do modelo de simulação, relativo ao evento "f".

Figura 53: Crescimento populacional para os cenários

Figura 54: Percentual de área urbanizada nas sub-bacias.

Figura 55: Evolução do potencial de escoamento nos cenários.

Figura 56: Utilização de bacias de detenção nos cenários.

Figura 57: Utilização de bacias de infiltração nos cenários.

Figura 58: Evolução do melhoramento de manancial urbano.

Figura 59: Rugosidade ao longo do principal rio da bacia do monjolinho. 


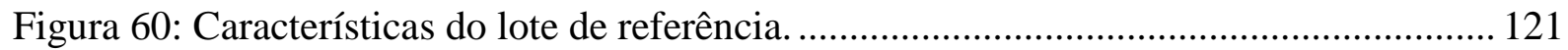

Figura 61: Curva de permanência de cheias para o ano de referência (2000)....................... 128

Figura 62: Curvas de permanência de cheias do cenário GO 2025. ..................................... 129

Figura 63: Curvas de permanência de cheias do cenário GO 2050. ...................................... 130

Figura 64: Curvas de permanência de cheias do cenário GO 2075. ..................................... 130

Figura 65: Curvas de permanência de cheias do cenário GO 2100. ...................................... 130

Figura 66: Curvas de permanência de cheias do cenário OS 2025 ...................................... 131

Figura 67: Curvas de permanência de cheias do cenário OS 2050 ..................................... 132

Figura 68: Curvas de permanência de cheias do cenário OS 2075 ...................................... 132

Figura 69: Curvas de permanência de cheias do cenário OS 2100 ...................................... 132

Figura 70: Curvas de permanência de cheias do cenário AM 2025 ..................................... 134

Figura 71: Curvas de permanência de cheias do cenário AM 2050...................................... 134

Figura 72: Curvas de permanência de cheias do cenário AM 2075 ...................................... 134

Figura 73: Curvas de permanência de cheias do cenário AM 2100...................................... 135

Figura 74: Curvas de permanência de cheias do cenário TG 2025 ...................................... 136

Figura 75: Curvas de permanência de cheias do cenário TG 2050 ....................................... 136

Figura 76: Curvas de permanência de cheias do cenário TG 2075 ...................................... 136

Figura 77: Curvas de permanência de cheias do cenário TG 2100....................................... 137

Figura 78: Relação entre os CN médios da bacia do Gregório em cada cenário. .................. 137

Figura 79: Avaliação dos benefícios e dos passivos dos cenários para a bacia do Gregório. 139

Figura 80: Evolução do parâmetro CN para os lotes urbanos............................................... 140

Figura 81: Evolução do armazenamento potencial de água no lote para os cenários. ............ 140

Figura 82: Valores de IPTU por área de lote por habitante para cada cenário. ..................... 141

Figura 83: Valores de IPTU por área construída por habitante para cada cenário................. 142 


\section{LISTA DE ABREVIATURAS E SIGLAS}

ALM

AM

AMC

BMP's

CIA

CIFOR

CBH-TJ

DFIS

CPD

EESC

FAO

FEA

FURG

GDP

GO

HEC

HU

IBGE

IPCC

IPH

IPTU

MA

MAP
Agência para o Desenvolvimento da Lagoa Mirim

Adapting Mosaic

Antecedent Moisture Condition

Best Management Practices

Central Intelligence Agency

Centro Internacional de Investigación Forestal

Comitê da Bacia Hidrográfica do Tietê-Jacaré

Setor de Hidráulica e Saneamento

Com Plano Diretor

Escola de Engenharia de São Carlos

Food and Agriculture Organization of the United Nations

Faculdade de Engenharia Agrícola

Fundação Universidade Federal do Rio Grande

Gross Domestic Product

Global Orchestration

Hydrologic Engineering Center

Hidrograma Unitário

Instituto Brasileiro de Geografia e Estatística

Intergovernmental Panel on Climate Changes

Instituto de Pesquisas Hidráulicas

Imposto Predial e Territorial Urbano

Millennium Ecosystem Assessment

Madre de Dios (Peru); Amazônia (Brasil) e Pando (Bolívia) 
MMA Ministério do Meio Ambiente

NIBH Núcleo Integrado de Bacias Hidrográficas

OECD Organization for Economic Co-Operation and Development

OS Order From Strength

PC Ponto de Controle

PNRH Plano Nacional de Recursos Hídricos

PNUD Programa das Nações Unidas para o Desenvolvimento

SAAE Serviço Autônomo de Água e Esgoto

SCS Soil Conservation Service

SEADE Fundação Sistema Estadual de Análise de Dados

SINGREH Sistema Nacional de Gerenciamento de Recursos Hídricos

SPD Sem Plano Diretor

SWITCH Sustainable Water Management Improves Tomorrow's Cities' Health

TFS Tatiane Furlaneto de Souza

TG TechnoGarden

UFPel Universidade Federal de Pelotas

UFRGS Universidade Federal do Rio Grande do Sul

UNESCO United Nations Educational, Scientific and Cultural Organization

UNEP United Nations Environment Programme

USDA United States Department of Agriculture

USEPA United States Environmental Protection Agency

USP Universidade de São Paulo 


\section{LISTA DE SÍMBOLOS}

Q Volume superficial acumulado [mm]

P Precipitação total acumulada [mm]

$\mathrm{I}_{\mathrm{a}} \quad$ Perdas iniciais [mm]

S Capacidade máxima de armazenamento no solo [mm]

CN Curva número [adm]

q Vazão de pico $\left[\mathrm{m}^{3} / \mathrm{s}\right]$

$\mathrm{T}_{\mathrm{p}} \quad$ Tempo de pico $[\mathrm{h}]$

$\mathrm{T}_{\mathrm{r}} \quad$ Tempo de duração da precipitação [h]

$\mathrm{T}_{\mathrm{c}} \quad$ Tempo de concentração da bacia [h]

Tb Tempo de base $[\mathrm{h}]$

$\mathrm{S} \quad$ Declividade da bacia $[\mathrm{m} / 10 \mathrm{~km}]$

A Área da bacia $\left[\mathrm{km}^{2}\right]$

$\mathrm{M}_{\mathrm{a}} \quad$ Percentual de aumento de áreas impermeáveis [\%]

$\mathrm{M}_{\mathrm{c}} \quad$ Percentual de aumento de áreas canalizadas [\%]

$\mathrm{f}_{1}$ e $\mathrm{f}_{2} \quad$ Fatores de redução no tempo de pico [adm]

K Tempo de deslocamento da onda no trecho de propagação

X Ponderador da influência das vazões de entrada e saída em função do armazenamento

$\mathrm{q}_{0} \quad$ Vazão específica de referência $\left[\mathrm{m}^{3} / \mathrm{s} / \mathrm{km}^{2}\right]$

C Celeridade da onda $[\mathrm{m} / \mathrm{s}]$

B Largura do canal [m]

h $\quad$ Altura do canal [m]

$\mathrm{S}_{0} \quad$ Declividade de fundo do canal $[\mathrm{m} / \mathrm{m}]$

q Vazão específica por unidade de largura do canal $\left[\mathrm{m}^{3} / \mathrm{s} . \mathrm{km}^{2} / \mathrm{m}\right]$ 
n Coeficiente de rugosidade de Manning [adm]

$\Delta_{\mathrm{x}} \quad$ Discretização espacial [m]

$\mathrm{w}_{1}$ e $\mathrm{w}_{2}$ Pesos das parcelas do IPTU

$S \quad$ Armazenamento potencial de água no lote [mm]

$Q \quad$ Vazão máxima instantânea $\left[\mathrm{m}^{3} / \mathrm{s}\right]$

$\mathrm{P}_{\text {total }} \quad$ Precipitação total [mm]

I média Intensidade média $[\mathrm{mm} / \mathrm{h}]$

IPA Índice de precipitação acumulada [mm]

Q total Vazão total $\left[\mathrm{m}^{3} / \mathrm{s}\right]$

$\mathrm{Q}_{\max } \quad$ Vazão máxima $\left[\mathrm{m}^{3} / \mathrm{s}\right]$

C Coeficiente de escoamento superficial [adm] 



\section{INTRODUÇÃO E JUSTIFICATIVA}

O processo de urbanização de médias e grandes cidades brasileiras é um problema crescente. No país, a ausência de planejamento determina, por exemplo: ocupação de áreas impróprias (encostas, planícies de inundação, zonas costeiras, áreas de proteção ambiental); falta de infra-estrutura de engenharia (fornecimento de água potável, provimento de energia elétrica, coleta e tratamento de esgoto doméstico, coleta de águas pluviais, coleta e disposição final adequadas de resíduos sólidos); falta de condições sociais mínimas (ausência de centros de saúde, de escolas, de segurança pública, de transporte, de espaços de lazer). Frente ao exposto, é evidente a multidisciplinaridade do tema. No referido contexto, este trabalho propõe-se principalmente a contribuir para o estudo das relações entre os aspectos hidrológicos e os usos do solo.

A drenagem urbana e o uso e ocupação do solo estão intimamente ligados. Alguns exemplos das conseqüências do mau planejamento de drenagem são: aumento de volumes de escoamento superficial, aumento de vazões máximas, aumento da velocidade do escoamento, redução de tempos de pico, transbordamento de calhas e canais e entupimento de bueiros. Uma interessante ferramenta que auxilia no processo de planejamento, especificamente no aspecto da drenagem urbana, é a construção de cenários. Esses instrumentos possibilitam a avaliação das respostas de um determinado ambiente sob diferentes condições de uso e ocupação do solo. Portanto, tendo em vista a preocupação no que diz respeito às conseqüências referidas, tanto por parte de especialistas quanto por parte de órgãos governamentais, estudos de possíveis cenários de longo prazo tornam-se uma ferramenta essencial para o auxílio na tomada de decisões.

A avaliação quantitativa de cenários de drenagem dá-se pela utilização de modelos hidrológicos. Esses modelos permitem uma representação de um sistema real, buscando melhor entendimento do comportamento de sub-bacias no processo de transformação chuva - 
vazão, tanto para condições observadas quanto para condições diferentes das observadas (cenários). No presente trabalho, o modelo hidrológico adotado foi o IPH-S1 e os métodos utilizados, dentre os disponíveis no modelo, foram, para a separação e propagação do escoamento superficial, o Método da Curva Número (SCS) e o Hidrograma Unitário Triangular (SCS), respectivamente. A adoção do referido modelo deveu-se principalmente a sua aplicabilidade à proposta deste estudo e por sua fácil manipulação (adaptado para ambiente Windows ${ }^{\circledR}$ ).

A área urbana de São Carlos freqüentemente apresenta problemas de inundações. Além disso, há uma tendência de crescimento da ocupação para montante das sub-bacias que compõem essa área, fato que acarretará o agravamento da situação. Vários trabalhos já dissertaram, do ponto de vista de cenários de curto prazo, sobre os efeitos da urbanização em algumas dessas sub-bacias. Sob este aspecto, a proposta da presente pesquisa vem ao encontro da tendência mundial de planejamento (Millennium Ecosystem Assessment, 2005) baseado em diretrizes que possam ser adequadas ao longo do tempo, viabilizando "gestões adaptativas”, objetivo somente alcançado pela utilização de cenários de longo prazo. Assim, entende-se que possam ser induzidos investimentos públicos e privados e ações nos sistemas de drenagem, por medidas estruturais e não estruturais, bem como possa ser fornecido algum subsídio técnico para elaboração de um Plano Diretor de Macrodrenagem.

Finalmente, na Figura 1 são apresentados esquematicamente os objetivos, a metodologia empregada na pesquisa e o resultados. 


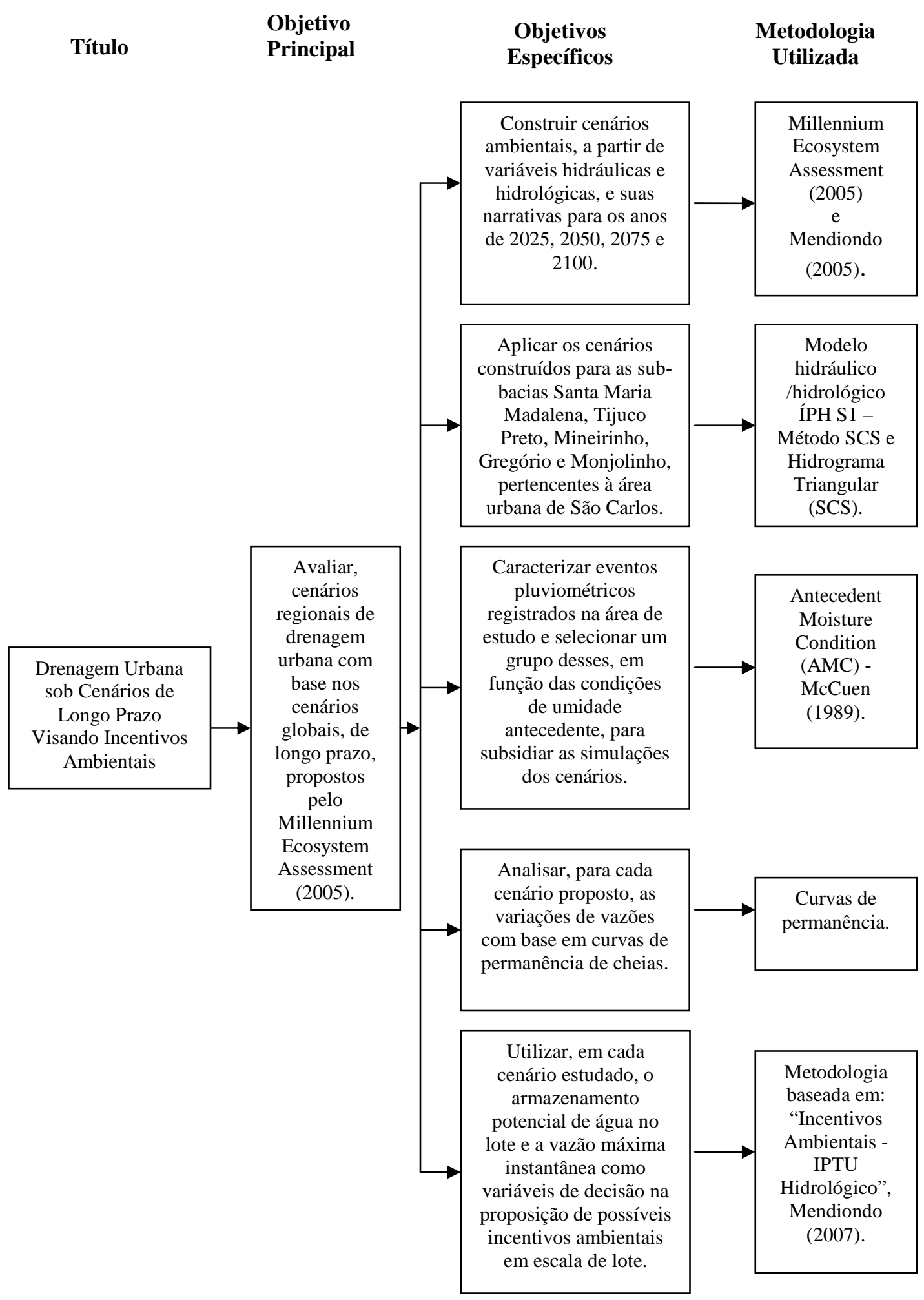

Figura 1: Quadro síntese de integração entre objetivos e metodologias. 


\section{OBJETIVOS}

\subsection{Objetivo Principal}

Avaliar cenários regionais de drenagem urbana com base nos cenários globais, de longo prazo, propostos pelo Millennium Ecosystem Assessment (2005).

\subsection{Objetivos Específicos}

a) Construir cenários ambientais, a partir de variáveis hidráulicas e hidrológicas, e suas narrativas para os anos de 2025, 2050, 2075 e 2100;

b) Aplicar os cenários construídos para as sub-bacias Santa Maria Madalena, Tijuco Preto, Mineirinho, Gregório e Monjolinho, pertencentes à área urbana de São Carlos;

c) Caracterizar eventos pluviométricos registrados na área de estudo e selecionar um grupo desses, em função das condições de umidade antecedente, para subsidiar as simulações dos cenários;

d) Analisar, para cada cenário proposto, as variações de vazões com base em curvas de permanência de cheias;

e) Utilizar, em cada cenário estudado, o armazenamento potencial de água no lote e a vazão máxima instantânea como variáveis de decisão na proposição de possíveis incentivos ambientais em escala de lote. 


\section{REVISÃO BIBLIOGRÁFICA}

\subsection{Processos de Urbanização}

A ocupação do território urbano modifica as características do ambiente através da utilização do solo por meio da implantação de indústrias, moradias, espaços públicos, bem como pelo uso dos recursos naturais para as atividades de subsistência e como insumos em processos produtivos.

A década de 60 foi marcada pelo acentuado processo de urbanização aliado com à intensa migração da população rural para áreas urbanas, fatores esses responsáveis pelo crescimento desordenado e diversificado dos grandes centros urbanos nos países em desenvolvimento. De acordo com Mastny e Cincotta (2005), o crescimento urbano ocorre de forma mais acentuada nesses países. Os autores relatam ainda a existência de projeções para a parcela urbana atingir $60 \%$ no ano de 2030 , sendo constatado o percentual de $43 \%$ no ano de 2003 e somente $18 \%$ em 1950.

Os autores supracitados ressaltam que o processo de urbanização é em geral um aspecto demográfico positivo, pois há contribuição para o crescimento econômico com prioridade na implementação de políticas de melhoria urbana como serviços de atendimento médico, de saneamento básico, de investimentos em educação, transporte, entre outros. Devido a este fato, muitas pessoas migram para os centros urbanos, com a esperança de melhores empregos, mais benefícios e, conseqüentemente, melhores condições de vida.

No entanto, esse crescimento populacional acelerado pode resultar em problemas como a escassez de água, aumento de áreas invadidas, disputa por vagas na rede pública de ensino, aumento da informalidade e/ou de subempregos e, por conseguinte, aumento da violência devido à ausência de infra-estrutura adequada para suprir as necessidades da 
população, fato esse, que pode ser constatado na maioria dos centros urbanos de países em desenvolvimento.

No que tange a área de recursos hídricos, pode-se afirmar que a urbanização descontrolada e não planejada acarreta o aumento de áreas impermeáveis; o assoreamento do leito, tamponamento, estrangulamento e canalização de rios e córregos; a diminuição e/ou supressão de áreas verdes, entre outros. Todos esses fatores são responsáveis pelas modificações no ciclo hidrológico e no comportamento da micro e macrodrenagem. Algumas dessas alterações são o aumento da velocidade de escoamento e a diminuição no tempo de ocorrência das vazões máximas, que coligadas resultam em freqüentes inundações. Como exemplo das consequiências das inundações, o PNUD (2004), em seu Informe Mundial, relata uma média anual de 196 milhões de pessoas em mais de 90 países que se encontram expostas a inundações catastróficas. Estima-se que morreram 170 mil pessoas em inundações em todo o mundo durante o período entre 1980 e 2000.

Quanto à qualidade dos cursos d'água, sua intensa utilização como fator de diluição de efluentes domésticos e industriais, bem como a poluição difusa de origem pluvial e o acúmulo de resíduos sólidos provenientes do lançamento por parte da população, ocasionam degradação ambiental, diminuição da capacidade de suporte do meio e aumento da proliferação de doenças de veiculação hídrica.

Em relação ao município de São Carlos, o processo de urbanização foi intensificado após a metade do século XX. Nos anos 70 houve uma modificação no processo de ocupação urbana com a expansão para áreas periféricas, que na maioria dos casos, possuíam infraestrutura precária.

Quanto às imposições, tanto físicas quanto sociais ou ambientais, ao crescimento urbano, Aguiar (1989) ressalta a dificuldade de urbanização em algumas regiões do município. Na região sul devido às altas declividades da bacia do Córrego Água Quente, 
algumas vezes superior a $15 \%$, na região sudoeste por causa da presença da rodovia para Ribeirão Bonito, e nas regiões nordeste e sudeste o obstáculo imposto pela Rodovia Washington Luiz e pela presença de mananciais preservados, respectivamente. Diante dessas dificuldades, o autor ressalta como regiões preferenciais ao crescimento urbano as regiões ao norte e a oeste da cidade, com maior ênfase para região norte.

\subsection{Medidas de Controle de Inundações}

De acordo com Tucci (1993), as enchentes em áreas urbanas são decorrentes de dois fatores: a ocupação das áreas ribeirinhas e a urbanização. O primeiro pode ser interpretado como processo natural com o rio ocupando seu leito maior durante eventos considerados extremos; já o segundo ocorre devido às implicações do processo de urbanização sobre o sistema hidráulico, onde o aumento de superfícies impermeáveis provoca o aumento do volume de escoamento superficial e a regularização de rios e córregos acarreta no aumento da velocidade de escoamento com diminuição no tempo de pico das cheias.

Como medidas de controle de inundações Baptista et al. (2005) descrevem duas abordagens: "clássica" e a de "tecnologias alternativas ou compensatórias". A primeira baseada nos princípios do higienismo do século XIX, visava à evacuação rápida das águas servidas em áreas urbanas por meio de condutos, de preferência subterrâneos. Já as “tecnologias alternativas" ou "tecnologias compensatórias" foram desenvolvidas na Europa e América do Norte a partir da década de 70, e têm por objetivo neutralizar os efeitos da urbanização sobre os processos hidrológicos. As novas tecnologias são baseadas no controle do volume e da velocidade do escoamento superficial por meio de armazenamento e/ou infiltração e podem ser classificadas de acordo com seu caráter estrutural ou não estrutural. As técnicas estruturais são subdivididas em: 
- Controle na fonte: poços de infiltração, valas ou valetas de armazenamento e/ou infiltração, trincheiras de infiltração, micro-reservatórios individuais, telhados armazenadores, pavimentos porosos;

- Controle centralizado: bacias de detenção (armazenamento em curto período) e bacias de retenção (armazenamento em longo período), bacias de infiltração, bacias de retenção e infiltração.

As tecnologias descritas são propostas por Butler \& Parkinson (1997) como ferramentas para uma "drenagem urbana sustentável", mas os autores apontam para a impossibilidade de atingi-la a médio prazo devido à não utilização dos conceitos de sustentabilidade por parte dos profissionais que atuam na área de drenagem urbana. No entanto, os mesmos defendem as práticas menos insustentáveis. Sob esse conceito, Pompêo (2000) ressalta a importância de se integrar o sistema de gestão de drenagem urbana com a participação social e a viabilidade econômica. A justificativa para tal abordagem dá-se pela amplitude do próprio conceito de desenvolvimento sustentável que, de acordo com Pronk e Haq (1992) ${ }^{1}$ apud Pompêo (2000), “relaciona-se com um processo de formulação de políticas que permitem um desenvolvimento que seja sustentável sob o ponto de vista econômico, social e ecológico".

Todas estas medidas são novas alternativas para a minimização das enchentes e inundações geradas pelo processo de urbanização. A adoção das mesmas não tem por objetivo substituir as medidas estruturais cujas metodologias já são consagradas, mas sim de atuar em conjunto com as demais, de forma a operar como mecanismos de planejamento de recursos hídricos com resultados a médio e longo prazo.

Um dos problemas enfrentados na utilização dessas medidas é a aceitação por parte dos moradores, principalmente, devido aos custos inerentes de implantação e da manutenção requerida. Costa Jr. (2003) propõe em seu trabalho o uso de microreservatórios de detenção e 
pavimentos permeáveis como medidas de controle no lote, e avalia o grau de aceitação por parte da população em relação à adoção de tais medidas. Em 70\% dos lotes avaliados não houve aceitação do uso de micro-reservatórios e, em $63,4 \%$ o uso de pavimentos permeáveis não foi aceito devido à limitação de áreas livres.

Iniciativas como da UNESCO - Institute for Water - Education (2007), através do Projeto Integrado SWITCH (Sustainable Water Management Improves Tomorrow's Cities' Health), buscam o desenvolvimento, a aplicação e a adaptação de extensas pesquisas científicas, tecnológicas e sócio-econômicas que contribuam para a sustentabilidade e o efetivo manejo das águas urbanas. A meta global do projeto de SWITCH é o estímulo à mudança do manejo adequado das águas urbanas. Para isso foi criado o plano denominado: "The City of the Future", com projeções de 30 a 50 anos, baseadas na construção de cenários e na visualização e resolução dos problemas referentes às águas urbanas. Esse plano está sendo aplicado, atualmente, nas seguintes cidades: Hamburgo (Alemanha), Birmingham (Reino Unido), Lodz (Polônia), Zaragoza (Espanha), Tel Aviv (Israel), Alexandria (Egito), Accra (Gana), Beijing (China), Chong Qing (China) e Belo Horizonte (Brasil). Idéias como essas que incluem a participação do Estado, da comunidade científica e da sociedade civil proporcionam melhorias na qualidade de vida e, portanto devem servir de exemplo.

\subsection{Cenários como Ferramenta de Planejamento}

No Brasil, a construção de cenários como técnica de apoio na tomada de decisões de longo prazo é ainda incipiente e empregada principalmente, por grandes corporações. No entanto, o sucesso dos resultados obtidos tem proporcionado um aumento considerável na sua utilização, um exemplo claro e recente do emprego de cenários na área governamental é o Plano Nacional de Recursos Hídricos (PNRH, 2006), que, em seu volume 2, aborda as questões relativas à oferta e qualidade de água. A iniciativa do PNRH é elogiável, porém o 
documento carece de uma abordagem hidrológica sistêmica (que englobe não somente a oferta de água, mas também sua utilização, seu tratamento, redução de consumo, reaproveitamento, segregação de águas pluviais, proposição de modelos que visem o combate às cheias e inundações, entre outros). Os primeiros movimentos, no sentido da utilização de "cenários", foram feitos; todavia, entende-se que essa ferramenta certamente foi subaproveitada até o presente momento.

\subsubsection{Histórico e metodologias de construção de cenários}

A curiosidade do homem em desvendar o futuro é algo tão antigo quanto a própria existência do ser humano. Brandi (2003) afirma que o exercício de tentar conhecer o futuro é "uma necessidade biológica, uma necessidade ligada ao instinto de sobrevivência". O mesmo autor descreve distintas formas de percepção do futuro e diagnostica, desde a antiguidade 4000 A.C. - até os dias atuais, episódios em que o homem gerou mecanismos para antever o futuro. As percepções descritas pelo autor são: Profecia, Predição, Projeção, Previsão e Prospectiva.

Um grande exemplo da utilização de cenários futuros como técnica de planejamento é o estudo denominado "Essay on the Principle of Population" realizado por Tomas Robert Malthus, no século XVIII que, por meio de extrapolações, "previu” cenários tendenciais de crescimento populacional. A partir desse, muito outros estudos com base em "previsões" extrapolativas foram realizados. De acordo com Porto et al (2001) apud Neves (2007), a metodologia extrapolativa revelou-se confiável até meados de 1970, período em que a estabilidade política, econômica e tecnológica predominava. No entanto, com a crise do petróleo essa estabilidade cedeu lugar a mudanças aceleradas na área tecnológica e na política, alterando assim a dinâmica do desenvolvimento e, colocando à prova os 
planejamentos fundamentados em cenários extrapolativos. Sob essa situação emergiu uma nova metodologia de construção de cenários denominada de prospectiva. Os cenários prospectivos se caracterizam por possibilitar não apenas um como nos cenários extrapolativos, mas múltiplos cenários, pois parte do princípio da incerteza do futuro (NEVES, 2007). Exemplos desses tipos de cenários podem ser visualizados na tabela 1.

Tabela 1: Exemplos de estudos de cenários ao longo do século.

\begin{tabular}{|c|c|c|c|}
\hline Autor & Estudo & Ano & Metodologia \\
\hline Thomas Robert Malthus & "Essay on the Principle of Population" & 1798 & Extrapolativa \\
\hline Henry George & "Progress and Poverty" & 1879 & Extrapolativa \\
\hline Ester Boserup & "The conditions of Agricultural Growth" & 1965 & Extrapolativa \\
\hline O Clube de Roma & "Limits to the Growth" & 1972 & Prospectiva \\
\hline OECD & "INTERFUTURES" & 1979 & Prospectiva \\
\hline Berendt et al & "Global 2000 report to the President" & 1980 & Extrapolativa \\
\hline Comissão Brundtland & "Our Common Future" & 1987 & $-\ldots-\ldots *$ \\
\hline Meadows et al & "Beyond the Limits" & 1992 & Prospectiva \\
\hline WRR & "Ground for Choices" & 1992 & Prospectiva \\
\hline FAO & "Agriculture Towards 2010" & 1995 & Prospectiva \\
\hline UNEP & "Global Environmental Outlook" & 1999 & Prospectiva \\
\hline IPCC & "Special Report on Emission Scenarios (SRES)" & 2000 & Prospectiva \\
\hline WSG & "The Great Transition" & 2001 & Prospectiva \\
\hline MA & "Millenium Ecosystem Assesment" & 2005 & Prospectiva \\
\hline The Millennium Project & "State of the Future" & 2006 & Prospectiva \\
\hline CIA & "O relatório da CIA - Como será o mundo em 2020" & 2006 & Prospectiva \\
\hline MMA - PNRH & "Águas para o Futuro: Cenários para 2020" & 2006 & Prospectiva \\
\hline
\end{tabular}

* Informação não disponível. Fonte: Leemans, 2007 (modificado).

Existem, atualmente, diversas metodologias de elaboração de cenários. Como pode ser observada na tabela 1, a construção de cenários pode ser realizada por uma única pessoa, ou por um grupo. Nos exemplos abordados, os cenários foram construídos a partir de visões de especialistas, no entanto, em escalas reduzidas, como a de cenários locais e regionais deve ser considerada a participação dos tomadores de decisão e dos "stakeholders" (pessoas 
diretamente envolvidas e interessadas no processo de construção de cenários e na obtenção dos resultados almejados).

Estudos como State of the Future (2006), Great Transitions (2002) e Millennium Ecosystem Assessment (2005) são exemplos de cenários construídos por um grande número de especialistas de todas as partes do mundo e podem ser interpretados como "uma visão do mundo para o próprio mundo". Já o trabalho intitulado O Relatório da CIA - Como Será o Mundo em 2020 (2006) foi realizado por estudiosos de um único país (EUA) e podem ser interpretado como "uma visão dos Estados Unidos para o mundo". Os cenários do PNRH (2006) foram feitos por especialistas brasileiros é, portanto, "uma visão do Brasil para o próprio Brasil".

Exemplo de construção de cenários com envolvimento dos "stakeholders" (cenários participativos) é o estudo denominado: "Cruzando Fronteras: Una Carretera en la Amazônia" (VELAVERDE, 2007). O mesmo relata diferentes cenários, para a região do MAP - Madre de Dios (Peru); Amazônia (Brasil) e Pando (Bolívia) - quando os governos dos três paises almejam a construção da "Estrada do Pacífico" a qual faria conexão entre essa região e o oceano pacífico.

Por ser o primeiro estudo a utilizar, como ferramenta de planejamento, a construção de cenários e também por sua relevância em nível nacional, no item seguinte são descritos, de maneira sucinta, os cenários propostos pelo PNRH (2006), bem como sua metodologia de construção.

\subsubsection{O caso do PNRH}

O estudo denominado “Água para o Futuro: Cenários para 2020” compreende parte do PNRH, finalizado em 2006. Com inspiração nos trabalhos de Michel Godet $(1993)^{2}$ e 
MACROPLAN (2004) ${ }^{3}$ e base em cenários mundiais, foram construídos três cenários nacionais. Para a construção dos mesmos foram realizadas 17 entrevistas, durante 1 mês, com representantes de órgãos governamentais, da sociedade civil e especialistas que englobaram questões como: situação atual dos recursos hídricos no Brasil, principais problemas e conflitos, evolução para os 15 anos subseqüentes e determinação das zonas críticas no Brasil com relação à escassez, ao uso indevido do solo, ao adensamento populacional entre outros. A figura 2 elucida, de forma esquemática, o processo de elaboração desses cenários o qual possui sete passos: estudo retrospectivo do sistema a ser cenarizado, descrição da situação desse sistema, identificação dos seus condicionantes de futuro, investigação morfológica, testes de plausibilidade dos cenários gerados, desenvolvimento dos cenários e comparação e quantificação dos cenários.

\section{Esquema lógico da construção dos cenários}

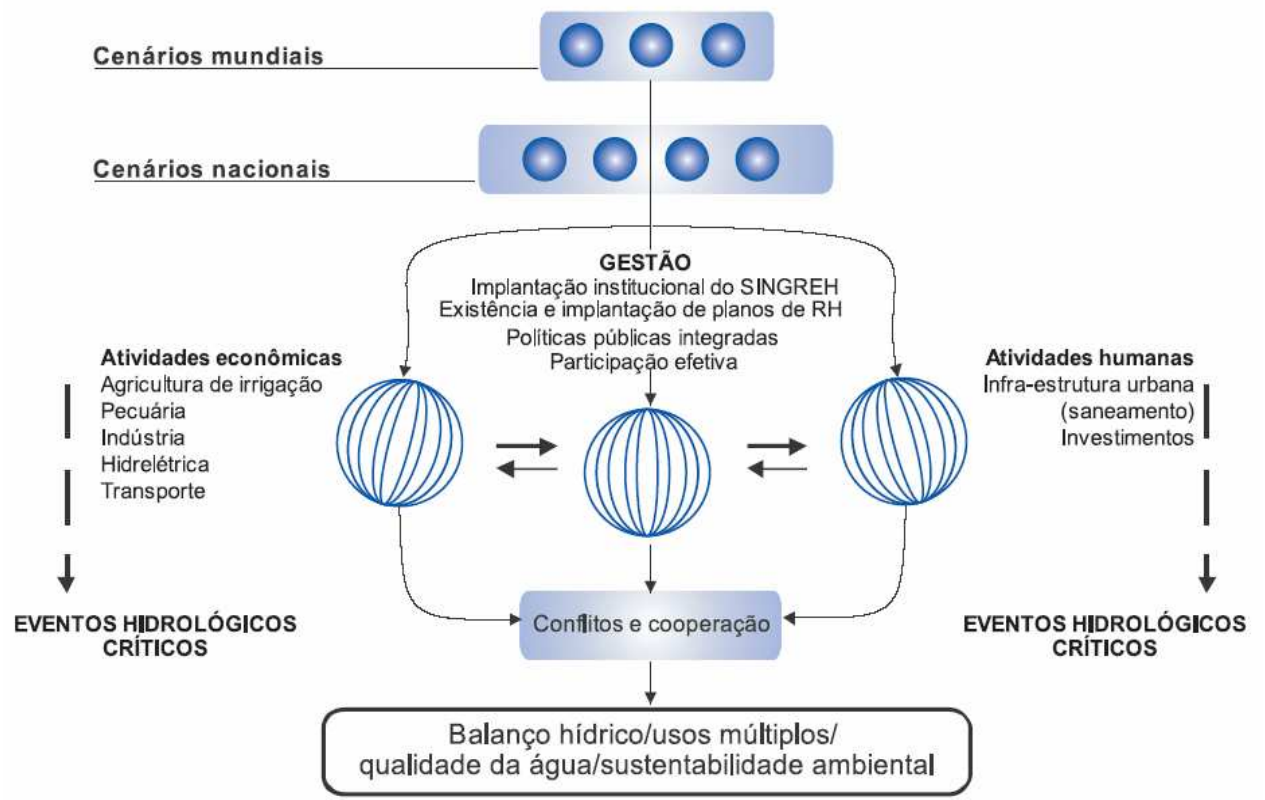

Figura 2: Representação lógica do processo de construção de cenários. Fonte: PNRH (2006) vol 2. p 23.

Os cenários elaborados para o PNRH (2006) foram denominados por: Água para Todos, Água para Alguns e Água para Poucos. 
Água para Todos - cenário de maior crescimento econômico, com políticas consistentes e integradas, com maior consciência sócio-ambiental por parte das indústrias e expansão das atividades econômicas como agricultura, instalação de usinas hidrelétrica e hidrovias, atividades que geram fortes impactos sobre os recursos hídricos, porém ocorrem de maneira declinante. A gestão do uso das águas seria mais eficaz, com um SINGREH (Sistema Nacional de Gerenciamento de Recursos Hídricos) fortalecido e, conseqüentemente, com a redução de forma lenta dos conflitos pela quantidade e dos danos em termos de qualidade das águas. Há redução da pobreza e das desigualdades sociais.

Água para Alguns - cenário de crescimento mediano, mas excludente, com aumento das desigualdades sociais. Há maiores impactos sobre os recursos hídricos devido à inexistência de um planejamento adequado ao uso múltiplo dos recursos hídricos com conflitos e problemas de uso agravados pela degradação dos cursos d'água.

Água para Poucos - inserido num mundo instável e fragmentado, o país sofre com a menor taxa de crescimento econômico e com o pequeno desenvolvimento das atividades ligadas à infra-estrutura urbana e logística. Predominam as atividades econômicas nãosustentáveis; não há investimento na proteção dos recursos hídricos, as águas superficiais e subterrâneas sofrem degradação gerando aumento na proliferação de doenças endêmicas de veiculação hídrica. Desta forma, crescem os conflitos devido à diminuição da oferta de água de boa qualidade.

Modernamente, tem sido verificada a construção de cenários regionais, como o caso do PNRH, a partir de cenários mundiais. De maneira análoga à construção de cenários do PNRH, os cenários avaliados nessa pesquisa foram construídos com base em cenários globais. 


\subsubsection{Millenium Ecosystem Assessment}

O estudo denominado Millennium Ecosystem Assessment (MA), um programa de trabalho internacional sobre os impactos que as mudanças nos ecossistemas causam ao bemestar humano e as opções de respostas a essas mudanças, foi desenvolvido com o intuito de atender às necessidades de informações científicas dos tomadores de decisões. Neste trabalho desenvolveram-se quatro cenários globais (Figura 3). Os cenários exploraram duas linhas de desenvolvimento global: globalizado e regionalizado; e duas abordagens diferentes de gestão dos ecossistemas: uma com ações reativas, e outra onde a gestão dos ecossistemas é pró-ativa com políticas de longo prazo (MA-Scenario Working Group, 2005).

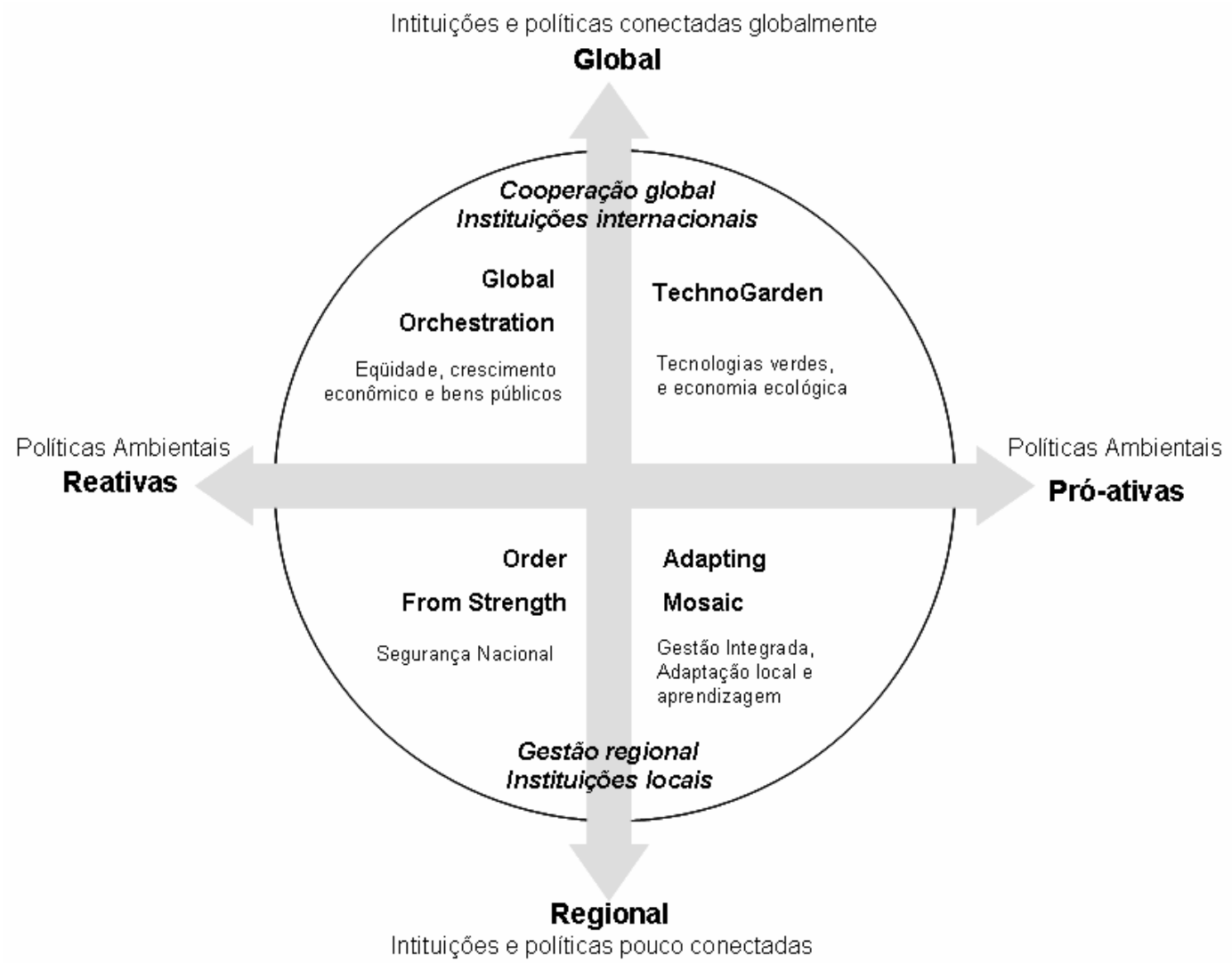

Figura 3: Estrutura dos Cenários.

(Fonte: Percy \& Lubchenco 2006, adaptado).

Considerada a maior avaliação já realizada sobre a saúde dos ecossistemas e preparada por 1360 especialistas de 95 países, com um extenso processo de revisão e consenso de 
cientistas de todo o mundo, foi planejada para atender os tomadores de decisão de governos, setor privado e sociedade civil.

Em sua composição o MA foi formado por 3 grupos: Condições, Cenários e Respostas. Para cada grupo foram dadas questões chave. Para o grupo "Cenários", a questão chave que direcionou o desenvolvimento dos cenários do Milênio foi:

Quais serão as conseqüências plausíveis das mudanças nas trajetórias de desenvolvimento para os ecossistemas e seus serviços e para o bem-estar humano?

A partir desta outras quatro questões mais específicas foram consideradas:

1) Quais são as conseqüências para os serviços dos ecossistemas e para o bem-estar humano de estratégias que enfatizam reformas econômico-politicas (redução dos subsídios e internalização das externalidades) como principal medida de planejamento?

2) Quais são as conseqüências para os serviços dos ecossistemas e para o bem-estar humano de estratégias que enfatizam a segurança e a proteção local e regional?

3) Quais são as conseqüências para os serviços dos ecossistemas e para o bem-estar humano de estratégias que enfatizam o desenvolvimento e o uso de tecnologias permitindo maior eco-eficiência e controle adaptativo?

4) Quais são as conseqüências para os serviços dos ecossistemas e para o bem-estar humano de estratégias que enfatizam o manejo adaptativo e a aprendizagem local sobre as conseqüências das intervenções nos serviços dos ecossistemas?

Com base nessas questões chaves foram desenvolvidos quatro cenários que exploram aspectos de futuros globais plausíveis e suas implicações para os serviços dos ecossistemas. Os cenários são: Global Orchestration (GO), Order From Strength (OS), Adapting Mosaic 
(AM) e TechnoGarden (TG); sendo dois deles dados em torno de políticas pró-ativas de manejo dos ecossistemas (AM e TG) e dois em torno de políticas reativas (GO e OS).

No cenário Global Orchestration, acredita-se, firmemente, na capacidade do ser humano em descobrir caminhos tecnológicos para reparar ou readaptar funções perdidas dos ecossistemas; além disso, os ecossistemas são encarados como resistentes aos impactos do homem, algo também considerado no cenário Order From Strength. No entanto, o foco de OS está na segurança nacional e no crescimento econômico, os ecossistemas são considerados somente após forte pressão econômica e social.

Quanto às políticas pró-ativas, no cenário TechnoGarden as mesmas surgem devido ao reconhecimento do valor econômico dos serviços dos ecossistemas. Já em Adapting Mosaic, as políticas emergem a partir de um forte reconhecimento do amplo valor dos serviços dos ecossistemas como suporte à vida e ao bem-estar humano e na necessidade de se trabalhar com a natureza e não contra ela.

No desenvolvimento da quantificação dos cenários foram incluídas relações entre crescimento populacional e as demandas por bens e provisão dos serviços dos ecossistemas como alimentação, energia e madeira/floresta. A quantificação dos cenários demonstrou menor crescimento econômico para os cenários com desenvolvimento de políticas regionais (OS e AM), como pode ser visualizado nas figuras 4 e 5.

As mudanças nos ecossistemas foram avaliadas a partir dos estudos sobre suas condições atuais e suas tendências. Os estudos relatam que a maior parte das forças impulsoras de degradação nos serviços do ecossistema ou permanecem constantes ou estão crescendo em intensidade na maioria dos ecossistemas (Figura 6).

As estimativas dos serviços de provisão, regulação e culturais variam muito em cada cenário e também entre os paises desenvolvidos e em desenvolvimento (Figura 7). 


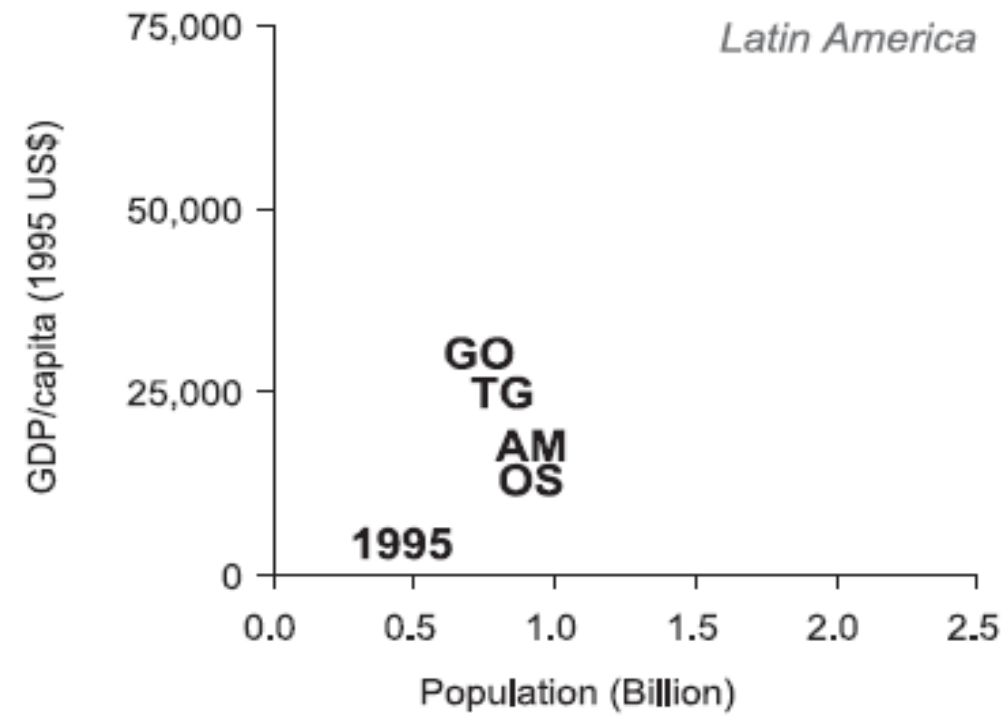

Figura 4: Projeção de mudanças na renda da população em cada cenário em 1995 e 2050 . O número 1995 indica o valor GPD (Gross Domestic Product) para este ano, as demais indicações GO, OS, AM e TG indicam o mesmo parâmetro para o ano de 2050.

Fonte: MA (2005).

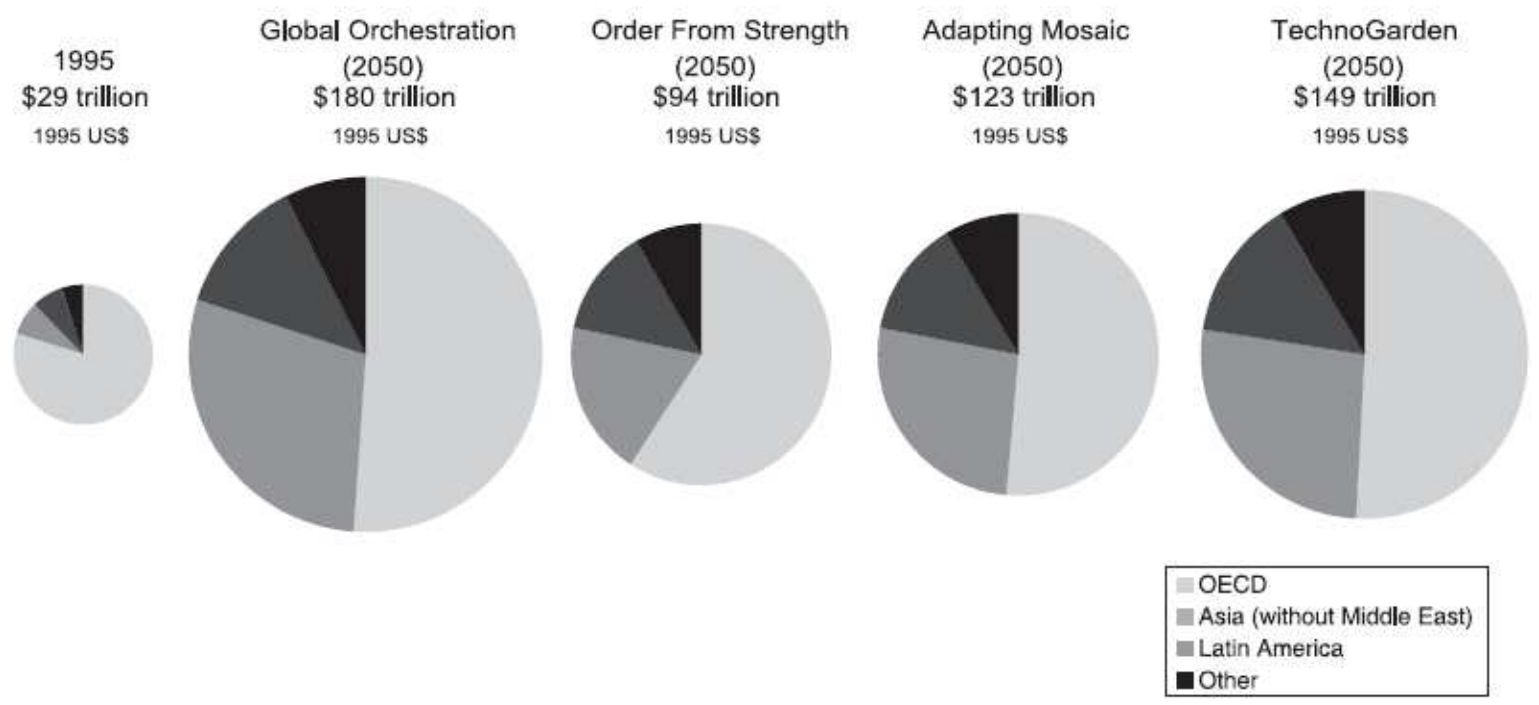

Figura 5: Projeção das mudanças na economia para os quatro cenários. Fonte: MA (2005) 


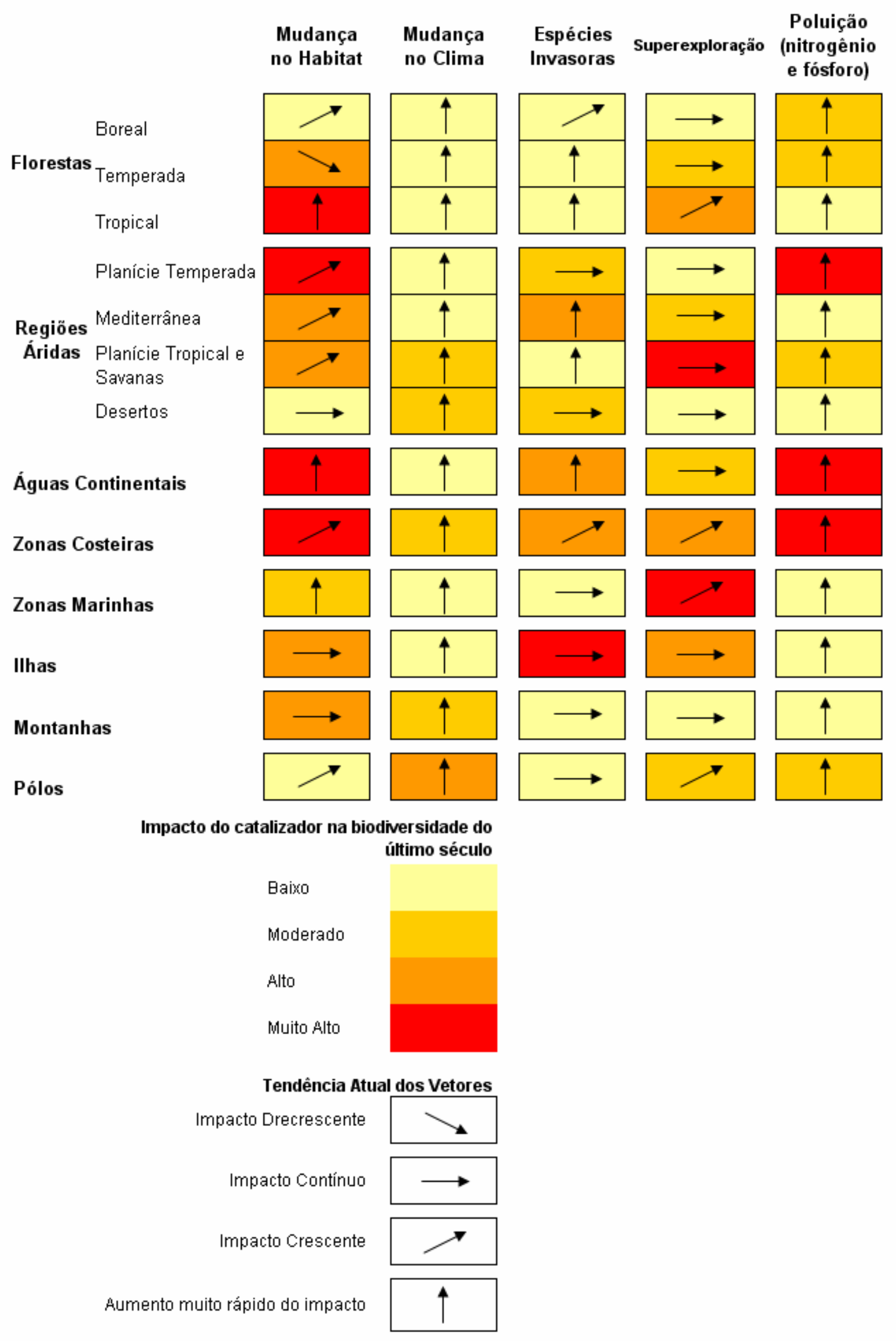

Figura 6: Avaliação dos principais vetores de mudança na biodiversidade e nos ecossistemas, e suas tendências.

Fonte: Percy \& Lubchenco (2006). 


\begin{tabular}{|c|c|c|c|c|c|c|c|c|}
\hline \multirow[b]{2}{*}{ Serviços de provisäo } & \multicolumn{2}{|c|}{ Global Orchestration } & \multicolumn{2}{|c|}{ Order From Strength } & \multicolumn{2}{|c|}{ Adapting Mosaic } & \multicolumn{2}{|c|}{ TechnoGarden } \\
\hline & \begin{tabular}{|c} 
Países \\
Desenvolvidos
\end{tabular} & $\begin{array}{c}\text { Paises em } \\
\text { Desenvolvimento }\end{array}$ & \begin{tabular}{|c} 
Países \\
Desenvolvidos
\end{tabular} & $\begin{array}{c}\text { Paises em } \\
\text { Desenvolvimento }\end{array}$ & \begin{tabular}{|c} 
Países \\
Desenvolvidos
\end{tabular} & $\begin{array}{c}\text { Paises em } \\
\text { Desenvolvimento }\end{array}$ & \begin{tabular}{|c} 
Países \\
Desenvolvidos
\end{tabular} & $\begin{array}{c}\text { Paises em } \\
\text { Desenvolvimento }\end{array}$ \\
\hline $\begin{array}{l}\text { Alimento (extensắo para a } \\
\text { qual a demanda é } \\
\text { encontrada) }\end{array}$ & $\boldsymbol{4}$ & $\boldsymbol{4}$ & $\leftrightarrow$ & $\downarrow$ & $\leftrightarrow$ & $\downarrow$ & $\boldsymbol{4}$ & $\boldsymbol{4}$ \\
\hline Combustivel & $\stackrel{4}{4}$ & $\stackrel{4}{4}$ & 4 & 4 & 4 & $\hat{4}$ & $\stackrel{4}{\leftrightarrow}$ & $\hat{4}$ \\
\hline Recursos genéticos & & & & & & & & \\
\hline $\begin{array}{l}\text { Descobertas } \\
\text { bioquímicas/farmacêuticas }\end{array}$ & $\downarrow$ & $\boldsymbol{4}$ & $\downarrow$ & $\downarrow$ & $\leftrightarrow$ & $\leftrightarrow$ & 4 & $\boldsymbol{4}$ \\
\hline $\begin{array}{l}\text { Recursos ornamentais } \\
\text { Água potável } \\
\end{array}$ & $\stackrel{\leftrightarrow}{4}$ & $\stackrel{\leftrightarrow}{\mathbf{P}}$ & $\leftrightarrow$ & $\downarrow$ & 4 & $\stackrel{4}{t}$ & $\stackrel{\leftrightarrow}{4}$ & $\stackrel{\leftrightarrow}{\leftrightarrow}$ \\
\hline $\begin{array}{l}\text { Serviços de regulaçāo } \\
\text { Regulaçăo da qualidade } \\
\text { do ar }\end{array}$ & $\leftrightarrow$ & $\leftrightarrow$ & $\leftrightarrow$ & $\downarrow$ & $\leftrightarrow$ & $\rightarrow$ & $\boldsymbol{4}$ & 4 \\
\hline Regulaçẵo do clima & $\leftrightarrow$ & $\rightarrow$ & $\downarrow$ & $\downarrow$ & $\leftrightarrow$ & $\leftrightarrow$ & 4 & $\boldsymbol{4}$ \\
\hline Regulaçẫo da água & $\leftrightarrow$ & $\downarrow$ & $\downarrow$ & $\downarrow$ & 4 & 4 & $\leftrightarrow$ & $\boldsymbol{4}$ \\
\hline Controle de erosăo & $\leftrightarrow$ & $\mathbf{t}$ & $\downarrow$ & $\downarrow$ & $\hat{4}$ & $\boldsymbol{4}$ & $\leftrightarrow$ & $\boldsymbol{4}$ \\
\hline $\begin{array}{l}\text { Purificação de água } \\
\text { Controle de }\end{array}$ & $\rightarrow$ & $\checkmark$ & $\downarrow$ & $\downarrow$ & $\mathbf{P}$ & $\mathbf{P}$ & & $\mathbf{P}$ \\
\hline doenças:humanos & $\rightarrow$ & $\mathbf{P}$ & $\leftrightarrow$ & $\checkmark$ & $\rightarrow$ & $\mathbf{P}$ & $\mathbf{P}$ & $\mathbf{P}$ \\
\hline $\begin{array}{l}\text { Controle de } \\
\text { doenças:pestes }\end{array}$ & $\leftrightarrow$ & $\downarrow$ & $\downarrow$ & $\downarrow$ & 4 & $\boldsymbol{4}$ & $\leftrightarrow$ & $\leftrightarrow$ \\
\hline Polinizaçẵo & $\downarrow$ & $\downarrow$ & $\downarrow$ & $\downarrow$ & $\leftrightarrow$ & $\leftrightarrow$ & $\downarrow$ & $\downarrow$ \\
\hline Proteçăo à tempestades & $\rightarrow$ & $\downarrow$ & $H$ & $\downarrow$ & $\mathbf{Y}$ & 4 & $\boldsymbol{P}$ & $\leftrightarrow$ \\
\hline $\begin{array}{l}\text { Serviços Culturais } \\
\text { Valores } \\
\text { espirituais/religiosos }\end{array}$ & $\leftrightarrow$ & $\leftrightarrow$ & $\leftrightarrow$ & $\downarrow$ & 4 & 4 & $\downarrow$ & $\downarrow$ \\
\hline $\begin{array}{l}\text { Valores estéticos } \\
\text { Recreacâo e ecoturismo }\end{array}$ & $\leftrightarrow$ & $\leftrightarrow$ & $\leftrightarrow$ & $\downarrow$ & 4 & 4 & $\leftrightarrow$ & $\leftrightarrow$ \\
\hline $\begin{array}{l}\text { Recreaçấo e ecoturismo } \\
\text { Diversidade cultural }\end{array}$ & $\downarrow$ & $\downarrow$ & $\downarrow$ & $\downarrow$ & $\boldsymbol{4}$ & $\boldsymbol{4}$ & $\downarrow$ & $\mathbf{9}$ \\
\hline $\begin{array}{l}\text { Sistemas de } \\
\text { aprendizagem (diversidade } \\
\text { e memória) }\end{array}$ & $\leftrightarrow$ & $\downarrow$ & $\downarrow$ & $\downarrow$ & 4 & 4 & $\leftrightarrow$ & $\leftrightarrow$ \\
\hline
\end{tabular}

Figura 7: Estimativa dos serviços de provisão, regulação e culturais para paises desenvolvidos e em desenvolvimento. Fonte: MA - Synthesis (2005) 


\subsubsection{Global Orchestration}

O cenário Global Orchestration (GO) é caracterizado por uma sociedade globalmente conectada com ênfase no comércio global e na liberalização econômica. Baseia-se em cooperações globais com vistas à proteção de bens e serviços públicos (saúde, educação infraestrutura); além da melhoria na economia e na sociedade.

Dá grande valor ao indivíduo, em detrimento do Estado; no entanto embora incentive práticas do desenvolvimento sustentável, a abordagem reativa do manejo dos ecossistemas torna as pessoas vulneráveis ao aparecimento de surpresas provenientes de ações tardias. Os problemas ambientais que estão relacionados com o bem-estar humano, somente são considerados após essa ligação se tornar evidente.

O crescimento econômico, a expansão da educação, e o aumento da classe média conduzem à necessidade por cidades adequadas (limpas), com menos poluição, e mais belezas naturais. A elevação da renda induz mudanças sobre padrão de consumo global, com aumento na demanda dos serviços dos ecossistemas - incluindo produtos agrícolas como carne, peixe e vegetais - e, provocando dessa forma, o declínio de outros como a conversão das florestas em áreas de cultivo e pastagem. Todavia, esses problemas recebem pouca atenção, pois não são facilmente evidenciados pela população, que vivem, em sua maioria, em áreas urbanas. Dessa forma, um enorme e crescente número de pessoas é afetado pela perda dos serviços básicos dos ecossistemas, que são essenciais para a vida humana.

Perdas na oferta de águas potável, falência na plantação, ocorrência de inundações, aumento de espécies invasoras e patogênicas são alguns exemplos das conseqüências do planejamento adotado nesse cenário.

Portanto, a questão chave a ser enfrentada nesse cenário é relação entre a abrupta expansão econômica e as mudanças imprevisíveis nos ecossistemas. 


\subsubsection{Order from Strength}

O cenário Order From Strength (OS) representa um mundo regionalizado e fragmentado, preocupado com segurança e proteção, enfatizando principalmente mercados regionais e, dando pequena atenção aos bens comuns, com abordagem reativas em relação ao manejo dos ecossistemas e atitudes individualistas.

Como o foco principal as nações põem-se a proteger suas fronteiras e seu povo, assim como também suas políticas ambientais com ênfase na segurança dos recursos naturais de forma crítica para o bem estar humano, defendendo os escassos recursos que lhes restam.

O comércio é restrito, grandes quantidades de dinheiro são investidas em sistemas de segurança, e lentas mudanças tecnológicas ocorrem devido às limitações no fluxo de bens e informações. Ocorre exagerada regionalização e elevada desigualdade global. Quando comparado com os demais cenários, o crescimento econômico está entre os mais baixos e o crescimento populacional é o mais elevado.

Como no cenário Global Orchestration (GO) o meio ambiente esta em segundo plano em relação às demais mudanças. Há a crença na habilidade dos seres humanos de criar inovações tecnológicas como soluções para os problemas ambientais após mudanças emergentes. Os serviços dos ecossistemas tornam-se mais vulneráveis, frágeis e variáveis. Por exemplo, existem parques e reservas com limites fixados, mas as mudanças climáticas guiam a extinção de muitas espécies. O baixo nível do comércio tende a restringir o número de invasões por espécies exóticas, os ecossistemas são menos resilientes e, devido a este fato, espécies invasoras têm maior facilidade de adaptação. Tratados sobre mudança climática global, pesca internacional, e comércio de espécies comprometidas são fracamente implementados, resultando em uma degradação global comum. 
Alguns benefícios potenciais, no entanto, podem ser destacados como: aumento na segurança das nações; menor expansão de espécies invasoras (pragas); controle do comércio e das doenças de fronteira; proteção dos ecossistemas de países ricos; proteção de indústrias locais. Como riscos têm-se: elevada desigualdade social conduzindo à desnutrição; a perda da liberdade, e outros declínios do bem-estar humano; rupturas na segurança; superexploração dos recursos naturais com intensa degradação ambiental em países pobres; baixo crescimento econômico.

\subsubsection{Adapting Mosaic}

O foco do cenário Adapting Mosaic (AM) está nas atividades políticas e econômicas em nível local, e em ecossistemas regionais em âmbito de bacias hidrográficas. Há investimento no capital social e humano, com o objetivo de aperfeiçoar o conhecimento sobre funcionamento e manejo dos ecossistemas, resultando na melhora do entendimento sobre resiliência, fragilidade e flexibilidade dos ecossistemas locais.

Existe o fortalecimento de instituições locais com formação de cooperativas e com a abordagem pró-ativa da gestão dos ecossistemas, por meio do manejo integrado. Esse cenário dá ênfase no aprendizado a partir de experiências em todos os processos de desenvolvimento.

Possui muitas técnicas de governabilidade em torno de nações e regiões, incluindo o manejo dos serviços dos ecossistemas. Algumas regiões exploram ativamente o manejo adaptativo, enquanto outras utilizam burocraticamente métodos rígidos para otimizar a performance dos ecossistemas, como práticas de comando e controle. Com isso, há diferenças nas repostas do ambiente, algumas áreas prosperam, enquanto outras desenvolvem severa desigualdade ou experiências de degradação ecológica. 
Eventualmente, o foco na governança local conduz à falhas no gerenciamento de interesses globais comum. Como solução há o desenvolvimento de redes entre comunidades, regiões e mesmo nações. As soluções que eram eficazes localmente são adotadas entre as redes. Essas redes de sucesso regional são especialmente comuns em situações onde existem benefícios mútuos no planejamento, como ao longo de vales do rio.

Quanto ao crescimento econômico, as taxas iniciais são baixas, mas aumentam ao longo do tempo.

\subsubsection{TechnoGarden}

O cenário TechnoGarden (TG) descreve um mundo globalizado que confia fortemente na tecnologia, principalmente às tecnologias ambientais que enfatizam uma abordagem próativa da gestão dos ecossistemas, denominadas tecnologias limpas.

O investimento em tecnologias verdes é acompanhado por significativo foco no desenvolvimento econômico e na educação, melhorando a vida das pessoas e ajudando-as a compreender que os ecossistemas são os responsáveis pelo fornecimento dos meios de subsistência da população.

Nesse cenário, elementos do bem-estar humano estão associados com declínio das relações socias, devido a grande perda da cultura local, dos costumes e do conhecimento tradicional, pois há um aumento de interações que ocorrem por meio da internet.

Em relação aos outros cenários, o crescimento populacional é relativamente alto e aumenta, enquanto a população em 2050 torna-se mediana.

A capacidade inovadora expande rapidamente o desenvolvimento das nações. A provisão confiável dos serviços dos ecossistemas como componente da expansão econômica, 
juntamente com a melhoria da tecnologia, devido ao aumento dos níveis de renda, eleva muitos pobres do mundo à classe média global.

No entanto, as soluções tecnológicas às vezes criam novos problemas e vulnerabilidades, com isso destruições ambientais em TG, afetam grande número de pessoas tornando-se algo comum.

A mudança para o futuro é de aprender como organizar sistemas sócio-ecológicos de modo que serviços ecológicos sejam mantidos sem taxas da sociedade habilitando-a a implementar novas soluções para problemas emergentes.

\subsubsection{Cenários Aplicados à Drenagem Urbana}

A utilização de cenário em estudos de drenagem urbana é uma ferramenta já consagrada pela comunidade científica. Inicialmente, as pesquisas avaliavam cenários tendenciais de crescimento urbano e usas implicações sobre os sistemas de drenagem; estudos subseqüentes comparavam cenários tendenciais a cenários que utilizavam alguma medida de mitigação como o cumprimento de diretrizes de Planos Diretores e de Planos de Bacias, por exemplo. No entanto, a escala temporal empregada nesses estudos é de curto e médio prazo.

Quanto à área de recursos hídricos especificamente, trabalhos que abordam o conceito de cenários e os utilizam para avaliações em termos de custos relacionados à secas ou inundações, demanda e disponibilidade hídrica, vazão máxima em eventos de inundações entre outros, podem ser citados (Macêdo et al., 2004; Ohnuma Jr, 2005; Mendes, 2005; Macêdo, 2005; Boldrin, 2005; Benini, 2005; Alves, 2005; Doll et al, 2000; Mendiondo, 2005 e 2006; e, Campana e Tucci, 1999).

A utilização dos cenários do Millennium Ecosystem Assessment (AM) com diferentes enfoques tem sido evidenciada como, por exemplo, os estudos realizados por Mendiondo 
(2004) em que tratam sobre demanda e oferta hídrica global a partir de uma visão hidrosolidária com vistas à cooperação em projetos transnacionais. O mesmo autor em trabalhos mais recentes (2006 e 2007), aborda o emprego desses cenários no planejamento de sistemas de alerta de riscos de inundações.

Estes são apenas alguns exemplos da utilização de cenários como ferramenta de planejamento na área de recursos hídricos, neste sentido há ainda que se aprofundar mais no assunto.

\subsection{Modelos Hidrológicos}

Modelo é uma representação de algum objeto ou de algum sistema real. No caso dos modelos hidrológicos há uma busca para a melhor compreensão dos fenômenos físicos que ocorrem em uma bacia hidrográfica, de forma a representar teoricamente estes fenômenos e de prever condições diferentes das observadas (Tucci, 1998). Esses modelos permitem ainda reconstituir séries hidrológicas, simular condições críticas e estudar o comportamento dos sistemas hidrológicos (Barth, 1987). Tornam-se, desta forma, ferramentas essenciais para o melhor gerenciamento dos recursos hídricos, quando o tomador de decisão necessita avaliar processos quantitativos em diferentes fases e/ou segundo diferentes cenários (Ohnuma Jr, 2005). A figura 8 apresenta, dentro de um estudo, a etapa na qual os modelos são utilizados. 


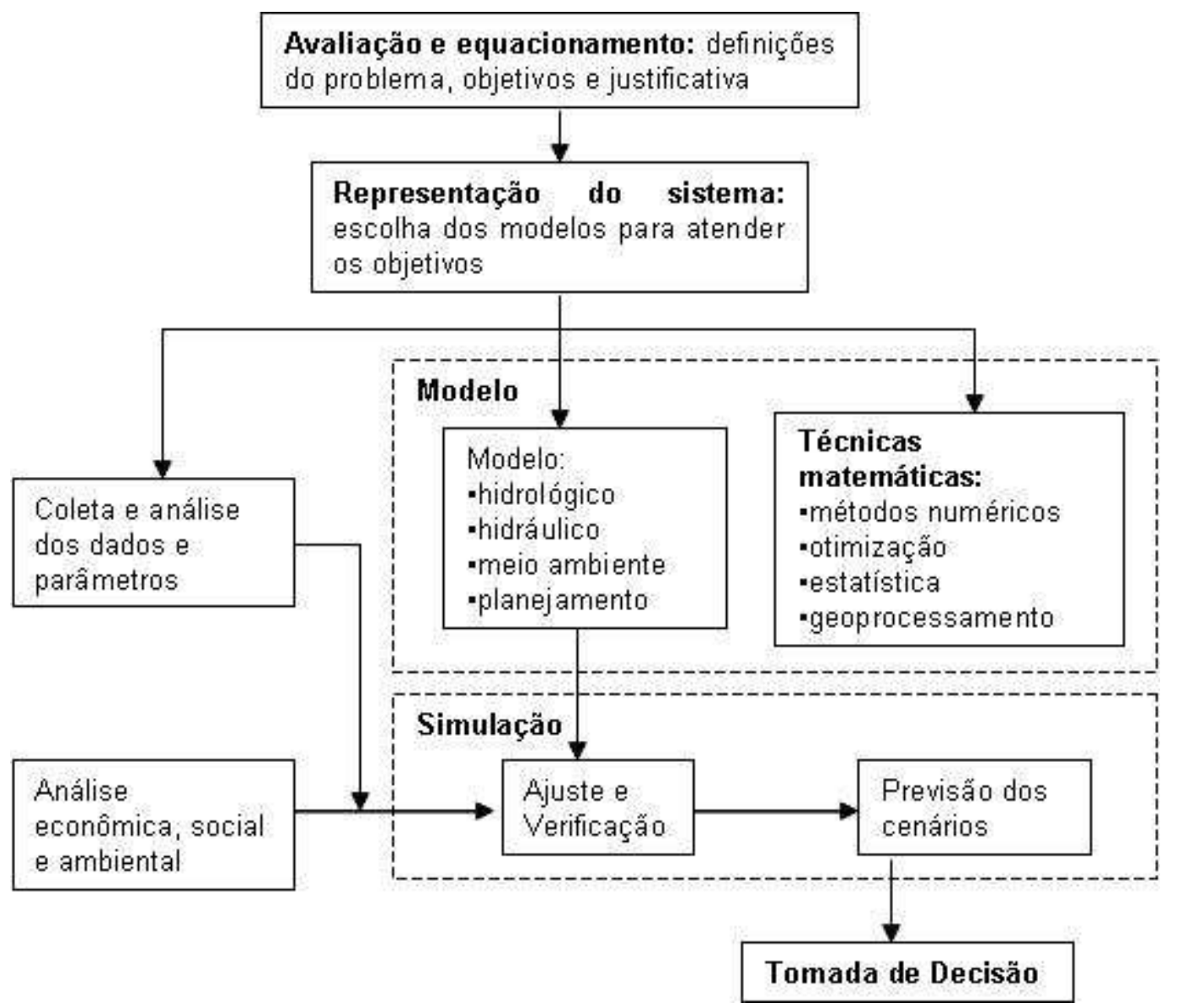

Figura 8: O modelo inserido nas fases de um estudo. Fonte: (Tucci, 1998).

Existe uma grande diversidade de modelos utilizados no gerenciamento dos recursos hídricos. São modelos que simulam operações em reservatórios, redes de canais e condutos, qualidade das águas em rios e reservatórios, gestão de sistemas múltiplos (canais, estações de tratamento, reservatórios), geração estocástica de vazões, processo precipitação-vazão, entre outros.

Os modelos hidrológicos de precipitação-vazão variam em função de alguns fatores como: número de parâmetros exigidos como dados de entrada, conceitos utilizados, simplificações adotadas. São classificados por Righetto (1998) e Tucci (1998) da seguinte maneira:

- contínuo ou discreto; 
- concentrado ou distribuído

- conceitual ou empírico;

- estocástico (probabilístico) ou determinístico;

- geomorfológicos ou baseados na topografia.

A estrutura dos modelos hidrológicos precipitação-vazão é, atualmente, baseada na discretização da bacia hidrográfica, nas variáveis de entrada, na estrutura básica da integração dos processos, na aquisição dos dados físicos da bacia e na determinação dos parâmetros Tucci (1998).

De acordo com o mesmo autor, pode se citar alguns modelos hidrológicos ditos “pioneiros”como: SSARR (Rockwood, 1958) ${ }^{4}$, STANFORD IV (Crawford e Linsley, 1966) Kentucky Model (James, 1970) ${ }^{6}$, Texas Watershed Model (Claborn e Moore, 1970) ${ }^{7}$, MIT (Harley et al., 1970) ${ }^{8}$, HEC-1 (US Army, 1973) ${ }^{9}$, Mero $\left(\right.$ Clarke, 1973) ${ }^{10}$.

Boldrin (2005) descreve modelos mais recentes e os reúne em dois grupos internacionais e nacionais. Como exemplos de modelos que compõem o primeiro grupo, podem-se citar: HEC-2 (USACE, 1990) ${ }^{11}$, TR-20 (SCS, 1992), PondPack (HAESTAD, 2003) $)^{12}$, MIKE 11 (DHI, 2003) ${ }^{13}$; já para o segundo grupo têm-se: IPH II, IPH III e IPH IV (Tucci, 1998), ABC 3, ABC 4, ABC 5 e ABC 6 (LabSid/PHD/POLI/USP - disponível em: http://143.107.96.240/labsid/Objetivos.aspx).

Lira (2003) utilizou em seu trabalho o modelo EESC modificado e cita dois outros modelos: DRENG-P21A (Machado, 1981) ${ }^{14}$ e HIDRO-SHS (Silva, 2003).

Entre os citados, o modelo hidrológico utilizado no presente trabalho é o Modelo IPH S1, o qual compreende como método de separação do escoamento, dentre outros, o já consagrado SCS. Já para representar o escoamento em rios, o modelo oferece o método Muskingum clássico e suas variações, além do escoamento em reservatórios pelo método de 
Puls e a derivação de vazões por meio de um algoritmo para separação de fluxo. Desta maneira, no tópico seguinte as características dos mesmos são descritas detalhadamente.

\subsubsection{Modelo IPH-S1}

O modelo IPH-S1, para Windows ${ }^{\circledR}$ versão 2.11, é um sistema computacional modulado formado por três componentes:

- leitura de dados e manejo de arquivos;

- modelos;

- impressão e graficação.

De maneira simplificada, pode-se afirmar que o modelo simula, através da alimentação dos dados de precipitação e das características das bacias e dos canais, a vazão nas seções de interesse.

Com base em diferentes cenários de uso e ocupação do solo, bem como de cenários climáticos (representados pela variação nas precipitações), pode-se prever o comportamento do sistema hidráulico de uma dada bacia a partir da mudança de alguns parâmetros.

Internamente, o mesmo é modulado de acordo com as "operações hidrológicas", e oferece as opções: escoamento em rios; propagação em reservatórios; transformação precipitação - vazão na bacia; entrada, soma ou derivação de hidrogramas.

A componente "modelos” está discretizada em dois módulos: Módulo Bacia e Módulo Rio. O programa permite a subdivisão das bacias em sub-bacias, com configuração baseada nos parâmetros de precipitação, precipitação efetiva e escoamento superficial. O módulo rio compreende os trechos d'água e é dividido em três partes: escoamento em rios, escoamento em reservatórios e derivação de vazões (IPH-UFRGS, ALM/FEA/IMF-UFPel, DFIS-FURG, 2004). Maiores detalhes sobre as configurações dos módulos bacia e rio, assim como dos métodos empregados em cada um, podem ser visualizados na figura 9. 


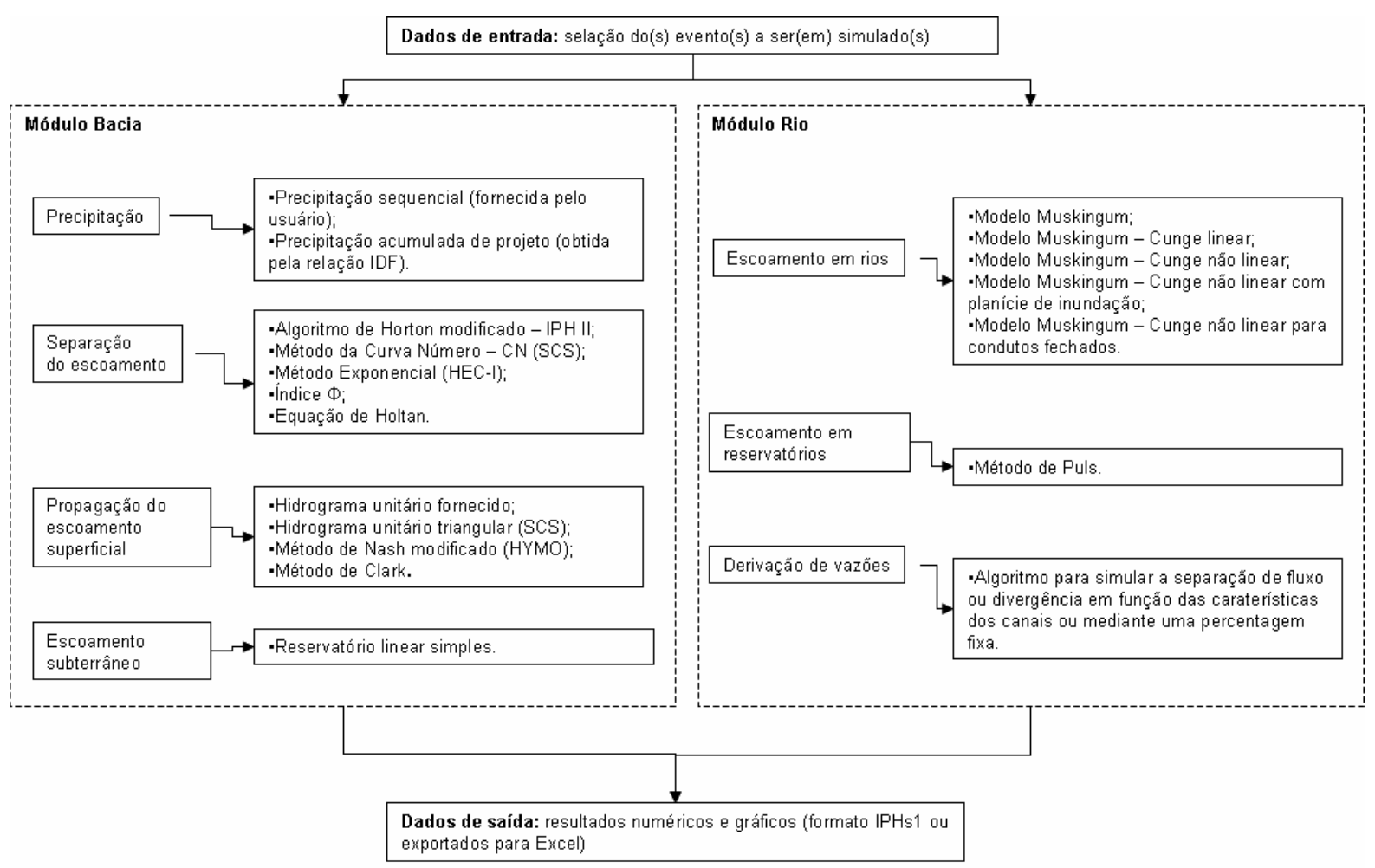

Figura 9: Configuração detalhada dos módulos bacia e rio com os métodos adotados.

\subsubsection{Método SCS}

Baseado no conceito de Curva Número, o método do SCS (Soil Conservation Service, 1975 apud Tucci 1998) é o método de separação de escoamento mais conhecido e empregado em todo o mundo, devido a sua fácil utilização e pelo reduzido número de parâmetros. A relação direta entre os parâmetros e as características das bacias é outro fator preponderante para sua escolha.

De acordo com Tomaz (2002) o mesmo é aplicável a áreas que variam entre $3 \mathrm{~km}^{2} \mathrm{e}$ $250 \mathrm{~km}^{2}$. Tucci (1998), no entanto, salienta que o método foi proposto inicialmente para simular de forma concentrada uma pequena bacia rural, mas pode ser utilizado para bacias maiores bastando para isso subdividi-las em sub-bacias e empregar em conjunto com um modelo de escoamento em rios e canais. 
Para determinação do volume superficial o método utiliza uma expressão que relaciona a precipitação total acumulada com o volume superficial acumulado, a infiltração e o escoamento da bacia, resultando em:

$$
Q=\frac{\left(P-I_{a}\right)^{2}}{\left(P-I_{a}\right)+S}
$$

em que:

Q: volume superficial acumulado ( $\mathrm{mm})$;

P: precipitação total acumulada $(\mathrm{mm})$;

$\mathrm{I}_{\mathrm{a}}:$ perdas iniciais $(\mathrm{mm})$;

S: capacidade máxima de armazenamento no solo (mm).

As perdas iniciais $\left(\mathrm{I}_{\mathrm{a}}\right)$ compreendem a parcela de água precipitada retida nas depressões no solo, interceptadas pela vegetação, infiltrada e/ou evaporada, antes da geração do escoamento superficial. $\mathrm{O}$ valor de $\mathrm{I}_{\mathrm{a}}$ foi determinado empiricamente para as condições dos solos dos Estados Unidos. A partir desse estudo, estimou-se como valor médio $20 \%$ da capacidade máxima de armazenamento do solo.

$$
I_{a}=0.2 S
$$

Desta maneira, ao adotar a relação acima descrita obtém-se:

$$
\begin{array}{lll}
Q=0 & \text { quando } & P<I_{a} \\
Q=\frac{(P-0,2 S)^{2}}{(P+0,8 S)} & \text { quando } & P>I_{a}
\end{array}
$$

Por meio da análise de mais de 3 mil tipos de solo com suas respectivas coberturas vegetais e plantações estabeleceu -se uma relação empírica entre a capacidade de armazenamento da bacia (S) e um índice denominado de Curva Número (CN). (CANHOLI, 2005).

$$
S=\frac{25400}{C N}-254
$$


em que:

S: capacidade máxima de armazenamento no solo (mm);

$\mathrm{CN}$ : curva número.

Conforme Tomaz (2002) podem ser descritas algumas limitações que dizem respeito às equações do método SCS. A primeira delas refere-se ao $\mathrm{CN}$ que descreve em muitos casos um valor médio de uma dada área sem levar em conta o parâmetro do tempo e da duração ou intensidade da chuva, por isso o autor recomenda a precaução no uso do CN. Outro fator que merece ter cautela é a abstração inicial $\left(\mathrm{I}_{\mathrm{a}}\right)$ que foi obtida inicialmente para bacias rurais e que para bacias urbanas pode implicar em aumento ou diminuição das perdas de água que podem não ser consideradas.

Os principais fatores que determinam o valor do parâmetro $\mathrm{CN}$ são os grupos hidrológicos do solo, as curvas tipo, as condições hidrológicas e as condições de umidade antecedentes. Entretanto, outro fator a ser considerado é se as saídas das áreas impermeáveis estão diretamente conectadas a rede de drenagem (área diretamente conectada) ou se as mesmas deságuam em áreas permeáveis (áreas não conectadas) e, por conseqüência, infiltram-se no solo (USDA, 1986).

Os grupos hidrológicos do solo são classificados, de acordo com suas taxas de infiltração mínima, em quatro grupos: A, B, C e D. Suas características são descritas abaixo com base em Tucci (1998), Canholi (2005), Porto e Setzer (1979) e Porto (1995), os dois últimos citados por Tomaz (2002).

Solo A: Solos arenosos com baixo teor de argila (menor que 10\%), sem presença de rochas nem camadas argilosas até a profundidade de $1,5 \mathrm{~m}$. Possuem alta taxa de infiltração mesmo quando saturados $(1,20 \mathrm{~cm} / \mathrm{h}-0,80 \mathrm{~cm} / \mathrm{h})$ e baixo escoamento superficial. 
Solo B: Solos arenosos menos profundos que os do tipo A, com menor teor de argila (10\% - 20\%), com menos finos, sem a presença de pedras e camadas argilosas até 1,5m, mas quase sempre com a camada mais densificada que a camada superficial. Menos permeáveis que o tipo A, porém com permeabilidade acima da média, com capacidade de infiltração de $0,80 \mathrm{~cm} / \mathrm{h}-0,40 \mathrm{~cm} / \mathrm{h}$.

Solo C: Solos pouco profundos, barrentos, com teor de argila entre $20 \%$ - 30\%, mas sem camadas de argilas impermeáveis ou contendo pedras até 1,20m. Possuem camada subsuperficial que impedem o fluxo descendente da água gerando escoamento superficial acima da média, com capacidade de infiltração de $0,40 \mathrm{~cm} / \mathrm{h}-0,15 \mathrm{~cm} / \mathrm{h}$.

Solo D: Solos argilosos (acima de 30\%) e ainda com camada densificada a uns $50 \mathrm{~cm}$ de profundidade, ou com nível freático elevado, ou solos rasos com camadas impermeáveis. Possuem baixa capacidade de infiltração $(0,15 \mathrm{~cm} / \mathrm{h}-0,00 \mathrm{~cm} / \mathrm{h})$, com maior geração de escoamento superficial.

Os valores de $\mathrm{CN}$ foram tabelas para áreas rurais e urbanas de acordo com o uso e a cobertura do solo. A escala do mesmo varia 0 a 100, no entanto, em termos práticos os limites utilizados ficam entre 1 e 98 que representam uma cobertura do solo permeável e totalmente impermeável, respectivamente. As tabelas 2 e 3 apresentam detalhadamente os valores de CN.

Tabela 2: Estimativa dos valores de $\mathrm{CN}$ para bacias rurais.

\begin{tabular}{cccccc}
\hline \multirow{2}{*}{ Uso do solo } & \multirow{2}{*}{ Superfície do solo } & \multicolumn{3}{c}{ Grupo de Solos } \\
\cline { 2 - 6 } & & $\mathbf{A}$ & $\mathbf{B}$ & $\mathbf{C}$ & $\mathbf{D}$ \\
\hline \multirow{2}{*}{ Solo lavrado } & Com sulcos retilíneos & 77 & 86 & 91 & 94 \\
\cline { 2 - 6 } & Em fileiras retas & 70 & 80 & 87 & 90 \\
\hline \multirow{3}{*}{ Plantações regulares } & Em curvas de nível & 67 & 77 & 83 & 87 \\
\cline { 2 - 6 } & Terraceado em nível & 64 & 76 & 84 & 88 \\
\cline { 2 - 6 } & Em fileiras retas & 64 & 76 & 84 & 88 \\
\hline \multirow{2}{*}{ Plantações de cereais } & Em curvas de nível & 62 & 74 & 82 & 85 \\
\cline { 2 - 6 } & Terraceado em nível & 60 & 71 & 79 & 82 \\
\cline { 2 - 6 } & Em fileiras retas & 62 & 75 & 83 & 87 \\
\hline
\end{tabular}


Continuação da Tabela 2: Estimativa dos valores de $\mathrm{CN}$ para bacias rurais.

Utilização ou cobertura do solo

Grupo de Solos

\begin{tabular}{|c|c|c|c|c|c|}
\hline \multirow{2}{*}{\multicolumn{2}{|c|}{ Utimzaçao ou copertura do solo }} & & & & \\
\hline & & A & B & C & D \\
\hline \multirow{5}{*}{ Plantações de legumes ou cultivados } & Em curvas de nível & 60 & 72 & 81 & 84 \\
\hline & Terraceado em nível & 57 & 70 & 78 & 89 \\
\hline & Pobres & 68 & 79 & 86 & 89 \\
\hline & Normais & 49 & 69 & 79 & 94 \\
\hline & Boas & 39 & 61 & 74 & 80 \\
\hline \multirow{3}{*}{ Pastagens } & $\begin{array}{l}\text { Pobres, em curvas de } \\
\text { nível }\end{array}$ & 47 & 67 & 81 & 88 \\
\hline & $\begin{array}{l}\text { Normais, em curvas de } \\
\text { nível }\end{array}$ & 25 & 59 & 75 & 83 \\
\hline & $\begin{array}{c}\text { Boas, em curvas de } \\
\text { nível }\end{array}$ & 6 & 35 & 70 & 79 \\
\hline \multirow{4}{*}{ Campos permanentes } & Normais & 30 & 58 & 71 & 78 \\
\hline & $\begin{array}{l}\text { Esparsas, de baixa } \\
\text { transpiração }\end{array}$ & 45 & 66 & 77 & 83 \\
\hline & Normais & 36 & 60 & 73 & 79 \\
\hline & $\begin{array}{l}\text { Densas, de alta } \\
\text { transpiração }\end{array}$ & 25 & 55 & 70 & 77 \\
\hline \multirow{3}{*}{$\begin{array}{c}\text { Chácaras } \\
\text { Estradas de Terra }\end{array}$} & Normais & 56 & 75 & 86 & 91 \\
\hline & Más & 72 & 82 & 87 & 89 \\
\hline & De superfície dura & 74 & 84 & 90 & 92 \\
\hline \multirow{4}{*}{ Florestas } & $\begin{array}{l}\text { Muito esparsas, baixa } \\
\text { transpiração }\end{array}$ & 56 & 75 & 86 & 91 \\
\hline & Esparsas & 46 & 68 & 78 & 84 \\
\hline & $\begin{array}{l}\text { Densas, de alta } \\
\text { transpiração }\end{array}$ & 26 & 52 & 62 & 69 \\
\hline & Normais & 36 & 60 & 70 & 76 \\
\hline
\end{tabular}

Fonte: Tucci (1993)

Tabela 3: Estimativa dos valores de CN para bacias urbanas e suburbanas.

\begin{tabular}{lcccc}
\hline \multirow{2}{*}{ Utilização ou cobertura do solo } & \multicolumn{4}{c}{ Grupo de Solos } \\
\cline { 2 - 5 } & A & B & C & D \\
\hline Zonas Cultivadas: sem conservação do solo & 72 & 81 & 88 & 91 \\
\hline \multicolumn{1}{c}{ com conservação do solo } & 62 & 71 & 78 & 81 \\
\hline Pastagens ou terrenos em más condições & 68 & 79 & 86 & 89 \\
\hline Baldios em boas condições & 39 & 61 & 74 & 80 \\
\hline Prado em boas condições & 30 & 58 & 71 & 78 \\
\hline Bosques ou zonas com cobertura ruim & 45 & 66 & 77 & 83 \\
\hline Florestais: cobertura boa & 25 & 55 & 70 & 77 \\
\hline
\end{tabular}


Continuação da Tabela 3: Estimativa dos valores de CN para bacias urbanas e suburbanas.

\section{Utilização ou cobertura do solo}

Grupo de Solos

$\begin{array}{llll}\text { A } & \text { B } & \text { C } & \text { D }\end{array}$

Espaços abertos, relvados, parques, campos de golfe, cemitérios, boas condições

\begin{tabular}{lllll}
\hline Com relva em mais de $75 \%$ da área & 39 & 61 & 74 & 80 \\
\hline Com relva de $50 \%$ a $75 \%$ da área & 49 & 69 & 79 & 84 \\
\hline Zonas comerciais e de escritórios & 89 & 92 & 94 & 95 \\
\hline Zonas industriais & 81 & 88 & 91 & 93 \\
\hline
\end{tabular}

Zonas residenciais

Lotes de $\mathrm{m}^{2} \quad \%$ média impermeável

\begin{tabular}{lccccc}
\hline$<500$ & 65 & 77 & 85 & 90 & 92 \\
\hline 1000 & 38 & 61 & 75 & 83 & 87 \\
\hline 1300 & 30 & 57 & 72 & 81 & 86 \\
\hline 2000 & 25 & 54 & 70 & 80 & 85 \\
\hline 4000 & 20 & 51 & 68 & 79 & 84 \\
\hline Parques de estacionamentos, telhados, viadutos, etc, & 98 & 98 & 98 & 98 \\
\hline
\end{tabular}

Arruamentos e estradas

\begin{tabular}{lllll}
\hline Asfaltadas e com drenagem de águas pluviais & 98 & 98 & 98 & 98 \\
\hline Paralelepípedos & 76 & 85 & 89 & 91 \\
\hline Terra & 72 & 82 & 87 & 89 \\
\hline
\end{tabular}

Fonte: Tucci (1993)

Para estimativa do parâmetro $\mathrm{CN}$ foram considerados três estados de umidade antecedente do solo, seco (AMC I), com umidade média correspondente a capacidade de campo (AMC II) e solos muito úmidos ou saturados (AMC III). Os valores de CN nas tabelas acima expostas foram estimados para solos em condições médias de umidade antecedente (AMC II). Nos casos em que o solo apresenta-se em uma das outras condições devem ser feitas correções de acordo com a tabela 4.

Tabela 4: Correção de CN para outras condições iniciais de umidade.

\begin{tabular}{ccc}
\hline Valores Médios (AMC II) & Correção para AMC I & Correção para AMC III \\
\hline 100 & 100 & 100 \\
\hline 95 & 87 & 98 \\
\hline 90 & 78 & 96 \\
\hline 85 & 70 & 94 \\
\hline
\end{tabular}


Continuação da Tabela 4: Correção de CN para outras condições iniciais de umidade.

\begin{tabular}{ccc}
\hline Valores Médios (AMC II) & Correção para AMC I & Correção para AMC III \\
\hline 80 & 63 & 91 \\
\hline 75 & 57 & 88 \\
\hline 70 & 51 & 85 \\
\hline 65 & 45 & 82 \\
\hline 60 & 40 & 78 \\
\hline 55 & 35 & 74 \\
\hline 50 & 31 & 70 \\
\hline 45 & 26 & 65 \\
\hline 40 & 22 & 60 \\
\hline 35 & 18 & 55 \\
\hline 30 & 15 & 50 \\
\hline 25 & 12 & 43 \\
\hline 20 & 9 & 37 \\
\hline 15 & 6 & 30 \\
\hline 10 & 4 & 22 \\
\hline 5 & 2 & 13
\end{tabular}

Fonte: Tucci (1998)

McCuen (1989) define os estados de umidade, para 5 dias de precipitação antecedente, em relação aos períodos latente e de crescimento da vegetação (Tabela 5).

Tabela 5: Limites para 5 dias de precipitação antecedente.

\begin{tabular}{lccc}
\hline \multicolumn{1}{c}{ Situação do Solo } & Condição do Solo & \multicolumn{2}{c}{ Chuva antecedente de 5 dias em mm } \\
\cline { 3 - 4 } & I & Período latente & Período de crescimento \\
\hline Solo Seco & II & $12,7 \mathrm{~mm}-27,94 \mathrm{~mm}$ & $35,56 \mathrm{~mm}$ \\
\hline $\begin{array}{l}\text { Solo sob condições } \\
\text { médias de umidade, } \\
\begin{array}{l}\text { condição normal das } \\
\text { tabelas de CN }\end{array}\end{array}$ & & \\
\hline $\begin{array}{l}\text { Solo úmido, com } \\
\text { precipitações nos últimos } \\
5 \text { dias, solo saturado }\end{array}$ & III & $>27,94 \mathrm{~mm}$ & $>53,34 \mathrm{~mm}$ \\
\hline
\end{tabular}

Fonte: McCuen (1989)

Como método de propagação do escoamento superficial, o modelo IPH-S1 possibilita a utilização de alguns métodos, dentre os quais, o método de separação do escoamento superficial da Curva Número (SCS) ao hidrograma unitário triangular do SCS - HU (10mm, t) - , obtido com base no valor de pico da vazão $(q)$ e no tempo de pico $\left(t_{p}\right)$ do hidrograma (Figura 10). 


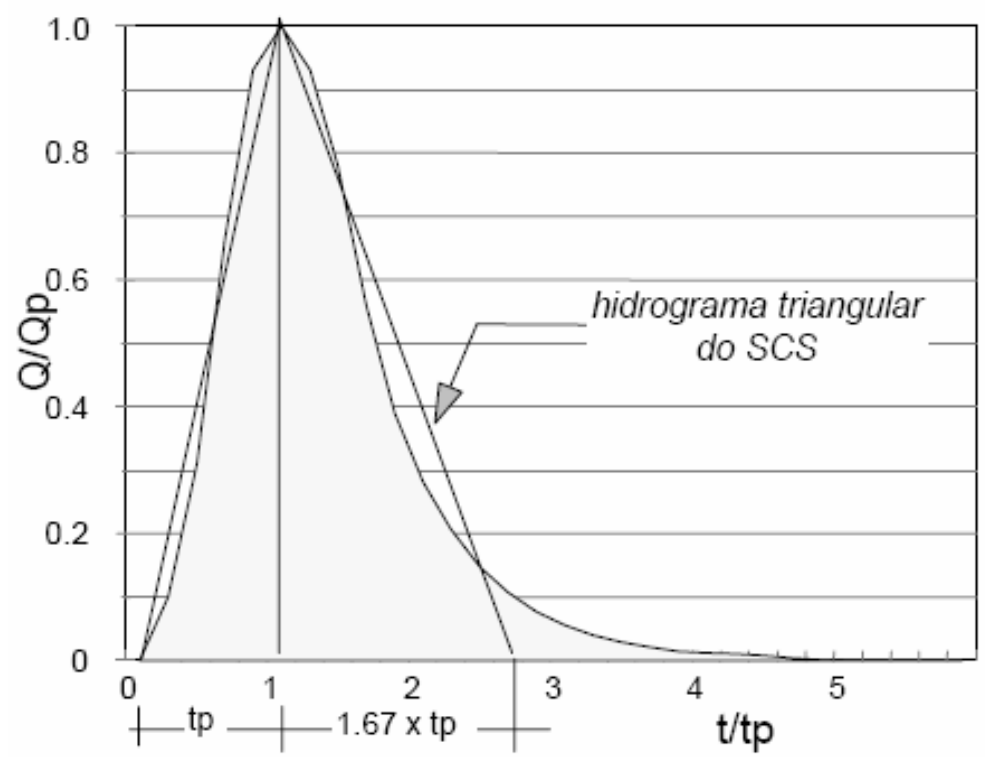

Figura 10: Hidrograma Unitário Triangular do SCS. Fonte: IPH-UFRGS, ALM/FEA/IMF-UFPel, DFIS-FURG (2004).

As equações que governam o método, de acordo com IPH-UFRGS, ALM/FEA/IMFUFPel, DFIS-FURG 2(004), são:

$$
\begin{aligned}
& q=\frac{2,08 A}{T_{p}} \\
& T_{p}=\frac{t_{r}}{2}+0,6 t_{c} \\
& T_{b}=T_{p}+t_{r}=2,67 T_{p} \\
& T_{c}=\frac{3,83 A^{0,41}}{S^{0,17}}
\end{aligned}
$$

em que:

q: vazão de pico $\left(\mathrm{m}^{3} / \mathrm{s}\right)$;

A: área da bacia $\left(\mathrm{km}^{2}\right)$;

$\mathrm{T}_{\mathrm{p}}$ : tempo de pico (h);

$\mathrm{t}_{\mathrm{r}}$ : duração da precipitação (h);

$\mathrm{T}_{\mathrm{c}}$ :tempo de concentração da bacia $(\mathrm{h})$;

$\mathrm{T}_{\mathrm{b}}$ : tempo de base $(\mathrm{h})$; 
S: declividade da bacia $(\mathrm{m} / 10 \mathrm{~km})$.

Tucci (1993) salienta que para bacias urbanas as quais possuem áreas impermeáveis e canalizações os tempos de deslocamento diminuem e, com isso os tempos de pico e de concentração são alterados, devendo, portanto ser feita uma correção nos tempos de pico. Propõe a adoção de 2 fatores denominados $\mathrm{f}_{1}$ e $\mathrm{f}_{2}$ relacionados com a redução no tempo de pico devido ao aumento das áreas impermeáveis e às canalizações, respectivamente. Apresenta ainda, dois gráficos que relacionam os percentuais de mudança com o $\mathrm{CN}$ da bacia.

Tucci (1998), apresenta a expressão que relaciona os fatores com o grau de mudança, dada por:

$$
t_{p}=t_{p}(\text { bacianatural }) f_{1} f_{2}
$$

Em que $\mathrm{f}_{1}$ e $\mathrm{f}_{2}$ são fatores de redução no tempo de pico.

Sendo:

$$
\begin{aligned}
& f_{1}=1-M_{a} K \\
& f_{2}=1-M_{c} K
\end{aligned}
$$

Em que $M_{a}$ é a percentagem de aumento de áreas impermeáveis e $M_{c}$ é a percentagem de aumento de áreas canalizadas e $\mathrm{K}$ é dado em função da curva número $(\mathrm{CN})$ por:

$$
K=\left(-0,02185 C N^{3}-0,4298 C N^{2}+335 C N-6789\right) \cdot 10^{-6}
$$

Como limitações do hidrograma unitário (HU), Tucci (2003) descreve:

1) representação linear do escoamento superficial a qual é, na realidade, dada por um comportamento não-linear;

2) consideração de distribuição uniforme da precipitação dentro do intervalo de tempo;

3) distribuição espacial uniforme da precipitação; 
4) erros dos métodos de separação do escoamento superficial e subterrâneo, que possibilitam a geração de dados hidrológicos para determinação do HU.

\subsubsection{Método Muskingum e suas variações}

O método Muskingum e suas diferentes versões estão inseridos no Módulo Rio do sistema operacional IPH S1, o qual compreende cinco métodos para representar o processo de propagação de cheias em canais, rios e reservatórios, e são denominados por:

a) Muskingum Clássico;

b) Muskingum-Cunge Linear;

c) Muskingum-Cunge Não Linear;

d) Muskingum-Cunge com Planície de Inundação;

e) Muskingum-Cunge para Condutos Fechados.

Como principal limitação tem-se a não consideração dos efeitos de jusante sobre o escoamento de montante o que ocorre, por exemplo, em rios que escoam para lagos ou mares.

A escolha do método depende das características do trecho a ser simulado, bem como dos dados disponíveis. No trabalho em questão a seleção é realizada com base nas características de cada cenário estudado.

a) Muskingum Clássico:

Desenvolvido em 1940 por McCarthy, esse método hidrológico foi concebido para a modelagem da propagação de cheias em cursos d'água onde a complexidade da geometria da calha principal e a de inundação dificultam a modelagem hidráulica do escoamento (Righetto, 
1998). O mesmo tem por base a equação da continuidade concentrada e uma função empírica que relaciona o armazenamento com as vazões de entrada e saída do trecho a ser simulado. De acordo com Barth et al. (1987), é um método do tipo Armazenamento, o qual possui como principal vantagem a utilização de poucos dados, além dos cálculos simples e do rápido uso. Como desvantagem, o mesmo autor destaca: a impossibilidade de utilização quando existem efeitos de jusante, a desconsideração do fluxo distribuído no rio ou canal e a não consideração dos termos dinâmicos.

Esse método leva em consideração dois parâmetros: $\mathrm{K}$ e $\mathrm{X}$; o primeiro representa $\mathrm{o}$ tempo de deslocamento da onda no trecho de propagação, enquanto o segundo pondera a influência das vazões de entrada e saída em função do armazenamento. No modelo IPH S1 os dados de entrada são: cota de fundo de montante (m), cota de fundo de jusante (m), altura do canal (m) e número de pontos da tabela na qual são inseridos os parâmetros $\mathrm{K}, \mathrm{X}$ e vazão $\left(\mathrm{m}^{3} / \mathrm{s}\right)$ para cada ponto.

b) Muskingum-Cunge Linear:

Cunge (1969) apud IPH-UFRGS, ALM/FEA/IMF-UFPel, DFIS-FURG (2004), a partir da premissa de igualdade entre difusão numérica produzida pelo método Muskingum e a difusão hidráulica real, transformou o método de Onda Cinemática de Muskingum em um método de Difusão.

Os parâmetros K e X são estimados com base nas características físicas do trecho de propagação e também na discretização espacial e temporal. Inicialmente, deve-se definir uma vazão específica de referência $\left(\mathrm{q}_{0}\right)$, normalmente adotada como sendo $2 / 3$ da vazão específica do pico do hidrograma de montante. De posse do valor de $\mathrm{q}_{0}$ e das características do canal o modelo estima a celeridade média da onda de cheia pela equação: 


$$
C=\frac{1}{B} \cdot \frac{d Q}{d h}
$$

Utilizando a equação de Manning para calcular a vazão total de canais prismáticos, a celeridade também pode ser estimada por:

$$
C=\frac{5}{3} \cdot \frac{S_{0}^{0,3} \cdot q^{0,4}}{n^{0,6}}
$$

em que:

C: celeridade da onda $(\mathrm{m} / \mathrm{s})$;

B: largura do canal (m);

h: altura do canal (m);

$\mathrm{S}_{0}$ : declividade de fundo do canal $(\mathrm{m} / \mathrm{m})$;

q: vazão específica por unidade de largura do canal $\left(\mathrm{m}^{3} / \mathrm{s} \cdot \mathrm{km}^{2}\right)$;

n: coeficiente de rugosidade de Manning.

Os parâmetros K e X constantes, uma vez adotada a discretização espacial e temporal, são estimados com base nas equações:

$$
\begin{aligned}
& X=0,5-\frac{q}{2 S_{0} c \Delta_{x}} \\
& K=\frac{\Delta_{x}}{c}
\end{aligned}
$$

em que:

c: celeridade da onda $(\mathrm{m} / \mathrm{s})$;

q: vazão específica por unidade de largura do canal $\left(\mathrm{m}^{3} / \mathrm{s} . \mathrm{km}^{2} / \mathrm{m}\right)$;

$\mathrm{S}_{0}$ : declividade de fundo do canal $(\mathrm{m} / \mathrm{m})$;

$\Delta_{\mathrm{X}}:$ discretização espacial (m); 
Contudo, para estimativa desses parâmetros deve-se cumprir as condições estabelecidas por Jones $(1981)^{15}$ apud IPH-UFRGS, ALM/FEA/IMF-UFPel, DFIS-FURG (2004), que relaciona os valores de $\mathrm{X}$ e $\mathrm{K} / \Delta \mathrm{t}$ para diferentes de erros de amortecimento e velocidade.

Os dados de entrada do modelo IPH S1 são: comprimento do trecho de propagação (m), cota de fundo de montante (m), cota de fundo de jusante (m), altura e largura do canal (m), rugosidade dos sub-trechos, vazão de referência $\left(\mathrm{m}^{3} / \mathrm{s}\right)$, número de sub-trechos, intervalo de tempo de cálculo (s).

c) Muskingum-Cunge Não Linear:

O método dito não linear possui o mesmo princípio do método linear, contudo diferencia-se pela variação dos parâmetros em função da vazão ao longo da simulação. As estimativas da celeridade da onda e do parâmetro X ocorrem a cada intervalo de tempo

Esse método deve ser utilizado quando a celeridade da onda de cheia varia significativamente com a magnitude das vazões (IPH-UFRGS, ALM/FEA/IMF-UFPel, DFISFURG (2004).

Com relação aos dados de entrada do modelo, são os mesmos do método anterior com exceção da vazão de referência $\left(q_{0}-\mathrm{m}^{3} / \mathrm{s}\right)$.

d) Muskingum-Cunge com Planície de Inundação:

De acordo com a obra supracitada esse método tem por base a metodologia apresentada por Miller e Cunge (1975) ${ }^{16}$, a qual utiliza o método de Muskingum-Cunge para os casos de extravasamento da calha principal do rio durante uma cheia. 
Conforme figura 11 os parâmetros K e X são estimados por:

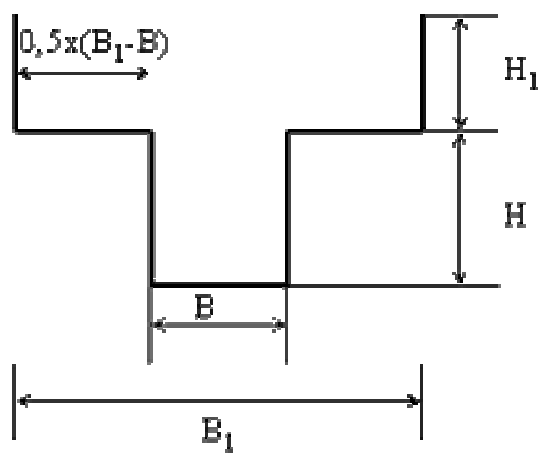

Figura 11: Seção transversal composta (Miller e Cunge, 1975).

Fonte: IPH-UFRGS, ALM/FEA/IMF-UFPel, DFIS-FURG (2004).

$$
\begin{aligned}
& K=\frac{\Delta_{x} \sum b_{i}}{1,33 S_{0}^{0,5} \sum \frac{b_{i}}{n_{i}} \cdot\left(h_{i}-Z_{i}\right)^{0,67}} \\
& X=0,5-0,5 \cdot \frac{K \cdot K}{S_{0}^{0,5} \Delta_{x}^{2} \sum b_{i}}
\end{aligned}
$$

em que:

$$
\begin{aligned}
h_{i} & =h-z_{i} \\
A & =\sum b_{i} \cdot h_{i} \\
\bar{K} & =\sum \frac{1}{n_{i}} \cdot b_{i} \cdot h_{i}^{5 / 3} \\
Q & =\bar{K} \cdot S_{0}{ }^{1 / 2}
\end{aligned}
$$

em que:

$$
\begin{aligned}
& \bar{K}=\text { condutividade hidráulica da seção transversal } \\
& \mathrm{n}=\text { coeficiente de Manning da subseção } i
\end{aligned}
$$

Desta forma, para cada par de valores K e X é estimada a vazão, para uma faixa de níveis e vazões de interesse, de acordo com a expressão: 


$$
Q=\frac{\left(Q_{t, j}+Q_{t, j+1}+Q_{t+1, j}\right)}{3}
$$

Como dados de entrada ao modelo têm-se: comprimento do trecho de propagação $(\mathrm{m})$, cota de fundo de montante (m), cota de fundo de jusante (m), altura - H - e largura - B - do canal (m), rugosidade dos sub-trechos, altura - H1 - e largura - B1 - da planície de inundação (m); rugosidade da planície de inundação, vazão de referência $\left(\mathrm{m}^{3} / \mathrm{s}\right)$, número de sub-trechos, intervalo de tempo de cálculo (s).

e) Muskingum-Cunge para Condutos Fechados

Para este método têm-se três tipos de seção (Figura 12): retangular, circular e trapezoidal. Cada um com seus respectivos dados de entrada.

Para esse método os dados de entrada estão separados em quatro tipos: dados gerais, trecho principal, trechos paralelos ao trecho principal e o tratamento de excessos. Os dados gerais requeridos são: comprimento do trecho $(\mathrm{m})$, cota de fundo de montante $(\mathrm{m})$, cota de fundo de jusante $(\mathrm{m})$, vazão de referência $\left(\mathrm{m}^{3} / \mathrm{s}\right)$, intervalo de simulação e sub-trechos tendo os três últimos possibilidade de cálculo automático. Já para o trecho principal têm-se: tipo de seção, diâmetro $(\mathrm{m})$, altura $(\mathrm{m})$, largura $(\mathrm{m})$, talude esquerdo $(1: \mathrm{z})$, talude direito $(1: \mathrm{z})$ e rugosidade.

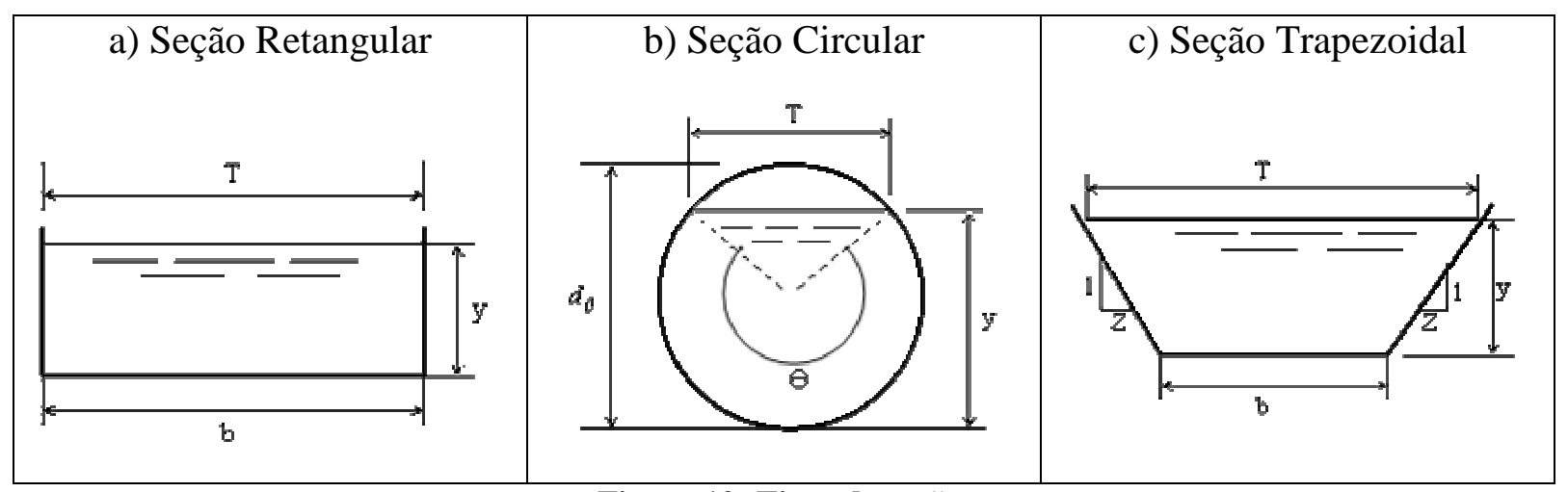

Figura 12: Tipos de seção.

Fonte: IPH-UFRGS, ALM/FEA/IMF-UFPel, DFIS-FURG (2004). 


\subsubsection{Curvas de Permanência na interpretação cenários}

Curvas de permanência são, de acordo com USEPA (2007), uma representação da distribuição da freqüência acumulada de dados históricos de vazão sobre um período especificado, relacionando valores de vazão ao percentual de ocorrência no tempo. Já Vogel e Fennessey (1994) as descrevem como as relações entre a magnitude e a freqüência de vazões (diárias, semanais, mensais) de um determinado curso d'água. Segundo os mesmos autores, algumas de suas aplicações são: planejamento de hidroelétricas, manejo da qualidade de água e estudos da sedimentação em rios e reservatórios, da demanda de água, do planejamento da irrigação, da adequação de hábitats em diferentes magnitudes e freqüências, e do aumento de vazões mínimas.

Bonta e Cleland (2003) apresentam um estudo sobre a avaliação da qualidade das águas por meio de curvas de permanência incluindo variáveis como variabilidade natural, incertezas e riscos. Dentre as conclusões destaca-se a constatação da possibilidade de utilização de curvas de permanência como ferramenta de quantificação das repostas da bacia hidrográfica em termos de mudança nos excessos, na concentração e carga após a implementação de BMP's (Best Management Practices) e, sobretudo como mecanismo de avaliação tanto de dados observados como de dados modelados.

Como ferramenta utilizada na interpretação de dados, as curvas de permanência podem ser empregadas na avaliação de cenários, os quais, na maioria das vezes, são entendidos a partir da avaliação de condicionantes como "tempo de retorno". A utilização da variável "tempo de retorno" é aplicável, principalmente à obras hidráulicas. Enquanto a variável "curva de permanência" é utilizada para conhecimento e avaliação do comportamento de um determinado cursos d'água, em termos de vazões (máximas, médias ou mínimas). Por meio das curvas de permanência, torna-se possível estimar as probabilidades de 
ocorrência de uma determinada faixa de vazões. Na estimativa da probabilidade de ocorrência de vazões máximas pode-se aliar ao estudo de índices de perigo inerentes às cheias e inundações (Souza et al., 2006). Já para a estimativa da probabilidade de ocorrência das vazões mínimas pode-se avaliar os períodos de maior estiagem, momento esse de grande preocupação por parte dos responsáveis pelos sistemas de abastecimento de água, em áreas urbanas. A utilização das curvas de permanência pode servir ainda, como ferramenta para obtenção da vazão ecológica, como por exemplo, o estudo realizado por Almeida Neto (2007).

Benini (2005) utilizou curvas de permanência para avaliação de diferentes cenários para a parcela de montante da sub-bacia do Córrego Mineirinho. As condições estudadas foram: cenário pré-urbanização (1972), cenário atual (2000), cenário tendêncial sem a adequação ao plano diretor (SPD - 2025) e cenário com utilização do plano diretor (CPD 2025). As vazões máximas específicas para os respectivos casos foram: $0,78 \mathrm{~m}^{3} / \mathrm{s} / \mathrm{km}^{2} ; 1,64$ $\mathrm{m}^{3} / \mathrm{s} / \mathrm{km}^{2} ; 3,84 \mathrm{~m}^{3} / \mathrm{s} / \mathrm{km}^{2}$ e $3,14 \mathrm{~m}^{3} / \mathrm{s} / \mathrm{km}^{2}$. Resultados esses, que demonstram a estreita relação entre os usos e ocupações do solo e a drenagem urbana, com vazões máximas maiores para o cenário com maior grau de impermeabilização. Porém, o estudo ressalta que mesmo adotando medidas contidas no plano diretor não há uma redução considerável das vazões máximas.

$\mathrm{Na}$ presente pesquisa procurou-se conhecer o comportamento, em termos de vazões máximas, de algumas sub-bacias em diferentes cenários. Para tanto, a melhor ferramenta a ser utilizada é a "curva de permanência". 


\subsection{Incentivos Ambientais}

Incentivos Ambientais podem ser entendidos como estímulos a manutenção e proteção do meio ambiente, em suas diversas formas. Provêm de iniciativas governamentais por meio de instrumentos políticos e/ou iniciativas privadas através de mecanismos de mercado. Podem estar vinculados a impostos, taxas, regimes de eco-rotulagem, acordos ambientais.

Uma forma simples e eficaz de promover o incentivo ambiental é aplicação de “impostos ambientais.” No Brasil o caminho que tem sido perseguido é o da associação de um incentivo ambiental ao IPTU (Imposto Predial e Territorial Urbano). O IPTU é um imposto municipal que inclui, na realidade, dois impostos: o imposto sobre a propriedade territorial urbana e sobre a propriedade predial urbana, que incidem sobre o terreno e a edificação, respectivamente (Denari, 2002); tem como base de cálculo o valor venal do imóvel, dado pelo valor estimado de avaliação do mesmo para compra e venda à vista considerando sua localização e características físicas. De maneira geral, a arrecadação do mesmo é aplicada na área da saúde, educação e obras (pavimentação, drenagem, etc). Exemplos de alguns municípios que utilizam a associação de incentivo e IPTU são: Porto Alegre, Manaus e Recife, onde são denominados "IPTU Verde" ou "IPTU Ecológico". No entanto, nesses casos, a variável em questão, na isenção parcial ou total do imposto, está diretamente relacionada à arborização dos lotes e a presença de área florestal, não levando, portanto em consideração variáveis de impermeabilização dos terrenos ou armazenamento das águas de chuva no lote.

Sob esse aspecto, a proposta do presente trabalho é de incluir no cálculo do IPTU "tradicional" uma componente ambiental com base em variáveis hidráulicas e hidrológicas, e avaliar o comportamento do mesmo em face dos diferentes cenários abordados. Desta forma, o imposto, denominado neste trabalho "IPTU Hidrológico", será mensurado por meio da metodologia elaborada por Mendiondo (2007). 
A redução do valor final do IPTU Hidrológico associada à maximização do armazenamento potencial de água no lote e/ou à minimização da vazão máxima instantânea, é uma proposta interessante quando implementadas medidas compensatórias em escala de lote urbano. Tais medidas podem ser: utilização de trincheiras de infiltração (Graciosa, 2005), cobertura verde leve (Almeida Neto et al., 2005), o armazenamento com posterior reúso de água de chuva (Raindroups, 2002; Alves et.al., 2007), utilização de pavimentos permeáveis e o aumento de áreas verdes (árvores e gramados).

O município de São Carlos, objeto de estudo desta pesquisa, em sua Lei Municipal $\mathrm{n}^{\circ}$ 13.692/05 estabelece em seus artigos 44 e 45 o desconto de até 2\% no valor do IPTU para os “imóveis edificados horizontais que possuírem, uma ou mais árvores, em frente ao seu imóvel” e para "os imóveis que possuírem no perímetro de seu terreno áreas efetivamente permeáveis com cobertura vegetal", respectivamente. A iniciativa apreciável, no entanto, no artigo seguinte (46) o município concede o desconto de até 50\% para os "imóveis não edificados que forem adequados ao estacionamento de veículos”. A interpretação puramente hidrológica do documento permite afirmar-se que há um descompasso entre os benefícios referidos: a construção de estacionamentos em área urbana sobre terrenos baldios, para a qual é oferecido desconto de $50 \%$ no valor do IPTU, normalmente, resulta em impermeabilização do terreno na sua integralidade, gerando grande impacto negativo na drenagem urbana e, ainda, contribuindo para aumento na freqüência de cheias e inundações; o plantio de árvores e a manutenção de áreas permeáveis, por sua vez, somente podem gerar resultados/impactos positivos ambientalmente e são merecedores de inexpressivos $2 \%$ de desconto sobre o valor do IPTU.

A cobrança pelos serviços ambientais tem sido alvo de muitas pesquisas. Atualmente, quatro tipos de serviços ambientais (CIFOR, 2006) são descritos internacionalmente: 
seqüestro e armazenamento de carbono, proteção da biodiversidade, proteção de bacias hidrográficas e manutenção de belezas cênicas.

Embora de difícil implementação, dada a necessidade de conciliação de interesses socioeconômicos e ambientais, muitas vezes conflitantes, entre as municipalidades e os proprietários de terrenos, já há estudos no âmbito nacional que comprovam a aplicabilidade de formas de cobrança visando incentivos à sustentabilidade. Silveira (2007) apresenta um modelo de cobrança pela drenagem urbana, o qual engloba duas cobranças: cobrança interna ao município e cobrança externa ao município, sendo a primeira relativa à taxa pelo serviço de drenagem e a segunda pelo uso da água. $\mathrm{O}$ autor sugere que tais cobranças gerarão duas novas arrecadações que serão repassadas ao município e a bacia hidrográfica, viabilizando em parte os planos diretores municipais e os planos de bacia hidrográfica; salienta, ainda, que a metodologia proposta tem por objetivo estimular iniciativas por parte da administração municipal e dos usuários urbanos promovendo o controle das águas pluviais. No âmbito da cobrança interna ao município, merece destaque a identificação de critérios que permitiam conferir ônus financeiro aos projetos que apresentavam maior ônus hidráulico. Nesse contexto, de crescente necessidade de valoração dos recursos naturais, é que se insere o conceito de incentivo ambiental em escala de lote. 


\section{MATERIAL E MÉTODOS}

\subsection{Narrativa dos Cenários Regionais de Drenagem Urbana}

A etapa de construção dos cenários teve por base o trabalho de Mendiondo (2005), no qual é proposta uma lista de 29 indicadores para construção de cenários regionais de drenagem urbana no longo prazo, sendo 21 destes relacionados à macrodrenagem e os demais à escala de lote (ANEXO A). O autor demonstra a partir de uma estimativa qualitativa a evolução de cada indicador ao longo do século em quatro horizontes temporais: 2025, 2050, 2075 e 2100, utiliza para isso 5 símbolos distintos: (-) diminuição, (- -) diminuição acentuada, $(+)$ aumento, $(++)$ aumento acentuado e $(0)$ estagnação.

Devido à complexidade de formulação dos cenários, bem como da limitação do método utilizado, no que diz respeito aos dados utilizados na transformação "chuva-vazão" foram utilizados 21 indicadores. A tabela 6 mostra os indicadores utilizados na presente pesquisa.

Tabela 6: Indicadores utilizados na construção dos cenários.

\begin{tabular}{c|l}
\hline Escala & \multicolumn{1}{c}{ Indicador } \\
\hline \multirow{5}{*}{ Macrodrenagem } & Crescimento populacional $(\% / \mathrm{ano})$ \\
& Densidade Populacional $\left(\mathrm{Hab} / \mathrm{km}^{2}\right)$ \\
& Potencial de escoamento $(\mathrm{adm})$ \\
& Declividade do canal $(\mathrm{m} / \mathrm{m})$ \\
& Sinuosidade do canal $(\mathrm{m} / \mathrm{m})$ \\
& Rugosidade do canal $(\mathrm{adm})$ \\
& Área impermeável diretamente conectada à rede pluvial $(\%)$ \\
& Largura da planície de inundação $(\mathrm{m})$ \\
& Rugosidade da planície de inundação $($ adm $)$ \\
& Bacia de detenção $\left(\mathrm{N}^{\circ} / \mathrm{km}^{2}\right)$ \\
& Bacia de infiltração $\left(\mathrm{N}^{\mathrm{o}} / \mathrm{km}^{2}\right)$ \\
& Melhoramento de manancial urbano $\left(\mathrm{N} \% / \mathrm{km}^{2}\right)$ \\
& Densidade de drenagem $\left(\mathrm{km} / \mathrm{km}^{2}\right)$ \\
\hline \multirow{5}{*}{ Lote } & Áreas impermeáveis conectadas aos lotes urbanos $(\%)$ \\
& Áreas impermeáveis em lotes urbanos $(\%)$ \\
& Solo descoberto nos Lotes $(\%)$ \\
& Tecnologias apropriadas de manejo na escala de lote - BMP- $\left(\mathrm{m}^{3} / \mathrm{lote}\right)$ \\
& Vegetação nos Lotes $(\%)$ \\
& Taxa do imposto de lote sobre a descarga máxima $(\%)$ \\
& Taxa do imposto de lote sobre o armazenamento pluvial $(\%)$ \\
& Grama nos Lotes $(\%)$ \\
\hline
\end{tabular}


A descrição dos cenários é dada pela caracterização dos mesmos ao longo dos períodos referentes à evolução temporal (2000-2025, 2025-2050, 2050-2075 e 2075-2100). Com o intuito de promover melhor entendimento, os cenários são apresentados de acordo com dois níveis: escala de macrodrenagem (bacia hidrográfica e rios/vales de inundação) e escala de lote (lotes urbanos).

\subsubsection{Cenários de Macrodrenagem}

\subsubsection{Global Orchestration}

A taxa de crescimento populacional permanece inalterada durante os primeiros 25 anos e decresce gradativamente nos demais, enquanto a densidade populacional aumenta até 2075, ocorrendo de maneira mais acentuada na primeira metade do século, já no último período permanece inalterada.

O potencial de escoamento aumenta nos primeiros 50 anos sendo de maneira mais acentuada durante os primeiros 25 anos, após 2050 este indicador permanece inalterado. Já o percentual de áreas impermeáveis conectadas a rede pluvial apresenta o mesmo comportamento do potencial de escoamento para os primeiros 25 anos, entre 2025 e 2075 continua um aumento, porém em menor proporção e no período seguinte permanece inalterado. Durante a primeira metade do século promove-se o aumento da declividade dos canais, diminuição da sinuosidade e da rugosidade, com esta última ocorrendo de forma mais acentuada até 2025. Entre 2050-2075 os três indicadores permanecem inalterados, no entanto no último período (2075-2100) há diminuição da declividade dos canais e aumento da $\underline{\text { sinuosidade e da rugosidade. }}$. Com relação às planícies de inundação, há diminuição da largura e da rugosidade até 2050 e entre 2050-2100 as mesmas permanecem inalteradas.

Há aumento na utilização de bacias de detenção até 2075, após este período permanecem inalteradas. As bacias de detenção têm o objetivo de minimizar os impactos das 
cheias, porém não têm a finalidade de dar um destino adequado às águas acumuladas, como seria o caso da utilização das bacias de infiltração que, sofrem diminuição nos primeiros 25 anos e depois permanecem inalteradas até 2100. Há diminuição do melhoramento de manancial urbano e da densidade de drenagem até 2025, entre 2025-2075 estes indicadores não são alterados, comportamento este que se estende para a densidade de drenagem também no último período, enquanto ocorre um aumento no melhoramento de manancial urbano. Entende-se por melhoramento do manancial urbano, em termos quantitativos, o aumento no número de rios e córregos em uma determinada bacia ou sub-bacia.

Tabela 7: Evolução dos indicadores - Cenário GO

\begin{tabular}{c|l|c|c|c|c|c}
\hline \multirow{2}{*}{ Escala } & \multicolumn{4}{c}{ Global Orchestration - global, reativo } \\
\cline { 2 - 6 } & Indicador & Unid. & 2025 & 2050 & 2075 & 2100 \\
\hline M & Crescimento Populacional & $\% / \mathrm{ano}$ & 0 & - & - & - \\
$\mathrm{A}$ & Densidade Populacional & $\mathrm{Hab} / \mathrm{km}^{2}$ & ++ & ++ & + & 0 \\
$\mathrm{C}$ & Potencial de Escoamento & - & ++ & + & 0 & 0 \\
$\mathrm{R}$ & Declividade do Canal & $\mathrm{m} / \mathrm{m}$ & + & + & 0 & - \\
$\mathrm{O}$ & Sinuosidade do Canal & $\mathrm{m} / \mathrm{m}$ & - & - & 0 & + \\
$\mathrm{D}$ & Rugosidade do Canal & & - & - & 0 & + \\
$\mathrm{R}$ & Áreas impermeáveis conectadas à rede pluvial & $\%$ & ++ & + & + & 0 \\
$\mathrm{E}$ & Largura da Planície de Inundação & $\mathrm{m}$ & - & - & 0 & 0 \\
$\mathrm{~N}$ & Rugosidade da Planície de Inundação & & - & - & 0 & 0 \\
$\mathrm{~A}$ & Bacia de Detenção & $\mathrm{N} / \mathrm{km}^{2}$ & + & + & + & 0 \\
$\mathrm{G}$ & Bacia de Infiltração & $\mathrm{N} / \mathrm{km}^{2}$ & - & - & 0 & 0 \\
E & Melhoramento de manancial urbano & $\mathrm{N} / \mathrm{km}^{2}$ & - & 0 & 0 & 0 \\
$\mathrm{M}$ & Densidade de Drenagem & $\mathrm{km} / \mathrm{km}^{2}$ & - & 0 & 0 & 0 \\
\hline
\end{tabular}

\subsubsection{Order From Strength}

A taxa de crescimento populacional aumenta nos primeiros 25 anos e diminui nos períodos subsequientes, enquanto a densidade populacional aumenta durante os cem anos, ocorrendo de forma mais acentuada nos primeiros 50 anos.

O potencial de escoamento aumenta até o ano 2075, ocorrendo de forma mais acentuada nos primeiros 50 anos, durante o período de 2075-2100 permanece inalterado. Já o percentual de áreas impermeáveis conectadas a rede pluvial aumenta durante os cem anos, ocorrendo de forma mais acentuada nos primeiros 50 anos. A declividade dos canais aumenta 
acentuadamente no primeiro quarto de século, continua a aumentar durante os 50 anos seguintes, porém em menor proporção e fica estagnada durante o último período (2075-2100). Já a sinuosidade do canal diminui acentuadamente nos primeiros 25 anos, diminui em menor proporção até 2050, permanece estagnado até 2075 e no último período torna a diminuir novamente. A rugosidade do canal diminui até 2075, ocorrendo de maneira mais acentuada nos primeiros 50 anos e no último período permanece estagnada. No que se refere às planícies de inundação, há diminuição da largura e da rugosidade até 2050, sendo mais acentuada nos primeiros 25 anos. Entre 2050 e 2075 há ainda diminuição da largura, porém em menor proporção e no período seguinte há estagnação. Já a rugosidade fica inalterada nos últimos 50 anos.

A sociedade neste cenário preocupa-se com a segurança e aborda os problemas ambientais de forma reativa, com isso investem pesadamente na construção de bacias de $\underline{\text { detenção }}$ até 2025 e em menor grau durante os períodos subseqüentes. Já o emprego de bacias de infiltração é desestimulado neste cenário, com diminuição nos três períodos iniciais e estagnação no último período, sendo a ocorrência da diminuição realizada de forma acentuada nos primeiros 25 anos.

Quanto ao melhoramento de manancial urbano e da densidade de drenagem, há diminuição de ambos indicadores nos primeiros 50 anos, sendo mais acentuada durante o período de 2000 a 2025. Entre 2050 e 2075 há ainda diminuição, porém menor do melhoramento de manancial urbano e no período seguinte há estagnação. Já a densidade de drenagem fica inalterada nos últimos 50 anos. 
Tabela 8: Evolução dos indicadores - Cenário OS

\begin{tabular}{|c|c|c|c|c|c|c|}
\hline \multirow{2}{*}{ Escala } & \multicolumn{6}{|c|}{ Order from Strength - regional, reativo } \\
\hline & Indicador & Unid. & 2025 & 2050 & 2075 & 2100 \\
\hline M & Crescimento Populacional & $\% /$ ano & + & - & - & - \\
\hline A & Densidade Populacional & $\mathrm{Hab} / \mathrm{km}^{2}$ & ++ & ++ & + & + \\
\hline $\mathrm{C}$ & Potencial de Escoamento & - & ++ & ++ & + & 0 \\
\hline $\mathrm{R}$ & Declividade do Canal & $\mathrm{m} / \mathrm{m}$ & ++ & + & + & 0 \\
\hline $\mathrm{O}$ & Sinuosidade do Canal & $\mathrm{m} / \mathrm{m}$ & -- & - & 0 & - \\
\hline $\mathrm{D}$ & Rugosidade do Canal & & - & -- & - & 0 \\
\hline $\mathrm{R}$ & Áreas impermeáveis conectadas à rede pluvial & $\%$ & ++ & ++ & + & + \\
\hline $\mathrm{E}$ & Largura da Planície de Inundação & $\mathrm{m}$ & -- & - & - & 0 \\
\hline $\mathrm{N}$ & Rugosidade da Planície de Inundação & & - & - & 0 & 0 \\
\hline A & Bacia de Detenção & $\mathrm{N}^{\mathrm{o}} / \mathrm{km}^{2}$ & ++ & + & + & + \\
\hline $\mathrm{G}$ & Bacia de Infiltração & $\mathrm{N}^{\mathrm{o}} / \mathrm{km}^{2}$ & - & - & - & 0 \\
\hline $\mathrm{E}$ & Melhoramento de manancial urbano & $\mathrm{N}^{\mathrm{o}} / \mathrm{km}^{2}$ & - & - & - & 0 \\
\hline M & Densidade de Drenagem & $\mathrm{km} / \mathrm{km}^{2}$ & -- & - & 0 & 0 \\
\hline
\end{tabular}

\subsubsection{Adapting Mosaic}

No cenário Adapting Mosaic a taxa de crescimento populacional diminui ao longo dos cem anos, enquanto a densidade demográfica aumenta nos primeiros 50 anos e a partir de então se torna constante.

$\mathrm{O}$ potencial de escoamento $(\mathrm{CN})$ aumenta nos primeiros 25 anos e permanece constante nos demais, assim como o percentual de áreas impermeáveis conectadas a rede pluvial. A declividade dos canais fica inalterada no primeiro quarto de século e diminui constantemente nos outros três quartos. A sinuosidade aumenta até 2075 e após este período permanece inalterada. A rugosidade do canal não se modifica nos primeiros 25 anos, no entanto, sofre aumento até 2075 e depois permanece constante até 2100 . Quanto às planícies de inundação, há permanência da largura nos primeiros 50 anos e posterior diminuição; já as rugosidades ficam inalteradas até 2025 e aumentam nos anos seguintes até 2100 .

Quanto à utilização de bacia de detenção e bacia de infiltração nesse cenário, há estagnação da primeira entre 2000-2025 e diminuição nos anos sucessivos; já para a segunda há aumento gradativo ao longo do horizonte temporal estudado. 
Há aumento na melhoria do manancial urbano em termos de quantidade de rios e córregos nos primeiros 50 anos e estagnação nos anos subseqüentes. Já a densidade de drenagem fica inalterada até 2025, mas aumenta nos anos seguintes.

Tabela 9: Evolução dos indicadores - Cenário AM

\begin{tabular}{c|l|c|c|c|c|c}
\hline \multirow{2}{*}{ Escala } & \multicolumn{5}{c}{ Adapting Mosaic - regional, proativo } \\
\cline { 2 - 6 } & Indicador & Unid. & 2025 & 2050 & 2075 & 2100 \\
\hline M & Crescimento Populacional & \%/ano & - & - & - & - \\
$\mathrm{A}$ & Densidade Populacional & Hab/km & + & + & 0 & 0 \\
$\mathrm{C}$ & Potencial de Escoamento & - & + & 0 & 0 & 0 \\
$\mathrm{R}$ & Declividade do Canal & $\mathrm{m} / \mathrm{m}$ & 0 & - & - & - \\
$\mathrm{O}$ & Sinuosidade do Canal & $\mathrm{m} / \mathrm{m}$ & + & + & + & 0 \\
$\mathrm{D}$ & Rugosidade do Canal & & 0 & + & + & 0 \\
$\mathrm{R}$ & Áreas impermeáveis conectadas à rede pluvial & $\%$ & + & 0 & 0 & 0 \\
$\mathrm{E}$ & Largura da Planície de Inundação & $\mathrm{m}$ & 0 & 0 & - & - \\
$\mathrm{N}$ & Rugosidade da Planície de Inundação & & 0 & + & + & + \\
$\mathrm{A}$ & Bacia de Detenção & $\mathrm{N} / \mathrm{km}^{2}$ & 0 & - & - & - \\
$\mathrm{G}$ & Bacia de Infiltração & $\mathrm{N} / \mathrm{km}^{2}$ & + & + & + & + \\
$\mathrm{E}$ & Melhoramento de manancial urbano & $\mathrm{N} / \mathrm{km}^{2}$ & + & + & 0 & 0 \\
$\mathrm{M}$ & Densidade de Drenagem & $\mathrm{km} / \mathrm{km}^{2}$ & 0 & + & + & + \\
\hline
\end{tabular}

\subsubsection{TechnoGarden}

No cenário TechnoGarden a taxa de crescimento populacional diminui acentuadamente nos primeiros 25 anos e torna a diminuir, porém em menor proporção nos três quartos de século seguinte. Já a densidade demográfica aumenta acentuadamente na primeira metade do século e permanece constante na segunda metade.

O potencial de escoamento (CN) fica inalterado até 2050, diminui um pouco até 2075 e no último período diminui acentuadamente. O percentual das áreas impermeáveis

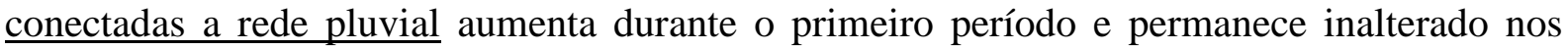
demais. A declividade dos canais diminui nos primeiros 25 anos, diminui acentuadamente nos 25 anos seguinte, permanece inalterada entre 2050-2075 e diminui novamente entre 20752100. A sinuosidade e a rugosidade dos canais aumentam até 2075 , ocorrendo de forma mais acentuada no período entre 2025-2050 e permanecem estagnadas entre 2075 e 2100. Quanto às planícies de inundação, há aumento acentuado da largura nos primeiros 25 anos e posterior 
aumento em menor grau nos 25 anos seguintes, para o período correspondente a 2075-2100 este indicador permanece inalterado; já as rugosidades aumentam até 2075 com aumento acentuado entre 2025-2050 e permanecem estagnadas nos anos seguintes até 2100 .

Quanto à utilização de bacia de detenção e bacia de infiltração nesse cenário, há diminuição da primeira em todos os períodos com queda acentuada no período de 2025-2050 e aumento da segunda em todos os períodos, com aumento acentuado nos primeiros 25 anos.

Há aumento na melhoria do manancial urbano em termos de quantidade de rios e córregos em todos os anos com aumento acentuado nos 50 primeiros anos. Já a densidade de drenagem aumenta em todos os anos com aumento acentuado durante a segunda metade do século.

Na tabela 10 é dada a evolução de cada indicador.

Tabela 10: Evolução dos indicadores - Cenário TG

\begin{tabular}{|c|c|c|c|c|c|c|}
\hline \multirow{2}{*}{ Escala } & \multicolumn{6}{|c|}{ TechnoGarden - global, proativo } \\
\hline & Indicador & Unid. & 2025 & 2050 & 2075 & 2100 \\
\hline $\mathrm{M}$ & Crescimento Populacional & $\% / a n o$ & -- & - & - & - \\
\hline A & Densidade Populacional & $\mathrm{Hab} / \mathrm{km}^{2}$ & ++ & ++ & 0 & 0 \\
\hline $\mathrm{C}$ & Potencial de Escoamento & - & 0 & 0 & - & - \\
\hline $\mathrm{R}$ & Declividade do Canal & $\mathrm{m} / \mathrm{m}$ & - & - - & 0 & - \\
\hline $\mathrm{O}$ & Sinuosidade do Canal & $\mathrm{m} / \mathrm{m}$ & + & ++ & + & 0 \\
\hline $\mathrm{D}$ & Rugosidade do Canal & & + & ++ & + & 0 \\
\hline $\mathrm{R}$ & Áreas impermeáveis conectadas à rede pluvial & $\%$ & + & 0 & 0 & 0 \\
\hline $\mathrm{E}$ & Largura da Planície de Inundação & $\mathrm{m}$ & ++ & + & 0 & 0 \\
\hline $\mathrm{N}$ & Rugosidade da Planície de Inundação & & + & ++ & + & 0 \\
\hline A & Bacia de Detenção & $\mathrm{N}^{\mathrm{o}} / \mathrm{km}^{2}$ & - & -- & - & - \\
\hline $\mathrm{G}$ & Bacia de Infiltração & $\mathrm{N}^{\mathrm{o}} / \mathrm{km}^{2}$ & ++ & + & + & + \\
\hline $\mathrm{E}$ & Melhoramento de manancial urbano & $\mathrm{N}^{\mathrm{o}} / \mathrm{km}^{2}$ & ++ & ++ & + & + \\
\hline M & Densidade de Drenagem & $\mathrm{km} / \mathrm{km}^{2}$ & + & + & ++ & ++ \\
\hline
\end{tabular}

\subsubsection{Cenários em Escala de Lote}

Os cenários para escala de lote foram construídos a partir da mudança dos seguintes parâmetros: Áreas impermeáveis conectadas aos lotes urbanos, Áreas impermeáveis em lotes 
urbanos, Solo descoberto nos Lotes, Tecnologias de manejo apropriadas para a escala de lote, Vegetação nos Lotes e Grama nos Lotes.

A narrativa desses cenários dá-se para um lote residencial com área de $200 \mathrm{~m}^{2}$. A verticalização de imóveis não foi considerada neste trabalho, embora seja sabida sua influencia sobre o escoamento das águas urbanas.

\subsubsection{Global Orchestration}

Há um aumento crescente até 2075 do percentual de áreas impermeáveis conectadas à

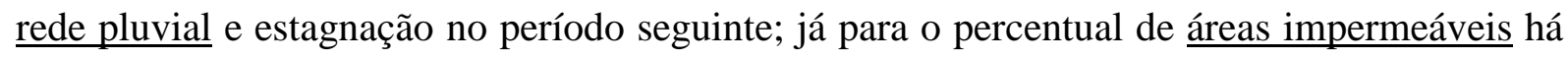
também aumento, porém somente nos primeiros 50 anos e estagnação a partir de 2050 até 2100. O percentual de solo descoberto aumenta no primeiro período (2000-2025) e permanece constante nos demais. A vegetação diminui até 2025, permanece inalterada entre 2025 e 2075 e aumenta entre 2075 e 2100 . O percentual de grama nos lotes aumenta até 2025, diminui entre 2025 e 2050, fica estagnado entre 2050 e 2075 e volta a diminuir no período seguinte. A utilização de tecnologias de manejo apropriadas para escala de lote (BMP's) como cisternas, trincheiras de infiltração, telhados verdes permanece inalterada nos primeiros 50 anos e aumenta nos 50 anos seguintes. A tabela 11 é apresentada como forma de melhor elucidar a caracterização do cenário GO.

Tabela 11: Evolução dos Indicadores para o Lote Típico - Cenário GO

\begin{tabular}{|c|c|c|c|c|c|c|}
\hline \multirow{2}{*}{ Escala } & \multicolumn{6}{|c|}{ Global Orchestration - global, reativo } \\
\hline & Indicador & Unid. & 2025 & 2050 & 2075 & 2100 \\
\hline & Áreas impermeáveis conectadas aos lotes urbanos & $\%$ & + & + & + & 0 \\
\hline $\mathrm{L}$ & Áreas impermeáveis em lotes urbanos & $\%$ & + & + & - & 0 \\
\hline $\mathrm{O}$ & Solo descoberto nos Lotes & $\%$ & + & 0 & 0 & 0 \\
\hline $\mathrm{T}$ & Tecnologias de manejo apropriadas para a escala de lote & $\mathrm{m}^{3}$ & 0 & 0 & + & + \\
\hline \multirow[t]{2}{*}{$\mathrm{E}$} & Vegetação nos Lotes & $\%$ & - & 0 & 0 & + \\
\hline & Grama nos Lotes & $\%$ & + & - & 0 & - \\
\hline
\end{tabular}




\subsubsection{Order from Strength}

A sociedade no cenário OS comporta-se de forma despreocupada com as questões ambientais e com os problemas sociais. Por ignorar medidas de precaução em relação às cheias urbanas, os lotes tornam-se mais impermeabilizados com grandes áreas construídas. As áreas impermeáveis conectadas à rede pluvial aumentam durante todos os períodos, sobretudo nos primeiros 50 anos onde há aumento acentuado deste indicador. Já para o percentual de áreas impermeáveis há aumento nos 50 primeiros anos sendo mais acentuado até 2025, há estagnação durante o período de 2050-2075 e diminuição nos últimos 25 anos. O percentual

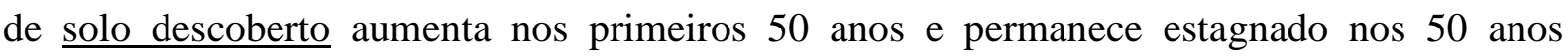
seguinte. A vegetação diminui até 2075, sobretudo no período correspondente entre 20002025 onde a diminuição ocorre de forma mais acentuada, e permanece inalterada entre 2075 e 2100. O percentual de grama nos lotes fica estagnado nos primeiros 25 anos, diminui no período de 2025 e 2075 e permanece estagnado no último período. A utilização de tecnologias de manejo apropriadas para escala de lote (BMP's) diminui entre 2000 e 2075, ocorrendo de forma mais acentuada nos primeiros 25 anos e fica inalterada entre 2075 e 2100 .

Na tabela 12 apresenta-se em detalhes a caracterização dos lotes para o cenário OS.

Tabela 12: Evolução dos Indicadores para o Lote Típico - Cenário OS

\begin{tabular}{|c|c|c|c|c|c|c|}
\hline \multirow{2}{*}{ Escala } & \multicolumn{6}{|c|}{ Order from Strength - regional, reativo } \\
\hline & Indicador & Unid. & 2025 & 2050 & 2075 & 2100 \\
\hline & Áreas impermeáveis conectadas aos lotes urbanos & $\%$ & ++ & ++ & + & + \\
\hline $\mathrm{L}$ & Áreas impermeáveis em lotes urbanos & $\%$ & ++ & + & 0 & - \\
\hline $\mathrm{O}$ & Solo descoberto nos Lotes & $\%$ & + & + & 0 & 0 \\
\hline $\mathrm{T}$ & Tecnologias de manejo apropriadas para a escala de lote & $\mathrm{m}^{3}$ & - & - & - & 0 \\
\hline \multirow[t]{2}{*}{$\mathrm{E}$} & Vegetação nos Lotes & $\%$ & - - & - & - & 0 \\
\hline & Grama nos Lotes & $\%$ & 0 & - & - & 0 \\
\hline
\end{tabular}

\subsubsection{Adapting Mosaic}

No que diz respeito aos lotes urbanos do cenário AM, não há alteração no percentual das áreas impermeáveis conectadas à rede pluvial durante o primeiro quarto de século, no entanto nos demais há uma diminuição gradativa deste indicador. Já o percentual das áreas 
impermeáveis não se altera até 2025 , diminui nos 50 anos seguintes e volta a estagnar até 2100. O percentual de solo descoberto diminui somente no período de 2025 a 2050 , nos demais permanece inalterado. A vegetação aumenta gradativamente ao longo dos anos. A grama sofre aumento no período entre 2025 e 2050, nos demais permanece inalterada. A utilização de tecnologias de manejo apropriadas para escala de lote (BMP's) aumenta gradativamente até 2075 , tanto em número de tecnologias adotadas como na sua capacidade de armazenar e/ou retardar o deslocamento das águas pluviais, e permanece inalterada durante o último período (2075-2100). No entanto, cabe ressaltar que pelo caráter regional do cenário Adapting Mosaic embora haja utilização de BMP's as mesmas não exigem conhecimento técnico muito apurado, compõem-se, portanto, por cisternas e utilização de telhados verdes.

A tabela 13 mostra o comportamento de cada indicador ao longo dos 100 anos para o cenário AM.

Tabela 13: Evolução dos Indicadores para o Lote Típico - Cenário AM

\begin{tabular}{|c|c|c|c|c|c|c|}
\hline \multirow{2}{*}{ Escala } & \multicolumn{6}{|c|}{ Adapting Mosaic - regional, proativo } \\
\hline & Indicador & Unid. & 2025 & 2050 & 2075 & 2100 \\
\hline & Áreas impermeáveis conectadas aos lotes urbanos & $\%$ & 0 & - & - & - \\
\hline $\mathrm{L}$ & Áreas impermeáveis em lotes urbanos & $\%$ & 0 & - & - & 0 \\
\hline $\mathrm{O}$ & Solo descoberto nos Lotes & $\%$ & - & - & 0 & 0 \\
\hline $\mathrm{T}$ & Tecnologias de manejo apropriadas para a escala de lote & $\mathrm{m}^{3}$ & + & + & + & 0 \\
\hline \multirow[t]{2}{*}{$\mathrm{E}$} & Vegetação nos Lotes & $\%$ & + & + & + & + \\
\hline & Grama nos Lotes & $\%$ & 0 & + & 0 & 0 \\
\hline
\end{tabular}

\subsubsection{TechnoGarden}

Em relação aos lotes urbanos, não há alteração no percentual das áreas impermeáveis

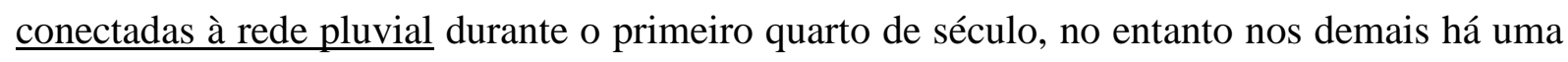
diminuição deste indicador, sendo sua ocorrência mais acentuada no período de 2025-2050. Já o percentual das áreas impermeáveis não se altera até 2025, diminui nos 50 anos seguintes, de forma mais acentuada entre 2050-2075 e aumenta até 2100. O percentual de solo descoberto diminui acentuadamente no período de 2025 a 2050, nos demais permanece inalterado. A vegetação aumenta acentuadamente nos primeiro 25 anos, aumenta em menor grau nos 50 
anos seguinte e permanece inalterado nos últimos 25 anos. A grama diminui entre 2025 e 2050, nos demais períodos permanece inalterada. A utilização de tecnologias de manejo apropriadas para escala de lote (BMP's) aumenta até 2075 sendo sua ocorrência maia acentuada nos primeiros 50 anos, tanto em número de tecnologias adotadas como na sua capacidade de armazenar e/ou retardar o deslocamento das águas pluviais, e permanece inalterada durante o último período (2075-2100). O cenário TG por ser globalmente conectado possui maior facilidade na obtenção de novas informações dentre elas as de caráter tecnológico, devido a este fato neste cenário inclui-se o emprego de trincheiras de infiltração como BMP's.

Na tabela 14 apresenta-se em detalhes a caracterização dos lotes para o cenário TG.

Tabela 14: Evolução dos Indicadores para o Lote Típico - Cenário TG

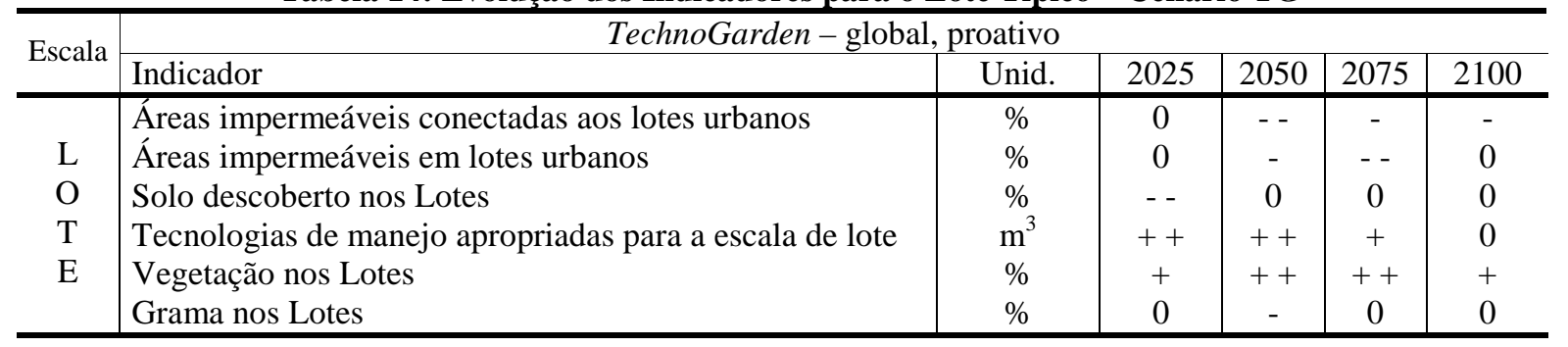




\section{2 Área de Estudo}

\subsubsection{Caracterização territorial}

O município de São Carlos (SP) dista 230 km da capital, 120 km de Campinas e 100 km de Ribeirão Preto. Está a uma altitude de 830 metros em relação ao nível do mar, com $22^{\circ} 02^{\prime \prime}$ de latitude Sul e $47^{\circ} 52^{\prime \prime}$ de longitude Oeste. Situa-se no centro do Estado de São Paulo com área aproximada de $1.141 \mathrm{~km}^{2}$ e população estimada de 212.956 habitantes (IBGE, 2007) (Figura 13).

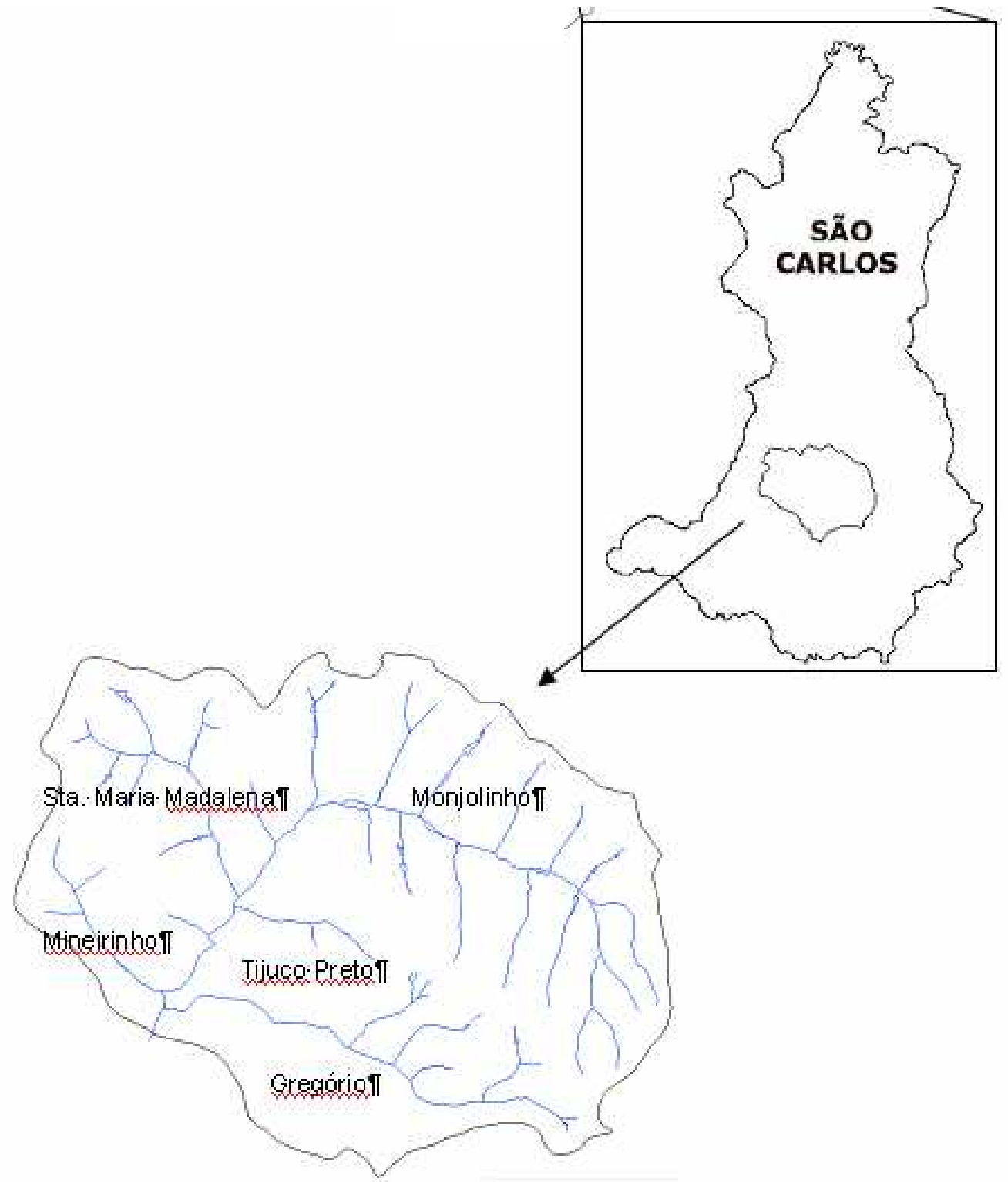

Figura 13: São Carlos e as sub-bacias de estudo. 
São Carlos possui elevado grau de urbanização $(96 \%)^{1}$ e de crescimento populacional (1,94\% a.a. no período de 2000-2007) (SEADE, 2007). É considerada como uma das cidades mais prósperas do oeste paulista (Relatório Pólis, 2002).

De acordo como o mesmo estudo (op. cit.), o surgimento e o desenvolvimento do município estão diretamente relacionados ao ciclo cafeeiro, todavia com a crise deste setor produtivo em meados de 1930, pequenas indústrias locais faliram e, somente a partir dos anos 70, com o processo de desconcentração industrial da capital, as cidades do interior do estado, como São Carlos, se beneficiaram. Nesta época a população rural representava 47\% do total; atualmente, apesar de possuir um vasto território rural, 95\% da população reside na área urbana, onde se encontra a base da economia do município com destaque para a indústria, o comércio e serviços.

O município de São Carlos está inserido em duas bacias hidrográficas (Figura 14): Mogi-Guaçu e Tietê-Jacaré. A primeira engloba as sub-bacias: das Araras, Mogi-Guaçu, das Gabirobas, das Cabeceiras, Chibarro, do Colombo e do Pântano. Já as sub-bacias do Monjolinho, do Feijão e do Jacaré-Guaçu compõem a Bacia do Tietê-Jacaré. A área de estudo do presente trabalho está inserida no segundo grupo, compreende as sub-bacias da parte montante da bacia do Monjolinho cuja área é de 78,00 $\mathrm{Km}^{2}$. As sub-bacias pertencentes a essa área são: Santa Maria Madalena $\left(12,00 \mathrm{Km}^{2}\right)$, Tijuco Preto $\left(3,40 \mathrm{Km}^{2}\right)$, Mineirinho $(5,70$ $\left.\mathrm{Km}^{2}\right)$ e Gregório $\left(17,30 \mathrm{Km}^{2}\right)$.

\subsubsection{Pedologia}

Embora o município de São Carlos possua, de acordo com Relatório Polis (2002), oito diferentes tipos de solo - latossolo roxo, latossolo vermelho escuro, latossolo vermelho

\footnotetext{
${ }^{1}$ Grau de urbanização é definido pelo percentual da população urbana em relação à população total.
} 
amarelo, podzólico vermelho amarelo, terra roxa estruturada, areia quartzosa profunda, solo litólicos e solo hidromórfico - apenas os três primeiros compõem as sub-bacias estudadas (Figura 15).

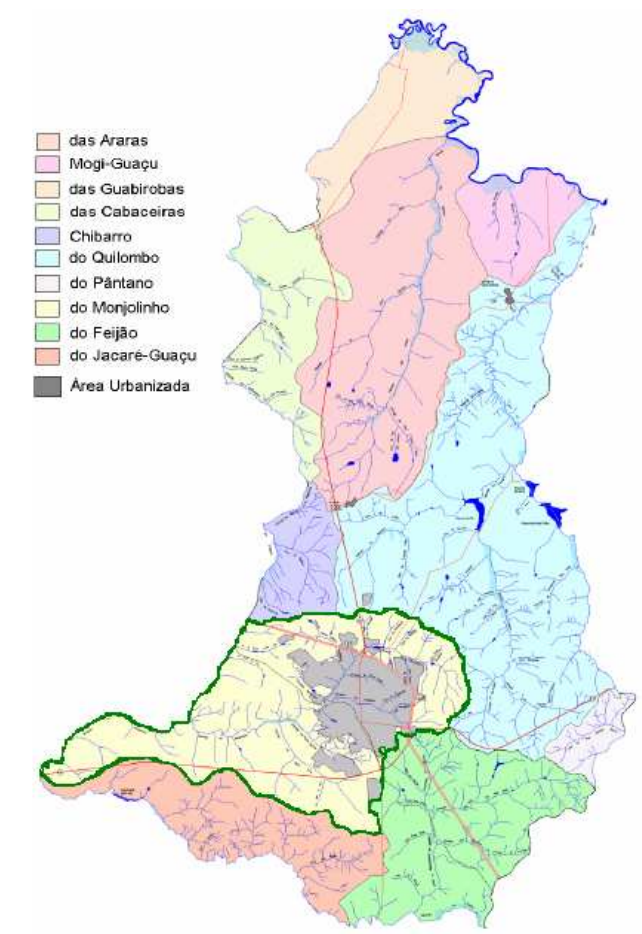

Figura 14: São Carlos e suas sub-bacias, com destaque para sub-bacia do Monjolinho. Fonte:Relatório Polis (2002)

\subsubsection{Uso do Solo Urbano}

São Carlos, segundo Lira (2003), é uma cidade com predominância de uso misto podendo-se encontrar uma grande diversidade de usos em áreas próximas como: residencial, comercial, serviços e pequenas empresas. A autora (op. cit) ressalta ainda que a lógica de ocupação do solo tem sido regulada por interesses do mercado imobiliário sem o planejamento de qualquer infra-estrutura. Para as 5 sub-bacias estudadas nesse trabalho, o uso e ocupação do solo ocorrem de acordo com as figuras 16 e 17. 


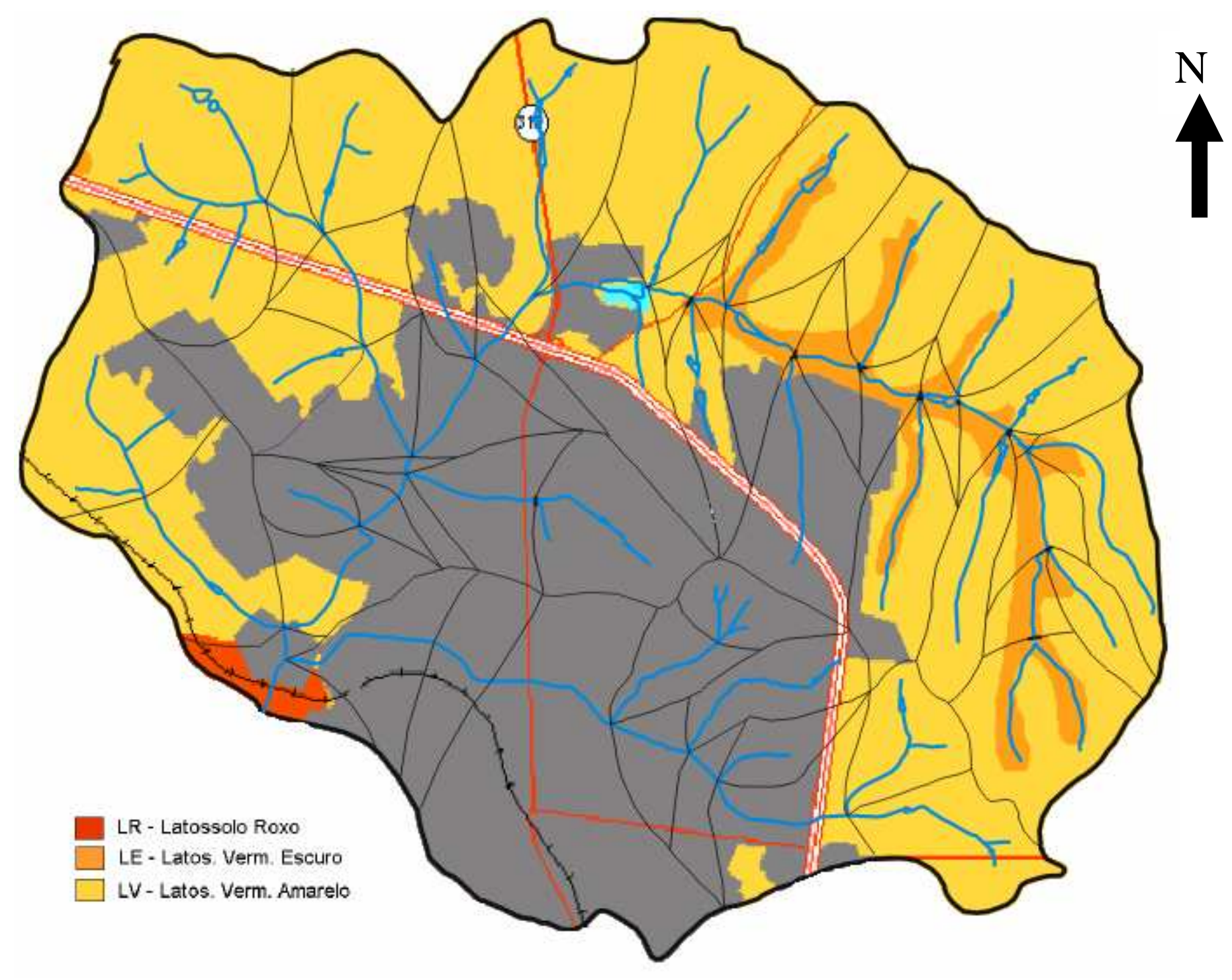

Figura 15: Tipos de solo das sub-bacia, onde a área cinza representa a ocupação urbana. Fonte: Relatório Pólis (2002), adaptado. 


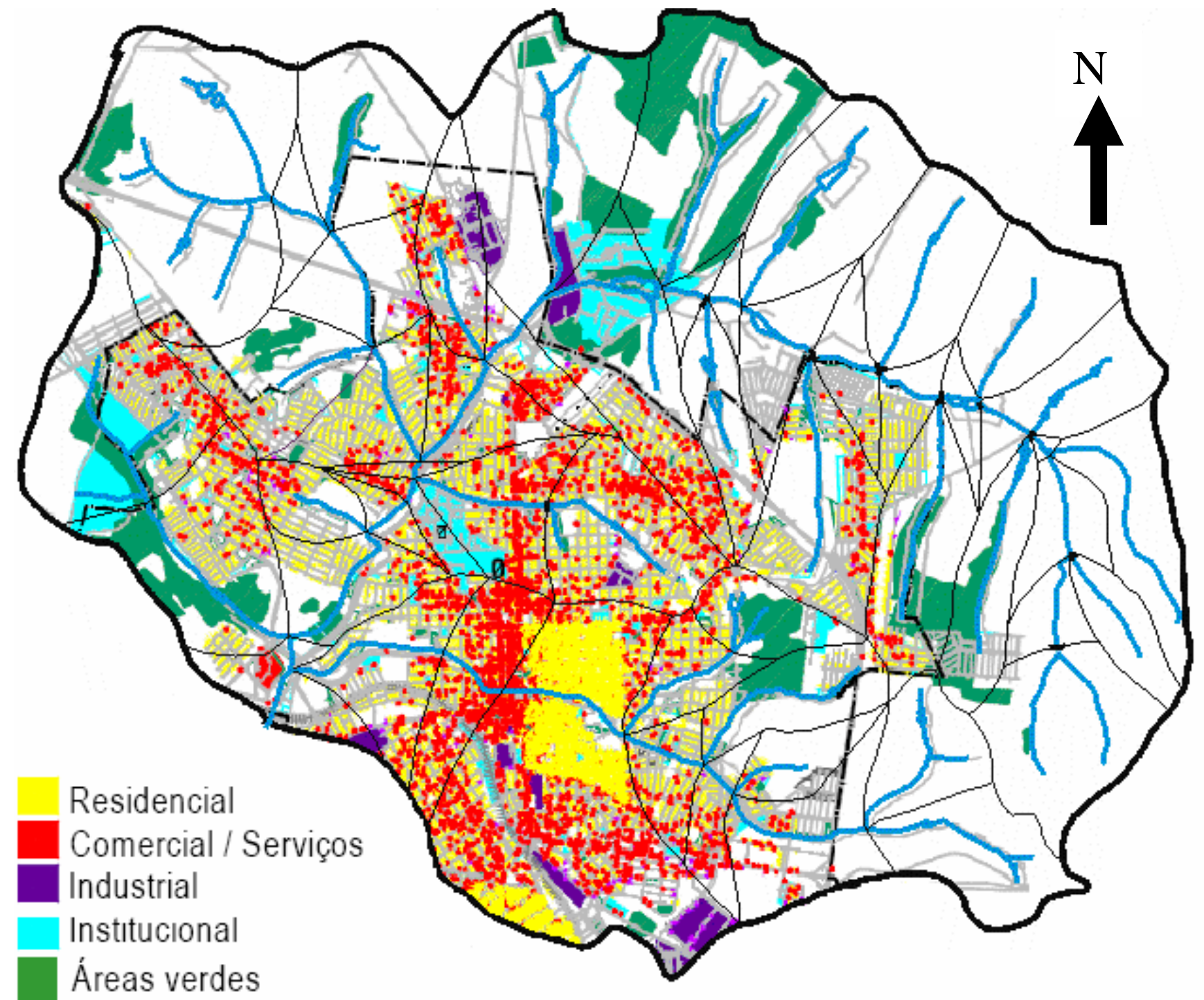

Figura 16: Uso e ocupação do solo urbano. Fonte: Relatório Polis, 2002 (adaptado). 


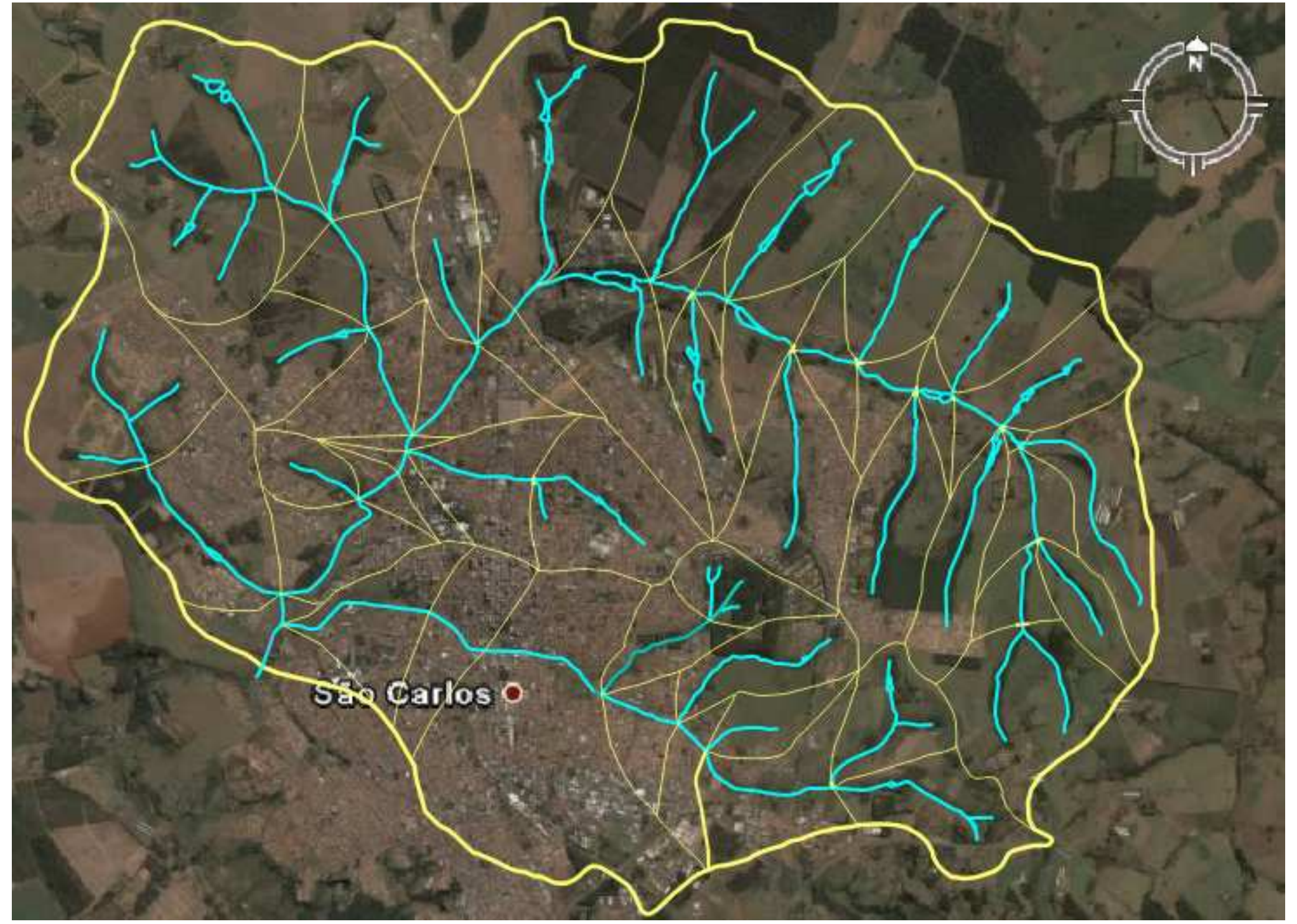

Figura 17: Sub-bacias pertencentes à área urbana de São Carlos.

Fonte: Adaptado de Google Earth ${ }^{\circledR}$ 


\subsubsection{Caracterização hidrológica}

Em relação aos aspectos hidrológicos, o clima no estado de São Paulo sofre influências de massas de ar Tropical Atlântica e Continental e Polar Atlântica, todas complementadas pela Equatorial Continental, advinda da Amazônia Ocidental. Desta forma, ao longo do ano têm-se diferentes características climáticas. As chuvas ocorrem mais intensamente de outubro a março, com o período de menor pluviosidade nos meses de abril a setembro. Em termos de área de abrangência, as precipitações diminuem do litoral para o interior do estado, em função da continentalidade, salvo casos onde o relevo é mais elevado (Sant'Anna Neto ${ }^{17}, 1995$ apud CBH-TJ, 2000).

Para a Bacia Tietê-Jacaré, onde se localiza a área urbana pertencente ao município de São Carlos, segundo CBH-TJ (2000), estudos realizados por Setzer $(1966)^{18}$ - com base na classificação do clima indicada por Köeppen -, há dois tipos climáticos característicos nesta região denominados por Cwa e $\mathrm{Cwb}$, com predomínio do primeiro. A caracterização de ambos é dada sucintamente pela Tabela 15 .

Tabela 15: Classificação Climática de acordo com Köeppen.

\begin{tabular}{ccccc}
\hline $\begin{array}{c}\text { Tipo } \\
\text { Climático }\end{array}$ & Símbolo & $\begin{array}{c}\text { Total de chuva } \\
\text { no período seco }\end{array}$ & $\begin{array}{c}\mathbf{T}_{\mathbf{m}}\left({ }^{\mathbf{0}} \mathbf{C}\right) \text { no mês } \\
\text { mais quente }\end{array}$ & $\begin{array}{c}\mathbf{T}_{\mathbf{m}}\left({ }^{\mathbf{0}} \mathbf{C}\right) \text { no mês } \\
\text { mais frio }\end{array}$ \\
\hline $\begin{array}{c}\text { Quente/ } \\
\text { inverno seco }\end{array}$ & Cwa & Menos de $30 \mathrm{~mm}$ & Acima de $22{ }^{\circ} \mathrm{C}$ & Abaixo de $18{ }^{\circ} \mathrm{C}$ \\
\hline $\begin{array}{c}\text { Temperado/ } \\
\text { inverno seco }\end{array}$ & $\mathrm{Cwb}$ & Menos de $30 \mathrm{~mm}$ & Abaixo de $22{ }^{\circ} \mathrm{C}$ & Abaixo de $18{ }^{\circ} \mathrm{C}$ \\
\hline & Fonte: Setzer $(1996)$ apud CBT-TJ $(2000)$ &
\end{tabular}

Segundo Silva (2003) a precipitação média anual da região do município de São Carlos é de 1200mm, aproximadamente. 


\subsection{Modelagem}

\subsubsection{Calibração e Validação}

As fases de calibração e validação do modelo servem para avaliar as suas respostas de forma a verificar se o mesmo simula adequadamente o sistema. São inseridos parâmetros e dados de entrada reais com o objetivo de comparar os resultados obtidos com os dados observados para uma mesma seção de interesse.

Para essa etapa foram escolhidas três seções, uma localizada na bacia do córrego Gregório e as outras duas ao longo do córrego Monjolinho como mostra figura 18. A justificativa para tal escolha baseia-se nos monitoramentos realizados pelo SAAE (Serviço Autônomo de Água e Esgoto de São Carlos) de São Carlos, nas seções do córrego Monjolinho, e; pelo NIBH (Núcleo Integrado de Bacias hidrográficas) na bacia do córrego Gregório.

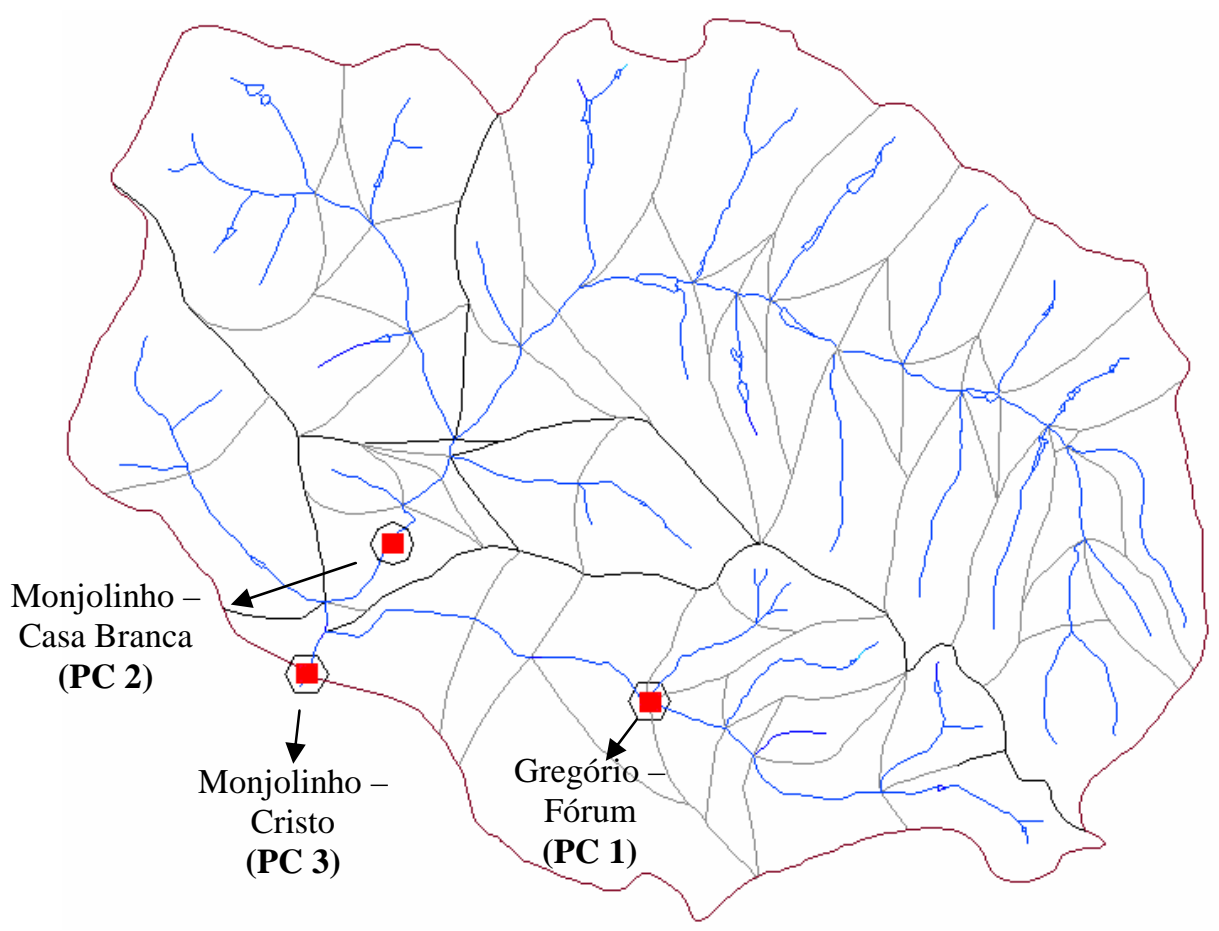

Figura 18: Seções de calibração e validação. 
As seções analisadas localizam-se na bacia do Gregório entre as ruas Major Antonio

Manoel de Matos e José Rodrigues Sampaio (próximo ao Fórum Municipal), e na bacia do

Monjolinho Av. Francisco Pereira Lopes (próximo ao restaurante Casa Branca) e Av.

Tancredo Neves (próximo à rotatória do Shopping Iguatemi) (Figuras 19 a 26).

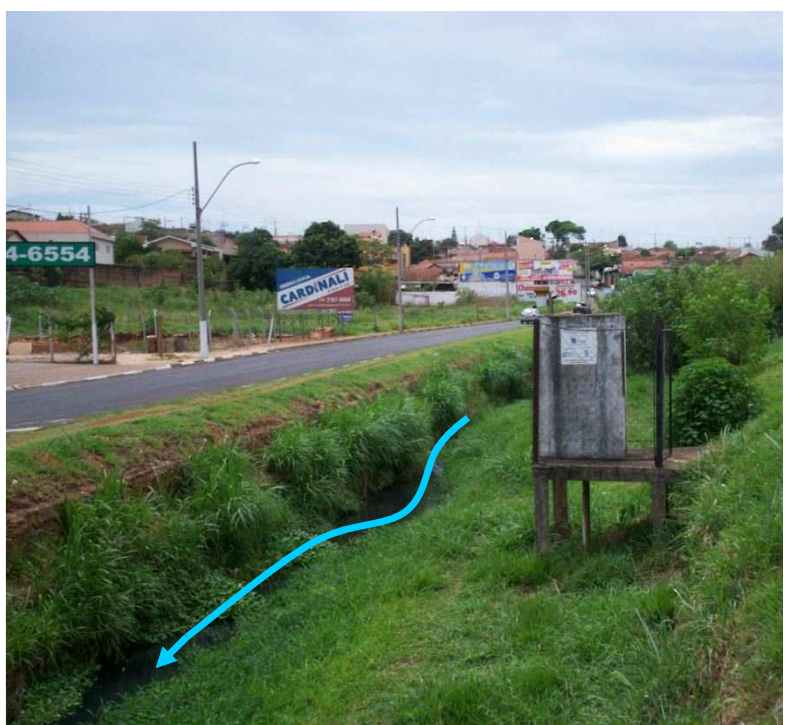

Figura 19: Posto pluvio-fluviométrico - Estação Fórum, localizada na bacia do Córrego Gregório. (Foto: TFS, 01/11/2007)

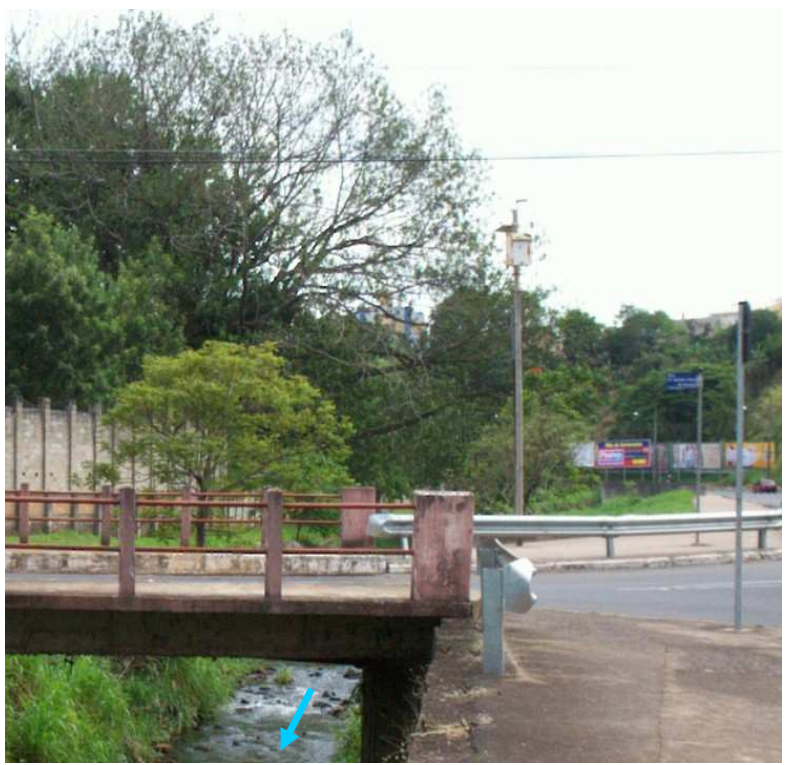

Figura 21: Posto hidrométrico monitorado pelo SAAE - Córrego Monjolinho, próximo ao restaurante Casa Branca. (Foto: TFS, 01/11/2007)

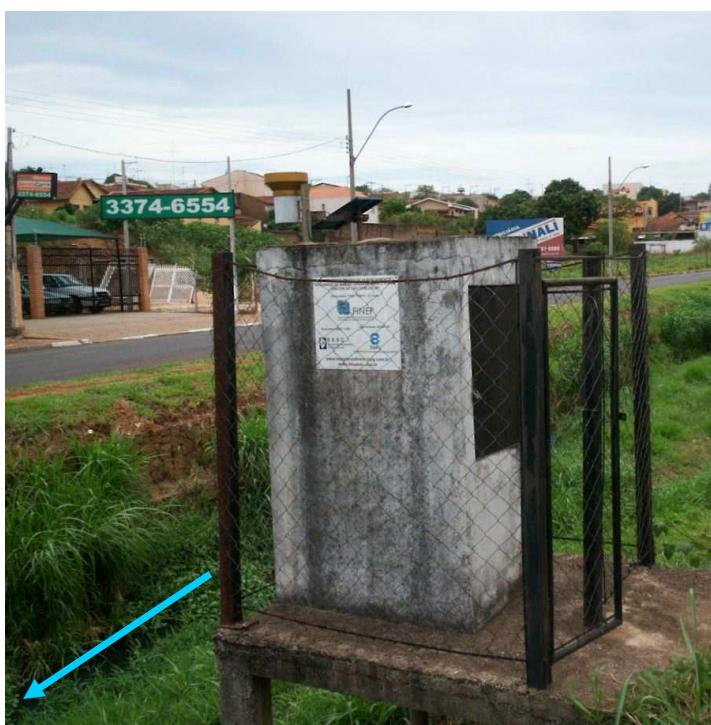

Figura 20: Detalhe do posto - Estação Fórum, localizada na bacia do Córrego Gregório. (Foto: TFS, 01/11/2007)

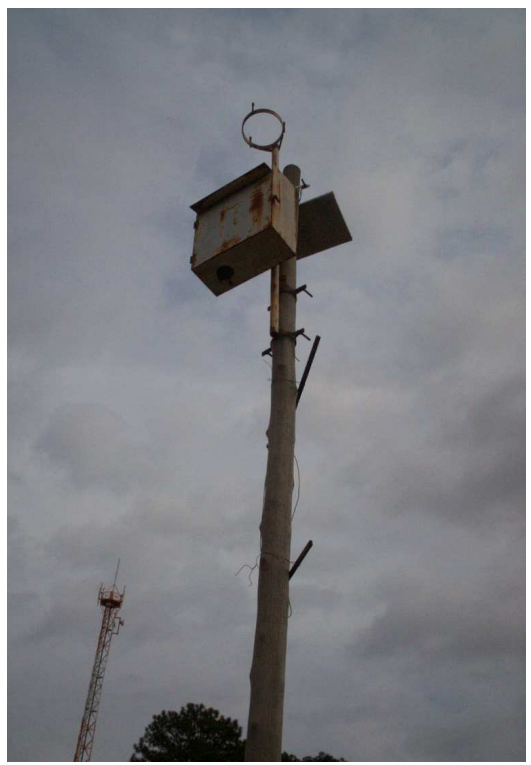

Figura 22: Detalhe do posto (Monjolinho - Casa Branca), hoje desativado. (Foto: TFS, 01/11/2007) 


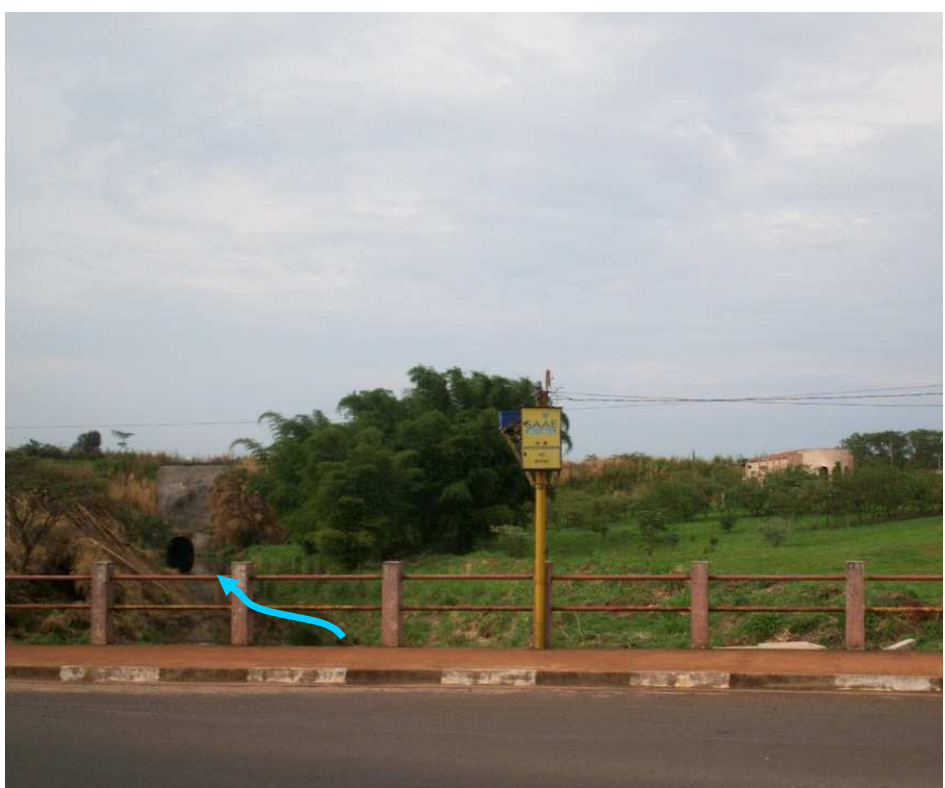

Figura 23: Posto hidrométrico monitorado pelo SAAE Próximo à rotatória do Shopping Iguatemi. Vista de montante para jusante. (Foto: TFS, 01/11/2007)

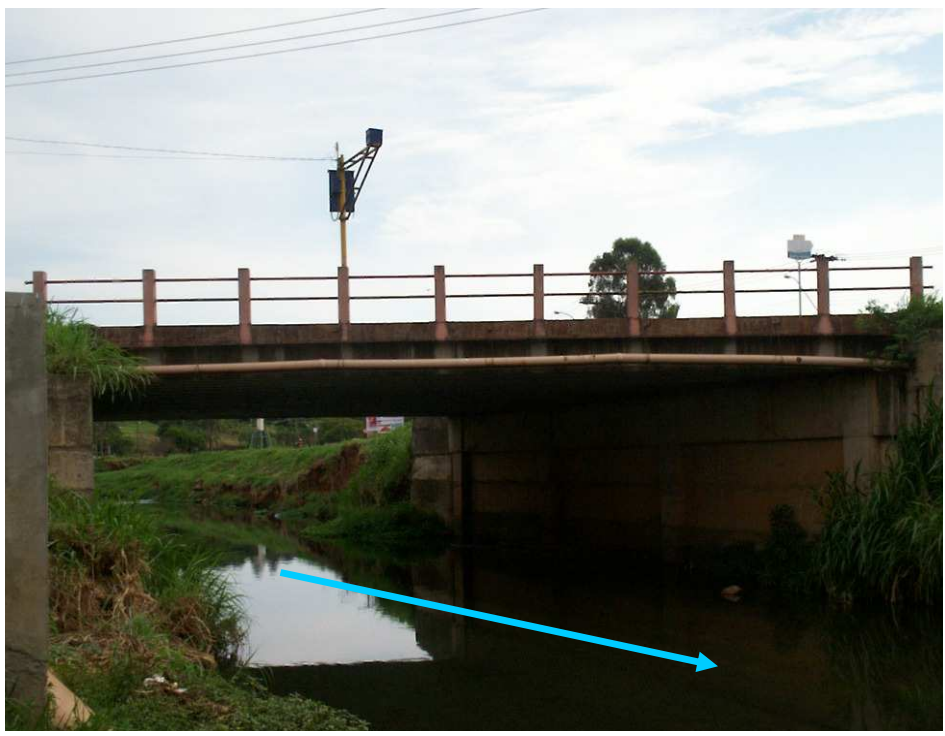

Figura 25: Posto hidrométrico monitorado pelo SAAE Próximo à rotatória do Shopping Iguatemi. Vista de jusante para montante. (Foto: TFS, 01/11/2007)

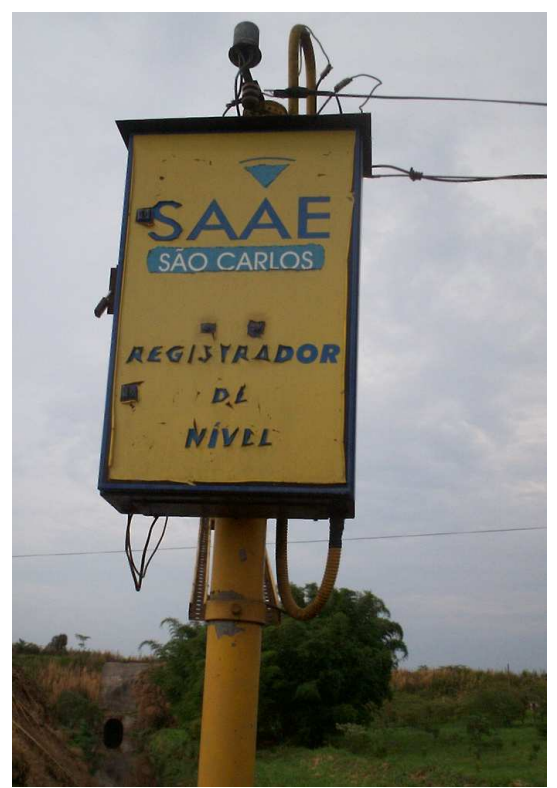

Figura 24: Detalhe frontal do posto. (Foto: TFS, 01/11/2007)

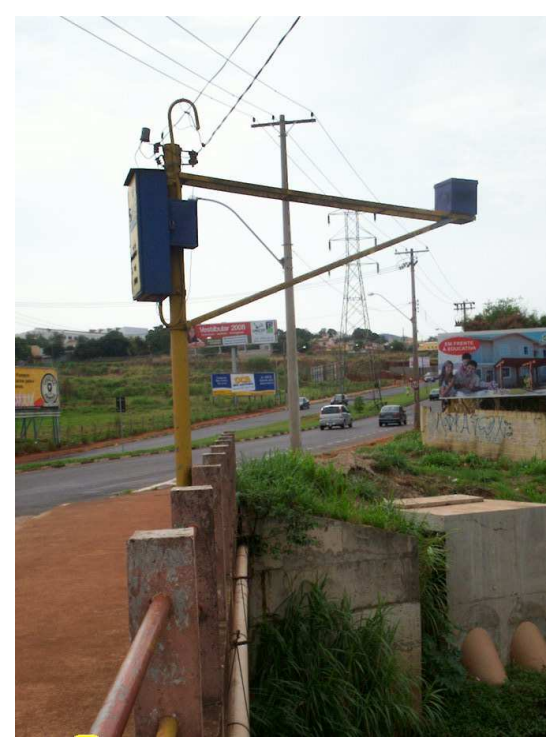

Figura 26: Detalhe lateral do posto. (Foto: TFS, 01/11/2007)

Nesse trabalho utilizou-se a seguinte denominação para os pontos de calibração: PC 1

(Bacia do Gregório), PC 2 (Bacia do Monjolinho - próximo ao restaurante Casa Branca) e PC 3 (Bacia do Monjolinho - próximo ao do shopping Iguatemi).

Os dados de precipitação e nível d'água obtidos através de uma estação pluviofluviométrica - Campbell Scientific ${ }^{\circledR}$ CR10 - instalada na seção do Fórum (Bacia do 
Gregório - PC 1) e fornecidos pelo NIBH (2007), são acumulados a cada minuto e correspondem ao período de 2004 à 2006. Já as observações hidrométricas, fornecidos pelo SAAE - São Carlos, compreendem o monitoramento realizado entre 2003 e 2006, com leituras a cada 30 minutos (PC 2 e PC 3). Os dados de precipitação e nível d'água de todos os postos analisados, bem como suas falhas podem ser vistas no APÊNDICE A. As falhas do posto pluviométrico (Estação Fórum) localizado na bacia do Córrego Gregório foram extraídos de Vasconcelos (2007).

Pela diferença nos intervalos de dados observados e simulados (5 e 30 minutos) e, conseqüentemente pela dificuldade de manipulação dos mesmos, optou-se por utilizar somente um indicador de qualidade no ajuste dos hidrogramas. O mesmo tem como função avaliar os erros percentuais dos volumes escoados dados em função das vazões observadas e simuladas.

$$
E V=\frac{\left[\sum_{t=1}^{n}\left(Q_{\text {sim }}\right)-\sum_{t=1}^{n}\left(Q_{o b s}\right)\right]}{\sum_{t=1}^{n t} Q_{o b s}} \cdot 100
$$

em que:

$Q_{o b s}=$ vazão observada;

$Q_{\text {sim }}=$ vazão simulada;

$\mathrm{n}=$ número passos de tempo de simulações;

$\mathrm{t}=$ intervalo de tempo.

Nesse estudo o ajuste dos parâmetros foi realizado manualmente pelo método da tentativa e erro. 


\subsubsection{Hidrogramas utilizados}

De posse de todos os dados - precipitação e nível d'água - os mesmos foram organizados e agrupados por ano de ocorrência de forma a se obter eventos que contivessem dados de precipitação e nível d'água nos três pontos de interesse durante um mesmo período, resultando em 10 eventos com precipitações maiores que 10mm, dos quais 6 foram selecionados, 3 para fase de calibração (Figuras 27 a 30) e 3 para fase de validação (Figuras 31 a 33).

Nas tabelas 16 e 17 encontram-se os eventos selecionados e suas principais características, dadas em função dos seguintes parâmetros:

- Precipitação total $\left(\mathrm{P}_{\text {total }}\right)$ : dada pelo total precipitado;

- Intensidade média $\left(\mathrm{I}_{\text {média }}\right)$ : razão entre lâmina total precipitada e tempo de duração da chuva;

- Índice de precipitação acumulada (IPA): precipitação acumulada nos 5 dias anteriores à ocorrência do evento;

- Umidade antecedente: dada em função do IPA para o período de crescimento da vegetação (item 3.4.4.1);

- Tipo de evento: dado em função do número de picos do hietograma (para 1 pico (1), para 2 picos (2), e assim por diante);

- Precipitação efetiva $\left(\mathrm{P}_{\text {efetiva }}\right)$ : razão entre o volume escoado e área da bacia;

- Vazão máxima $\left(\mathrm{Q}_{\max }\right)$ : vazão de pico do hidrograma;

- Coeficiente de escoamento superficial (C): razão entre precipitação efetiva e a precipitação total. 
Tabela 16: Caracterização dos eventos utilizados nas fases de calibração e validação.

\begin{tabular}{|c|c|c|c|c|c|c|c|c|c|}
\hline Evento & Utilização & Data & $\begin{array}{l}\text { Horário de } \\
\text { ocorrência }\end{array}$ & $\begin{array}{c}\text { Duração } \\
\text { (min) }\end{array}$ & $\begin{array}{c}\text { Precip. } \\
\text { Total } \\
(\mathbf{m m})\end{array}$ & $\begin{array}{c}\mathbf{I}_{\text {média }} \\
(\mathbf{m m} / \mathbf{h})\end{array}$ & $\begin{array}{c}\text { IPA } \\
(\mathbf{m m})\end{array}$ & $\begin{array}{c}\text { Umidade } \\
\text { Antecedente }\end{array}$ & Tipo \\
\hline $\mathrm{a}$ & Calibração & $09 / 01 / 2004(2)$ & $13: 55-14: 55$ & 60 & 15,50 & 1,19 & 40,4 & AMC II & 1 \\
\hline $\mathrm{b}$ & Calibração & 09/01/2004(3) & $19: 30-21: 15$ & 105 & 22,50 & 0,58 & 56,6 & AMC III & 1 \\
\hline $\mathrm{c}$ & Calibração & $30 / 01 / 2004$ & $16: 20-17: 35$ & 75 & 41,80 & 2,09 & $163,9^{*}$ & AMC III & 1 \\
\hline $\mathrm{d}$ & Validação & $01 / 11 / 2003$ & $21: 50-22: 50$ & 65 & 13,60 & 0,90 & 31,4 & AMC I & 1 \\
\hline $\mathrm{e}$ & Validação & $27 / 12 / 2003$ & $14: 30-14: 55$ & 25 & 15,20 & 5,07 & 11,4 & AMC I & 1 \\
\hline $\mathrm{f}$ & Validação & $31 / 12 / 2003$ & $11: 50-13: 15$ & 85 & 16,50 & 0,65 & 24,2 & AMC I & 1 \\
\hline
\end{tabular}

*Dado utilizado de outra estação pluviométrica (FADISC - Bacia Gregório).

Tabela 17:Caracterização dos eventos utilizados nas fases de calibração e validação. Continuação.

\begin{tabular}{|c|c|c|c|c|c|c|c|c|c|}
\hline \multirow[b]{2}{*}{ Evento } & \multicolumn{3}{|c|}{ C. Gregório - PC 1} & \multicolumn{3}{|c|}{ C. Monjolinho - Casa Branca-PC 2} & \multicolumn{3}{|c|}{ C. Monjolinho-Cristo - PC 3} \\
\hline & $\begin{array}{l}\mathbf{P}_{\text {efetiva }} \\
(\mathbf{m m})\end{array}$ & $\mathbf{Q}_{\max }\left(\mathbf{m}^{3} / \mathbf{s}\right)$ & $\mathbf{C}$ & $\begin{array}{l}\mathbf{P}_{\text {efetiva }} \\
(\mathbf{m m})\end{array}$ & $\begin{array}{c}\mathbf{Q}_{\max } \\
\left(\mathbf{m}^{3} / \mathbf{s}\right)\end{array}$ & $\mathbf{C}$ & $\begin{array}{l}\mathbf{P}_{\text {efetiva }} \\
(\mathbf{m m}))\end{array}$ & $\begin{array}{c}Q_{\max } \\
(\mathbf{m} 3 / \mathbf{s})\end{array}$ & $\mathbf{C}$ \\
\hline $\mathrm{a}$ & 8,60 & 9,90 & 0,555 & 1,12 & 29,10 & 0,072 & 1,09 & 67,97 & 0,070 \\
\hline $\mathrm{c}$ & 20,10 & 20,90 & 0,893 & 2,70 & 39,80 & 0,120 & 2,40 & 109,70 & 0,107 \\
\hline $\mathrm{c}$ & 25,50 & 60,00 & 0,610 & -------* & ------** & ------** & 3,19 & 223,60 & 0,076 \\
\hline $\mathrm{d}$ & 6,26 & 4,72 & 0,460 & 0,54 & 9,53 & 0,040 & 0,54 & 30,94 & 0,040 \\
\hline $\mathrm{e}$ & 7,50 & 6,90 & 0,493 & 1,00 & 24,90 & 0,066 & 0,80 & 38,43 & 0,053 \\
\hline $\mathrm{f}$ & 11,70 & 9,90 & 0,709 & 1,40 & 26,00 & 0,085 & 1,20 & 43,50 & 0,073 \\
\hline
\end{tabular}

*Dados inconsistentes.

A estimativa das vazões baseou-se, para a seção localizada no córrego Gregório (PC 1), na curva chave proposta por Lima et al. (2007). Os autores estimaram, a partir dos dados de Silva (2003), a relação entre altura e a vazão utilizando o método de regressão não linear.

$$
Q=8,278 \cdot h^{2,2517} \quad\left(\mathrm{R}^{2}=0,99\right)
$$

em que:

$$
\begin{aligned}
& Q=\text { vazão }\left(\mathrm{m}^{3} / \mathrm{s}\right) ; \\
& h=\text { nível d'água }(\mathrm{m}) ;
\end{aligned}
$$

Já para as demais seções, PC 2 e PC 3, a estimativa da vazão deu-se considerando o modelo de onda cinemática através da fórmula de Manning.

$$
Q=\frac{1}{n} \cdot S_{0}^{1 / 2} \cdot A \cdot R_{H}{ }^{2 / 3}
$$

em que:

$$
\text { Q: vazão }\left(\mathrm{m}^{3} / \mathrm{s}\right) \text {; }
$$

n: coeficiente de rugosidade de Manning; 
$\mathrm{S}_{0}$ : declividade de fundo do canal $(\mathrm{m} / \mathrm{m})$

A: área da seção transversal $\left(\mathrm{m}^{2}\right)$;

$\mathrm{R}_{\mathrm{H}}$ : raio hidráulico $(\mathrm{m})$.

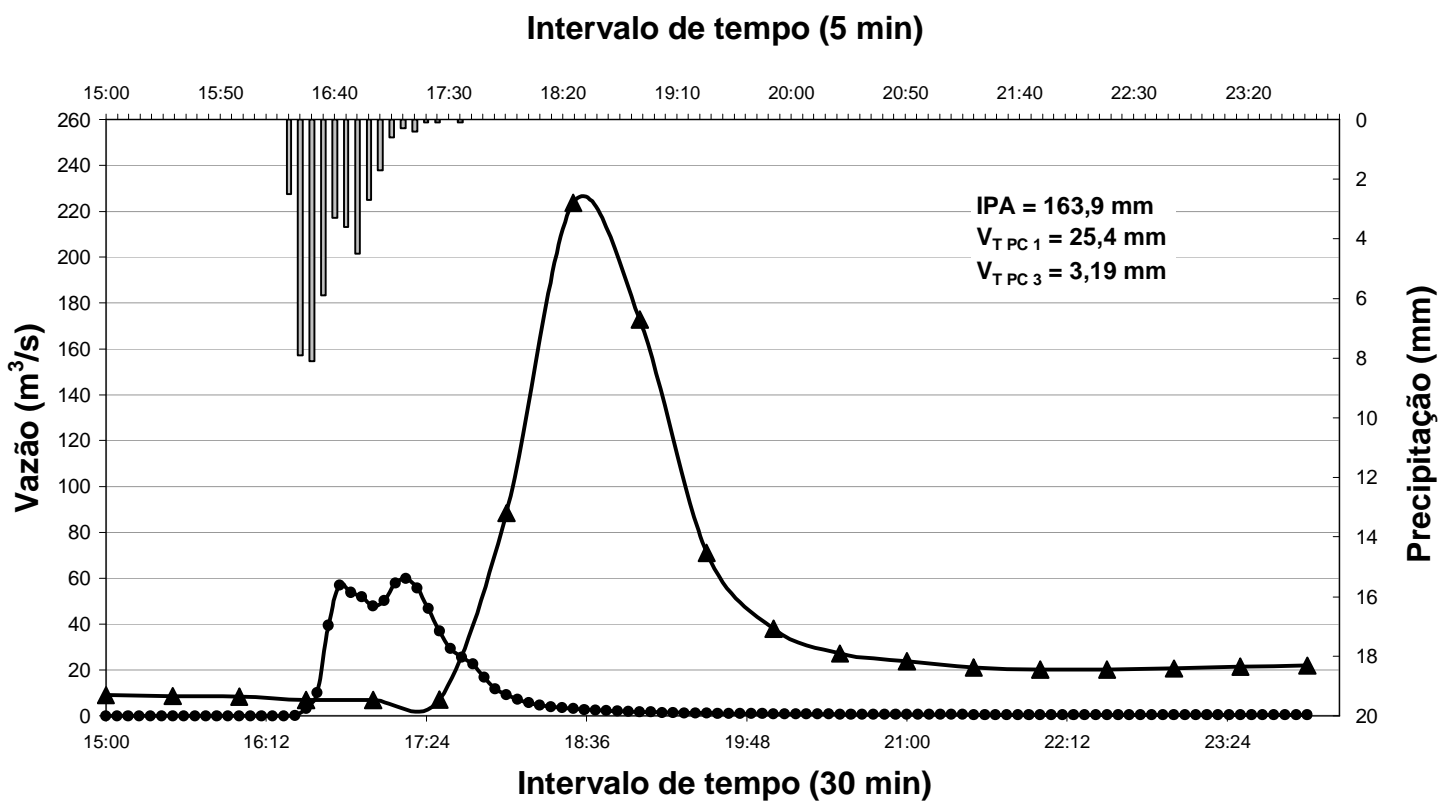

Figura 27: Precipitação observada $(41,8 \mathrm{~mm})$ e hidrogramas observados dados em função das vazões e utilizados na fase de calibração. Dia: 30/01/2004, evento (c).

Intervalo de tempo (5 min)

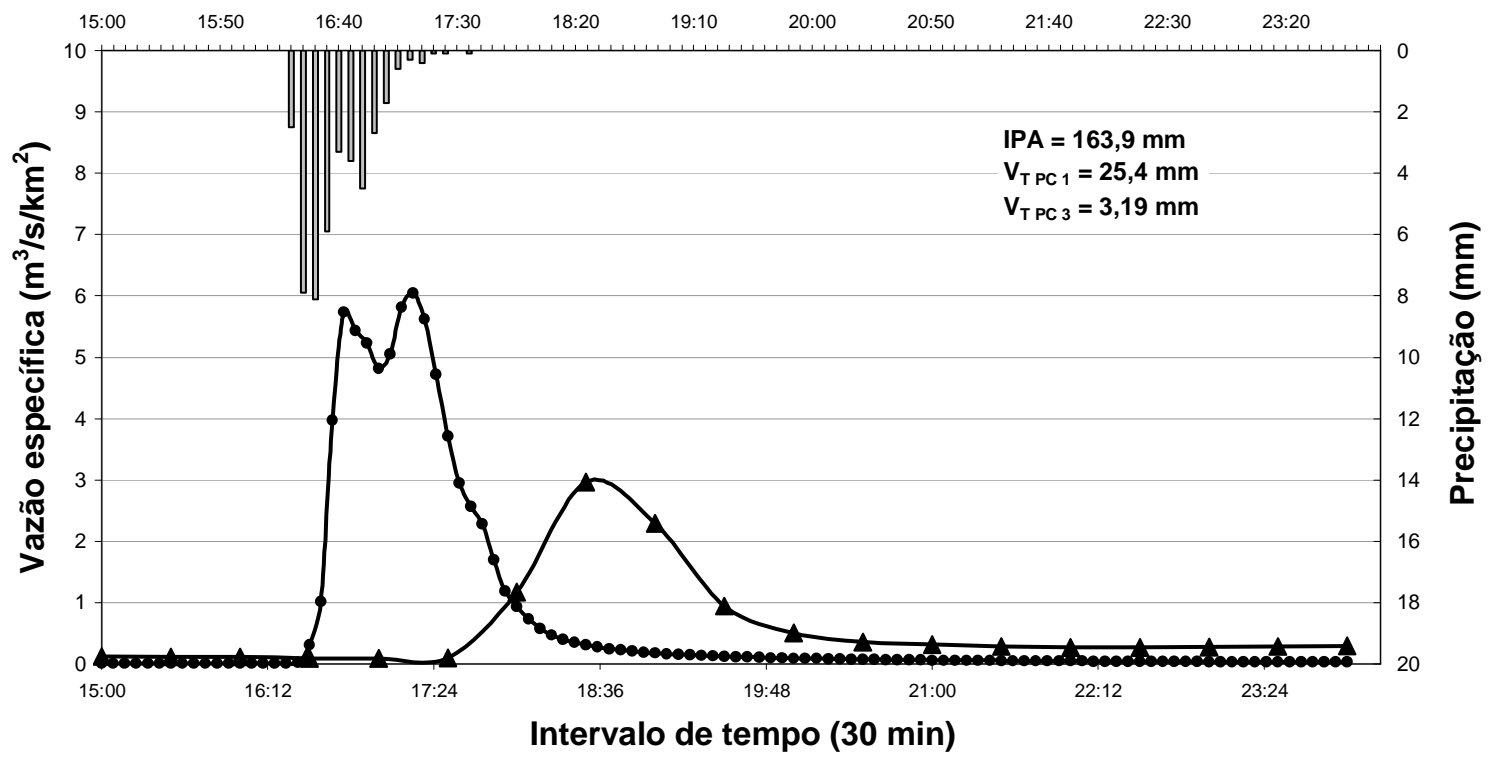

$\square$ Precipitação $\rightarrow$-PC 1- Obs $\rightarrow$-PC 3 - Obs

Figura 28: Precipitação observada (41,8 mm) e hidrogramas observados dados em função das vazões específicas e utilizados na fase de calibração. Dia: 30/01/2004, evento (c). 
Intervalo de tempo (5 min)

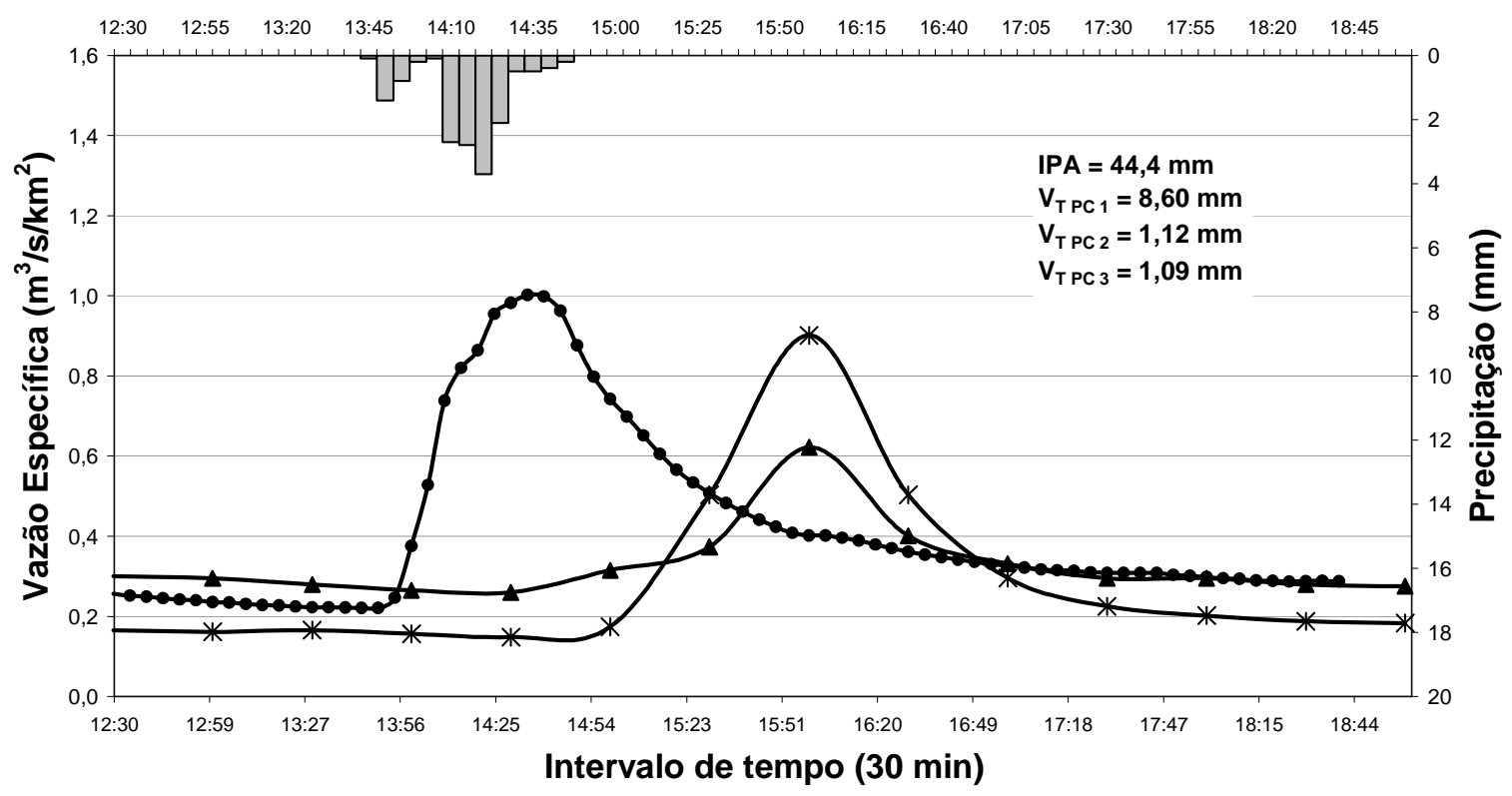

$\square$ Precipitação $\rightarrow$-PC 1 - Obs $\rightarrow$ PC 2 - Obs $\rightarrow$ * PC 3 - Obs

Figura 29: Precipitação observada (15,5 mm) e hidrogramas observados em função das vazões específicas e utilizados na fase de calibração. Dia: 09/01/2004, evento (a).

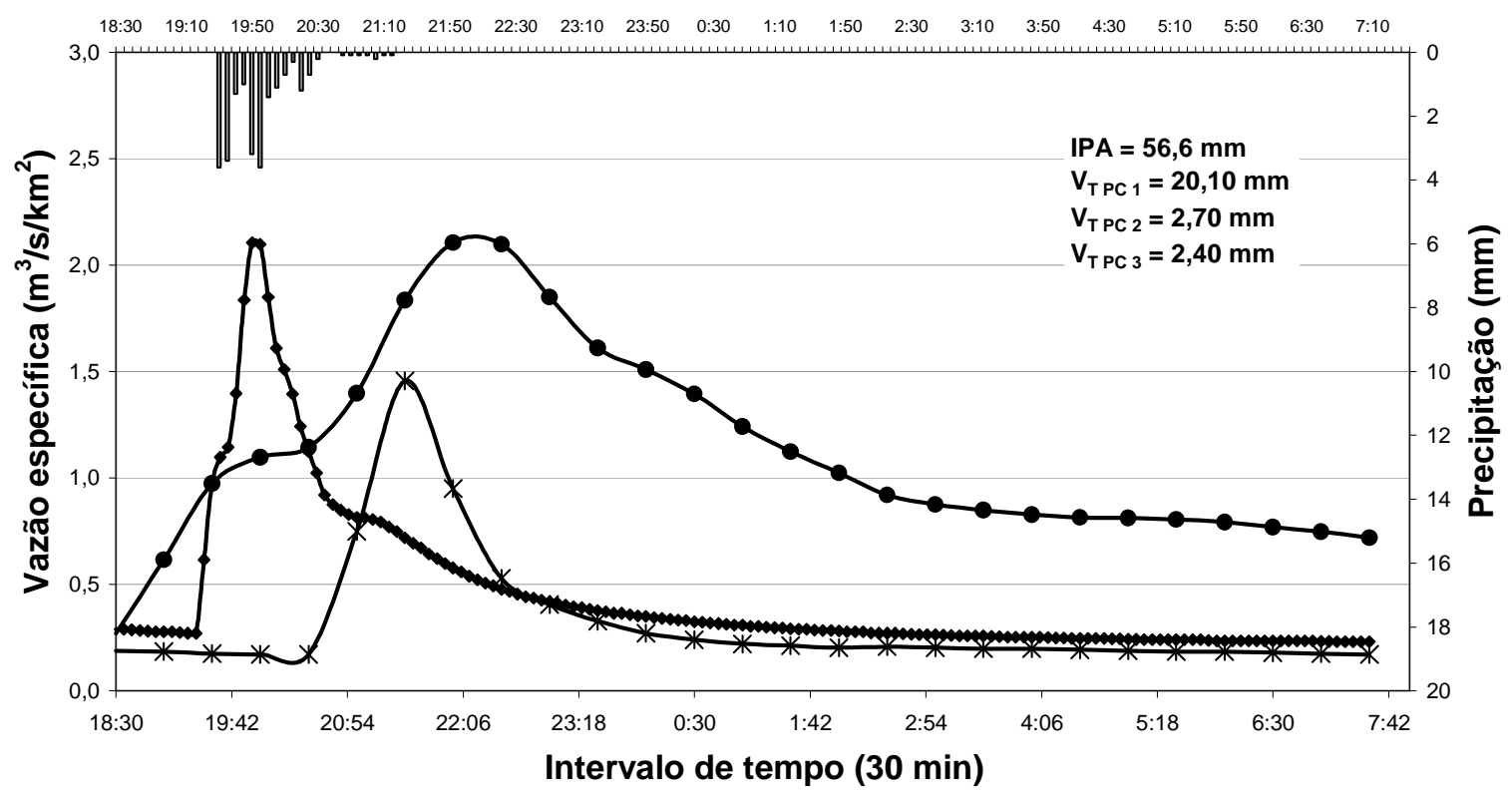

$\square$ Precipitação $\rightarrow$ ๑PC 1 - Obs $\rightarrow$ PC 2 - Obs $\rightarrow$ * -PC 3 - Obs

Figura 30: Precipitação observada (22,5 mm) e hidrogramas observados em função das vazões específicas e utilizados na fase de calibração. Dia: 09/01/2004, evento (b). 
Intervalo de tempo (5 $\mathrm{min})$

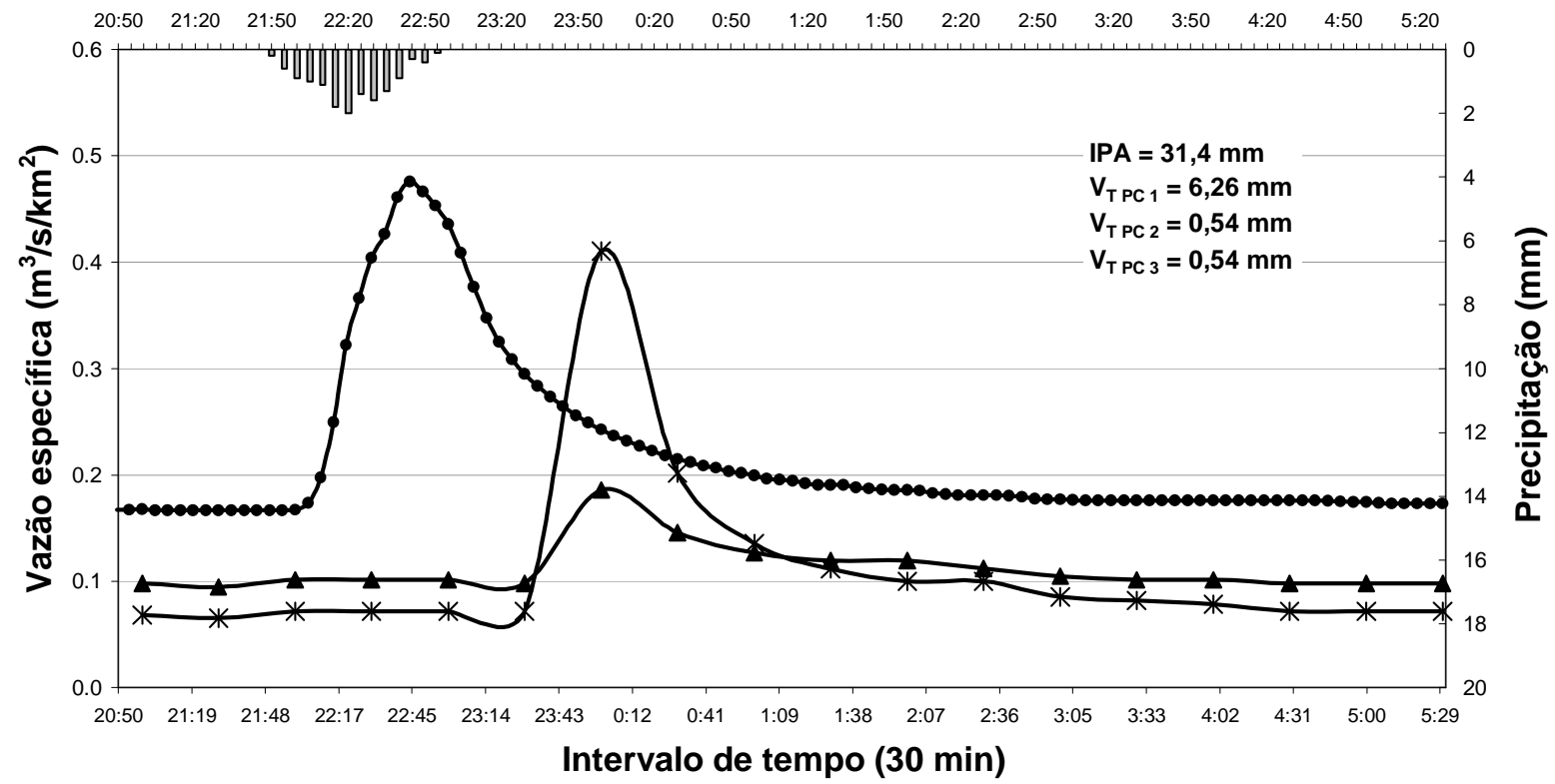

$\rightleftharpoons$ Precipitação $\rightarrow$-PC 1- Obs $\rightarrow$-PC 2 - Obs $\rightarrow$ *PC 3 - Obs

Figura 31: Precipitação observada $(13,6 \mathrm{~mm})$ e hidrogramas observados em função das vazões específicas e utilizados na fase de validação. Dia: 01/11/2003, evento (d).

\section{Intervalo de tempo (5 min)}

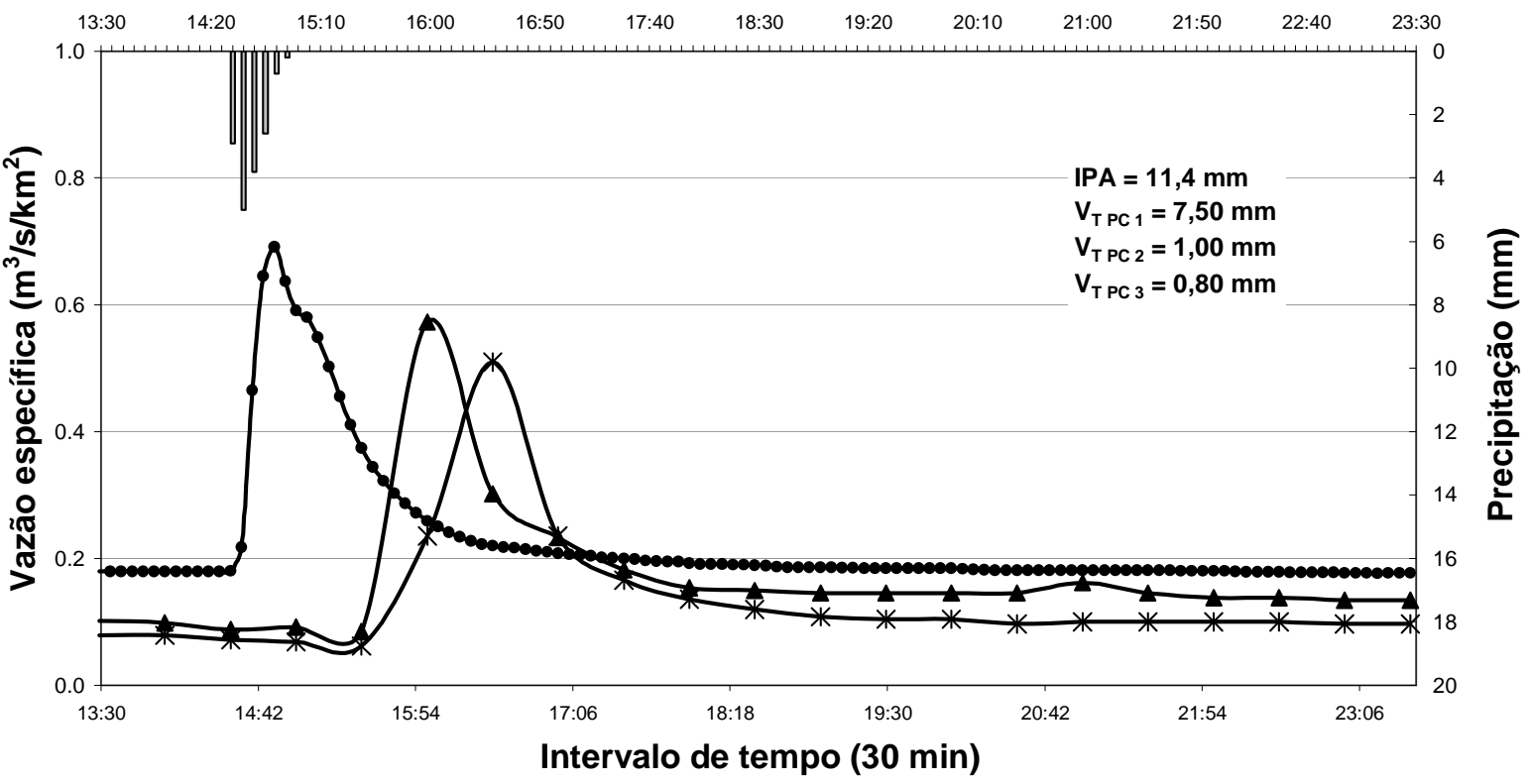

$\rightleftarrows$ Precipitação $\rightarrow$-PC 1 - Obs $\leftarrow$-PC 2 - Obs $\rightarrow$ * $-\mathrm{PC} 3$ - Obs

Figura 32: Precipitação observada (15,2 mm) e hidrogramas observados em função das vazões específicas e utilizados na fase de validação. Dia: 27/12/2003, evento (e). 
Intervalo de tempo (5 min)

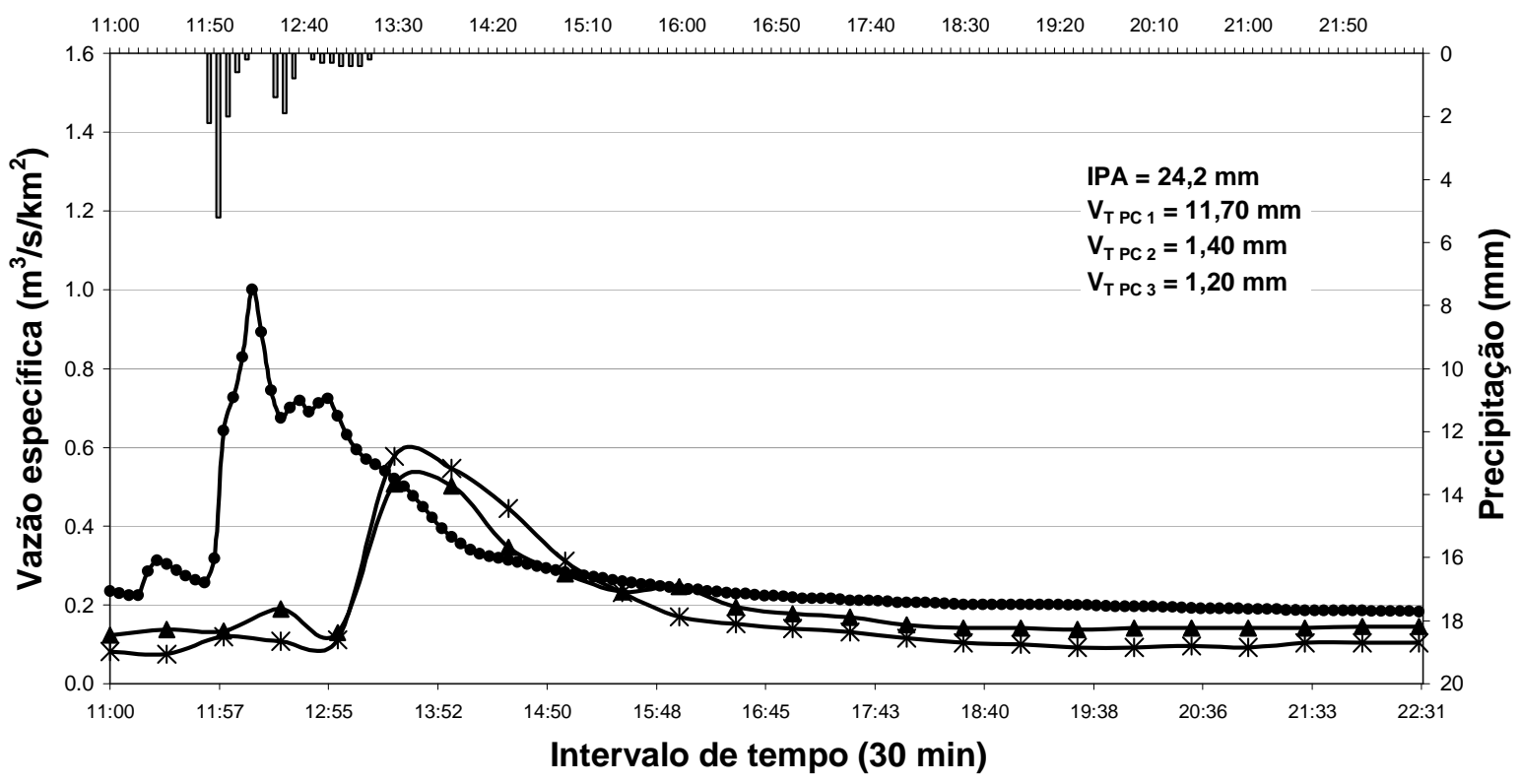

$\varpi$ Precipitação $\rightarrow$ PC 1 - Obs $\leftarrow$-PC 2 - Obs $\rightarrow$-PC 3 - Obs

Figura 33: Precipitação observada $(16,5 \mathrm{~mm})$ e hidrogramas observados em função das vazões específicas e utilizados na fase de validação. Dia: 31/12/2003, evento (f).

\subsubsection{Ajuste do modelo IPH S1}

Como já apresentado no item 3.4.1.2, a entrada de dados de seção transversal de um rio ou canal, no Modelo IPH S1, pode ser dada em função dos formatos: retangular, retangular com planície de inundação (seção composta), circular e trapezoidal, dados de acordo com o método de propagação de cheias adotado.

Com o intuito de auxiliar as etapas de calibração e validação do modelo, foram realizados levantamentos de seções transversais e declividades em quatro pontos de interesse: seções de calibração (PC 1, PC 2 e PC 3 descritas no item 4.3.1) e seção localizada no cruzamento da Rua Miguel Petroni com a Avenida Francisco Pereira Lopes (próxima à USP). 
De posse dos dados obtidos: seção transversal, declividade, área e perímetro molhados, velocidade e vazão; procurou-se obter seções regulares que contivessem as mesmas características hidráulicas das sessões reais.

Dessa forma, a partir das seções transversais levantadas (irregulares) foram obtidas seções regulares (canal desenhado em destaque nas figuras). Para tanto, foram calculadas para cada seção irregular vazões em oito alturas diferentes. Utilizando a ferramenta Solver $\left(\right.$ Excel $\left.^{\circledR}\right)$, procurou-se minimizar a soma quadrado das diferenças entre as vazões obtidas para as seções irregulares e para as regulares nessas oito alturas diferentes, variando a rugosidade equivalente e a largura da seção regular. Dessa forma, foram obtidos os dimensionamentos das seções regulares (Figuras 34 a 37), mais detalhes dos dados obtidos podem ser visualizados no Apêndice B. As vazões foram estimadas a partir da fórmula de Manning (Equação 4.2). Os valores médios de rugosidade foram estimados com base nas características do canal real e com informações obtidas da literatura, por meio de Chow (1959), Neves (1968), Tomaz (2002) e Porto (2003).
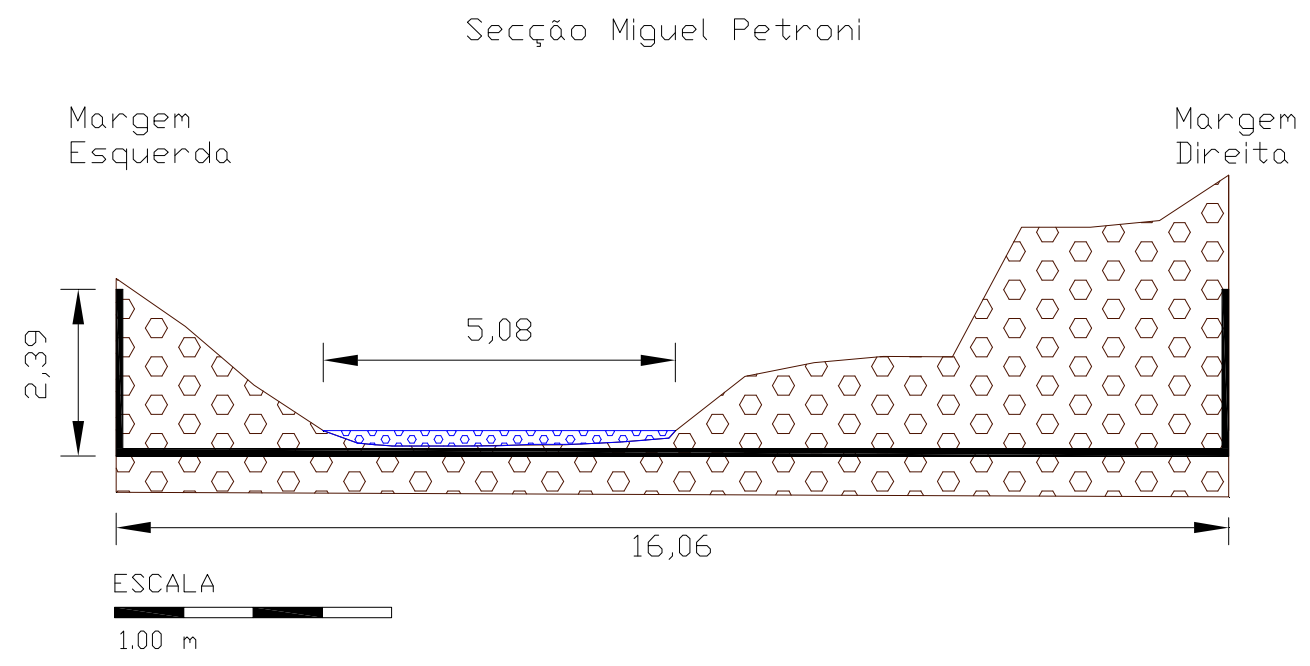

Figura 34: Seção transversal, rotatória na Rua Miguel Petroni. 


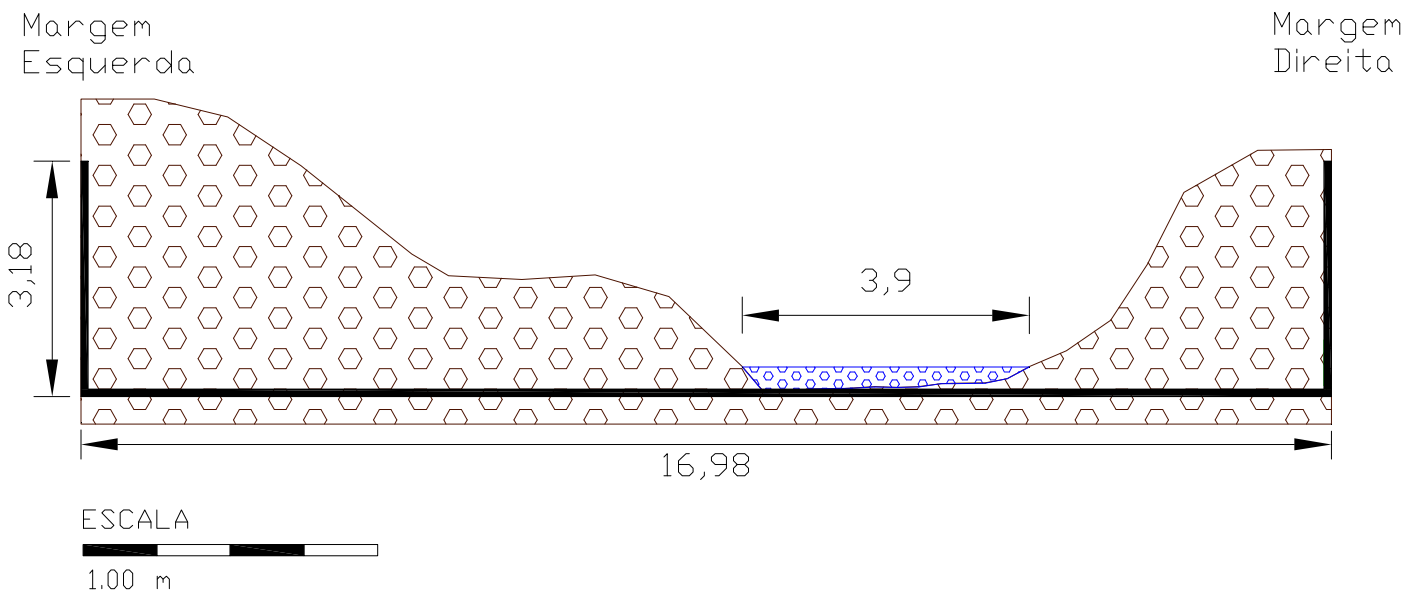

Figura 35: Seção transversal do ponto de controle 1 (PC 1), bacia do Córrego Gregório.

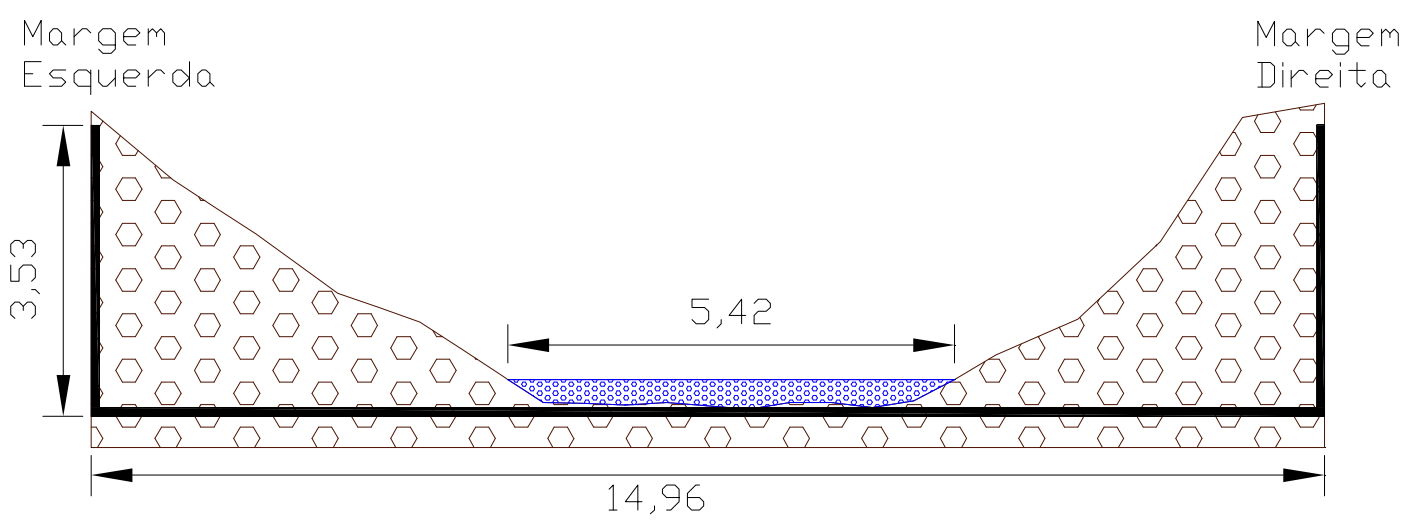

ESCALA

$1.00 \mathrm{~m}$

Figura 36: Seção transversal do ponto de controle 2 (PC 2), bacia do Córrego Monjolinho (Casa Branca).

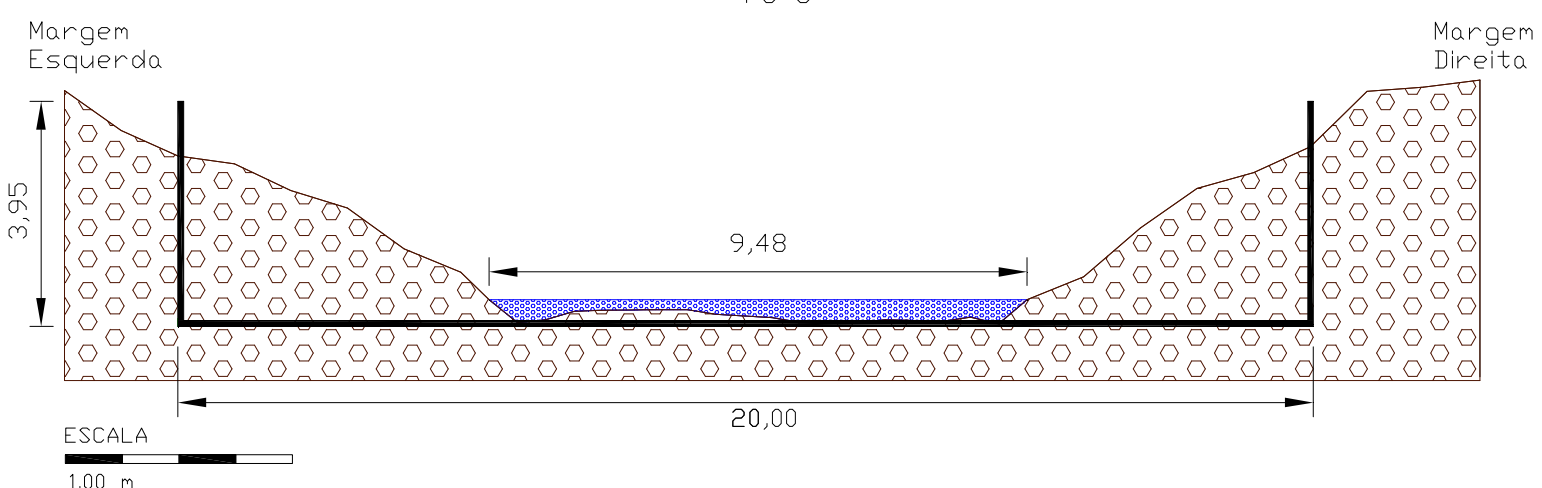

Figura 37: Seção transversal do ponto de controle 3 (PC 3), bacia do Córrego Monjolinho (Shopping Iguatemi). 
Como forma de avaliar a consistências das características hidráulicas das seções obtidas, construí-se para cada ponto de interesse curvas chave das seções regulares e irregulares (Figuras 38 a 41). Para a seção do Córrego Gregório utilizou-se a curva chave proposta por Lima et al (2007), as demais foram estimadas utilizando-se a fórmula de Manning.

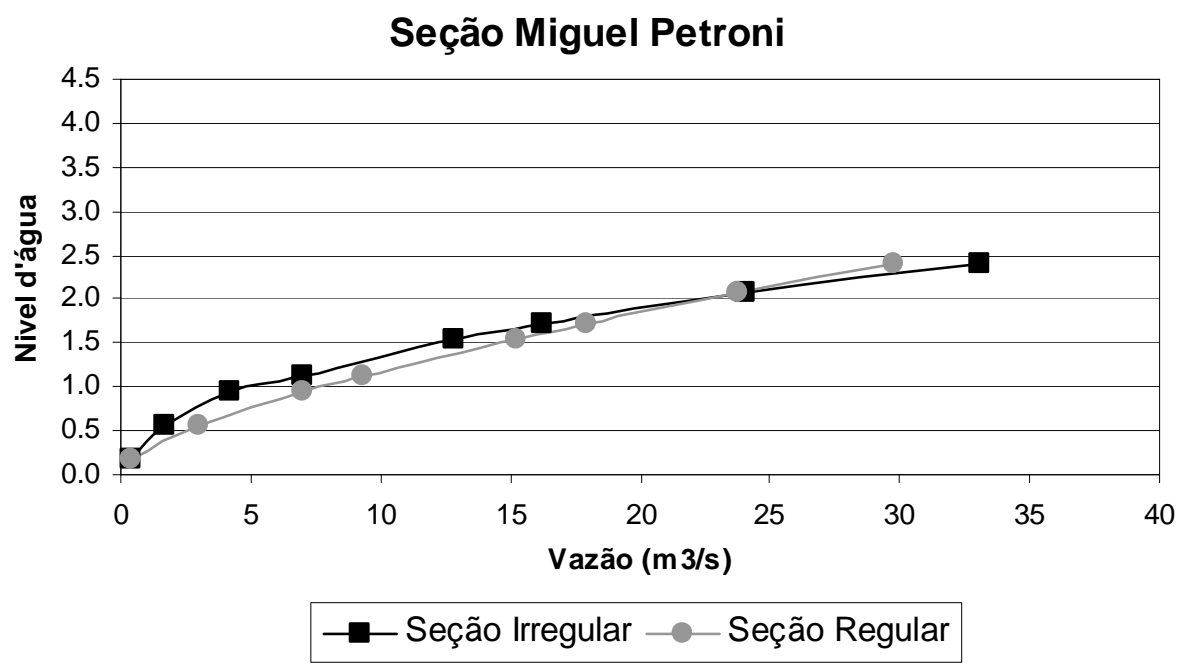

Figura 38: Estimativa da seção fictícia a partir da seção real da Rua Miguel Petroni, Bacia Monjolinho.

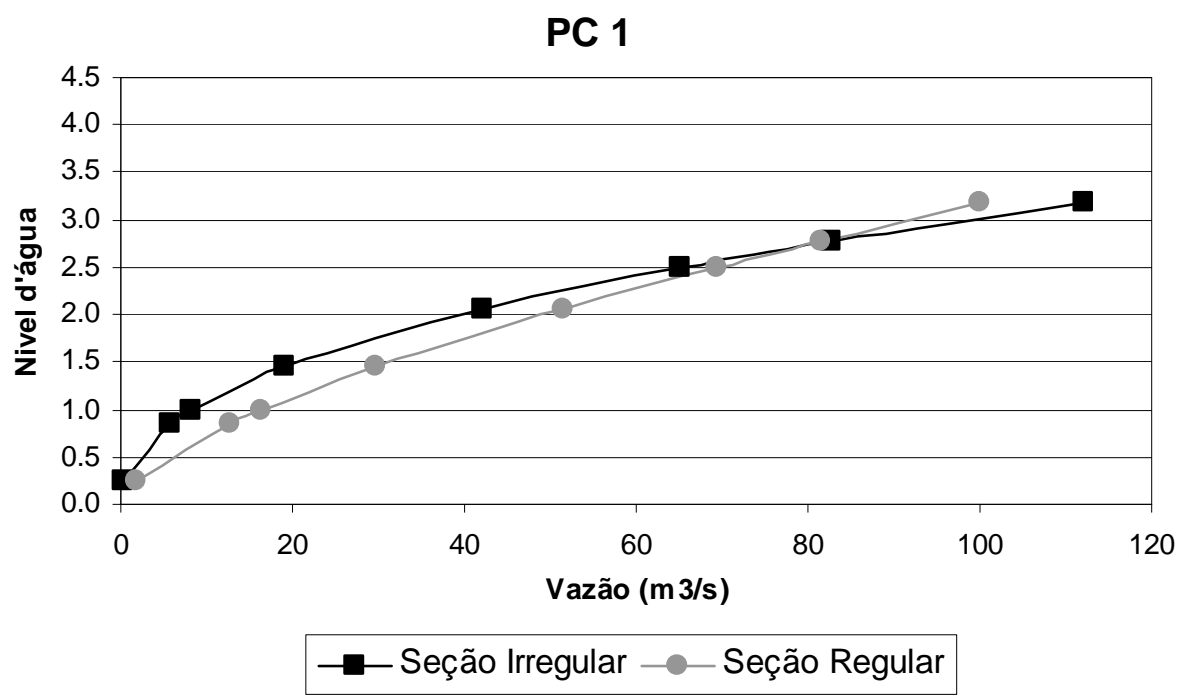

Figura 39: Estimativa da seção fictícia a partir da seção real do PC 1, Bacia do Gregório. 


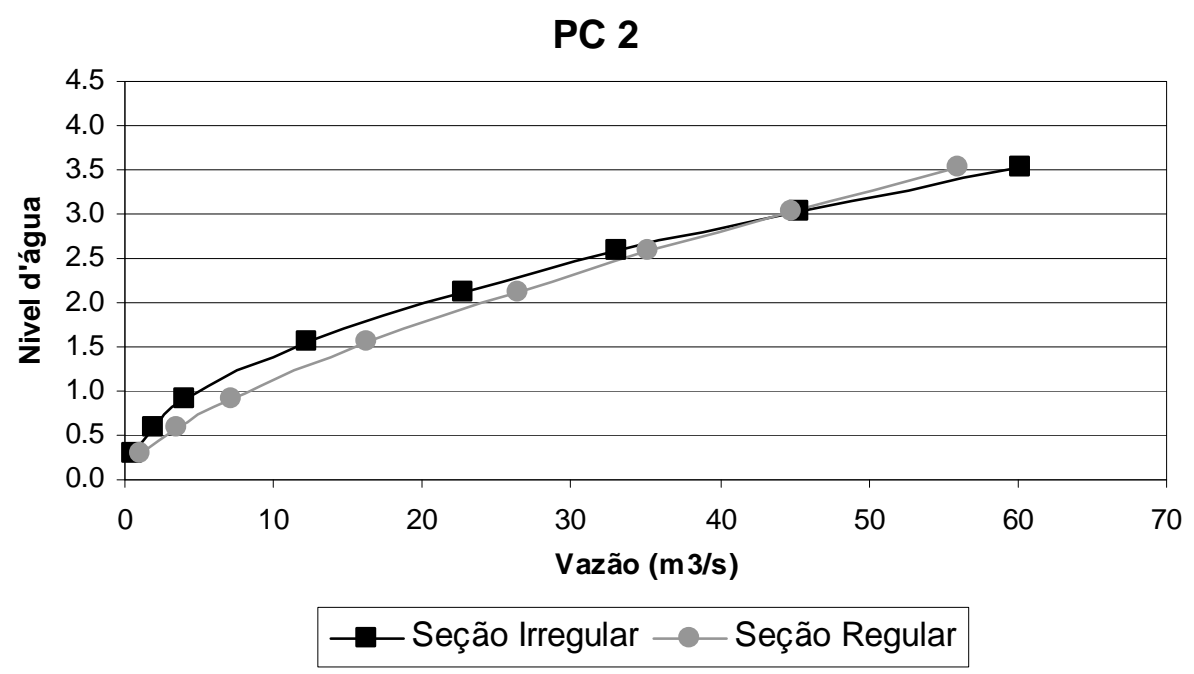

Figura 40: Estimativa da seção fictícia a partir da seção real do PC 2, Bacia Monjolinho (Casa Branca).

PC 3

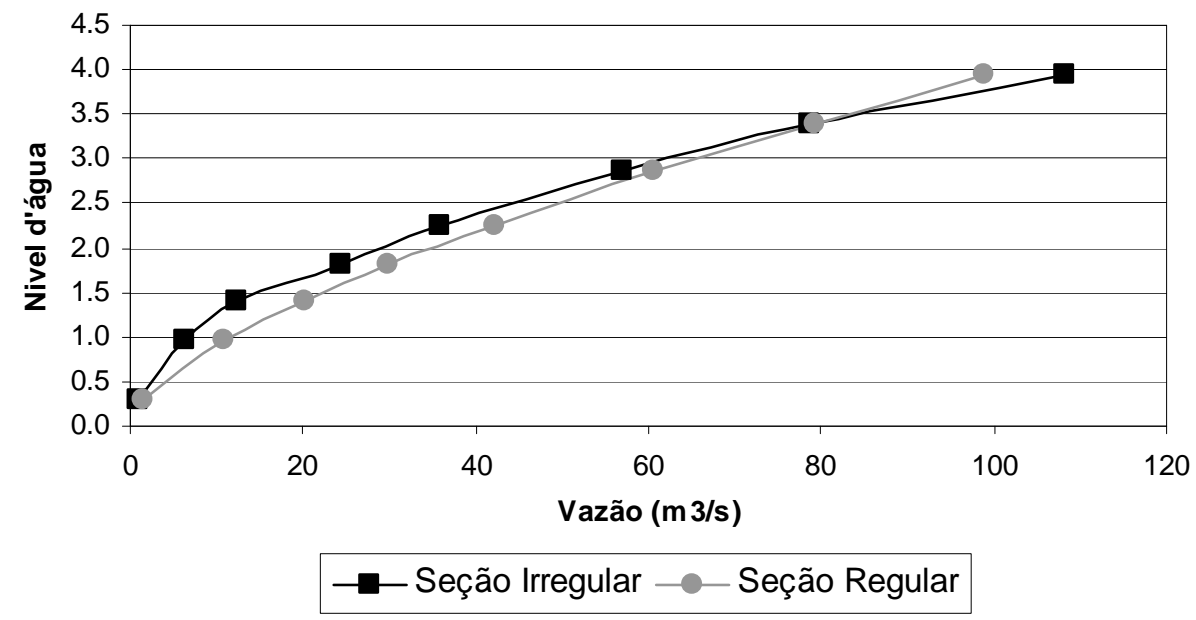

Figura 41: Estimativa da seção fictícia a partir da seção real, Bacia Monjolinho (Shopping Iguatemi).

A partir dessa estimativa foram obtidas as seções regulares para "seção plena" considerada como a altura máxima admitida em cada seção. A tabela 18 mostra as dimensões obtidas para as seções regulares.

Tabela 18: Dimensões das seções regulares.

\begin{tabular}{cccc}
\hline \multicolumn{4}{c}{ Dimensionamento } \\
Seção & Altura $(\mathbf{m})$ & Largura $(\mathbf{m})$ & $\mathbf{n}$ \\
\hline Miguel Petroni & 2,39 & 16,80 & 0,100 \\
PC 1 & 3,18 & 20,00 & 0,096 \\
PC 2 & 3,53 & 15,00 & 0,107 \\
PC 3 & 3.95 & 20,00 & 0,062 \\
\hline
\end{tabular}




\subsubsection{Caracterização e seleção dos eventos para simulação}

Conforme descrito no item 4.3.1, os dados de precipitação foram obtidos através da estação pluvio-fluviométrica instalada na seção do Fórum (Bacia do Gregório) e correspondem ao período de 2004 a 2006. O monitoramento é feito com uma discretização temporal de 1 minuto, no entanto, para o presente trabalho as leituras foram acumuladas em intervalos de 5 minutos.

Primeiramente, para obtenção dos eventos de precipitação a serem simulados, os eventos foram agrupados e, posteriormente selecionados apenas aqueles com lâmina superior a 10mm. A partir de então, foram caracterizados em função dos seguintes parâmetros: $P_{\text {total, }}$, $I_{\text {média, }}$ IPA, umidade antecedente, tipo de evento $\left(\mathbf{1}, \mathbf{2}, 3\right.$ ou 4), $P_{\text {efetiva }}, Q_{\max }$ e $C$ já descritos no item 4.2.2.1. Além desses acrescentou-se mais um parâmetro:

- Tipo de intensidade: A: para intensidades média inferiores à $10 \mathrm{~mm} / \mathrm{h}$;

B: para intensidades médias entre $10 \mathrm{~mm} / \mathrm{h}$ e $20 \mathrm{~mm} / \mathrm{h}$;

\subsubsection{Simulação dos Cenários}

$\mathrm{Na}$ escala de macrodrenagem (bacia hidrográfica), a simulação dos cenários foi realizada, através do sistema operacional IPH S1, utilizando o método de Número de Curva do SCS (Soil Conservation Service, 1975) para transformação chuva-vazão com tempo de concentração dado pela expressão "Lag Fórmula - SCS" e, para a propagação do escoamento superficial o hidrograma unitário triangular do SCS. Já para o escoamento em rios utilizou-se o método Muskingum-Cunge em suas diferentes versões, de acordo com a peculiaridade de cada cenário proposto. Com o intuito de observar as mudanças ocorridas em cada cenário foram selecionados cinco seções de interesse, sendo quatro distribuídas ao longo do curso 
principal do Rio Monjolinho e um na região do Mercado Municipal de São Carlos, na Bacia do Córrego Gregório, zona de freqüentes inundações. A figura 42 apresenta as seções de avaliação em destaque, as mesmas são denominadas da seguinte maneira: Monj $1\left(22 \mathrm{~km}^{2}\right)$, Monj $2\left(52 \mathrm{~km}^{2}\right)$, Monj $3\left(77 \mathrm{~km}^{2}\right)$, Monj $4\left(78 \mathrm{~km}^{2}\right)$ e Greg $\left(15 \mathrm{~km}^{2}\right)$.

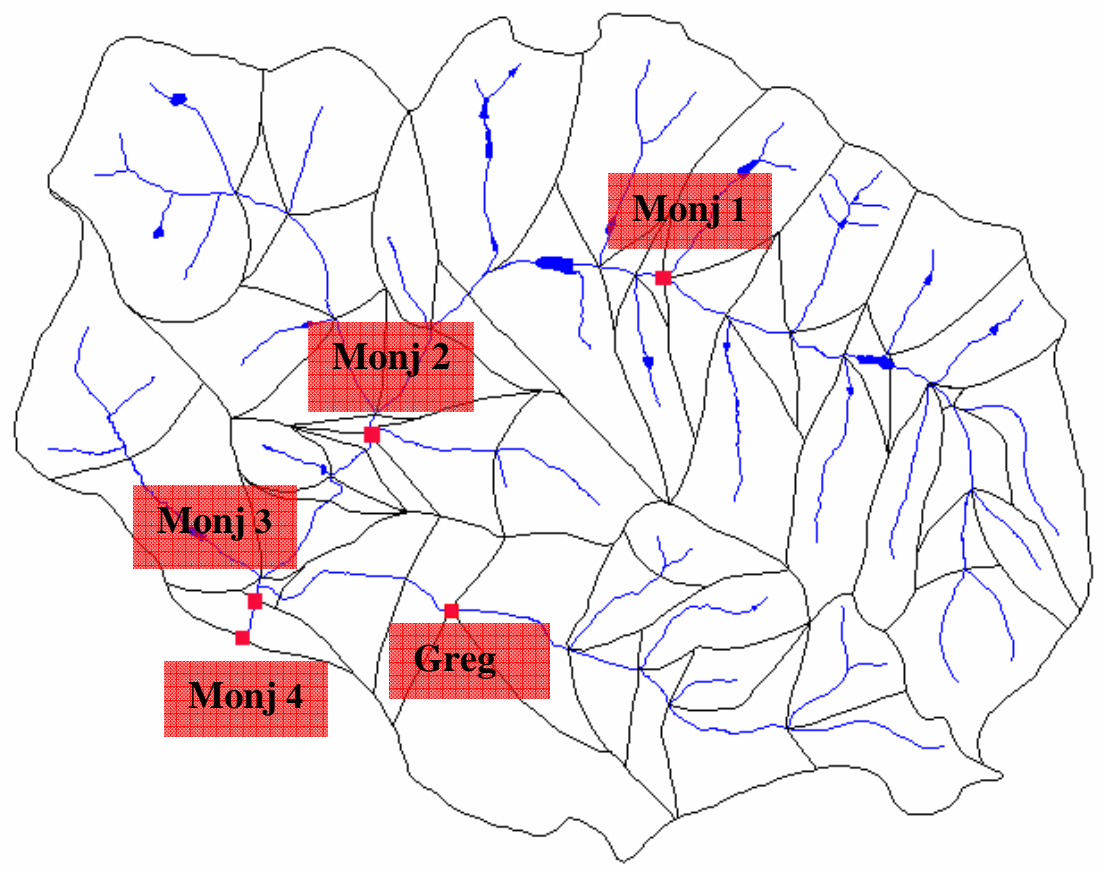

Figura 42: Seções de avaliação dos resultados das simulações. 


\subsection{Aplicação dos Incentivos Ambientais}

A aplicação dos incentivos ambientais em escala de lote é dada em função das características dos cenários propostos pelo Millennium Ecosystem Assessment (2005). Esses

cenários são traçados com base em duas linhas de desenvolvimento: Globalizado e Regionalizado. O primeiro caracteriza-se por seu um cenários globalmente conectados enquanto o segundo por ser um cenário focado em comunidades locais com visão espacial mais restrita. Para aplicação dos incentivos ambientais, são denominados, neste trabalho, dois tipos de cenários: o cenário focado na visão da "bacia hidrográfica" e o cenário focado na visão do "lote" com pouca preocupação com a escala de bacia hidrográfica. O primeiro é denominado "Cenário Espacial", enquanto o segundo é denominado por "Cenário Pontual". Para melhor entendimento das relações entre estes cenários ver figura 43.

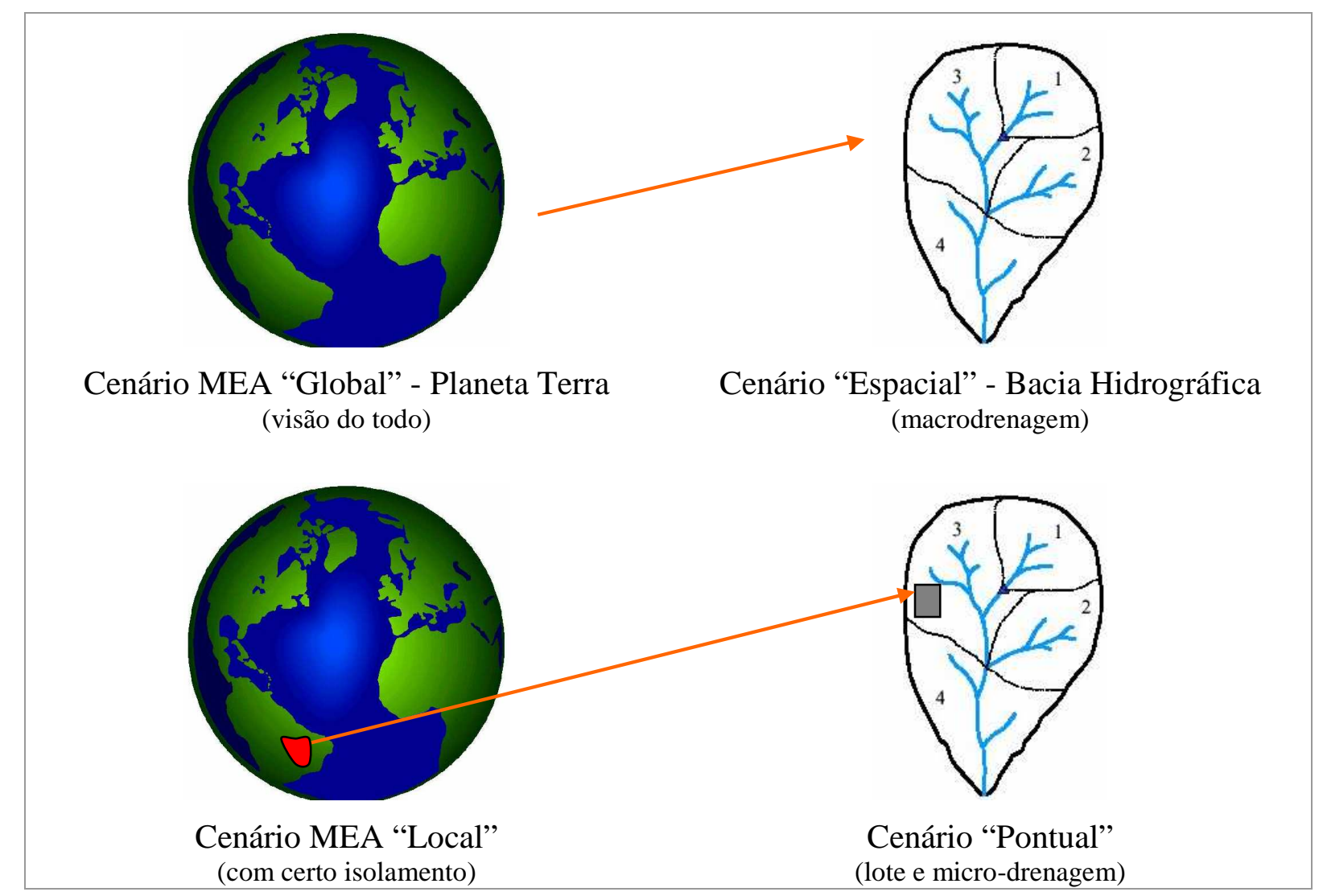

Figura 43: Analogia entre cenários "Global/Local" e "Espacial/Pontual". 


\subsubsection{Definição da Expressão do Incentivo Ambiental}

A estimativa do incentivo ambiental está baseada em três escalas: lote, microdrenagem e macrodrenagem (equação 4.5). As intervenções realizadas no lote, no bairro ou na bacia hidrográfica interferem no incentivo aplicado, podendo o contribuinte "receber" um valor monetário caso realize benfeitorias, ou "pagar" um valor monetário devido a sua "inação" ou realização de modificações que interferem negativamente em quaisquer umas das escalas. No entanto, para este estudo são consideradas somente a escala de lote e a de macrodrenagem, devido à complexidade de avaliação da microdrenagem. $\mathrm{O}$ incentivo ambiental é proposto neste trabalho pela seguinte expressão:

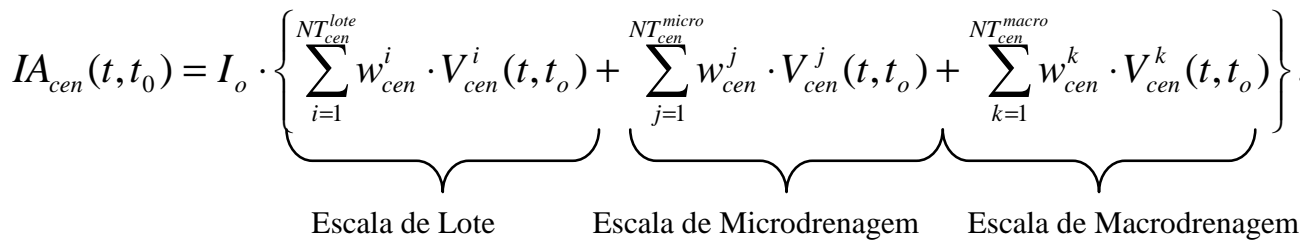

em que:

Variável Unid. Definição

Número real (positivo, nulo ou negativo), de incentivo ao serviço ambiental, $I A_{c e n}\left(t, t_{o}\right) \quad \pm \$ \quad$ descentralizado na escala de lote, no tempo $t$ e relativo ao serviço ambiental do ano base $t_{\mathrm{o}}$ e para um dado cenário; depende de tipos de cenários reativos/próativos e "espacial/pontual";

$I_{0} \quad \$ \quad$ Valor histórico de referência do lote;

$t$ Ano Tempo, contínuo, do horizonte (temporal) do cenário de longo prazo;

$t_{o} \quad$ Ano Tempo, fixo, do horizonte (temporal) de referência, p.ex. ano base;

Cenário de longo prazo para drenagem urbana

cen Categ. $=\left\{\mathrm{OS}^{\prime}:\right.$ Order from Strength adaptado, $\mathrm{GO}^{\prime}:$ Global Orchestration adaptado, $\mathrm{TG}^{\prime}$ :

TechnoGarden adaptado, AM': Adapting Mosaic adaptado\};

$i \quad$ - Contador de tipos de valoração na escala de lote, $i=1,2, \ldots, N T_{\text {cen }}^{\text {lote }}$;

$j \quad$ - Contador de tipos de valoração na micro-drenagem, $j=1,2, \ldots, N T_{\text {cen }}^{\text {micro }}$;

$k \quad$ - $\quad$ Contador de tipos de valoração na macro-drenagem, $j=1,2, . ., N T_{\text {cen }}^{\text {macro }}$;

$N T_{c e n}^{\text {lote }} \quad$ - $\quad$ Número inteiro de tipos de valoração no lote para um dado cenário; 


\begin{tabular}{|c|c|c|}
\hline Variável & Unid. & Definição \\
\hline$N T_{\text {cen }}^{\text {micro }}$ & - & $\begin{array}{l}\text { Número inteiro de tipos de valoração de micro-drenagem para um dado } \\
\text { cenário; }\end{array}$ \\
\hline$N T_{\text {cen }}^{\text {macro }}$ & - & Número de tipos de valoração de macro-drenagem para um dado cenário; \\
\hline$w_{c e n}^{i}$ & $\%$ & Peso relativo de tipo de valoração de lote para um dado cenário; \\
\hline$w_{c e n}^{j}$ & $\%$ & $\begin{array}{l}\text { Peso relativo de tipo de valoração da micro-drenagem para um dado } \\
\text { cenário; }\end{array}$ \\
\hline$w_{c e n}^{k}$ & $\%$ & $\begin{array}{l}\text { Peso relativo de tipo de valoração da micro-drenagem para um dado } \\
\text { cenário; }\end{array}$ \\
\hline
\end{tabular}
$=V_{\text {mercado }}\left(t, t_{o}\right)-I A_{c e n}\left(t, t_{o}\right)=I_{o} \varepsilon\left(t, t_{o}\right)-I A_{c e n}\left(t, t_{o}\right)$; valor monetário da taxa urbana estimada a partir da soma de dois termos:

1) valor histórico de referência $I_{o}$ vezes um fator $0 I_{o} \leq \varepsilon\left(t, t_{o}\right) \leq \lambda I_{o}$ e

$\lambda \geq 0$, de benfeitorias de construção, de localização e de serviços prestados pela Prefeitura, na escala de lote e no tempo $t$ do cenário, em comparação com o ano base $t_{\mathrm{o}}$, p.ex. IPTU (VALOR A PAGAR);

2) incentivo ambiental no tempo $t$ do cenário, em comparação com o ano base $t_{\mathrm{o}}$ (INCENTIVO A RECEBER);

Quociente adimensional, número real (positivo, nulo ou negativo) do tipo $V_{c e n}^{i}\left(t, t_{o}\right) \quad \pm$ adim. de valoração do serviço ambiental $i$, realizada na escala de lote e no tempo $t$ do cenário, em comparação com o ano base $t_{\mathrm{o}}$;

Quociente adimensional, número real (positivo, nulo ou negativo) do tipo $V_{c e n}^{j}\left(t, t_{o}\right) \quad \pm$ adim. de valoração do serviço ambiental $i$, na escala de micro-drenagem e no tempo $t$ do cenário, em comparação com o ano base $t_{\mathrm{o}}$;

Quociente adimensional, número real (positivo, nulo ou negativo) do tipo $V_{c e n}^{k}\left(t, t_{o}\right) \quad \pm$ adim. de valoração do serviço ambiental $i$, na escala de macro-drenagem e no tempo $t$ do cenário, em comparação com o ano base $t_{\mathrm{o}}$;

$\underline{\mathrm{mm}}=\left\{1-\left[S_{\text {cen }}^{\text {pot (lot) }}(t)-S^{\text {pot(lote) }}\left(t_{o}\right)\right] \div S^{\text {pot(lote) }}\left(t_{o}\right)\right\}$; exemplo da valoração relativa do $V_{\text {cen }}^{i=1}\left(t, t_{o}\right) \quad \mathrm{mm} \quad$ serviço ambiental $i=1$, de aumentar a reserva potencial de umidade no lote, para o tempo $t$ do cenário em comparação com o ano base $t_{\mathrm{o}}$;

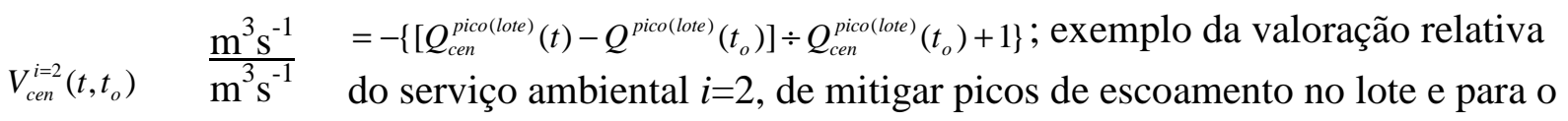
tempo $t$ do cenário, em comparação com o ano base $t_{\mathrm{o}}$; $=-\left\{\left[D B O_{\text {cen }}^{\text {picol(lote) }}(t)-D B O^{\text {pico(lote) }}\left(t_{o}\right)\right] \div D B O_{\text {cen }}^{\text {picolote) }}\left(t_{o}\right)+1\right\} ;$ exemplo da valoração $V_{\text {cen }}^{i=3}\left(t, t_{o}\right) \quad \mathrm{mgL}^{-1} \quad$ relativa do serviço ambiental $i=1$, de mitigar picos de demanda bioquímica de oxigênio do escoamento oriundo do lote, para o tempo $t$ do cenário em comparação com o ano base $t_{\mathrm{o}}$;

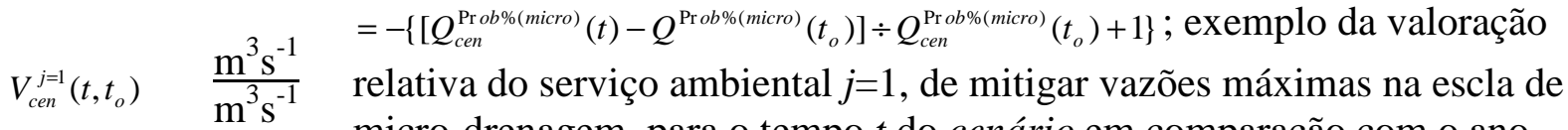
micro-drenagem, para o tempo $t$ do cenário em comparação com o ano base $t_{\mathrm{o}}$; 
Variável Unid. Definição $=-\left\{\left[Q_{\text {cen }}^{\text {Prob\%(macro) }}(t)-Q^{\text {Prob\%(macro) }}\left(t_{o}\right)\right] \div Q_{\text {con }}^{\text {Prob\%(macro) }}\left(t_{o}\right)+1\right\} ;$ exemplo da valoração

$V_{c e n}^{k=1}\left(t, t_{o}\right) \quad \underline{\mathrm{m}^{3} \mathrm{~s}^{-1}} \quad$ relativa do serviço ambiental $k=1$, de mitigar vazões máximas de permanência do escoamento na macro-drenagem, para o tempo $t$ do cenário em comparação com o ano base $t_{\mathrm{o}}$;

De posse do conhecimento de todas as variáveis utilizadas na aplicação dos incentivos ambientais em escala de lote urbano, e com base na expressão que define incentivo ambiental (equação 4.5), pôde-se relacionar esta expressão com os quatro cenários estudados (GO, OS, AM e TG). Para cada cenário obteve-se uma expressão final diferente, fato este decorrente das peculiaridades de cada cenário.

No cenário Global Orchestration os incentivos ambientais são introduzidos, para compensar a falta de serviços ambientais na escala de macrodrenagem (bacia hidrográfica), pois é um cenário reativo que não respeita o princípio da precaução e não se preocupa com os problemas de micro-drenagem e de escala de lote, por isso não é feita nenhuma referência a estes serviços. Assim a expressão que define o incentivo ambiental para o cenário GO é:

$$
\begin{aligned}
& I A_{G O^{\prime}}\left(t, t_{o}\right)=I_{o} \cdot\{\overbrace{\sum_{i=1}^{N T_{G O^{\prime}}^{\text {lote }}} w_{G O^{\prime}}^{i} \cdot V_{G O^{\prime}}^{i}\left(t, t_{o}\right)}^{=0}+\overbrace{\sum_{j=1}^{N T_{G O^{\text {micro }}}} w_{G O^{\prime}}^{j} \cdot V_{G O^{\prime}}^{j}\left(t, t_{o}\right)}^{=0}+\overbrace{\sum_{k=1}^{N T_{G O^{\prime}}^{\text {macro }} w_{G O^{\prime}}^{k} \cdot V_{G O^{\prime}}^{k}\left(t, t_{o}\right)}}^{\neq 0}\} ; \\
& \forall w_{G O^{\prime}}^{i}=0 ; \forall w_{G O^{\prime}}^{j}=0 ; \sum_{k=1}^{N T_{G O^{m}}^{\text {macro }}} w_{G O^{\prime}}^{k}=1
\end{aligned}
$$

Em Order from Strength por seu caráter reativo e seu desenvolvimento focado em questões pontuais com nenhuma preocupação com as questões ambientais, não há interesse em criar incentivos ambientais. Desta forma, a expressão fica:

$$
\begin{aligned}
& I A_{O S^{\prime}}\left(t, t_{o}\right)=I_{o} \cdot\{\overbrace{\sum_{i=1}^{N T_{O S^{\prime}}^{\text {lote }}} w_{O S^{\prime}}^{i} \cdot V_{O S^{\prime}}^{i}\left(t, t_{o}\right)+\sum_{j=1}^{N T_{O S^{\prime} S^{\text {mico }}}} w_{O S^{\prime}}^{j} \cdot V_{O S^{\prime}}^{j}\left(t, t_{o}\right)+\sum_{k=1}^{N T_{O S^{\prime}}^{\text {macro }}} w_{O S^{\prime}}^{k} \cdot V_{O S^{\prime}}^{k}\left(t, t_{o}\right)}^{=0}\} \\
& \forall w_{O S^{\prime}}^{i, j, k}=0 ;
\end{aligned}
$$


Com relação aos somatórios dos pesos relativos à valoração das componentes de lote, microdrenagem e macrodrenagem, para o cenário GO somente a componente macrodrenagem está relacionada à aplicação dos incentivos ambientais, assim a soma deste elemento é constante e igual a um. Já para o cenário OS, cuja aplicação de incentivos ambientais não é realizada, o somatório dos pesos é constante e igual a zero ao longo dos anos. A figura 44 mostra esse comportamento para ambos cenários.

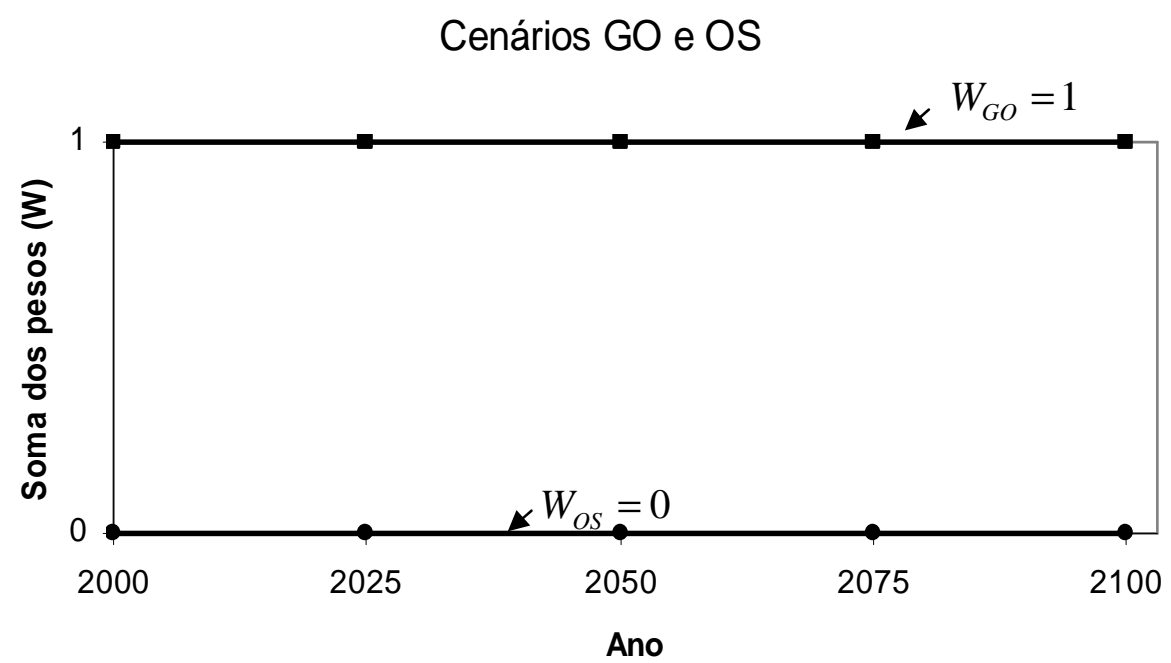

Figura 44: Evolução do somatório dos pesos relativos a valoração para os cenários GO e OS.

Por dar relevância as questões pontuais, no cenário Adapting Mosaic os incentivos ambientais são proporcionais aos serviços contra-prestados pelo cidadão na escala de lote e seus efeitos diretos na microescala, sem considerar o efeito espacial na macrodrenagem. Assim a componente relacionada à macro-drenagem não existe neste cenário e a expressão de incentivo ambiental é a seguinte:

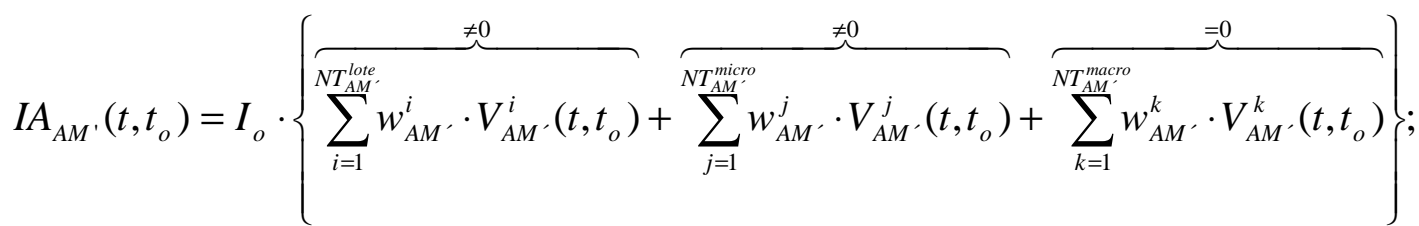

$$
\begin{aligned}
& \sum_{i=1}^{N T_{A M^{\prime}}^{T_{\text {lote }}}} w_{A M^{\prime}}^{i}+\sum_{j=1}^{N T_{A M^{m}}^{\text {micro }}} w_{A M^{\prime}}^{j}=1 ; \forall w_{A M^{\prime}}^{k}=0
\end{aligned}
$$


Os pesos referentes ao armazenamento potencial de água no lote e a vazão máxima para o cenário AM evoluem de acordo com a figura 45, com maiores valores para o peso relativo ao armazenamento potencial ao longo de todos os anos em comparação com o peso sobre a vazão máxima.

\section{Cenário AM}

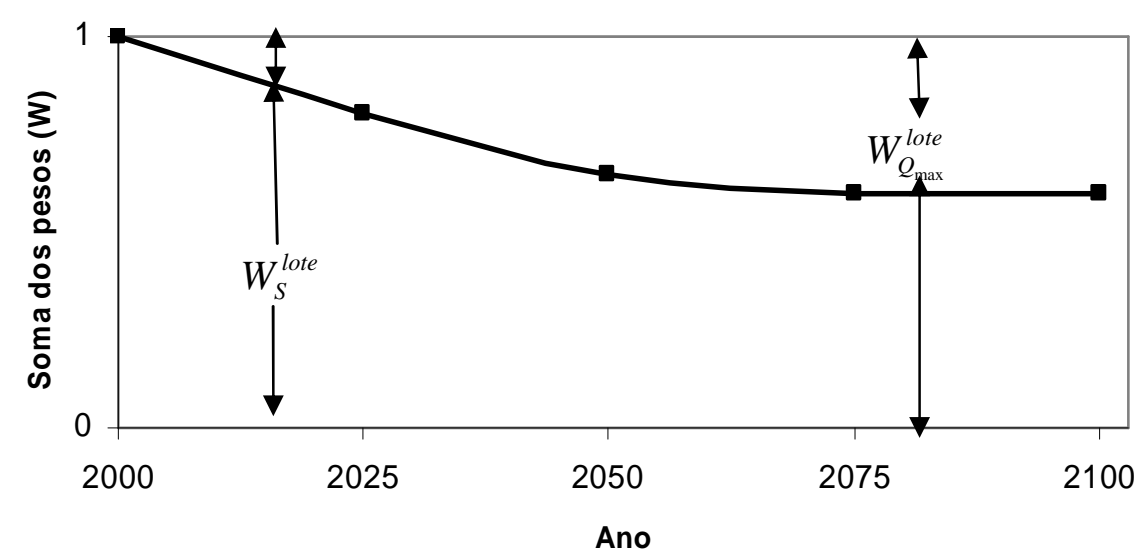

Figura 45: Evolução do somatório dos pesos relativos à valoração para o cenário AM.

Em TechnoGarden, por ser um cenário pró-ativo e global, os incentivos ambientais são proporcionais aos serviços contra-prestados, pelo cidadão, na escala de lote, e seus efeitos diretos e indiretos na micro e na macrodrenagem, respectivamente. A expressão relativa ao incentivo proposta para este cenário é descrita abaixo.

$$
\begin{aligned}
& I A_{T G^{\prime}}\left(t, t_{o}\right)=I_{o} \cdot\{\overbrace{\sum_{i=1}^{N T_{T G^{\prime}}^{\text {lote }}} w_{T G^{\prime}}^{i} \cdot V_{T G^{\prime}}^{i}\left(t, t_{o}\right)}^{\neq 0}+\overbrace{\sum_{j=1}^{N T_{T G^{\prime}}^{\text {micro }}} w_{T G^{\prime}}^{j} \cdot V_{T G^{\prime}}^{j}\left(t, t_{o}\right)}^{\neq 0}+\overbrace{\sum_{k=1}^{N T_{T G^{\prime}}^{\text {macro }}} w_{T G^{\prime}}^{k} \cdot V_{T G^{\prime}}^{k},\left(t, t_{o}\right)}^{\neq 0}\} ; \\
& \sum_{i=1}^{N T_{T G^{\prime}}^{\text {lote }}} w_{T G^{\prime}}^{i}+\sum_{j=1}^{N T_{T G^{\prime}}^{\text {micro }}} w_{T G^{\prime}}^{j}+\sum_{k=1}^{N T_{T G^{\prime}}^{\text {macro }}} w_{T G^{\prime}}^{k}=1
\end{aligned}
$$

Por ter como visão de espaço de planejamento à bacia hidrográfica, até 2075 os maiores pesos são aqueles referentes à macrodrenagem, enquanto os pesos referentes à 
microdrenagem e a escala de lote são menores. Entre 2075 e 2100 os pesos de ambos componentes se equiparam (Figura 46).

\section{Cenário TG}

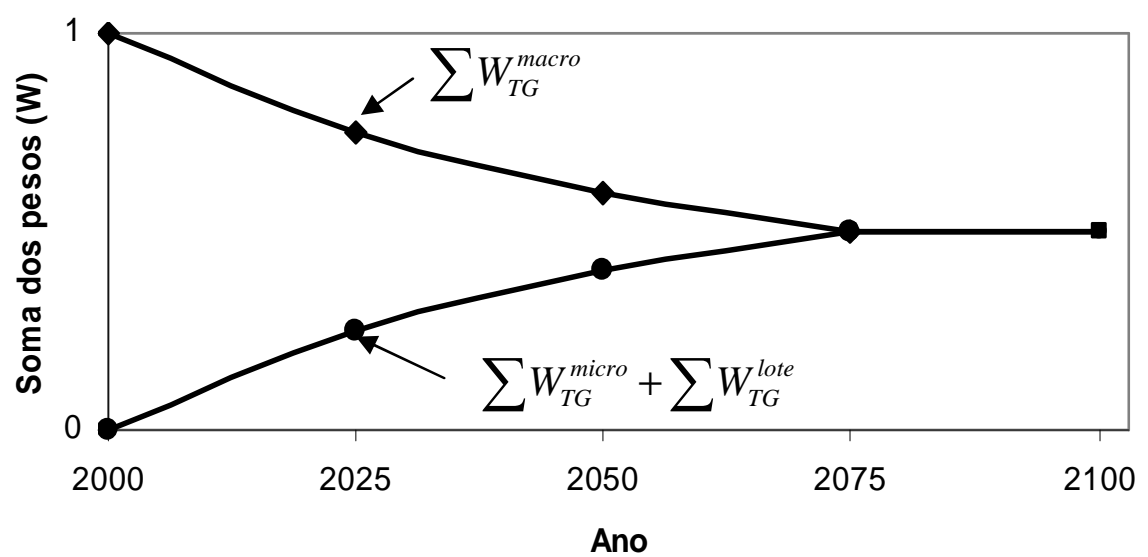

Figura 46: Evolução do somatório dos pesos relativos à valoração para o cenário TG.

Os valores de cada peso, em cada cenário, podem ser apresentados em diferentes proporções, no entanto, para esta pesquisa, foram adotados aqueles já apresentados sob forma de gráficos.

4.4.2 Armazenamento e vazão como variáveis de decisão na proposição de incentivos ambientais

Mendiondo (2007) propõe a inclusão de variáveis hidráulicas e hidrológicas como o armazenamento potencial de água no lote e a vazão máxima instantânea, como uma componente relacionada ao incentivo ambiental no cálculo do IPTU, resultando em um IPTU dito coerente. A expressão proposta resulta em:

$$
I P T U_{\text {coerente }}=\left(w_{1} \times I P T U_{\text {armazenamento }}\right)+\left(w_{2} \times I P T U_{\text {Qmáxima }}\right)
$$

em que: 
$\mathrm{w}_{1}$ e $\mathrm{w}_{2}=$ pesos de cada parcela do IPTU;

$I P T U_{\text {armazenamento }}=$ em função do armazenamento potencial de água no lote;

$I P T U_{\mathrm{Qmáxima}}=$ em função da vazão máxima instantânea produzida pelo lote.

Cada parcela de IPTU é calculada pelas seguintes expressões:

$$
\begin{aligned}
& I P T U_{\text {ano"t" }}=I P T U_{\text {ano"base" }} \times\left[1-\frac{\left(S_{\text {ano"t" }}-S_{\text {ano"base" }}\right)}{S_{\text {ano"base" }}}\right] \\
& I P T U_{\text {ano"t" }}=I P T U_{\text {ano"base" }} \times\left[1+\frac{\left(Q_{\text {ano"t" }}-Q_{\text {ano"base" }}\right)}{Q_{\text {ano"base" }}}\right]
\end{aligned}
$$

em que:

ano " $\mathrm{t}$ " = ano que se pretende calcular o IPTU;

ano "base" = ano de referência para o cálculo do IPTU;

$S=$ armazenamento potencial de água no lote;

$Q=$ vazão máxima instantânea.

Maior detalhamento sobre esta proposta é dado em Ribeiro (2007).

Aliando a metodologia de incentivos ambientais à proposta dada por Mendiondo (2007), tem-se aplicação de incentivos ambientais em escala de lote a partir da vazão máxima instantânea e do armazenamento potencial de água no lote. As expressões resultantes desta combinação resultam em:

- para a vazão máxima instantânea:

$$
V F=I_{\text {mercado }}+I_{0}\left(\frac{Q(t)-Q\left(t_{0}\right)}{Q\left(t_{0}\right)}\right)
$$

Termo de pagamento por serviços ambientais com base nas vazões máximas 
em que:

$$
\begin{aligned}
& \mathrm{V}_{\mathrm{F}}=\text { valor final da taxa a ser paga pelo cidadão; } \\
& I=\text { valor da taxa de mercado; } \\
& I_{0}=\text { valor do peso relativo ao incentivo ambiental; } \\
& Q(t)=\text { vazão máxima instantânea para o ano } t \text {; } \\
& Q\left(t_{0}\right)=\text { vazão máxima instantânea para o ano } t_{0} .
\end{aligned}
$$

Quando o termo de pagamento por serviços ambientais for negativo (-) há penalização e o contribuinte paga um valor superior aquele que pagaria sem incentivo, devido a sua contribuição para o aumento das cheias na bacia, já se o termo for positivo (+) há um incentivo, ou seja, o contribuinte colaborar para um serviço ambiental por meio da utilização de tecnologias apropriadas para escala de lote como utilização de cisterna, telhado verde, trincheira de infiltração, pavimento poroso ou pela diminuição de sua área impermeável.

- para armazenamento potencial de água no lote:

$$
V F=I_{\text {mercado }}+I_{0} \underbrace{\left(\frac{S\left(t_{0}\right)-S(t)}{S\left(t_{0}\right)}\right)}
$$

Termo de pagamento por serviços ambientais com base no armazenamento potencial

em que:

$\mathrm{V}_{\mathrm{F}}=$ valor final da taxa a ser paga pelo cidadão;

$I=$ valor da taxa de mercado;

$I_{0}=$ valor do peso relativo ao incentivo ambiental;

$S\left(t_{0}\right)=$ armazenamento potencial de água no lote $t_{0} ;$

$S(t)=$ armazenamento potencial de água no lote $t$. 
Quando o termo de pagamento por serviços ambientais resultar em $\mathrm{S}\left(\mathrm{t}_{0}\right)>\mathrm{S}(\mathrm{t})$ ocorre diminuição do armazenamento potencial e, portanto o cidadão deve pagar por esse serviço ambiental impactado, sendo, desta forma, penalizado. Se $S\left(t_{0}\right)<S(t)$ há colaboração com o serviço e, portanto o contribuinte é incentivado proporcionalmente.

Para o cenário Global Orchestration, globalizado com planejamento visando somente à bacia hidrográfica, a expressão de incentivo ambiental resulta na componente ambiental dada somente pela vazão máxima instantânea dada por:

$$
I A=W_{1}+\left[\frac{Q(t)-Q\left(t_{0}\right)}{Q\left(t_{0}\right)}\right]
$$

em que:

$$
\mathrm{W}_{1}=\text { pesos relativo à vazão máxima instantânea, neste caso igual a } 1 \text {. }
$$

Para o cenário Order from Strength como incentivo ambiental é inexistente, IA = 0. Já para o cenário Adapting Mosaic, que visa somente a escala pontual (lote) o incentivo é dado por:

$$
I A=W_{A M^{\prime}}^{\text {lote }}(1) \cdot \frac{S\left(t_{0}\right)-S(t)}{S\left(t_{0}\right)}+W_{A M^{\prime}}^{\text {lote }}(2) \cdot \frac{Q(t)-Q\left(t_{0}\right)}{Q\left(t_{0}\right)}=1
$$

em que:

$$
W_{A M^{\prime}}^{\text {lote }}(1)+W_{A M}^{\text {lote }}(2)=1
$$

Para TechnoGarden um cenário completo que tem visão espacial e local a expressão contem as três componentes do incentivo ambiental, embora neste trabalho a escala micro não seja abordada. Desta forma a expressão resulta em:

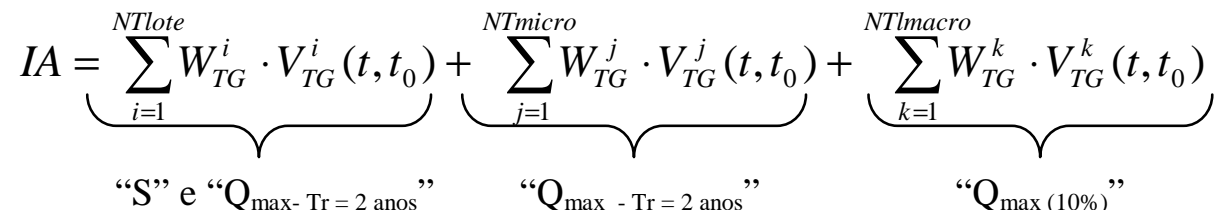

em que: 


$$
\begin{aligned}
I A= & \underbrace{W_{T G}^{i} \cdot \frac{S^{i}\left(t_{0}\right)-S(t)}{S^{i}\left(t_{0}\right)}+W_{T G}^{j} \cdot \frac{Q_{T r}^{j}(t)-Q_{T r}^{j}\left(t_{0}\right)}{Q_{T r}^{j}\left(t_{0}\right)}+W_{T G}^{k} \cdot \frac{Q_{10 \%}^{k}(t)-Q_{10 \%}^{k}\left(t_{0}\right)}{Q_{10 \%}^{k}\left(t_{0}\right)}}_{\text {"Pagamento pelo Serviço Ambiental" }} \\
& \mathrm{e}: \quad{ }^{i}+W_{T G}^{j}+W_{T G}^{k}=1
\end{aligned}
$$

\subsubsection{Simulação dos Cenários em Escala de Lote}

Para escala de lote a simulação da transformação chuva-vazão consistiu na aplicação do método racional, com uma precipitação de período de retorno de dois anos e duração de 15 minutos. Aplicou-se a fórmula de intensidade máxima de precipitação para São Carlos e obteve-se a partir das características dos lotes, em termos de $\mathrm{CN}$ e Potencial de Armazenamento de Água no Solo, a vazão máxima instantânea para cada cenário estudado.

$\mathrm{O}$ armazenamento potencial de água no lote foi dado em função do $\mathrm{CN}$ dos lotes e a vazão máxima instantânea com base na intensidade máxima de precipitação. Para o valor das perdas iniciais (Ia) considerou-se o valor constante de $20 \%$ do armazenamento potencial, para todos os cenários, embora se saiba das diferenças que podem existir nesta estimativa para lotes com utilização de cisternas, telhado verde, trincheiras. Ohnuma Jr (2006) estuda, entre outras coisas, as variações das perdas iniciais (Ia) em um lote experimental para diferentes eventos de precipitação e salienta as grandes variações obtidas em função da forte dependência da saturação do solo.

Já estimativa do IPTU foi dada com base na Planta Genérica de Valores do Município de São Carlos (Lei $N^{\circ}$ 13.692, 2005). Uma área localizada no centro da cidade inserida na Bacia do Córrego Gregório foi escolhida e, com base na obra supracitada, obtiveram-se os valores unitários $\left(\mathrm{R} \$ / \mathrm{m}^{2}\right)$ relativos à área territorial e a área construída. De posse dos cenários 
construídos em escala de lote $\left(200 \mathrm{~m}^{2}\right)$ e dos valores brutos de área construída (dado pelo somatório da área impermeável e da área impermeável diretamente conectada) pode-se estimar um valor de IPTU a ser cobrado para cada cenário a partir da seguinte expressão:

$I P T U=$ áreaterritorial $* V U T+$ areaconstruída $* V U A *$ aliquota

em que:

área territorial $=$ área do terreno $\left(\mathrm{m}^{2}\right)$;

área construída $=$ área construída no terreno $\left(\mathrm{m}^{2}\right)$;

VTU = valor unitário relativo à área territorial;

VTA = valor unitário relativo à área construída;

alíquota $=$ constante para todos os casos $(1,5 \%)$.

A partir do valor do IPTU para cada cenário foi estimado o incentivo ou taxação a ser cobrada. 


\section{RESULTADOS E DISCUSSÕES}

Nesse item são dados os resultados de cada etapa da pesquisa, bem como as discussões por eles geradas.

\subsection{Calibração e Validação}

A calibração consiste em uma importante etapa na fase inicial do trabalho, em que se avalia a consistência dos dados de caracterização da área estudada, bem como a sensibilidade de cada parâmetro no modelo utilizado. Já a validação tem por finalidade confirmar o sucesso ou o insucesso da etapa anterior.

Cada estudo tem um objetivo a ser alcançado e, por conseguinte um caminho a ser traçado e uma resposta a ser obtida. Não constitui objetivo deste trabalho obter uma perfeita calibração, nem encontrar os valores ideais para cada parâmetro do modelo utilizado; e sim demonstrar o comportamento hidráulico e hidrológico das bacias estudadas para um dado ano de referência, neste caso ano 2000 e a partir dele criar cenários futuros de drenagem urbana. Desta forma, são apresentados (Tabela 20) os valores médios dos parâmetros encontrados para o ano de referência.

Como descrito no item 4.3.1 a qualidade dos ajustes dos hidrogramas é avaliada neste trabalho, por meio dos erros percentuais dos volumes escoados, dados em função das vazões observadas e simuladas. Observa-se na tabela 19 os valores dos erros percentuais referentes a cada ponto de controle. Os valores negativos representam volumes superiores para as vazões observadas. Embora alguns erros tenham se aproximado de $20 \%$, os valores foram considerados satisfatórios para este trabalho. 
Tabela 19: Erros dos volumes escoados e simulados, dados em percentuais.

\begin{tabular}{cccc}
\hline \multirow{2}{*}{ Sessões } & \multicolumn{3}{c}{ Eventos utilizados na fase de validação } \\
& $01 / 11 / 2003$ & $27 / 12 / 2003$ & $31 / 12 / 2003$ \\
\hline PC 1 & 8,1 & 4,8 & $-20,1$ \\
PC 2 & 3,4 & $-14,7$ & 11,2 \\
PC 3 & 3,0 & 1,6 & $-19,1$ \\
\hline
\end{tabular}

Nas páginas seguintes são apresentados a configuração das sub-bacias para o cenário do ano de referencia (Ano 2000) e os hidrogramas resultantes das fases de calibração e validação (Figura 47 a 52). Maior detalhamento a respeito dos valores dos parâmetros utilizados nas etapas de calibração e validação pode ser visualizado no APÊNDICE D. 


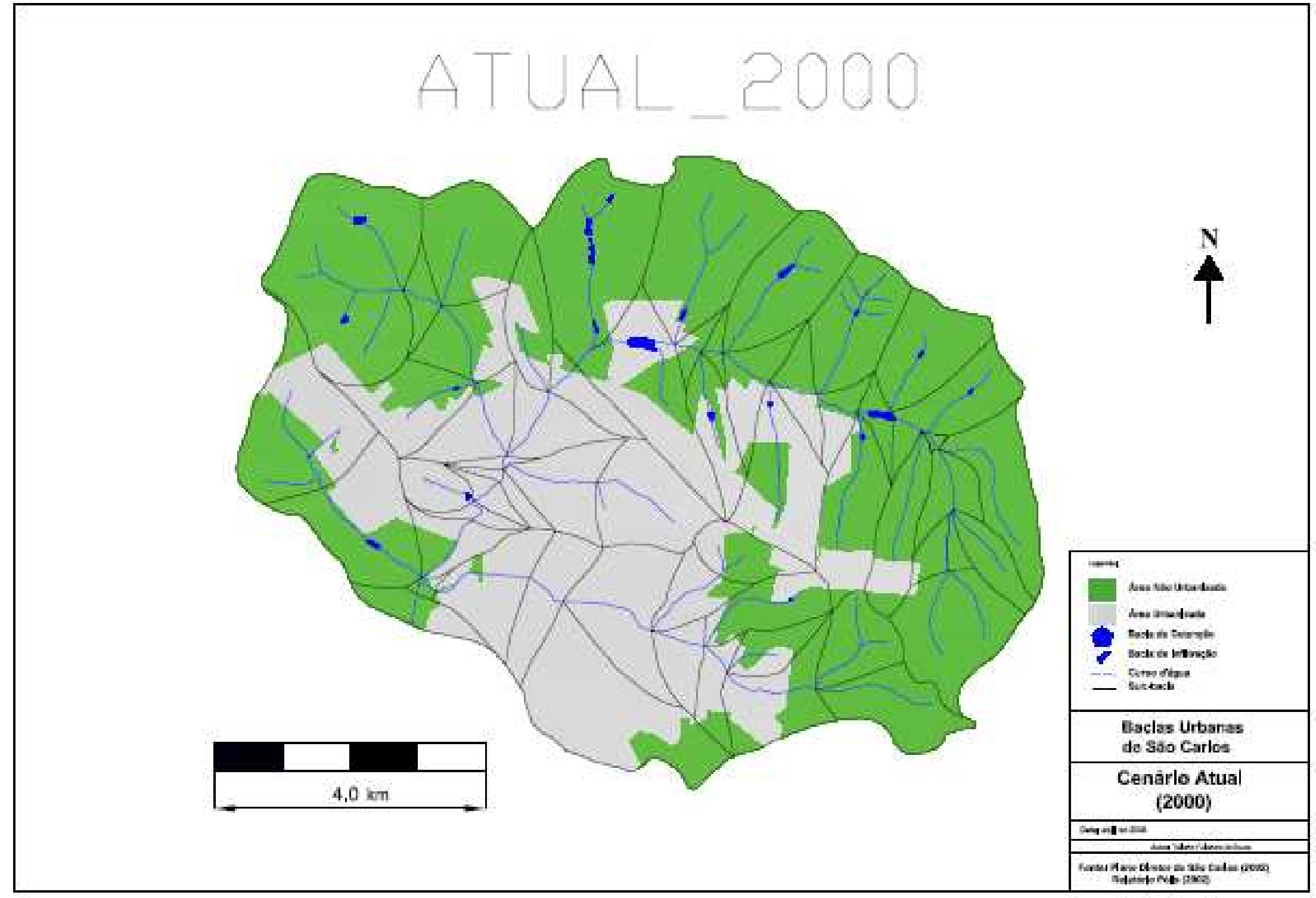




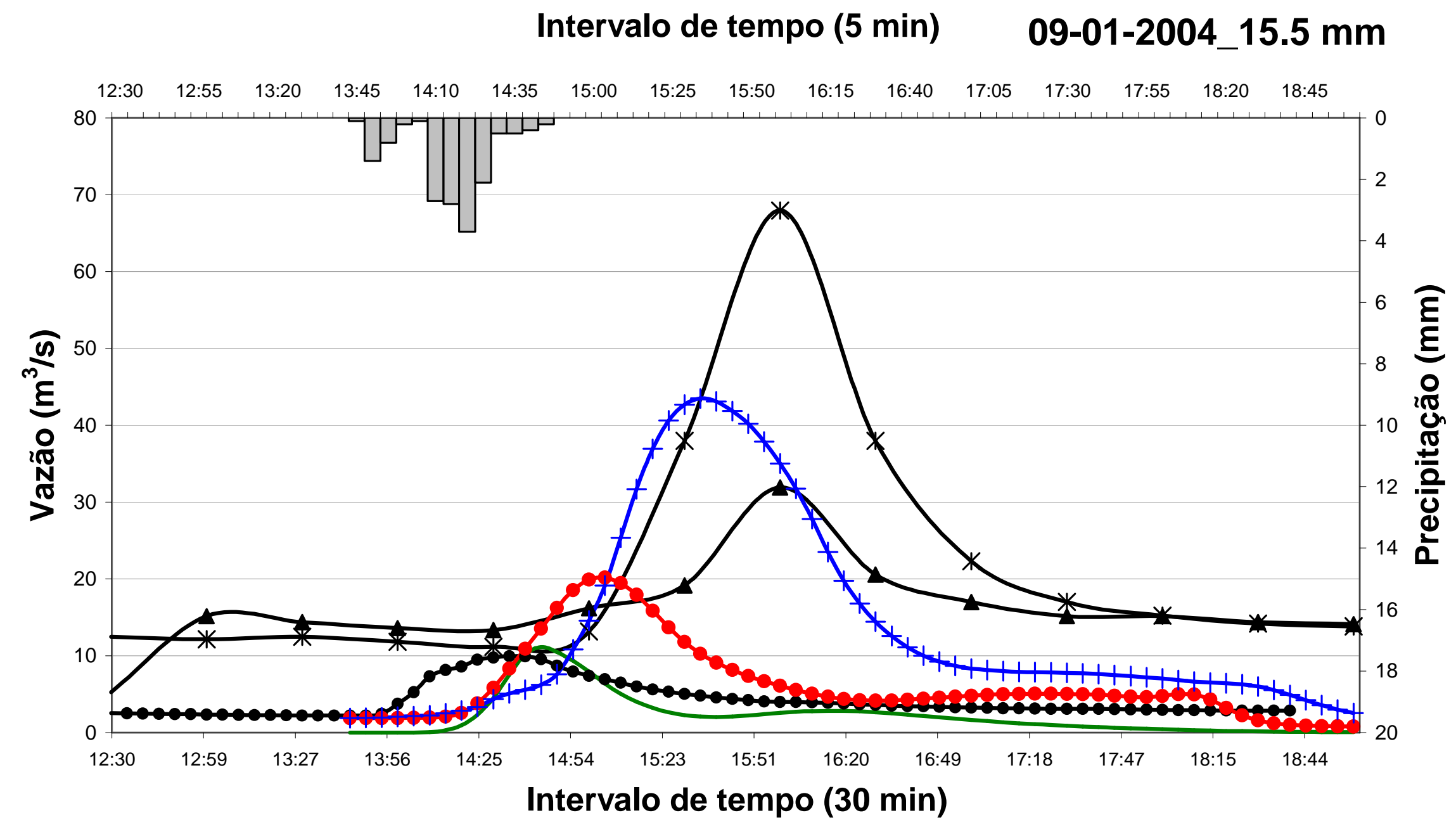

$\square$ Precipitação $\rightarrow$ PC 1- Obs $\longrightarrow$ PC 2 - Obs $\rightarrow$ * PC 3 - Obs $\longrightarrow$ PC 1- Sim $\longrightarrow$ PC 2- Sim $\longrightarrow$ PC 3- Sim

Figura 47: Gráfico das vazões simuladas e observadas nos três pontos de controle para efeitos de calibração do modelo de simulação, relativo ao evento “a”. 
Intervalo de tempo (5 min)

09-01-2004_22.5 mm

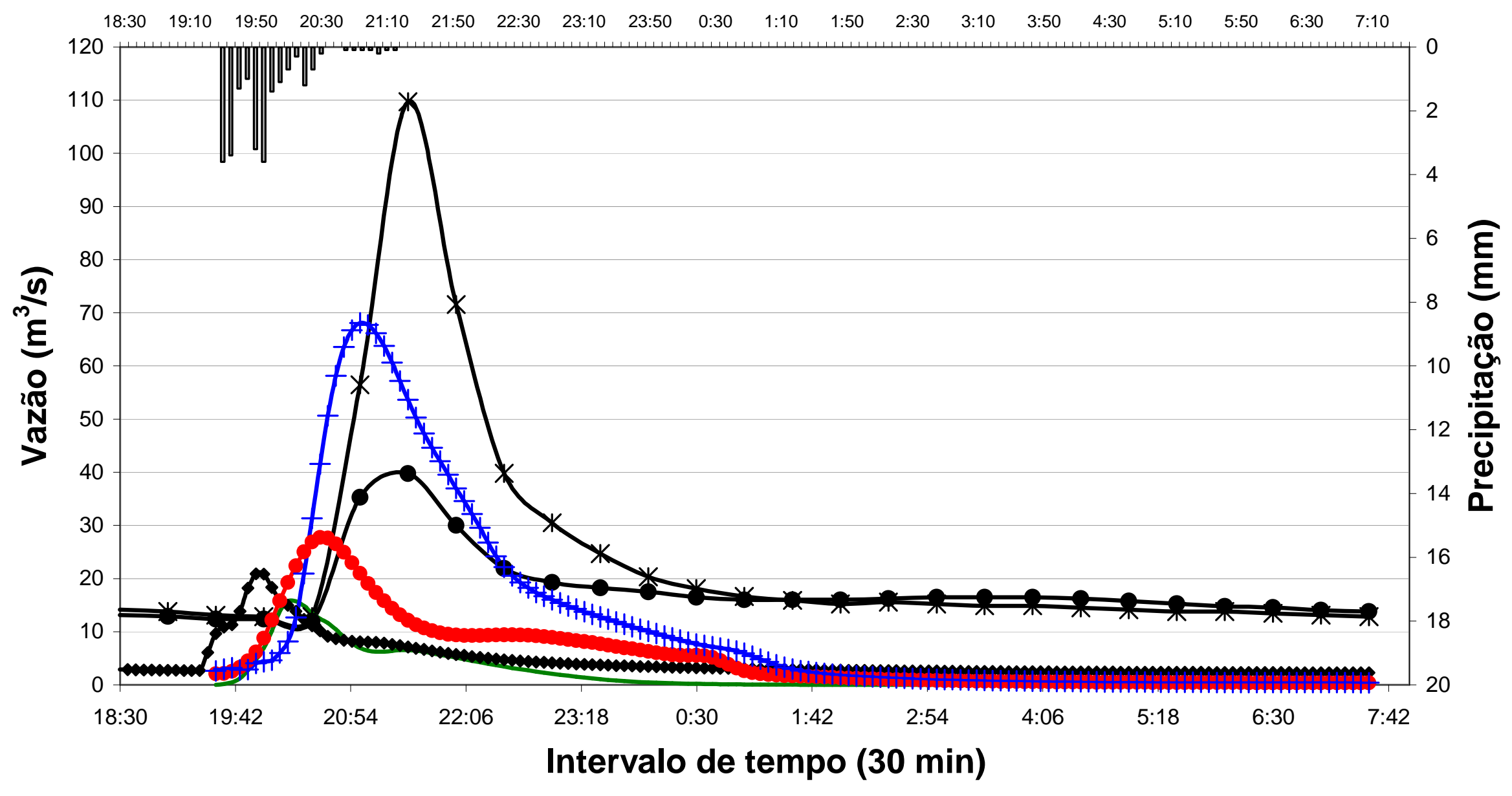

$\square$ Precipitação $\rightarrow$ PC 1- Obs $\bullet-P C 2$ - Obs $\rightarrow$ * 3 C 3 Obs $\longrightarrow$ PC 1- Sim $\rightarrow$ PC 2- Sim $\longrightarrow$-PC 3- Sim

Figura 48: Gráfico das vazões simuladas e observadas nos três pontos de controle para efeitos de calibração do modelo de simulação, relativo ao evento "b". 


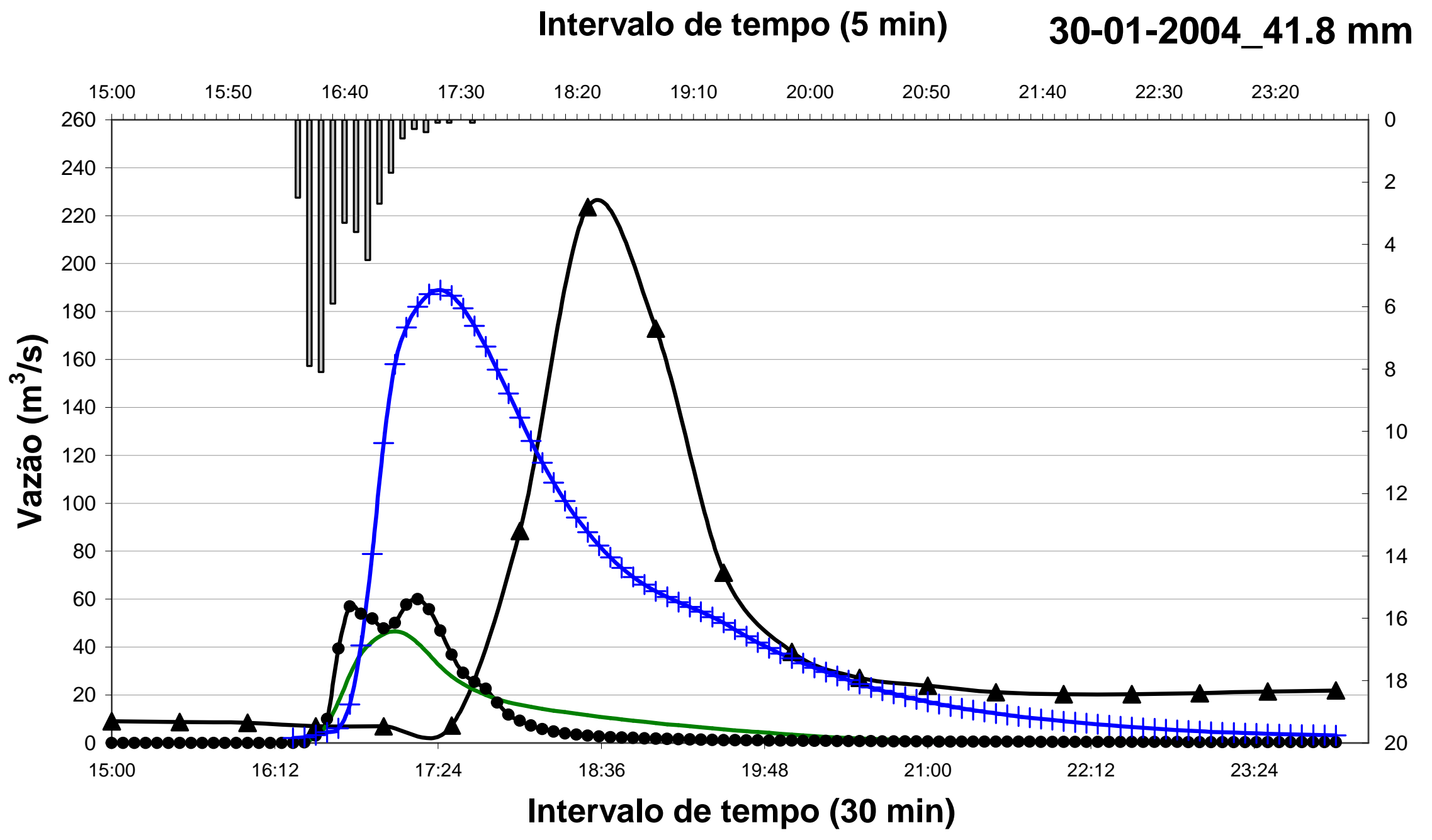

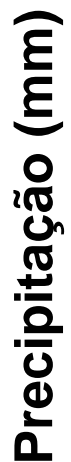

$\square$ Precipitação $\rightarrow$-PC 1- Obs $\rightarrow$ PC 3 - Obs —PC 1- Sim —PC 3- Sim

Figura 49 Gráfico das vazões simuladas e observadas nos três pontos de controle para efeitos de calibração do modelo de simulação, relativo ao evento "c". 
Intervalo de tempo (5 min)

01-11-2003_13.6 mm

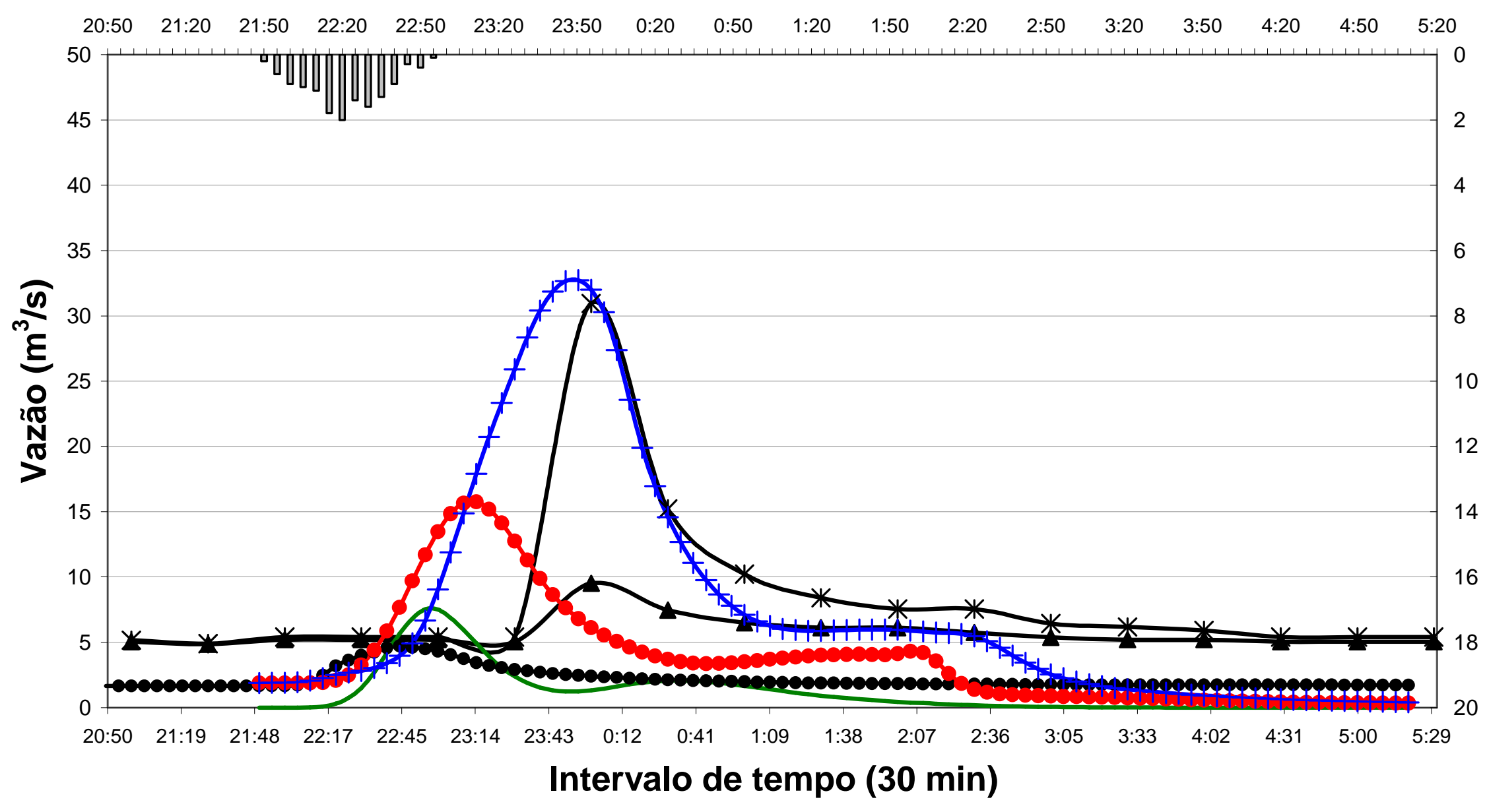

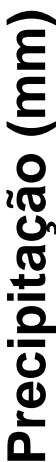

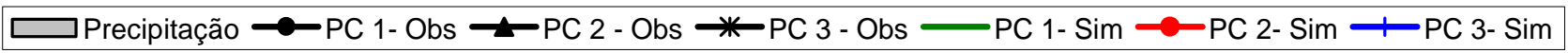

Figura 50: Gráfico das vazões simuladas e observadas nos três pontos de controle para efeitos de validação do modelo de simulação, relativo ao evento "d". 
Intervalo de tempo (5 min)

27-12-2003_15.2 mm

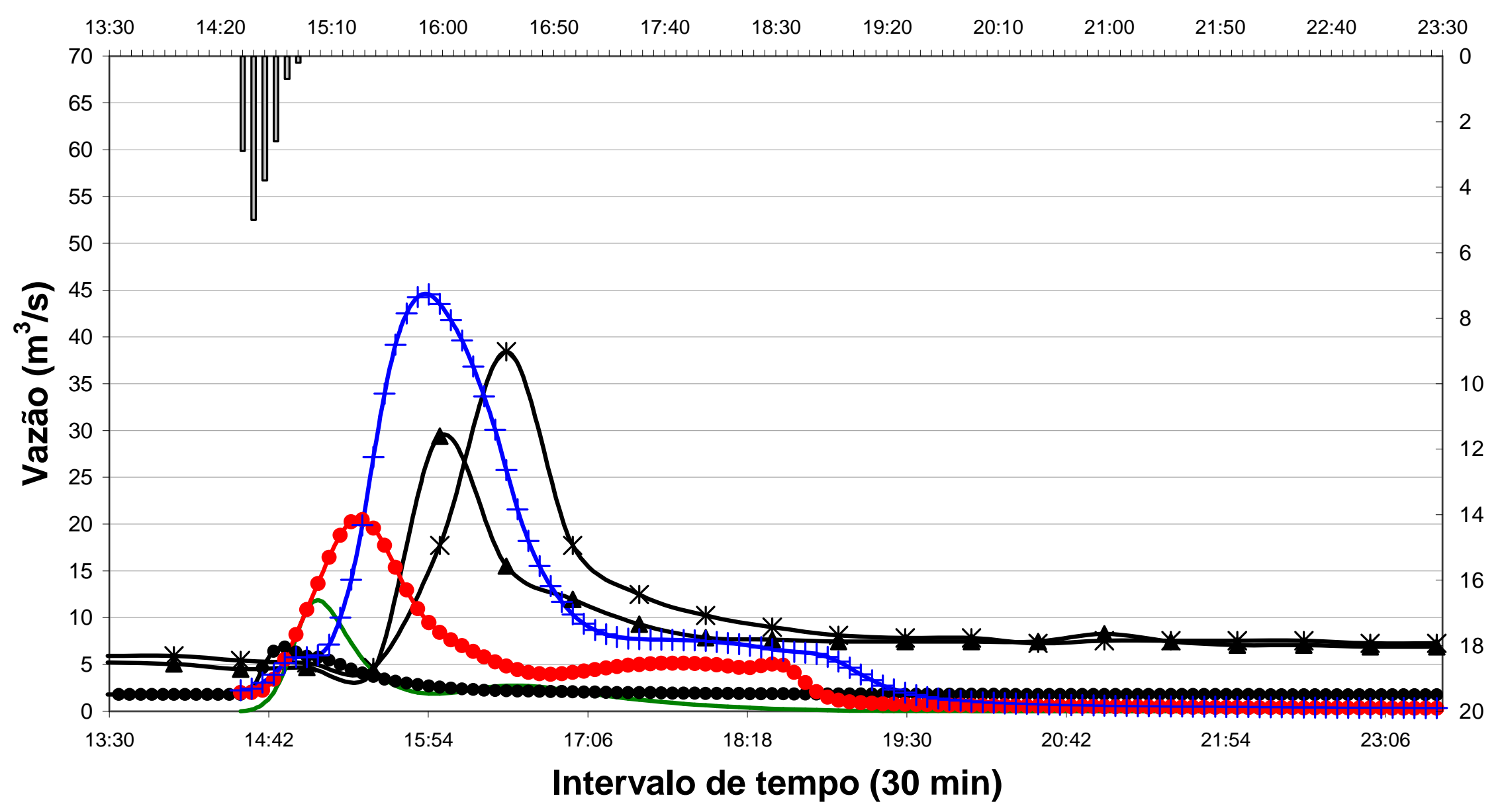

$\frac{E}{E}$

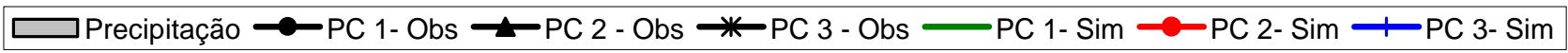

Figura 51: Gráfico das vazões simuladas e observadas nos três pontos de controle para efeitos de validação do modelo de simulação, relativo ao evento “e”. 
Intervalo de tempo (5 min)

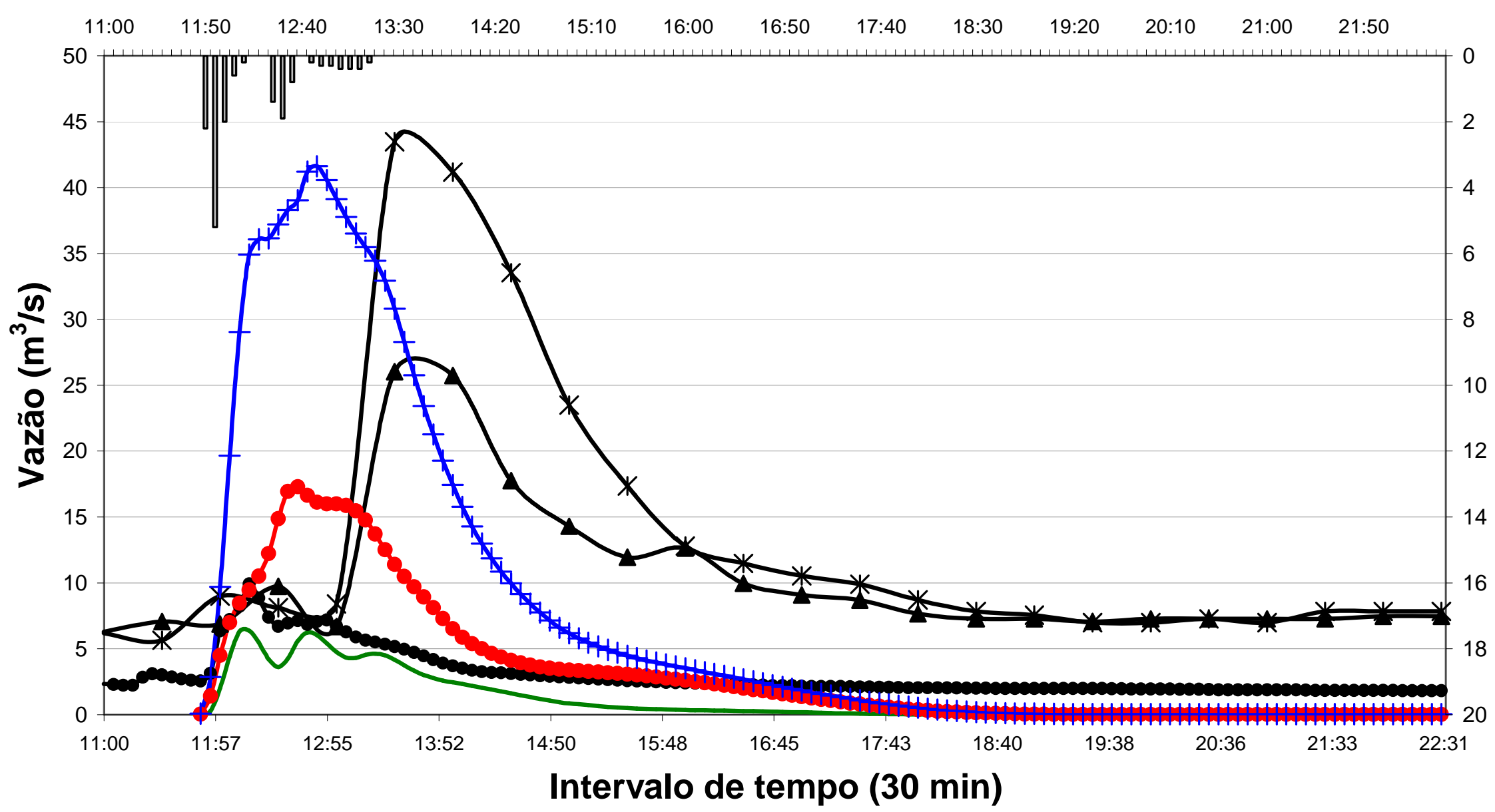

$\square$ Precipitação $\rightarrow$ PC 1- Obs $\multimap$ PC 2 - Obs $\rightarrow$ * 3 - Obs $\longrightarrow$ PC 1- Sim $\rightarrow$ PC 2- Sim —PC 3- Sim 


\subsection{Caracterização e seleção dos eventos a serem simulados nos cenários}

Como descrito no item 4.2.2 os dados de precipitação correspondente ao período de 2004 a 2006, foram agrupados e selecionados aqueles com lâmina superior à 10mm. A partir de então, os mesmo foram classificados de acordo com nove parâmetros. Os valores desses parâmetros podem ser observados na tabela 20 .

Tabela 20: Caracterização dos eventos de precipitação..

\begin{tabular}{|c|c|c|c|c|c|c|c|c|c|c|}
\hline EVENTO & DATA & $\begin{array}{c}\text { IPA } \\
(\mathbf{m m})\end{array}$ & $\begin{array}{l}\mathbf{P}_{\text {total }} \\
(\mathbf{m m})\end{array}$ & $\begin{array}{c}\mathbf{I}_{\text {media }} \\
(\mathbf{m m} / \mathbf{h})\end{array}$ & $\begin{array}{c}\mathbf{Q}_{\max } \\
\left(\mathbf{m}^{3} / \mathbf{s}\right)\end{array}$ & $\begin{array}{l}P_{\text {efetiva }} \\
(\mathbf{m m})\end{array}$ & $\begin{array}{c}\text { Tipo } \\
\text { Intensidade }\end{array}$ & $\begin{array}{c}\text { Tipo } \\
\text { Evento }\end{array}$ & C & $\begin{array}{c}\text { Umidade } \\
\text { antecedente }\end{array}$ \\
\hline 1 & $06 / 02 / 04$ & 1,4 & 10,10 & 10,1 & 6,62 & 1,33 & B & 1 & 0,13 & AMC I \\
\hline 2 & $06 / 02 / 04$ & 11,5 & 31,70 & 0,4 & 37,47 & 25,79 & A & 1 & 0,81 & AMC I \\
\hline 3 & $14 / 02 / 04$ & 3,9 & 36,20 & 0,1 & 13,88 & 21,31 & A & 3 & 0,59 & AMC I \\
\hline 4 & $14 / 02 / 04 *$ & 41,2 & 15,05 & 0,4 & 10,39 & 10,62 & $\mathbf{A}$ & 2 & 0,71 & AMC II \\
\hline 5 & $15 / 02 / 04$ & 56,3 & 17,10 & 0,1 & 11,87 & 15,54 & A & 2 & 0,91 & AMC III \\
\hline 6 & $16 / 02 / 04$ & 75,3 & 10,00 & 1,3 & 11,94 & 9,68 & A & 1 & 0,97 & AMC III \\
\hline 7 & $23 / 02 / 04$ & 6,3 & 29,30 & 0,0 & 15,74 & 24,58 & A & 4 & 0,84 & AMC I \\
\hline 8 & $23 / 02 / 04$ & 41,4 & 12,90 & 0,3 & 11,46 & 11,06 & $\mathbf{A}$ & 2 & 0,86 & AMC II \\
\hline 9 & $24 / 02 / 04$ & 63,4 & 20,70 & 0,1 & 10,50 & 18,68 & A & 1 & 0,90 & AMC III \\
\hline 10 & 03/03/04 & 0,0 & 18,20 & 3,9 & 12,11 & 11,19 & A & 1 & 0,61 & AMC I \\
\hline 11 & $20 / 05 / 04$ & 24,2 & 10,60 & 0,0 & 4,76 & 8,90 & A & 3 & 0,84 & AMC I \\
\hline 12 & $25 / 05 / 04$ & 13,6 & 31,00 & 1,2 & 52,26 & 13,77 & A & 2 & 0,44 & AMC I \\
\hline 13 & $27 / 05 / 04$ & 44,9 & 14,50 & $\mathbf{0 , 0}$ & 6,26 & 12,80 & $\mathbf{A}$ & 2 & $\mathbf{0 , 8 8}$ & AMC II \\
\hline 14 & $14 / 06 / 04$ & 2,0 & 13,20 & 0,0 & 6,75 & 10,74 & A & 2 & 0,81 & AMC I \\
\hline 15 & $21 / 07 / 04$ & 11,0 & 15,80 & 0,2 & 10,14 & 6,61 & A & 1 & 0,42 & AMC I \\
\hline 16 & $15 / 10 / 04$ & 29,5 & 10,40 & 20,8 & 12,77 & 5,78 & B & 1 & 0,56 & AMC I \\
\hline 17 & $19 / 10 / 04$ & 28,4 & 21,90 & 0,1 & 11,62 & 12,14 & A & 3 & 0,55 & AMC I \\
\hline 18 & $21 / 10 / 04$ & 32,9 & 9,40 & 0,1 & 6,70 & 8,27 & A & 2 & 0,88 & AMC I \\
\hline 19 & $13 / 11 / 04$ & 7,7 & 30,30 & 0,2 & 11,97 & 14,72 & A & 3 & 0,49 & AMC I \\
\hline 20 & 17/11/04 & 41,6 & 36,70 & 0,2 & 11,53 & 14,86 & $\mathbf{A}$ & 4 & 0,40 & AMC II \\
\hline 21 & $18 / 11 / 04$ & 78,7 & 11,90 & 0,1 & 9,05 & 8,38 & A & 1 & 0,70 & AMC III \\
\hline 22 & $20 / 11 / 04$ & 66,4 & 10,50 & 4,2 & 21,47 & 8,78 & $\mathrm{~A}$ & 1 & 0,84 & AMC III \\
\hline 23 & $15 / 02 / 05$ & 0,0 & 10,50 & 1,2 & 0,49 & 0,74 & A & 1 & 0,07 & AMC I \\
\hline 24 & $26 / 02 / 05$ & 5,3 & 13,30 & 0,9 & 18,52 & 4,67 & A & 1 & 0,35 & AMC I \\
\hline 25 & $27 / 02 / 05$ & 18,7 & 16,70 & 0,1 & 14,92 & 5,85 & A & 2 & 0,35 & AMC I \\
\hline 26 & $15 / 03 / 05$ & 20,4 & 14,70 & 1,1 & 19,24 & 5,32 & A & 2 & 0,36 & AMC I \\
\hline 27 & $16 / 03 / 05$ & 40,5 & 58,00 & 0,2 & 43,31 & 46,81 & $\mathbf{A}$ & 3 & $\mathbf{0 , 8 1}$ & AMC II \\
\hline 28 & $17 / 03 / 05$ & 98,5 & 20,00 & 0,3 & 19,61 & 10,99 & A & 1 & 0,55 & AMC III \\
\hline 29 & $22 / 05 / 05$ & 0,0 & 16,10 & 0,1 & 4,60 & 8,66 & A & 1 & 0,54 & AMC I \\
\hline 30 & $24 / 05 / 05$ & 25,0 & 24,00 & 1,1 & 19,46 & 9,49 & A & 1 & 0,40 & AMC I \\
\hline 31 & $24 / 05 / 05$ & 49,5 & 18,20 & 0,1 & 9,86 & 9,36 & $\mathbf{A}$ & 1 & $\mathbf{0 , 5 1}$ & AMC II \\
\hline 32 & $15 / 08 / 05$ & 0,0 & 12,00 & 2,0 & 19,86 & 4,44 & A & 3 & 0,37 & AMC I \\
\hline 33 & 05/09/05 & 10,1 & 12,90 & 0,3 & 7,68 & 3,93 & A & 1 & 0,30 & AMC I \\
\hline 34 & $\begin{array}{l}05 / 10 / 05 \\
06 / 10 / 05\end{array}$ & 6,0 & 14,70 & 0,0 & 6,22 & 4,37 & A & 2 & 0,30 & AMC I \\
\hline 35 & 07/10/05 & 21,7 & 40,50 & 0,4 & 23,00 & 19,69 & A & 3 & 0,49 & AMC I \\
\hline
\end{tabular}


Continuação da Tabela 20: Caracterização dos eventos de precipitação.

\begin{tabular}{|c|c|c|c|c|c|c|c|c|c|c|}
\hline EVENTO & DATA & $\begin{array}{c}\text { IPA } \\
(\mathbf{m m})\end{array}$ & $\begin{array}{l}\mathbf{P}_{\text {total }} \\
(\mathbf{m m})\end{array}$ & $\begin{array}{c}\mathbf{I}_{\text {media }} \\
(\mathbf{m m} / \mathbf{h})\end{array}$ & $\begin{array}{c}Q_{\max } \\
\left(\mathrm{m}^{3} / \mathbf{s}\right)\end{array}$ & $\begin{array}{l}\mathbf{P}_{\text {efetiva }} \\
(\mathbf{m m})\end{array}$ & $\begin{array}{c}\text { Tipo } \\
\text { Intensidade }\end{array}$ & $\begin{array}{c}\text { Tipo } \\
\text { Evento }\end{array}$ & $\mathbf{C}$ & $\begin{array}{c}\text { Umidade } \\
\text { antecedente }\end{array}$ \\
\hline 36 & $22 / 10 / 05$ & 7,4 & 11,50 & 0,3 & 6,27 & 6,22 & A & 2 & 0,54 & AMC I \\
\hline 37 & $26 / 10 / 05$ & 24,7 & 13,6 & 0,5 & 12,07 & 9,08 & A & 1 & 0,67 & AMC I \\
\hline 38 & $29 / 10 / 05$ & 25,5 & 14,90 & 0,1 & 6,68 & 7,83 & A & 2 & 0,53 & AMC I \\
\hline 39 & $04 / 11 / 05$ & 2,3 & 19,60 & 0,3 & 9,29 & 12,70 & A & 2 & 0,65 & AMC I \\
\hline 40 & $06 / 11 / 05$ & 23,9 & 17,70 & 1,9 & 20,86 & 11,72 & A & 1 & 0,66 & AMC I \\
\hline 41 & 09/11/05 & 41,6 & 20,20 & 0,9 & 11,30 & 14,71 & $\mathbf{A}$ & 1 & 0,73 & AMC II \\
\hline 42 & $19 / 11 / 05$ & 25,3 & 15,00 & 0,9 & 12,92 & 8,40 & A & 1 & 0,56 & AMC I \\
\hline 43 & $19 / 01 / 06$ & 0,1 & 30,90 & 0,7 & 15,20 & 7,43 & A & 1 & 0,24 & AMC I \\
\hline 44 & $29 / 01 / 06$ & 3,1 & 10,25 & 0,1 & 4,64 & 7,25 & A & 1 & 0,71 & AMC I \\
\hline 45 & $07 / 02 / 06$ & 6,60 & 17,60 & 10,6 & 18,72 & 5,61 & B & 1 & 0,32 & AMC I \\
\hline 46 & $\begin{array}{l}10 / 02 / 06 \\
11 / 02 / 06\end{array}$ & 54,3 & 36,80 & 0,0 & 11,23 & 16,95 & A & 2 & 0,46 & AMC III \\
\hline 47 & $12 / 02 / 06$ & 101,0 & 12,20 & 0,0 & 3,99 & 7,51 & A & 3 & 0,62 & AMC III \\
\hline 48 & $13 / 02 / 06$ & 106,9 & 13,30 & 0,1 & 6,64 & 10,53 & A & 2 & 0,79 & AMC III \\
\hline 49 & $15 / 02 / 06$ & 85,2 & 41,20 & 0,3 & 35,05 & 19,75 & A & 1 & 0,48 & AMC III \\
\hline 50 & $22 / 02 / 06$ & 17,70 & 13,03 & 0,2 & 6,16 & 11,92 & A & 2 & 0,91 & AMC I \\
\hline 51 & $27 / 02 / 06$ & 6,7 & 12,30 & 0,6 & 5,94 & 6,35 & A & 1 & 0,52 & AMC I \\
\hline 52 & $21 / 03 / 06$ & 7,50 & 50,30 & 0,2 & 66,34 & 36,39 & A & 1 & 0,72 & AMC I \\
\hline 53 & $23 / 03 / 06$ & 55,0 & 15,80 & 0,2 & 22,95 & 10,38 & A & 1 & 0,66 & AMC III \\
\hline 54 & 06/04/06 & 8,70 & 17,20 & 0,2 & 7,85 & 9,83 & A & 1 & 0,57 & AMC I \\
\hline 55 & $25 / 06 / 06$ & 0,0 & 12,90 & 0,9 & 11,88 & 7,66 & A & 2 & 0,59 & AMC I \\
\hline 56 & $19 / 11 / 06$ & 3,1 & 12,50 & 0,4 & 10,01 & 7,50 & A & 2 & 0,60 & AMC I \\
\hline 57 & $04 / 12 / 06$ & 2,4 & 11,70 & 0,2 & 29,22 & 10,67 & A & 1 & 0,91 & AMC I \\
\hline
\end{tabular}

Os dados destacados em negrito na tabela 20, referem-se aos eventos escolhidos para as simulações, dados em função das condições de umidade antecedente, que para esse trabalho foi escolhida como tipo AMC II. A justificativa para tal seleção baseia-se no fato das condições de umidade antecedente interferirem diretamente no escoamento superficial. Desta forma, procurou-se avaliar as simulações dos cenários em condições medianas, onde uma parcela da chuva é absorvida pelo solo e outra escoada superficialmente.

A tabela 213 contém mais detalhes sobre os eventos empregados nas simulações. No Apêndice C podem ser vistas as relações entre os eventos e os parâmetros a eles relacionados com maior detalhamento. 
Tabela 21: Características dos eventos utilizados na simulação dos cenários.

\begin{tabular}{cccccc}
\hline Evento & Data & $\begin{array}{c}\text { Horário de } \\
\text { ocorrência }\end{array}$ & $\begin{array}{c}\text { Duração } \\
\text { (min) }\end{array}$ & $\begin{array}{c}\text { Precipitação } \\
\text { Total (mm) }\end{array}$ & $\begin{array}{c}\text { Precipitação } \\
\text { Efetiva (mm) }\end{array}$ \\
\hline 4 & $14 / 02 / 04$ & $18: 30-21: 55$ & 205 & 15,05 & 10,62 \\
8 & $23 / 02 / 04$ & $13: 30-15: 20$ & 110 & 12,90 & 11,06 \\
13 & $27 / 05 / 04$ & $20: 05-02: 15$ & 370 & 14,50 & 12,80 \\
20 & $17 / 11 / 04$ & $14: 50-18: 20$ & 210 & 36,70 & 14,86 \\
27 & $16 / 03 / 05$ & $06: 15-11: 55$ & 340 & 58,00 & 46,81 \\
31 & $24 / 05 / 05$ & $03: 35-08: 10$ & 275 & 18,20 & 9,36 \\
41 & $09 / 11 / 05$ & $15: 30-16: 50$ & 80 & 20,20 & 14,71 \\
\hline
\end{tabular}

\subsection{Cenários Construídos na Escala de Bacia Hidrográfica}

A base de construção dos cenários consistiu na estimativa de dois indicadores chave para a série temporal analisada: a taxa de crescimento populacional e o percentual de área urbanizada. A primeira foi estimada com base na taxa geométrica de crescimento anual pra São Carlos dada por 1,94\% a.a entre 2000 e 2007 (SEADE, 2008) e em acordo com a tabela de evolução qualitativa dos cenários, proposta por Mendiondo (2006). A segunda foi estimada a partir do indicador anterior aliado à evolução da densidade populacional e ao potencial de escoamento.

As taxas geométricas de crescimento populacional aplicadas para cada cenário são descritas na tabela 22 e os resultados por elas gerados podem ser visualizados pela figura 53 . Cabe ressaltar que o valor do número de habitantes é referente ao município de São Carlos e não somente às sub-bacias estudadas. No entanto, como $95 \%$ da população de São Carlos concentra-se na área urbana e as sub-bacias estão inseridas nesta área, pode-se utilizar os resultados obtidos como indicadores na construção desses cenários.

Tabela 22: Taxa de crescimento populacional para São Carlos.

\begin{tabular}{ccccc}
\hline Ano & $\begin{array}{c}\text { GO } \\
\% \mathrm{a} \mathrm{a}\end{array}$ & $\begin{array}{c}\text { OS } \\
\% \mathrm{a} \mathrm{a}\end{array}$ & $\begin{array}{c}\text { AM } \\
\% \mathrm{a} \mathrm{a}\end{array}$ & $\begin{array}{c}\text { TG } \\
\% \mathrm{a} \mathrm{a}\end{array}$ \\
\hline 2025 & 1.40 & 1.80 & 1.00 & 0.70 \\
2050 & 0.70 & 1.20 & 0.75 & 0.50 \\
2075 & 0.35 & 0.80 & 0.50 & 0.30 \\
2100 & 0.15 & 0.50 & 0.25 & 0.20 \\
\hline
\end{tabular}




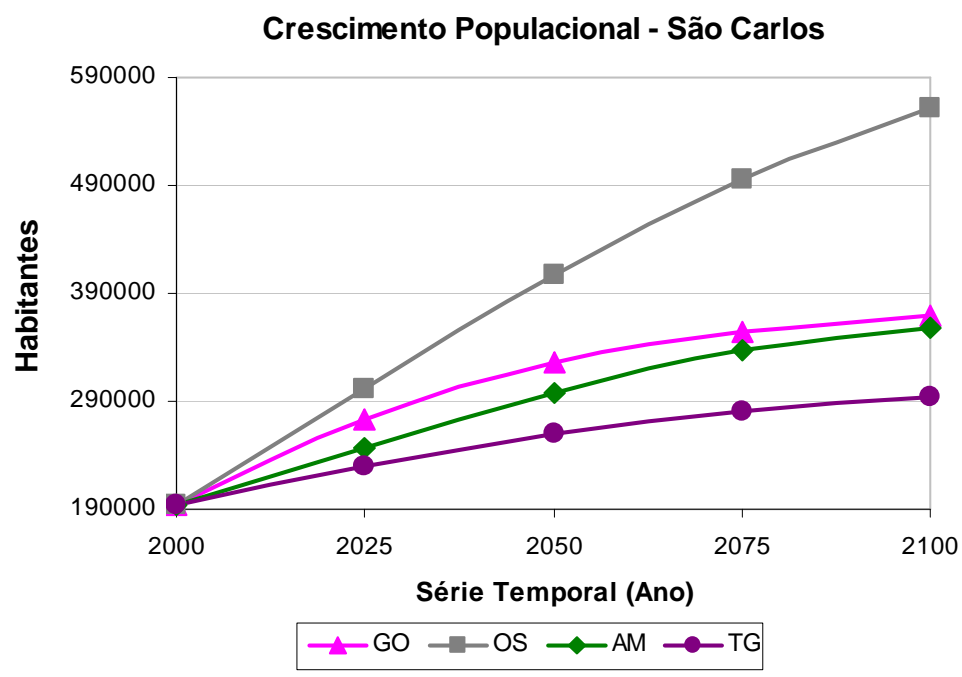

Figura 53: Crescimento populacional para os cenários

Já o percentual de área urbana, estimado somente para as sub-bacias estudadas, foi realizado com base nos estudos de Aguiar (1989). O percentual para cada cenário pode ser visualizado pela figura 54

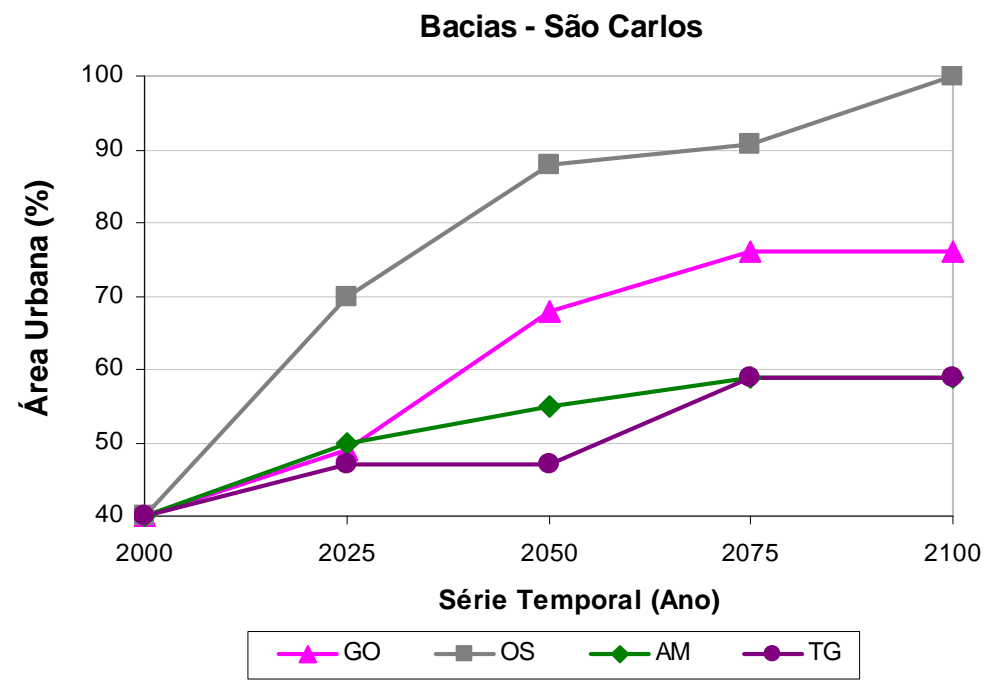

Figura 54: Percentual de área urbanizada nas sub-bacias.

A partir da estimativa desses dois indicadores chave realizou-se a modificações dos demais indicadores (potencial de escoamento; declividade, sinuosidade e rugosidade do canal; largura e rugosidade da planície de inundação; bacia de detenção e de infiltração; melhoramento de manancial urbano; densidade de drenagem) de acordo com a tabela de 
evolução qualitativa dos cenários, proposta por Mendiondo (2006) aliada as peculiaridades de cada uma das sub-bacias estudadas. De forma a melhor elucidar essa etapa é apresentada a evolução temporal dos principais indicadores utilizados na construção dos cenários. Os valores de tais indicadores refletem valores médios para a sub-bacia do Monjolinho.

Como é possível observar pela Figura 55 o percentual de área urbana refletido pelo potencial de escoamento é maior para os cenários reativos (GO e OS) quando comparado ao valor de referência (Ano 2000) e aos cenários pró-ativos (AM e TG), embora, para o cenário AM, haja um leve aumento nos primeiros 25 anos.

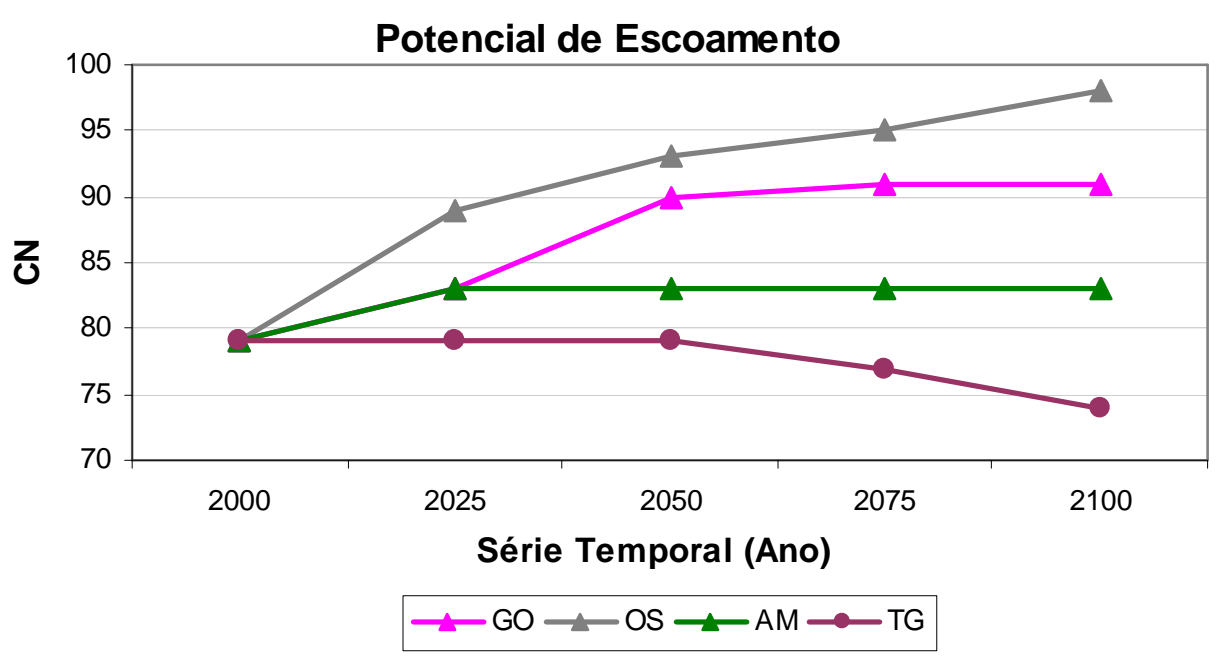

Figura 55: Evolução do potencial de escoamento nos cenários.

A escolha do local de implantação das bacias de detenção e de infiltração, bem como as modificações ao longo dos cursos d'água teve por base a interpretação das principais características dos cenários (visão global x visão local), assim para os cenários globais (GO e TG) as primeiras alterações foram realizadas para o curso d'água principal e, para os cenários locais (OS e AM) as primeiras alterações foram realizadas nos cursos d'água secundários.

As bacias de detenção (Figura 56) foram amplamente utilizadas nos cenários reativos (GO e OS) ao contrário das bacias de infiltração (Figura 57). Isso se deveu ao fato das 
primeiras terem somente a função de atenuar as ondas de cheia, enquanto as segundas além desta função são também capazes de promover a infiltração.

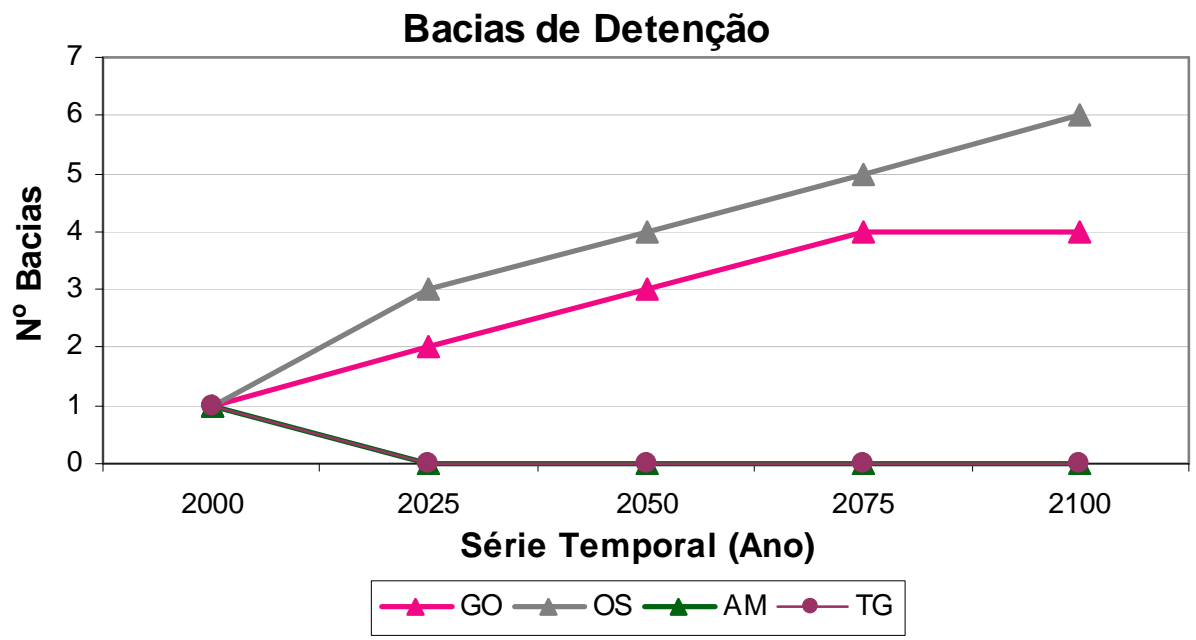

Figura 56: Utilização de bacias de detenção nos cenários.

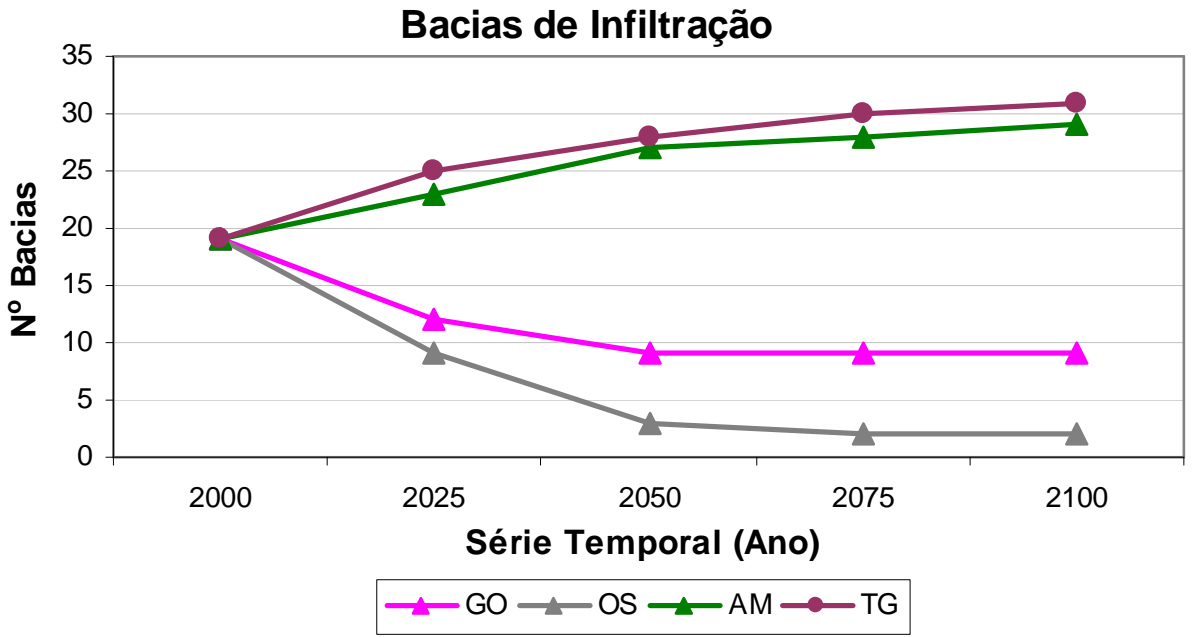

Figura 57: Utilização de bacias de infiltração nos cenários.

O indicador denominado "melhoramento de manancial urbano", pode ser dado segundo duas visões, de ordem qualitativa e quantitativa. Qualitativamente pode-se interpretálo de acordo com a condição do curso d'água dado segundo alguns parâmetros como: oxigênio dissolvido, demanda bioquímica de oxigênio, demanda química de oxigênio, entre outros. Já quantitativamente, o melhoramento de manancial urbano pode ser interpretado pelo destamponamento de rios e abertura de novos rios em locais propícios. Neste trabalho tal 
indicador foi explorado somente pela visão quantitativa com aumento no número de rios para os cenários pró-ativos (valores positivos) e supressão nos cenários reativos (valores negativos) (Figura 58).

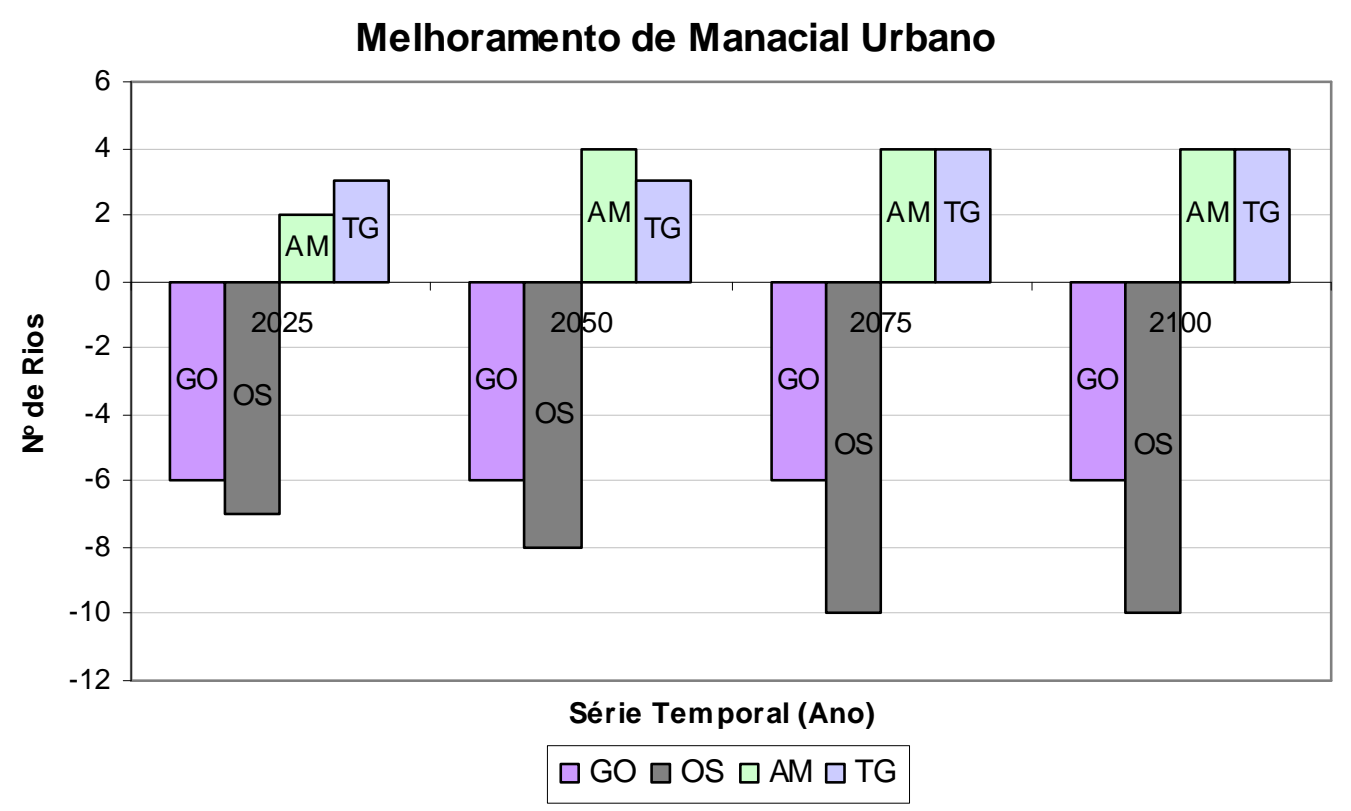

Figura 58: Evolução do melhoramento de manancial urbano.

Outros indicadores também importantes na construção e avaliação dos cenários são a rugosidade e a sinuosidade dos canais. Desta forma, como resultado da criação dos cenários tem-se o aumento da rugosidade e da sinuosidade nos cenários pró-ativos (AM e TG) e diminuição nos demais. As alterações na sinuosidade dos canais podem ser relacionadas ao comprimento dos mesmos. A Figura 59 demonstra maiores valores do comprimento do rio principal da bacia do Monjolinho para os cenários AM e TG, que podem ser interpretados como maior sinuosidade, enquanto os de menor comprimento (GO e OS) indicam retificação do canal. 
Rio Principal - Bacia do Monjolinho

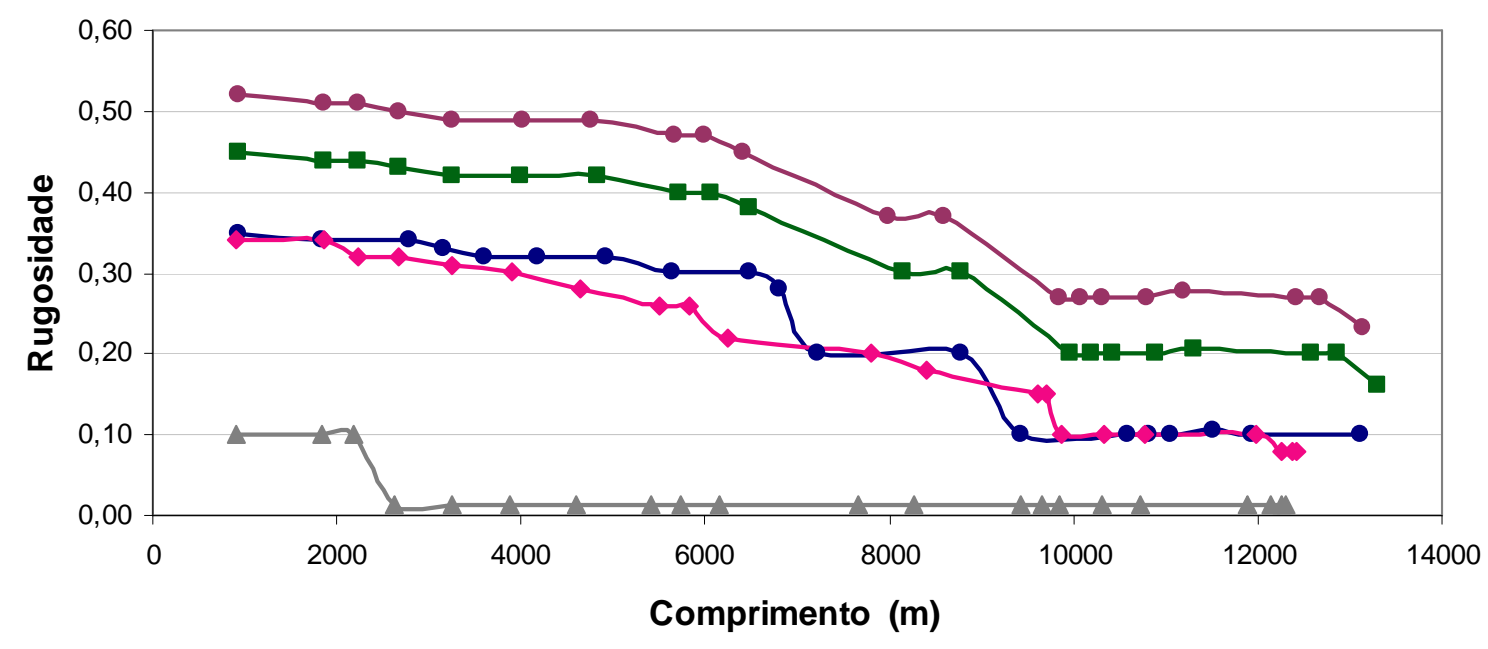

$\rightarrow$ Ano $2000 \multimap$ GO $2100 \rightarrow$ OS $2100 \rightarrow$ AM $2100 \multimap$ TG 2100

Figura 59: Rugosidade ao longo do principal rio da bacia do monjolinho.

É necessário ressaltar uma importante etapa para a construção desses cenários, a adaptação dos cenários qualitativos (Mendiondo, 2006) em cenários quantitativos, pois essa adequação é única para cada indivíduo. Souza e Mendiondo (2007) relatam o estudo de diferentes percepções na construção de cenários feito por alguns especialistas da área de recursos hídricos e demonstram que podem ocorrer variações na percepção de cada um, e que tais variações podem existir na construção desses cenários levantando uma questão relevante com relação ao processo de construção, conferindo certa incerteza a metodologia. Embora a incerteza seja parte do processo os autores afirmam que as possíveis modificações que devam ser realizadas nos cenários construídos não devem inviabilizar a utilização de cenários e sim deve-se avaliar os cenários ao longo do tempo realizando uma gestão adaptativa para melhor adequação do cenário às necessidades e as condições atuais.

Nas páginas seguintes são apresentadas as configurações das sub-bacias para cada cenário. Maior detalhamento a respeito dos valores dos parâmetros utilizados nas simulações pode ser visualizado no APÊNDICE D. 


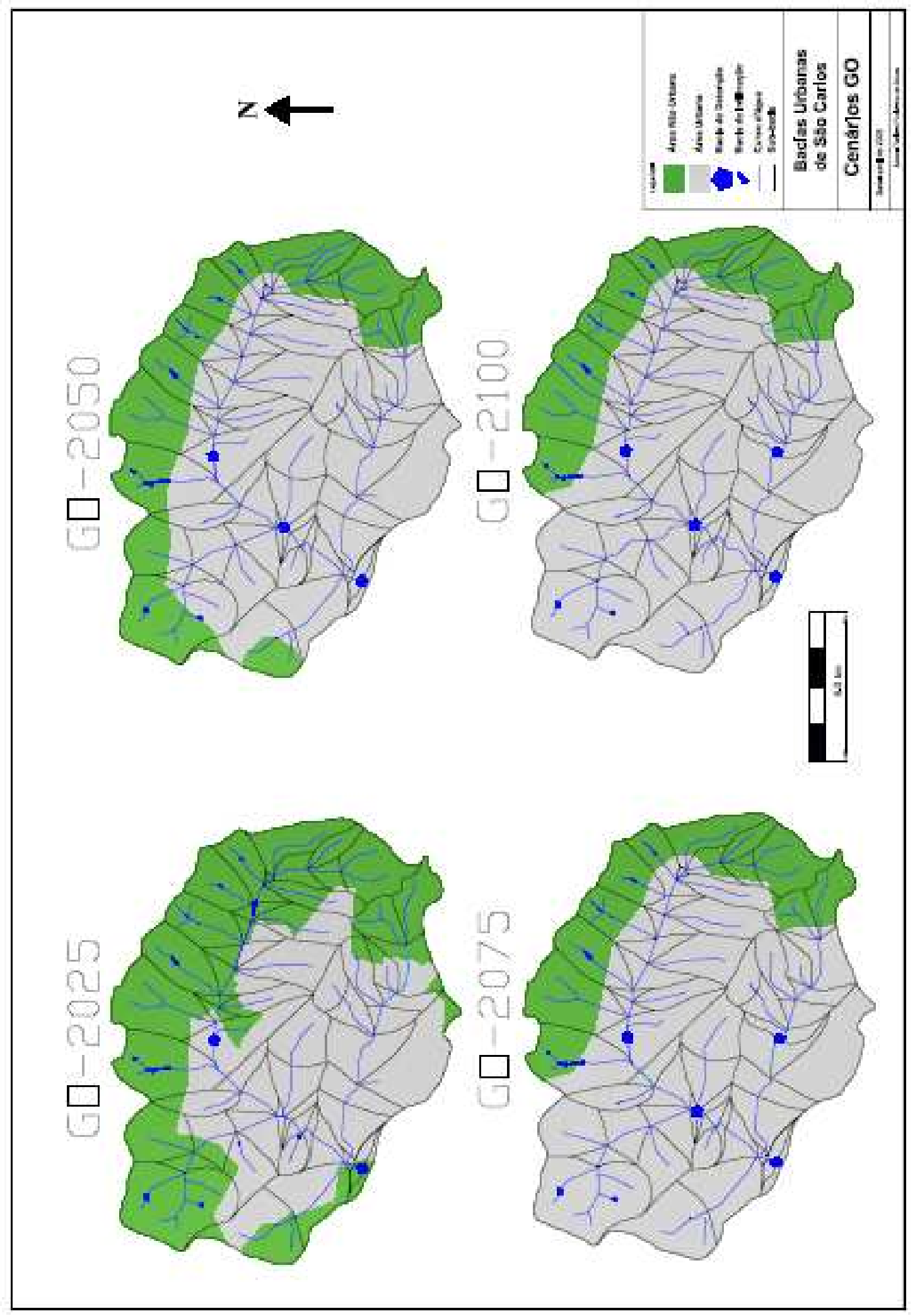




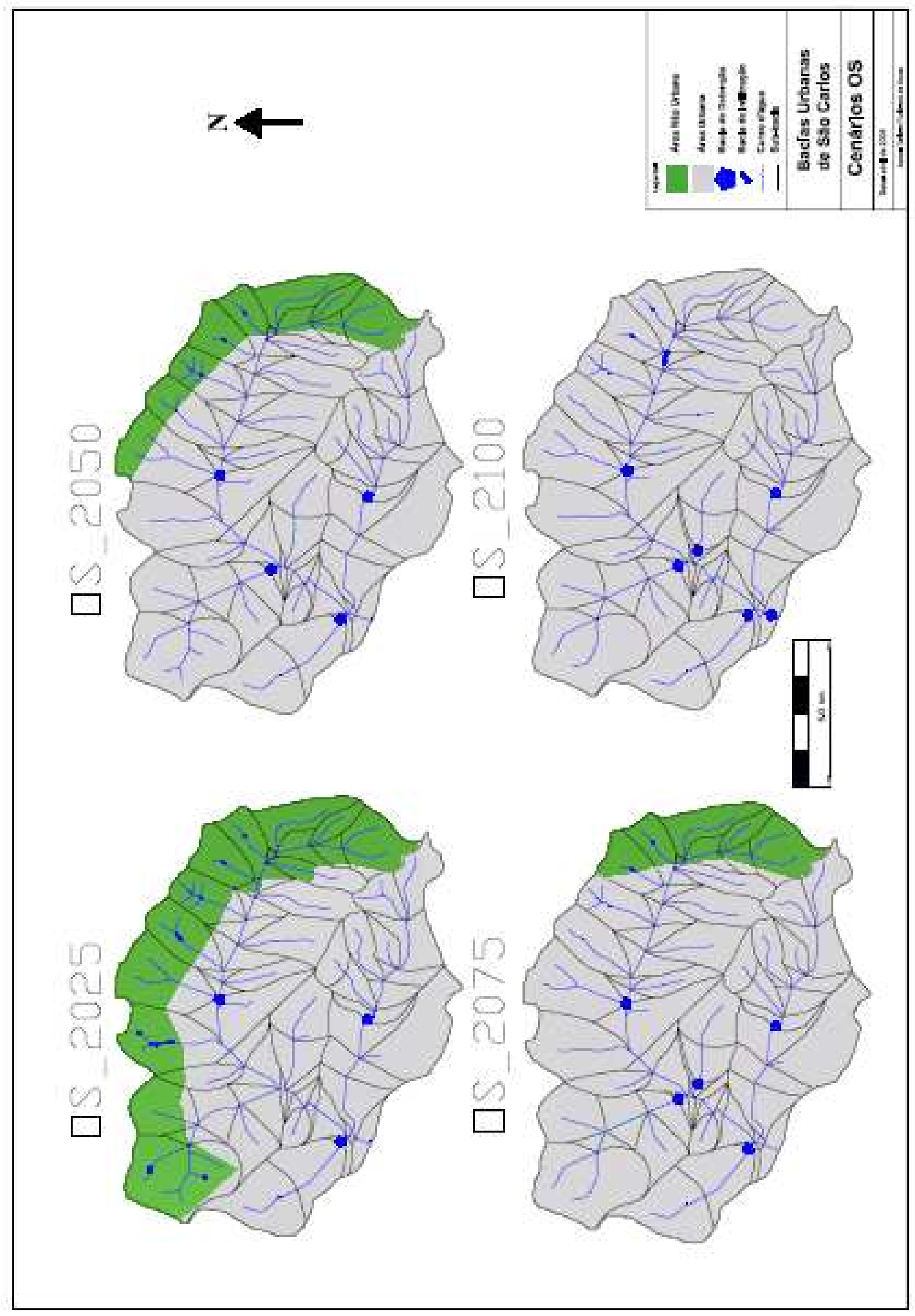




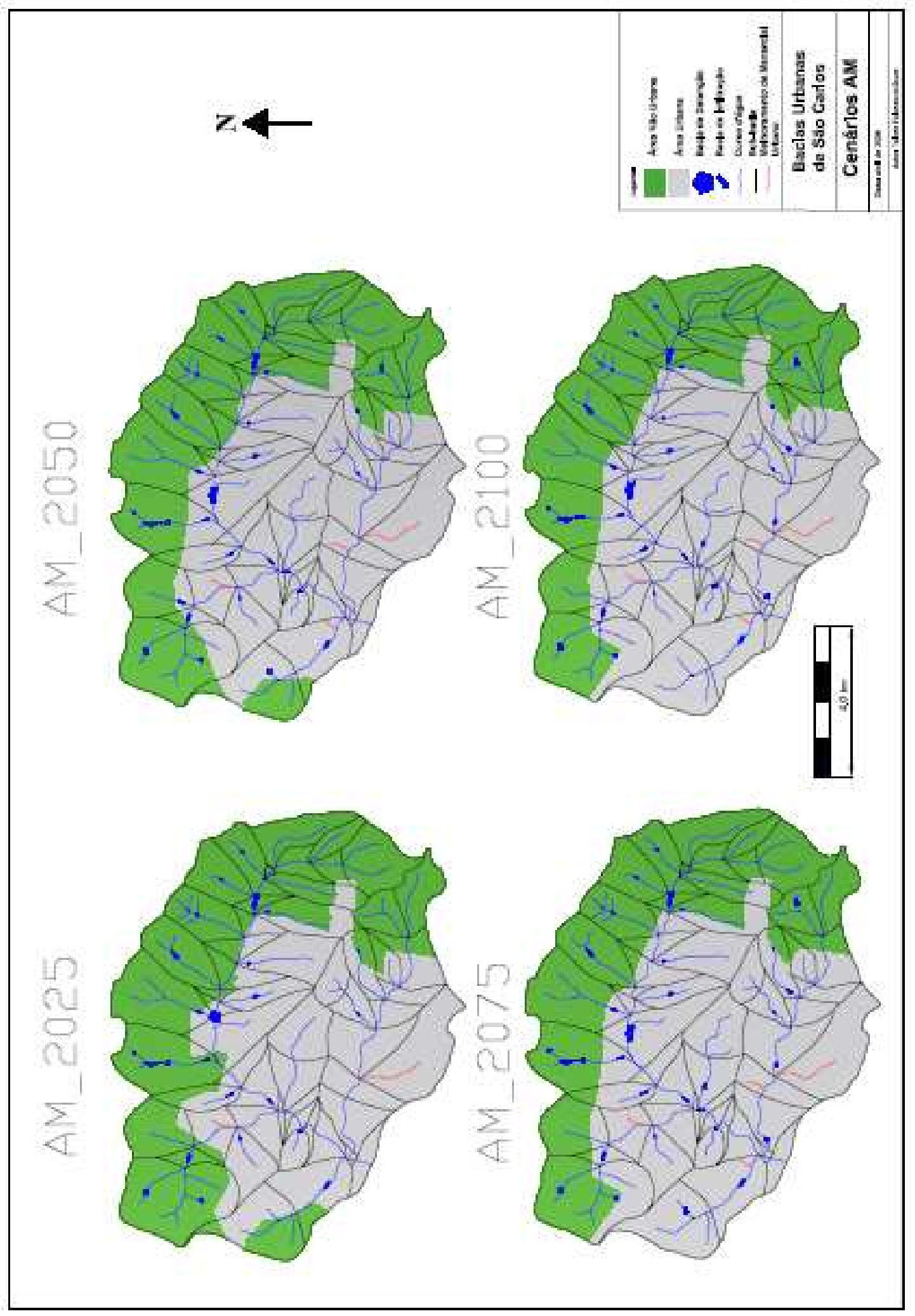




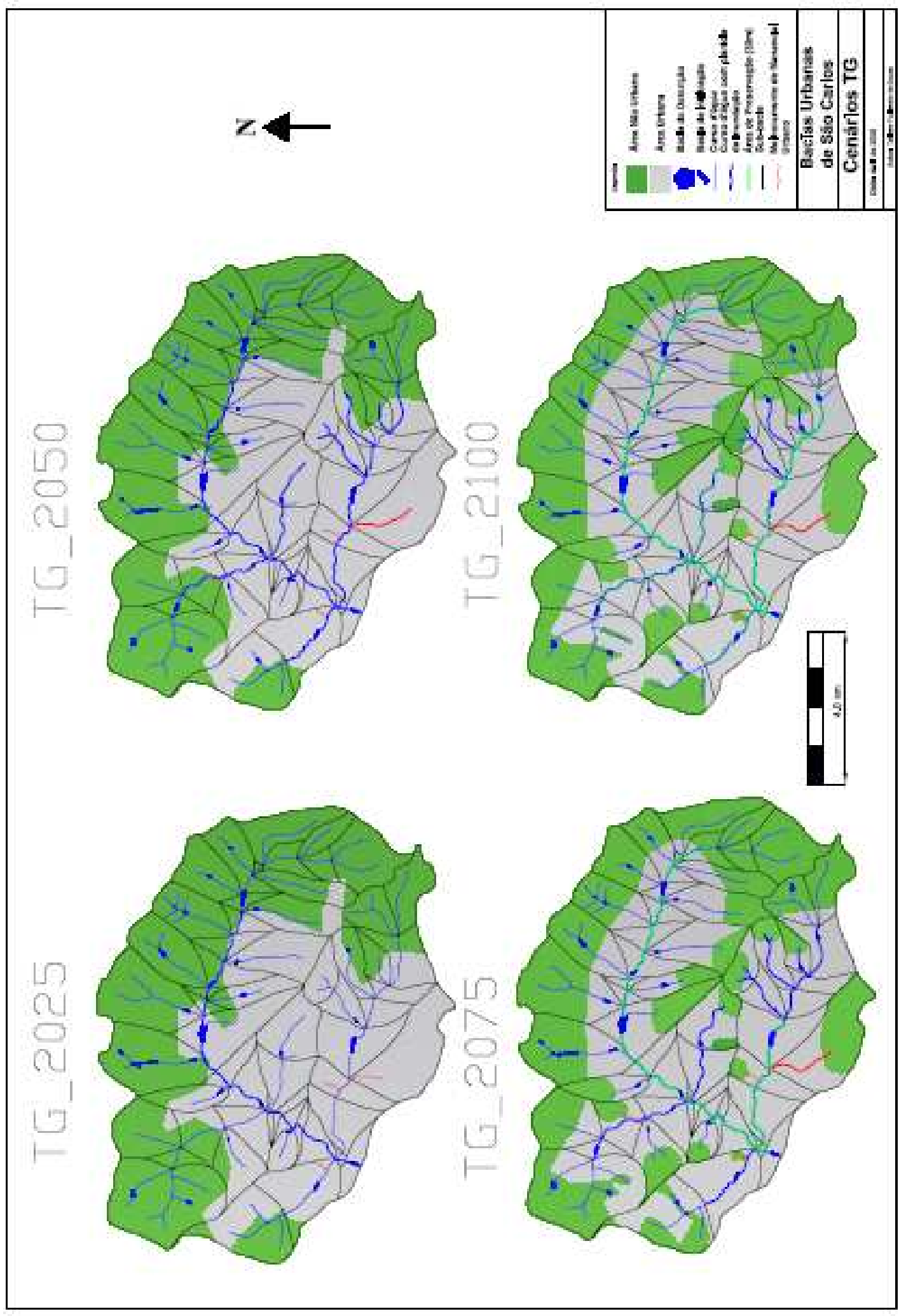




\subsection{Cenários Construídos na escala de Lote Urbano}

Neste item são descritos os cenários referentes ao lote urbano. Adotou-se como lote tipo para todas as sub-bacias um lote urbano residencial de $200 \mathrm{~m}^{2}$ sem interferências de verticalização. Na figura 60 tem-se a representação esquemática em função do percentual de área ocupada em cada uso e as características detalhadas do lote.

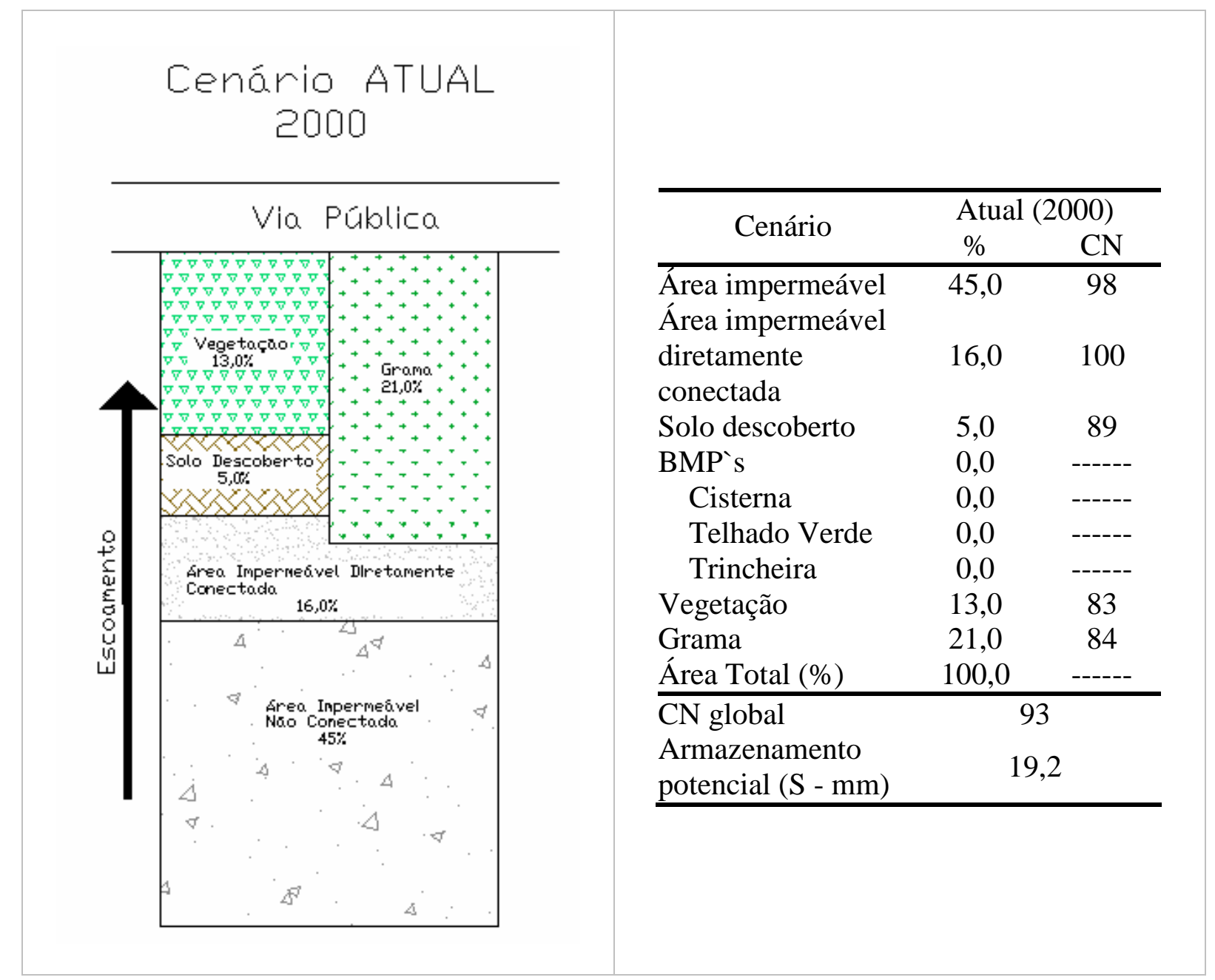

Figura 60: Características do lote de referência.

Para os demais cenários segue a apresentação das características de cada um através de tabelas e figuras. 


\subsubsection{Global Orchestration}

Tabela 23: Características do lote pertencente ao cenário GO.

\begin{tabular}{|c|c|c|c|c|c|c|c|c|}
\hline \multirow{2}{*}{ Cenário } & \multicolumn{2}{|c|}{ GO 2025} & \multicolumn{2}{|c|}{ GO 2050} & \multicolumn{2}{|c|}{ GO 2075} & \multicolumn{2}{|c|}{ GO 2100} \\
\hline & $\%$ & $\mathbf{C N}$ & $\%$ & $\mathbf{C N}$ & $\%$ & $\mathbf{C N}$ & $\%$ & $\mathbf{C N}$ \\
\hline Área impermeável & 47,0 & 98 & 50,0 & 98 & 47,0 & 98 & 47,0 & 98 \\
\hline $\begin{array}{l}\text { Área impermeável } \\
\text { diretamente } \\
\text { conectada }\end{array}$ & 17,0 & 100 & 20,0 & 100 & 21,4 & 100 & 21,4 & 100 \\
\hline $\begin{array}{l}\text { Solo descoberto } \\
\text { BMP`s }\end{array}$ & 7,0 & 89 & 7,0 & 89 & 7,0 & 89 & 7,0 & 89 \\
\hline Cisterna & 0,0 & ------ & 0,0 & ------ & 1,6 & ------ & 3,5 & ----- \\
\hline Telhado Verde & 0,0 & ------ & 0,0 & ------ & 0,0 & ------ & 0,0 & ----- \\
\hline Trincheira & 0,0 & ----- & 0,0 & ----- & 0,0 & ----- & 0,0 & --- \\
\hline Vegetação & 6,0 & 83 & 6,0 & 83 & 6,0 & 83 & 8,1 & 83 \\
\hline Grama & 23,0 & 84 & 17,0 & 84 & 17,0 & 84 & 13,0 & 84 \\
\hline Área Total (\%) & 100,0 & ------ & 100,0 & ------ & 100,0 & ------ & 100,0 & \\
\hline$\overline{\mathrm{CN}}$ global & \multicolumn{2}{|c|}{94} & \multicolumn{2}{|c|}{94} & \multicolumn{2}{|c|}{90} & \\
\hline $\begin{array}{l}\text { Armazenamento } \\
\text { potencial }(\mathrm{S}-\mathrm{mm})\end{array}$ & \multicolumn{2}{|c|}{17,4} & \multicolumn{2}{|c|}{14,8} & \multicolumn{2}{|c|}{29,2} & \multicolumn{2}{|c|}{62,5} \\
\hline
\end{tabular}

\subsubsection{Order From Strength}

Tabela 24: Características do lote pertencente ao cenário OS.

\begin{tabular}{|c|c|c|c|c|c|c|c|c|}
\hline \multirow{2}{*}{ Cenário } & \multicolumn{2}{|c|}{ OS 2025} & \multicolumn{2}{|c|}{ OS 2050} & \multicolumn{2}{|c|}{ OS 2075} & \multicolumn{2}{|c|}{ OS 2100} \\
\hline & $\%$ & $\mathbf{C N}$ & $\%$ & $\mathbf{C N}$ & $\%$ & $\mathbf{C N}$ & $\%$ & $\mathbf{C N}$ \\
\hline Área impermeável & 49,0 & 98 & 51,0 & 98 & 51,0 & 98 & 49,0 & 98 \\
\hline $\begin{array}{l}\text { Área impermeável } \\
\text { diretamente conectada }\end{array}$ & 19,0 & 100 & 22,0 & 100 & 24,0 & 100 & 26,0 & 100 \\
\hline Solo descoberto & 6,0 & 89 & 8,0 & 89 & 16,0 & 89 & 16,0 & 89 \\
\hline BMP`s & & & & & & & & \\
\hline Cisterna & ------ & ----- & ------ & ----- & ----- & ----- & ------ & $----\cdot$ \\
\hline Telhado Verde & ------ & ------ & ------ & ------ & ------ & ----- & ------ & $----\cdot$ \\
\hline Trincheira & ----- & ----- & ----- & ------ & ----- & ------ & ------ & ----- \\
\hline Vegetação & 5,0 & 83 & 3,0 & 83 & 2,0 & 83 & 2,0 & 83 \\
\hline Grama & 21,0 & 84 & 16,0 & 84 & 7,0 & 84 & 7,0 & 84 \\
\hline Área Total $(\%)$ & 100,0 & ------ & 100,0 & ------ & 100,0 & ------ & 100,0 & ---- \\
\hline $\mathrm{CN}$ global & 9 & & & & 96 & & 96 & \\
\hline $\begin{array}{l}\text { Armazenamento } \\
\text { potencial }(\mathrm{S}-\mathrm{mm})\end{array}$ & 15 & & & & 11 & & 11 , & \\
\hline
\end{tabular}




\subsubsection{Adapting Mosaic}

Tabela 25: Características do lote pertencente ao cenário AM.

\begin{tabular}{|c|c|c|c|c|c|c|c|c|}
\hline \multirow{2}{*}{ Cenário } & \multicolumn{2}{|c|}{ AM 2025} & \multicolumn{2}{|c|}{ AM 2050} & \multicolumn{2}{|c|}{ AM 2075} & \multicolumn{2}{|c|}{ AM 2100} \\
\hline & $\%$ & $\mathrm{CN}$ & $\%$ & $\mathrm{CN}$ & $\%$ & $\mathrm{CN}$ & $\%$ & $\mathrm{CN}$ \\
\hline Área impermeável & 45,0 & 98 & 34,1 & 98 & 34,1 & 98 & 34,1 & 98 \\
\hline $\begin{array}{l}\text { Área impermeável } \\
\text { diretamente conectada }\end{array}$ & 16,0 & 100 & 13,0 & 100 & 9,4 & 100 & 6,4 & 100 \\
\hline Solo descoberto & 2,0 & 89 & 0,0 & 89 & 0,0 & 89 & 0,0 & 89 \\
\hline \multicolumn{9}{|l|}{ BMP`s } \\
\hline Cisterna & 1,0 & ------ & 1,0 & ------ & 1,6 & ------ & 1,6 & ----- \\
\hline Telhado Verde & ------ & ------ & 7,9 & ------ & 7,9 & ------ & 7,9 & ------ \\
\hline Trincheira & ------ & ------ & ------ & ------ & ------ & ------ & ------ & ------ \\
\hline Vegetação & 15,0 & 83 & 18,0 & 83 & 21,0 & 83 & 24,0 & 83 \\
\hline Grama & 21,0 & 84 & 26,0 & 84 & 26,0 & 84 & 26,0 & 84 \\
\hline Área Total (\%) & 100,0 & ------ & 100,0 & ------ & 100,0 & ------ & 100,0 & $----\cdot$ \\
\hline$\overline{\mathrm{CN}}$ global & \multicolumn{2}{|c|}{86} & \multicolumn{2}{|c|}{78} & \multicolumn{2}{|c|}{73} & \multicolumn{2}{|c|}{72} \\
\hline $\begin{array}{l}\text { Armazenamento } \\
\text { potencial }(\mathrm{S}-\mathrm{mm})\end{array}$ & \multicolumn{2}{|c|}{42,3} & \multicolumn{2}{|c|}{71,6} & \multicolumn{2}{|c|}{96,0} & \multicolumn{2}{|c|}{97,8} \\
\hline
\end{tabular}

\subsubsection{TechnoGarden}

Tabela 26: Características do lote pertencente ao cenário TG.

\begin{tabular}{|c|c|c|c|c|c|c|c|c|}
\hline \multirow{2}{*}{ Cenário } & \multicolumn{2}{|c|}{ TG 2025} & \multicolumn{2}{|c|}{ TG 2050} & \multicolumn{2}{|c|}{ TG 2075} & \multicolumn{2}{|c|}{ TG 2100} \\
\hline & $\%$ & $\mathrm{CN}$ & $\%$ & $\mathrm{CN}$ & $\%$ & $\mathrm{CN}$ & $\%$ & $\mathrm{CN}$ \\
\hline Área impermeável & 45,0 & 98 & 42,0 & 98 & 33,0 & 98 & 33,0 & 98 \\
\hline $\begin{array}{l}\text { Área impermeável } \\
\text { diretamente conectada }\end{array}$ & 16,0 & 100 & 8,0 & 100 & 6,0 & 100 & 3,4 & 100 \\
\hline Solo descoberto & 1,0 & 89 & 1,0 & 89 & 1,0 & 89 & 1,0 & 89 \\
\hline BMP`s & & & & & & & & \\
\hline Cisterna & 1,6 & ------ & 1,6 & ------ & 1,6 & ------ & 1,6 & 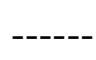 \\
\hline Telhado Verde & ------ & ------ & 7,5 & ----- & 7,5 & ------ & 7,5 & $----\cdot$ \\
\hline Trincheira & ------ & ----- & ----- & ------ & 2,5 & ----- & 2,5 & $---\cdot-$ \\
\hline Vegetação & 15,5 & 83 & 21,0 & 83 & 29,4 & 83 & 32,0 & 83 \\
\hline Grama & 21,0 & 84 & 19,0 & 84 & 19,0 & 84 & 19,0 & 84 \\
\hline Área Total (\%) & 100,0 & ----- & 100,0 & ------ & 100,0 & ----- & 100,0 & ------ \\
\hline CN global & \multicolumn{2}{|c|}{75} & \multicolumn{2}{|c|}{62} & \multicolumn{2}{|c|}{52} & \multicolumn{2}{|c|}{50} \\
\hline $\begin{array}{l}\text { Armazenamento } \\
\text { potencial }(\mathrm{S}-\mathrm{mm})\end{array}$ & \multicolumn{2}{|c|}{85,7} & \multicolumn{2}{|c|}{154,9} & \multicolumn{2}{|c|}{232,1} & \multicolumn{2}{|c|}{252,9} \\
\hline
\end{tabular}




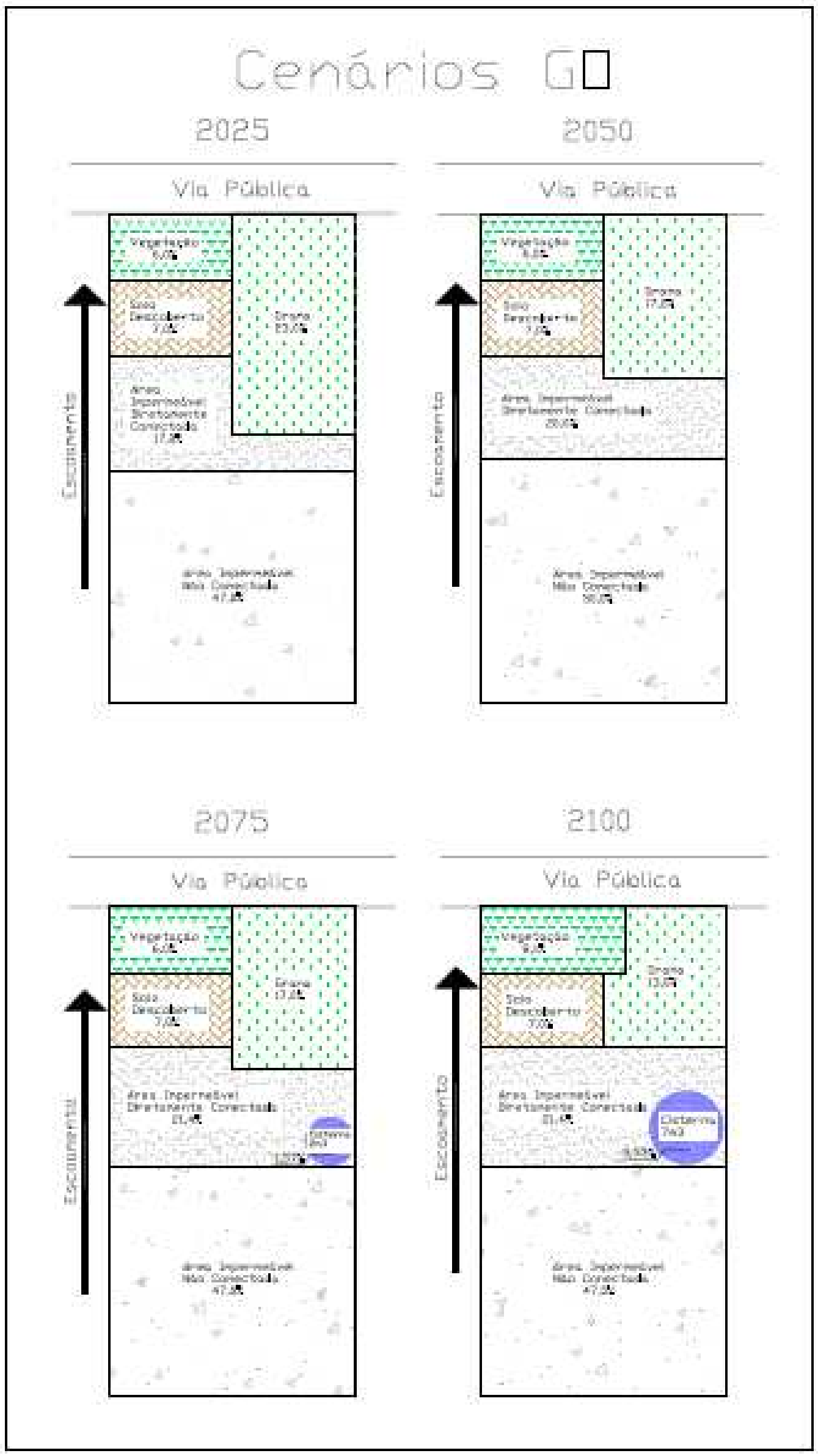




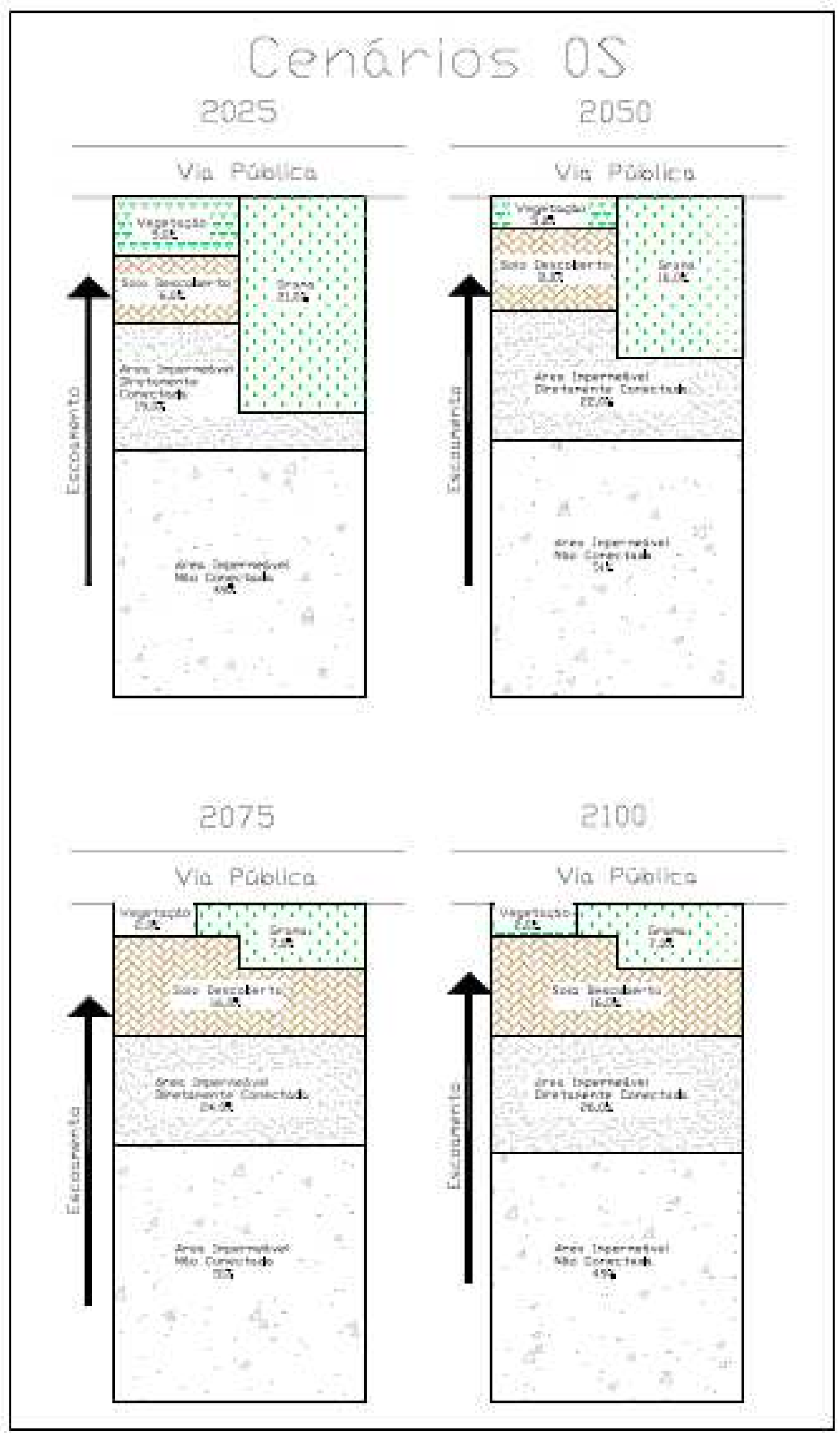




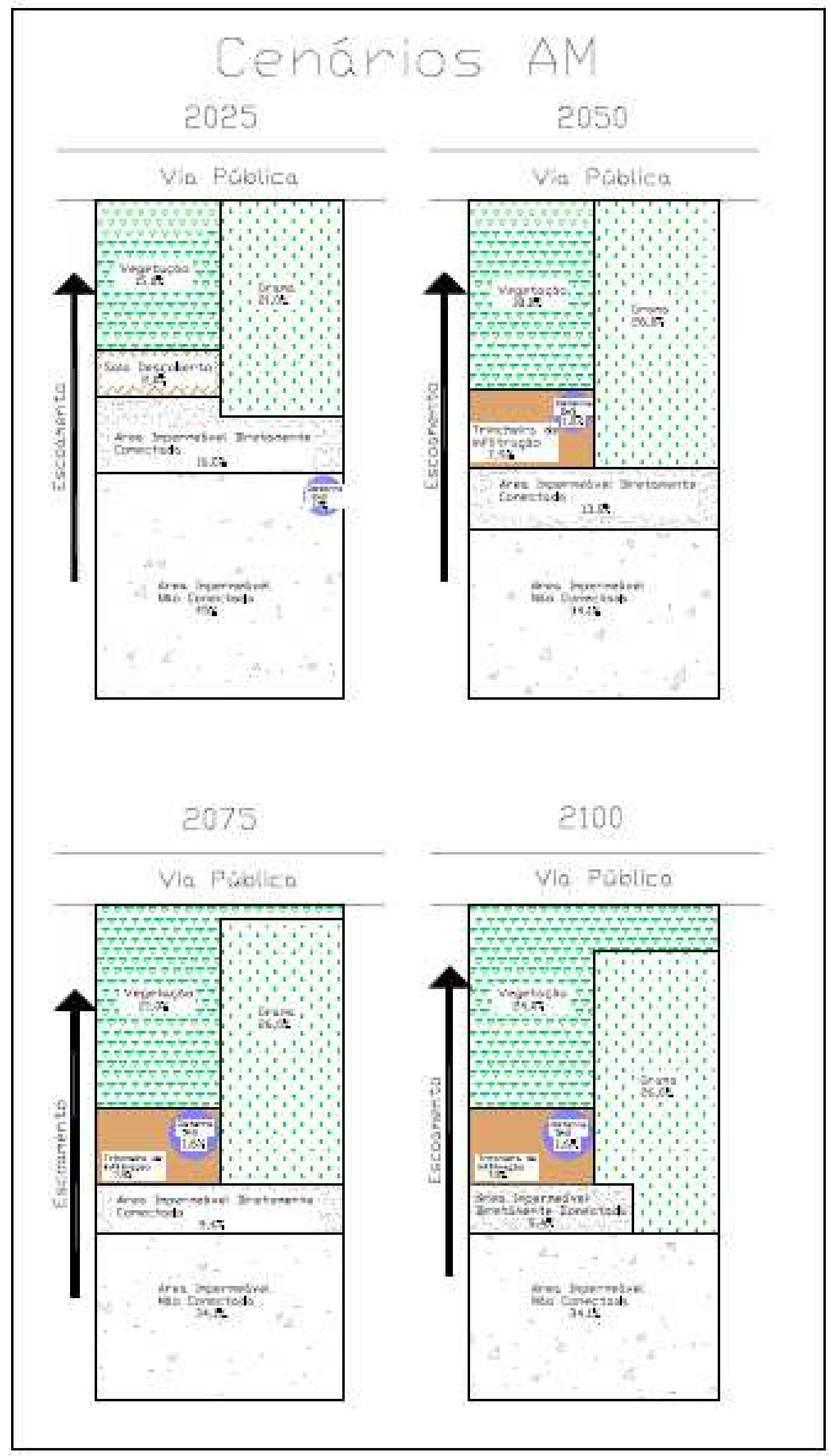




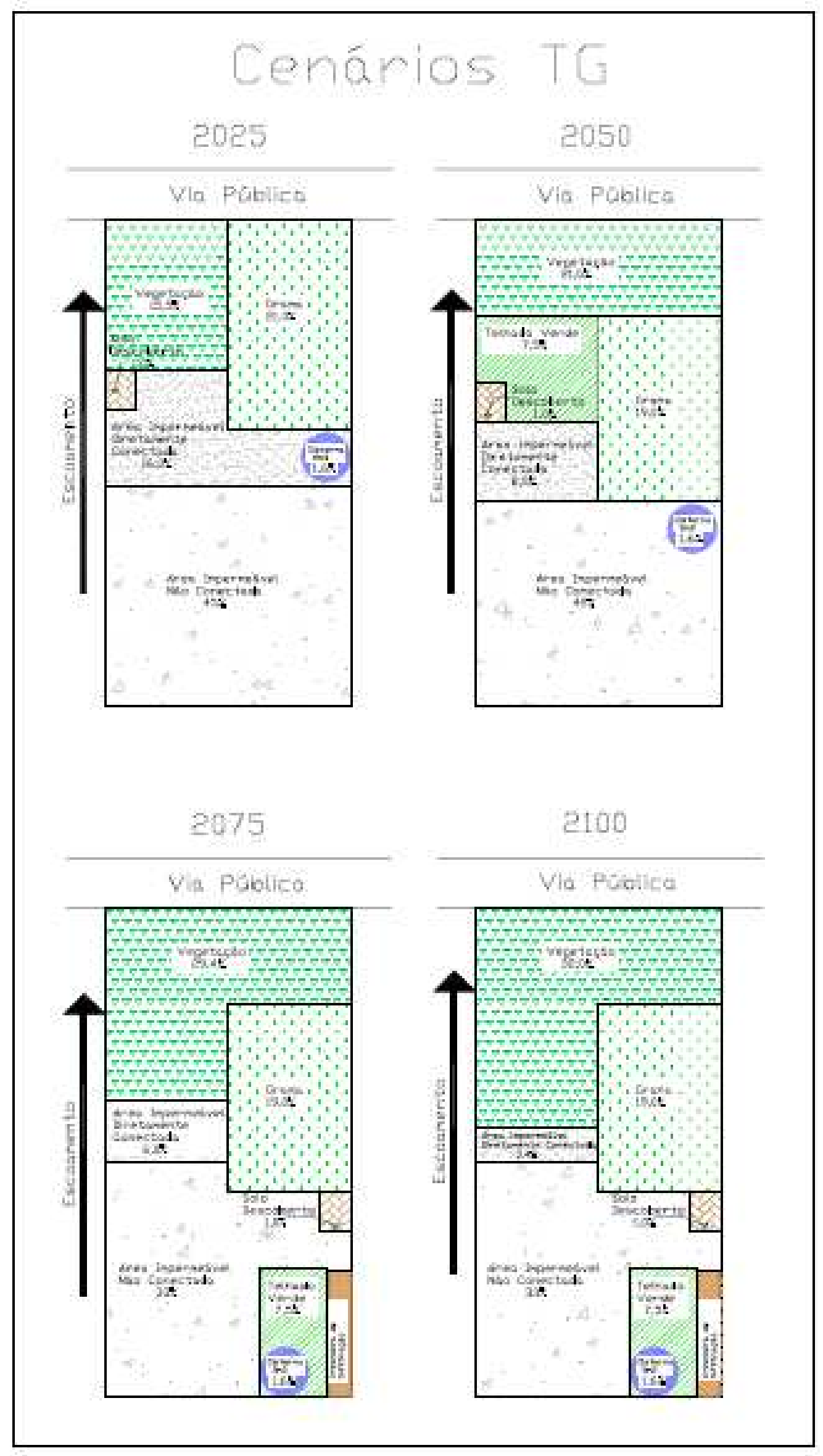




\subsection{Simulações dos Cenários}

\subsubsection{Escala Bacia Hidrográfica}

De maneira a atingir os objetivos propostos deste trabalho de pesquisa, os resultados das simulações dos cenários são apresentados em termos de curvas de permanência construídas a partir dos resultados das simulações.

O cenário de referência foi simulado para os mesmos eventos que os demais cenários para melhor compreensão das mudanças ocorridas em cada cenário futuro. O resultado desta simulação pode ser visualizado pela figura 61.

Ano Referência - 2000

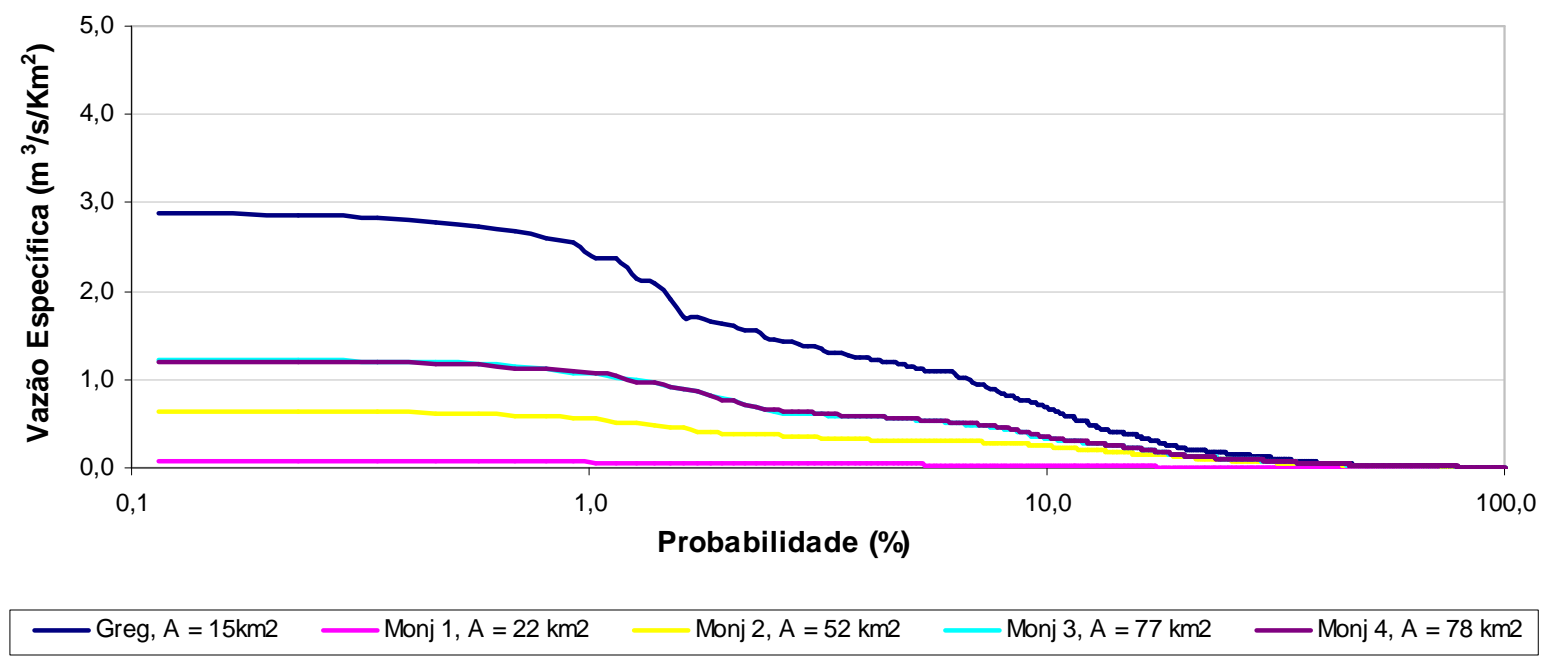

Figura 61: Curva de permanência de cheias para o ano de referência (2000).

Percebe-se pela figura supracitada maiores valores de vazão específica $\left(2,8 \mathrm{~m}^{3} / \mathrm{s} / \mathrm{km}^{2}\right)$ para a seção denominada "Greg" relacionada à sub-bacia do Gregório, com ponto analisado em frente ao mercado municipal. No entanto, é importante ressaltar que a esta vazão está vinculada a uma baixa probabilidade de ocorrência $(0,1 \%)$. Ao observarem-se as vazões relacionadas a uma maior probabilidade de ocorrência (10\%) nota-se uma diminuição das vazões, em todas as seções analisadas (menor que $1 \mathrm{~m}^{3} / \mathrm{s} / \mathrm{km}^{2}$ ). Mas, o importante a ser 
discutido é a ocorrência de baixas vazões para altas probabilidades e, além disso, a ocorrência de maiores vazões em um ponto crítico da área urbana de São Carlos localizada nas proximidades do Mercado Municipal (Bacia do Gregório).

\section{a) Global Orchestration}

Este cenário globalizado e reativo ao longo dos primeiros 50 anos sofre aumento acelerado do percentual urbano, com aumento da densidade populacional e, conseqüentemente realiza inúmeras transformações nos cursos d'água existentes. Desta forma, sofre consequiências graves com o aumento da probabilidade de ocorrências de maiores vazões principalmente em um ponto já crítico da cidade (Figura 62 e 63).

No entanto, a partir da constatação de que a política adotada neste cenário gera problemas, tenta-se reverter à situação, por meio de medidas como utilização de bacias de detenção e, principalmente pela diminuição da taxa de crescimento urbano. Assim, há uma considerável diminuição nos valores de vazão máxima, sobretudo no que se refere à seção localizada nas proximidades do mercado municipal (Figura 64 e 65).

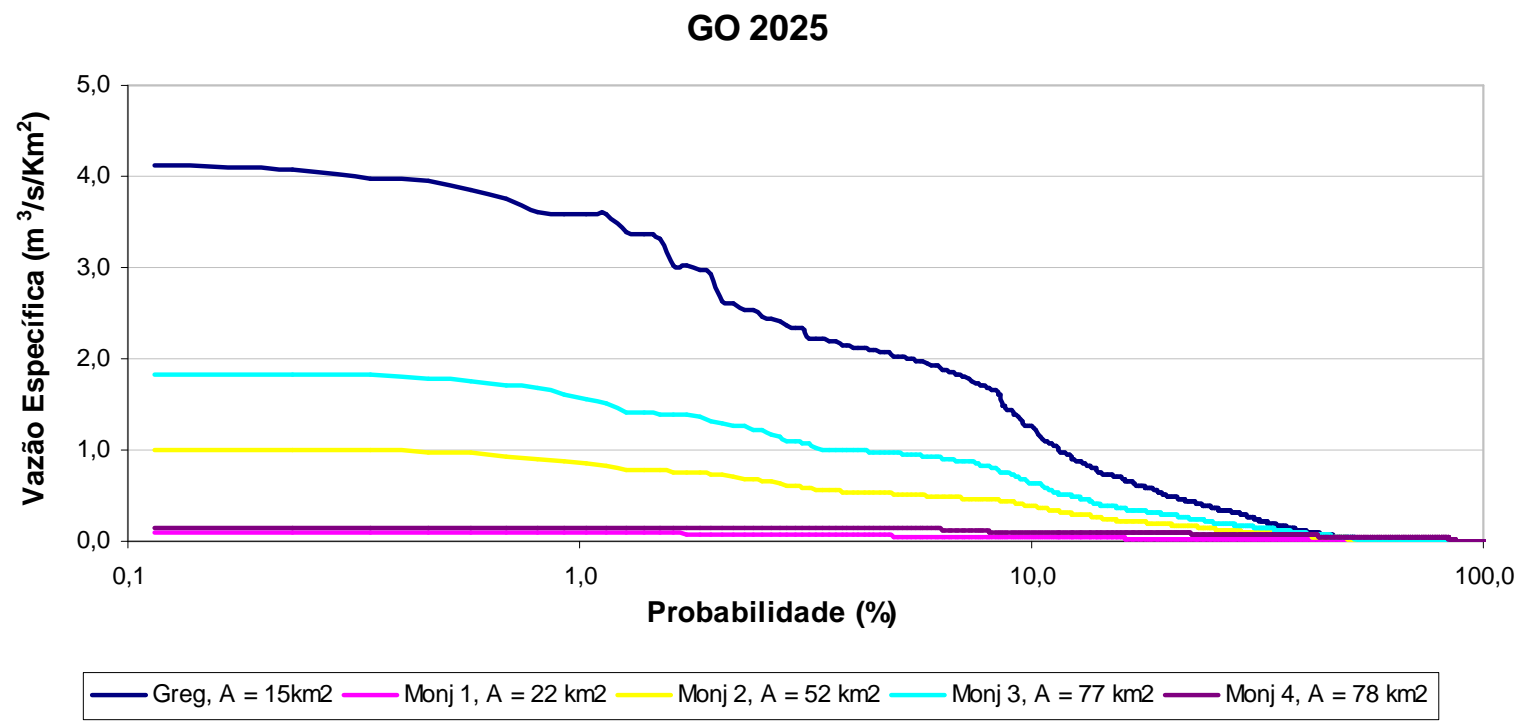

Figura 62: Curvas de permanência de cheias do cenário GO 2025. 


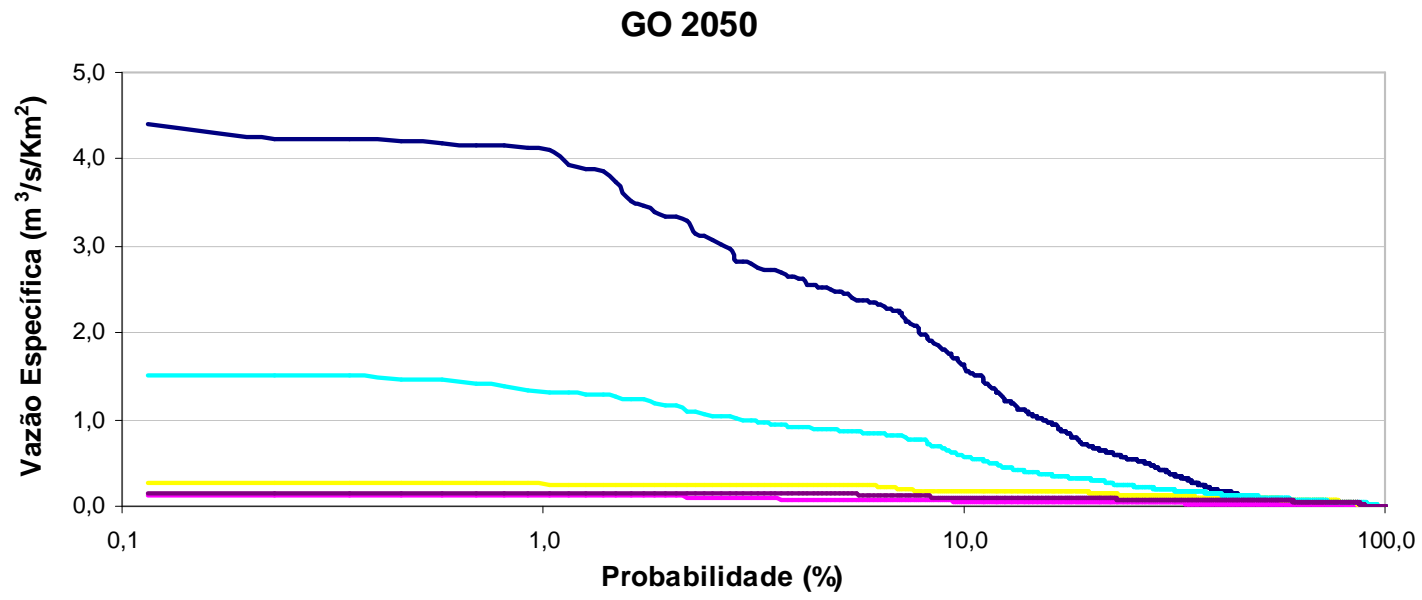

$\longrightarrow$ Greg, A = 15km2 Monj 1, A = $22 \mathrm{~km} 2 \longrightarrow$ Monj 2, A = $52 \mathrm{~km} 2-$ Monj 3, A = $77 \mathrm{~km} 2-$ Monj 4, A = 78 km2

Figura 63: Curvas de permanência de cheias do cenário GO 2050.

GO 2075

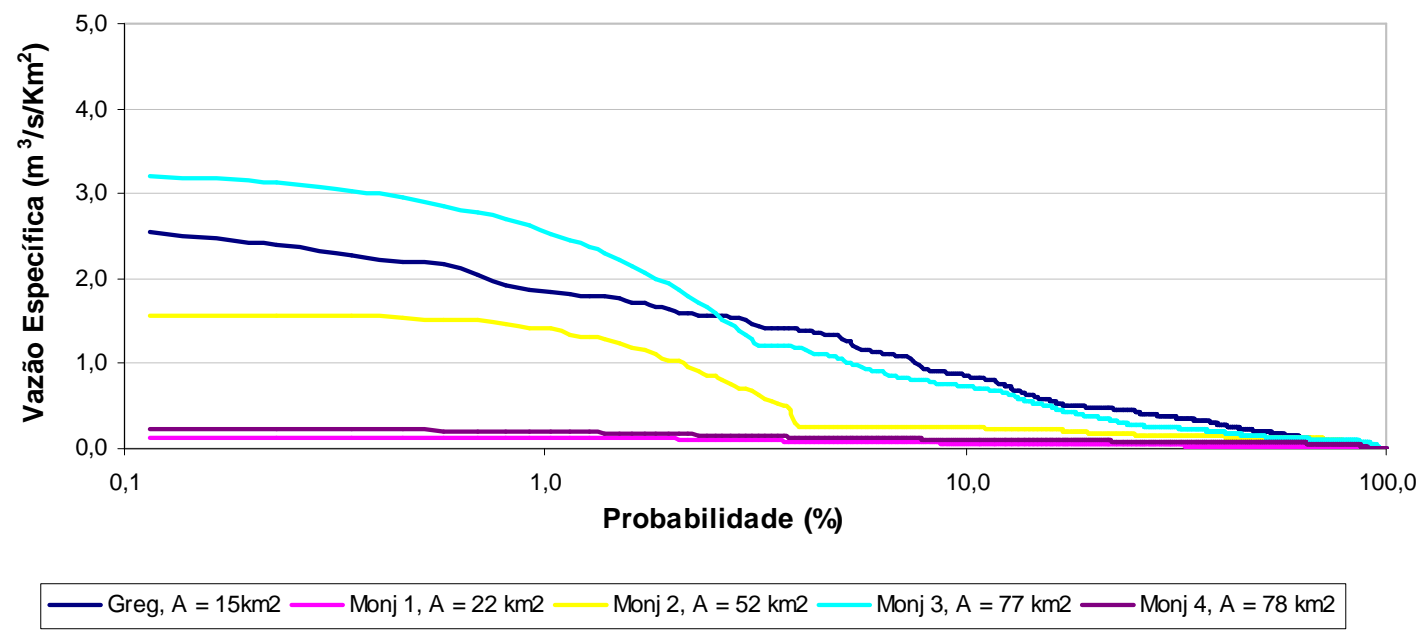

Figura 64: Curvas de permanência de cheias do cenário GO 2075.

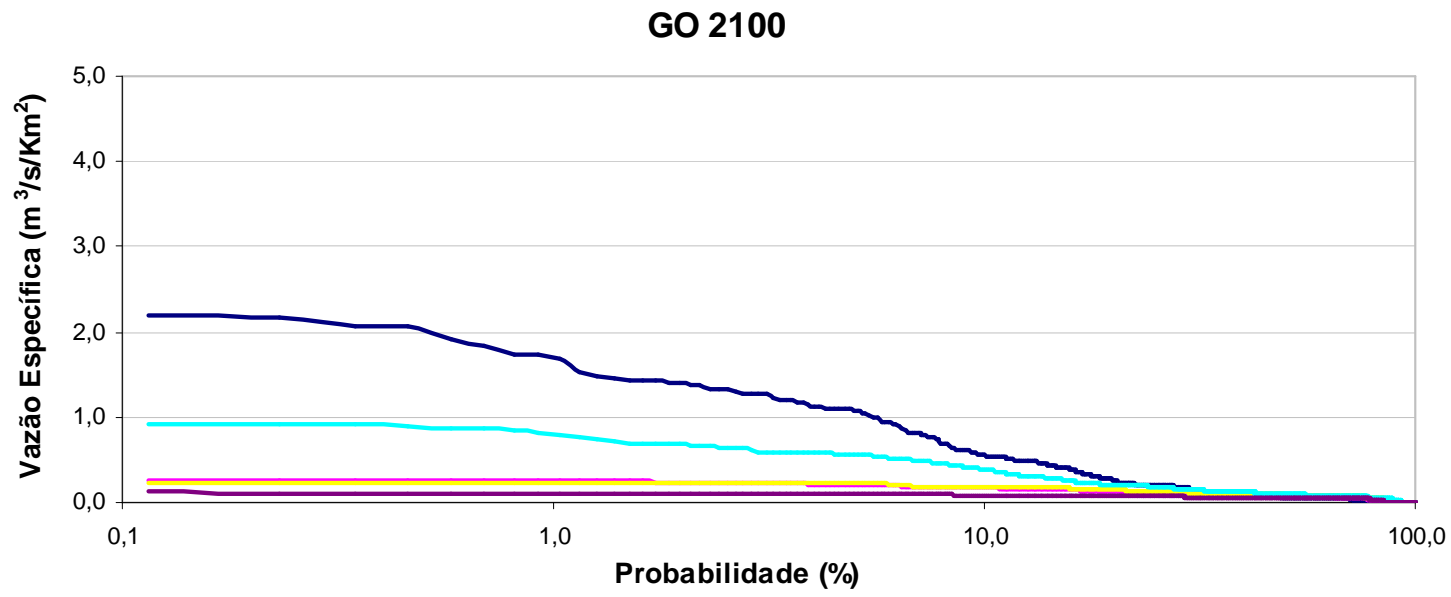

Greg, $A=15 \mathrm{~km} 2-$ Monj 1, A = $22 \mathrm{~km} 2-$ Monj 2, A = $52 \mathrm{~km} 2-$ Monj 3, A = $77 \mathrm{~km} 2 \longrightarrow$ Monj 4, A = 78 km2

Figura 65: Curvas de permanência de cheias do cenário GO 2100. 
b) Order from Strength

Como o cenário anterior este também é caracterizado por ser reativo no que diz respeito às questões dos ecossistemas, no entanto difere-se na linha de desenvolvimento, que para este é caracterizada pela regionalização, com avaliação segregada dos problemas e das soluções para tal.

Há neste cenário aumento do percentual de áreas urbanizadas, do potencial de escoamento, da declividade e da supressão e do tamponamento de rios e córregos gerando aumento de vazões ao longo de todos os anos em todas as seções analisadas. Como medida de mitigação há a utilização exagerada de bacias de detenção e o alargamento dos canais já construídos. Todas estas modificações podem ser observadas em termos de vazões pelas figuras 66 a 69.

OS 2025

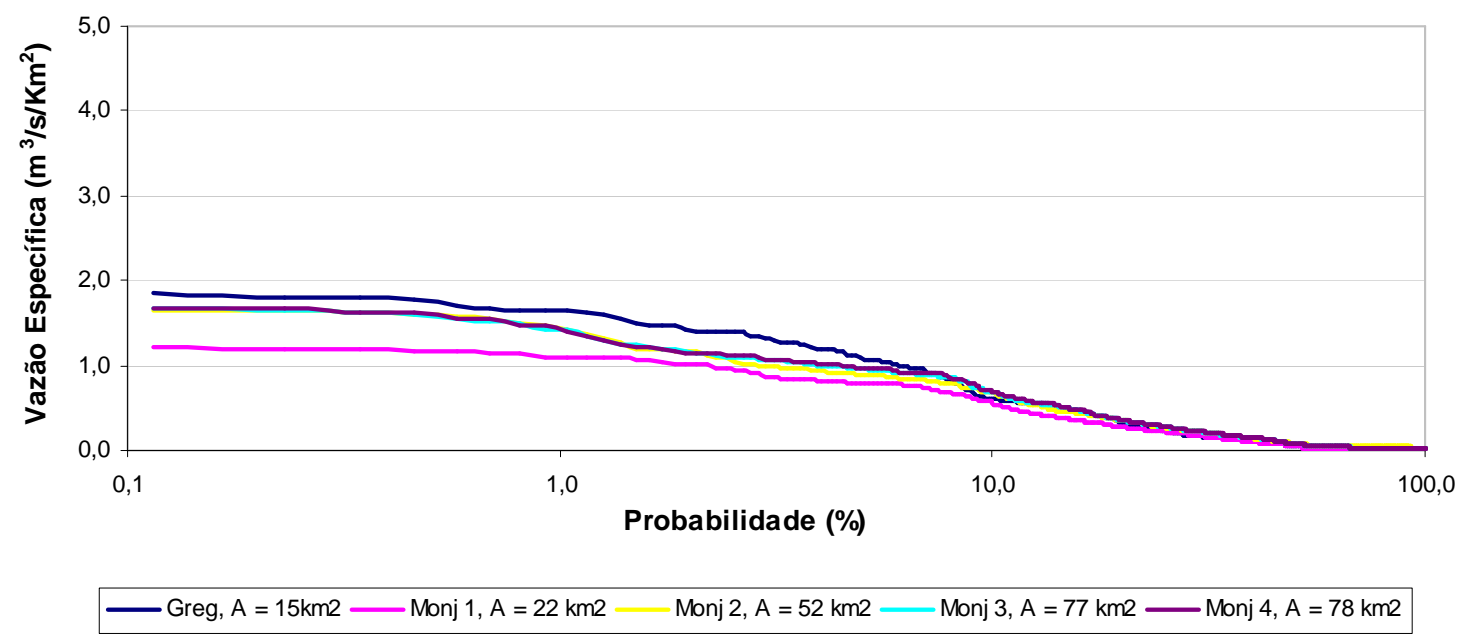

Figura 66: Curvas de permanência de cheias do cenário OS 2025. 
OS 2050

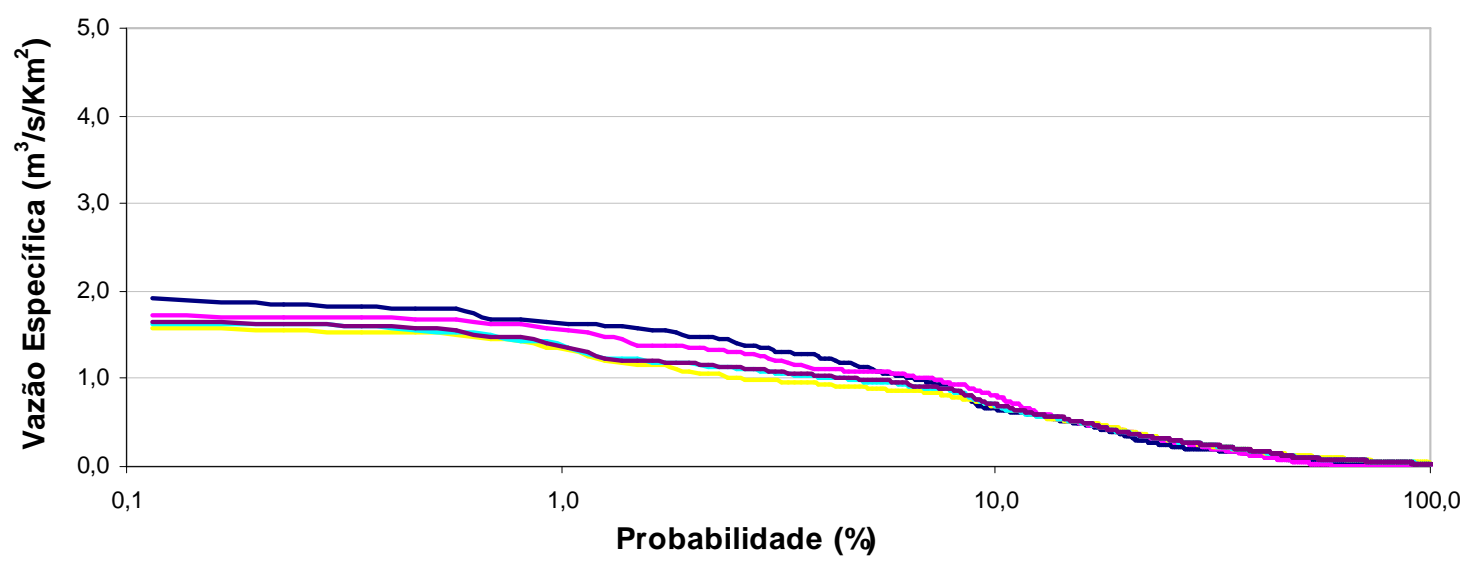

- Greg, $A=15 \mathrm{~km} 2-$ Monj 1, A = $22 \mathrm{~km} 2 \quad$ Monj 2, A = 52 km2 Monj 3, A = 77 km2 $\longrightarrow$ Monj 4, A = 78 km2

Figura 67: Curvas de permanência de cheias do cenário OS 2050.

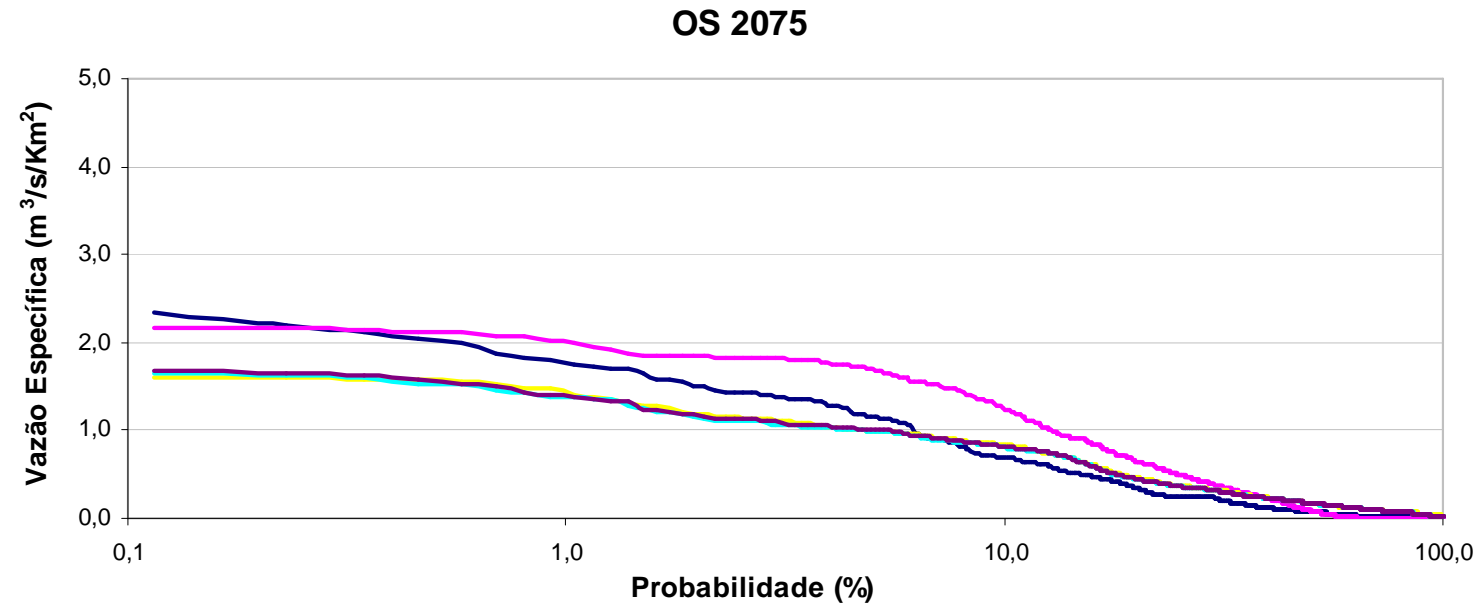

$\longrightarrow$ Greg, A = 15km2 Monj 1, A = 22 km2 Monj 2, A = 52 km2 Monj 3, A = 77 km2 - Monj 4, A = 78 km2

Figura 68: Curvas de permanência de cheias do cenário OS 2075.

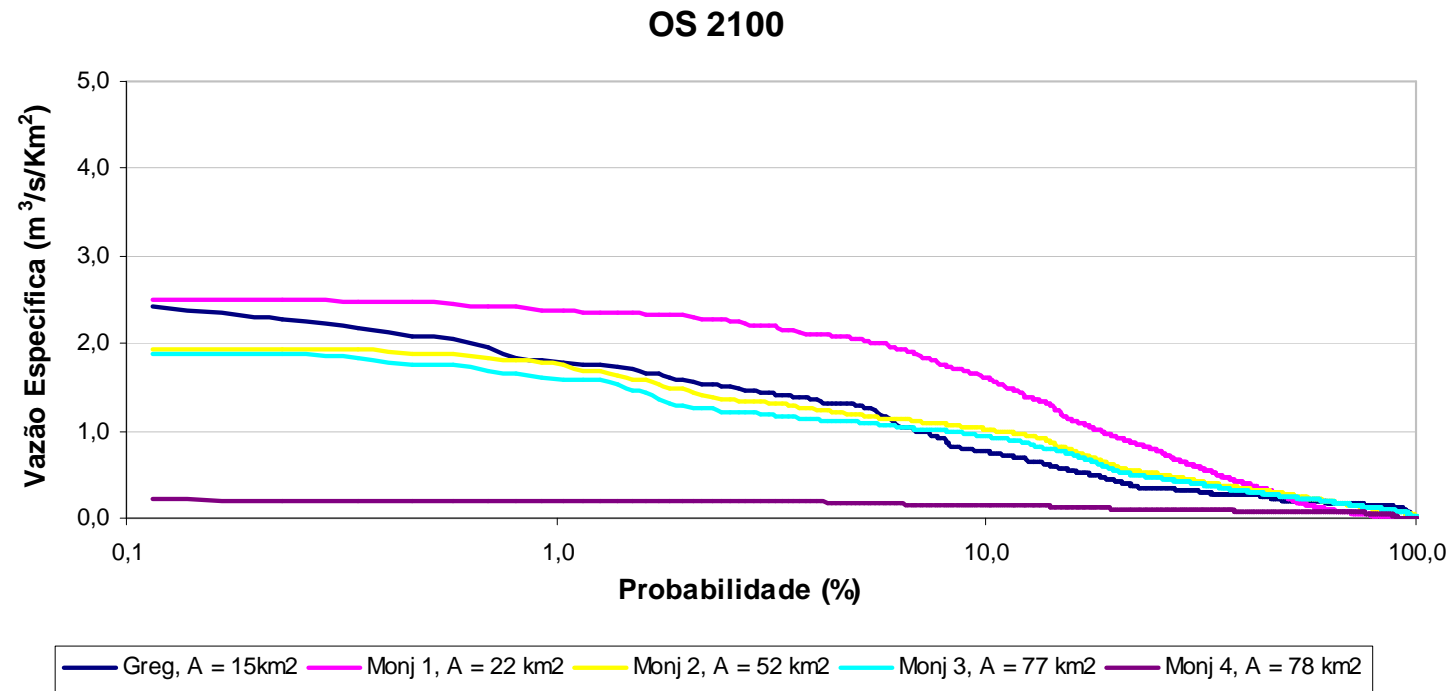

Figura 69: Curvas de permanência de cheias do cenário OS 2100. 


\section{c) Adapting Mosaic}

Este cenário é caracterizado pelo seu caráter pró-ativo em relação aos serviços dos ecossistemas e regionalizado em relação às políticas adotadas.

O foco da política de planejamento deste cenário é o atendimento das necessidades locais e, por não ser globalmente conectado não dispõe de informações importantes para resolução de seus problemas. Desta forma, embora tenha preocupação com relação a utilização dos serviços do ecossistemas, suas medidas não são tão eficientes quanto aquelas adotadas pelos cenários reativos prova disto são as altas vazões encontradas neste cenários (Figuras 70 a 73). O comportamento das vazões das seções "Greg” e "Monj 3" deste cenários assemelham-se ao cenário GO 2025 esta peculiaridade ocorre possivelmente devido ao percentual de área urbanizada que se assemelha em ambos cenários, outro fator a ser considerado é a utilização de uma bacia de detenção na parte alta do curso principal do rio Monjolinho. É provável que as demais seções (“Monj 1", “Monj 2", "Monj 4”) tivessem o mesmo comportamento que as anteriores, não fosse a utilização de uma bacia de detenção entre as seções "Monj 3”, "Monj 4” no cenário GO 2025.

Uma limitação importante a ser considerada nas simulações deste cenário é a impossibilidade de avaliação da atenuação destas cheias por meio das inúmeras bacias de infiltração criadas neste cenário. O modelo hidrológico - hidráulico, bem como o método utilizado dispõem somente de uma ferramenta que pode ser caracterizada por uma "bacia de detenção”. Desta forma, a avaliação deste cenário em si torna-se prejudicada.

O aumento da sinuosidade e da rugosidade e a diminuição da declividade podem ter interferido na diminuição das vazões das seções "Monj 2", "Monj 3", "Monj 4" a partir de 2025. 


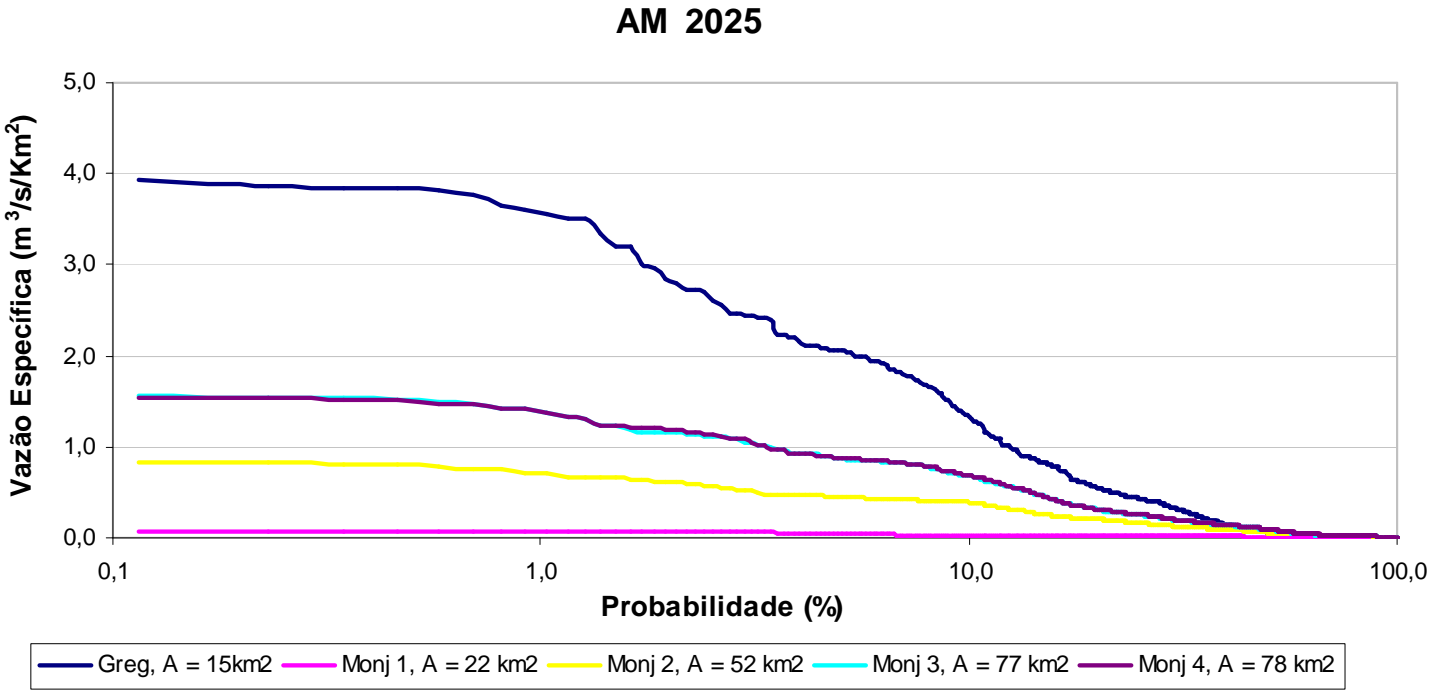

Figura 70: Curvas de permanência de cheias do cenário AM 2025.

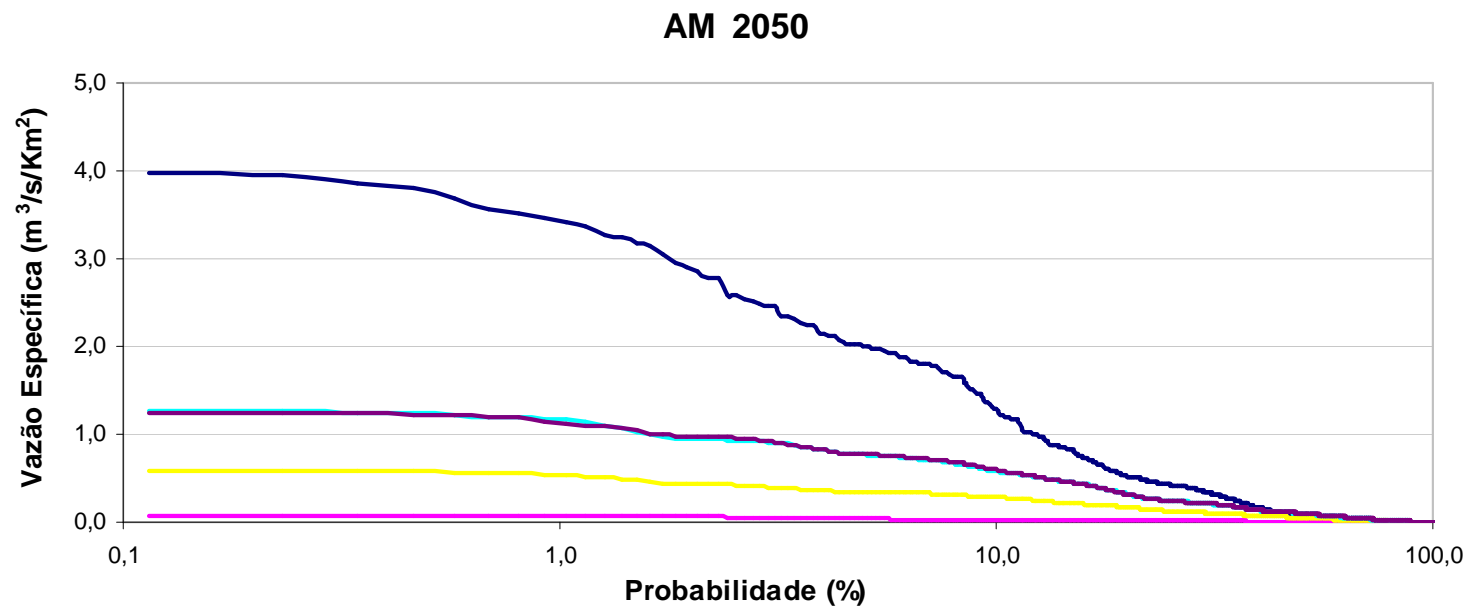

Greg, A = 15km2 Monj 1, A = $22 \mathrm{~km} 2 \quad$ Monj 2, A = 52 km2 Monj 3, A = 77 km2 Monj 4, A = 78 km2

Figura 71: Curvas de permanência de cheias do cenário AM 2050.

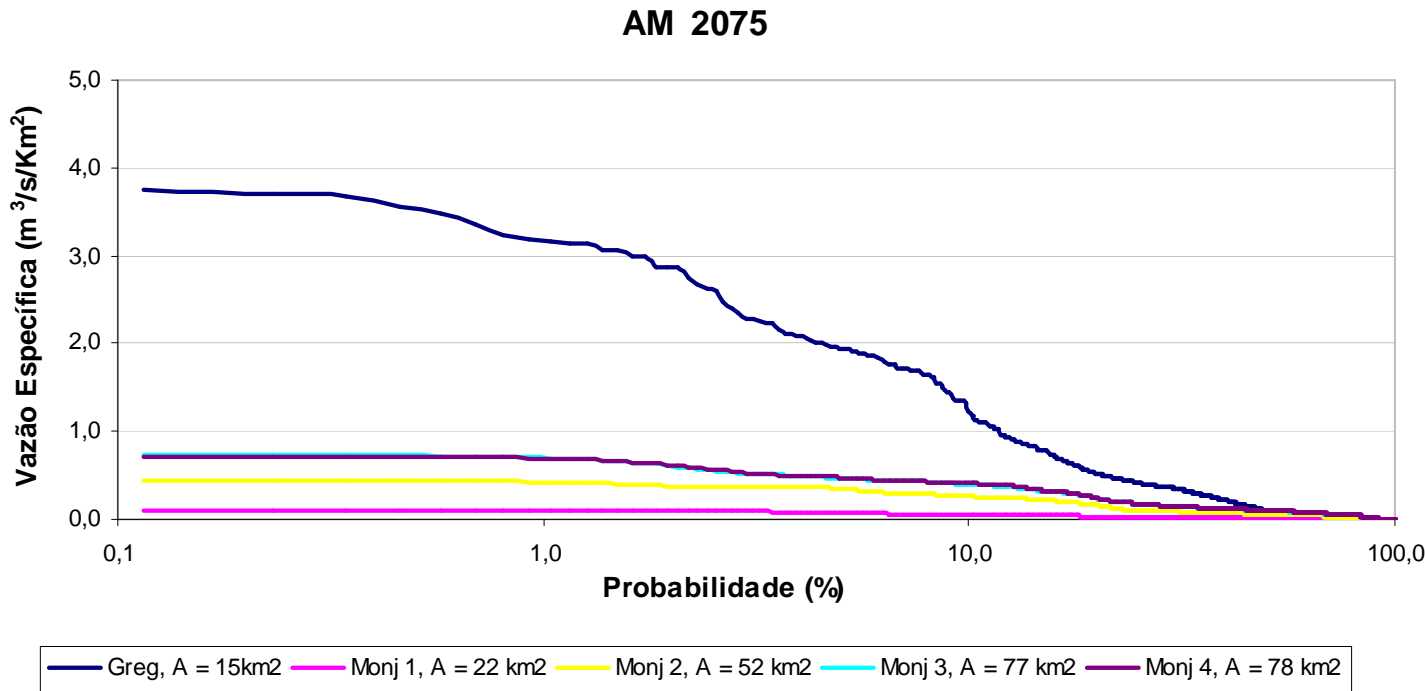

Figura 72: Curvas de permanência de cheias do cenário AM 2075. 


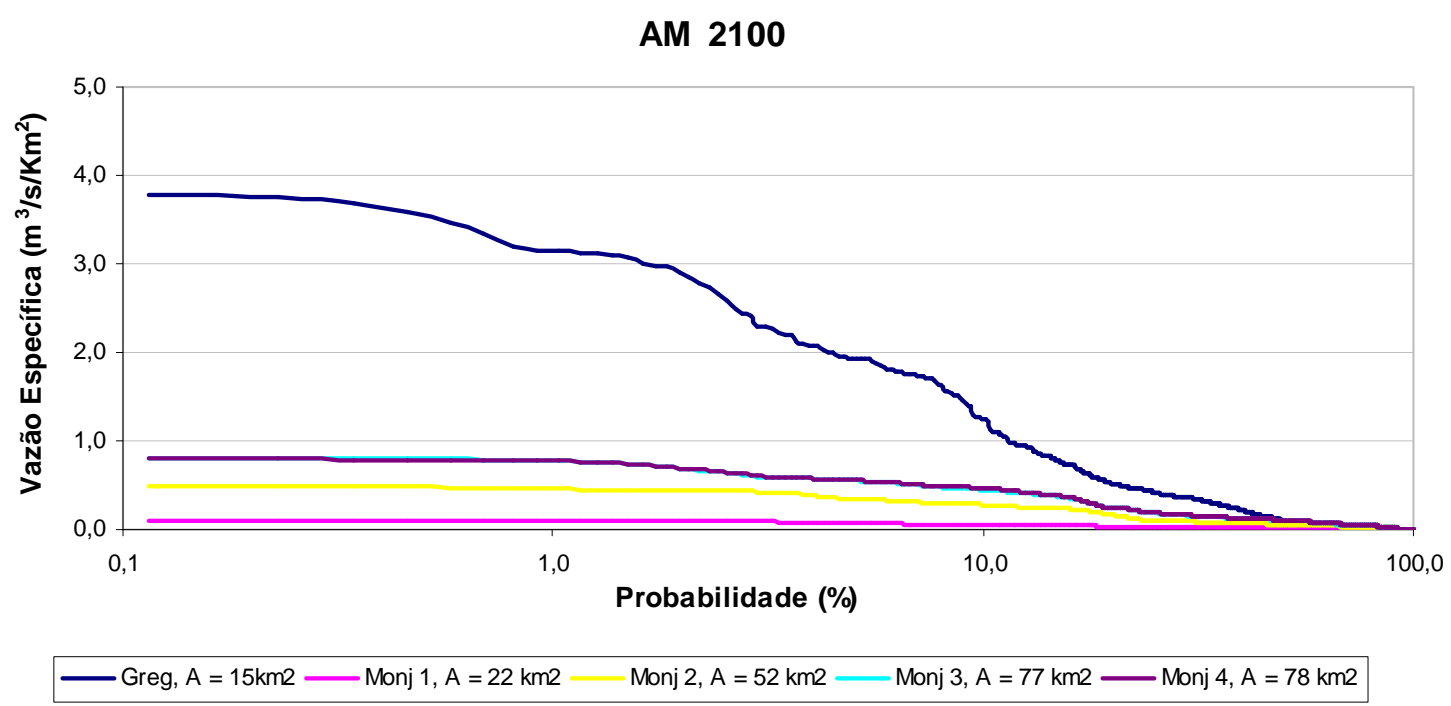

Figura 73: Curvas de permanência de cheias do cenário AM 2100.

\section{d) TechnoGarden}

TechnoGarden é um cenário pró-ativo e globalmente conectado. Considera questões ambientais, com a preservação de mananciais e manutenção da qualidade dos cursos d'água, com disponibilidade de obter informações detalhadas sobre inovações tecnológicas, entre outras, com baixo crescimento demográfico e baixo potencial de escoamento, é a priori o melhor cenário. No entanto, ressalta-se o mesmo problema descrito para o cenário AM, com avaliação prejudicada, devido à limitação do modelo e do método utilizado no que se refere ao processo de infiltração.

O alargamento dos rios e córregos juntamente com suas planícies de inundação é o principal fator para redução das vazões máximas em todas as seções analisadas. Neste cenário as planícies de inundação são preservadas e controladas ao longo do tempo, nos primeiros anos há alargamento ao longo do rio principal da bacia do Monjolinho e, a partir de 2075 os rios secundários. Este cenário é o único a apresentar vazões, com 10\% de probabilidade, menores que $1 \mathrm{~m}^{3} / \mathrm{s} / \mathrm{km}^{2}$ para todas as seções em todos os anos de estudo (Figura 74 a 77 ). 
TG 2025

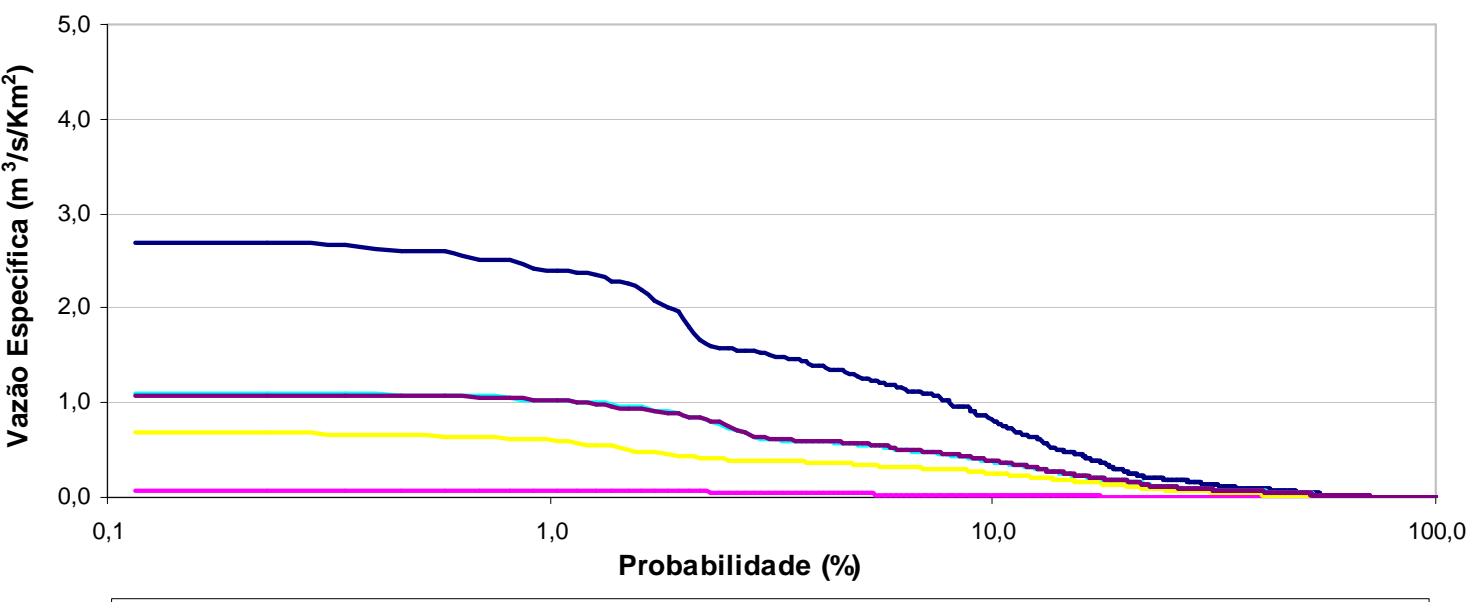

Greg, A = 15km2 Monj 1, A = $22 \mathrm{~km} 2-$ Monj 2, A = $52 \mathrm{~km} 2 \longrightarrow$ Monj 3, A = $77 \mathrm{~km} 2-$ Monj 4, A = $78 \mathrm{~km} 2$

Figura 74: Curvas de permanência de cheias do cenário TG 2025.

TG 2050

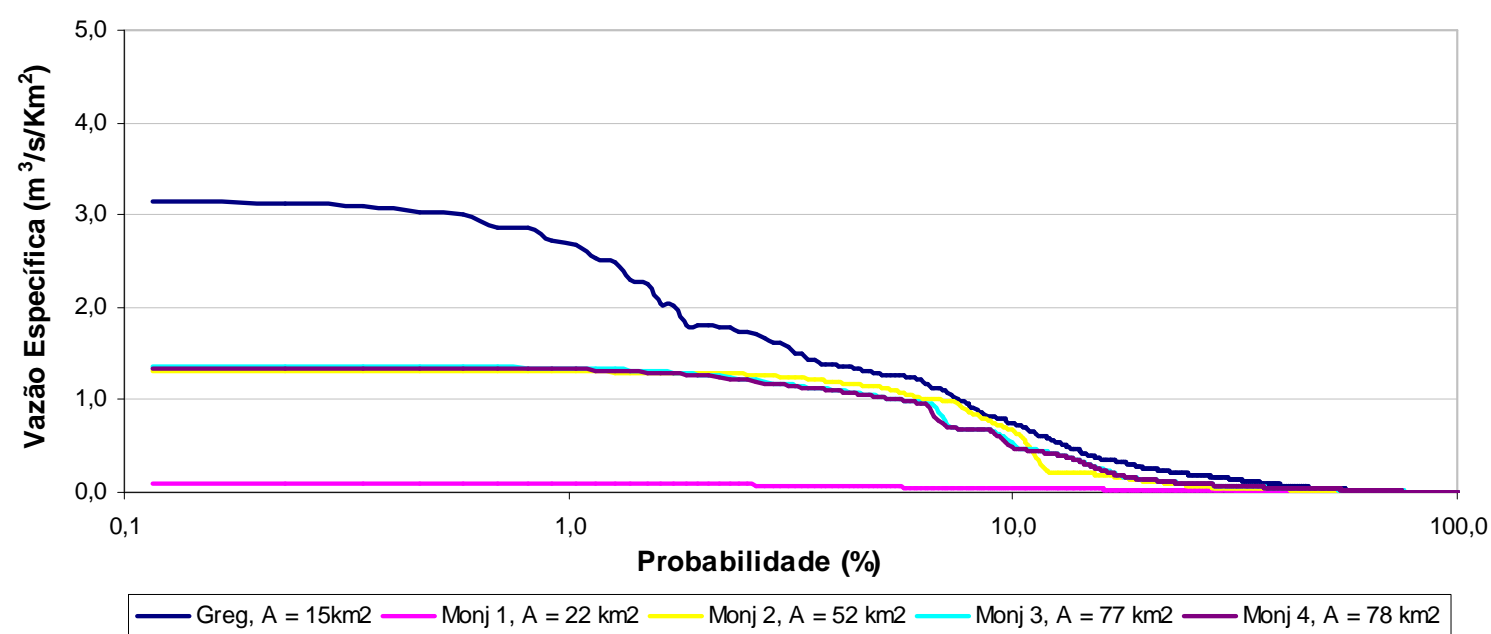

Figura 75: Curvas de permanência de cheias do cenário TG 2050.

TG 2075

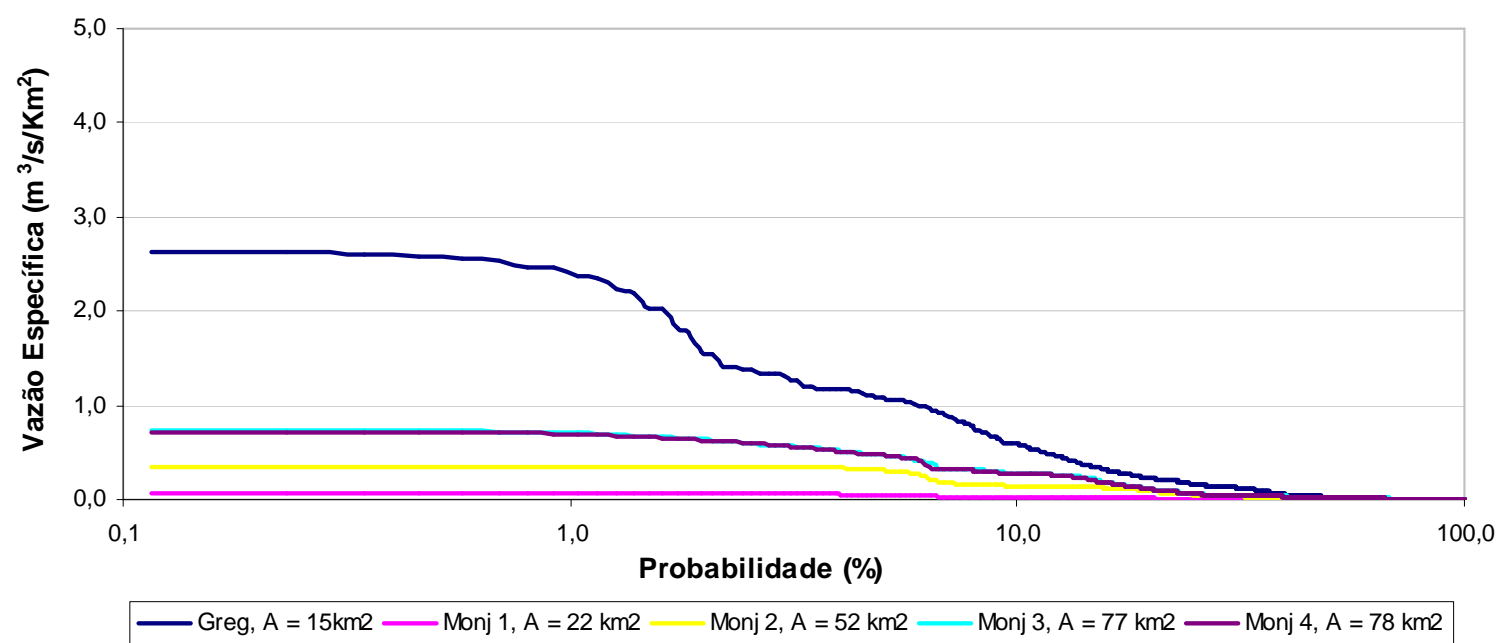

Figura 76: Curvas de permanência de cheias do cenário TG 2075. 
TG 2100

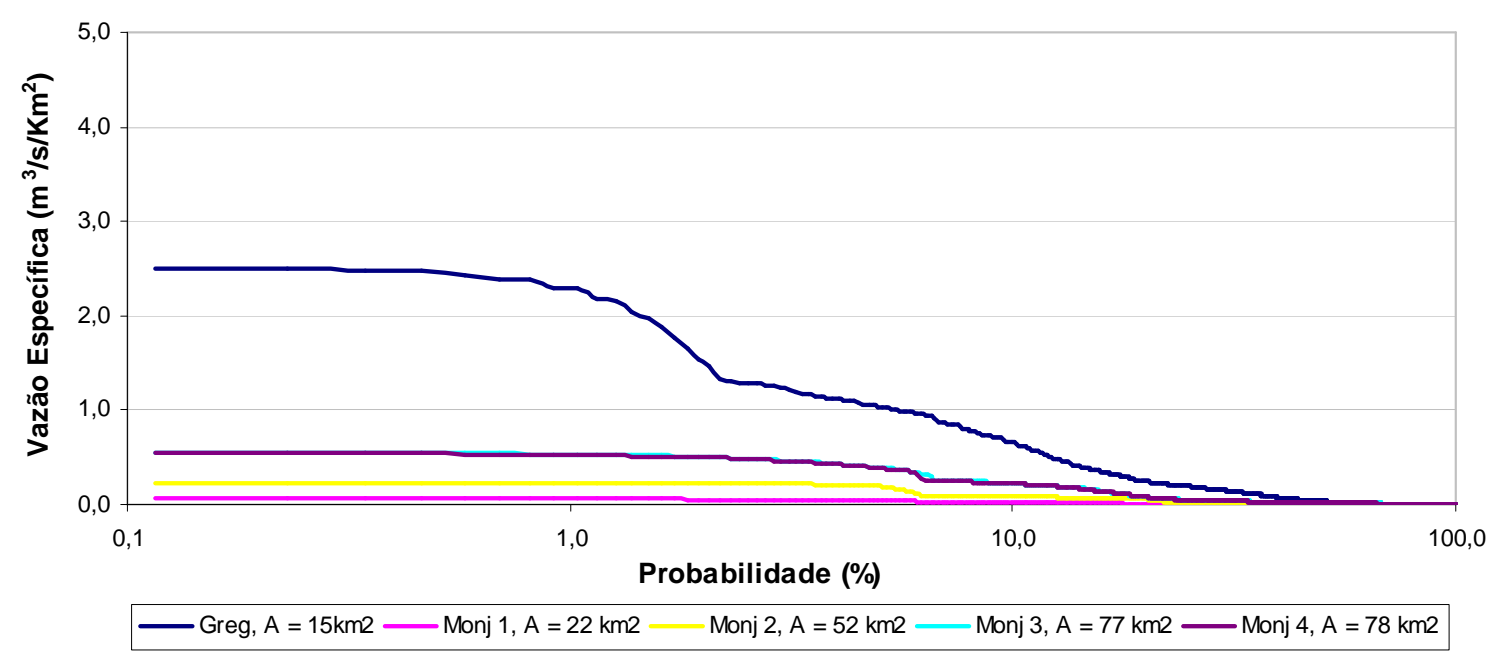

Figura 77: Curvas de permanência de cheias do cenário TG 2100.

e) Bacia do Córrego Gregório - Avaliação

Por sua importância para a área urbana de São Carlos, já que é uma região de intensa atividade comercial e, sobretudo, por ser esta a região que mais sofre as conseqüências das cheias urbanas, uma análise em separado é realizada.

Os valores médios de $\mathrm{CN}$ estimados em todos os cenários são apresentados na figura 78. Podem-se perceber maiores valores de $\mathrm{CN}$ médios para o cenário OS e menores para o cenário TG.

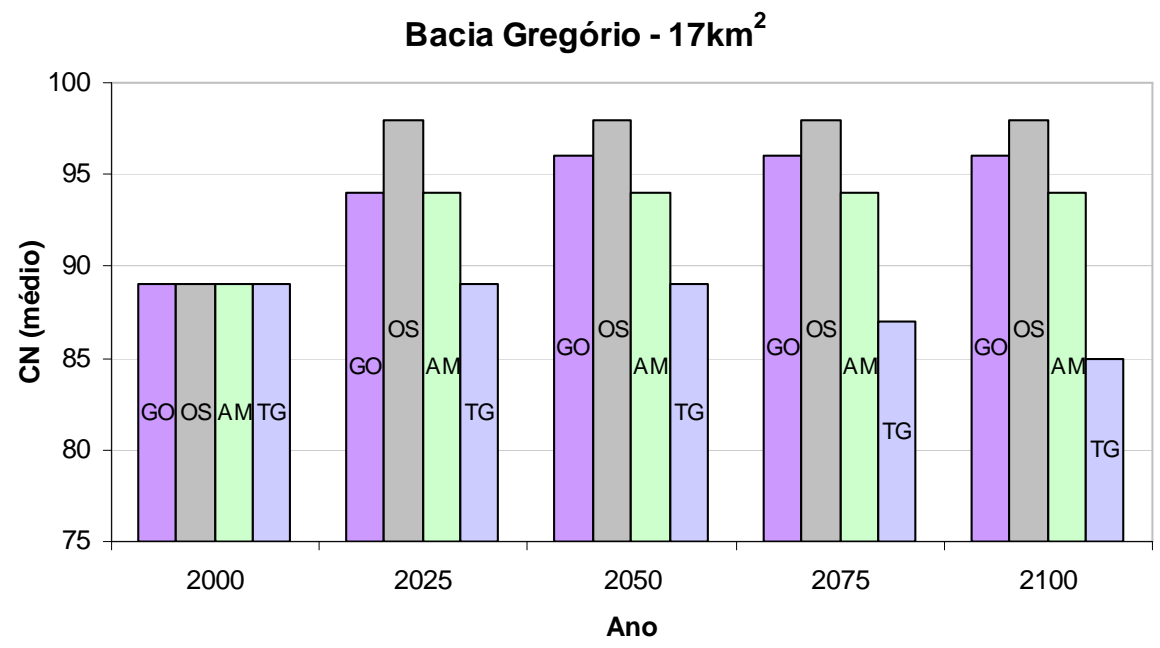

Figura 78: Relação entre os CN médios da bacia do Gregório em cada cenário. 
Na figura 79 é apresentada a relação entre CN médio de cada cenário e a vazão com probabilidade de ocorrência de $10 \%$. A figura está dividida em quatro quadrantes (A, B, C e D), e a cada um pode-se relacionar um passivo ambiental ou um benefício ambiental que o cenário confere quando comparado ao cenário de referência (ano 2000). Para o quadrante A, há um passivo relacionado às vazões com $10 \%$ de ocorrência e um benefício relacionado aos baixos valores de $\mathrm{CN}$ médio quando comparado com o ano de referência. Para o quadrante $\mathrm{B}$, há um passivo relacionado às vazões com $10 \%$ de ocorrência e um passivo relacionado aos altos valores de $\mathrm{CN}$ médio. Para o quadrante $\mathrm{C}$, há um benefício relacionado às vazões com $10 \%$ de ocorrência e um benefício relacionado aos baixos valores de CN médio. Já para o quadrante $\mathrm{D}$, há um benefício relacionado às vazões com $10 \%$ de ocorrência e um passivo relacionado aos baixos valores de $\mathrm{CN}$ médio. A partir desta análise restrita, pode-se observar que o único cenário possui benefícios ambientais para os dois fatores analisados (quadrante C) é TechnoGarden. AM apesar de ser um cenário pró-ativo insere-se no quadrante $\mathrm{C}$, é o único que ao longo do tempo permanece sempre no mesmo quadrante, sempre com passivos ambientais, com altos valores de $\mathrm{CN}$ e altos valores de vazão específica com $10 \%$ de probabilidade de ocorrência. Dentre os reativos, OS apresenta-se com altos valores de CN e baixos valores de e vazões com $10 \%$ de ocorrência, fato este decorrente do intenso processo de ocupação urbana ocorrido na bacia como um todo aliado a utilização de bacias de detenção de grande capacidade. 


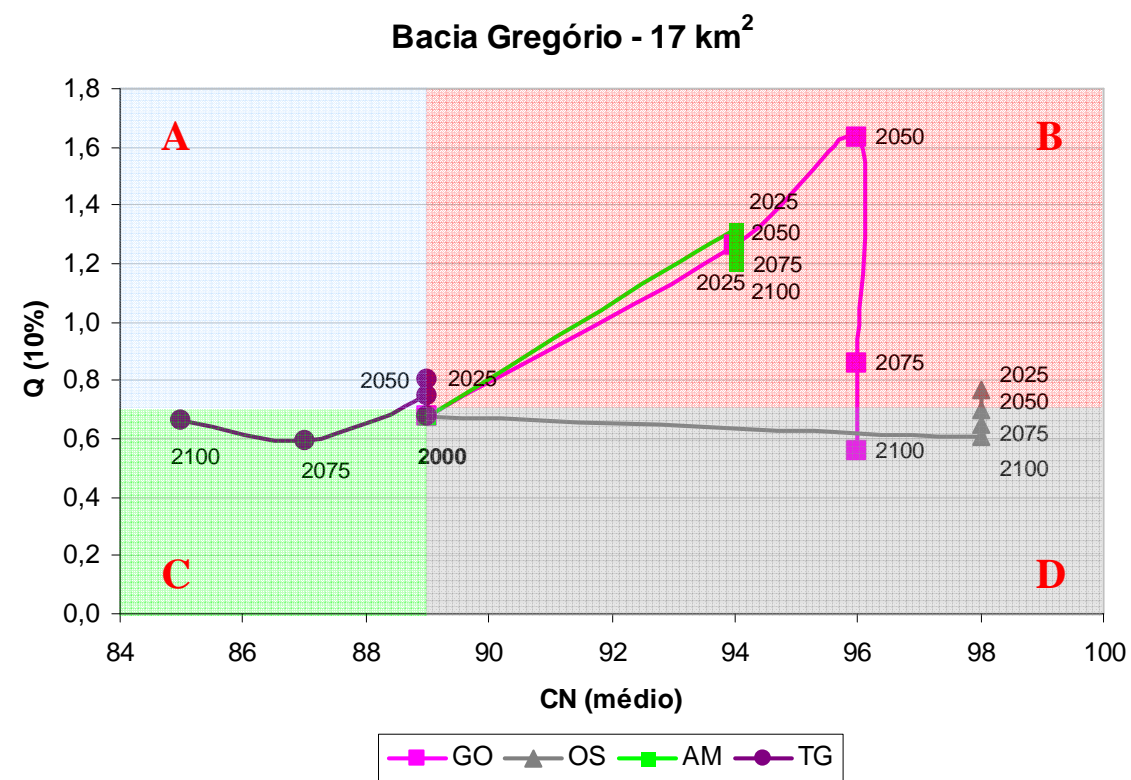

Figura 79: Avaliação dos benefícios e dos passivos de cada cenário para a bacia do Gregório.

\subsubsection{Escala de Lote}

As simulações referentes ao lotes residências urbanos foram realizadas com base no método racional para estimativa da vazão máxima instantânea a qual por sua vez é dependente do armazenamento potencial de água no lote (S), dado em função de CN. Desta forma, apresenta-se nas figuras 80 e 81 as variações de $\mathrm{CN}$ e S, respectivamente. Como é possível perceber os cenários pró-ativos (AM e TG) possuem menores valores de $\mathrm{CN}$ e, conseqüentemente maiores valores de potencial de armazenamento de água no lote, já os cenários reativos (GO e OS), apresentam comportamentos opostos. 


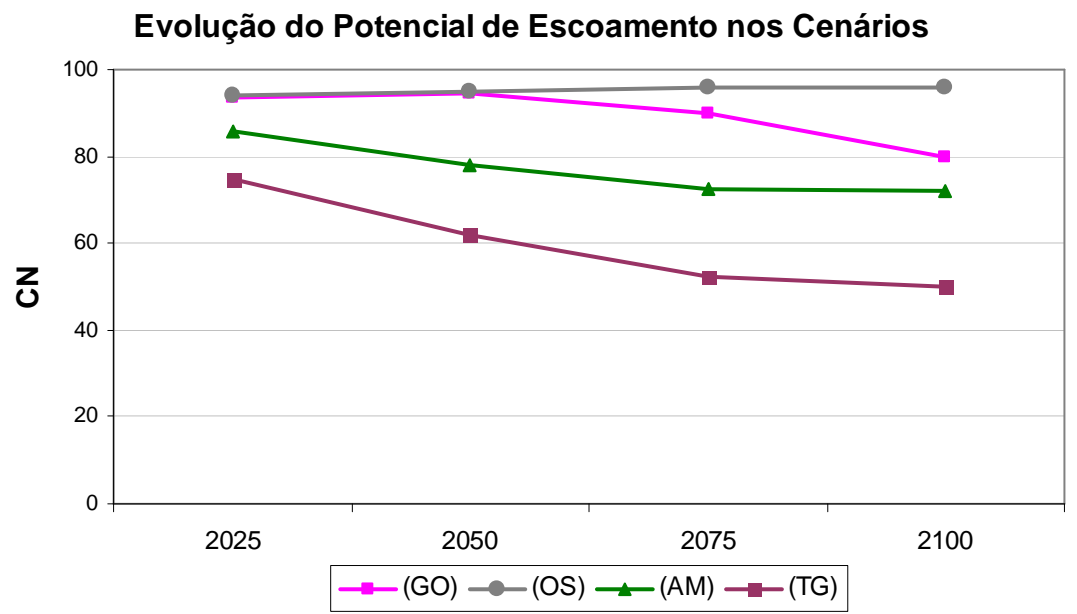

Figura 80: Evolução do parâmetro $\mathrm{CN}$ para os lotes urbanos.

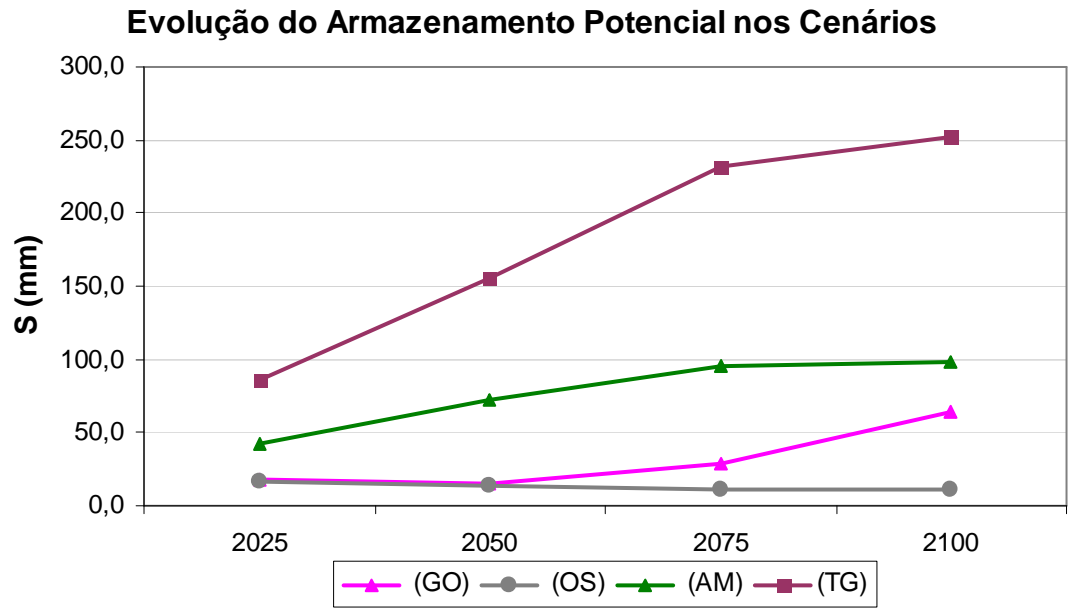

Figura 81: Evolução do armazenamento potencial de água no lote para os cenários.

No que se refere à estimativa do incentivo ambiental, o mesmo foi avaliado para a parcela de montante da bacia do Córrego Gregório com exutório localizado na região do mercado municipal (seção Greg $\mathrm{A}=15 \mathrm{~km}^{2}$ ). Para tal avaliação fez-se necessário o agrupamento de dados de vazão máxima instantânea, vazão com $10 \%$ de probabilidade (seção "Greg”) e área construída no lote - dada pela soma da área impermeável com área impermeável diretamente conectada -. Os resultados estão descritos na tabela 27. 
Tabela 27: Parâmetros utilizados na estimativa do IPTU com incentivo ambiental.

\begin{tabular}{lccccc}
\hline \multicolumn{1}{c}{ Parâmetro } & Cenário & GO & OS & AM & TG \\
\hline \multirow{2}{*}{ Vazão Máxima } & 2025 & 1,432 & 1,560 & 0,382 & 0,002 \\
Instantânea (1/s) & 2050 & 1,642 & 1,782 & 0,039 & 0,000 \\
& 2075 & 0,777 & 1,991 & 0,003 & 0,000 \\
& 2100 & 0,089 & 2,003 & 0,005 & 0,000 \\
\hline Vazão com 10\% de & 2025 & 1,26 & 0,61 & 1,32 & 0,80 \\
probabilidade de & 2050 & 1,63 & 0,65 & 1,29 & 0,75 \\
ocorrência & 2075 & 0,86 & 0,70 & 1,20 & 0,59 \\
$\left(\mathrm{~m}^{3} / \mathrm{s} / \mathrm{km}^{2}\right)$ & 2100 & 0,56 & 0,77 & 1,24 & 0,66 \\
\hline \multirow{3}{*}{ Área edificada } & 2025 & 128,0 & 136,0 & 122,0 & 122,0 \\
$\left(\mathrm{~km}^{2}\right)$ & 2050 & 140,0 & 146,0 & 94,2 & 100,0 \\
& 2075 & 136,8 & 150,0 & 87,0 & 78,0 \\
& 2100 & 136,8 & 150,0 & 81,0 & 72,8 \\
\hline
\end{tabular}

De posse destes dados e com base na Planta Genérica de Valores de São Carlos foram estimados IPTU's para cada cenário estudado. A partir da metodologia adotada neste trabalho os incentivos ambientais foram calculados e, posteriormente acoplados ao valor do IPTU. Os resultados são apresentados pelas figuras 82 e 83 . Adotou-se um lote tipo de $200 \mathrm{~m}^{2}$, com 4 habitantes cada.

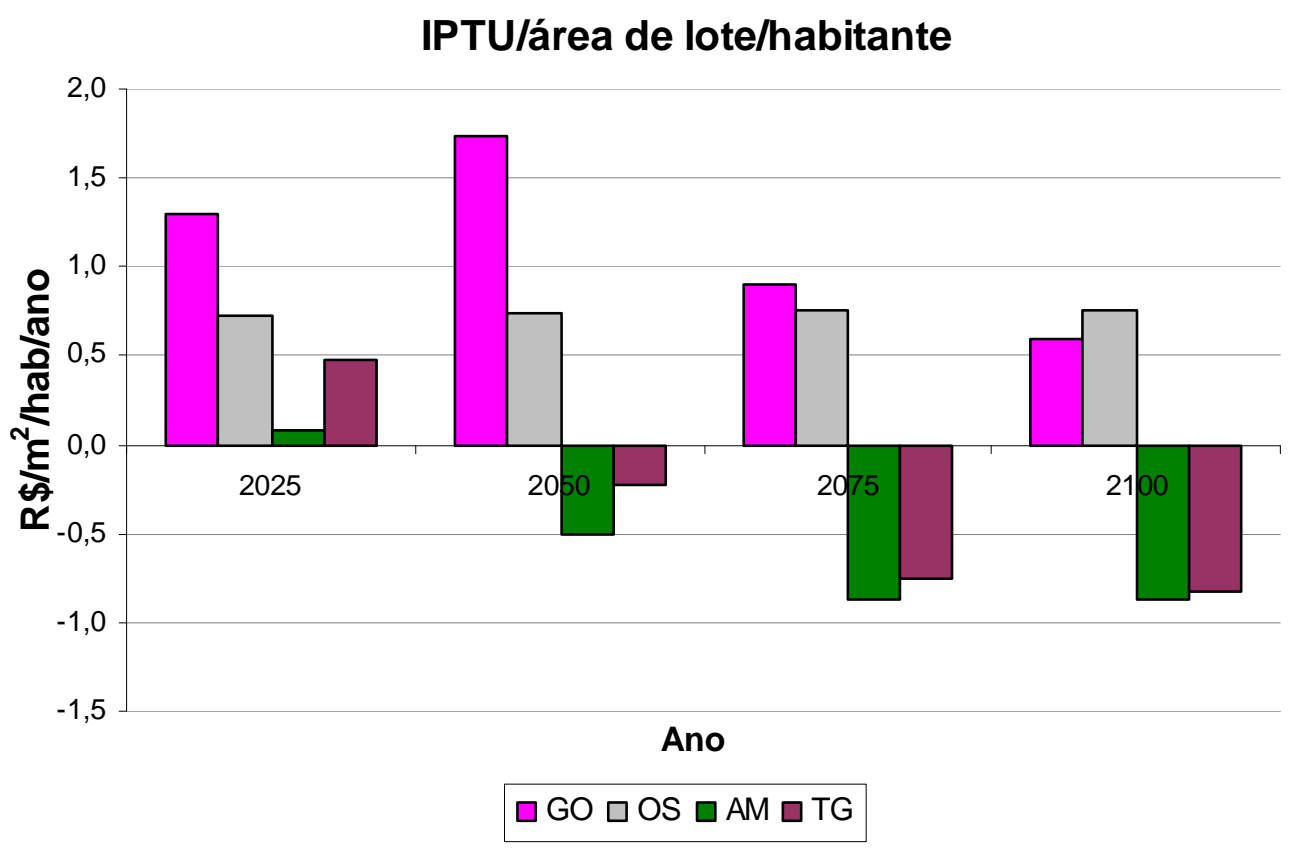

Figura 82: Valores de IPTU por área de lote por habitante para cada cenário. 


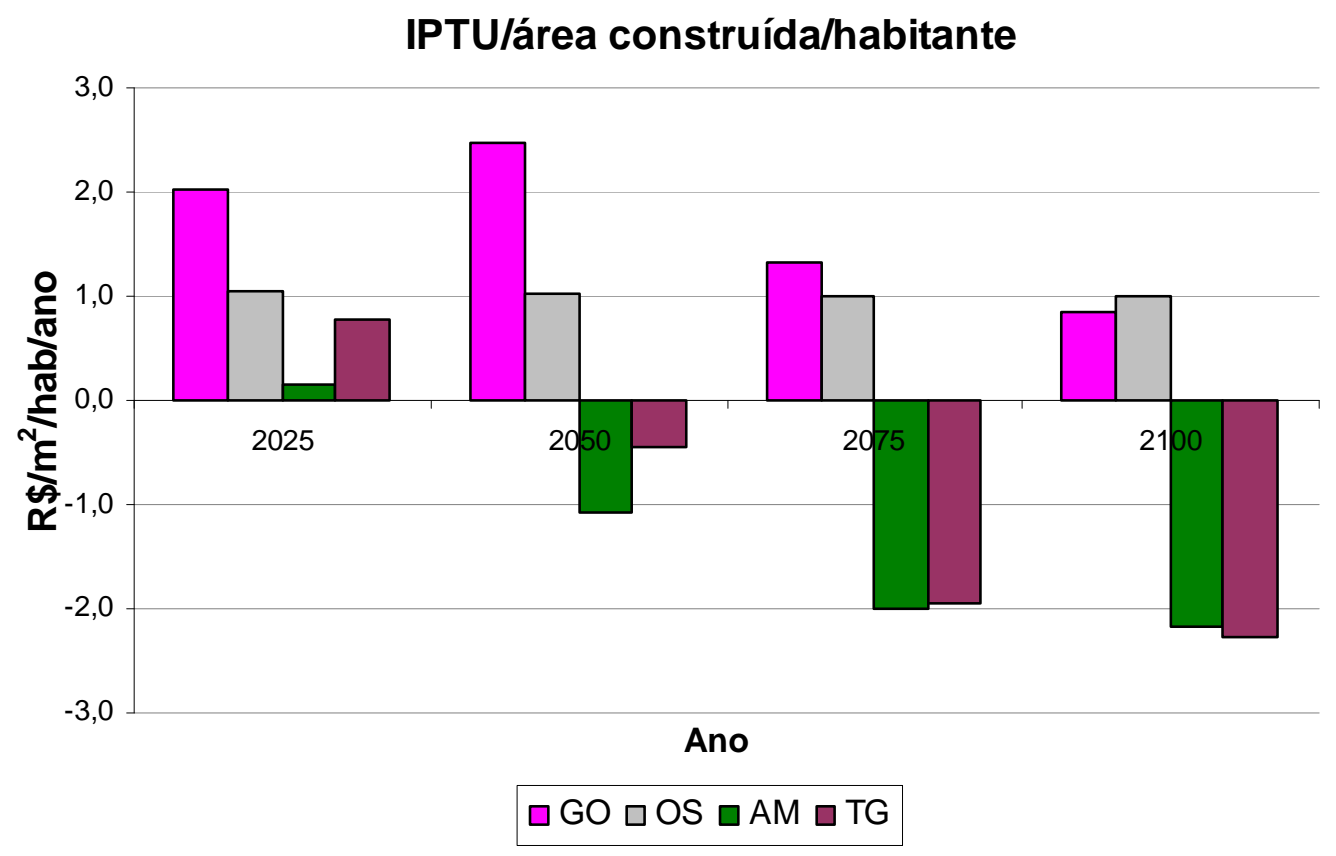

Figura 83: Valores de IPTU por área construída por habitante para cada cenário.

Os valores de IPTU com aplicação de incentivos ambientais sofrem aumento no cenário reativo GO, ou seja, há uma penalização por parte do poder público sobre o cidadão que contribui de maneira negativa para os serviços ambientais, com agravamento das inundações na bacia hidrográfica. No entanto, a partir de 2075 para o cenário GO há uma diminuição no valor do IPTU devido a utilização de cisterna no lote, essa medida contribui para a mitigação de cheias na bacia. Já o cenário OS não adota a política de incentivos ambientais, assim ao longo dos anos o valor do imposto permanece quase constante, variando apenas em função da área edificada. Este cenário pode ser entendido com o cenário atual, onde ninguém recebe um incentivo por contribuir para melhoria da drenagem urbana, mas também não recebe qualquer punição por contribuir para o aumento das cheias.

Já para o cenário AM nos primeiro 25 anos já há uma melhora no aumento do potencial de armazenamento, entretanto não é um aumento suficiente para que o contribuinte deixe de pagar o imposto e comece a receber incentivos. A partir desta data, no entanto, o cidadão passa a receber incentivo por contribuir com a minimização de cheias e inundações. 
O cenário TG apresenta comportamento semelhante ao do AM, no entanto sem atingir valores tão altos de incentivo quanto este, isto ocorre possivelmente pela componente relacionada a vazão com $10 \%$ de probabilidade a qual possui maior peso nos primeiros 50 anos (em torno de $70 \%$ ) e diminui, embora não muito nos anos subseqüentes (50\%). Com a variação destes pesos podem-se conseguir valores superiores para TG. Situações como as apresentadas por AM e TG estão ainda longe de ser alcançadas, principalmente em um município que atribui 50\% de redução no IPTU para áreas transformadas em estacionamentos, com altos índices de impermeabilização. 


\section{CONCLUSÕES E RECOMENDAÇÕES}

As conclusões são apresentadas com base nos objetivos traçados no item 2.

Construir cenários ambientais, a partir de variáveis hidráulicas e hidrológicas, e suas narrativas para os anos de 2025, 2050, 2075 e 2100.

Os cenários foram construídos com base nas características dos cenários globais e na evolução qualitativa de alguns indicadores de drenagem urbana. Tais indicadores foram agrupados em duas escalas: Bacia Hidrográfica e Lote Residencial Urbano. O primeiro compreende: crescimento e densidade populacional; potencial de escoamento; declividade, sinuosidade e rugosidade do canal; área impermeável conectada à rede pluvial, largura e rugosidade da planície de inundação; bacia de detenção e de infiltração, melhoramento de manancial urbano e densidade de drenagem. Já na escala de lote os indicadores são: áreas impermeáveis conectadas aos lotes urbanos; áreas impermeáveis em lotes urbanos; solo descoberto nos lotes, tecnologias de manejo apropriadas para a escala de lote; vegetação e grama nos lotes.

Os indicadores da escala de bacia hidrográfica que sofreram maiores modificações e, portanto, que foram os principais responsáveis pelas interferências realizadas em cada cenário foram: crescimento populacional, percentual de área urbanizada, potencial de escoamento, largura da planície de inundação, sinuosidade e declividade do canal.

Aplicar os cenários construídos para as sub-bacias Santa Maria Madalena, Tijuco Preto, Mineirinho, Gregório e Monjolinho, pertencentes à área urbana de São Carlos.

A partir da estimativa do crescimento populacional e do percentual de área urbanizada para todos os cenários, os mesmos foram construídos. Uma vez definidas as características de cada cenário, sua aplicação consistiu na adaptação às peculiaridades de cada sub-bacia. 
Ao que se refere às características dos cursos d'água, para os cenários globais (GO e TG), as primeiras modificações foram atribuídas ao rio principal da bacia e, posteriormente aos rios das sub-bacias componentes. Já para os cenários regionais (OS e AM) as primeiras modificações foram aplicadas aos rios principais de cada sub-bacia e em seguida ao rio principal pertencente à bacia. Procurou-se manter uma evolução espacial dos indicadores ao longo das bacias (montante - jusante).

$\underline{\text { Caracterizar eventos pluviométricos registrados na área de estudo e selecionar um grupo }}$ desses, em função das condições de umidade antecedente, para subsidiar as simulações dos cenários.

Embora a série temporal utilizada para avaliação e caracterização dos eventos pluviométricos tenha sido pequena (3 anos), o número de dados manipulados foi muito grande, pois a discretização temporal da estação utilizada foi de 1 minuto. Desta forma, foi necessário manuseá-los, transformando-os em uma série com intervalo de 5 minutos, para assim utiliza-los nas simulações.

Por meio da caracterização pode-se perceber que a maior parte dos eventos caracterizados possui condições de umidade antecedente I. No entanto, apesar do número de eventos com condições de umidade antecedente II ter se mostrado em menor número, foi considerado satisfatório, para realização das simulações.

Analisar, para cada cenário proposto, as variações de vazões com base em curvas de permanência de cheias.

Os resultados demonstrados por meio de curvas de permanência evidenciam estimativas inesperadas, com menores valores de vazão máxima para os cenários reativos. Uma possível justificativa para tal acontecimento é a intensa utilização de bacias de detenção 
responsáveis pelo retardo e pela diminuição nos picos de vazão. No entanto, o comportamento de toda a bacia, nestes cenários, segue a mesma tendência com valores aproximados de vazões nos pontos analisados. Ao avaliarem-se os passivos e os benefícios ambientais com base nas vazões com probabilidade de ocorrência de $10 \%$ e nos valores médios de $\mathrm{CN}$, o cenário que com mais benefícios é o TG e aquele com mais passivos é o GO.

$\underline{\text { Utilizar, em cada cenário estudado, o armazenamento potencial de água no lote e a vazão }}$ máxima instantânea como variáveis de decisão na proposição de possíveis incentivos ambientais em escala de lote.

A aplicação de incentivos ambientais em escala de lote baseada em parâmetros hidráulico e hidrológicos mostrou-se uma ferramenta simples e de rápida obtenção dos resultados. Embora os cenários propostos tenham sido construídos para um "lote tipo" os custos estimados $\left(\mathrm{R} \$ / \mathrm{m}^{2}\right)$ são aplicáveis para condições atuais.

No cenário reativo GO o cidadão sofre uma penalização devido a sua contribuição para aumento de cheias e inundações ao longo dos anos, já o cenário OS por não aplicar a política de incentivos ambientais o contribuinte não sofre com penalização, mas também não recebe incentivo. O cenário $\mathrm{AM}$ possui as maiores taxas de incentivo a partir de $2050 \mathrm{o}$ contribuinte não paga mais pelo IPTU e sim recebe um valor monetário do município por realizar benfeitorias para o bem comum. O cenário TG tem o mesmo comportamento de AM, no entanto, por ser um cenário global o incentivo é ponderado para cada parcela (macrodrenagem e escala de lote), isso resulta em menores valores dos incentivos prestados por TG, ou seja, o município considera como o melhor contribuinte aquele que contribui de maneira eqüitativa tanto para melhoria de seu lote como para melhoria da drenagem urbana na bacia hidrográfica. 
Avaliar cenários regionais de drenagem urbana com base nos cenários globais, de longo prazo, propostos pela Avaliação Ecossistêmica do Milênio.

O exercício de imaginar diferentes cenários plausíveis para um determinado contexto, gera a possibilidade de alguns dos fatores relacionados ocorrerem, ou algo parecido ao imaginado ocorrer. Desta forma, as soluções para as possíveis interferências ou os problemas que possam vir a acontecer são facilmente detectáveis, uma vez que a situação já tenha sido imaginada anteriormente.

Os cenários criados neste trabalho basearam-se nas características hidráulicas hidrológicas e naquelas que interferem diretamente nestas, como o tipo de uso e ocupação do solo e a densidade populacional. Foram com isso, gerados quatro cenários em uma escala temporal de 100 anos. A probabilidade de um destes cenários tornar-se real exatamente como foi descrito é muito pequena, todavia a probabilidade de elementos inseridos nestes cenários ocorrerem é alta, e podem acorrer combinados, como a utilização de bacias de detenção (GO e OS) em conjunto com recuperação das planícies de inundações (AM e TG), por exemplo. 


\section{SUGESTÕES}

Pesquisas relativas à utilização de cenário de longo prazo como ferramenta para o planejamento da drenagem urbana ainda são incipientes. Nesse contexto propõem-se, para realização de trabalhos futuros, os seguintes temas:

(1) Estudos de cenários de longo prazo com menores discretizações temporais como por exemplo de 4 anos - de forma a possibilitar aos tomadores de decisão o planejamento durante seu período de mandato.

(2) Inclusão da variação climática como um parâmetro na construção de cenários de longo prazo.

(3) Avaliação de cenários de longo prazo a partir de eventos extremos.

(4) Comparação da avaliação de cenário de longo prazo por diferentes métodos de separação e propagação do escoamento - Método SCS e IPH II;

(5) Estimativa da cobrança pelo uso da água em cenários de longo prazo.

(6) Incentivos ambientais para cidades de médio porte: uma abordagem hidrológica.

(7) Utilização de procedimento sistemático de calibração. 


\section{REFERÊNCIAS BIBLIOGRÁFICAS}

AGUIAR, R. L. (1989). Mapeamento Geotécnico da Área de Expansão de São Carlos. Dissertação de mestrado. vol 1 e vol 2. Escola de Engenharia de São Carlos. Universidade de São Paulo. 130p.

ALMEIDA NETO, P. de; OHNUMA Jr., A. A.; CUNHA, A. P. S. R.; MENDINDO, E. M. (2005). Análise Quali-quantitativo do Escoamento Superficial Gerado pela Água da Chuva através da Cobertura Verde Leve. VI Encontro Nacional de Águas Urbanas, Belo Horizonte (MG).

ALMEIDA NETO, P. (2007). Hidrogramas Experimentais de Áreas Alagadas da Micro Bacia do Rio Jacupiranguinha, Baixo Ribeira do Iguape, SP. Dissertação de mestrado. Escola de Engenharia de São Carlos, Universidade de São Paulo. 176p.

ALVES, E. M. (2005). Medidas Não Estruturais na Prevenção de Enchentes em Bacias Urbanas. Cenários para a Bacia do Gregório, São Carlos - SP. Dissertação de mestrado. Escola de Engenharia de São Carlos, Universidade de São Paulo. 149p.

ALVES, F. A. O.; MENEZES FILHO, F. C.; COSTA, A. R. (2007). Estimativa de Volume para Micro-Reservatório Domiciliar no Controle de Cheias Urbanas. XVII Simpósio Brasileiro de Recursos Hídricos. São Paulo/SP.

BAPTISTA, M.; NASCIMENTO, N.; BARRAUD, S. (2005) - Técnicas Compensatórias em Drenagem Urbana. Porto Alegre: Edit. Universidade/ UFRGS/ ABRH. $1^{\circ}$ Edição. 266p.

BARTH, F. T. et al. (1987). Modelos de Gerenciamento de Recursos Hídricos. Coleção ABRH de Recursos Hídricos. Porto Alegre: Edit. Universidade/UFRGS/ABRH. 526p.

BENINI, R. (2005). Cenários de Ocupação Urbana e seus Impactos no Ciclo Hidrológico na Bacia do Córrego Mineirinho, São Carlos - SP. EESC/USP/São Carlos. Dissertação de mestrado. Escola de Engenharia de São Carlos, Universidade de São Paulo. 122p.

BOLDRIN, R. S. (2005). Avaliação de Cenários de Inundações Urbanas a partir de Medidas Não Estruturais de Controle: Trecho da Bacia do Córrego Gregório, São Carlos/SP. Dissertação de mestrado. Escola de Engenharia de São Carlos, Universidade de São Paulo. 203p.

BONTA, J. V.; CLELAND, B. (2003). Incorporation Natural Variability, Uncertainty, and Risk into Water Quality Evaluations Using Duration Curves. Journal of the American Water Resources Association. Dez/2003. p. 1481-1496.

BRANDI, R. (2003). A Inteligência Estratégica e os Cenários no contexto do Planejamento Estratégico. Curso de Especialização em Inteligência Organizacional e Competitiva na Sociedade da Informação (UnB). Apresentação em Power Point®. Disponível em: http://www.unb.br/fa/cid/ceic/disciplinas/palestrarb.ppt. Acessado em agosto de 2007. 
BUTLER, D. PARKINSON, J. (1997). Towards Sustainable Urban Drainage. Water Science Technology. Vol 35, nº 09, p. 53-63, Ed. Elsevier Science Ltd.

CAMPANA, N. A.; TUCCI, C. E. M. (2001). Predicting floods from urban development scenarios: case study of the Dilúvio Basin, Porto Alegre, Brazil. Urban Water. 113 $124 \mathrm{p}$

CANHOLI, A. P. (2005). Drenagem Urbana e Controle de Enchentes. Ed: Oficina de Textos.

CBH-TJ (2000). Comitê da Bacia Hidrográfica do Tietê-Jacaré - Relatório Zero Diagnóstico da situação atual dos Recursos Hídricos e estabelecimento de diretrizes técnicas para a elaboração do Plano da Bacia hidrográfica do Tietê-Jacaré Relatório Final n. ${ }^{\circ} 40.674,528$ p. 1 CD-ROM..

CHOW, V. T. (1959). Open Channel Hydraulics. International Student Edition. Ed. McGrawWill Kogakusha, LTD.

CIA (2006). O Relatório da CIA - Como Será o Mundo em 2020. Tradução de Peres, M. N. e Blanc, C. São Paulo. Ed. Ediouro.

CIFOR (2006). Pagos por servicios ambientales: Princípios básicos esenciales. Centro Internacional de Investigación Forestal. Occasional Paper $N^{\circ} 42$ (s).

COSTA Jr, L. L da (2003). Avaliação do Uso e Ocupação do Solo e do Emprego de Medidas de Controle de Inundações no Lote. Dissertação de mestrado. Universidade Federal de São Carlos. 138p.

DENARI, Z. (2002). Curso de Direito Tributário. Editora Atlas S.A. - $8^{\circ}$ edição. Cap 23, p. $307-310$.

DÖLL, P.; MENDIONDO, E. M.; FUHR, D. (2000). Desenvolvimento de Cenários como uma Ferramenta para o Planejamento Regional. Center for Environmental Systems Reserch, University of Kassel, Alemanha. Material para o Workshop SRH-WAVES para cenários conjuntos em Ceará. 7p. (Disponível em: http://www.usf.unikassel.de/waves/portug/index.htm)

GLENN, J. C. GORDON, T. J. (2006). 2006 State of the Future. The Millennium Project. American Council for United Nations University. 129 p.

GRACIOSA, M. C. P. (2005). Trincheiras de Infiltração como Tecnologia Alternativa em Drenagem Urbana: Modelagem Experimental e Numérica. Dissertação de mestrado. Escola de Engenharia de São Carlos, Universidade de São Paulo. 259p.

IPH-UFRGS, ALM/FEA/IMF-UFPel e DFIS-FURG. (2004) Manual de Fundamentos. IPHS1 para Windows, Versão 2.11, IPH-UFRGS, Porto Alegre, RS.

IBGE (2007). Instituto Brasileiro de Geográfica e Estatística. Disponível em: http:// http://www.ibge.gov.br/home/. Acessado em julho de 2007.

LEEMANS, R. (2007). Scenario Analysis. In: Curso Internacional sobre Construção de Cenários Ambientais. Módulo I 24-27 Abril. São Paulo /SP. 
LEI MUNICIPAL No 13.692 (2005) - Planta Genérica de Valores do Município de São Carlos. Disponível em: http://site.camarasaocarlos.sp.gov.br/. Acessado em junho de 2007.

LIMA, G.; BOLDRIN, R. S.; OHNUMA Jr, A. A.; MENDIONDO, E. M.; MAUAD, F. F. (2007). Análise de incertezas de observações hidrológicas e sua influência na modelagem de pequenas bacias urbanas. Revista Brasileira de Recursos Hídricos, Porto Alegre, v.12, n1, p.107-116.

LIRA, A. M. (2003). Avaliação das Condições do Sistema de Macrodrenagem da Cidade de São Carlos - SP. Dissertação de Mestrado. Escola de Engenharia de São Carlos, Universidade de São Paulo. 188p.

MACÊDO, R. F.; SOUZA, S. A.; ANDRADE, J. P. M.; MENDINDO, E. M. (2004). Cenários de Políticas de Controle de Impactos devido a Inundações. I Seminário Latino Americano de Políticas Públicas em Recursos Hídricos, Brasília.

MACÊDO, R. F. (2005). Proposta Metodológica para Análise de Cenários de Disponibilidade e Oferta Hídrica. Dissertação de mestrado. Escola de Engenharia de São Carlos, Universidade de São Paulo. 177p.

MASTNY, L.; CINCOTTA, R. P. (2005) Analisando as ligações entre população e segurança. In: LOPES, C (Apresentação); MULLETT, H.; MULLET, C. (Tradução). Estado do Mundo, 2005: Estado do Consumo e o consumo sustentável. Worldwatch Institute. Salvador: UMA, 2005.

MCCUEN, R. H. (1989). Hydrologic Analysis and Design. Prentice Hall Inc.

MENDES, H. C. (2005). Urbanização e Impactos Ambientais: Histórico de Inundações e Alagamentos na Bacia do Gregório, São Carlos - SP. Dissertação de mestrado. Escola de Engenharia de São Carlos, Universidade de São Paulo. 325p.

MENDIONDO, E. M. (2007). Scenarios Water Capital Powered by Early-Warning Systems. Submitted to Japan Hydrology. Res. Letters on 23 March (2007).

MENDIONDO, E. M. (2007). Incentivos Ambientais - "IPTU Hidrológico". Mini-curso apresentado no VII ENAU. São Carlos/SP.

MENDIONDO, E. M. (2006). Early Warning Systems for Urban Water Security Management. IAP Water Programme Regional Workshop for the Americas, Brasil.

MENDIONDO, E. M. (2005) - Flood risk management of urban waters in humid tropics: early-warning, protection and rehabilitation, Invited Paper In: C. Tucci \& J.Goldenfum (orgs.) Workshop on Integrated Urban Water Managmt. in Humid Tropics, UNESCO IHP-VI (Int. Hydrol. Program), 2-3 April 2005, Foz de Iguaçu, Brazil.

MENDIONDO, E. M. (2004). Gestão Hídrica Sustentável em Bacias Sul Americanas para o Século XXI - Desafios da Hidro-Solidariedade em Projetos Transnacionais. Relatório do Núcleo Integrado de Bacias Hidrográficas - NIBH-SHS/EESC/USP. Disponível em: http://www.shs.eesc.usp.br/laboratorios/hidraulica. Acessado em junho de 2007. 
MILLENNIUM ECOSYSTEM ASSESSMENT (MA), Scenario Working Group (2005) Four Scenarios, In S. R. Carpenter, P. L. Pingali, E. M. Bennett, M. B. Zurek (editors). Ecosystems and Human Well-being: Scenarios, Island Press: Washington, v.2., Chapter 8, p.223-294.

MILLENNIUM ECOSYSTEM ASSESSMENT (MA), (2005). Ecosystems and Human Wellbeing: Synthesis. Island Press, Washington, DC.

NEVES, E. T. (1968). Curso de Hidráulica. 2a Edição. Editora Globo. Porto Alegre.

NEVES, M. J. M. (2007). O Uso do Planejamento Por Cenários em Recursos Hídricos: Uma Revisão. XVII Simpósio Brasileiro de Recursos Hídricos. São Paulo/SP.

NIBH (2007). Núcleo Integrado de Bacias Hidrográficas, do Departamento de Hidráulica e Saneamento - SHS, Escola de Engenharia de São Carlos - EESC, Universidade de São Paulo - USP. Disponível em: www.shs.eesc.usp.br/laboratorios/hidraulica. Acessado em novembro de 2007.

OHNUMA Jr, A. A. (2005). Cenários de Reuso de Água Pluvial e Controle de Drenagem visando a Recuperação Ambiental da Micro-Bacia do Alto Tijuco Preto, São Carlos/SP. Dissertação de mestrado. Escola de Engenharia de São Carlos, Universidade de São Paulo. 192p.

OHNUMA JR, A. A. (2006). Medidas não-convencionais de reservação d' água para o controle da poluição em lotes urbanos. Qualificação de Doutorado. Ciências da Engenharia Ambiental. Departamento de Hidráulica e Saneamento. Escola de Engenharia de São Carlos. Universidade de São Paulo. 40p.

PERCY, S.; LUBCHENCO, J. Coordenadores da Equipe de Síntese. (2006). Ecossistemas e Bem-estar Humano - Oportunidades e Desafios para Empresas e a Indústria. Relatório da Avaliação Ecossistêmica do Milênio. (Disponível em: http://cebds.dynalias.net/cebds/docnoticia/cop8-ecos-bem-estar-humanooportunidades -desafios.pdf)

PLANO NACIONAL DE RECURSOS HÍDRICOS (2006). Águas para o Futuro: Cenário para 2020. Vol 2. Ministério do Meio Ambiente, Secretaria de Recursos Hídricos. Brasília. 96 p. (Disponível em: http://pnrh.cnrh-srh.gov.br/)

PNUD (2004). Un Informe Mundial. La Reducción de Riesgos de Desastres. Un Desafío para el Desarrollo. (Disponível em: www.undp.org/bcpr)

POMPÊO, C. A. (2000) - Drenagem Urbana Sustentável. Revista Brasileira de Recursos Hídricos; vol. 5; $\mathrm{n}^{\circ} 1 ; \mathrm{p}$ 15-23. Porto Alegre, RS.

SETZER, J. PORTO, R. L.L. (1979). Tentativa de Avaliação de Escoamento Superficial de Acordo com o Solo e o seu Recobrimento Vegetal nas Condições do Estado de São Paulo. Boletim Técnico DAEE, São Paulo, 2 (2); p. 82-135. Maio/Agosto.

PORTO, R. M. (2003). Hidráulica Básica. Projeto REENGE, EESC/USP. 
RASKIN, P.; BANURI, T.; GALLOPÍN, G.; GUTMAN, P.; HAMMOND, A.; KATES, R.; SWART, R.. (2002). Great Transition: The Promise and Lure of the Times Ahead. A report of the Global Scenarios Group.

RIBEIRO, C. A. G. (2007). Hidrossolidariedade como Gestão Participativa para Riscos de Inundações com Associação de Bacias. Dissertação de mestrado. Escola de Engenharia de São Carlos, Universidade de São Paulo. 161p.

RIGHETTO, A. M. (1998). Hidrologia e Recursos Hídricos. Projeto REENGE, EESC/USP. $1^{a}$ edição.

RAINDROPS, G. (2002). Aproveitamento da Água de Chuva. Ed. Organic Trading, Curitiba, PR. 196p.

RELATÓRIO PÓLIS (2002). Assessoria Técnica para Elaboração do Plano Diretor de São Carlos. Leitura Técnica da Cidade (Produto 1). São Paulo.

SEADE - Fundação Sistema Estadual de Análise de Dados (2008). Perfil Municipal de São Carlos. Disponível em: www.seade.gov.br/produtos/perfil/perfil.php. Acessado em fevereiro de 2008.

SILVA, K. A. (2003). Análise da Variabilidade Espacial da Precipitação e Parâmetros Hidrológicos em Bacia Experimental Urbana: Estudo da Transformação da Chuva em uma Pequena Bacia Hidrográfica Urbana. Tese de doutorado. Escola de Engenharia de São Carlos, Universidade de São Paulo. 325p.

SILVEIRA, G. L. (2007). Cobrança pela drenagem urbana de águas pluviais: incentivo à sustentabilidade. Relatório de pós-doutorado. Disponível em: http://www.hidroprojetos.ctlab.ufsm.br. Acessado em julho de 2008.

SOUZA, T. F.; MENDIONDO, E. M. (2007). Percepções de Longo Prazo para Drenagem Urbana. XVII Simpósio Brasileiro de Recursos Hídricos. São Paulo/SP.

SOUZA, T. F.; CABALlERO CAMPOS, P. F. MENDIONDO, E. M. (2007). Gestão Descentralizada de Risco de Inundações para a Segurança Pessoal e Comunitária. IIV ENAU. São Carlos/SP.

TOMAZ, P. (2002). Cálculos Hidrológicos e Hidráulicos para Obras Municipais. Piscinões, Galerias, Bueiros, Canais. Métodos SCS, Denver, Santa Bárbara, Racional, TR-55. Editora Navegar. 475 p.

TUCCI, C. E. M. (1993). Hidrologia - Ciência e Aplicação. Porto Alegre: Edit. Universidade/ UFRGS/ ABRH. $3^{\circ}$ Edição. 943p.

TUCCI, C. E. M. (1998). Modelos Hidrológicos. Porto Alegre: Edit. Universidade/ UFRGS/ ABRH. 669p.

TUCCI, C. E. M. (2003). Parâmetros do Hidrograma Unitário para Bacias Urbanas Brasileiras. Revista Brasileira de Recursos Hídricos; vol. 8; n 2; p 195-199. Porto Alegre, RS. 
UNESCO/IHE (2007). SWITCH Integrated Project - Sustainable Water Management Improves Tomorrow's Cities' Health). Disponível em: http://www.switchurbanwater.eu. Acessado em outubro de 2007.

USDA (U.S. Department of Agriculture - Soil Conservation Service) (1986). Urban Hydrology for Small Watersheds TR-55

USEPA (U.S. Environmental Protection Agency) (2007). An Approach for Using Load Duration Curves in the Development of TDMLs (Total Maximum Daily Load). EPA841-B-07-006. Disponível em: http://www.epa.gov.owow/tdml/techsupp/html. Acessado em setembro de 2007.

VASCONCELOS, A. F. (2007). Relatório Final de Atividades - Projeto: Micro - Sistema de Alerta Antecipada na Prevenção de Desastres Hidrológicos junto à Defesa Civil. 51p.

VELAVERDE, S. J. (2007). Cruzando Fronteras: Una Carretera en la Amazônia. In: Curso Internacional sobre Construção de Cenários Ambientais. Módulo II 08-10 Maio. São Paulo /SP. Apresentação adaptada e traduzida de: Velarde SJ, RP Prieto, M Lopez, F Patino and J Ugarte. 2005. What if? ...A series of aspirations, dreams, worries...different scenarios. 20 September 2005. Participatory Research \& Scaling Up, AFNET/DMP Training Workshop, September 19-30, 2005. Nairobi, Kenya (Seminar).

VOGEL, R. M.; FENNESSEY, N. M. (1994). Flow-Duration Curves. I: New Interpretation and Confidence Intervals. Journal of Water Resources Planning and Management, volume $120, \mathrm{n}^{\mathrm{o}} 4$, pp. 485-504 


\section{ANEXOS}

ANEXO A

Tabela A1 - Parâmetros hidrológicos relacionados à drenagem urbana e indicados de acordo com a proposta de cenários globais.

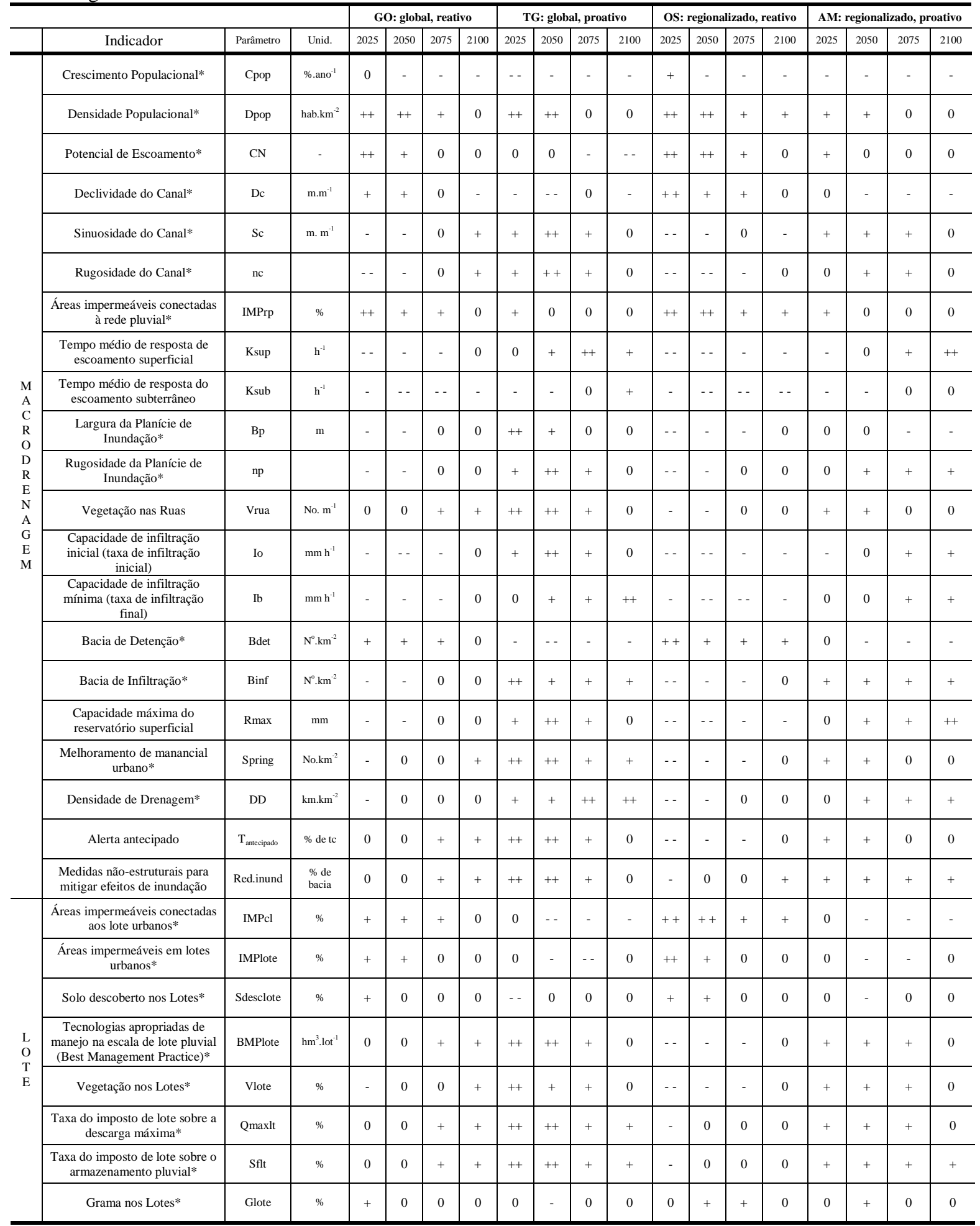

Adaptado de Mendiondo, E. M. (2005) - Flood risk management of urban waters in humid tropics: early-warning, protection and rehabilitation, Invited Paper In: C. Tucci \& J.Goldenfum (orgs.) Workshop on Integrated Urban Water Managmt. in Humid Tropics, UNESCO IHP-VI (Int. Hydrol. Program), 2-3 April 2005, Foz de Iguaçu, Brazil. 


\section{ANEXO B}

- Configuração das bacias e sub-bacias pertencentes a área urbana de São Carlos.

Fonte: Lira (2003) 


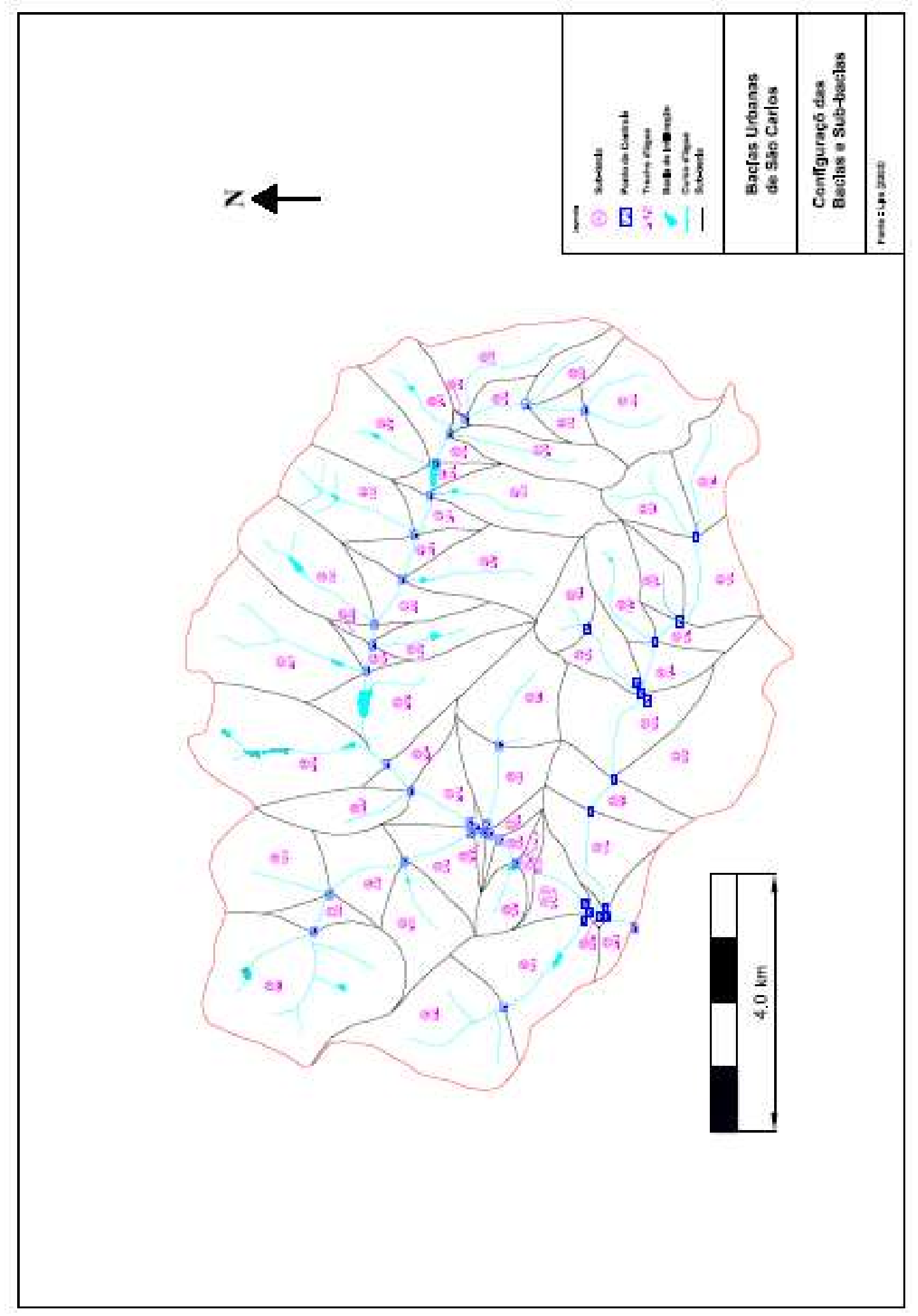




\section{APÊNDICES}

APÊNDICE A

- Precipitações;

- Níveis Hidrométricos;

- Falhas Registradas. 
Precipitações (fev-dez/2004)

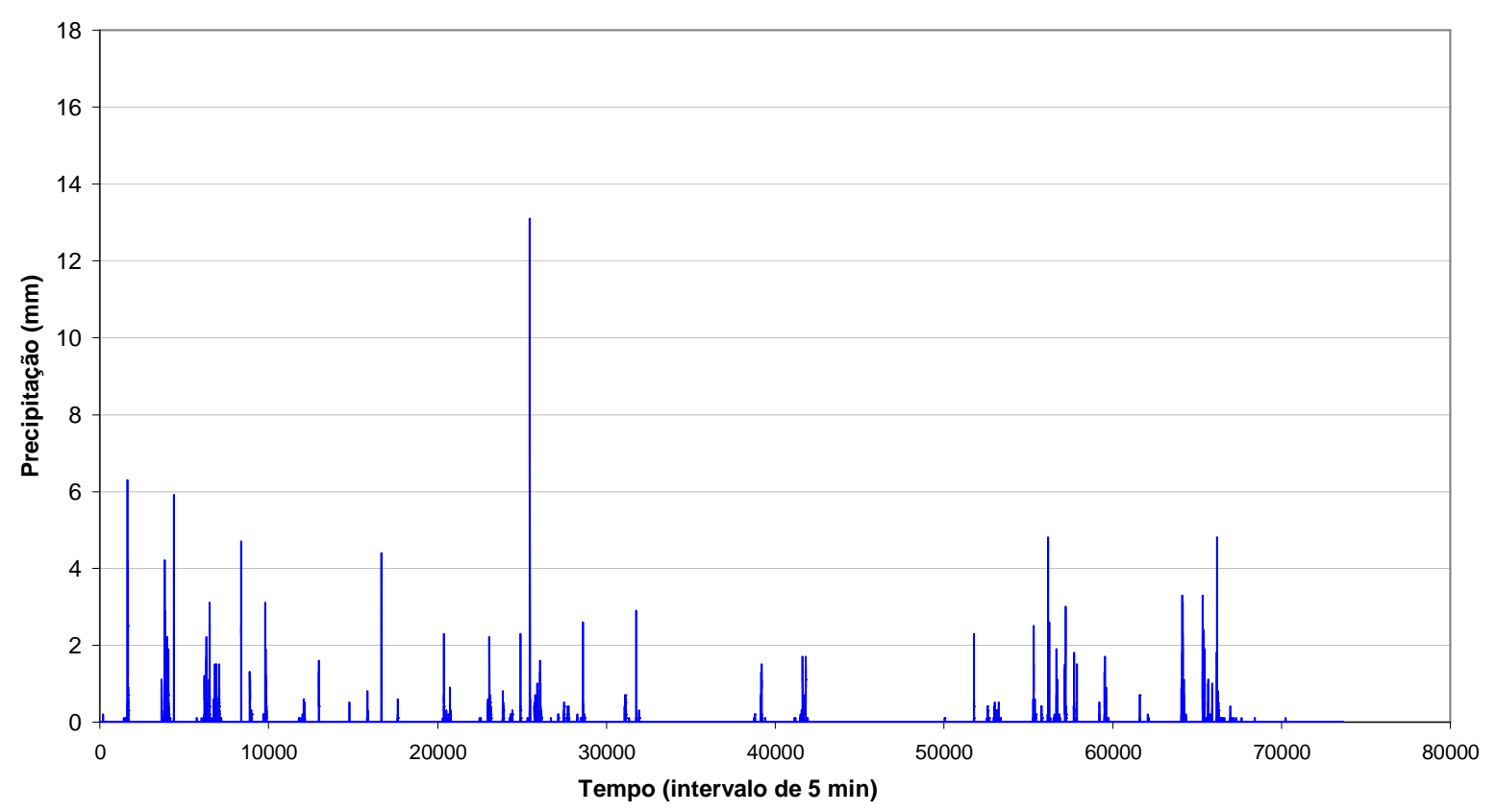

Figura A1 - Precipitações ocorridas entre 01/02/2004 e 31/12/2004, registradas na bacia do córrego Gregório.

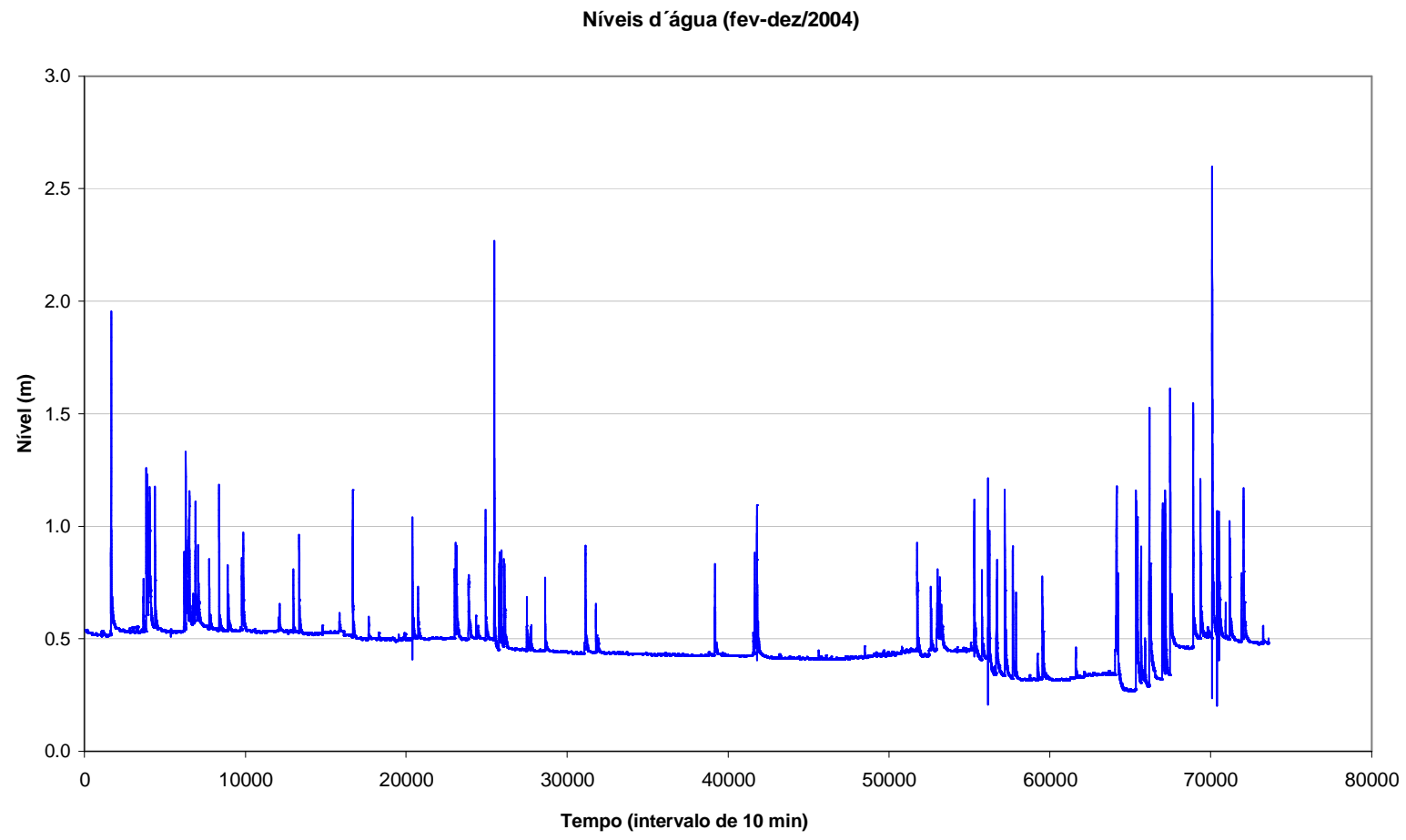

Figura A2 - Níveis hidrométricos ocorridos entre 01/02/2004 e 31/12/2004, registrados na bacia do córrego Gregório. 
Precipitações (Jan-dez/2005)

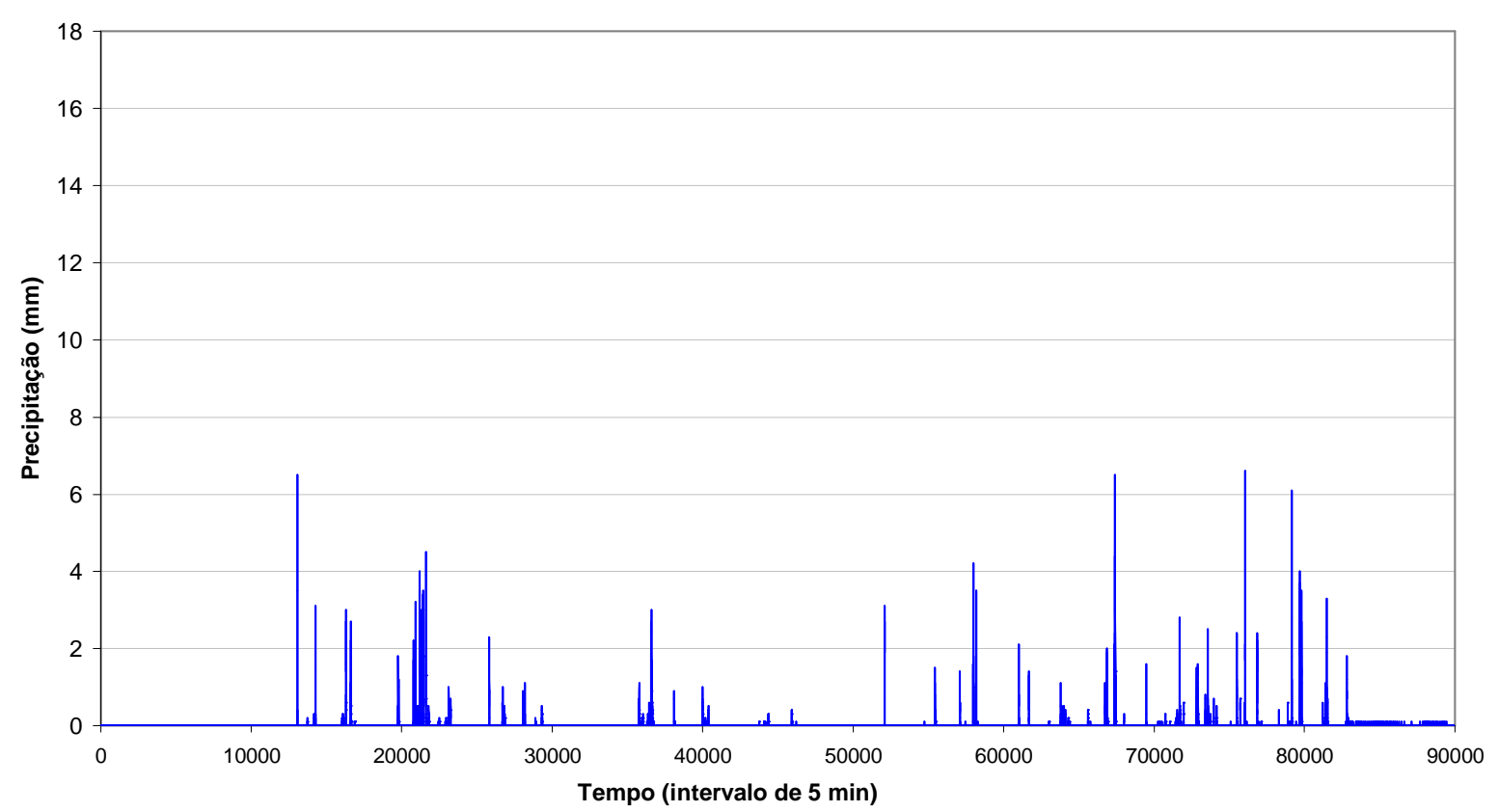

Figura A3 - Precipitações ocorridas entre 01/01/2005 e 31/12/2005, registradas na bacia do córrego Gregório.

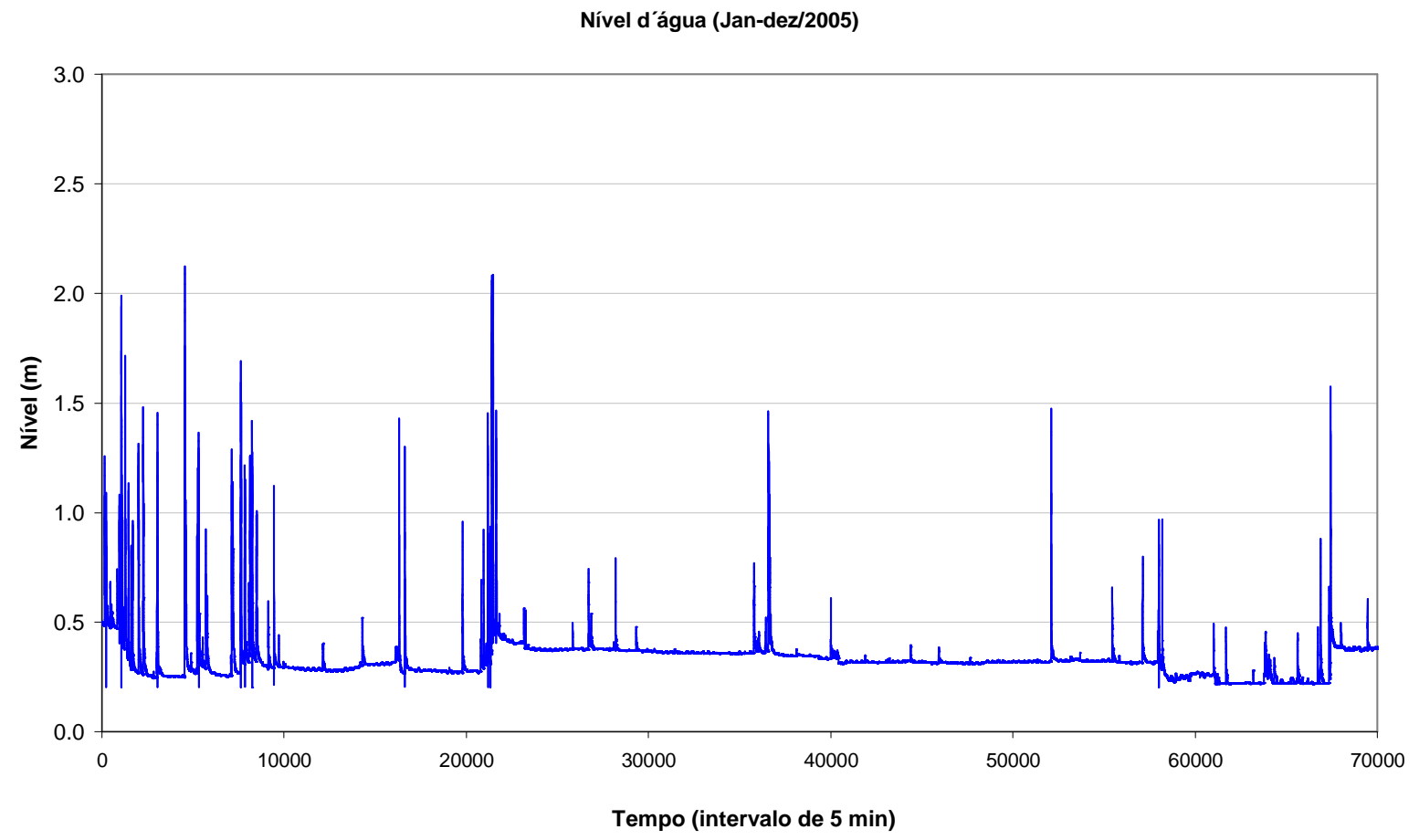

Figura A4 - Níveis hidrométricos ocorridos entre 01/01/2005 e 31/12/2005, registrados na bacia do córrego Gregório. 
Precipitações (Jan-dez/2006)

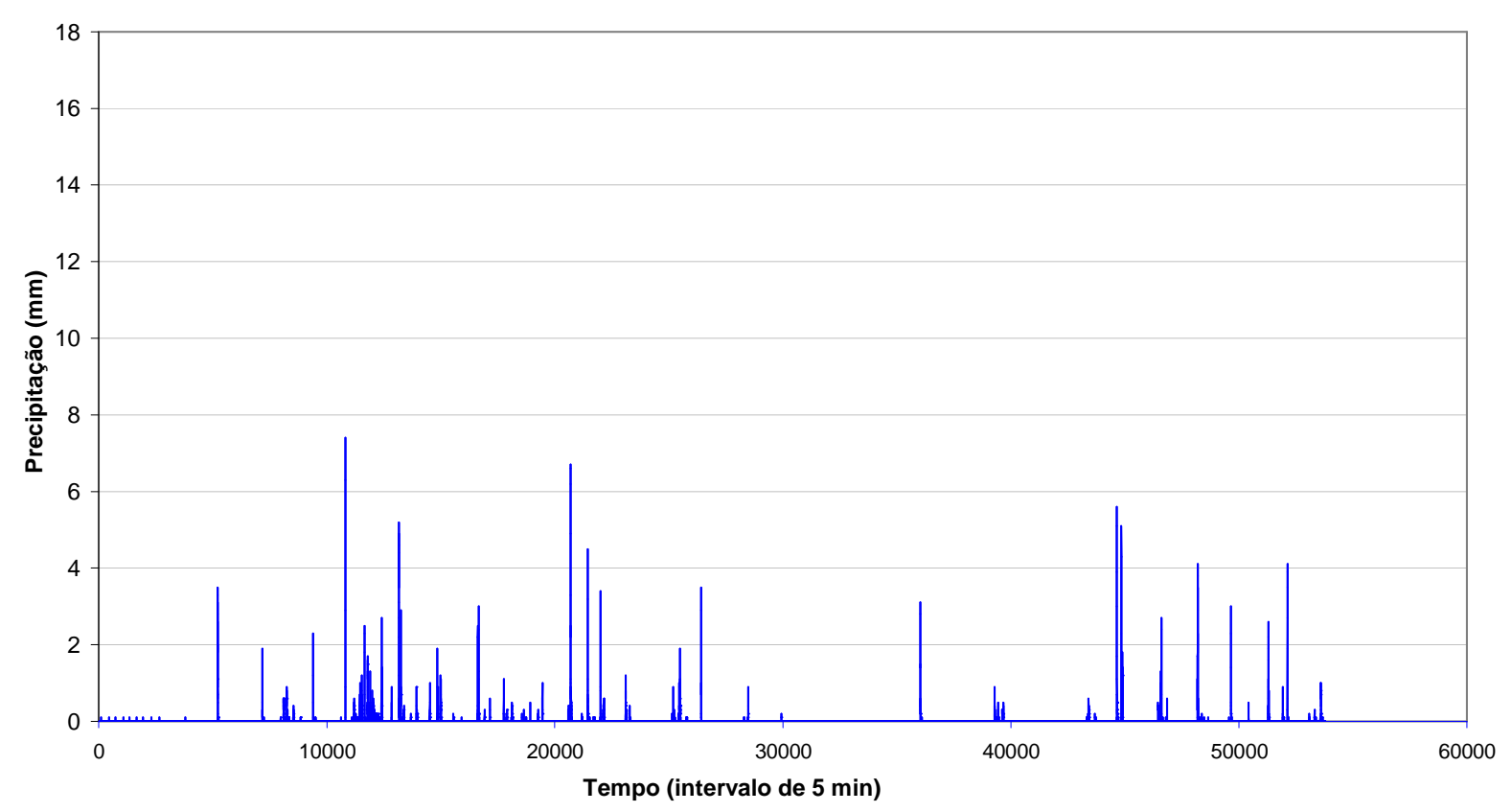

Figura A5 - Precipitações ocorridas entre 01/02/2006 e 05/12/2006, registradas na bacia do córrego Gregório.

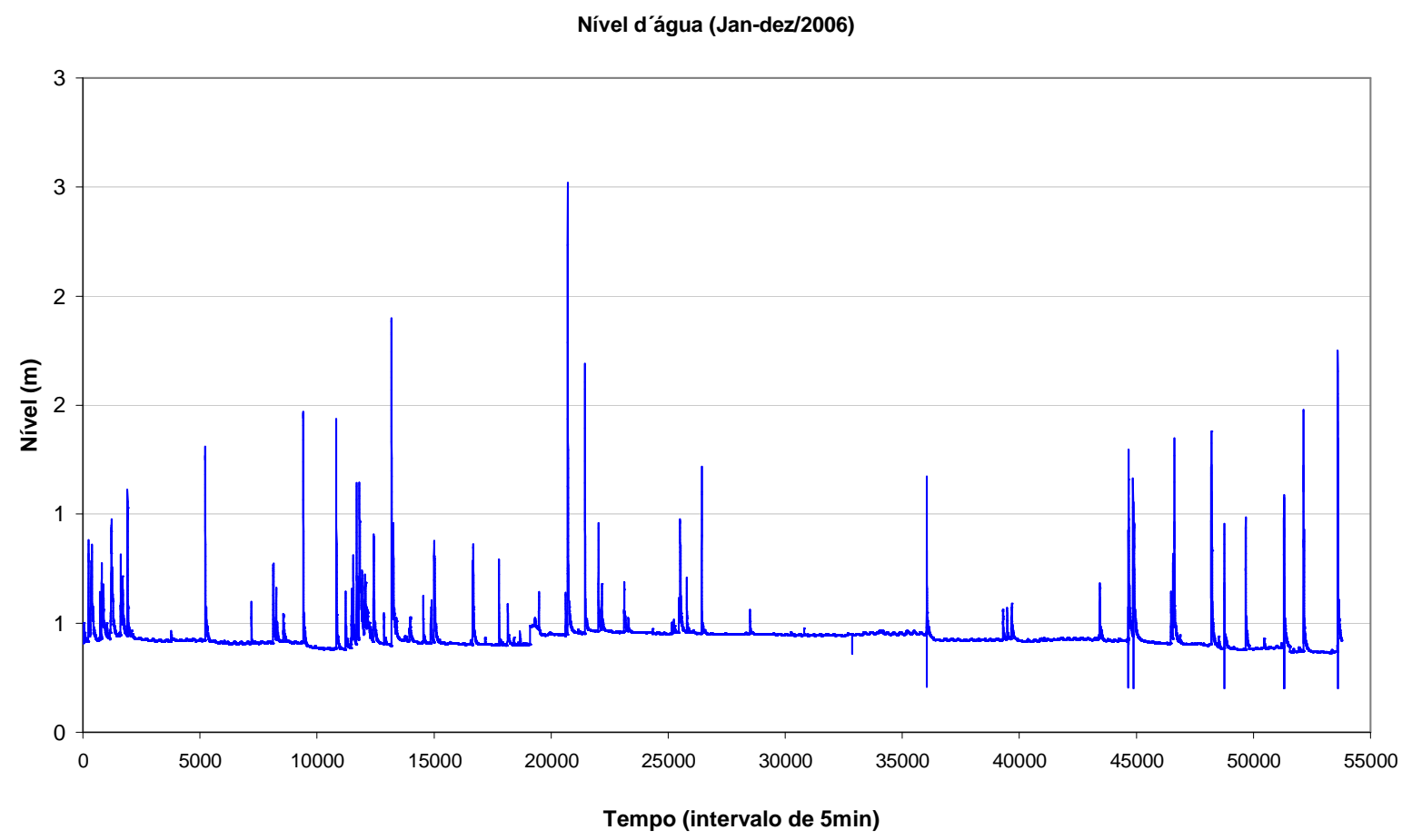

Figura A6 - Níveis hidrométricos ocorridos entre 01/01/2006 e 05/12/2006, registrados na bacia do córrego Gregório. 
Tabela A1 - Falhas apresentadas nas leituras do pluviômetro e do linígrafo situados próximo ao FORUM (Bacia do Gregório).

\begin{tabular}{|c|c|c|c|c|c|}
\hline Ano & Mês & $\begin{array}{c}\text { Dias } \\
\text { (Calendário } \\
\text { Juliano) } \\
\end{array}$ & $\begin{array}{c}\text { Dias } \\
\text { (Calendário } \\
\text { Gregoriano) } \\
\end{array}$ & $\begin{array}{l}\text { Início da falha } \\
\text { [dia - hora] }\end{array}$ & $\begin{array}{l}\text { Término da falha } \\
\text { [dia - hora] }\end{array}$ \\
\hline \multirow{9}{*}{2004} & Jan & 6 a 7 & 06 a $07 / 01$ & $6-20: 06$ & $7-3: 05$ \\
\hline & Mar & 78 a 85 & 18 a $25 / 03$ & $78-10: 23$ & $85-15: 23$ \\
\hline & Abr & 96 a 103 & 05 a $12 / 04$ & $96-11: 12$ & $103-16: 12$ \\
\hline & Abr & 104 a 111 & 13 a $20 / 04$ & $104-15: 30$ & $111-20: 30$ \\
\hline & Abr/Mai & 121 a 123 & $30 / 04$ a $02 / 05$ & $121-10: 57$ & $123-00: 01$ \\
\hline & Ago & 218 a 225 & 06 a $10 / 12$ & $218-08: 42$ & $225-13: 42$ \\
\hline & Set & 265 a 267 & 21 a 23/09 & $265-10: 58$ & $267-8: 21$ \\
\hline & Out/Nov & 305 a 306 & $31 / 10$ a $01 / 11$ & $305-00: 01$ & $306-00: 01$ \\
\hline & Nov/Dez & 324 a 342 & 19/11 a 07/12 & $324-17: 21$ & $342-10: 09$ \\
\hline \multirow{3}{*}{2005} & Mar/Abr & 81 a 98 & $22 / 03$ a $08 / 04$ & $81-13: 48$ & $98-12: 49$ \\
\hline & Jun/Jul & 172 a 187 & $21 / 06$ a $06 / 07$ & $172-17: 22$ & $187-3: 33$ \\
\hline & Dez & 357 a 364 & 23 a $30 / 12$ & $357-14: 26$ & $364-19: 32$ \\
\hline \multirow{19}{*}{2006} & Mar & 67 a 74 & 08 a $15 / 03$ & $67-7: 34$ & $74-12: 39$ \\
\hline & Mai & 122 a 137 & 02 a $17 / 05$ & $122-17: 56$ & $137-12: 29$ \\
\hline & Mai & 137 a 144 & 17 a $24 / 05$ & $137-13: 55$ & $144-19: 00$ \\
\hline & Mai/Jun & 149 a 156 & $29 / 05$ a $05 / 06$ & $149-8: 57$ & $156-14: 03$ \\
\hline & Jun & 156 a 171 & 05 a 20/06 & $156-19: 44$ & $171-5: 55$ \\
\hline & Jun/Jul & 178 a 185 & $27 / 06$ a 04/07 & $178-10: 24$ & $185-15: 29$ \\
\hline & Jul & 186 a 193 & 05 a $12 / 07$ & $186-10: 03$ & $193-15: 08$ \\
\hline & Jul & 200 a 207 & 19 a 26/07 & $200-14: 47$ & $207-19: 52$ \\
\hline & Jul/Ago & 212 a 219 & $31 / 07$ a 07/08 & $212-11: 02$ & $219-16: 07$ \\
\hline & Ago/Set & 220 a 248 & 08/08 a 05/09 & $220-8: 26$ & $248-15: 56$ \\
\hline & Set & 262 a 269 & 19 a $26 / 09$ & $262-7: 16$ & $269-12: 21$ \\
\hline & Set/Out & 271 a 278 & $28 / 09$ a $05 / 10$ & $271-13: 55$ & $278-19: 00$ \\
\hline & Out & 287 a 294 & 14 a $21 / 10$ & $287-11: 13$ & $294-16: 18$ \\
\hline & Out & 297 a 304 & 24 a $31 / 10$ & $297-7: 06$ & $304-12: 12$ \\
\hline & Nov & 311 a 318 & 07 a $14 / 11$ & $311-6: 24$ & $318-11: 29$ \\
\hline & Nov & 324 a 331 & 20 a $27 / 11$ & $324-13: 01$ & $331-18: 06$ \\
\hline & Dez & 339 a 346 & 5 a $12 / 12$ & $339-9: 40$ & $346-14: 45$ \\
\hline & Dez & 351 a 358 & 17 a $24 / 12$ & $351-15: 13$ & $358-9: 26$ \\
\hline & Dez/Jan & 362 a 4 & $\begin{array}{c}28 / 12 / 2006 \text { a } \\
01 / 01 / 2007\end{array}$ & $362-9: 44$ & $4-14: 52$ \\
\hline
\end{tabular}

Fonte: Vasconcelos e Mendiondo (2007). 
- Dados de Nível d'água fornecidos pelo SAAE

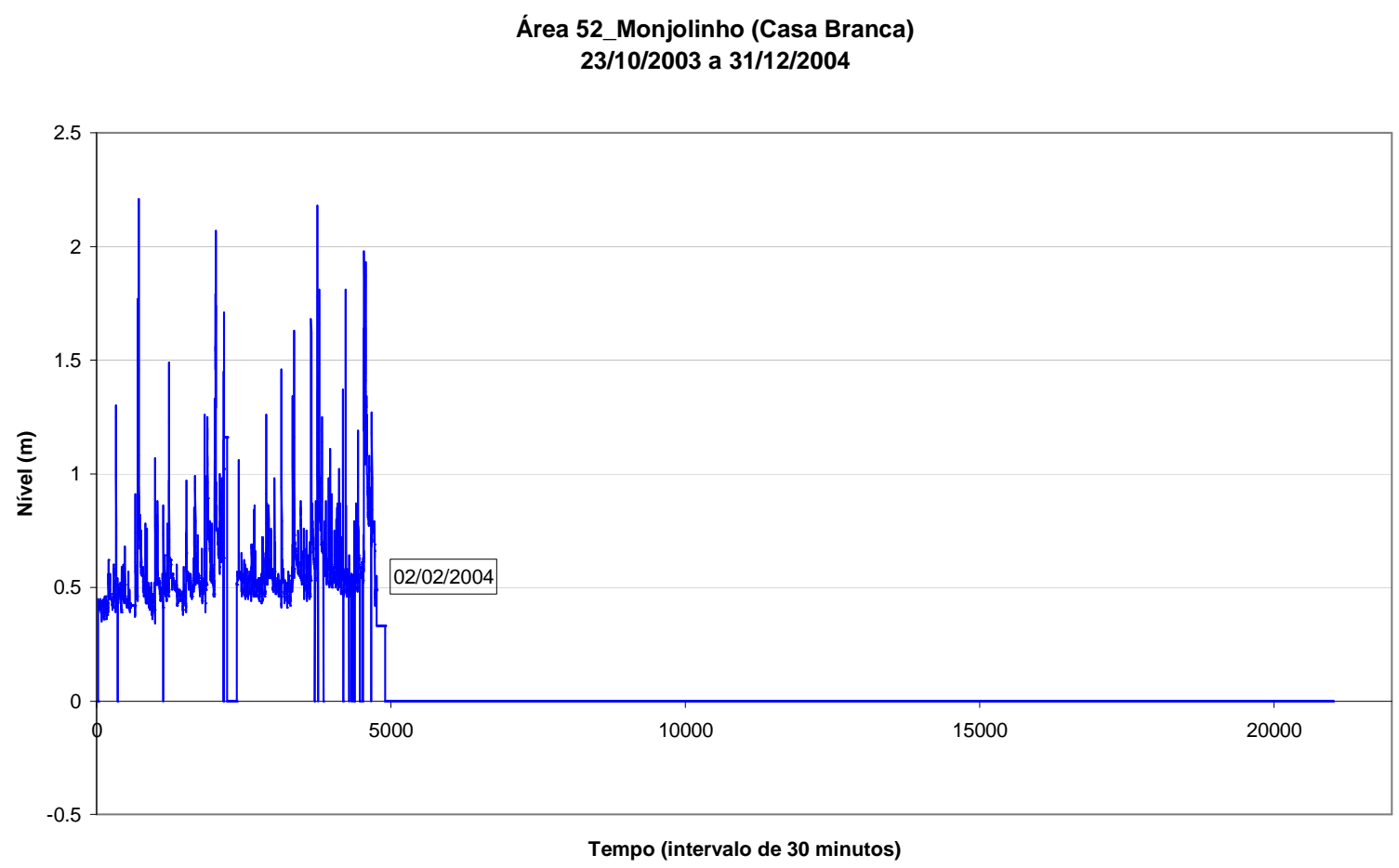

Figura A7 - Níveis hidrométricos ocorridos entre 23/10/2003 e 31/12/2004, registrados na bacia do córrego Monjolinho (Av. Francisco Pereira Lopes, próximo ao restaurante Casa Branca).

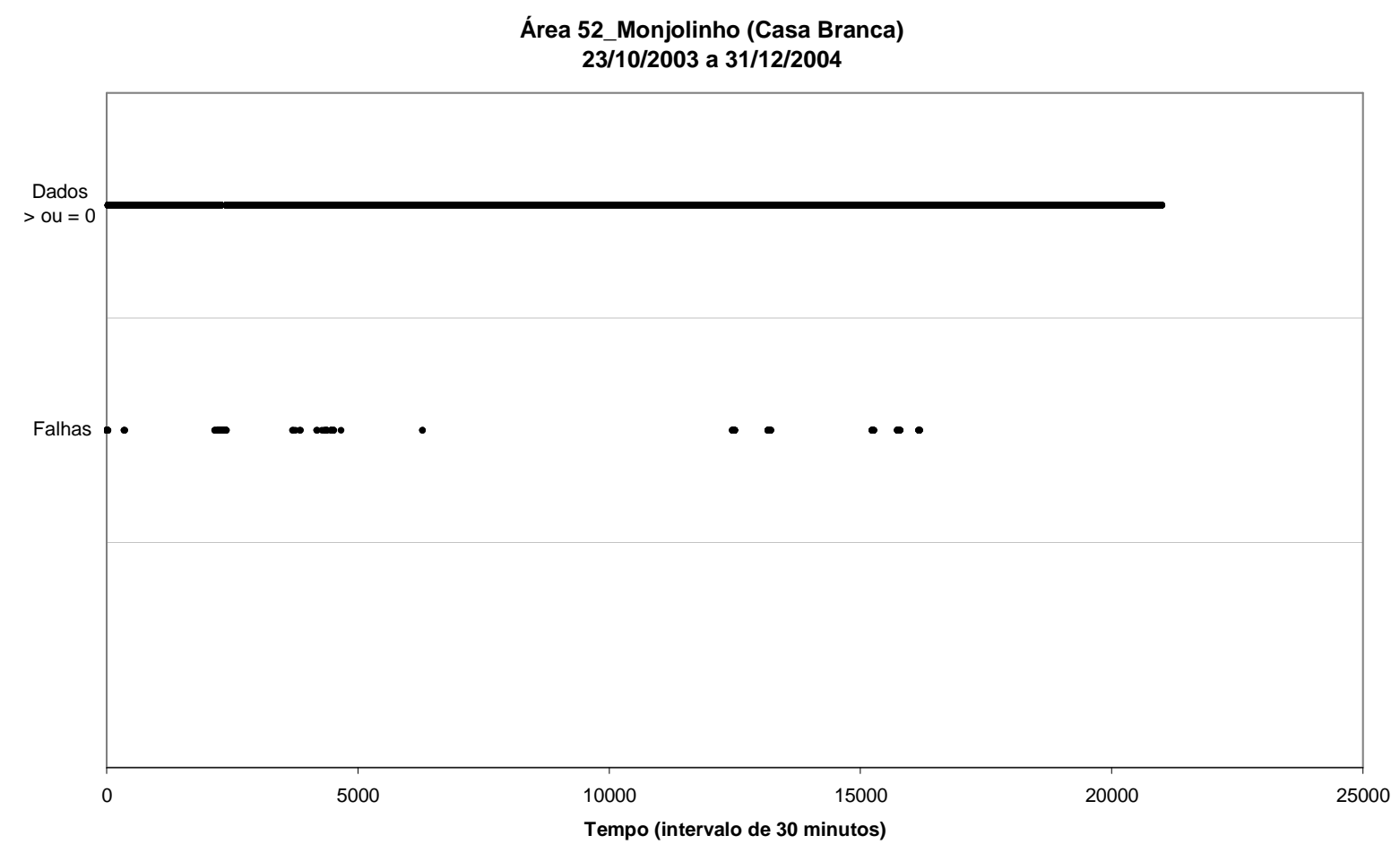

Figura A8 - Falhas registradas no monitoramento de dados hidrométrico ocorridos entre 23/10/2003 e 31/12/2004, registrados na bacia do córrego Monjolinho (Av. Francisco Pereira Lopes, próximo ao restaurante Casa Branca). 


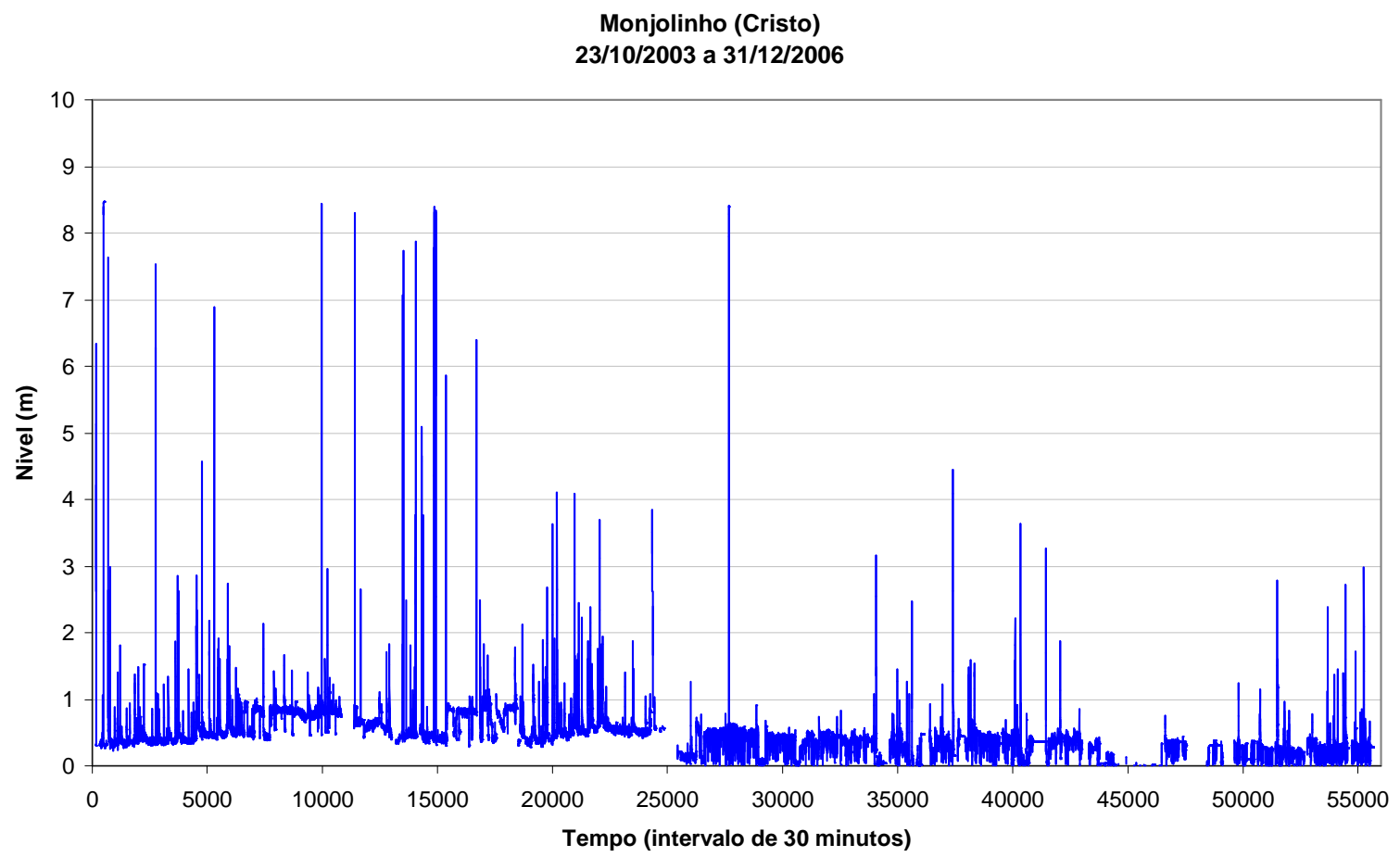

Figura A9 - Níveis hidrométricos ocorridos entre 23/10/2003 e 31/12/2006, registrados na bacia do córrego Monjolinho (Av. Tancredo Neves, próximo à rotatória do shopping Iguatemi).

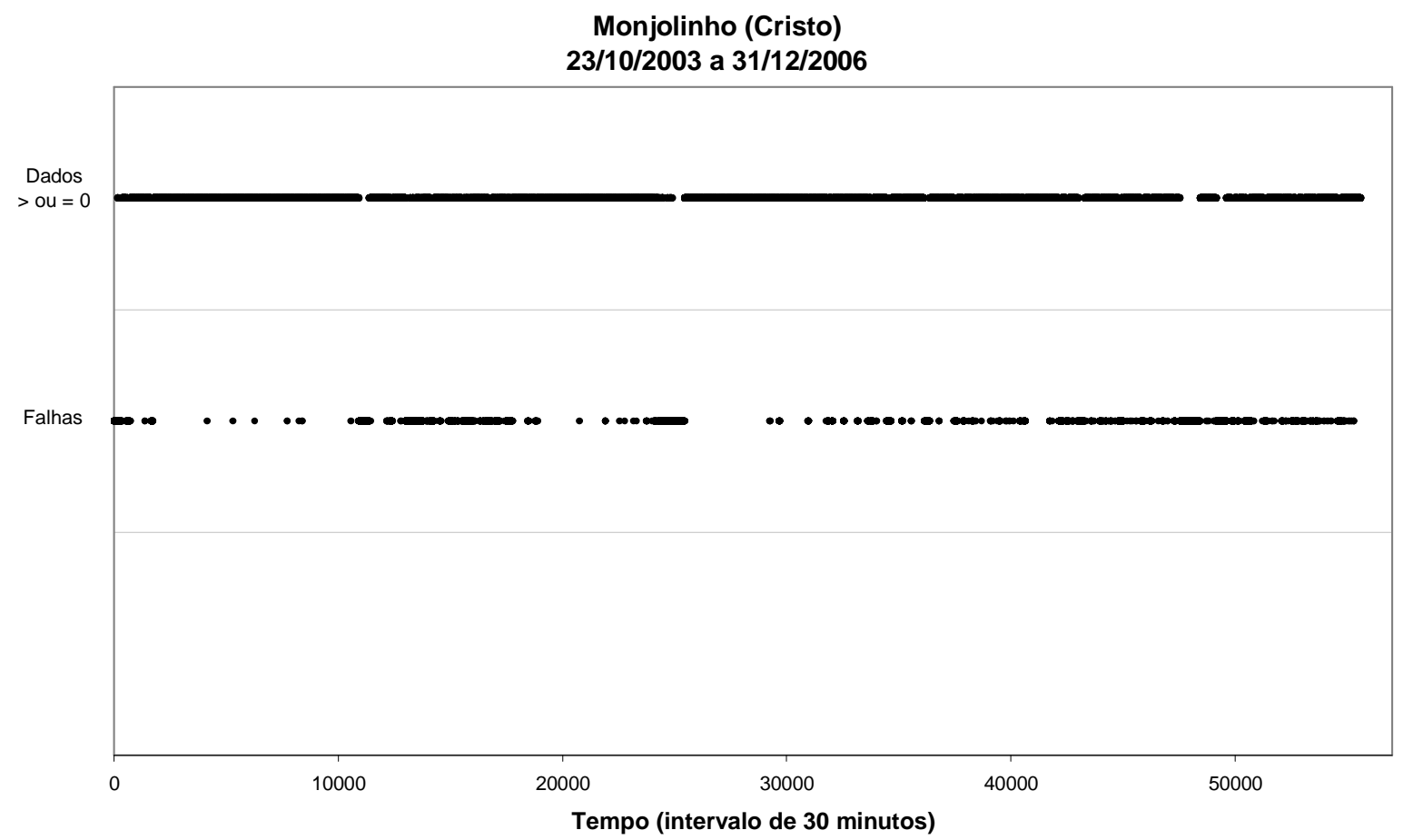

Figura A10 - Falhas registradas no monitoramento de dados hidrométrico ocorridos entre 23/10/2003 e 31/12/2004, registrados na bacia do córrego Monjolinho (Av. Tancredo Neves, próximo à rotatória do shopping Iguatemi). 


\section{APÊNDICE B}

Tabela B1 - Estimativa do dimensionamento das seções irregulares (i) e regulares (r) para 8 alturas distintas, em cada seção.

\begin{tabular}{|c|c|c|c|c|c|c|c|c|}
\hline Seção & Vazões & $\begin{array}{c}\text { Altura } \\
(\mathbf{m})\end{array}$ & $\begin{array}{c}\text { Vazão seção } \\
\text { irregular } \\
\left(\mathbf{m}^{3} / \mathbf{s}\right)\end{array}$ & $\begin{array}{c}\text { Vazão } \\
\text { seção regular } \\
\left(\mathbf{m}^{3} / \mathbf{s}\right)\end{array}$ & $\begin{array}{c}\text { Declividade } \\
(\mathbf{m} / \mathbf{m})\end{array}$ & n & $\underset{(\mathrm{m})}{\operatorname{Largura}}$ & $\begin{array}{c}\text { Soma dos } \\
\text { quadrados das } \\
\text { diferenças } \\
\left(\mathbf{m}^{3} / \mathbf{s}\right) \\
\end{array}$ \\
\hline \multirow{8}{*}{$\begin{array}{l}\text { Miguel } \\
\text { Petroni }\end{array}$} & Q 1 & 0.17 & 0.387 & 0.424 & \multirow{8}{*}{0,0024} & \multirow{8}{*}{0.100} & \multirow{8}{*}{16.8} & \multirow{8}{*}{34,5} \\
\hline & Q 2 & 0.56 & 1.657 & 2.999 & & & & \\
\hline & Q 3 & 0.95 & 4.249 & 7.034 & & & & \\
\hline & Q 4 & 1.13 & 7.059 & 9.274 & & & & \\
\hline & Q 5 & 1.55 & 12.807 & 15.259 & & & & \\
\hline & Q 6 & 1.72 & 16.270 & 17.946 & & & & \\
\hline & Q 7 & 2.06 & 24.011 & 23.711 & & & & \\
\hline & Q 8 & 2.39 & 33.092 & 29.752 & & & & \\
\hline \multirow{8}{*}{ PC 1} & Q 1 & 0.25 & 0.364 & 1.707 & \multirow{8}{*}{0,0070} & \multirow{8}{*}{0.096} & \multirow{8}{*}{20} & \multirow{8}{*}{479,0} \\
\hline & Q 2 & 0.85 & 5.740 & 12.634 & & & & \\
\hline & Q 3 & 1 & 8.278 & 16.413 & & & & \\
\hline & Q 4 & 1.45 & 19.118 & 29.685 & & & & \\
\hline & Q 5 & 2.06 & 42.167 & 51.484 & & & & \\
\hline & Q 6 & 2.5 & 65.218 & 69.410 & & & & \\
\hline & Q 7 & 2.78 & 82.837 & 81.629 & & & & \\
\hline & Q 8 & 3.18 & 112.135 & 100.052 & & & & \\
\hline \multirow{8}{*}{ PC 2} & Q 1 & 0.28 & 0.522 & 1.034 & \multirow{8}{*}{0,0004} & \multirow{8}{*}{0.107} & \multirow{8}{*}{15} & \multirow{8}{*}{65,7} \\
\hline & Q 2 & 0.6 & 1.922 & 3.585 & & & & \\
\hline & Q 3 & 0.92 & 3.985 & 7.123 & & & & \\
\hline & Q 4 & 1.55 & 12.226 & 16.193 & & & & \\
\hline & Q 5 & 2.13 & 22.753 & 26.390 & & & & \\
\hline & Q 6 & 2.58 & 33.023 & 35.233 & & & & \\
\hline & Q 7 & 3.03 & 45.285 & 44.737 & & & & \\
\hline & Q 8 & 3.53 & 60.282 & 55.949 & & & & \\
\hline \multirow{8}{*}{ PC 3} & Q 1 & 0.3 & 0.947 & 1.650 & \multirow{8}{*}{0,0015} & \multirow{8}{*}{0.062} & \multirow{8}{*}{20} & \multirow{8}{*}{249,4} \\
\hline & Q 2 & 0.96 & 6.464 & 10.999 & & & & \\
\hline & Q 3 & 1.4 & 12.472 & 20.093 & & & & \\
\hline & Q 4 & 1.8 & 24.394 & 29.852 & & & & \\
\hline & Q 5 & 2.25 & 35.857 & 42.233 & & & & \\
\hline & Q 6 & 2.85 & 56.864 & 60.662 & & & & \\
\hline & Q 7 & 3.4 & 78.582 & 79.159 & & & & \\
\hline & Q 8 & 3.95 & 108.168 & 98.943 & & & & \\
\hline
\end{tabular}




\section{APÊNDICE C}

- Relações de precipitação efetiva versus precipitação total, entre as precipitações utilizadas na fase de calibração.

- Classificação das precipitações em função das condições de umidade antecedente, coeficiente de escoamento superficial e intensidade média. 


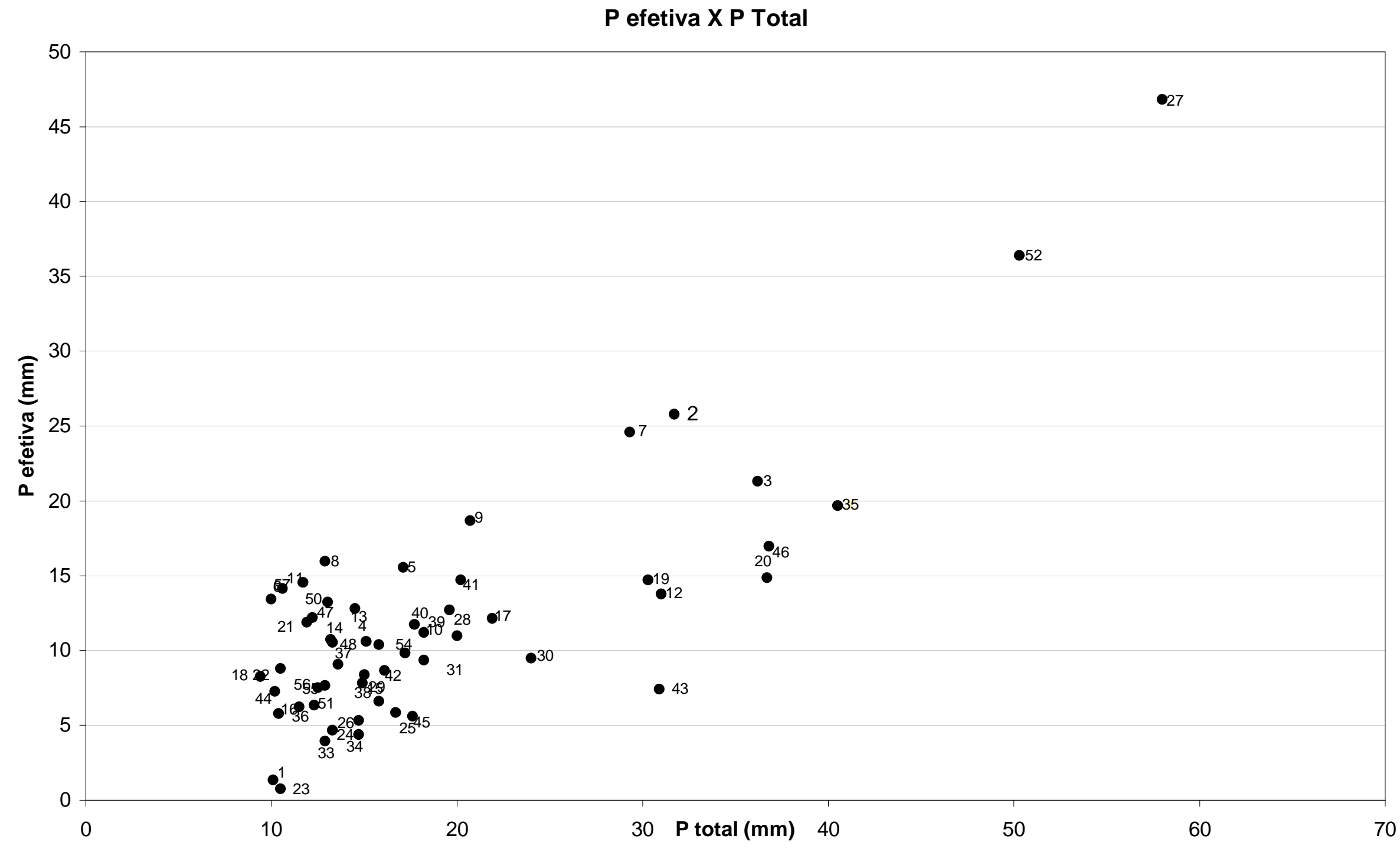

Figura C1 - Precipitação total versus precipitação efetiva (os números ao lado de cada ponto correspondem ao número do evento). 


\section{Umidade Antecedente - AMC I}

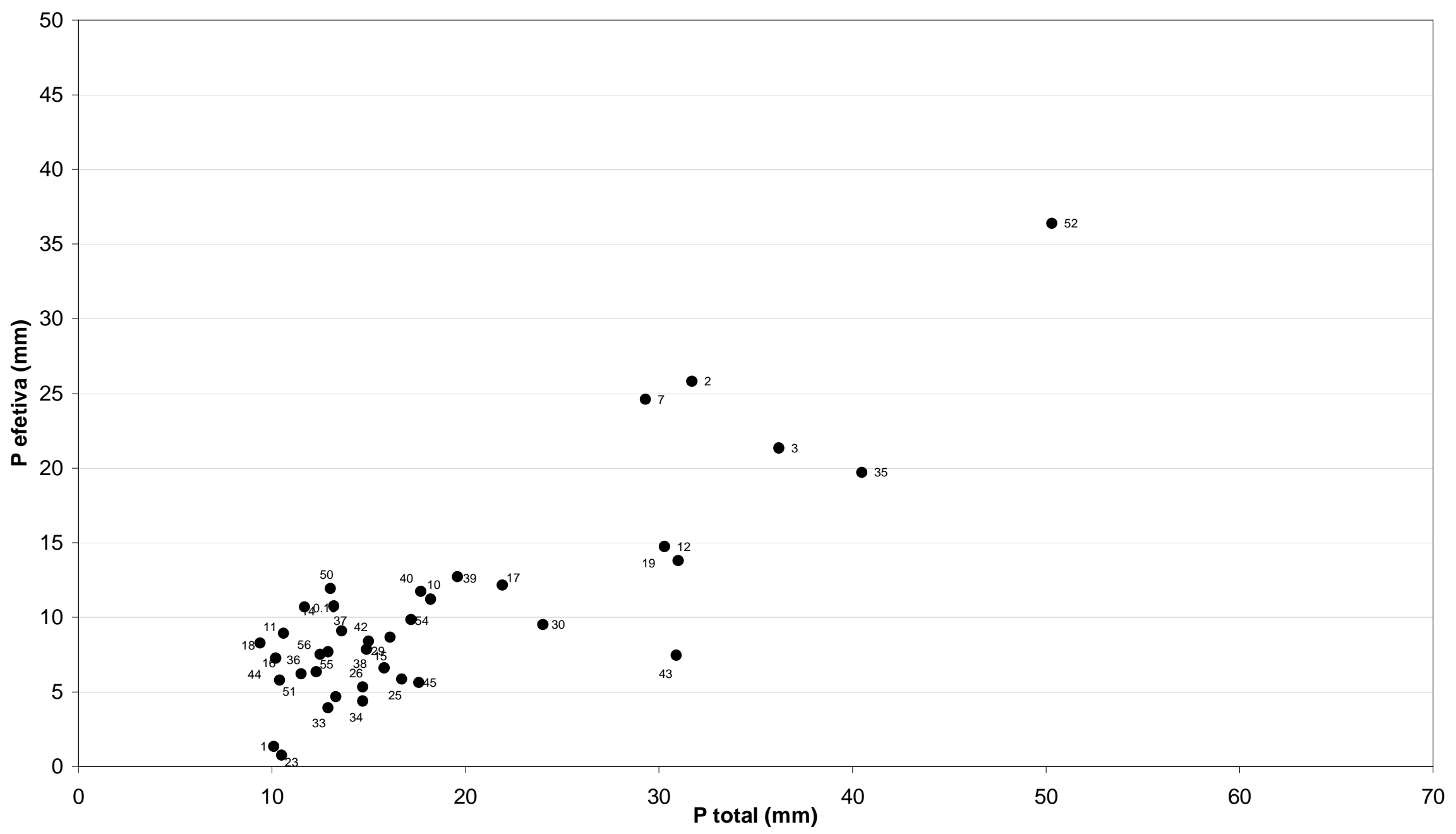

Figura C2 - Precipitação total versus precipitação efetiva para os eventos com condições de umidade antecedente I (os números ao lado de cada ponto correspondem ao número do evento). 


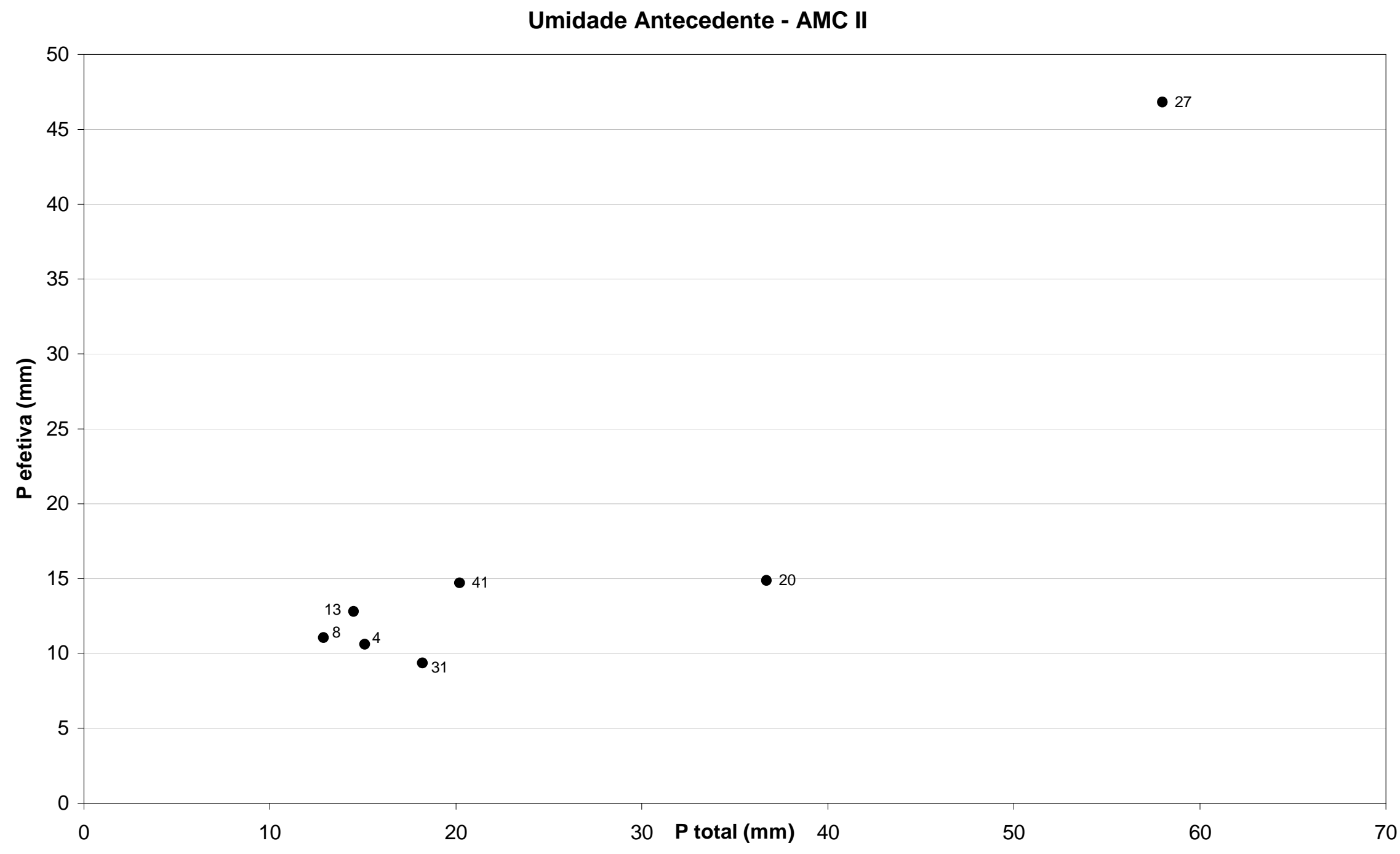

Figura C3 - Precipitação total versus precipitação efetiva para os eventos com condições de umidade antecedente II (os números ao lado de cada ponto correspondem ao número do evento). 


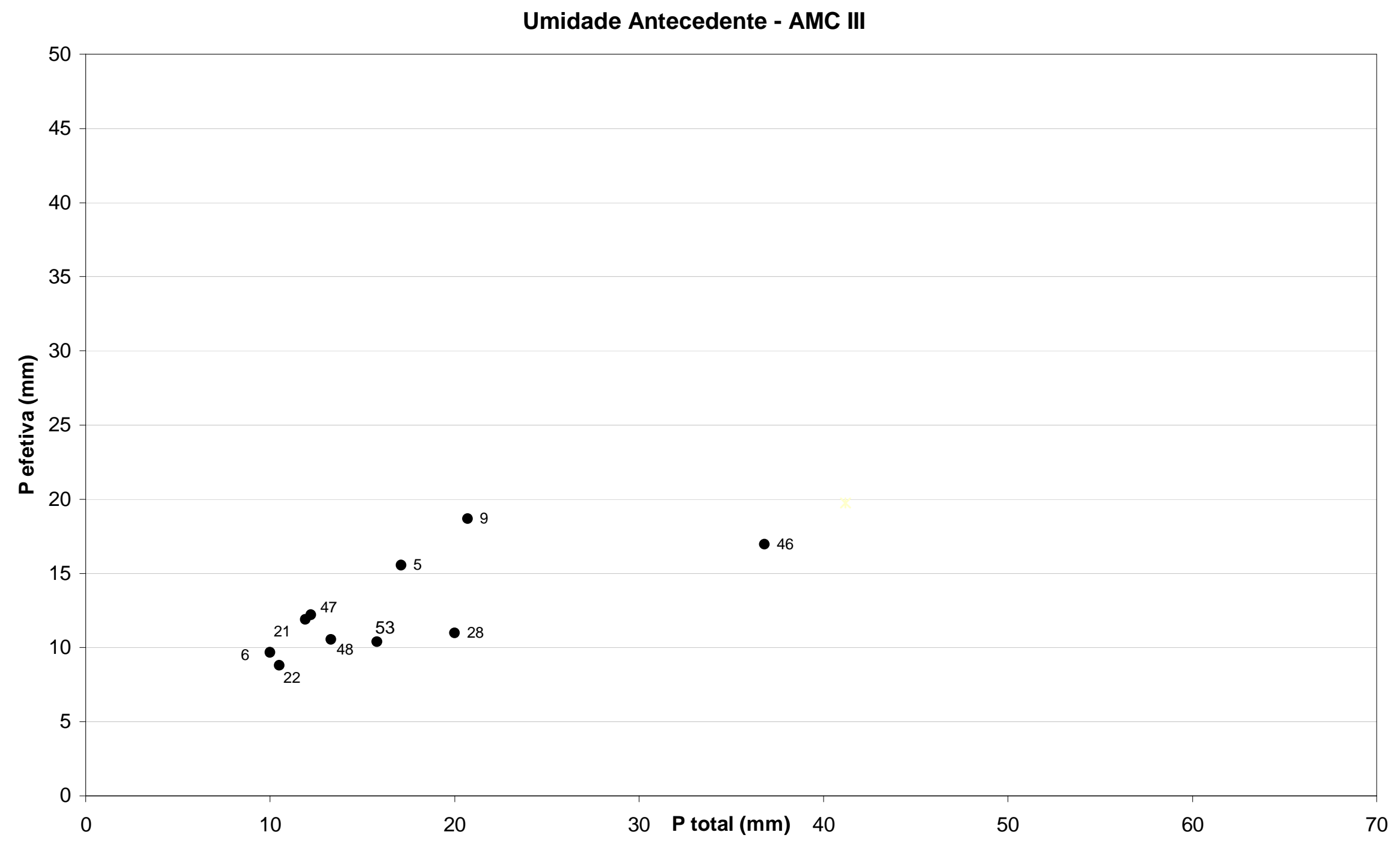

Figura C4 - Precipitação total versus precipitação efetiva para os eventos com condições de umidade antecedente III (os números ao lado de cada ponto correspondem ao número do evento). 


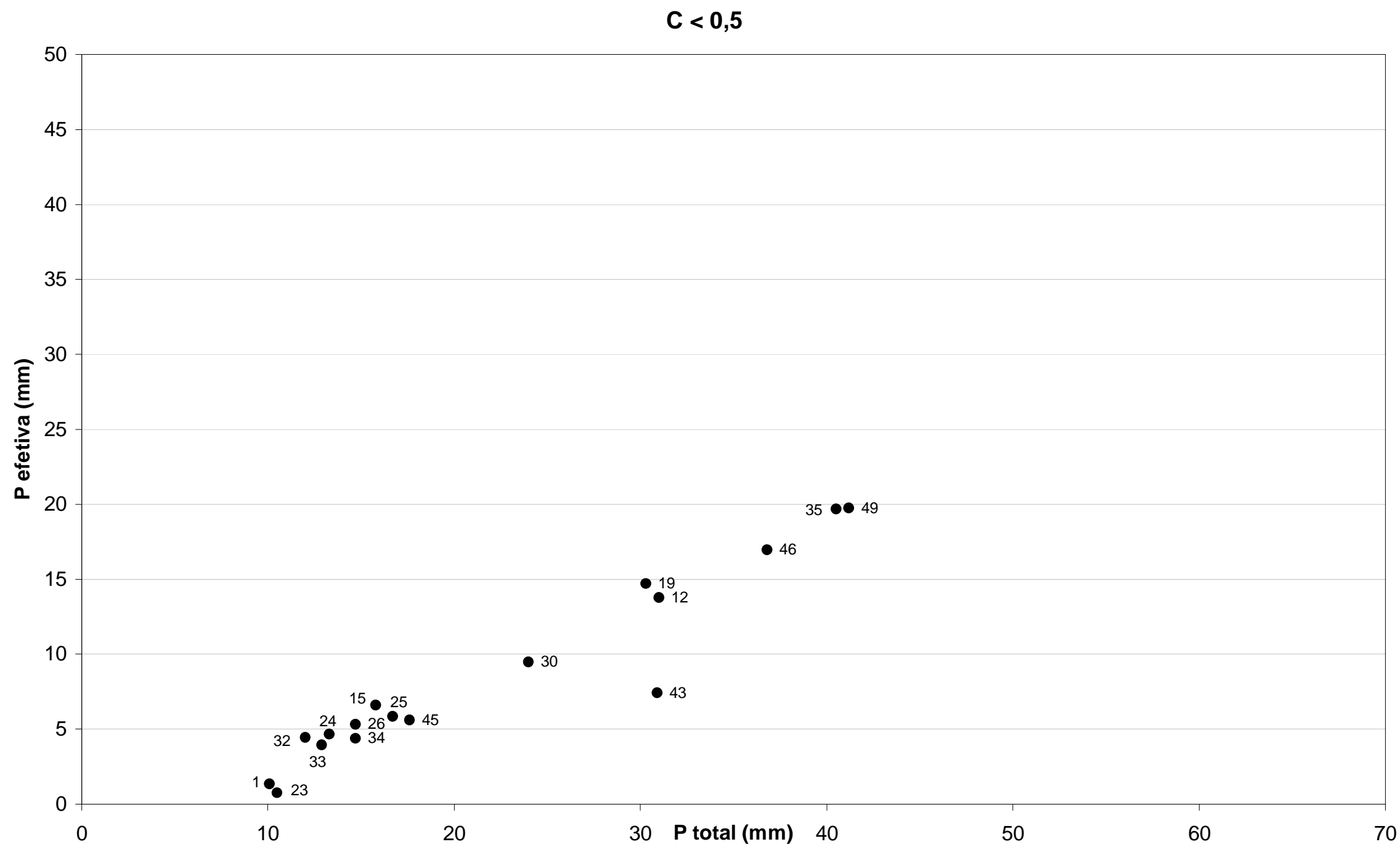

Figura C5 - Precipitação total versus precipitação efetiva para os eventos com coeficiente de escoamento superficial inferior a 0,50 (os números ao lado de cada ponto correspondem ao número do evento). 


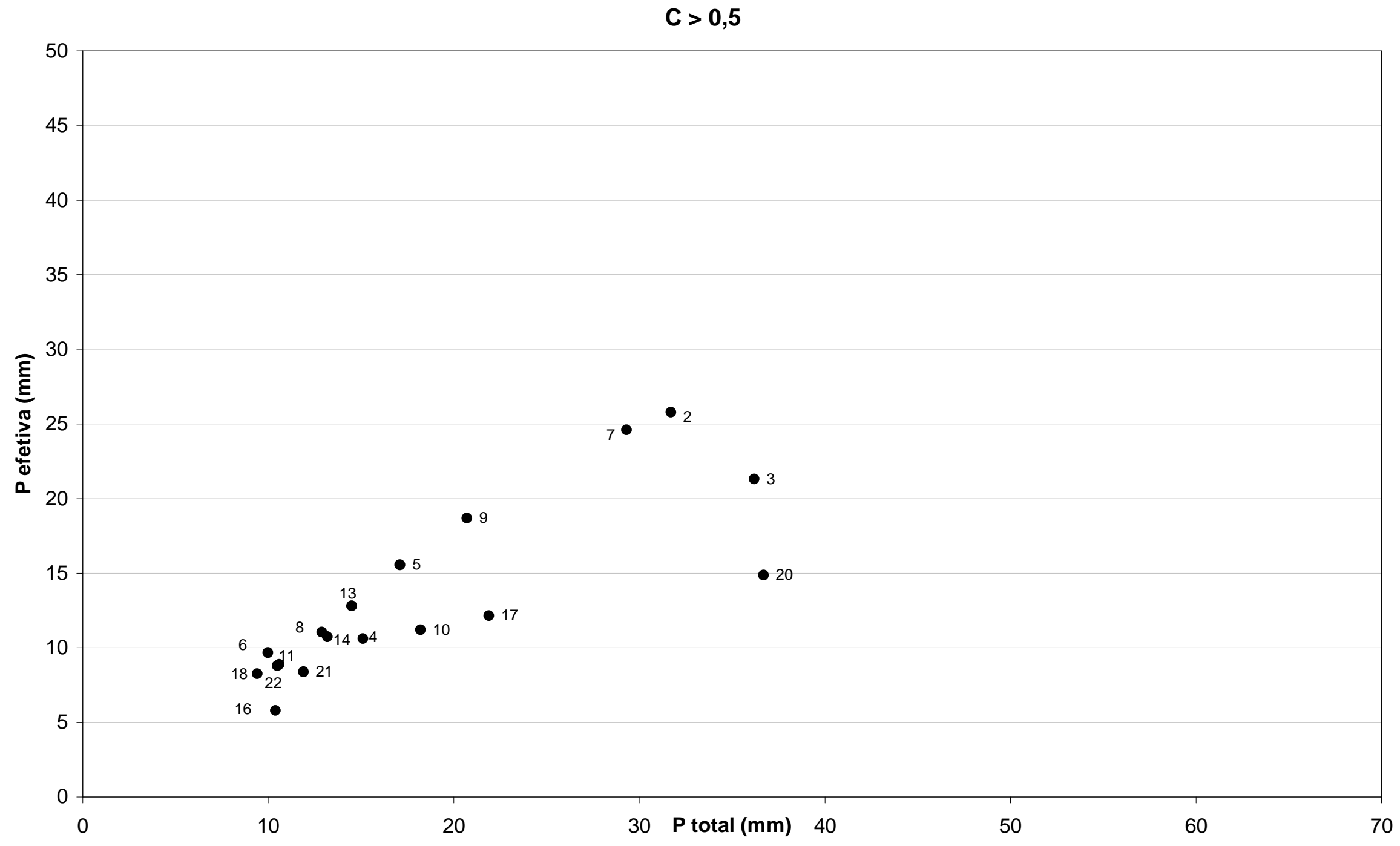

Figura C6 - Precipitação total versus precipitação efetiva para os eventos com coeficiente de escoamento superficial superior a 0,50 (os números ao lado de cada ponto correspondem ao número do evento). 


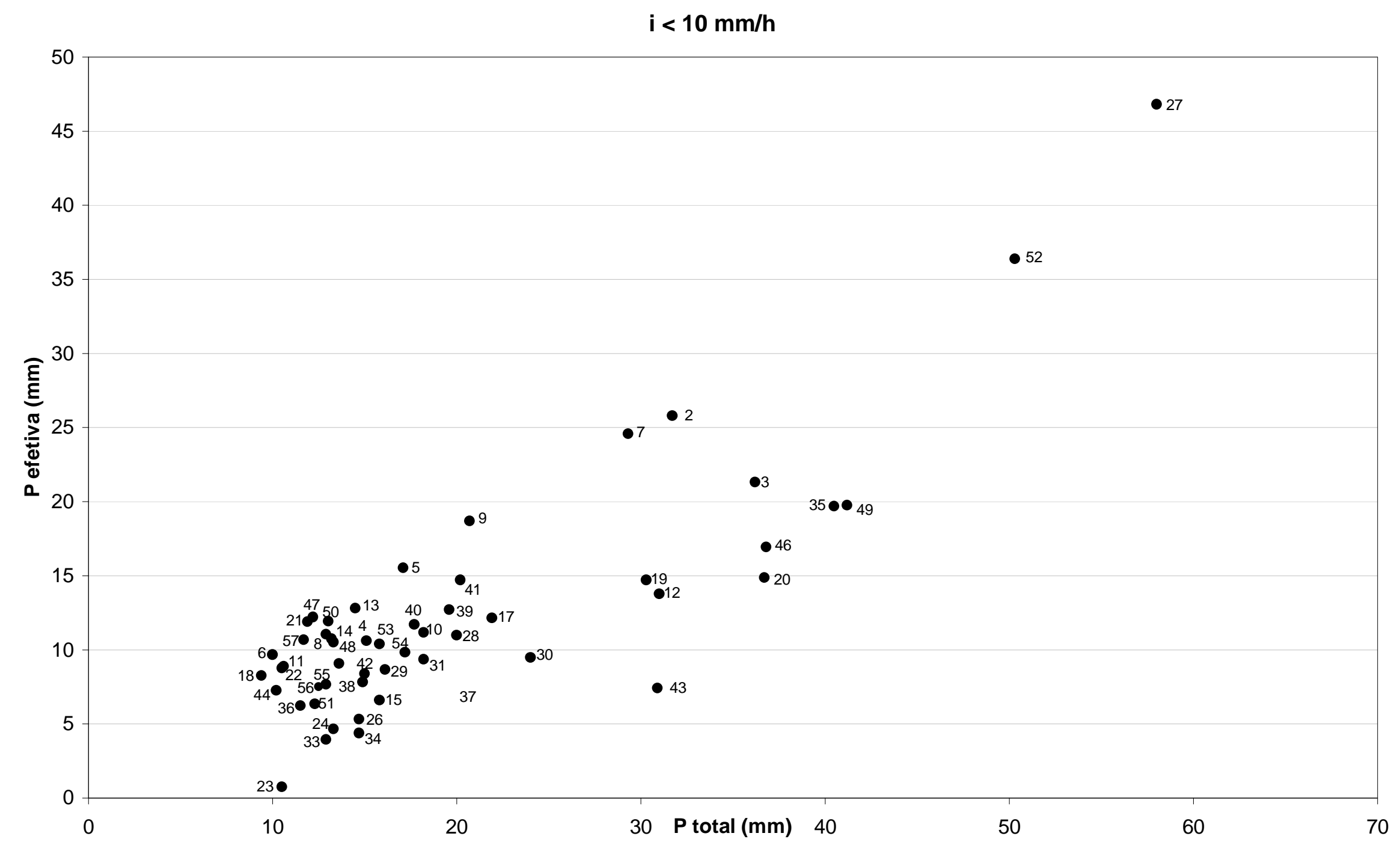

Figura C7 - Precipitação total versus precipitação efetiva para os eventos com intensidade média inferior à 10mm/h (os números ao lado de cada ponto correspondem ao número do evento). 


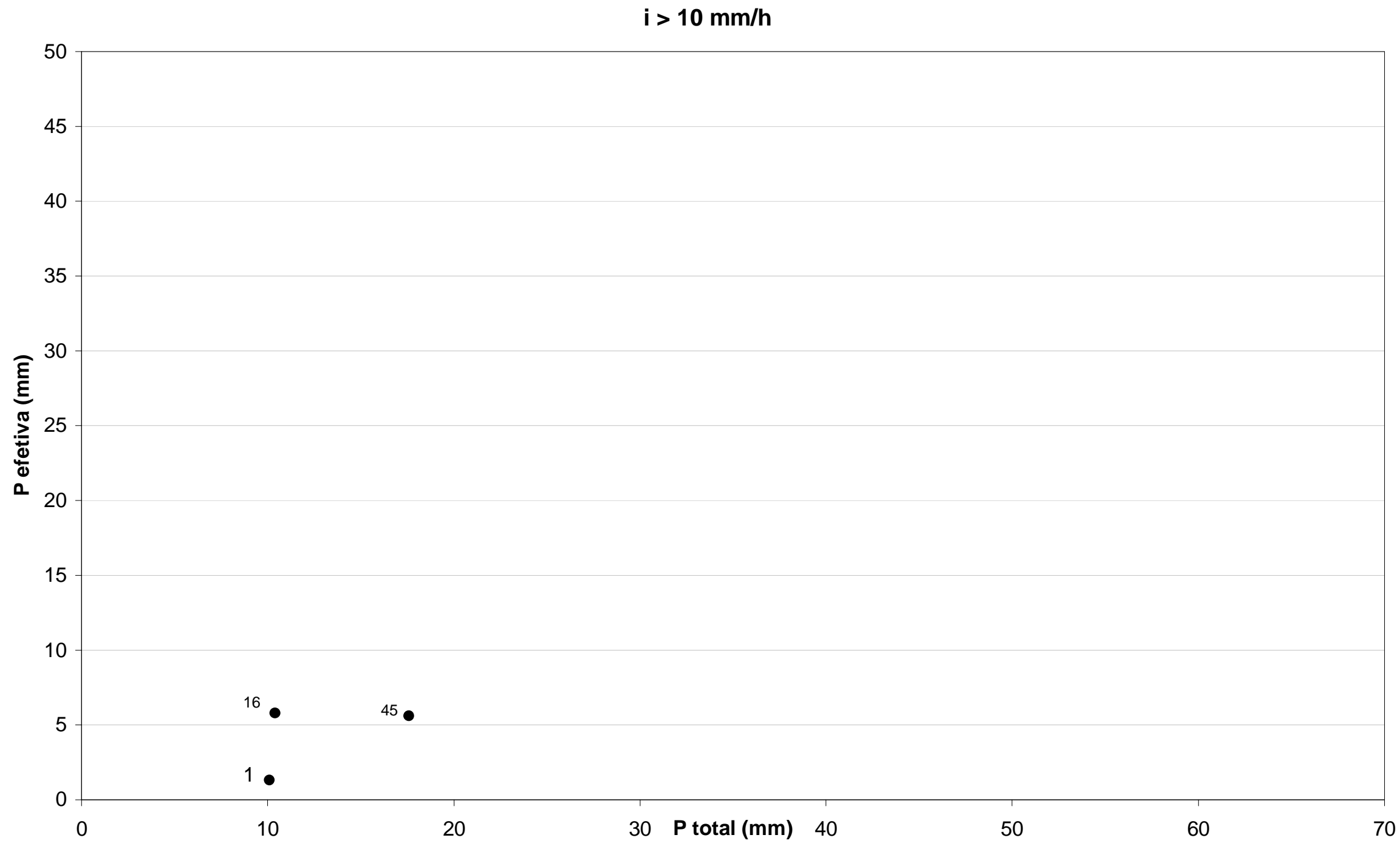

Figura C8 - Precipitação total versus precipitação efetiva para os eventos com intensidade média superior à $10 \mathrm{~mm} / \mathrm{h}$ (os números ao lado de cada ponto correspondem ao número do evento). 


\section{APÊNDICE D}

Valores dos parâmetros utilizados nas simulações dos cenários. Os parâmetros são apresentados de acordo com a divisão em módulo do sistema operacional IPH S1 (Módulo Bacia e Módulo Rio), de acordo com a seqüência:

- Global Orchestration;

- Order from Strength;

- Adapting Mosaic;

- TechnoGarden.

Para melhor entendimento da localização das "sub-bacias" e dos "trechos" indicados nas tabelas, ver ANEXO B. 
Tabela D1: Dados de entrada do modelo para o ano de referência - Módulo Bacia.

\begin{tabular}{|c|c|c|c|c|c|c|c|c|}
\hline & $\begin{array}{l}\text { Sub- } \\
\text { bacia }\end{array}$ & $\begin{array}{c}\text { Área } \\
\left(\mathbf{k m}^{2}\right)\end{array}$ & $\mathrm{CN}$ & $\begin{array}{c}\mathbf{L} \\
(\mathbf{m})\end{array}$ & $\begin{array}{l}\mathbf{C M} \\
(\mathbf{m})\end{array}$ & $\begin{array}{c}\text { CJ } \\
(\mathbf{m})\end{array}$ & $\begin{array}{c}\mathbf{S} \\
(\mathbf{m} / \mathbf{m})\end{array}$ & $\begin{array}{c}\text { Tc } \\
(\mathrm{min})\end{array}$ \\
\hline \multirow{27}{*}{ Monjolinho } & 1 & 2,40 & 58 & 1350,2 & 910,0 & 871,6 & 0,028 & 114,0 \\
\hline & 2 & 0,51 & 58 & 918,3 & 871,6 & 858,0 & 0,015 & 116,0 \\
\hline & 3 & 0,74 & 58 & 1193,3 & 890,0 & 858,0 & 0,027 & 106,3 \\
\hline & 4 & 0,76 & 58 & 944,6 & 858,0 & 855,0 & 0,003 & 256,3 \\
\hline & 5 & 1,85 & 58 & 2209,3 & 895,0 & 855,0 & 0,018 & 211,8 \\
\hline & 6 & 0,06 & 65 & 373,5 & 855,0 & 850,0 & 0,013 & 49,7 \\
\hline & 7 & 1,37 & 72 & 2018,8 & 898,0 & 850,0 & 0,024 & 118,1 \\
\hline & 8 & 1,31 & 65 & 1440,9 & 898,0 & 850,0 & 0,033 & 92,8 \\
\hline & 9 & 0,22 & 65 & 436,3 & 850,0 & 840,0 & 0,023 & 43,0 \\
\hline & 10 & 1,80 & 65 & 1316,2 & 877,0 & 838,0 & 0,030 & 91,6 \\
\hline & 11 & 0,36 & 72 & 585,4 & 840,0 & 839,0 & 0,002 & 163,6 \\
\hline & 12 & 1,95 & 80 & 2168,6 & 898,0 & 838,0 & 0,028 & 92,1 \\
\hline & 13 & 0,52 & 72 & 736,3 & 839,0 & 838,0 & 0,001 & 220,5 \\
\hline & 14 & 1,99 & 58 & 2116,7 & 898,0 & 836,0 & 0,029 & 160,9 \\
\hline & 15 & 0,70 & 80 & 738,8 & 838,0 & 837,5 & 0,001 & 248,9 \\
\hline & 16 & 2,22 & 88 & 2189,1 & 879,0 & 837,5 & 0,019 & 84,3 \\
\hline & 17 & 0,98 & 80 & 837,0 & 837,5 & 837,0 & 0,001 & 292,8 \\
\hline & 18 & 2,33 & 65 & 2463,2 & 876,0 & 836,0 & 0,016 & 204,2 \\
\hline & 19 & 0,18 & 80 & 321,0 & 837,0 & 836,0 & 0,003 & 59,6 \\
\hline & 20 & 1,06 & 80 & 1540,7 & 859,0 & 835,0 & 0,016 & 93,4 \\
\hline & 21 & 0,26 & 88 & 410,0 & 836,0 & 835,0 & 0,002 & 61,6 \\
\hline & 22 & 3,64 & 65 & 2434,6 & 862,0 & 832,0 & 0,012 & 232,2 \\
\hline & 23 & 2,68 & 93 & 1568,0 & 835,0 & 825,0 & 0,006 & 89,4 \\
\hline & 24 & 3,64 & 72 & 2619,8 & 879,0 & 825,0 & 0,021 & 156,2 \\
\hline & 25 & 0,66 & 93 & 629,9 & 825,0 & 820,0 & 0,008 & 38,6 \\
\hline & 26 & 1,12 & 93 & 1166,4 & 858,0 & 819,0 & 0,033 & 30,8 \\
\hline & 27 & 1,06 & 93 & 1178,4 & 820,0 & 810,0 & 0,008 & 61,7 \\
\hline \multirow{6}{*}{$\begin{array}{l}\text { Sta Maria } \\
\text { Madalena }\end{array}$} & 28 & 5,24 & 65 & 1691,2 & 858,0 & 837,0 & 0,012 & 172,8 \\
\hline & 29 & 0,47 & 65 & 626,9 & 837,0 & 829,0 & 0,013 & 77,1 \\
\hline & 30 & 2,18 & 65 & 1257,5 & 857,0 & 829,0 & 0,022 & 101,8 \\
\hline & 31 & 1,29 & 72 & 1328,5 & 829,0 & 816,0 & 0,010 & 131,7 \\
\hline & 32 & 1,54 & 65 & 1212,4 & 855,0 & 816,0 & 0,032 & 82,3 \\
\hline & 33 & 1,22 & 88 & 1184,4 & 816,0 & 810,0 & 0,005 & 99,8 \\
\hline Outras & 34 & 0,14 & 93 & 229,2 & 810,0 & 805,0 & 0,022 & 10,4 \\
\hline \multirow{2}{*}{ Tijuco Preto } & 35 & 2,01 & 93 & 1385,0 & 860,0 & 815,0 & 0,032 & 35,9 \\
\hline & 36 & 1,39 & 93 & 1457,5 & 815,0 & 805,0 & 0,007 & 81,3 \\
\hline \multirow{5}{*}{ Outras } & 37 & 0,31 & 93 & 223,0 & 805,0 & 800,0 & 0,022 & 10,0 \\
\hline & 38 & 0,32 & 80 & 458,5 & 800,0 & 785,0 & 0,033 & 24,4 \\
\hline & 39 & 0,66 & 88 & 879,2 & 800,0 & 785,0 & 0,017 & 42,8 \\
\hline & 40_a & 0,24 & 80 & 431,0 & 785,0 & 783,0 & 0,005 & 61,8 \\
\hline & 40_b & 0,84 & 80 & 1174,6 & 783,0 & 780,0 & 0,003 & 185,7 \\
\hline \multirow{2}{*}{ Mineirinho } & 41 & 3,14 & 80 & 1758,6 & 858,0 & 823,0 & 0,020 & 91,9 \\
\hline & 42 & 2,56 & 80 & 2149,2 & 823,0 & 780,0 & 0,020 & 107,6 \\
\hline
\end{tabular}




\begin{tabular}{ccccccccc}
\hline \multicolumn{6}{c}{ Continuação da Tabela D1: Dados de entrada do modelo para o ano de referência - Módulo Bacia. } \\
\hline & $\begin{array}{c}\text { Sub- } \\
\text { bacia }\end{array}$ & $\begin{array}{c}\text { Área } \\
\left(\mathbf{k m}^{2}\right)\end{array}$ & $\mathbf{C N}$ & $\begin{array}{c}\mathbf{L} \\
\mathbf{( m )}\end{array}$ & $\begin{array}{c}\mathbf{C M} \\
\mathbf{( m )}\end{array}$ & $\begin{array}{c}\mathbf{C J} \\
(\mathbf{m})\end{array}$ & $\begin{array}{c}\mathbf{S} \\
(\mathbf{m} / \mathbf{m})\end{array}$ & $\begin{array}{c}\text { Tc } \\
(\mathbf{m i n})\end{array}$ \\
\hline \multirow{6}{*}{ Gregório } & 43 & 1,55 & 83 & 1831,7 & 912,0 & 850,0 & 0,034 & 65,5 \\
& 44 & 1,19 & 85 & 1688,4 & 899,0 & 850,0 & 0,029 & 62,6 \\
& 45 & 1,65 & 86 & 1433,6 & 850,0 & 845,0 & 0,003 & 149,3 \\
& 46 & 0,68 & 86 & 858,9 & 880,0 & 845,0 & 0,041 & 29,0 \\
& 47 & 0,63 & 90 & 546,6 & 845,0 & 840,0 & 0,009 & 37,4 \\
& 48 & 1,22 & 86 & 1853,5 & 900,0 & 840,0 & 0,032 & 60,2 \\
& 50 & 0,72 & 90 & 812,0 & 840,0 & 815,0 & 0,031 & 28,0 \\
& 51 & 0,94 & 86 & 482,4 & 877,0 & 858,0 & 0,039 & 18,6 \\
& 52 & 2,27 & 92 & 1489,4 & 815,0 & 800,0 & 0,010 & 73,9 \\
& 53 & 3,74 & 93 & 912,1 & 838,0 & 800,0 & 0,042 & 22,7 \\
& 54 & 1,28 & 95 & 664,1 & 800,0 & 780,0 & 0,030 & 19,0 \\
\multirow{6}{*}{ Exutório } & 55 & 0,62 & 95 & 1816,9 & 780,0 & 770,0 & 0,006 & 99,3 \\
\hline & 56 & 0,10 & 95 & 278,3 & 780,0 & 770,0 & 0,036 & 8,7 \\
& 57 & 0,71 & 88 & 450,9 & 770,0 & 760,0 & 0,022 & 22,0 \\
\hline
\end{tabular}


TabelaD2: Dados de entrada do modelo para o ano de referência - Módulo Rio.

\begin{tabular}{|c|c|c|c|c|c|c|c|c|c|}
\hline \multirow[b]{2}{*}{ Bacia } & \multirow[b]{2}{*}{ Trecho } & \multirow{2}{*}{$\begin{array}{c}\mathbf{L} \\
(\mathbf{m})\end{array}$} & \multirow{2}{*}{$\begin{array}{c}\mathbf{S} \\
(\mathbf{m} / \mathbf{m})\end{array}$} & \multicolumn{3}{|c|}{ Canal } & \multicolumn{3}{|c|}{ Planície de Inundação } \\
\hline & & & & $\begin{array}{c}\text { Altura } \\
(\mathbf{m})\end{array}$ & $\begin{array}{c}\text { Largura } \\
\text { (m) }\end{array}$ & $\mathbf{n}$ & $\begin{array}{c}\text { Altura } \\
(\mathbf{m})\end{array}$ & $\begin{array}{c}\text { Largura } \\
\text { (m) }\end{array}$ & $\mathbf{n}$ \\
\hline \multirow{20}{*}{ Monjolinho } & 1.2 .1 & 918,32 & 0,015 & 1,0 & 1,2 & 0,35 & \multirow{20}{*}{$\begin{array}{l}1,0 \\
1,0\end{array}$} & \multirow{20}{*}{$\begin{array}{l}100,0 \\
100,0\end{array}$} & \multirow{20}{*}{$\begin{array}{l}0,25 \\
0,30\end{array}$} \\
\hline & 1.3 .1 & 944,55 & 0,003 & 1,0 & 1,2 & 0,34 & & & \\
\hline & 1.4 .1 & 373,46 & 0,013 & 1,0 & 2,0 & 0,34 & & & \\
\hline & 1.5 .1 & 436,33 & 0,023 & 1,0 & 2,0 & 0,33 & & & \\
\hline & 1.6 .1 & 585,41 & 0,002 & 1,0 & 3,0 & 0,32 & & & \\
\hline & 1.7.1 & 736,25 & 0,001 & 1,0 & 3,5 & 0,32 & & & \\
\hline & 1.8 .1 & 738,76 & 0,001 & 2,0 & 3,5 & 0,32 & & & \\
\hline & 1.9 .1 & 837,00 & 0,001 & 3,0 & 4,0 & 0,30 & & & \\
\hline & 1.10 .1 & 321,02 & 0,003 & 1,0 & 5,0 & 0,30 & & & \\
\hline & 1.11 .1 & 410,01 & 0,002 & 1,0 & 5,0 & 0,28 & & & \\
\hline & 1.12 .1 & 1568,01 & 0,006 & 1,0 & 5,0 & 0,20 & & & \\
\hline & 1.13 .1 & 629,92 & 0,008 & 1,0 & 5,0 & 0,20 & & & \\
\hline & 1.14 .1 & 1178,43 & 0,008 & 2,5 & 8,0 & 0,10 & & & \\
\hline & 3.2 .1 & 229,19 & 0,022 & 2,5 & 10,0 & 0,10 & & & \\
\hline & 5.2 .1 & 222,97 & 0,022 & 3,0 & 10,0 & 0,10 & & & \\
\hline & 5.3 .1 & 458,52 & 0,033 & 3,5 & 15,0 & 0,10 & & & \\
\hline & 5.4.1_a & 430,96 & 0,005 & 3,5 & 16,0 & 0,11 & & & \\
\hline & 5.4.1_b & 1174,64 & 0,003 & 3,5 & 16,0 & 0,10 & & & \\
\hline & 10.2 .1 & 278,25 & 0,036 & 3,5 & 18,0 & 0,10 & & & \\
\hline & 11.2 .1 & 450,93 & 0,022 & 3,5 & 18,0 & 0,06 & & & \\
\hline Tijuco Preto & 4.2 .1 & 1457,51 & 0,007 & 1,5 & 3,5 & 0,02 & & & \\
\hline \multirow{3}{*}{$\begin{array}{l}\text { Sta Maria } \\
\text { do Leme }\end{array}$} & 2.2 .1 & 626,90 & 0,013 & 1,4 & 1,9 & 0,32 & & & \\
\hline & 2.3.1 & 1328,52 & 0,010 & 1,5 & 3,0 & 0,30 & & & \\
\hline & 2.4 .1 & 1184,43 & 0,005 & 1,5 & 3,0 & 0,28 & & & \\
\hline Mineirinho & 6.2 .1 & 2149,17 & 0,020 & 0,6 & 3,8 & 0,06 & & & \\
\hline \multirow{7}{*}{ Gregório } & 7.2 .1 & 1433,63 & 0,003 & 2,5 & 5,0 & 0,20 & & & \\
\hline & 7.3.1 & 546,60 & 0,009 & 3,0 & 10,0 & 0,10 & & & \\
\hline & 7.4.1 & 812,02 & 0,031 & 3,2 & 20,0 & 0,10 & & & \\
\hline & 9.2 .1 & 1489,44 & 0,010 & 3,0 & 20,0 & 0,02 & & & \\
\hline & 9.3 .1 & 664,06 & 0,030 & 3,0 & 20,0 & 0,03 & \multirow{3}{*}{1,0} & \multirow{3}{*}{60,0} & \multirow{3}{*}{0,250} \\
\hline & 9.4 .1 & 1816,90 & 0,006 & 2,5 & 10,0 & 0,20 & & & \\
\hline & 8.2 .1 & 1350,38 & 0,032 & 2,5 & 5,0 & 0,10 & & & \\
\hline
\end{tabular}


TabelaD3: Dados de entrada do modelo para o cenário GO 2025 - Módulo Bacia.

\begin{tabular}{|c|c|c|c|c|c|c|c|c|}
\hline & $\begin{array}{c}\text { Sub- } \\
\text { bacia }\end{array}$ & $\begin{array}{l}\text { Área } \\
\left(\mathbf{k m}^{2}\right)\end{array}$ & $\mathrm{CN}$ & $\begin{array}{c}\mathbf{L} \\
(\mathbf{m})\end{array}$ & $\mathbf{C M}$ & CJ & $\begin{array}{c}\mathbf{S} \\
(\mathbf{m} / \mathbf{m}) \\
\end{array}$ & $\begin{array}{c}\text { Tc } \\
\text { (min) }\end{array}$ \\
\hline \multirow{27}{*}{ Monjolinho } & 1 & 2,40 & 58 & 1350,23 & 910,0 & 871,6 & 0,028 & 112,9 \\
\hline & 2 & 0,51 & 59 & 903,00 & 871,6 & 857,0 & 0,016 & 105,9 \\
\hline & 3 & 0,74 & 58 & 1193,32 & 890,0 & 857,0 & 0,028 & 104,7 \\
\hline & 4 & 0,76 & 58 & 939,92 & 857,0 & 854,0 & 0,003 & 254,6 \\
\hline & 5 & 1,85 & 58 & 2209,28 & 895,0 & 854,0 & 0,017 & 209,2 \\
\hline & 6 & 0,06 & 65 & 369,05 & 854,0 & 849,0 & 0,013 & 49,0 \\
\hline & 7 & 1,37 & 77 & 2018,83 & 898,0 & 849,0 & 0,024 & 101,4 \\
\hline & 8 & 1,31 & 65 & 1440,90 & 898,0 & 849,0 & 0,034 & 91,9 \\
\hline & 9 & 0,22 & 65 & 428,86 & 849,0 & 838,0 & 0,026 & 40,1 \\
\hline & 10 & 1,80 & 65 & 1316,21 & 877,0 & 838,0 & 0,030 & 91,6 \\
\hline & 11 & 0,36 & 72 & 585,41 & 838,0 & 837,0 & 0,008 & 163,6 \\
\hline & 12 & 1,95 & 85 & 2168,56 & 898,0 & 837,0 & 0,028 & 77,2 \\
\hline & 13 & 0,52 & 77 & 635,97 & 837,0 & 836,0 & 0,002 & 158,1 \\
\hline & 14 & 1,99 & 58 & 2116,66 & 898,0 & 836,0 & 0,029 & 160,9 \\
\hline & 15 & 0,70 & 85 & 717,41 & 836,0 & 835,5 & 0,001 & 202,4 \\
\hline & 16 & 2,22 & 92 & 2189,14 & 879,0 & 835,5 & 0,020 & 70,4 \\
\hline & 17 & 0,98 & 85 & 814,76 & 835,5 & 835,0 & 0,001 & 238,8 \\
\hline & 18 & 2,33 & 65 & 2463,18 & 876,0 & 835,0 & 0,017 & 201,7 \\
\hline & 19 & 0,18 & 80 & 321,02 & 835,0 & 834,0 & 0,003 & 59,6 \\
\hline & 20 & 1,06 & 85 & 1540,68 & 859,0 & 834,0 & 0,016 & 77,3 \\
\hline & 21 & 0,26 & 92 & 402,40 & 834,0 & 832,0 & 0,005 & 36,3 \\
\hline & 22 & 3,64 & 70 & 2434,62 & 862,0 & 832,0 & 0,012 & 201,4 \\
\hline & 23 & 2,68 & 94 & 1541,31 & 832,0 & 825,0 & 0,004 & 101,3 \\
\hline & 24 & 3,64 & 78 & 2619,82 & 879,0 & 825,0 & 0,021 & 131,5 \\
\hline & 25 & 0,66 & 98 & 606,87 & 825,0 & 818,5 & 0,011 & 25,2 \\
\hline & 26 & 1,12 & 94 & 1166,43 & 858,0 & 818,5 & 0,034 & 29,7 \\
\hline & 27 & 1,06 & 98 & 1166,93 & 818,5 & 808,0 & 0,009 & 46,5 \\
\hline \multirow{6}{*}{$\begin{array}{l}\text { Sta Maria } \\
\text { Madalena }\end{array}$} & 28 & 5,24 & 65 & 1691,19 & 858,0 & 837,0 & 0,012 & 172,8 \\
\hline & 29 & 0,47 & 65 & 615,20 & 837,0 & 828,0 & 0,015 & 70,9 \\
\hline & 30 & 2,18 & 70 & 1257,45 & 857,0 & 828,0 & 0,023 & 86,8 \\
\hline & 31 & 1,29 & 72 & 1286,60 & 828,0 & 814,2 & 0,011 & 121,2 \\
\hline & 32 & 1,54 & 78 & 1212,37 & 855,0 & 814,2 & 0,0334 & 55,3 \\
\hline & 33 & 1,22 & 98 & 1165,40 & 814,2 & 808,0 & 0,005 & 60,4 \\
\hline Outras & 34 & 0,14 & 98 & 215,28 & 808,0 & 805,0 & 0,014 & 9,7 \\
\hline Tijuco & 35 & 2,01 & 98 & 1450,50 & 860,0 & 815,0 & 0,031 & 29,8 \\
\hline Preto & 36 & 1,39 & 98 & 1457,51 & 815,0 & 805,0 & 0,007 & 63,6 \\
\hline \multirow{5}{*}{ Outras } & 37 & 0,31 & 98 & 202,64 & 805,0 & 800,0 & 0,025 & 6,9 \\
\hline & 38 & 0,32 & 98 & 453,30 & 800,0 & 785,0 & 0,033 & 11,4 \\
\hline & 39 & 0,66 & 98 & 879,18 & 800,0 & 785,0 & 0,017 & 26,9 \\
\hline & 40_a & 0,24 & 98 & 430,96 & 785,0 & 783,0 & 0,005 & 29,2 \\
\hline & 40_b & 0,84 & 98 & 1150,99 & 783,0 & 779,0 & 0,003 & 73,9 \\
\hline \multirow{2}{*}{ Mineirinho } & 41 & 3,14 & 85 & 1758,55 & 858,0 & 822,0 & 0,020 & 76,5 \\
\hline & 42 & 2,56 & 85 & 2016,65 & 822,0 & 779,0 & 0,021 & 83,6 \\
\hline
\end{tabular}


Continuação da Tabela D3: Dados de entrada do modelo para o cenário GO 2025 - Módulo Bacia.

\begin{tabular}{ccccccccc}
\hline & $\begin{array}{c}\text { Sub- } \\
\text { bacia }\end{array}$ & $\begin{array}{c}\text { Área } \\
\left(\mathbf{k m}^{\mathbf{2}}\right)\end{array}$ & $\mathbf{C N}$ & $\begin{array}{c}\mathbf{L} \\
\mathbf{( m )}\end{array}$ & $\mathbf{C M}$ & $\mathbf{C J}$ & $\begin{array}{c}\mathbf{S} \\
(\mathbf{m} / \mathbf{m})\end{array}$ & $\begin{array}{c}\text { Tc } \\
(\mathbf{m i n})\end{array}$ \\
\hline \multirow{6}{*}{ Gregório } & 43 & 1,55 & 83 & 1831,66 & 912,0 & 850,0 & 0,034 & 65,5 \\
& 44 & 1,19 & 85 & 1688,37 & 899,0 & 850,0 & 0,029 & 62,6 \\
& 45 & 1,65 & 91 & 1410,00 & 850,0 & 845,0 & 0,003 & 122,3 \\
& 46 & 0,68 & 91 & 858,89 & 880,0 & 845,0 & 0,041 & 24,3 \\
& 47 & 0,63 & 95 & 543,60 & 845,0 & 824,0 & 0,039 & 14,4 \\
& 48 & 1,22 & 91 & 1853,49 & 900,0 & 824,0 & 0,041 & 44,8 \\
& 50 & 0,72 & 98 & 809,70 & 824,0 & 815,0 & 0,011 & 31,2 \\
& 51 & 0,94 & 98 & 482,37 & 877,0 & 858,0 & 0,039 & 11,0 \\
& 52 & 2,27 & 98 & 1350,38 & 858,0 & 815,0 & 0,032 & 27,8 \\
& 53 & 3,74 & 95 & 581,66 & 811,0 & 799,5 & 0,020 & 21,2 \\
& 54 & 1,28 & 98 & 658,36 & 799,5 & 779,0 & 0,031 & 15,8 \\
& 55 & 0,62 & 98 & 1802,69 & 779,0 & 767,0 & 0,008 & 76,5 \\
\hline \multirow{6}{*}{ Exutório } & 56 & 0,10 & 96 & 270,20 & 779,0 & 767,0 & 0,044 & 7,3 \\
& $57 \_a$ & 0,41 & 78 & 100,00 & 767,0 & 760,0 & 0,070 & 5,2 \\
& $57 \_b$ & 0,30 & 90 & 50,00 & 760,0 & 757,0 & 0,060 & 2,1 \\
\hline
\end{tabular}


Tabela D4: Dados de entrada do modelo para o cenário GO 2025 - Módulo Rio.

\begin{tabular}{|c|c|c|c|c|c|c|c|c|c|}
\hline & \multirow[b]{2}{*}{ Trecho } & \multirow{2}{*}{$\begin{array}{c}\mathbf{L} \\
(\mathbf{m})\end{array}$} & \multirow{2}{*}{$\begin{array}{c}\mathbf{S} \\
(\mathbf{m} / \mathbf{m})\end{array}$} & \multicolumn{3}{|c|}{ Canal } & \multicolumn{3}{|c|}{ Planície de Inundação } \\
\hline & & & & $\begin{array}{c}\begin{array}{c}\text { Altura } \\
(\mathbf{m})\end{array} \\
\text { (n) }\end{array}$ & $\begin{array}{c}\text { Largura } \\
\text { (m) }\end{array}$ & $\mathbf{n}$ & $\begin{array}{c}\text { Altura } \\
(\mathbf{m})\end{array}$ & $\begin{array}{l}\text { Largura } \\
\text { (m) }\end{array}$ & $\mathbf{n}$ \\
\hline \multirow{21}{*}{ Monjolinho } & 1.2 .1 & 903,0 & 0,016 & 1,0 & 1,2 & 0,34 & \multirow{21}{*}{$\begin{array}{l}1,0 \\
1,0\end{array}$} & \multirow{21}{*}{$\begin{array}{l}30,0 \\
30,0\end{array}$} & \multirow{21}{*}{$\begin{array}{l}0,20 \\
0,25\end{array}$} \\
\hline & 1.3 .1 & 939,9 & 0,003 & 1,0 & 1,2 & 0,33 & & & \\
\hline & 1.4 .1 & 369,1 & 0,014 & 1,0 & 2,0 & 0,33 & & & \\
\hline & 1.5.1 & 428,9 & 0,026 & 1,0 & 2,0 & 0,32 & & & \\
\hline & 1.6 .1 & 585,4 & 0,002 & 1,0 & 3,0 & 0,31 & & & \\
\hline & 1.7.1 & 636,0 & 0,002 & 1,0 & 3,5 & 0,29 & & & \\
\hline & 1.8 .1 & 717,4 & 0,001 & 1,0 & 3,5 & 0,26 & & & \\
\hline & 1.9 .1 & 814,8 & 0,001 & 1,0 & 4,0 & 0,25 & & & \\
\hline & 1.10 .1 & 321,0 & 0,003 & 1,0 & 5,0 & 0,19 & & & \\
\hline & 1.11 .1 & 402,4 & 0,005 & 1,0 & 5,0 & 0,19 & & & \\
\hline & 1.12 .1 & 1541,3 & 0,004 & 1,0 & 5,0 & 0,09 & & & \\
\hline & 1.13 .1 & 606,9 & 0,011 & 1,0 & 5,0 & 0,09 & & & \\
\hline & 1.14 .1 & 1166,9 & 0,009 & 2,5 & 8,0 & 0,07 & & & \\
\hline & 3.2 .1 & 215,3 & 0,014 & 2,5 & 10,0 & 0,02 & & & \\
\hline & 5.2 .1 & 202,6 & 0,025 & 3,0 & 10,0 & 0,02 & & & \\
\hline & 5.3 .1 & 453,3 & 0,033 & 3,5 & 15,0 & 0,02 & & & \\
\hline & 5.4.1_a & 431,0 & 0,005 & 3,5 & 16,0 & 0,02 & & & \\
\hline & 5.4.1_b & 1151,0 & 0,003 & 3,5 & 16,0 & 0,02 & & & \\
\hline & 10.2.1 & 270,2 & 0,044 & 3,5 & 18,0 & 0,02 & & & \\
\hline & 11.2.1_a & 100,0 & 0,070 & 3,5 & 18,0 & 0,02 & & & \\
\hline & 11.2.1_b & 50,0 & 0,060 & 2,0 & 8,0 & 0,02 & & & \\
\hline Tijuco Preto & 4.2 .1 & 1457,5 & 0,007 & 1,5 & 3,5 & 0,015 & & & \\
\hline \multirow{3}{*}{$\begin{array}{l}\text { Sta Maria } \\
\text { do Leme }\end{array}$} & 2.2 .1 & 615,2 & 0,015 & 1,4 & 1,9 & 0,31 & & & \\
\hline & 2.3.1 & 1286,6 & 0,011 & 1,5 & 3,0 & 0,02 & & & \\
\hline & 2.4 .1 & 1165,4 & 0,005 & 1,5 & 3,0 & 0,02 & & & \\
\hline Mineirinho & 6.2 .1 & 2016,7 & 0,021 & 0,6 & 3,8 & 0,04 & & & \\
\hline \multirow{7}{*}{ Gregório } & 7.2 .1 & 1410,0 & 0,003 & 2,5 & 5,0 & 0,09 & & & \\
\hline & 7.3.1 & 543,6 & 0,039 & 3,0 & 10,0 & 0,07 & & & \\
\hline & 7.4.1 & 809,7 & 0,011 & 3,0 & 10,0 & 0,05 & & & \\
\hline & 9.2 .1 & 1466,0 & 0,011 & 3,0 & 10,0 & 0,025 & & & \\
\hline & 9.3 .1 & 658,4 & 0,031 & 3,0 & 8,0 & 0,02 & \multirow{3}{*}{1,0} & \multirow{3}{*}{30,0} & \multirow{3}{*}{0,20} \\
\hline & 9.4 .1 & 1802,7 & 0,008 & 2,5 & 8,0 & 0,02 & & & \\
\hline & 8.2.1 & 1350,4 & 0,032 & 2,5 & 5,0 & 0,09 & & & \\
\hline
\end{tabular}


Tabela D5: Dados de entrada do modelo para o cenário GO 2050 - Módulo Bacia.

\begin{tabular}{|c|c|c|c|c|c|c|c|c|}
\hline & $\begin{array}{l}\text { Sub- } \\
\text { bacia }\end{array}$ & $\begin{array}{l}\text { Área } \\
\left(\mathbf{k m}^{2}\right)\end{array}$ & $\mathbf{C N}$ & $\begin{array}{c}\mathbf{L} \\
(\mathbf{m})\end{array}$ & $\begin{array}{l}\text { CM } \\
(\mathbf{m})\end{array}$ & $\begin{array}{l}\text { CJ } \\
(\mathbf{m})\end{array}$ & $\begin{array}{c}\mathbf{S} \\
(\mathbf{m} / \mathbf{m})\end{array}$ & $\begin{array}{c}\text { Tc } \\
\text { (min) }\end{array}$ \\
\hline \multirow{26}{*}{ Monjolinho } & 1 & 2,40 & 58 & 1350,23 & 910,0 & 871,6 & 0,028 & 113,3 \\
\hline & 2 & 0,51 & 60 & 901,18 & 871,6 & 857,0 & 0,016 & 103,6 \\
\hline & 3 & 0,74 & 58 & 1185,59 & 890,0 & 857,0 & 0,028 & 103,8 \\
\hline & 4 & 0,76 & 63 & 922,33 & 857,0 & 854,0 & 0,003 & 214,6 \\
\hline & 5 & 1,85 & 59 & 2173,61 & 895,0 & 854,0 & 0,019 & 197,0 \\
\hline & 6 & 0,06 & 98 & 364,04 & 854,0 & 849,0 & 0,014 & 14,8 \\
\hline & 7 & 1,37 & 80 & 2001,80 & 898,0 & 849,0 & 0,024 & 92,5 \\
\hline & 8 & 1,31 & 68 & 1396,93 & 898,0 & 849,0 & 0,035 & 80,7 \\
\hline & 9 & 0,22 & 98 & 425,84 & 849,0 & 838,0 & 0,026 & 12,2 \\
\hline & 10 & 1,80 & 68 & 1267,45 & 877,0 & 838,0 & 0,031 & 79,7 \\
\hline & 11 & 0,36 & 98 & 555,64 & 838,0 & 837,0 & 0,002 & 57,4 \\
\hline & 12 & 1,95 & 98 & 2137,09 & 898,0 & 837,0 & 0,029 & 42,3 \\
\hline & 13 & 0,52 & 98 & 635,97 & 837,0 & 836,0 & 0,002 & 68,4 \\
\hline & 14 & 1,99 & 65 & 2101,74 & 898,0 & 836,0 & 0,029 & 133,2 \\
\hline & 15 & 0,70 & 98 & 717,41 & 836,0 & 835,5 & 0,001 & 113,1 \\
\hline & 16 & 2,22 & 98 & 2112,79 & 879,0 & 835,5 & 0,021 & 49,4 \\
\hline & 17 & 0,98 & 98 & 814,76 & 835,5 & 835,0 & 0,001 & 133,5 \\
\hline & 18 & 2,33 & 68 & 2189,93 & 876,0 & 835,0 & 0,019 & 158,4 \\
\hline & 19 & 0,18 & 98 & 321,02 & 835,0 & 834,0 & 0,003 & 28,1 \\
\hline & 20 & 1,06 & 98 & 1478,18 & 859,0 & 834,0 & 0,017 & 40,9 \\
\hline & 21 & 0,26 & 98 & 402,40 & 834,0 & 832,0 & 0,005 & 26,7 \\
\hline & 22 & 3,64 & 73 & 2410,94 & 862,0 & 832,0 & 0,012 & 183,1 \\
\hline & 23 & 2,68 & 98 & 1524,08 & 832,0 & 825,0 & 0,005 & 80,5 \\
\hline & 24 & 3,64 & 80 & 2506,53 & 879,0 & 825,0 & 0,022 & 116,8 \\
\hline & 25 & 0,66 & 98 & 606,87 & 825,0 & 818,5 & 0,011 & 25,2 \\
\hline & 26 & 1,12 & 95 & 1146,39 & 858,0 & 818,5 & 0,034 & 27,6 \\
\hline \multirow{7}{*}{$\begin{array}{l}\text { Sta Maria } \\
\text { Madalena }\end{array}$} & 27 & 1,06 & 98 & 1157,89 & 818,5 & 808,0 & 0,009 & 46,0 \\
\hline & 28 & 5,24 & 70 & 1691,19 & 858,0 & 837,0 & 0,012 & 149,9 \\
\hline & 29 & 0,47 & 80 & 615,20 & 837,0 & 825,0 & 0,020 & 39,9 \\
\hline & 30 & 2,18 & 72 & 1250,45 & 857,0 & 825,0 & 0,026 & 77,6 \\
\hline & 31 & 1,29 & 98 & 1268,18 & 825,0 & 814,2 & 0,009 & 51,0 \\
\hline & 32 & 1,54 & 98 & 1207,93 & 855,0 & 814,2 & 0,034 & 24,6 \\
\hline & 33 & 1,22 & 98 & 1165,40 & 814,2 & 808,0 & 0,005 & 60,4 \\
\hline Outras & 34 & 0,14 & 98 & 215,28 & 808,0 & 805,0 & 0,014 & 9,7 \\
\hline \multirow{2}{*}{ Tijuco Preto } & 35 & 2,01 & 98 & 1358,35 & 860,0 & 815,0 & 0,033 & 27,3 \\
\hline & 36 & 1,39 & 98 & 1447,06 & 815,0 & 805,0 & 0,007 & 63,0 \\
\hline \multirow{5}{*}{ Outras } & 37 & 0,31 & 98 & 202,64 & 805,0 & 800,0 & 0,025 & 6,9 \\
\hline & 38 & 0,32 & 98 & 452,06 & 800,0 & 785,0 & 0,033 & 11,3 \\
\hline & 39 & 0,66 & 98 & 628,19 & 790,0 & 785,0 & 0,008 & 30,1 \\
\hline & $40-\mathrm{a}$ & 0,24 & 98 & 430,96 & 785,0 & 783,0 & 0,005 & 29,2 \\
\hline & $40-b$ & 0,84 & 98 & 1146,24 & 783,0 & 770,0 & 0,011 & 40,8 \\
\hline \multirow{2}{*}{ Mineirinho } & 41 & 3,14 & 87 & 1473,94 & 858,0 & 822,0 & 0,024 & 56,6 \\
\hline & 42 & 2,56 & 98 & 1991,92 & 822,0 & 770,0 & 0,026 & 41,8 \\
\hline
\end{tabular}




\begin{tabular}{ccccccccc}
\hline \multicolumn{6}{c}{ Continuação da Tabela D5: Dados de entrada do modelo para o cenário GO 2050 - Módulo Bacia. } \\
\hline & $\begin{array}{c}\text { Sub- } \\
\text { bacia }\end{array}$ & $\begin{array}{c}\text { Área } \\
\left(\mathbf{k m}^{2}\right)\end{array}$ & $\mathbf{C N}$ & $\begin{array}{c}\mathbf{L} \\
(\mathbf{m})\end{array}$ & $\begin{array}{c}\mathbf{C M} \\
(\mathbf{m})\end{array}$ & $\begin{array}{c}\mathbf{C J} \\
(\mathbf{m})\end{array}$ & $\begin{array}{c}\mathbf{S} \\
(\mathbf{m} / \mathbf{m})\end{array}$ & $\begin{array}{c}\text { Tc } \\
(\mathbf{m i n})\end{array}$ \\
\hline \multirow{6}{*}{ Gregório } & 43 & 1,55 & 85 & 1827,32 & 912,0 & 850,0 & 0,034 & 61,3 \\
& 44 & 1,19 & 85 & 1672,71 & 899,0 & 850,0 & 0,029 & 61,5 \\
& 45 & 1,65 & 98 & 1410,00 & 850,0 & 845,0 & 0,004 & 86,1 \\
& 46 & 0,68 & 98 & 708,67 & 880,0 & 845,0 & 0,049 & 13,3 \\
& 47 & 0,63 & 98 & 543,60 & 845,0 & 824,0 & 0,039 & 12,2 \\
& 48 & 1,22 & 98 & 1621,73 & 900,0 & 824,0 & 0,047 & 26,5 \\
& 59 & 0,72 & 98 & 809,70 & 824,0 & 815,0 & 0,011 & 31,2 \\
& 51 & 0,94 & 98 & 286,89 & 877,0 & 858,0 & 0,066 & 5,6 \\
& 52 & 2,27 & 98 & 1466,00 & 815,0 & 799,5 & 0,011 & 51,4 \\
& 53 & 3,74 & 98 & 398,14 & 809,0 & 799,5 & 0,024 & 12,1 \\
& 54 & 1,28 & 98 & 658,36 & 799,5 & 779,0 & 0,031 & 15,8 \\
& 55 & 0,62 & 98 & 1802,69 & 779,0 & 760,0 & 0,011 & 60,8 \\
\hline \multirow{6}{*}{ Exutório } & 56 & 0,10 & 98 & 269,30 & 770,0 & 760,0 & 0,037 & 7,1 \\
& $57 \_a$ & 0,41 & 98 & 100,00 & 760,0 & 757,6 & 0,024 & 4,0 \\
& $57 \_b$ & 0,30 & 98 & 50,00 & 757,6 & 757,0 & 0,012 & 3,2 \\
\hline
\end{tabular}


Tabela D6: Dados de entrada do modelo para o cenário GO 2050 - Módulo Rio.

\begin{tabular}{|c|c|c|c|c|c|c|c|c|c|}
\hline & \multirow[b]{2}{*}{ Trecho } & \multirow{2}{*}{$\begin{array}{c}\mathbf{L} \\
(\mathbf{m})\end{array}$} & \multirow{2}{*}{$\begin{array}{c}\mathbf{S} \\
(\mathbf{m} / \mathbf{m})\end{array}$} & \multicolumn{3}{|c|}{ Canal } & \multicolumn{3}{|c|}{ Planície de Inundação } \\
\hline & & & & $\begin{array}{c}\text { Altura } \\
(\mathbf{m})\end{array}$ & $\begin{array}{c}\text { Largur } \\
\text { a (m) }\end{array}$ & $\mathbf{n}$ & $\begin{array}{c}\text { Altura } \\
\text { (m) }\end{array}$ & $\begin{array}{c}\text { Largura } \\
\text { (m) }\end{array}$ & $\mathbf{n}$ \\
\hline \multirow{21}{*}{ Monjolinho } & 1.2 .1 & 901,2 & 0,016 & 1,0 & 1,2 & 0,32 & \multirow{21}{*}{$\begin{array}{l}1,0 \\
1,0\end{array}$} & \multirow{21}{*}{$\begin{array}{l}20,0 \\
20,0\end{array}$} & \multirow{21}{*}{$\begin{array}{l}0,15 \\
0,20\end{array}$} \\
\hline & 1.3 .1 & 922,3 & 0,003 & 1,0 & 1,2 & 0,32 & & & \\
\hline & 1.4 .1 & 364,0 & 0,014 & 1,0 & 2,0 & 0,31 & & & \\
\hline & 1.5 .1 & 425,8 & 0,026 & 1,0 & 2,0 & 0,30 & & & \\
\hline & 1.6 .1 & 555,6 & 0,002 & 1,0 & 3,0 & 0,29 & & & \\
\hline & 1.7 .1 & 636,0 & 0,002 & 1,0 & 3,5 & 0,29 & & & \\
\hline & 1.8 .1 & 717,4 & 0,001 & 1,0 & 3,5 & 0,26 & & & \\
\hline & 1.9 .1 & 814,8 & 0,001 & 1,0 & 4,0 & 0,25 & & & \\
\hline & 1.10 .1 & 321,0 & 0,003 & 1,0 & 5,0 & 0,19 & & & \\
\hline & 1.11 .1 & 402,4 & 0,005 & 1,0 & 5,0 & 0,19 & & & \\
\hline & 1.12 .1 & 1524,1 & 0,004 & 1,0 & 5,0 & 0,09 & & & \\
\hline & 1.13 .1 & 606,9 & 0,010 & 1,0 & 5,0 & 0,09 & & & \\
\hline & 1.14 .1 & 1157,9 & 0,009 & 2,5 & 8,0 & 0,07 & & & \\
\hline & 3.2 .1 & 215,3 & 0,014 & 2,5 & 10,0 & 0,02 & & & \\
\hline & 5.2 .1 & 202,6 & 0,025 & 3,0 & 10,0 & 0,02 & & & \\
\hline & 5.3 .1 & 452,1 & 0,033 & 3,5 & 15,0 & 0,02 & & & \\
\hline & 5.4.1_a & 431,0 & 0,004 & 3,5 & 16,0 & 0,02 & & & \\
\hline & 5.4.1_b & 1146,2 & 0,011 & 3,5 & 16,0 & 0,02 & & & \\
\hline & 10.2 .1 & 269,3 & 0,037 & 3,5 & 18,0 & 0,02 & & & \\
\hline & 11.2.1_a & 100,0 & 0,024 & 3,5 & 18,0 & 0,02 & & & \\
\hline & 11.2.1_b & 50,0 & 0,012 & 2,0 & 8,0 & 0,02 & & & \\
\hline Tijuco Preto & 4.2 .1 & 1447,1 & 0,007 & 1,5 & 3,5 & 0,02 & & & \\
\hline \multirow{3}{*}{$\begin{array}{l}\text { Sta Maria } \\
\text { Madalena }\end{array}$} & 2.2 .1 & 615,2 & 0,019 & 1,4 & 1,9 & 0,31 & & & \\
\hline & 2.3.1 & 1268,2 & 0,008 & 1,5 & 3,0 & 0,02 & & & \\
\hline & 2.4 .1 & 1165,4 & 0,005 & 1,5 & 3,0 & 0,02 & & & \\
\hline Mineirinho & 6.2 .1 & 1991,9 & 0,026 & 0,6 & 3,8 & 0,04 & & & \\
\hline \multirow{7}{*}{ Gregório } & 7.2 .1 & 1410,0 & 0,003 & 2,5 & 5,0 & 0,09 & & & \\
\hline & 7.3 .1 & 543,6 & 0,037 & 3,0 & 10,0 & 0,07 & & & \\
\hline & 7.4 .1 & 809,7 & 0,011 & 3,0 & 10,0 & 0,05 & & & \\
\hline & 9.2 .1 & 1466,0 & 0,011 & 3,0 & 10,0 & 0,03 & & & \\
\hline & 9.3 .1 & 658,4 & 0,031 & 3,0 & 8,0 & 0,02 & \multirow{3}{*}{1,0} & \multirow{3}{*}{20,0} & \multirow{3}{*}{0,15} \\
\hline & 9.4 .1 & 1802,7 & 0,011 & 2,5 & 8,0 & 0,02 & & & \\
\hline & 8.2 .1 & 1316,8 & 0,033 & 2,5 & 5,0 & 0,09 & & & \\
\hline
\end{tabular}


Tabela D7: Dados de entrada do modelo para o cenário GO 2075 - Módulo Bacia.

\begin{tabular}{|c|c|c|c|c|c|c|c|c|}
\hline & $\begin{array}{l}\text { Sub- } \\
\text { bacia }\end{array}$ & $\begin{array}{l}\text { Área } \\
\left(\mathbf{k m}^{2}\right)\end{array}$ & $\mathrm{CN}$ & $\begin{array}{c}\mathbf{L} \\
(\mathbf{m})\end{array}$ & $\begin{array}{l}\text { CM } \\
\text { (m) }\end{array}$ & $\begin{array}{c}\text { CJ } \\
(\mathbf{m})\end{array}$ & $\begin{array}{c}\mathbf{S} \\
(\mathbf{m} / \mathbf{m})\end{array}$ & $\begin{array}{c}\text { Tc } \\
(\mathbf{m i n})\end{array}$ \\
\hline \multirow{27}{*}{ Monjolinho } & 1 & 2,40 & 58 & 1350,23 & 910,0 & 871,6 & 0,028 & 113,3 \\
\hline & 2 & 0,51 & 60 & 901,18 & 871,6 & 857,0 & 0,016 & 103,6 \\
\hline & 3 & 0,74 & 58 & 1185,59 & 890,0 & 857,0 & 0,028 & 103,8 \\
\hline & 4 & 0,76 & 63 & 922,33 & 857,0 & 854,0 & 0,003 & 214,6 \\
\hline & 5 & 1,85 & 59 & 2173,61 & 895,0 & 854,0 & 0,019 & 197,0 \\
\hline & 6 & 0,06 & 98 & 364,04 & 854,0 & 849,0 & 0,014 & 14,8 \\
\hline & 7 & 1,37 & 80 & 2001,8 & 898,0 & 849,0 & 0,024 & 92,5 \\
\hline & 8 & 1,31 & 68 & 1396,93 & 898,0 & 849,0 & 0,035 & 80,7 \\
\hline & 9 & 0,22 & 98 & 425,84 & 849,0 & 838,0 & 0,026 & 12,2 \\
\hline & 10 & 1,80 & 68 & 1267,45 & 877,0 & 838,0 & 0,031 & 79,7 \\
\hline & 11 & 0,36 & 98 & 555,64 & 838,0 & 837,0 & 0,002 & 57,4 \\
\hline & 12 & 1,95 & 98 & 2137,09 & 898,0 & 837,0 & 0,029 & 42,3 \\
\hline & 13 & 0,52 & 98 & 635,97 & 837,0 & 836,0 & 0,002 & 68,4 \\
\hline & 14 & 1,99 & 65 & 2101,74 & 898,0 & 836,0 & 0,029 & 133,2 \\
\hline & 15 & 0,70 & 98 & 717,41 & 836,0 & 835,5 & 0,001 & 113,1 \\
\hline & 16 & 2,22 & 98 & 2112,79 & 879,0 & 835,5 & 0,021 & 49,4 \\
\hline & 17 & 0,98 & 98 & 814,76 & 835,5 & 835,0 & 0,001 & 133,5 \\
\hline & 18 & 2,33 & 68 & 2189,93 & 876,0 & 835,0 & 0,019 & 158,4 \\
\hline & 19 & 0,18 & 98 & 321,02 & 835,0 & 834,0 & 0,003 & 28,1 \\
\hline & 20 & 1,06 & 98 & 1478,18 & 859,0 & 834,0 & 0,017 & 40,9 \\
\hline & 21 & 0,26 & 98 & 402,4 & 834,0 & 832,0 & 0,005 & 69,2 \\
\hline & 22 & 3,64 & 73 & 2410,94 & 862,0 & 832,0 & 0,012 & 70,6 \\
\hline & 23 & 2,68 & 98 & 1524,08 & 832,0 & 825,0 & 0,005 & 80,5 \\
\hline & 24 & 3,64 & 98 & 2506,53 & 879,0 & 825,0 & 0,022 & 55,3 \\
\hline & 25 & 0,66 & 98 & 606,87 & 825,0 & 818,5 & 0,011 & 25,2 \\
\hline & 26 & 1,12 & 98 & 1146,39 & 858,0 & 818,5 & 0,034 & 23,4 \\
\hline & 27 & 1,06 & 98 & 1157,89 & 818,5 & 808,0 & 0,009 & 46,0 \\
\hline \multirow{6}{*}{$\begin{array}{l}\text { Sta Maria do } \\
\text { Leme }\end{array}$} & 28 & 5,24 & 98 & 1691,19 & 858,0 & 837,0 & 0,012 & 53,2 \\
\hline & 29 & 0,47 & 98 & 615,2 & 837,0 & 825,0 & 0,020 & 18,9 \\
\hline & 30 & 2,18 & 98 & 1250,45 & 857,0 & 825,0 & 0,026 & 29,1 \\
\hline & 31 & 1,29 & 98 & 1268,18 & 825,0 & 814,2 & 0,009 & 51,0 \\
\hline & 32 & 1,54 & 98 & 1207,93 & 855,0 & 814,2 & 0,034 & 24,6 \\
\hline & 33 & 1,22 & 98 & 1165,4 & 814,2 & 808,0 & 0,005 & 60,4 \\
\hline Outras & 34 & 0,14 & 98 & 215,28 & 808,0 & 805,0 & 0,014 & 9,7 \\
\hline \multirow{2}{*}{ Tijuco Preto } & 35 & 2,01 & 98 & 1358,35 & 860,0 & 815,0 & 0,033 & 27,3 \\
\hline & 36 & 1,39 & 98 & 1447,06 & 815,0 & 805,0 & 0,007 & 63,0 \\
\hline \multirow{5}{*}{ Outras } & 37 & 0,31 & 98 & 202,64 & 805,0 & 800,0 & 0,025 & 6,9 \\
\hline & 38 & 0,32 & 98 & 452,06 & 800,0 & 785,0 & 0,033 & 11,3 \\
\hline & 39 & 0,66 & 98 & 628,19 & 790,0 & 785,0 & 0,008 & 30,1 \\
\hline & $40-\mathrm{a}$ & 0,24 & 98 & 430,96 & 785,0 & 783,0 & 0,005 & 29,2 \\
\hline & $40-\mathrm{b}$ & 0,84 & 98 & 1146,24 & 783,0 & 767,0 & 0,014 & 36,8 \\
\hline \multirow{2}{*}{ Mineirinho } & 41 & 3,14 & 87 & 1473,94 & 858,0 & 822,0 & 0,024 & 56,6 \\
\hline & 42 & 2,56 & 98 & 1991,92 & 822,0 & 767,0 & 0,028 & 40,7 \\
\hline
\end{tabular}


Continuação Tabela D7: Dados de entrada do modelo para o cenário GO 2075 - Módulo Bacia.

\begin{tabular}{ccccccccc}
\hline & $\begin{array}{c}\text { Sub- } \\
\text { bacia }\end{array}$ & $\begin{array}{c}\text { Área } \\
\left(\mathbf{k m}^{2}\right)\end{array}$ & $\mathbf{C N}$ & $\begin{array}{c}\mathbf{L} \\
(\mathbf{m})\end{array}$ & $\begin{array}{c}\mathbf{C M} \\
\mathbf{( m )}\end{array}$ & $\begin{array}{c}\mathbf{C J} \\
(\mathbf{m})\end{array}$ & $\begin{array}{c}\mathbf{S} \\
(\mathbf{m} / \mathbf{m})\end{array}$ & $\begin{array}{c}\text { Tc } \\
(\mathbf{m i n})\end{array}$ \\
\hline \multirow{6}{*}{ Gregório } & 43 & 1,55 & 85 & 1827,32 & 912,0 & 850,0 & 0,034 & 61,3 \\
& 44 & 1,19 & 85 & 1672,71 & 899,0 & 850,0 & 0,029 & 61,5 \\
& 45 & 1,65 & 98 & 1410,0 & 850,0 & 845,0 & 0,004 & 86,1 \\
& 46 & 0,68 & 98 & 708,67 & 880,0 & 845,0 & 0,049 & 13,3 \\
& 47 & 0,63 & 98 & 543,6 & 845,0 & 824,0 & 0,039 & 12,2 \\
& 48 & 1,22 & 98 & 1621,73 & 900,0 & 824,0 & 0,047 & 26,5 \\
& 50 & 0,72 & 98 & 809,70 & 824,0 & 815,0 & 0,011 & 31,2 \\
& 51 & 0,94 & 98 & 286,89 & 877,0 & 858,0 & 0,066 & 5,6 \\
& $52 \_a$ & 0,69 & 98 & 1316,81 & 858,0 & 815,0 & 0,033 & 26,9 \\
& 52 b & 1,58 & 98 & 215,00 & 815,0 & 810,0 & 0,023 & 7,5 \\
& 53 & 3,74 & 98 & 398,14 & 809,0 & 799,5 & 0,024 & 12,1 \\
& 54 & 1,28 & 98 & 658,36 & 799,5 & 779,0 & 0,031 & 15,8 \\
& 55 & 0,62 & 98 & 1802,69 & 779,0 & 760,0 & 0,011 & 60,8 \\
& 56 & 0,10 & 98 & 269,3 & 767,0 & 760,0 & 0,026 & 8,5 \\
& $57 \_a$ & 0,41 & 98 & 100,00 & 760,0 & 757,6 & 0,024 & 4,0 \\
& $57 \_b$ & 0,30 & 98 & 50,00 & 757,6 & 757,0 & 0,012 & 3,2 \\
\hline
\end{tabular}


Tabela D8: Dados de entrada do modelo para o cenário GO 2075 - Módulo Rio.

\begin{tabular}{|c|c|c|c|c|c|c|c|c|c|}
\hline & \multirow[b]{2}{*}{ Trecho } & \multirow{2}{*}{$\begin{array}{c}\mathbf{L} \\
(\mathbf{m})\end{array}$} & \multirow{2}{*}{$\begin{array}{c}\mathbf{S} \\
(\mathbf{m})\end{array}$} & \multicolumn{3}{|c|}{ Canal } & \multicolumn{3}{|c|}{ Planície de Inundação } \\
\hline & & & & $\begin{array}{c}\text { Altura } \\
(\mathbf{m})\end{array}$ & $\begin{array}{c}\text { Largura } \\
(\mathbf{m})\end{array}$ & $\mathbf{n}$ & $\begin{array}{c}\text { Altura } \\
\text { (m) }\end{array}$ & $\begin{array}{c}\text { Largura } \\
\text { (m) }\end{array}$ & $\mathbf{n}$ \\
\hline \multirow{21}{*}{ Monjolinho } & 1.2 .1 & 901,2 & 0,016 & 1,0 & 1,2 & 0,32 & & & \\
\hline & 1.3 .1 & 922,3 & 0,003 & 1,0 & 1,2 & 0,32 & & & \\
\hline & 1.4 .1 & 364,0 & 0,014 & 1,0 & 2,0 & 0,31 & & & \\
\hline & 1.5.1 & 425,8 & 0,026 & 1,0 & 2,0 & 0,30 & & & \\
\hline & 1.6 .1 & 555,6 & 0,002 & 1,0 & 3,0 & 0,29 & & & \\
\hline & 1.7 .1 & 636,0 & 0,002 & 1,0 & 3,5 & 0,29 & & & \\
\hline & 1.8 .1 & 717,4 & 0,001 & 1,0 & 3,5 & 0,26 & & & \\
\hline & 1.9 .1 & 814,8 & 0,001 & 1,0 & 4,0 & 0,25 & & & \\
\hline & 1.10 .1 & 321,0 & 0,003 & 1,0 & 5,0 & 0,19 & & & \\
\hline & 1.11 .1 & 402,4 & 0,005 & 1,0 & 5,0 & 0,19 & & & \\
\hline & 1.12 .1 & 1524,1 & 0,005 & 1,0 & 5,0 & 0,09 & 1,0 & 20,0 & 0,15 \\
\hline & 1.13 .1 & 606,9 & 0,011 & 1,0 & 5,0 & 0,09 & 1,0 & 20,0 & 0,20 \\
\hline & 1.14 .1 & 1157,9 & 0,009 & 2,5 & 8,0 & 0,07 & & & \\
\hline & 3.2 .1 & 215,3 & 0,014 & 2,5 & 10,0 & 0,02 & & & \\
\hline & 5.2 .1 & 202,6 & 0,025 & 3,0 & 10,0 & 0,02 & & & \\
\hline & 5.3 .1 & 452,1 & 0.033 & 3,5 & 15,0 & 0,02 & & & \\
\hline & 5.4.1_a & 431,0 & 0,005 & 3,5 & 16,0 & 0,02 & & & \\
\hline & 5.4.1_b & 1146,2 & 0,014 & 3,5 & 16,0 & 0,02 & & & \\
\hline & 10.2 .1 & 269,3 & 0,026 & 3,5 & 18,0 & 0,02 & & & \\
\hline & 11.2.1_a & 100,0 & 0,024 & 3,5 & 18,0 & 0,02 & & & \\
\hline & 11.2.1_b & 50,0 & 0,012 & 2,0 & 8,0 & 0,02 & & & \\
\hline Tijuco Preto & 4.2 .1 & 1447,1 & 0,007 & 1,5 & 3,5 & 0,02 & & & \\
\hline \multirow{3}{*}{$\begin{array}{l}\text { Sta Maria } \\
\text { Madalena }\end{array}$} & 2.2 .1 & 615,2 & 0,020 & 1,4 & 1,9 & 0,31 & & & \\
\hline & 2.3 .1 & 1268,2 & 0,009 & 1,5 & 3,0 & 0,02 & & & \\
\hline & 2.4 .1 & 1165,4 & 0,005 & 1,5 & 3,0 & 0,02 & & & \\
\hline Mineirinho & 6.2 .1 & 1991,9 & 0,028 & 0,6 & 3,8 & 0,04 & & & \\
\hline \multirow{8}{*}{ Gregório } & 7.2 .1 & 1410,0 & 0,004 & 2,5 & 5,0 & 0,09 & & & \\
\hline & 7.3 .1 & 543,6 & 0,039 & 3,0 & 10,0 & 0,07 & & & \\
\hline & 7.4 .1 & 809,7 & 0,011 & 3,0 & 10,0 & 0,05 & & & \\
\hline & 9.2.1_a & 215,0 & 0,023 & 3,0 & 10,0 & 0,03 & & & \\
\hline & 9.2.1_b & 995,0 & 0,011 & 3,0 & 10,0 & 0,03 & & & \\
\hline & $9.3 . \overline{1}$ & 658,4 & 0,031 & 3,0 & 8,0 & 0,02 & \multirow{3}{*}{1,0} & \multirow{3}{*}{20,0} & \multirow{3}{*}{0,15} \\
\hline & 9.4 .1 & 1802,7 & 0,011 & 2,5 & 8,0 & 0,02 & & & \\
\hline & 8.2 .1 & 1316,8 & 0,033 & 2,5 & 5,0 & 0,09 & & & \\
\hline
\end{tabular}


Tabela D9: Dados de entrada do modelo para o cenário GO 2100 - Módulo Bacia.

\begin{tabular}{|c|c|c|c|c|c|c|c|c|}
\hline & $\begin{array}{c}\text { Sub- } \\
\text { bacia }\end{array}$ & $\begin{array}{l}\text { Área } \\
\left(\mathbf{k m}^{2}\right)\end{array}$ & $\mathrm{CN}$ & $\begin{array}{c}\mathbf{L} \\
(\mathbf{m})\end{array}$ & $\begin{array}{l}\mathbf{C M} \\
(\mathbf{m})\end{array}$ & $\begin{array}{l}\mathbf{C J} \\
(\mathbf{m})\end{array}$ & $\begin{array}{c}\mathbf{S} \\
(\mathbf{m} / \mathbf{m})\end{array}$ & $\begin{array}{c}\text { Tc } \\
(\mathbf{m i n})\end{array}$ \\
\hline \multirow{27}{*}{ Monjolinho } & 1 & 2,40 & 58 & 1350,23 & 910,0 & 871,6 & 0,028 & 113,3 \\
\hline & 2 & 0,51 & 60 & 915,60 & 871,6 & 857,0 & 0,016 & 105,8 \\
\hline & 3 & 0,74 & 58 & 1185,59 & 890,0 & 857,0 & 0,028 & 103,8 \\
\hline & 4 & 0,76 & 63 & 934,37 & 857,0 & 854,0 & 0,003 & 218,3 \\
\hline & 5 & 1,85 & 59 & 2173,61 & 895,0 & 854,0 & 0,019 & 197,0 \\
\hline & 6 & 0,06 & 98 & 381,17 & 854,0 & 852,0 & 0,005 & 24,9 \\
\hline & 7 & 1,37 & 80 & 2001,80 & 898,0 & 852,0 & 0,023 & 95,5 \\
\hline & 8 & 1,31 & 68 & 1396,93 & 898,0 & 852,0 & 0,033 & 83,3 \\
\hline & 9 & 0,22 & 98 & 435,08 & 852,0 & 846,0 & 0,014 & 17,0 \\
\hline & 10 & 1,80 & 68 & 1267,45 & 877,0 & 846,0 & 0,024 & 89,5 \\
\hline & 11 & 0,36 & 98 & 591,75 & 846,0 & 841,0 & 0,008 & 27,8 \\
\hline & 12 & 1,95 & 98 & 2137,09 & 898,0 & 841,0 & 0,027 & 43,8 \\
\hline & 13 & 0,52 & 98 & 652,59 & 841,0 & 839,0 & 0,003 & 50,0 \\
\hline & 14 & 1,99 & 65 & 2101,74 & 898,0 & 839,0 & 0,028 & 136,6 \\
\hline & 15 & 0,70 & 98 & 728,20 & 839,0 & 835,0 & 0,005 & 40,8 \\
\hline & 16 & 2,22 & 98 & 2112,79 & 879,0 & 835,0 & 0,021 & 49,1 \\
\hline & 17 & 0,98 & 98 & 869,72 & 835,0 & 834,0 & 0,001 & 102,7 \\
\hline & 18 & 2,33 & 68 & 218,99 & 876,0 & 834,0 & 0,192 & 7,8 \\
\hline & 19 & 0,18 & 98 & 326,86 & 834,0 & 833,0 & 0,003 & 28,8 \\
\hline & 20 & 1,06 & 98 & 1478,18 & 859,0 & 833,0 & 0,018 & 40,1 \\
\hline & 21 & 0,26 & 98 & 407,77 & 833,0 & 830,0 & 0,007 & 22,2 \\
\hline & 22 & 3,64 & 73 & 2410,94 & 862,0 & 830,0 & 0,013 & 177,3 \\
\hline & 23 & 2,68 & 98 & 1549,21 & 830,0 & 825,0 & 0,003 & 97,3 \\
\hline & 24 & 3,64 & 80 & 2506,53 & 879,0 & 825,0 & 0,022 & 116,8 \\
\hline & 25 & 0,66 & 98 & 614,57 & 825,0 & 818,5 & 0,011 & 25,7 \\
\hline & 26 & 1,12 & 95 & 1146,39 & 858,0 & 818,5 & 0,034 & 27,6 \\
\hline & 27 & 1,06 & 98 & 1203,40 & 818,5 & 810,0 & 0,007 & 53,7 \\
\hline \multirow{6}{*}{$\begin{array}{l}\text { Sta Maria } \\
\text { Madalena }\end{array}$} & 28 & 5,24 & 70 & 1691,19 & 858,0 & 837,0 & 0,012 & 149,9 \\
\hline & 29 & 0,47 & 80 & 642,41 & 837,0 & 830,0 & 0,011 & 55,2 \\
\hline & 30 & 2,18 & 72 & 1250,45 & 857,0 & 830,0 & 0,022 & 84,5 \\
\hline & 31 & 1,29 & 98 & 1329,05 & 830,0 & 814,2 & 0,012 & 44,8 \\
\hline & 32 & 1,54 & 98 & 1207,93 & 855,0 & 814,2 & 0,034 & 24,6 \\
\hline & 33 & 1,22 & 98 & 1252,08 & 814,2 & 810,0 & 0,003 & 80,5 \\
\hline Outras & 34 & 0,14 & 98 & 100,00 & 810,0 & 809,0 & 0,010 & 6,2 \\
\hline \multirow{2}{*}{ Tijuco Preto } & 35 & 2,01 & 98 & 1358,35 & 860,0 & 815,0 & 0,033 & 27,3 \\
\hline & 36 & 1,39 & 98 & 1303,01 & 815,0 & 809,0 & 0,005 & 70,9 \\
\hline \multirow{5}{*}{ Outras } & 37 & 0,31 & 98 & 150,00 & 809,0 & 800,0 & 0,060 & 3,5 \\
\hline & 38 & 0,32 & 98 & 473,34 & 800,0 & 789,0 & 0,023 & 14,0 \\
\hline & 39 & 0,66 & 98 & 661,00 & 790,0 & 789,0 & 0,002 & 71,9 \\
\hline & $40-a$ & 0,24 & 98 & 430,96 & 789,0 & 786,0 & 0,007 & 23,8 \\
\hline & $40-\mathrm{b}$ & 0,84 & 98 & 1221,47 & 786,0 & 780,0 & 0,005 & 65,2 \\
\hline \multirow{2}{*}{ Mineirinho } & 41 & 3,14 & 87 & 1473,94 & 858,0 & 822,0 & 0,024 & 56,6 \\
\hline & 42 & 2,56 & 98 & 2083,82 & 822,0 & 780,0 & 0,020 & 49,4 \\
\hline
\end{tabular}


Continuação da Tabela D9: Dados de entrada do modelo para o cenário GO 2100 - Módulo Bacia.

\begin{tabular}{ccccccccc}
\hline & $\begin{array}{c}\text { Sub- } \\
\text { bacia }\end{array}$ & $\begin{array}{c}\text { Área } \\
(\mathbf{k m})\end{array}$ & $\mathbf{C N}$ & $\begin{array}{c}\mathbf{L} \\
\mathbf{( m )}\end{array}$ & $\begin{array}{c}\mathbf{C M} \\
(\mathbf{m})\end{array}$ & $\begin{array}{c}\mathbf{C J} \\
(\mathbf{m})\end{array}$ & $\begin{array}{c}\mathbf{S} \\
(\mathbf{m} / \mathbf{m})\end{array}$ & $\begin{array}{c}\text { Tc } \\
(\mathbf{m i n})\end{array}$ \\
\hline \multirow{6}{*}{ Gregório } & 43 & 1,55 & 85 & 1827,32 & 912,0 & 850,0 & 0,034 & 61,3 \\
& 44 & 1,19 & 85 & 1672,71 & 899,0 & 850,0 & 0,029 & 61,5 \\
& 45 & 1,65 & 98 & 1434,48 & 850,0 & 847,0 & 0,002 & 113,7 \\
& 46 & 0,68 & 98 & 708,67 & 880,0 & 847,0 & 0,047 & 13,7 \\
& 47 & 0,63 & 98 & 583,75 & 847,0 & 829,0 & 0,031 & 14,4 \\
& 48 & 1,22 & 98 & 1621,73 & 900,0 & 829,0 & 0,044 & 27,4 \\
& 50 & 0,72 & 98 & 858,50 & 829,0 & 816,0 & 0,015 & 28,0 \\
& 51 & 0,94 & 98 & 286,89 & 877,0 & 858,0 & 0,066 & 5,6 \\
& $52 \_a$ & 0,69 & 98 & 1316,81 & 858,0 & 816,0 & 0,032 & 27,2 \\
& $52 \_b$ & 1,58 & 98 & 995,00 & 810,0 & 800,0 & 0,010 & 38,7 \\
& 53 & 3,74 & 98 & 398,14 & 809,0 & 800,0 & 0,023 & 12,4 \\
& 54 & 1,28 & 98 & 658,36 & 800,0 & 779,0 & 0,032 & 15,6 \\
& 55 & 0,62 & 98 & 1856,75 & 779,0 & 775,0 & 0,002 & 137,7 \\
\hline \multirow{6}{*}{ Exutório } & 56 & 0,10 & 98 & 283,90 & 780,0 & 775,0 & 0,018 & 10,7 \\
& $57 \_a$ & 0,41 & 98 & 100,00 & 775,0 & 773,0 & 0,020 & 4,4 \\
& $57 \_b$ & 0,30 & 98 & 50,00 & 773,0 & 770,0 & 0,060 & 1,4 \\
\hline
\end{tabular}


Tabela D10: Dados de entrada do modelo para o cenário GO 2100 - Módulo Rio.

\begin{tabular}{|c|c|c|c|c|c|c|c|c|c|}
\hline & \multirow[b]{2}{*}{ Trecho } & \multirow{2}{*}{$\begin{array}{c}\mathbf{L} \\
(\mathbf{m})\end{array}$} & \multirow{2}{*}{$\begin{array}{c}\mathbf{S} \\
(\mathbf{m})\end{array}$} & \multicolumn{3}{|c|}{ Canal } & \multicolumn{3}{|c|}{ Planície de Inundação } \\
\hline & & & & $\begin{array}{c}\text { Altura } \\
(\mathbf{m})\end{array}$ & $\begin{array}{c}\text { Largura } \\
(\mathbf{m})\end{array}$ & $\mathbf{n}$ & $\begin{array}{c}\text { Altura } \\
(\mathbf{m})\end{array}$ & $\begin{array}{c}\text { Largura } \\
\text { (m) }\end{array}$ & $\mathbf{n}$ \\
\hline \multirow{21}{*}{ Monjolinho } & 1.2 .1 & 915,6 & 0,02 & 1,0 & 1,2 & 0,34 & \multirow{21}{*}{$\begin{array}{l}1,0 \\
1,0\end{array}$} & \multirow{21}{*}{$\begin{array}{l}20,0 \\
20,0\end{array}$} & \multirow{21}{*}{$\begin{array}{l}0,15 \\
0,20\end{array}$} \\
\hline & 1.3 .1 & 934,4 & 0,00 & 1,0 & 1,2 & 0,34 & & & \\
\hline & 1.4 .1 & 381,2 & 0,01 & 1,0 & 2,0 & 0,32 & & & \\
\hline & 1.5 .1 & 435,1 & 0,01 & 1,0 & 2,0 & 0,32 & & & \\
\hline & 1.6 .1 & 591,8 & 0,01 & 1,0 & 3,0 & 0,31 & & & \\
\hline & 1.7 .1 & 652,6 & 0,00 & 1,0 & 3,5 & 0,30 & & & \\
\hline & 1.8 .1 & 728,2 & 0,01 & 1,0 & 3,5 & 0,28 & & & \\
\hline & 1.9 .1 & 869,7 & 0,00 & 1,0 & 4,0 & 0,26 & & & \\
\hline & 1.10 .1 & 326,9 & 0,00 & 1,0 & 5,0 & 0,26 & & & \\
\hline & 1.11 .1 & 407,8 & 0,26 & 1,0 & 5,0 & 0,22 & & & \\
\hline & 1.12 .1 & 1549,2 & 0,00 & 1,0 & 5,0 & 0,20 & & & \\
\hline & 1.13 .1 & 614,6 & 0,01 & 1,0 & 5,0 & 0,18 & & & \\
\hline & 1.14 .1 & 1203,4 & 0,01 & 2,5 & 8,0 & 0,15 & & & \\
\hline & 3.2 .1 & 100,0 & 0,01 & 2,5 & 10,0 & 0,15 & & & \\
\hline & 5.2 .1 & 150,0 & 0,06 & 3,0 & 10,0 & 0,10 & & & \\
\hline & 5.3 .1 & 473,3 & 0,02 & 3,5 & 15,0 & 0,10 & & & \\
\hline & 5.4.1_a & 431,0 & 0,01 & 3,5 & 16,0 & 0,10 & & & \\
\hline & 5.4.1_b & 1221,5 & 0,00 & 3,5 & 16,0 & 0,10 & & & \\
\hline & 10.2 .1 & 283,9 & 0,02 & 3,5 & 18,0 & 0,08 & & & \\
\hline & 11.2.1_a & 100,0 & 0,02 & 3,5 & 18,0 & 0,08 & & & \\
\hline & 11.2.1_b & 50,0 & 0,06 & 2,0 & 8,0 & 0,08 & & & \\
\hline Tijuco Preto & 4.2 .1 & 1303,0 & 0,00 & 1,5 & 3,5 & 0,10 & & & \\
\hline \multirow{3}{*}{$\begin{array}{l}\text { Sta Maria } \\
\text { Madalena }\end{array}$} & 2.2 .1 & 642,4 & 0,01 & 1,4 & 1,9 & 0,31 & & & \\
\hline & 2.3.1 & 1329,1 & 0,01 & 1,5 & 3,0 & 0,25 & & & \\
\hline & 2.4 .1 & 1252,1 & 0,00 & 1,5 & 3,0 & 0,15 & & & \\
\hline Mineirinho & 6.2 .1 & 2083,8 & 0,02 & 0,6 & 3,8 & 0,15 & & & \\
\hline \multirow{8}{*}{ Gregório } & 7.2 .1 & 1434,5 & 0,00 & 2,5 & 5,0 & 0,29 & & & \\
\hline & 7.3 .1 & 583,8 & 0,03 & 3,0 & 10,0 & 0,24 & & & \\
\hline & 7.4 .1 & 858,5 & 0,02 & 3,0 & 10,0 & 0,19 & & & \\
\hline & 9.2.1_a & 215,0 & 0,03 & 3,0 & 10,0 & 0,15 & & & \\
\hline & 9.2.1_b & 995,0 & 0,01 & 3,0 & 10,0 & 0,15 & & & \\
\hline & $9.3 . \overline{1}$ & 658,4 & 0,03 & 3,0 & 8,0 & 0,10 & \multirow{3}{*}{1,0} & \multirow{3}{*}{20,0} & \multirow{3}{*}{0,15} \\
\hline & 9.4 .1 & 1856,8 & 0,00 & 2,5 & 8,0 & 0,10 & & & \\
\hline & 8.2 .1 & 1316,8 & 0,03 & 2,5 & 5,0 & 0,20 & & & \\
\hline
\end{tabular}




\section{Order From Strength}

Tabela D11: Dados de entrada do modelo para o cenário OS 2025 - Módulo Bacia.

\begin{tabular}{|c|c|c|c|c|c|c|c|c|}
\hline & $\begin{array}{l}\text { Sub- } \\
\text { bacia }\end{array}$ & $\begin{array}{c}\text { Área } \\
\left(\mathbf{k m}^{2}\right)\end{array}$ & $\mathbf{C N}$ & $\begin{array}{c}\mathbf{L} \\
(\mathbf{m})\end{array}$ & $\begin{array}{l}\mathrm{CM} \\
(\mathbf{m})\end{array}$ & $\begin{array}{l}\text { CJ } \\
\text { (m) }\end{array}$ & $\begin{array}{c}\mathbf{S} \\
(\mathbf{m} / \mathbf{m})\end{array}$ & $\begin{array}{c}\text { Tc } \\
\text { (min) }\end{array}$ \\
\hline \multirow{27}{*}{ Monjolinho } & 1 & 2,40 & 58 & 1350,2 & 910,0 & 871,6 & 0,028 & 112,9 \\
\hline & 2 & 0,51 & 58 & 901,18 & 871,6 & 857,0 & 0,016 & 108,2 \\
\hline & 3 & 0,74 & 58 & 1193,3 & 890,0 & 857,0 & 0,028 & 104,7 \\
\hline & 4 & 0,76 & 58 & 922,33 & 857,0 & 854,0 & 0,003 & 248,4 \\
\hline & 5 & 1,85 & 58 & 2209,3 & 895,0 & 854,0 & 0,019 & 209,2 \\
\hline & 6 & 0,06 & 65 & 364,04 & 854,0 & 849,0 & 0,014 & 48,1 \\
\hline & 7 & 1,37 & 79 & 2018,8 & 898,0 & 849,0 & 0,024 & 96,9 \\
\hline & 8 & 1,31 & 65 & 1440,9 & 898,0 & 849,0 & 0,034 & 91,9 \\
\hline & 9 & 0,22 & 65 & 425,84 & 849,0 & 838,0 & 0,026 & 39,8 \\
\hline & 10 & 1,80 & 65 & 1316,2 & 877,0 & 838,0 & 0,030 & 91,6 \\
\hline & 11 & 0,36 & 79 & 582,89 & 838,0 & 837,0 & 0,002 & 135,0 \\
\hline & 12 & 1,95 & 98 & 2168,6 & 898,0 & 837,0 & 0,028 & 43,1 \\
\hline & 13 & 0,52 & 98 & 635,97 & 837,0 & 836,0 & 0,002 & 68,4 \\
\hline & 14 & 1,99 & 63 & 2116,7 & 898,0 & 836,0 & 0,029 & 141,1 \\
\hline & 15 & 0,70 & 98 & 717,41 & 836,0 & 835,5 & 0,001 & 113,1 \\
\hline & 16 & 2,22 & 98 & 2189,1 & 879,0 & 835,5 & 0,020 & 51,7 \\
\hline & 17 & 0,98 & 98 & 814,76 & 835,5 & 835,0 & 0,001 & 133,5 \\
\hline & 18 & 2,33 & 69 & 2463,2 & 876,0 & 835,0 & 0,017 & 179,9 \\
\hline & 19 & 0,18 & 98 & 321,02 & 835,0 & 834,0 & 0,003 & 28,1 \\
\hline & 20 & 1,06 & 98 & 1540,7 & 859,0 & 834,0 & 0,016 & 43,2 \\
\hline & 21 & 0,26 & 98 & 402,4 & 834,0 & 832,0 & 0,005 & 26,7 \\
\hline & 22 & 3,64 & 69 & 2434,6 & 862,0 & 832,0 & 0,012 & 207,1 \\
\hline & 23 & 2,68 & 98 & 1524,08 & 832,0 & 825,0 & 0,005 & 80,5 \\
\hline & 24 & 3,64 & 75 & 2619,8 & 879,0 & 825,0 & 0,021 & 142,0 \\
\hline & 25 & 0,66 & 98 & 606,87 & 825,0 & 818,5 & 0,011 & 25,2 \\
\hline & 26 & 1,12 & 95 & 1166,4 & 858,0 & 818,5 & 0,034 & 28,3 \\
\hline & 27 & 1,06 & 98 & 1157,89 & 818,5 & 808,0 & 0,009 & 46,0 \\
\hline \multirow{6}{*}{$\begin{array}{l}\text { Sta Maria } \\
\text { Madalena }\end{array}$} & 28 & 5,24 & 67 & 1691,2 & 858,0 & 837,0 & 0,012 & 162,9 \\
\hline & 29 & 0,47 & 72 & 626,9 & 837,0 & 827,0 & 0,016 & 56,5 \\
\hline & 30 & 2,18 & 81 & 1257,5 & 857,0 & 827,0 & 0,024 & 62,3 \\
\hline & 31 & 1,29 & 98 & 1328,5 & 827,0 & 814,0 & 0,010 & 49,4 \\
\hline & 32 & 1,54 & 98 & 1212,4 & 855,0 & 814,0 & 0,034 & 24,7 \\
\hline & 33 & 1,22 & 98 & 1165,4 & 814,0 & 808,0 & 0,005 & 61,4 \\
\hline Outras & 34 & 0,14 & 98 & 215,28 & 808,0 & 805,0 & 0,014 & 9,7 \\
\hline \multirow{2}{*}{ Tijuco Preto } & 35 & 2,01 & 98 & 1385,0 & 860,0 & 815,0 & 0,032 & 28,0 \\
\hline & 36 & 1,39 & 98 & 1447,1 & 815,0 & 805,0 & 0,007 & 63,0 \\
\hline \multirow{5}{*}{ Outras } & 37 & 0,31 & 98 & 202,64 & 805,0 & 800,0 & 0,025 & 6,9 \\
\hline & 38 & 0,32 & 98 & 452,06 & 800,0 & 785,0 & 0,033 & 11,3 \\
\hline & 39 & 0,66 & 98 & 879,2 & 790,0 & 785,0 & 0,006 & 46,6 \\
\hline & $40-a$ & 0,24 & 98 & 430,96 & 785,0 & 783,0 & 0,005 & 29,2 \\
\hline & $40-b$ & 0,84 & 98 & 1146,24 & 783,0 & 767,0 & 0,014 & 36,8 \\
\hline \multirow{3}{*}{ Mineirinho } & 41 & 3,14 & 98 & 1758,6 & 858,0 & 822,0 & 0,020 & 42,8 \\
\hline & 42_a & 2,33 & 98 & 1624,3 & 822,0 & 799,0 & 0,014 & 48,2 \\
\hline & $42 \_b$ & 0,23 & 98 & 93,05 & 799,0 & 767,0 & 0,344 & 1,0 \\
\hline
\end{tabular}


Continuação da Tabela D11: Dados de entrada do modelo para o cenário OS 2025 - Módulo Bacia.

\begin{tabular}{ccccccccc}
\hline & $\begin{array}{c}\text { Sub- } \\
\text { bacia }\end{array}$ & $\begin{array}{c}\text { Área } \\
\left(\mathbf{k m}^{2}\right)\end{array}$ & $\mathbf{C N}$ & $\begin{array}{c}\mathbf{L} \\
(\mathbf{m})\end{array}$ & $\begin{array}{c}\mathbf{C M} \\
(\mathbf{m})\end{array}$ & $\begin{array}{c}\mathbf{C J} \\
\mathbf{( m )}\end{array}$ & $\begin{array}{c}\mathbf{S} \\
(\mathbf{m} / \mathbf{m})\end{array}$ & $\begin{array}{c}\text { Tc } \\
(\mathbf{m i n})\end{array}$ \\
\hline & 43 & 1,55 & 98 & 1831,7 & 912,0 & 850,0 & 0,034 & 34,4 \\
& 44 & 1,19 & 98 & 1688,4 & 899,0 & 850,0 & 0,029 & 34,8 \\
& 45 & 1,65 & 98 & 1433,6 & 850,0 & 845,0 & 0,003 & 88,0 \\
& 46 & 0,68 & 98 & 858,9 & 880,0 & 845,0 & 0,041 & 17,1 \\
Córrego & 47 & 0,63 & 98 & 546,6 & 845,0 & 824,0 & 0,038 & 12,3 \\
Gregório & 48 & 1,22 & 98 & 1853,5 & 900,0 & 824,0 & 0,041 & 31,5 \\
& 50 & 0,72 & 98 & 812,0 & 824,0 & 815,0 & 0,011 & 31,3 \\
& 51 & 0,94 & 98 & 482,4 & 877,0 & 858,0 & 0,039 & 11,0 \\
& $52 \_a$ & 0,69 & 98 & 1350,4 & 858,0 & 815,0 & 0,032 & 27,8 \\
& $52 \_b$ & 1,58 & 98 & 215,00 & 815,0 & 810,0 & 0,023 & 7,5 \\
& 53 & 3,74 & 98 & 586,00 & 810,0 & 799,5 & 0,011 & 37,8 \\
& 54 & 1,28 & 98 & 617,59 & 799,5 & 779,0 & 0,033 & 14,5 \\
\multirow{2}{*}{ Exutório } & 55 & 0,62 & 98 & 1782,68 & 779,0 & 760,0 & 0,011 & 59,9 \\
\hline & 56 & 0,10 & 98 & 269,3 & 767,0 & 760,0 & 0,026 & 8,5 \\
& 57 & 0,71 & 98 & 450,9 & 760,0 & 759,0 & 0,002 & 43,7 \\
\hline
\end{tabular}


Tabela D12: Dados de entrada do modelo para o cenário OS 2025 - Módulo Rio.

\begin{tabular}{|c|c|c|c|c|c|c|c|c|c|}
\hline & \multirow[b]{2}{*}{ Trecho } & \multirow[b]{2}{*}{$\begin{array}{c}\mathbf{L} \\
(\mathbf{m})\end{array}$} & \multirow[b]{2}{*}{$\begin{array}{c}\mathbf{S} \\
(\mathbf{m})\end{array}$} & \multicolumn{3}{|c|}{ Canal } & \multicolumn{3}{|c|}{ Planície de Inundação } \\
\hline & & & & $\begin{array}{c}\text { Altura } \\
\text { (m) }\end{array}$ & $\begin{array}{c}\text { Largura } \\
(\mathbf{m})\end{array}$ & $\mathbf{n}$ & $\begin{array}{c}\text { Altura } \\
(\mathbf{m})\end{array}$ & $\begin{array}{c}\text { Largura } \\
\text { (m) }\end{array}$ & $\mathbf{n}$ \\
\hline \multirow{20}{*}{ Monjolinho } & 1.2 .1 & 901,2 & 0,016 & 1,0 & 2,0 & 0,300 & \multirow{20}{*}{$\begin{array}{l}1,0 \\
1,0\end{array}$} & \multirow{20}{*}{$\begin{array}{l}40,0 \\
40,0\end{array}$} & \multirow{20}{*}{$\begin{array}{l}0,080 \\
0,080\end{array}$} \\
\hline & 1.3 .1 & 922,3 & 0,003 & 1,0 & 2,0 & 0,300 & & & \\
\hline & 1.4 .1 & 364,0 & 0,014 & 1,0 & 2,0 & 0,300 & & & \\
\hline & 1.5.1 & 425,8 & 0,026 & 1,0 & 2,0 & 0,300 & & & \\
\hline & 1.6 .1 & 582,9 & 0,002 & 1,0 & 3,0 & 0,300 & & & \\
\hline & 1.7.1 & 636,0 & 0,002 & 1,0 & 3,5 & 0,014 & & & \\
\hline & 1.8 .1 & 717,4 & 0,001 & 1,0 & 3,5 & 0,014 & & & \\
\hline & 1.9 .1 & 814,8 & 0,001 & 1,0 & 3,5 & 0,014 & & & \\
\hline & 1.10 .1 & 321,0 & 0,003 & 1,0 & 4,0 & 0,014 & & & \\
\hline & 1.11 .1 & 402,4 & 0,005 & 1,0 & 5,0 & 0,014 & & & \\
\hline & 1.12 .1 & 1524,1 & 0,005 & 1,5 & 10,0 & 0,014 & & & \\
\hline & 1.13 .1 & 606,9 & 0,011 & 1,5 & 10,0 & 0,014 & & & \\
\hline & 1.14 .1 & 1157,9 & 0,009 & 2,5 & 15,0 & 0,014 & & & \\
\hline & 3.2 .1 & 215,3 & 0,014 & 2,5 & 15,0 & 0,014 & & & \\
\hline & 5.2 .1 & 202,6 & 0,025 & 3,0 & 16,0 & 0,014 & & & \\
\hline & 5.3 .1 & 452,1 & 0,033 & 3,0 & 16,0 & 0,014 & & & \\
\hline & 5.4.1_a & 431,0 & 0,005 & 3,0 & 16,0 & 0,014 & & & \\
\hline & 5.4.1_b & 1146,2 & 0,014 & 3,0 & 17,0 & 0,014 & & & \\
\hline & 10.2 .1 & 269,3 & 0,026 & 3,0 & 18,0 & 0,014 & & & \\
\hline & 11.2.1_a & 450,9 & 0,002 & 3,5 & 18,0 & 0,014 & & & \\
\hline Tijuco Preto & 4.2 .1 & 1447,1 & 0,007 & 2,0 & 4,0 & 0,010 & & & \\
\hline \multirow{3}{*}{$\begin{array}{l}\text { Sta Maria } \\
\text { Madalena }\end{array}$} & 2.2 .1 & 626,9 & 0,016 & \multicolumn{2}{|c|}{$\Phi=2.0$} & 0,013 & & & \\
\hline & 2.3 .1 & 1328,5 & 0,010 & \multicolumn{2}{|c|}{$\Phi=1.5$} & 0,013 & & & \\
\hline & 2.4 .1 & 1165,4 & 0,005 & \multicolumn{2}{|c|}{$\Phi=2.0$} & 0,013 & & & \\
\hline \multirow{2}{*}{ Mineirinho } & $\overline{6.2 .1 \_\mathrm{a}}$ & 1624,3 & 0,014 & \multicolumn{2}{|c|}{$\Phi=2.0$} & 0,013 & & & \\
\hline & 6.2.1_b & 93,1 & 0,344 & \multicolumn{2}{|c|}{$\Phi=1.0$} & 0,013 & & & \\
\hline \multirow{8}{*}{ Gregório } & 7.2 .1 & 1433,6 & 0,003 & \multirow{2}{*}{\multicolumn{2}{|c|}{$\begin{array}{c}\Phi=2 \text { e } \Phi=1,5 \\
\Phi=2 *(1.5)\end{array}$}} & 0,013 & & & \\
\hline & 7.3.1 & 546,6 & 0,038 & & & 0,013 & & & \\
\hline & 7.4 .1 & 812,0 & 0,011 & 3,0 & 6,0 & 0,014 & & & \\
\hline & 9.2.1_a & 215,0 & 0,023 & 3,5 & 15,0 & 0,014 & & & \\
\hline & 9.2.2_b & 995,0 & 0,011 & 3,0 & 8,0 & 0,014 & & & \\
\hline & $9.3 . \overline{1}$ & 617,6 & 0,033 & 3,0 & 8,0 & 0,014 & & & \\
\hline & 9.4 .1 & 1782,7 & 0,011 & 3,0 & 10,0 & 0,014 & & & \\
\hline & 8.2 .1 & 1350,4 & 0,032 & 2,0 & 5,0 & 0,014 & & & \\
\hline
\end{tabular}


Tabela D13: Dados de entrada do modelo para o cenário OS 2050 - Módulo Bacia.

\begin{tabular}{|c|c|c|c|c|c|c|c|c|}
\hline & $\begin{array}{l}\text { Sub- } \\
\text { bacia }\end{array}$ & $\begin{array}{l}\text { Área } \\
\left(\mathbf{k m}^{2}\right)\end{array}$ & $\mathbf{C N}$ & $\begin{array}{c}\mathbf{L} \\
(\mathbf{m})\end{array}$ & $\begin{array}{l}\mathrm{CM} \\
(\mathbf{m})\end{array}$ & $\begin{array}{l}\mathbf{C J} \\
(\mathbf{m})\end{array}$ & $\begin{array}{c}\mathbf{S} \\
(\mathbf{m} / \mathbf{m})\end{array}$ & $\begin{array}{c}\text { Tc } \\
(\mathbf{m i n})\end{array}$ \\
\hline \multirow{27}{*}{ Monjolinho } & 1 & 2,40 & 62 & 1350,23 & 910,0 & 870,6 & 0,029 & 99,4 \\
\hline & 2 & 0,51 & 63 & 901,18 & 870,6 & 855,5 & 0,017 & 92,9 \\
\hline & 3 & 0,74 & 58 & 1193,32 & 890,0 & 855,5 & 0,029 & 102,4 \\
\hline & 4 & 0,76 & 70 & 922,33 & 855,5 & 854,0 & 0,002 & 253,7 \\
\hline & 5 & 1,85 & 58 & 2209,28 & 895,0 & 854,0 & 0,019 & 209,2 \\
\hline & 6 & 0,06 & 68 & 364,04 & 854,0 & 849,0 & 0,014 & 44,5 \\
\hline & 7 & 1,37 & 98 & 2018,83 & 898,0 & 849,0 & 0,024 & 43,9 \\
\hline & 8 & 1,31 & 67 & 1440,90 & 898,0 & 849,0 & 0,034 & 85,9 \\
\hline & 9 & 0,22 & 98 & 425,84 & 849,0 & 838,0 & 0,026 & 12,2 \\
\hline & 10 & 1,80 & 68 & 1316,21 & 877,0 & 838,0 & 0,030 & 83,7 \\
\hline & 11 & 0,36 & 98 & 582,89 & 838,0 & 837,0 & 0,002 & 61,1 \\
\hline & 12 & 1,95 & 98 & 2168,56 & 898,0 & 837,0 & 0,028 & 43,1 \\
\hline & 13 & 0,52 & 98 & 635,97 & 837,0 & 836,0 & 0,002 & 68,4 \\
\hline & 14 & 1,99 & 75 & 2116,66 & 898,0 & 836,0 & 0,029 & 101,3 \\
\hline & 15 & 0,70 & 98 & 717,41 & 836,0 & 835,5 & 0,001 & 113,1 \\
\hline & 16 & 2,22 & 98 & 2189,14 & 879,0 & 835,5 & 0,020 & 51,7 \\
\hline & 17 & 0,98 & 98 & 814,76 & 835,5 & 835,0 & 0,001 & 133,5 \\
\hline & 18 & 2,33 & 79 & 2463,18 & 876,0 & 835,0 & 0,017 & 136,5 \\
\hline & 19 & 0,18 & 98 & 324,19 & 835,0 & 834,0 & 0,003 & 28,5 \\
\hline & 20 & 1,06 & 98 & 1540,68 & 859,0 & 834,0 & 0,016 & 43,2 \\
\hline & 21 & 0,26 & 98 & 402,40 & 834,0 & 832,0 & 0,005 & 26,7 \\
\hline & 22 & 3,64 & 80 & 2434,62 & 862,0 & 832,0 & 0,012 & 152,3 \\
\hline & 23 & 2,68 & 98 & 1524,08 & 832,0 & 825,0 & 0,005 & 80,5 \\
\hline & 24 & 3,64 & 98 & 1754,35 & 879,0 & 825,0 & 0,031 & 34,8 \\
\hline & 25 & 0,66 & 98 & 606,87 & 825,0 & 818,5 & 0,011 & 25,2 \\
\hline & 26 & 1,12 & 98 & 1108,91 & 858,0 & 818,5 & 0,036 & 22,4 \\
\hline & 27 & 1,06 & 98 & 1157,89 & 818,5 & 808,0 & 0,009 & 46,0 \\
\hline \multirow{7}{*}{$\begin{array}{l}\text { Sta Maria } \\
\text { Madalena }\end{array}$} & 28 & 5,24 & 98 & 1691,19 & 858,0 & 837,0 & 0,012 & 53,2 \\
\hline & 29 & 0,47 & 98 & 615,22 & 837,0 & 830,0 & 0,011 & 24,8 \\
\hline & 30 & 2,18 & 98 & 1257,45 & 857,0 & 837,0 & 0,016 & 41,2 \\
\hline & 31 & 1,29 & 98 & 1251,09 & 837,0 & 814,0 & 0,018 & 34,4 \\
\hline & 32 & 1,54 & 98 & 1205,42 & 855,0 & 814,0 & 0,034 & 24,5 \\
\hline & 33_a & 1,03 & 98 & 794,31 & 814,0 & 812,0 & 0,003 & 64,6 \\
\hline & $33 \_b$ & 0,19 & 98 & 141,23 & 812,0 & 808,0 & 0,028 & 4,8 \\
\hline Outras & 34 & 0,14 & 98 & 215,28 & 808,0 & 805,0 & 0,014 & 9,7 \\
\hline \multirow{2}{*}{ Tijuco Preto } & 35 & 2,01 & 98 & 1384,95 & 860,0 & 815,0 & 0,032 & 28,0 \\
\hline & 36 & 1,39 & 98 & 1419,61 & 815,0 & 805,0 & 0,007 & 61,4 \\
\hline \multirow{5}{*}{ Outras } & 37 & 0,31 & 98 & 202,64 & 805,0 & 800,0 & 0,025 & 6,9 \\
\hline & 38 & 0,32 & 98 & 452,06 & 800,0 & 785,0 & 0,033 & 11,3 \\
\hline & 39 & 0,66 & 98 & 821,82 & 790,0 & 785,0 & 0,006 & 42,7 \\
\hline & $40-a$ & 0,24 & 98 & 430,96 & 785,0 & 783,0 & 0,005 & 29,2 \\
\hline & $40-\mathrm{b}$ & 0,84 & 98 & 1146,24 & 783,0 & 766,5 & 0,014 & 36,2 \\
\hline \multirow{3}{*}{ Mineirinho } & 41 & 3,14 & 98 & 1758,55 & 858,0 & 822,0 & 0,020 & 42,8 \\
\hline & 42_a & 2,33 & 98 & 1624,28 & 822,0 & 800,0 & 0,014 & 49,3 \\
\hline & $42 \_b$ & 0,23 & 98 & 93,05 & 800,0 & 766,5 & 0,360 & 1,0 \\
\hline
\end{tabular}


Continuação da Tabela D13: Dados de entrada do modelo para o cenário OS 2050 - Módulo Bacia.

\begin{tabular}{ccccccccc}
\hline & $\begin{array}{c}\text { Sub- } \\
\text { bacia }\end{array}$ & $\begin{array}{c}\text { Área } \\
\left.\mathbf{( k m}^{2}\right)\end{array}$ & $\mathbf{C N}$ & $\begin{array}{c}\mathbf{L} \\
(\mathbf{m})\end{array}$ & $\begin{array}{c}\mathbf{C M} \\
(\mathbf{m})\end{array}$ & $\begin{array}{c}\mathbf{C J} \\
(\mathbf{m})\end{array}$ & $\begin{array}{c}\mathbf{S} \\
(\mathbf{m} / \mathbf{m})\end{array}$ & $\begin{array}{c}\text { Tc } \\
(\mathbf{m i n})\end{array}$ \\
\hline \multirow{6}{*}{ Gregório } & 43 & 1,55 & 98 & 1831,66 & 912,0 & 850,0 & 0,034 & 34,4 \\
& 44 & 1,19 & 98 & 1688,37 & 899,0 & 850,0 & 0,029 & 34,8 \\
& 45 & 1,65 & 98 & 1398,27 & 850,0 & 845,0 & 0,004 & 85,2 \\
& 46 & 0,68 & 98 & 846,80 & 880,0 & 845,0 & 0,041 & 16,8 \\
& 47 & 0,63 & 98 & 543,73 & 845,0 & 824,0 & 0,039 & 12,2 \\
& 48 & 1,22 & 98 & 1772,20 & 900,0 & 824,0 & 0,043 & 29,7 \\
& 59 & 0,72 & 98 & 809,56 & 824,0 & 815,0 & 0,011 & 31,2 \\
& 51 & 0,94 & 98 & 428,37 & 877,0 & 858,0 & 0,044 & 9,4 \\
& $52-\mathrm{a}$ & 0,64 & 98 & 1291,09 & 858,0 & 815,0 & 0,033 & 26,2 \\
& $52 \_b$ & 1,58 & 98 & 215,00 & 815,0 & 810,0 & 0,023 & 7,5 \\
& 53 & 3,74 & 98 & 585,00 & 810,0 & 799,5 & 0,011 & 37,8 \\
& 54 & 1,28 & 98 & 617,59 & 799,0 & 799,5 & 0,016 & 20,0 \\
\multirow{2}{*}{ Exutório } & 55 & 0,62 & 98 & 1782,68 & 778,0 & 759,0 & 0,011 & 59,9 \\
\hline & 56 & 0,10 & 98 & 269,30 & 766,5 & 759,0 & 0,028 & 8,2 \\
& 57 & 0,71 & 98 & 439,03 & 759,0 & 758,0 & 0,002 & 42,2 \\
\hline
\end{tabular}


Tabela D14: Dados de entrada do modelo para o cenário OS 2050 - Módulo Rio.

\begin{tabular}{|c|c|c|c|c|c|c|c|c|c|}
\hline & \multirow[b]{2}{*}{ Trecho } & \multirow[b]{2}{*}{$\begin{array}{c}\mathbf{L} \\
(\mathbf{m})\end{array}$} & \multirow[b]{2}{*}{$\begin{array}{c}\mathbf{S} \\
(\mathbf{m})\end{array}$} & \multicolumn{3}{|c|}{ Canal } & \multicolumn{3}{|c|}{ Planície de Inundação } \\
\hline & & & & $\begin{array}{c}\text { Altura } \\
(\mathbf{m})\end{array}$ & $\begin{array}{l}\text { Largura } \\
\text { (m) }\end{array}$ & $\mathbf{n}$ & $\begin{array}{c}\text { Altura } \\
(\mathbf{m})\end{array}$ & $\begin{array}{l}\text { Largura } \\
\text { (m) }\end{array}$ & $\mathbf{n}$ \\
\hline \multirow{20}{*}{ Monjolinho } & 1.2 .1 & 901,2 & 0,017 & 1,0 & 2,0 & 0,10 & \multirow{20}{*}{$\begin{array}{l}1,0 \\
1,0\end{array}$} & \multirow{20}{*}{$\begin{array}{l}20,0 \\
20,0\end{array}$} & \multirow{20}{*}{$\begin{array}{l}0,080 \\
0,080\end{array}$} \\
\hline & 1.3 .1 & 922,3 & 0,002 & 1,0 & 2,0 & 0,10 & & & \\
\hline & 1.4 .1 & 364,0 & 0,014 & 1,0 & 2,0 & 0,10 & & & \\
\hline & 1.5 .1 & 425,8 & 0,026 & 1,0 & 2,0 & 0,014 & & & \\
\hline & 1.6 .1 & 582,9 & 0,002 & 1,0 & 3,0 & 0,014 & & & \\
\hline & 1.7 .1 & 636,0 & 0,002 & 1,5 & 3,5 & 0,014 & & & \\
\hline & 1.8 .1 & 717,4 & 0,001 & 1,5 & 3,5 & 0,014 & & & \\
\hline & 1.9 .1 & 814,8 & 0,001 & 1,5 & 4,0 & 0,014 & & & \\
\hline & 1.10 .1 & 324,2 & 0,003 & 1,5 & 5,0 & 0,014 & & & \\
\hline & 1.11 .1 & 402,4 & 0,005 & 1,5 & 5,0 & 0,014 & & & \\
\hline & 1.12 .1 & 1524,1 & 0,005 & 2,0 & 13,0 & 0,014 & & & \\
\hline & 1.13 .1 & 606,9 & 0,011 & 2,5 & 15,0 & 0,014 & & & \\
\hline & 1.14 .1 & 1157,9 & 0,009 & 2,5 & 16,0 & 0,014 & & & \\
\hline & 3.2 .1 & 215,3 & 0,014 & 2,5 & 16,0 & 0,014 & & & \\
\hline & 5.2 .1 & 202,6 & 0,025 & 3,0 & 16,0 & 0,014 & & & \\
\hline & 5.3 .1 & 452,1 & 0,033 & 3,0 & 16,0 & 0,014 & & & \\
\hline & 5.4.1_a & 431,0 & 0,005 & 3,0 & 17,0 & 0,014 & & & \\
\hline & 5.4.1_b & 1146,2 & 0,014 & 3,0 & 18,0 & 0,014 & & & \\
\hline & 10.2 .1 & 269,3 & 0,028 & 3,5 & 18,0 & 0,014 & & & \\
\hline & 11.2.1 & 439,0 & 0,002 & 2,0 & 4,0 & 0,014 & & & \\
\hline Tijuco Preto & 4.2 .1 & 1419,6 & 0,007 & 2,0 & 4,0 & 0,01 & & & \\
\hline \multirow{4}{*}{$\begin{array}{l}\text { Sta Maria } \\
\text { Madalena }\end{array}$} & 2.2 .1 & 615,2 & 0,011 & 1,5 & 4,0 & 0,014 & & & \\
\hline & 2.3 .1 & 1251,1 & 0,018 & 2,0 & 4,0 & 0,014 & & & \\
\hline & 2.4.1_a & 794,3 & 0,003 & 2,5 & 6,0 & 0,014 & & & \\
\hline & 2.4.1_b & 141,2 & 0,028 & 2,5 & 6,0 & 0,014 & & & \\
\hline \multirow{2}{*}{ Mineirinho } & $6.2 .1 \_\mathrm{a}$ & 1624,3 & 0,014 & \multicolumn{2}{|c|}{$\Phi=2.0$} & 0,013 & & & \\
\hline & 6.2.2_b & 93,1 & 0,360 & \multicolumn{2}{|c|}{$\Phi=1.0$} & 0,013 & & & \\
\hline \multirow{8}{*}{ Gregório } & 7.2 .1 & 1398,3 & 0,004 & 2,5 & 5,0 & 0,014 & & & \\
\hline & 7.3 .1 & 543,7 & 0,039 & 3,0 & 8,0 & 0,014 & & & \\
\hline & 7.4 .1 & 809,6 & 0,011 & 3,0 & 10,0 & 0,014 & & & \\
\hline & 9.2.1_a & 215,0 & 0,023 & 3,0 & 10,0 & 0,014 & & & \\
\hline & 9.2.1_b & 995,0 & 0,011 & 3,0 & 8,0 & 0,014 & & & \\
\hline & 9.3 .1 & 617,6 & 0,035 & 3,0 & 8,0 & 0,014 & & & \\
\hline & 9.4 .1 & 1782,7 & 0,011 & 3,0 & 10,0 & 0,014 & & & \\
\hline & 8.2 .1 & 1291,1 & 0,033 & 2,0 & 5,0 & 0,013 & & & \\
\hline
\end{tabular}


Tabela D15: Dados de entrada do modelo para o cenário OS 2075 - Módulo Bacia.

\begin{tabular}{|c|c|c|c|c|c|c|c|c|}
\hline & $\begin{array}{c}\text { Sub- } \\
\text { bacia }\end{array}$ & $\begin{array}{l}\text { Área } \\
\left(\mathbf{k m}^{2}\right)\end{array}$ & $\mathbf{C N}$ & $\mathbf{L}(\mathbf{m})$ & $\begin{array}{l}\mathbf{C M} \\
(\mathbf{m})\end{array}$ & $\begin{array}{c}\mathbf{C J} \\
(\mathbf{m})\end{array}$ & $\begin{array}{c}\mathbf{S} \\
(\mathbf{m} / \mathbf{m})\end{array}$ & $\begin{array}{c}\text { Tcc } \\
(\mathbf{m i n})\end{array}$ \\
\hline \multirow{27}{*}{ Monjolinho } & 1 & 2,40 & 62 & 1350,23 & 910,0 & 870,6 & 0,029 & 99,4 \\
\hline & 2 & 0,51 & 63 & 901,18 & 870,6 & 855,5 & 0,017 & 92,9 \\
\hline & 3 & 0,74 & 58 & 1193,32 & 890,0 & 855,5 & 0,029 & 102,4 \\
\hline & 4 & 0,76 & 79 & 922,33 & 855,5 & 854,0 & 0,002 & 197,1 \\
\hline & 5 & 1,85 & 83 & 2209,28 & 895,0 & 854,0 & 0,019 & 103,3 \\
\hline & 6 & 0,06 & 68 & 364,04 & 854,0 & 849,0 & 0,014 & 44,5 \\
\hline & 7 & 1,37 & 98 & 2000,00 & 898,0 & 849,0 & 0,025 & 43,3 \\
\hline & 8 & 1,31 & 67 & 1440,90 & 898,0 & 849,0 & 0,034 & 85,9 \\
\hline & 9 & 0,22 & 98 & 425,84 & 849,0 & 838,0 & 0,026 & 12,2 \\
\hline & 10 & 1,80 & 95 & 1316,21 & 877,0 & 838,0 & 0,030 & 33,2 \\
\hline & 11 & 0,36 & 98 & 582,89 & 838,0 & 837,0 & 0,002 & 61,1 \\
\hline & 12 & 1,95 & 98 & 2147,09 & 898,0 & 837,0 & 0,028 & 42,6 \\
\hline & 13 & 0,52 & 98 & 635,97 & 837,0 & 836,0 & 0,002 & 68,4 \\
\hline & 14 & 1,99 & 98 & 2058,83 & 898,0 & 836,0 & 0,030 & 40,0 \\
\hline & 15 & 0,70 & 98 & 717,41 & 836,0 & 835,5 & 0,001 & 113,1 \\
\hline & 16 & 2,22 & 98 & 1857,89 & 879,0 & 835,5 & 0,023 & 41,8 \\
\hline & 17 & 0,98 & 98 & 814,76 & 835,5 & 835,0 & 0,001 & 133,5 \\
\hline & 18 & 2,33 & 98 & 2201,93 & 876,0 & 835,0 & 0,019 & 53,7 \\
\hline & 19 & 0,18 & 98 & 324,19 & 835,0 & 834,0 & 0,003 & 28,5 \\
\hline & 20 & 1,06 & 98 & 1477,18 & 859,0 & 834,0 & 0,017 & 40,9 \\
\hline & 21 & 0,26 & 98 & 402,40 & 834,0 & 832,0 & 0,005 & 26,7 \\
\hline & 22 & 3,64 & 98 & 2434,62 & 862,0 & 832,0 & 0,012 & 71,5 \\
\hline & 23 & 2,68 & 98 & 1524,08 & 832,0 & 825,0 & 0,005 & 80,5 \\
\hline & 24 & 3,64 & 98 & 1973,79 & 879,0 & 825,0 & 0,027 & 40,6 \\
\hline & 25 & 0,66 & 98 & 606,87 & 825,0 & 818,5 & 0,011 & 25,2 \\
\hline & 26 & 1,12 & 98 & 1108,91 & 858,0 & 818,5 & 0,036 & 22,4 \\
\hline & 27 & 1,06 & 98 & 1157,89 & 818,5 & 806,5 & 0,010 & 43,0 \\
\hline \multirow{7}{*}{$\begin{array}{l}\text { Sta Maria } \\
\text { Madalena }\end{array}$} & 28 & 5,24 & 98 & 1691,19 & 858,0 & 837,0 & 0,012 & 53,2 \\
\hline & 29 & 0,47 & 98 & 615,20 & 837,0 & 830,0 & 0,011 & 24,8 \\
\hline & 30 & 2,18 & 98 & 1248,19 & 857,0 & 837,0 & 0,016 & 36,7 \\
\hline & 31 & 1,29 & 98 & 1251,09 & 837,0 & 814,0 & 0,018 & 34,4 \\
\hline & 32 & 1,54 & 98 & 1205,42 & 855,0 & 814,0 & 0,034 & 24,5 \\
\hline & 33_a & 1,03 & 98 & 794,31 & 814,0 & 812,0 & 0,003 & 64,6 \\
\hline & 33_b & 0,19 & 98 & 141,23 & 812,0 & 806,5 & 0,039 & 4,1 \\
\hline Outras & 34 & 0,14 & 98 & 215,28 & 806,5 & 804,5 & 0,009 & 11,8 \\
\hline \multirow{3}{*}{ Tijuco Preto } & 35 & 2,01 & 98 & 1332,22 & 860,0 & 815,0 & 0,034 & 26,7 \\
\hline & 36_a & 1,16 & 98 & 899,44 & 815,0 & 813,0 & 0,002 & 75,9 \\
\hline & 36_b & 0,23 & 98 & 281,13 & 813,0 & 804,5 & 0,030 & 8,1 \\
\hline \multirow{5}{*}{ Outras } & 37 & 0,31 & 98 & 202,01 & 804,5 & 800,0 & 0,022 & 7,3 \\
\hline & 38 & 0,32 & 98 & 452,06 & 800,0 & 785,0 & 0,033 & 11,3 \\
\hline & 39 & 0,66 & 98 & 821,82 & 790,0 & 785,0 & 0,006 & 42,7 \\
\hline & $40-\mathrm{a}$ & 0,24 & 98 & 430,96 & 785,0 & 783,0 & 0,005 & 29,2 \\
\hline & $40-b$ & 0,84 & 98 & 1146,24 & 783,0 & 766,0 & 0,015 & 35,7 \\
\hline \multirow{3}{*}{ Mineirinho } & 41 & 3,14 & 98 & 1691,52 & 858,0 & 822,0 & 0,021 & 40,7 \\
\hline & 42_a & 2,33 & 98 & 1624,28 & 822,0 & 800,0 & 0,014 & 49,3 \\
\hline & 42_a & 0,23 & 98 & 93,05 & 800,0 & 766,0 & 0,365 & 1,0 \\
\hline
\end{tabular}




\begin{tabular}{|c|c|c|c|c|c|c|c|c|}
\hline \multicolumn{9}{|c|}{ Continuação da Tabela D15: Dados de entrada do modelo para o cenário OS 2075 - Módulo Bacia } \\
\hline & $\begin{array}{l}\text { Sub- } \\
\text { bacia }\end{array}$ & $\begin{array}{l}\text { Área } \\
\left(\mathbf{k m}^{2}\right)\end{array}$ & $\mathbf{C N}$ & $\mathbf{L}(\mathbf{m})$ & $\begin{array}{l}\mathbf{C M} \\
(\mathbf{m})\end{array}$ & $\begin{array}{c}\mathbf{C J} \\
(\mathbf{m})\end{array}$ & $\begin{array}{c}\mathbf{S} \\
(\mathbf{m} / \mathbf{m})\end{array}$ & $\begin{array}{c}\text { Tc } \\
(\mathbf{m i n})\end{array}$ \\
\hline \multirow{14}{*}{ Gregório } & 43 & 1,55 & 98 & 1832,20 & 912,0 & 850,0 & 0,034 & 34,4 \\
\hline & 44 & 1,19 & 98 & 1413,79 & 899,0 & 850,0 & 0,035 & 27,6 \\
\hline & 45 & 1,65 & 98 & 1398,27 & 850,0 & 845,0 & 0,004 & 85,2 \\
\hline & 46 & 0,68 & 98 & 766,00 & 880,0 & 845,0 & 0,046 & 14,7 \\
\hline & 47 & 0,63 & 98 & 543,60 & 845,0 & 824,0 & 0,039 & 12,2 \\
\hline & 48 & 1,22 & 98 & 1826,20 & 900,0 & 824,0 & 0,042 & 30,9 \\
\hline & 49 & 0,72 & 98 & 809,70 & 824,0 & 815,0 & 0,011 & 31,2 \\
\hline & 50 & 0,94 & 98 & 482,37 & 877,0 & 858,0 & 0,039 & 11,0 \\
\hline & 51 & 0,84 & 98 & 1291,09 & 858,0 & 815,0 & 0,033 & 26,2 \\
\hline & 52_a & 0,69 & 98 & 215,00 & 815,0 & 810,0 & 0,023 & 7,5 \\
\hline & 52_b & 1,58 & 98 & 995,00 & 810,0 & 799,5 & 0,011 & 37,8 \\
\hline & 53 & 3,74 & 98 & 398,14 & 809,0 & 799,5 & 0,024 & 12,1 \\
\hline & 54 & 1,28 & 98 & 617,59 & 799,5 & 778,0 & 0,035 & 14,2 \\
\hline & 55 & 0,62 & 98 & 1782,68 & 778,0 & 758,5 & 0,011 & 59,1 \\
\hline \multirow[t]{2}{*}{ Exutório } & 56 & 0,10 & 98 & 269,30 & 766,0 & 758,5 & 0,028 & 8,2 \\
\hline & 57 & 0,71 & 98 & 439,03 & 758,5 & 756,5 & 0,005 & 29,9 \\
\hline
\end{tabular}


Tabela D16: Dados de entrada do modelo para o cenário OS 2075 - Módulo Rio.

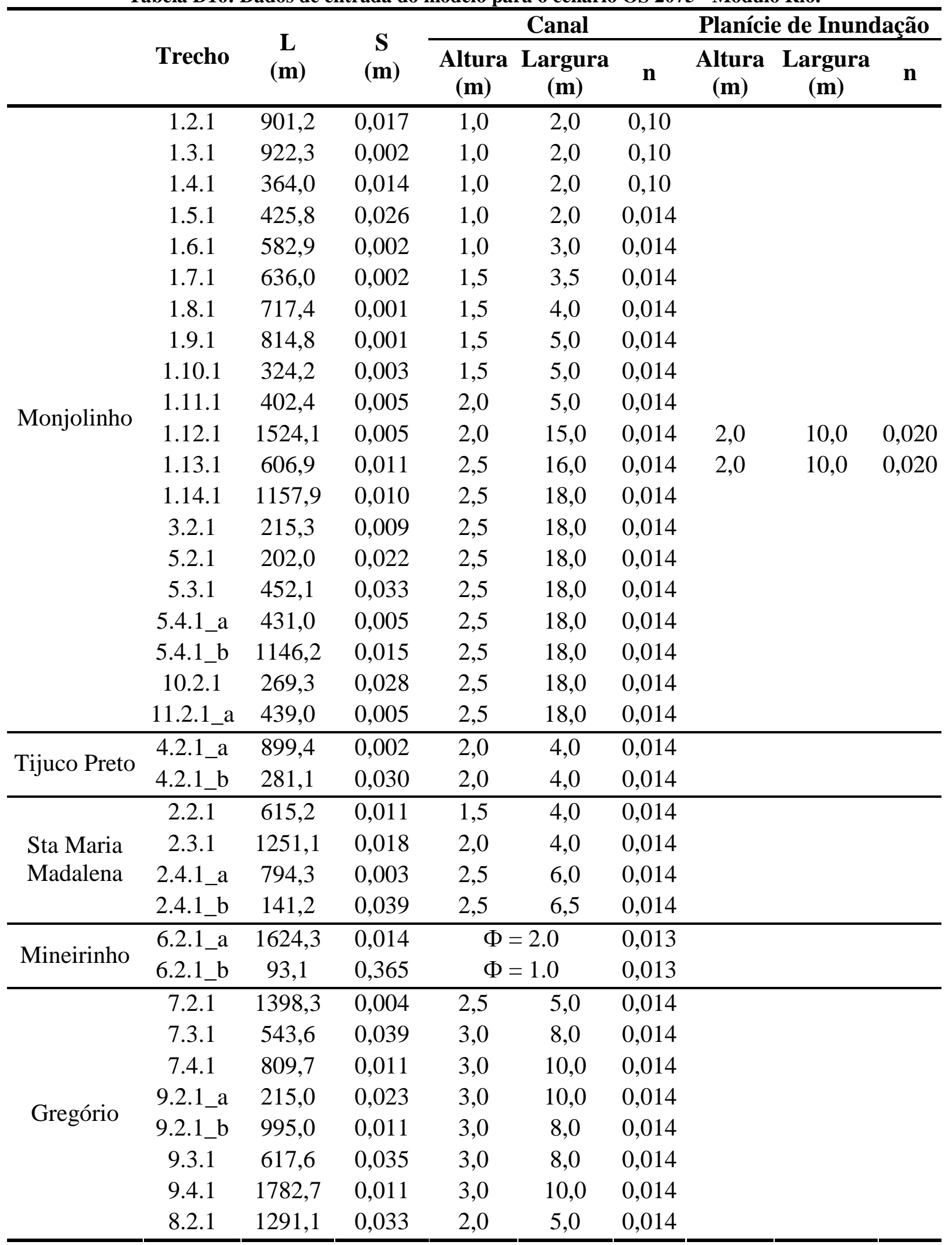


Tabela D17: Dados de entrada do modelo para o cenário OS 2100 - Módulo Bacia.

\begin{tabular}{|c|c|c|c|c|c|c|c|c|}
\hline & $\begin{array}{c}\text { Sub- } \\
\text { bacia }\end{array}$ & $\begin{array}{c}\text { Área } \\
(\mathbf{k m 2})\end{array}$ & $\mathrm{CN}$ & $\begin{array}{c}\mathbf{L} \\
(\mathbf{m})\end{array}$ & $\begin{array}{l}\mathbf{C M} \\
(\mathbf{m})\end{array}$ & $\begin{array}{l}\text { CJ } \\
(\mathbf{m})\end{array}$ & $\begin{array}{c}\mathbf{S} \\
(\mathbf{m} / \mathbf{m})\end{array}$ & $\begin{array}{c}\text { Tc } \\
\text { (min) }\end{array}$ \\
\hline \multirow{27}{*}{ Monjolinho } & 1 & 2,40 & 98 & 1350,23 & 910,0 & 870,6 & 0,029 & 29,0 \\
\hline & 2 & 0,51 & 98 & 901,18 & 870,6 & 855,5 & 0,017 & 27,7 \\
\hline & 3 & 0,74 & 98 & 2209,28 & 890,0 & 855,5 & 0,016 & 58,8 \\
\hline & 4 & 0,76 & 98 & 922,33 & 855,5 & 854,0 & 0,002 & 90,5 \\
\hline & 5 & 1,85 & 98 & 2000,00 & 895,0 & 854,0 & 0,021 & 47,4 \\
\hline & 6 & 0,06 & 98 & 364,04 & 854,0 & 849,0 & 0,014 & 14,8 \\
\hline & 7 & 1,37 & 98 & 2000,00 & 898,0 & 849,0 & 0,025 & 43,3 \\
\hline & 8 & 1,31 & 98 & 1316,21 & 898,0 & 849,0 & 0,037 & 25,1 \\
\hline & 9 & 0,22 & 98 & 425,84 & 849,0 & 838,0 & 0,026 & 12,2 \\
\hline & 10 & 1,80 & 98 & 1196,14 & 877,0 & 838,0 & 0,033 & 24,9 \\
\hline & 11 & 0,36 & 98 & 635,97 & 838,0 & 837,0 & 0,002 & 68,4 \\
\hline & 12 & 1,95 & 98 & 2147,09 & 898,0 & 837,0 & 0,028 & 42,6 \\
\hline & 13 & 0,52 & 98 & 635,97 & 837,0 & 836,0 & 0,002 & 68,4 \\
\hline & 14 & 1,99 & 98 & 2058,83 & 898,0 & 836,0 & 0,030 & 40,0 \\
\hline & 15 & 0,70 & 98 & 717,41 & 836,0 & 835,5 & 0,001 & 113,1 \\
\hline & 16 & 2,22 & 98 & 1857,89 & 879,0 & 835,5 & 0,023 & 41,8 \\
\hline & 17 & 0,98 & 98 & 814,76 & 835,5 & 835,0 & 0,001 & 133,5 \\
\hline & 18 & 2,33 & 98 & 2201,93 & 876,0 & 835,0 & 0,019 & 53,7 \\
\hline & 19 & 0,18 & 98 & 324,19 & 835,0 & 834,0 & 0,003 & 28,5 \\
\hline & 20 & 1,06 & 98 & 1477,18 & 859,0 & 834,0 & 0,017 & 40,9 \\
\hline & 21 & 0,26 & 98 & 402,40 & 834,0 & 832,0 & 0,005 & 26,7 \\
\hline & 22 & 3,64 & 98 & 1524,08 & 862,0 & 832,0 & 0,020 & 38,9 \\
\hline & 23 & 2,68 & 98 & 1524,08 & 832,0 & 825,0 & 0,005 & 80,5 \\
\hline & 24 & 3,64 & 98 & 1973,79 & 879,0 & 825,0 & 0,027 & 40,6 \\
\hline & 25 & 0,66 & 98 & 606,87 & 825,0 & 818,5 & 0,011 & 25,2 \\
\hline & 26 & 1,12 & 98 & 1108,91 & 858,0 & 818,5 & 0,036 & 22,4 \\
\hline & 27 & 1,06 & 98 & 1157,89 & 818,5 & 806,5 & 0,010 & 43,0 \\
\hline \multirow{7}{*}{$\begin{array}{l}\text { Sta Maria } \\
\text { Madalena }\end{array}$} & 28 & 5,24 & 98 & 1691,19 & 858,0 & 837,0 & 0,012 & 53,2 \\
\hline & 29 & 0,47 & 98 & 615,20 & 837,0 & 830,0 & 0,011 & 24,8 \\
\hline & 30 & 2,18 & 98 & 1248,19 & 857,0 & 837,0 & 0,016 & 36,7 \\
\hline & 31 & 1,29 & 98 & 1251,09 & 837,0 & 814,0 & 0,018 & 34,4 \\
\hline & 32 & 1,54 & 98 & 1205,42 & 855,0 & 814,0 & 0,034 & 24,5 \\
\hline & 33_a & 1,03 & 98 & 794,31 & 814,0 & 812,0 & 0,003 & 64,6 \\
\hline & 33_b & 0,19 & 98 & 141,23 & 812,0 & 806,5 & 0,039 & 4,1 \\
\hline Outras & 34 & 0,14 & 98 & 215,28 & 806,5 & 804,5 & 0,009 & 11,8 \\
\hline \multirow{3}{*}{ Tijuco Preto } & 35 & 2,01 & 98 & 1332,22 & 860,0 & 815,0 & 0,034 & 26,7 \\
\hline & 36_a & 1,16 & 98 & 899,44 & 815,0 & 813,0 & 0,002 & 75,9 \\
\hline & 36_a & 0,23 & 98 & 281,13 & 813,0 & 804,5 & 0,030 & 8,1 \\
\hline \multirow{4}{*}{ Outras } & 37 & 0,31 & 98 & 202,01 & 804,5 & 800,0 & 0,022 & 7,3 \\
\hline & 38 & 0,32 & 98 & 452,06 & 800,0 & 785,0 & 0,033 & 11,3 \\
\hline & 39 & 0,66 & 98 & 821,82 & 790,0 & 785,0 & 0,006 & 42,7 \\
\hline & $40-\mathrm{a}$ & 0,24 & 98 & 430,96 & 785,0 & 783,0 & 0,005 & 29,2 \\
\hline
\end{tabular}


Continuação da Tabela D17: Dados de entrada do modelo para o cenário OS 2100 - Módulo Bacia.

\begin{tabular}{|c|c|c|c|c|c|c|c|c|}
\hline & $\begin{array}{l}\text { Sub- } \\
\text { bacia }\end{array}$ & $\begin{array}{c}\text { Área } \\
(\mathbf{k m 2})\end{array}$ & $\mathrm{CN}$ & $\begin{array}{c}\mathbf{L} \\
(\mathbf{m})\end{array}$ & $\begin{array}{l}\text { CM } \\
\text { (m) }\end{array}$ & $\begin{array}{l}\text { CJ } \\
(\mathbf{m})\end{array}$ & $\begin{array}{c}\mathbf{S} \\
(\mathbf{m} / \mathbf{m})\end{array}$ & $\begin{array}{c}\text { Tc } \\
(\mathbf{m i n})\end{array}$ \\
\hline & $40-b$ & 0,84 & 98 & 1146,24 & 783,0 & 766,0 & 0,015 & 35,7 \\
\hline \multirow{3}{*}{ Mineirinho } & 41 & 3,14 & 98 & 1691,52 & 858,0 & 822,0 & 0,021 & 40,7 \\
\hline & 42_a & 2,33 & 98 & 1624,28 & 822,0 & 800,0 & 0,014 & 49,3 \\
\hline & 42_b & 0,23 & 98 & 93,05 & 800,0 & 766,0 & 0,365 & 1,0 \\
\hline \multirow{14}{*}{ Gregório } & 43 & 1,55 & 98 & 1832,20 & 912,0 & 850,0 & 0,034 & 34,4 \\
\hline & 44 & 1,19 & 98 & 1413,79 & 899,0 & 850,0 & 0,035 & 27,6 \\
\hline & 45 & 1,65 & 98 & 1398,27 & 850,0 & 845,0 & 0,004 & 85,2 \\
\hline & 46 & 0,68 & 98 & 766,00 & 880,0 & 845,0 & 0,046 & 14,7 \\
\hline & 47 & 0,63 & 98 & 543,60 & 845,0 & 824,0 & 0,039 & 12,2 \\
\hline & 48 & 1,22 & 98 & 1826,20 & 900,0 & 824,0 & 0,042 & 30,9 \\
\hline & 49 & 0,72 & 98 & 809,70 & 824,0 & 815,0 & 0,011 & 31,2 \\
\hline & 50 & 0,94 & 98 & 482,37 & 877,0 & 858,0 & 0,039 & 11,0 \\
\hline & 51 & 0,84 & 98 & 1291,09 & 858,0 & 815,0 & 0,033 & 26,2 \\
\hline & 52_a & 0,69 & 98 & 215,00 & 815,0 & 810,0 & 0,023 & 7,5 \\
\hline & 52_b & 1,58 & 98 & 995,00 & 810,0 & 799,5 & 0,011 & 37,8 \\
\hline & 53 & 3,74 & 98 & 398,14 & 809,0 & 799,5 & 0,024 & 12,1 \\
\hline & 54 & 1,28 & 98 & 617,59 & 799,5 & 778,0 & 0,035 & 14,2 \\
\hline & 55 & 0,62 & 98 & 1782,68 & 778,0 & 758,5 & 0,011 & 59,1 \\
\hline \multirow{3}{*}{ Exutório } & 56 & 0,10 & 98 & 269,30 & 766,0 & 758,5 & 0,028 & 8,2 \\
\hline & 57_a & 0,41 & 98 & 100,00 & 758,5 & 757,5 & 0,01 & 6,2 \\
\hline & 57_b & 0,30 & 98 & 50,00 & 757,5 & 756,5 & 0,005 & 5,0 \\
\hline
\end{tabular}


Tabela D18: Dados de entrada do modelo para o cenário OS 2100 - Módulo Rio.

\begin{tabular}{|c|c|c|c|c|c|c|c|c|c|}
\hline & \multirow[b]{2}{*}{ Trecho } & \multirow{2}{*}{$\begin{array}{c}\mathbf{L} \\
(\mathbf{m})\end{array}$} & \multirow{2}{*}{$\begin{array}{c}\mathbf{S} \\
(\mathbf{m})\end{array}$} & \multicolumn{3}{|c|}{ Canal } & \multicolumn{3}{|c|}{ Planície de Inundação } \\
\hline & & & & $\begin{array}{c}\text { Altura } \\
(\mathbf{m})\end{array}$ & $\begin{array}{c}\text { Largura } \\
(\mathbf{m})\end{array}$ & $\mathbf{n}$ & $\begin{array}{c}\text { Altura } \\
(\mathbf{m})\end{array}$ & $\begin{array}{c}\text { Largura } \\
(\mathbf{m})\end{array}$ & $\mathbf{n}$ \\
\hline \multirow{21}{*}{ Monjolinho } & 1.2 .1 & 901,2 & 0,017 & 1,0 & 2,0 & 0,10 & \multirow{21}{*}{$\begin{array}{l}2,0 \\
2,0\end{array}$} & \multirow{21}{*}{$\begin{array}{l}10,0 \\
10,0\end{array}$} & \multirow{21}{*}{$\begin{array}{l}0,020 \\
0,020\end{array}$} \\
\hline & 1.3.1 & 922,3 & 0,002 & 1,0 & 2,0 & 0,10 & & & \\
\hline & 1.4 .1 & 364,0 & 0,014 & 1,0 & 2,0 & 0,10 & & & \\
\hline & 1.5.1 & 425,8 & 0,026 & 1,0 & 2,0 & 0,014 & & & \\
\hline & 1.6.1 & 636,0 & 0,002 & 1,0 & 3,0 & 0,014 & & & \\
\hline & 1.7.1 & 636,0 & 0,002 & 1,5 & 3,5 & 0,014 & & & \\
\hline & 1.8 .1 & 717,4 & 0,001 & 1,5 & 4,0 & 0,014 & & & \\
\hline & 1.9 .1 & 814,8 & 0,001 & 1,5 & 5,0 & 0,014 & & & \\
\hline & 1.10 .1 & 324,2 & 0,003 & 1,5 & 5,0 & 0,014 & & & \\
\hline & 1.11 .1 & 402,4 & 0,005 & 2,0 & 15,0 & 0,014 & & & \\
\hline & 1.12 .1 & 1524,1 & 0,005 & 2,0 & 15,0 & 0,014 & & & \\
\hline & 1.13 .1 & 606,9 & 0,011 & 2,5 & 16,0 & 0,014 & & & \\
\hline & 1.14 .1 & 1157,9 & 0,010 & 2,5 & 18,0 & 0,014 & & & \\
\hline & 3.2 .1 & 215,3 & 0,009 & 2,5 & 18,0 & 0,014 & & & \\
\hline & 5.2 .1 & 202,0 & 0,022 & 2,5 & 18,0 & 0,014 & & & \\
\hline & 5.3 .1 & 452,1 & 0,033 & 2,5 & 18,0 & 0,014 & & & \\
\hline & 5.4.1_a & 431,0 & 0,005 & 2,5 & 18,0 & 0,014 & & & \\
\hline & 5.4.1_b & 1146,2 & 0,015 & 2,5 & 18,0 & 0,014 & & & \\
\hline & 10.2 .1 & 269,3 & 0,028 & 2,5 & 18,0 & 0,014 & & & \\
\hline & 11.2.1_a & 100,0 & 0,010 & 2,5 & 18,0 & 0,014 & & & \\
\hline & $11.2,1 \_b$ & 50,0 & 0,005 & 2,00 & 18,00 & 0,014 & & & \\
\hline Tijuco & 4.2.1_a & 899,4 & 0,002 & 2,0 & 4,0 & 0,014 & & & \\
\hline Preto & 4.2.1_b & 281,1 & 0,030 & 2,0 & 4,0 & 0,014 & & & \\
\hline \multirow{4}{*}{$\begin{array}{l}\text { Sta Maria } \\
\text { Madalena }\end{array}$} & 2.2 .1 & 615,2 & 0,011 & 1,5 & 4,0 & 0,014 & & & \\
\hline & 2.3 .1 & 1251,1 & 0,018 & 2,0 & 4,0 & 0,014 & & & \\
\hline & 2.4.1_a & 794,3 & 0,003 & 2,5 & 6,0 & 0,014 & & & \\
\hline & 2.4.1_b & 141,2 & 0,039 & 2,5 & 6,5 & 0,014 & & & \\
\hline \multirow{10}{*}{ Gregório } & $6.2 .1 \_\mathrm{a}$ & 1624,3 & 0,014 & \multicolumn{2}{|c|}{$\Phi=2.0$} & 0,013 & & & \\
\hline & 6.2.1_b & 93,1 & 0,365 & \multicolumn{2}{|c|}{$\Phi=1.0$} & 0,013 & & & \\
\hline & 7.2 .1 & 1398,3 & 0,004 & 2,5 & 5,0 & 0,014 & & & \\
\hline & 7.3.1 & 543,6 & 0,039 & 3,0 & 8,0 & 0,014 & & & \\
\hline & 7.4 .1 & 809,7 & 0,011 & 3,0 & 10,0 & 0,014 & & & \\
\hline & 9.2.1_a & 215,0 & 0,010 & 3,0 & 10,0 & 0,014 & & & \\
\hline & 9.2.1_b & 995,0 & 0,005 & 3,0 & 8,0 & 0,014 & & & \\
\hline & 9.3 .1 & 617,6 & 0,035 & 3,0 & 8,0 & 0,014 & & & \\
\hline & 9.4 .1 & 1782,7 & 0,011 & 3,0 & 10,0 & 0,014 & & & \\
\hline & 8.2 .1 & 1291,1 & 0,033 & 2,0 & 5,0 & 0,014 & & & \\
\hline
\end{tabular}


Tabela D19: Dados de entrada do modelo para o cenário AM 2025 - Módulo Bacia.

\begin{tabular}{|c|c|c|c|c|c|c|c|c|}
\hline & $\begin{array}{l}\text { Sub- } \\
\text { bacia }\end{array}$ & $\begin{array}{c}\text { Área } \\
\left(\mathbf{k m}^{2}\right)\end{array}$ & $\mathrm{CN}$ & $\begin{array}{c}\mathbf{L} \\
(\mathbf{m})\end{array}$ & $\begin{array}{l}\mathbf{C M} \\
(\mathbf{m})\end{array}$ & $\begin{array}{l}\mathbf{C J} \\
(\mathbf{m})\end{array}$ & $\begin{array}{c}\mathbf{S} \\
(\mathbf{m} / \mathbf{m}) \\
\end{array}$ & $\begin{array}{c}\text { Tc } \\
\text { (min) }\end{array}$ \\
\hline \multirow{27}{*}{ Monjolinho } & 1 & 2,40 & 58 & 1350,2 & 910,0 & 871,6 & 0,028 & 114,0 \\
\hline & 2 & 0,51 & 58 & 918,3 & 871,6 & 858,0 & 0,015 & 113,5 \\
\hline & 3 & 0,74 & 58 & 1193,3 & 890,0 & 858,0 & 0,027 & 106,3 \\
\hline & 4 & 0,76 & 58 & 944,6 & 858,0 & 855,0 & 0,003 & 256,3 \\
\hline & 5 & 1,85 & 58 & 2209,3 & 895,0 & 855,0 & 0,018 & 211,8 \\
\hline & 6 & 0,06 & 65 & 373,5 & 855,0 & 850,0 & 0,013 & 49,7 \\
\hline & 7 & 1,37 & 74 & 2018,8 & 898,0 & 850,0 & 0,024 & 111,7 \\
\hline & 8 & 1,31 & 65 & 1440,9 & 898,0 & 850,0 & 0,033 & 92,8 \\
\hline & 9 & 0,22 & 65 & 436,3 & 850,0 & 840,0 & 0,023 & 43,0 \\
\hline & 10 & 1,80 & 65 & 1316,2 & 877,0 & 840,0 & 0,028 & 94,0 \\
\hline & 11 & 0,36 & 72 & 585,4 & 840,0 & 839,0 & 0,002 & 163,6 \\
\hline & 12 & 1,95 & 82 & 2168,6 & 898,0 & 839,0 & 0,027 & 86,8 \\
\hline & 13 & 0,52 & 74 & 736,3 & 839,0 & 838,0 & 0,001 & 208,6 \\
\hline & 14 & 1,99 & 58 & 2116,7 & 898,0 & 838,0 & 0,028 & 163,6 \\
\hline & 15 & 0,70 & 82 & 738,8 & 838,0 & 837,5 & 0,001 & 232,7 \\
\hline & 16 & 2,22 & 98 & 2189,1 & 879,0 & 837,5 & 0,019 & 52,9 \\
\hline & 17 & 0,98 & 82 & 837,0 & 837,5 & 837,0 & 0,001 & 273,7 \\
\hline & 18 & 2,33 & 65 & 2463,2 & 876,0 & 837,0 & 0,016 & 206,8 \\
\hline & 19 & 0,18 & 82 & 321,0 & 837,0 & 836,0 & 0,003 & 55,7 \\
\hline & 20 & 1,06 & 82 & 1540,7 & 859,0 & 836,0 & 0,015 & 89,2 \\
\hline & 21 & 0,26 & 90 & 410,0 & 836,0 & 835,0 & 0,002 & 57,3 \\
\hline & 22 & 3,64 & 68 & 2434,6 & 862,0 & 835,0 & 0,011 & 223,9 \\
\hline & 23 & 2,68 & 95 & 1568,0 & 835,0 & 825,0 & 0,006 & 82,5 \\
\hline & 24 & 3,64 & 75 & 2619,8 & 879,0 & 825,0 & 0,021 & 143,7 \\
\hline & 25 & 0,66 & 95 & 629,9 & 825,0 & 820,0 & 0,008 & 35,7 \\
\hline & 26 & 1,12 & 95 & 1166,4 & 858,0 & 820,0 & 0,033 & 28,8 \\
\hline & 27 & 1,06 & 98 & 1196,9 & 820,0 & 810,0 & 0,008 & 49,2 \\
\hline \multirow{6}{*}{$\begin{array}{l}\text { Sta Maria } \\
\text { Madalena }\end{array}$} & 28 & 5,24 & 68 & 1691,2 & 858,0 & 837,0 & 0,012 & 158,1 \\
\hline & 29 & 0,47 & 68 & 642,4 & 837,0 & 829,0 & 0,012 & 72,8 \\
\hline & 30 & 2,18 & 68 & 1257,5 & 857,0 & 829,0 & 0,022 & 93,2 \\
\hline & 31 & 1,29 & 75 & 1329,1 & 829,0 & 816,0 & 0,010 & 121,2 \\
\hline & 32 & 1,54 & 76 & 1212,4 & 855,0 & 816,0 & 0,032 & 60,9 \\
\hline & 33 & 1,22 & 98 & 1252,1 & 816,0 & 810,0 & 0,005 & 67,3 \\
\hline Outras & 34 & 0,14 & 98 & 226,9 & 810,0 & 805,0 & 0,022 & 8,0 \\
\hline \multirow{2}{*}{ Tijuco Preto } & 35 & 2,01 & 98 & 1385,0 & 860,0 & 815,0 & 0,032 & 28,0 \\
\hline & 36 & 1,39 & 98 & 1487,4 & 815,0 & 805,0 & 0,007 & 65,3 \\
\hline \multirow{5}{*}{ Outras } & 37 & 0,31 & 98 & 228,4 & 805,0 & 800,0 & 0,022 & 8,1 \\
\hline & 38 & 0,32 & 98 & 467,6 & 800,0 & 785,0 & 0,032 & 11,8 \\
\hline & 39 & 0,66 & 98 & 658,3 & 800,0 & 785,0 & 0,023 & 18,5 \\
\hline & $40-\mathrm{a}$ & 0,24 & 98 & 404,9 & 785,0 & 782,0 & 0,007 & 22,0 \\
\hline & $40-b$ & 0,84 & 98 & 1174,6 & 782,0 & 780,0 & 0,002 & 107,4 \\
\hline \multirow{2}{*}{ Mineirinho } & 41 & 3,14 & 82 & 1758,6 & 858,0 & 823,0 & 0,020 & 85,9 \\
\hline & 42 & 2,56 & 82 & 1998,2 & 823,0 & 780,0 & 0,022 & 91,5 \\
\hline
\end{tabular}


Continuação da Tabela D19: Dados de entrada do modelo para o cenário AM 2025 - Módulo Bacia.

\begin{tabular}{ccccccccc}
\hline & $\begin{array}{c}\text { Sub- } \\
\text { bacia }\end{array}$ & $\begin{array}{c}\text { Área } \\
\left(\mathbf{k m}^{2}\right)\end{array}$ & $\mathbf{C N}$ & $\begin{array}{c}\mathbf{L} \\
(\mathbf{m})\end{array}$ & $\begin{array}{c}\mathbf{C M} \\
(\mathbf{m})\end{array}$ & $\begin{array}{c}\mathbf{C J} \\
(\mathbf{m})\end{array}$ & $\begin{array}{c}\mathbf{S} \\
(\mathbf{m} / \mathbf{m})\end{array}$ & $\begin{array}{c}\text { Tc } \\
(\mathbf{m i n})\end{array}$ \\
\hline \multirow{6}{*}{ Gregório } & 43 & 1,55 & 83 & 1831,7 & 912,0 & 850,0 & 0,034 & 65,8 \\
& 44 & 1,19 & 85 & 1688,4 & 899,0 & 850,0 & 0,029 & 62,2 \\
& 45 & 1,65 & 88 & 1446,7 & 850,0 & 845,0 & 0,003 & 142,7 \\
& 46 & 0,68 & 88 & 858,9 & 880,0 & 845,0 & 0,041 & 27,4 \\
& 47 & 0,63 & 98 & 538,8 & 845,0 & 840,0 & 0,009 & 24,6 \\
& 48 & 1,22 & 88 & 1853,5 & 900,0 & 840,0 & 0,032 & 56,9 \\
& 50 & 0,72 & 98 & 858,5 & 840,0 & 815,0 & 0,029 & 20,2 \\
& 51 & 0,94 & 98 & 482,4 & 877,0 & 858,0 & 0,039 & 11,0 \\
& 52 & 2,27 & 98 & 1350,4 & 858,0 & 815,0 & 0,032 & 27,8 \\
\multirow{2}{*}{ Exutório } & 53 & 3,74 & 98 & 1746,1 & 815,0 & 800,0 & 0,010 & 54,4 \\
& 54 & 1,28 & 98 & 684,0 & 838,0 & 800,0 & 0,022 & 41,3 \\
& 55 & 0,62 & 98 & 1856,8 & 780,0 & 780,0 & 0,029 & 16,8 \\
& 56 & 0,10 & 98 & 278,3 & 780,0 & 775,0 & 0,003 & 123,1 \\
\hline
\end{tabular}


Tabela D20: Dados de entrada do modelo para o cenário AM 2025 - Módulo Rio.

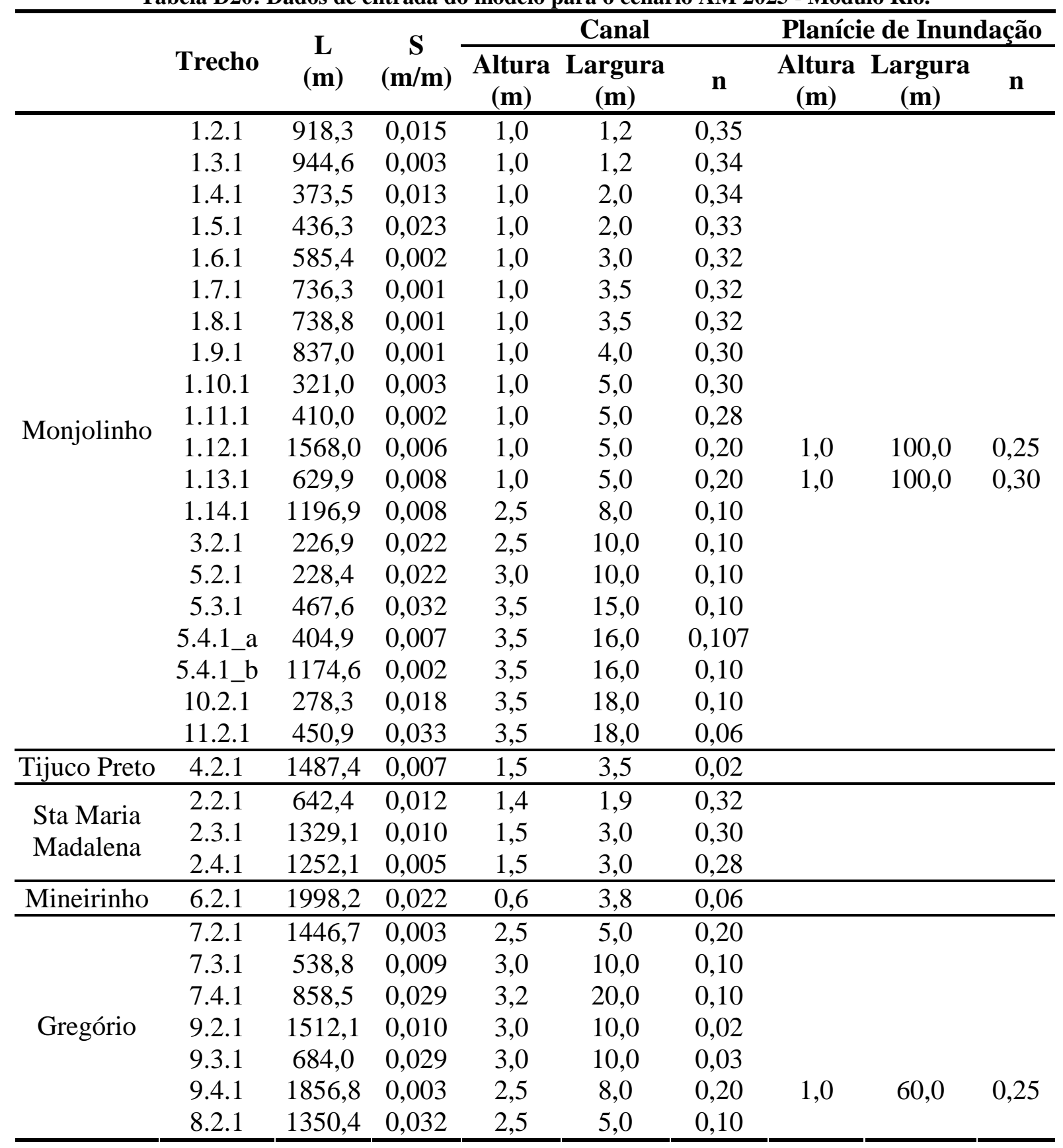


Tabela D21: Dados de entrada do modelo para o cenário AM 2050 - Módulo Bacia.

\begin{tabular}{|c|c|c|c|c|c|c|c|c|}
\hline & $\begin{array}{l}\text { Sub- } \\
\text { bacia }\end{array}$ & $\begin{array}{l}\text { Área } \\
\left(\mathbf{k m}^{2}\right)\end{array}$ & $\mathbf{C N}$ & $\begin{array}{c}\mathbf{L} \\
(\mathbf{m})\end{array}$ & $\begin{array}{l}\mathbf{C M} \\
(\mathbf{m})\end{array}$ & $\begin{array}{c}\mathbf{C J} \\
(\mathbf{m})\end{array}$ & $\begin{array}{c}\mathbf{S} \\
(\mathbf{m} / \mathbf{m})\end{array}$ & $\begin{array}{c}\text { Tc } \\
(\mathbf{m i n})\end{array}$ \\
\hline \multirow{27}{*}{ Monjolinho } & 1 & 2,40 & 58 & 1350,2 & 910,0 & 871,6 & 0,028 & 114,0 \\
\hline & 2 & 0,51 & 58 & 918,3 & 871,6 & 858,0 & 0,015 & 113,5 \\
\hline & 3 & 0,74 & 58 & 1193,3 & 890,0 & 858,0 & 0,027 & 106,3 \\
\hline & 4 & 0,76 & 58 & 944,6 & 858,0 & 855,0 & 0,003 & 256,3 \\
\hline & 5 & 1,85 & 58 & 2209,3 & 895,0 & 855,0 & 0,018 & 211,8 \\
\hline & 6 & 0,06 & 65 & 373,5 & 855,0 & 850,0 & 0,013 & 49,7 \\
\hline & 7 & 1,37 & 74 & 2018,8 & 898,0 & 850,0 & 0,024 & 111,7 \\
\hline & 8 & 1,31 & 65 & 1440,9 & 898,0 & 850,0 & 0,033 & 92,8 \\
\hline & 9 & 0,22 & 65 & 436,3 & 850,0 & 840,0 & 0,023 & 43,0 \\
\hline & 10 & 1,80 & 65 & 1316,2 & 877,0 & 840,0 & 0,028 & 94,0 \\
\hline & 11 & 0,36 & 72 & 585,4 & 840,0 & 839,0 & 0,002 & 163,6 \\
\hline & 12 & 1,95 & 82 & 2168,6 & 898,0 & 839,0 & 0,027 & 86,8 \\
\hline & 13 & 0,52 & 74 & 736,3 & 839,0 & 838,0 & 0,001 & 208,6 \\
\hline & 14 & 1,99 & 58 & 2116,7 & 898,0 & 838,0 & 0,028 & 163,6 \\
\hline & 15 & 0,70 & 82 & 738,8 & 838,0 & 837,5 & 0,001 & 232,7 \\
\hline & 16 & 2,22 & 98 & 2189,1 & 879,0 & 837,5 & 0,019 & 52,9 \\
\hline & 17 & 0,98 & 82 & 837,0 & 837,5 & 837,0 & 0,001 & 273,7 \\
\hline & 18 & 2,33 & 65 & 2463,2 & 876,0 & 837,0 & 0,016 & 206,8 \\
\hline & 19 & 0,18 & 82 & 321,0 & 837,0 & 836,0 & 0,003 & 55,7 \\
\hline & 20 & 1,06 & 82 & 1540,7 & 859,0 & 836,0 & 0,015 & 89,2 \\
\hline & 21 & 0,26 & 90 & 410,0 & 836,0 & 835,0 & 0,002 & 57,3 \\
\hline & 22 & 3,64 & 68 & 2434,6 & 862,0 & 835,0 & 0,011 & 223,9 \\
\hline & 23 & 2,68 & 95 & 1568,0 & 835,0 & 825,0 & 0,006 & 82,5 \\
\hline & 24 & 3,64 & 75 & 2619,8 & 879,0 & 825,0 & 0,021 & 143,7 \\
\hline & 25 & 0,66 & 95 & 629,9 & 825,0 & 820,0 & 0,008 & 35,7 \\
\hline & 26 & 1,12 & 95 & 1166,4 & 858,0 & 820,0 & 0,033 & 28,8 \\
\hline & 27 & 1,06 & 98 & 1196,9 & 820,0 & 815,0 & 0,004 & 69,6 \\
\hline \multirow{6}{*}{$\begin{array}{l}\text { Sta Maria } \\
\text { Madalena }\end{array}$} & 28 & 5,24 & 68 & 1691,2 & 858,0 & 837,0 & 0,012 & 158,1 \\
\hline & 29 & 0,47 & 68 & 642,4 & 837,0 & 829,0 & 0,012 & 72,8 \\
\hline & 30 & 2,18 & 68 & 1257,5 & 857,0 & 829,0 & 0,022 & 93,2 \\
\hline & 31 & 1,29 & 75 & 1329,1 & 829,0 & 816,0 & 0,010 & 121,2 \\
\hline & 32 & 1,54 & 76 & 1239,7 & 855,0 & 816,0 & 0,031 & 62,7 \\
\hline & 33 & 1,22 & 98 & 1252,1 & 816,0 & 815,0 & 0,001 & 165,0 \\
\hline Outras & 34 & 0,14 & 98 & 226,9 & 815,0 & 812,0 & 0,013 & 10,3 \\
\hline \multirow{2}{*}{ Tijuco Preto } & 35 & 2,01 & 98 & 1501,5 & 860,0 & 815,0 & 0,030 & 31,1 \\
\hline & 36 & 1,39 & 98 & 1487,4 & 815,0 & 812,0 & 0,002 & 119,1 \\
\hline \multirow{5}{*}{ Outras } & 37 & 0,31 & 98 & 228,4 & 812,0 & 804,0 & 0,035 & 6,4 \\
\hline & 38 & 0,32 & 98 & 467,6 & 804,0 & 790,0 & 0,030 & 12,3 \\
\hline & 39 & 0,66 & 98 & 843,7 & 800,0 & 790,0 & 0,012 & 31,2 \\
\hline & $40-\mathrm{a}$ & 0,24 & 98 & 404,9 & 790,0 & 783,0 & 0,017 & 14,4 \\
\hline & $40-\mathrm{b}$ & 0,84 & 98 & 1174,6 & 783,0 & 781,0 & 0,002 & 107,4 \\
\hline \multirow{2}{*}{ Mineirinho } & 41 & 3,14 & 82 & 1758,6 & 858,0 & 823,0 & 0,020 & 85,9 \\
\hline & 42 & 2,56 & 82 & 1998,2 & 823,0 & 781,0 & 0,021 & 92,5 \\
\hline
\end{tabular}


Continuação da Tabela D21: Dados de entrada do modelo para o cenário AM 2050 - Módulo Bacia.

\begin{tabular}{ccccccccc}
\hline & $\begin{array}{c}\text { Sub- } \\
\text { bacia }\end{array}$ & $\begin{array}{c}\text { Área } \\
\left(\mathbf{k m} \mathbf{2}^{2}\right.\end{array}$ & $\mathbf{C N}$ & $\begin{array}{c}\mathbf{L} \\
(\mathbf{m})\end{array}$ & $\begin{array}{c}\mathbf{C M} \\
(\mathbf{m})\end{array}$ & $\begin{array}{c}\mathbf{C J} \\
(\mathbf{m})\end{array}$ & $\begin{array}{c}\mathbf{S} \\
(\mathbf{m} / \mathbf{m})\end{array}$ & $\begin{array}{c}\text { Tc } \\
(\mathbf{m i n})\end{array}$ \\
\hline & 43 & 1,55 & 83 & 1831,7 & 912,0 & 850,0 & 0,034 & 65,8 \\
& 44 & 1,19 & 85 & 1688,4 & 899,0 & 850,0 & 0,029 & 62,2 \\
& 45 & 1,65 & 88 & 1446,7 & 850,0 & 845,0 & 0,003 & 142,7 \\
& 46 & 0,68 & 88 & 858,9 & 880,0 & 845,0 & 0,041 & 27,4 \\
Gregório & 47 & 0,63 & 98 & 538,8 & 845,0 & 840,0 & 0,009 & 24,6 \\
& 48 & 1,22 & 88 & 1853,5 & 900,0 & 840,0 & 0,032 & 56,9 \\
& 49 & 0,72 & 98 & 858,5 & 840,0 & 815,0 & 0,029 & 20,2 \\
& 50 & 0,94 & 98 & 482,4 & 877,0 & 858,0 & 0,039 & 11,0 \\
& 51 & 0,84 & 98 & 1526,3 & 858,0 & 815,0 & 0,028 & 32,5 \\
& 52 & 2,27 & 98 & 1512,1 & 815,0 & 800,0 & 0,010 & 54,4 \\
& 53 & 3,74 & 98 & 1839,8 & 838,0 & 800,0 & 0,021 & 44,1 \\
\multirow{2}{*}{ Exutório } & 54 & 1,28 & 98 & 684,0 & 800,0 & 780,0 & 0,029 & 16,8 \\
& 55 & 0,62 & 98 & 1856,8 & 780,0 & 778,0 & 0,001 & 194,7 \\
\hline
\end{tabular}


Tabela D22: Dados de entrada do modelo para o cenário AM 2050 - Módulo Rio.

\begin{tabular}{|c|c|c|c|c|c|c|c|c|c|}
\hline & \multirow[b]{2}{*}{ Trecho } & \multirow{2}{*}{$\begin{array}{c}\mathbf{L} \\
(\mathbf{m})\end{array}$} & \multirow{2}{*}{$\begin{array}{c}\mathbf{S} \\
(\mathbf{m} / \mathbf{m})\end{array}$} & \multicolumn{3}{|c|}{ Canal } & \multicolumn{3}{|c|}{ Planície de Inundação } \\
\hline & & & & $\begin{array}{c}\text { Altura } \\
(\mathbf{m})\end{array}$ & $\begin{array}{l}\text { Largura } \\
(\mathbf{m})\end{array}$ & $\mathbf{n}$ & $\begin{array}{l}\text { Altura } \\
\text { (m) }\end{array}$ & $\begin{array}{l}\text { Largura } \\
\text { (m) }\end{array}$ & $\mathbf{n}$ \\
\hline \multirow{20}{*}{ Monjolinho } & 1.2 .1 & 918,3 & 0,015 & 1,0 & 1,2 & 0,40 & \multirow{20}{*}{$\begin{array}{l}1,0 \\
1,0\end{array}$} & \multirow{20}{*}{$\begin{array}{l}100,0 \\
100,0\end{array}$} & \multirow{20}{*}{$\begin{array}{l}0,30 \\
0,35\end{array}$} \\
\hline & 1.3 .1 & 944,6 & 0,003 & 1,0 & 1,2 & 0,39 & & & \\
\hline & 1.4 .1 & 373,5 & 0,013 & 1,0 & 2,0 & 0,39 & & & \\
\hline & 1.5.1 & 436,3 & 0,023 & 1,0 & 2,0 & 0,38 & & & \\
\hline & 1.6.1 & 585,4 & 0,002 & 1,0 & 3,0 & 0,37 & & & \\
\hline & 1.7.1 & 736,3 & 0,001 & 1,0 & 3,5 & 0,37 & & & \\
\hline & 1.8 .1 & 738,8 & 0,001 & 1,0 & 3,5 & 0,37 & & & \\
\hline & 1.9 .1 & 837,0 & 0,001 & 1,0 & 4,0 & 0,35 & & & \\
\hline & 1.10 .1 & 321,0 & 0,003 & 1,0 & 5,0 & 0,35 & & & \\
\hline & 1.11 .1 & 410,0 & 0,002 & 1,0 & 5,0 & 0,33 & & & \\
\hline & 1.12 .1 & 1568,0 & 0,006 & 1,0 & 5,0 & 0,25 & & & \\
\hline & 1.13 .1 & 629,9 & 0,008 & 1,0 & 5,0 & 0,25 & & & \\
\hline & 1.14 .1 & 1196,9 & 0,004 & 2,5 & 8,0 & 0,15 & & & \\
\hline & 3.2 .1 & 226,9 & 0,013 & 2,5 & 10,0 & 0,15 & & & \\
\hline & 5.2 .1 & 228,4 & 0,035 & 3,0 & 10,0 & 0,15 & & & \\
\hline & 5.3 .1 & 467,6 & 0,030 & 3,5 & 15,0 & 0,15 & & & \\
\hline & 5.4.1_a & 404,9 & 0,017 & 3,5 & 16,0 & 0,16 & & & \\
\hline & 5.4.1_b & 1174,6 & 0,002 & 3,5 & 16,0 & 0,15 & & & \\
\hline & 10.2 .1 & 278,3 & 0,011 & 3,5 & 18,0 & 0,15 & & & \\
\hline & 11.2.1 & 450,9 & 0,007 & 3,5 & 18,0 & 0,11 & & & \\
\hline Tijuco Preto & 4.2 .1 & 1487,4 & 0,002 & 1,5 & 3,5 & 0,07 & & & \\
\hline \multirow{3}{*}{$\begin{array}{l}\text { Sta Maria } \\
\text { Madalena }\end{array}$} & 2.2 .1 & 642,4 & 0,012 & 1,4 & 1,9 & 0,37 & & & \\
\hline & 2.3 .1 & 1329,1 & 0,010 & 1,5 & 3,0 & 0,35 & & & \\
\hline & 2.4 .1 & 1252,1 & 0,001 & 1,5 & 3,0 & 0,33 & & & \\
\hline \multirow[t]{4}{*}{ Mineirinho } & 6.2 .1 & 1998,2 & 0,021 & 0,6 & 3,8 & 0,11 & & & \\
\hline & 7.2 .1 & 1446,7 & 0,003 & 2,5 & 5,0 & 0,25 & & & \\
\hline & 7.3 .1 & 538,8 & 0,009 & 3,0 & 10,0 & 0,15 & & & \\
\hline & 7.4 .1 & 858,5 & 0,029 & 3,2 & 20,0 & 0,15 & & & \\
\hline \multirow[t]{4}{*}{ Gregório } & 9.2 .1 & 1512,1 & 0,010 & 3,0 & 10,0 & 0,07 & & & \\
\hline & 9.3 .1 & 684,0 & 0,029 & 3,0 & 10,0 & 0,08 & \multirow{3}{*}{1,0} & \multirow{3}{*}{60,0} & \multirow{3}{*}{0,25} \\
\hline & 9.4 .1 & 1856,8 & 0,001 & 2,5 & 8,0 & 0,25 & & & \\
\hline & 8.2 .1 & 1526,3 & 0,028 & 2,5 & 5,0 & 0,15 & & & \\
\hline
\end{tabular}


Tabela D23: Dados de entrada do modelo para o cenário AM 2075 - Módulo Bacia.

\begin{tabular}{|c|c|c|c|c|c|c|c|c|}
\hline & $\begin{array}{c}\text { Sub- } \\
\text { bacia }\end{array}$ & $\begin{array}{c}\text { Área } \\
\left(\mathbf{k m}^{2}\right)\end{array}$ & $\mathrm{CN}$ & $\begin{array}{c}\mathbf{L} \\
(\mathbf{m})\end{array}$ & $\begin{array}{l}\mathbf{C M} \\
(\mathbf{m})\end{array}$ & $\begin{array}{c}\mathbf{C J} \\
(\mathbf{m})\end{array}$ & $\begin{array}{c}\mathbf{S} \\
(\mathbf{m} / \mathbf{m})\end{array}$ & $\begin{array}{c}\text { Tc } \\
\text { (min) }\end{array}$ \\
\hline \multirow{27}{*}{ Monjolinho } & 1 & 2,40 & 58 & 1350,2 & 910,0 & 871,6 & 0,028 & 114,0 \\
\hline & 2 & 0,51 & 58 & 918,3 & 871,6 & 858,0 & 0,015 & 113,5 \\
\hline & 3 & 0,74 & 58 & 1193,3 & 890,0 & 858,0 & 0,027 & 106,3 \\
\hline & 4 & 0,76 & 58 & 944,6 & 858,0 & 855,0 & 0,003 & 256,3 \\
\hline & 5 & 1,85 & 58 & 2209,3 & 895,0 & 855,0 & 0,018 & 211,8 \\
\hline & 6 & 0,06 & 65 & 373,5 & 855,0 & 850,0 & 0,013 & 49,7 \\
\hline & 7 & 1,37 & 74 & 2018,8 & 898,0 & 850,0 & 0,024 & 111,7 \\
\hline & 8 & 1,31 & 65 & 1440,9 & 898,0 & 850,0 & 0,033 & 92,8 \\
\hline & 9 & 0,22 & 65 & 436,3 & 850,0 & 840,0 & 0,023 & 43,0 \\
\hline & 10 & 1,80 & 65 & 1316,2 & 877,0 & 840,0 & 0,028 & 94,0 \\
\hline & 11 & 0,36 & 72 & 585,4 & 840,0 & 839,0 & 0,002 & 163,6 \\
\hline & 12 & 1,95 & 82 & 2168,6 & 898,0 & 839,0 & 0,027 & 86,8 \\
\hline & 13 & 0,52 & 74 & 736,3 & 839,0 & 837,0 & 0,003 & 147,5 \\
\hline & 14 & 1,99 & 58 & 2116,7 & 898,0 & 837,0 & 0,029 & 162,2 \\
\hline & 15 & 0,70 & 82 & 837,2 & 837,0 & 836,0 & 0,001 & 193,6 \\
\hline & 16 & 2,22 & 98 & 2189,1 & 879,0 & 836,0 & 0,020 & 52,0 \\
\hline & 17 & 0,98 & 82 & 891,0 & 836,0 & 835,0 & 0,001 & 209,9 \\
\hline & 18 & 2,33 & 65 & 2463,2 & 876,0 & 835,0 & 0,017 & 201,7 \\
\hline & 19 & 0,18 & 82 & 344,3 & 835,0 & 834,0 & 0,003 & 61,0 \\
\hline & 20 & 1,06 & 82 & 1540,7 & 859,0 & 834,0 & 0,016 & 85,6 \\
\hline & 21 & 0,26 & 90 & 410,5 & 834,0 & 833,0 & 0,002 & 57,3 \\
\hline & 22 & 3,64 & 68 & 2434,6 & 862,0 & 833,0 & 0,012 & 216,1 \\
\hline & 23 & 2,68 & 95 & 1663,9 & 833,0 & 825,0 & 0,005 & 99,7 \\
\hline & 24 & 3,64 & 75 & 2619,8 & 879,0 & 825,0 & 0,021 & 143,7 \\
\hline & 25 & 0,66 & 95 & 629,9 & 825,0 & 821,0 & 0,006 & 39,9 \\
\hline & 26 & 1,12 & 95 & 1166,4 & 858,0 & 821,0 & 0,032 & 29,2 \\
\hline & 27 & 1,06 & 98 & 1196,9 & 821,0 & 817,0 & 0,003 & 77,8 \\
\hline \multirow{6}{*}{$\begin{array}{l}\text { Sta Maria } \\
\text { Madalena }\end{array}$} & 28 & 5,24 & 68 & 1691,2 & 858,0 & 837,0 & 0,012 & 158,1 \\
\hline & 29 & 0,47 & 68 & 642,4 & 837,0 & 829,0 & 0,012 & 72,8 \\
\hline & 30 & 2,18 & 68 & 1257,5 & 857,0 & 829,0 & 0,022 & 93,2 \\
\hline & 31 & 1,29 & 75 & 1329,1 & 829,0 & 820,0 & 0,007 & 145,6 \\
\hline & 32 & 1,54 & 76 & 1239,7 & 855,0 & 820,0 & 0,028 & 66,1 \\
\hline & 33 & 1,22 & 98 & 1252,1 & 820,0 & 817,0 & 0,002 & 95,2 \\
\hline Outras & 34 & 0,14 & 98 & 226,9 & 817,0 & 814,0 & 0,013 & 10,3 \\
\hline \multirow{2}{*}{ Tijuco Preto } & 35 & 2,01 & 98 & 1501,5 & 860,0 & 815,0 & 0,030 & 31,1 \\
\hline & 36 & 1,39 & 98 & 1487,4 & 815,0 & 814,0 & 0,001 & 206,4 \\
\hline \multirow{5}{*}{ Outras } & 37 & 0,31 & 98 & 228,4 & 814,0 & 804,0 & 0,044 & 5,7 \\
\hline & 38 & 0,32 & 98 & 467,6 & 804,0 & 793,0 & 0,024 & 13,8 \\
\hline & 39 & 0,66 & 98 & 843,7 & 800,0 & 793,0 & 0,008 & 37,3 \\
\hline & $40-a$ & 0,24 & 98 & 404,9 & 793,0 & 786,0 & 0,017 & 14,4 \\
\hline & $40-b$ & 0,84 & 98 & 1280,8 & 786,0 & 781,0 & 0,004 & 76,0 \\
\hline \multirow{2}{*}{ Mineirinho } & 41 & 3,14 & 82 & 1758,6 & 858,0 & 823,0 & 0,020 & 85,9 \\
\hline & 42 & 2,56 & 82 & 1998,2 & 823,0 & 781,0 & 0,021 & 92,5 \\
\hline
\end{tabular}


Continuação da Tabela D23: Dados de entrada do modelo para o cenário AM 2075 - Módulo Bacia.

\begin{tabular}{ccccccccc}
\hline & $\begin{array}{c}\text { Sub- } \\
\text { bacia }\end{array}$ & $\begin{array}{c}\text { Área } \\
(\mathbf{k m})\end{array}$ & $\mathbf{C N}$ & $\begin{array}{c}\mathbf{L} \\
(\mathbf{m})\end{array}$ & $\begin{array}{c}\mathbf{C M} \\
(\mathbf{m})\end{array}$ & $\begin{array}{c}\mathbf{C J} \\
(\mathbf{m})\end{array}$ & $\begin{array}{c}\mathbf{S} \\
(\mathbf{m} / \mathbf{m})\end{array}$ & $\begin{array}{c}\text { Tc } \\
(\mathbf{m i n})\end{array}$ \\
\hline \multirow{6}{*}{ Gregório } & 43 & 1,55 & 83 & 1831,7 & 912,0 & 850,0 & 0,034 & 65,8 \\
& 44 & 1,19 & 85 & 1688,4 & 899,0 & 850,0 & 0,029 & 62,2 \\
& 45 & 1,65 & 88 & 1446,7 & 850,0 & 846,0 & 0,003 & 159,6 \\
& 46 & 0,68 & 88 & 858,9 & 880,0 & 846,0 & 0,040 & 27,8 \\
& 47 & 0,63 & 98 & 538,8 & 846,0 & 842,0 & 0,007 & 27,6 \\
& 48 & 1,22 & 88 & 1853,5 & 900,0 & 842,0 & 0,031 & 57,8 \\
& 50 & 0,72 & 98 & 858,5 & 842,0 & 817,0 & 0,029 & 20,2 \\
& 51 & 0,94 & 98 & 482,4 & 877,0 & 858,0 & 0,039 & 11,0 \\
& 52 & 2,27 & 98 & 1526,3 & 858,0 & 817,0 & 0,027 & 33,3 \\
\multirow{2}{*}{ Exutório } & 53 & 3,74 & 98 & 1839,8 & 817,0 & 804,0 & 0,009 & 58,5 \\
& 54 & 1,28 & 98 & 684,0 & 804,0 & 804,0 & 0,018 & 46,7 \\
& 55 & 0,62 & 98 & 1856,8 & 780,0 & 778,0 & 0,001 & 194,7 \\
\hline
\end{tabular}


Tabela D24: Dados de entrada do modelo para o cenário AM 2075 - Módulo Rio

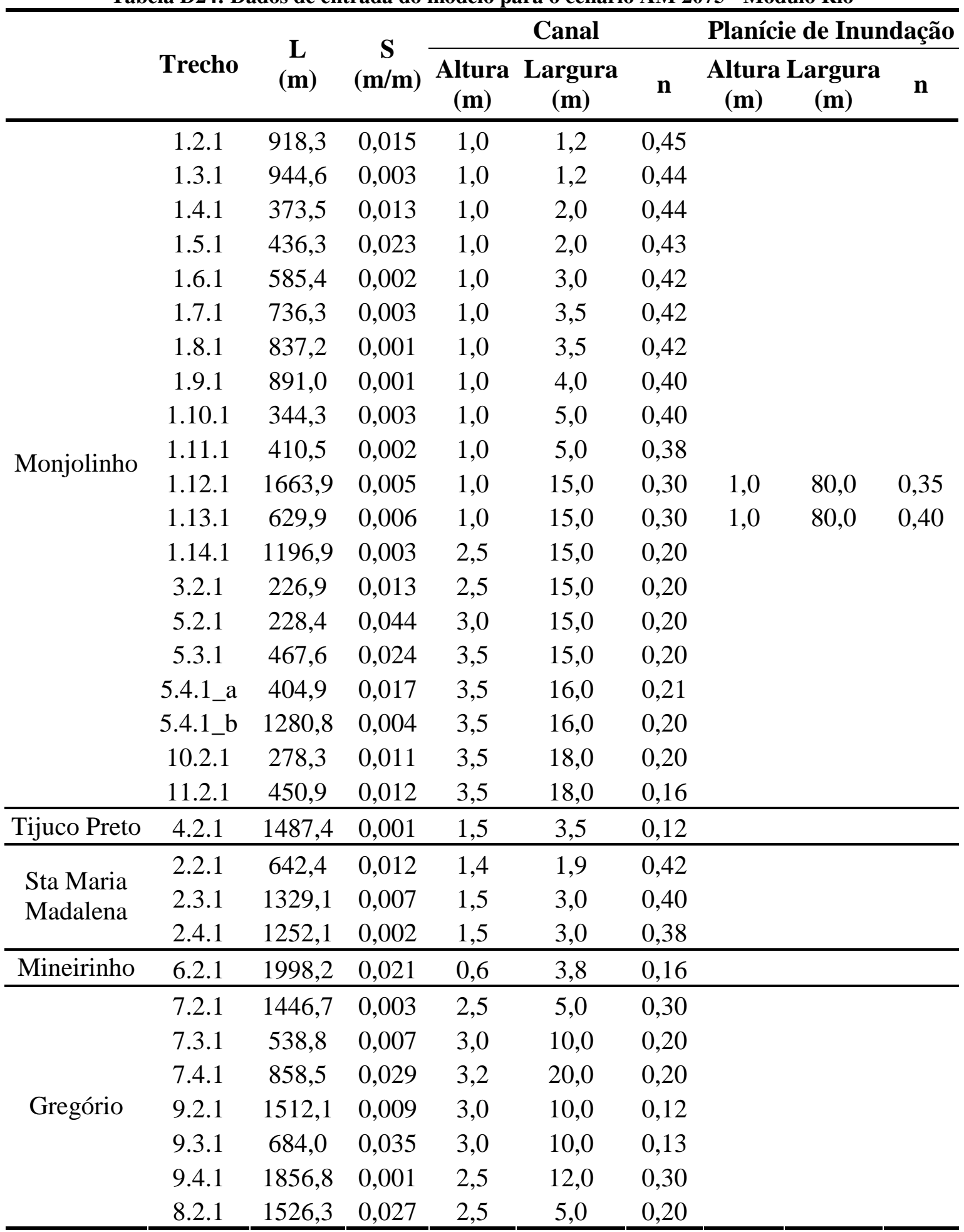


Tabela D25: Dados de entrada do modelo para o cenário AM 2100 - Módulo Bacia.

\begin{tabular}{|c|c|c|c|c|c|c|c|c|}
\hline & $\begin{array}{l}\text { Sub- } \\
\text { bacia }\end{array}$ & $\begin{array}{l}\text { Área } \\
\left(\mathbf{k m}^{2}\right)\end{array}$ & $\mathrm{CN}$ & $\begin{array}{c}\mathbf{L} \\
(\mathbf{m})\end{array}$ & $\begin{array}{l}\mathbf{C M} \\
(\mathbf{m})\end{array}$ & $\begin{array}{c}\mathbf{C J} \\
(\mathbf{m})\end{array}$ & $\begin{array}{c}\mathbf{S} \\
(\mathbf{m} / \mathbf{m})\end{array}$ & $\begin{array}{c}\text { Tc } \\
(\mathbf{m i n})\end{array}$ \\
\hline \multirow{27}{*}{ Monjolinho } & 1 & 2,40 & 58 & 1350,2 & 910,0 & 871,6 & 0,028 & 114,0 \\
\hline & 2 & 0,51 & 58 & 918,3 & 871,6 & 858,0 & 0,015 & 113,5 \\
\hline & 3 & 0,74 & 58 & 1193,3 & 890,0 & 858,0 & 0,027 & 106,3 \\
\hline & 4 & 0,76 & 58 & 944,6 & 858,0 & 855,0 & 0,003 & 256,3 \\
\hline & 5 & 1,85 & 58 & 2209,3 & 895,0 & 855,0 & 0,018 & 211,8 \\
\hline & 6 & 0,06 & 65 & 373,5 & 855,0 & 850,0 & 0,013 & 49,7 \\
\hline & 7 & 1,37 & 74 & 2018,8 & 898,0 & 850,0 & 0,024 & 111,7 \\
\hline & 8 & 1,31 & 65 & 1440,9 & 898,0 & 850,0 & 0,033 & 92,8 \\
\hline & 9 & 0,22 & 65 & 436,3 & 850,0 & 840,0 & 0,023 & 43,0 \\
\hline & 10 & 1,80 & 65 & 1316,2 & 877,0 & 840,0 & 0,028 & 94,0 \\
\hline & 11 & 0,36 & 72 & 585,4 & 840,0 & 839,0 & 0,002 & 163,6 \\
\hline & 12 & 1,95 & 82 & 2168,6 & 898,0 & 839,0 & 0,027 & 86,8 \\
\hline & 13 & 0,52 & 74 & 736,3 & 839,0 & 837,0 & 0,003 & 147,5 \\
\hline & 14 & 1,99 & 58 & 2116,7 & 898,0 & 837,0 & 0,029 & 162,2 \\
\hline & 15 & 0,70 & 82 & 837,2 & 837,0 & 836,0 & 0,001 & 193,6 \\
\hline & 16 & 2,22 & 98 & 2189,1 & 879,0 & 836,0 & 0,020 & 52,0 \\
\hline & 17 & 0,98 & 82 & 891,0 & 836,0 & 835,0 & 0,001 & 209,9 \\
\hline & 18 & 2,33 & 65 & 2463,2 & 876,0 & 835,0 & 0,017 & 201,7 \\
\hline & 19 & 0,18 & 82 & 344,3 & 835,0 & 834,0 & 0,003 & 61,0 \\
\hline & 20 & 1,06 & 82 & 1540,7 & 859,0 & 834,0 & 0,016 & 85,6 \\
\hline & 21 & 0,26 & 90 & 410,5 & 834,0 & 833,0 & 0,002 & 57,3 \\
\hline & 22 & 3,64 & 68 & 2434,6 & 862,0 & 833,0 & 0,012 & 216,1 \\
\hline & 23 & 2,68 & 95 & 1663,9 & 833,0 & 825,0 & 0,005 & 99,7 \\
\hline & 24 & 3,64 & 75 & 2619,8 & 879,0 & 825,0 & 0,021 & 143,7 \\
\hline & 25 & 0,66 & 95 & 629,9 & 825,0 & 821,0 & 0,006 & 39,9 \\
\hline & 26 & 1,12 & 95 & 1166,4 & 858,0 & 821,0 & 0,032 & 29,2 \\
\hline & 27 & 1,06 & 98 & 1196,9 & 821,0 & 817,0 & 0,003 & 77,8 \\
\hline \multirow{6}{*}{$\begin{array}{l}\text { Sta Maria } \\
\text { Madalena }\end{array}$} & 28 & 5,24 & 68 & 1691,2 & 858,0 & 837,0 & 0,012 & 158,1 \\
\hline & 29 & 0,47 & 68 & 642,4 & 837,0 & 829,0 & 0,012 & 72,8 \\
\hline & 30 & 2,18 & 68 & 1257,5 & 857,0 & 829,0 & 0,022 & 93,2 \\
\hline & 31 & 1,29 & 75 & 1329,1 & 829,0 & 820,0 & 0,007 & 145,6 \\
\hline & 32 & 1,54 & 76 & 1239,7 & 855,0 & 820,0 & 0,028 & 66,1 \\
\hline & 33 & 1,22 & 98 & 1252,1 & 820,0 & 817,0 & 0,002 & 95,2 \\
\hline Outras & 34 & 0,14 & 98 & 226,9 & 817,0 & 814,0 & 0,013 & 10,3 \\
\hline \multirow{2}{*}{ Tijuco Preto } & 35 & 2,01 & 98 & 1501,5 & 860,0 & 815,0 & 0,030 & 31,1 \\
\hline & 36 & 1,39 & 98 & 1487,4 & 815,0 & 814,0 & 0,001 & 206,4 \\
\hline \multirow{5}{*}{ Outras } & 37 & 0,31 & 98 & 228,4 & 814,0 & 804,0 & 0,044 & 5,7 \\
\hline & 38 & 0,32 & 98 & 467,6 & 804,0 & 793,0 & 0,024 & 13,8 \\
\hline & 39 & 0,66 & 98 & 843,7 & 800,0 & 793,0 & 0,008 & 37,3 \\
\hline & $40-\mathrm{a}$ & 0,24 & 98 & 404,9 & 793,0 & 786,0 & 0,017 & 14,4 \\
\hline & $40-\mathrm{b}$ & 0,84 & 98 & 1280,8 & 786,0 & 781,0 & 0,004 & 76,0 \\
\hline \multirow{2}{*}{ Mineirinho } & 41 & 3,14 & 82 & 1758,6 & 858,0 & 823,0 & 0,020 & 85,9 \\
\hline & 42 & 2,56 & 82 & 1998,2 & 823,0 & 781,0 & 0,021 & 92,5 \\
\hline
\end{tabular}


Continuação da Tabela D25: Dados de entrada do modelo para o cenário AM 2100 - Módulo Bacia.

\begin{tabular}{ccccccccc}
\hline & $\begin{array}{c}\text { Sub- } \\
\text { bacia }\end{array}$ & $\begin{array}{c}\text { Área } \\
\left(\mathbf{k m}^{\mathbf{2}}\right)\end{array}$ & $\mathbf{C N}$ & $\begin{array}{c}\mathbf{L} \\
(\mathbf{m})\end{array}$ & $\begin{array}{c}\mathbf{C M} \\
(\mathbf{m})\end{array}$ & $\begin{array}{c}\mathbf{C J} \\
(\mathbf{m})\end{array}$ & $\begin{array}{c}\mathbf{S} \\
(\mathbf{m} / \mathbf{m})\end{array}$ & $\begin{array}{c}\text { Tc } \\
(\mathbf{m i n})\end{array}$ \\
\hline \multirow{6}{*}{ Gregório } & 43 & 1,55 & 83 & 1831,7 & 912,0 & 850,0 & 0,034 & 65,8 \\
& 44 & 1,19 & 85 & 1688,4 & 899,0 & 850,0 & 0,029 & 62,2 \\
& 45 & 1,65 & 88 & 1446,7 & 850,0 & 846,0 & 0,003 & 159,6 \\
& 46 & 0,68 & 88 & 858,9 & 880,0 & 846,0 & 0,040 & 27,8 \\
& 47 & 0,63 & 98 & 538,8 & 846,0 & 842,0 & 0,007 & 27,6 \\
& 48 & 1,22 & 88 & 1853,5 & 900,0 & 842,0 & 0,031 & 57,8 \\
& 50 & 0,72 & 98 & 858,5 & 842,0 & 817,0 & 0,029 & 20,2 \\
& 51 & 0,94 & 98 & 482,4 & 877,0 & 858,0 & 0,039 & 11,0 \\
& 52 & 2,27 & 98 & 1512,1 & 817,0 & 804,0 & 0,009 & 58,5 \\
\multirow{2}{*}{ Exutório } & 53 & 3,74 & 98 & 1839,8 & 838,0 & 804,0 & 0,018 & 46,7 \\
& 54 & 1,28 & 98 & 684,0 & 804,0 & 780,0 & 0,035 & 15,3 \\
& 55 & 0,62 & 98 & 1856,8 & 780,0 & 778,0 & 0,001 & 194,7 \\
\hline
\end{tabular}


Tabela D26: Dados de entrada do modelo para o cenário AM 2100 - Módulo Rio.

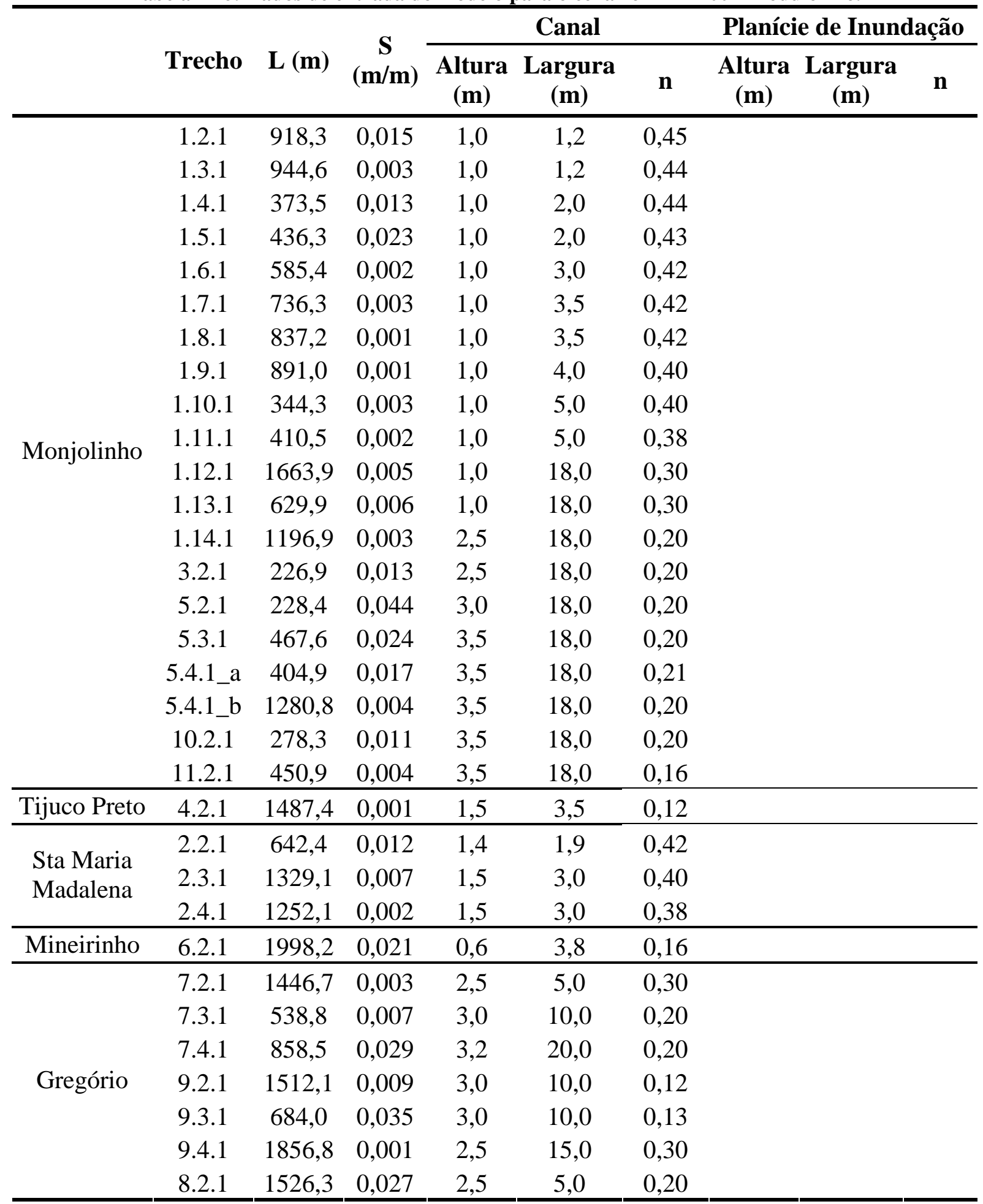




\section{TechnoGarden}

Tabela D27: Dados de entrada do modelo para o cenário TG 2025 - Módulo Bacia.

\begin{tabular}{|c|c|c|c|c|c|c|c|c|}
\hline & $\begin{array}{l}\text { Sub- } \\
\text { bacia }\end{array}$ & $\begin{array}{l}\text { Área } \\
\left(\mathbf{k m}^{2}\right)\end{array}$ & $\mathbf{C N}$ & $\begin{array}{c}\mathbf{L} \\
(\mathbf{m})\end{array}$ & $\begin{array}{l}\mathrm{CM} \\
(\mathbf{m})\end{array}$ & $\begin{array}{l}\text { CJ } \\
\text { (m) }\end{array}$ & $\begin{array}{c}\mathbf{S} \\
(\mathbf{m} / \mathbf{m})\end{array}$ & $\begin{array}{c}\text { Tc } \\
(\mathbf{m i n})\end{array}$ \\
\hline \multirow{27}{*}{ Monjolinho } & 1 & 2,40 & 58 & 1350,2 & 910,0 & 871,6 & 0,028 & 114,0 \\
\hline & 2 & 0,51 & 58 & 918,3 & 871,6 & 858,0 & 0,015 & 116,0 \\
\hline & 3 & 0,74 & 58 & 1193,3 & 890,0 & 858,0 & 0,027 & 106,3 \\
\hline & 4 & 0,76 & 58 & 944,6 & 858,0 & 855,0 & 0,003 & 256,3 \\
\hline & 5 & 1,85 & 58 & 2209,3 & 895,0 & 855,0 & 0,018 & 211,8 \\
\hline & 6 & 0,06 & 65 & 373,5 & 855,0 & 850,0 & 0,013 & 49,7 \\
\hline & 7 & 1,37 & 72 & 2018,8 & 898,0 & 850,0 & 0,024 & 118,1 \\
\hline & 8 & 1,31 & 65 & 1440,9 & 898,0 & 850,0 & 0,033 & 92,8 \\
\hline & 9 & 0,22 & 65 & 436,3 & 850,0 & 840,0 & 0,023 & 43,0 \\
\hline & 10 & 1,80 & 65 & 1316,2 & 877,0 & 840,0 & 0,028 & 94,0 \\
\hline & 11 & 0,36 & 72 & 585,4 & 840,0 & 839,0 & 0,002 & 163,6 \\
\hline & 12 & 1,95 & 80 & 2168,6 & 898,0 & 839,0 & 0,027 & 92,9 \\
\hline & 13 & 0,52 & 72 & 747,1 & 839,0 & 838,0 & 0,001 & 224,7 \\
\hline & 14 & 1,99 & 58 & 2116,7 & 898,0 & 838,0 & 0,028 & 163,6 \\
\hline & 15 & 0,70 & 80 & 754,5 & 838,0 & 837,5 & 0,001 & 255,8 \\
\hline & 16 & 2,22 & 88 & 2189,1 & 879,0 & 837,5 & 0,019 & 84,3 \\
\hline & 17 & 0,98 & 80 & 902,2 & 837,5 & 837,0 & 0,001 & 322,8 \\
\hline & 18 & 2,33 & 65 & 2463,2 & 876,0 & 837,0 & 0,016 & 206,8 \\
\hline & 19 & 0,18 & 80 & 323,4 & 837,0 & 836,0 & 0,003 & 60,1 \\
\hline & 20 & 1,06 & 80 & 1540,7 & 859,0 & 836,0 & 0,015 & 95,4 \\
\hline & 21 & 0,26 & 88 & 416,7 & 836,0 & 835,0 & 0,002 & 62,9 \\
\hline & 22 & 3,64 & 65 & 2434,6 & 862,0 & 835,0 & 0,011 & 244,8 \\
\hline & 23 & 2,68 & 93 & 1575,0 & 835,0 & 825,0 & 0,006 & 89,9 \\
\hline & 24 & 3,64 & 72 & 2619,8 & 879,0 & 825,0 & 0,021 & 156,2 \\
\hline & 25 & 0,66 & 93 & 621,5 & 825,0 & 820,0 & 0,008 & 38,0 \\
\hline & 26 & 1,12 & 93 & 1166,4 & 858,0 & 820,0 & 0,033 & 31,2 \\
\hline & 27 & 1,06 & 93 & 1248,1 & 820,0 & 810,0 & 0,008 & 66,5 \\
\hline \multirow{6}{*}{$\begin{array}{l}\text { Sta Maria } \\
\text { Madalena }\end{array}$} & 28 & 5,24 & 65 & 1691,2 & 858,0 & 837,0 & 0,012 & 172,8 \\
\hline & 29 & 0,47 & 65 & 626,9 & 837,0 & 829,0 & 0,012 & 77,1 \\
\hline & 30 & 2,18 & 65 & 1257,5 & 857,0 & 829,0 & 0,022 & 101,8 \\
\hline & 31 & 1,29 & 72 & 1328,5 & 829,0 & 816,0 & 0,010 & 131,7 \\
\hline & 32 & 1,54 & 65 & 1212,4 & 855,0 & 816,0 & 0,032 & 82,3 \\
\hline & 33 & 1,22 & 88 & 1184,4 & 816,0 & 810,0 & 0,005 & 99,8 \\
\hline Outras & 34 & 0,14 & 93 & 229,2 & 810,0 & 805,0 & 0,022 & 10,4 \\
\hline \multirow{2}{*}{ Tijuco Preto } & 35 & 2,01 & 93 & 1385,0 & 860,0 & 815,0 & 0,032 & 35,9 \\
\hline & 36 & 1,39 & 93 & 1457,5 & 815,0 & 805,0 & 0,007 & 81,3 \\
\hline \multirow{5}{*}{ Outras } & 37 & 0,31 & 93 & 223,0 & 805,0 & 800,0 & 0,022 & 10,0 \\
\hline & 38 & 0,32 & 80 & 490,4 & 800,0 & 785,0 & 0,031 & 26,7 \\
\hline & 39 & 0,66 & 88 & 879,2 & 800,0 & 785,0 & 0,017 & 42,8 \\
\hline & $40-\mathrm{a}$ & 0,24 & 80 & 406,1 & 785,0 & 782,0 & 0,007 & 46,7 \\
\hline & $40-\mathrm{b}$ & 0,84 & 80 & 1231,4 & 782,0 & 780,0 & 0,002 & 241,8 \\
\hline \multirow{2}{*}{ Mineirinho } & 41 & 3,14 & 80 & 1758,6 & 858,0 & 823,0 & 0,020 & 88,7 \\
\hline & 42 & 2,56 & 80 & 2149,2 & 823,0 & 780,0 & 0,020 & 100,6 \\
\hline
\end{tabular}


Continuação da Tabela D27: Dados de entrada do modelo para o cenário TG 2025 - Módulo Bacia.

\begin{tabular}{lcccccccc}
\hline & $\begin{array}{c}\text { Sub- } \\
\text { bacia }\end{array}$ & $\begin{array}{c}\text { Área } \\
\left(\mathbf{k m}^{2}\right)\end{array}$ & $\mathbf{C N}$ & $\begin{array}{c}\mathbf{L} \\
(\mathbf{m})\end{array}$ & $\begin{array}{c}\mathbf{C M} \\
(\mathbf{m})\end{array}$ & $\begin{array}{c}\mathbf{C J} \\
(\mathbf{m})\end{array}$ & $\begin{array}{c}\mathbf{S} \\
(\mathbf{m} / \mathbf{m})\end{array}$ & $\begin{array}{c}\text { Tc } \\
(\mathbf{m i n})\end{array}$ \\
\hline \multirow{6}{*}{ Gregório } & 43 & 1,55 & 83 & 1831,7 & 912,0 & 850,0 & 0,034 & 65,5 \\
& 44 & 1,19 & 85 & 1688,4 & 899,0 & 850,0 & 0,029 & 62,6 \\
& 45 & 1,65 & 86 & 1433,6 & 850,0 & 845,0 & 0,003 & 149,3 \\
& 46 & 0,68 & 86 & 858,9 & 880,0 & 845,0 & 0,041 & 29,0 \\
& 47 & 0,63 & 90 & 546,6 & 845,0 & 840,0 & 0,009 & 37,4 \\
& 48 & 1,22 & 86 & 1853,5 & 900,0 & 840,0 & 0,032 & 60,2 \\
& 59 & 0,72 & 90 & 812,0 & 840,0 & 815,0 & 0,031 & 28,0 \\
& 51 & 0,94 & 86 & 482,4 & 877,0 & 858,0 & 0,039 & 18,6 \\
& 52 & 2,27 & 92 & 1489,4 & 815,0 & 800,0 & 0,010 & 73,9 \\
Exutório & 53 & 3,74 & 93 & 912,1 & 838,0 & 800,0 & 0,042 & 22,7 \\
& 54 & 1,28 & 95 & 664,1 & 800,0 & 780,0 & 0,030 & 19,0 \\
& 55 & 0,62 & 95 & 1816,9 & 780,0 & 775,0 & 0,003 & 140,5 \\
\hline
\end{tabular}


Tabela D28: Dados de entrada do modelo para o cenário TG 2025 - Módulo Rio.

\begin{tabular}{|c|c|c|c|c|c|c|c|c|c|}
\hline & Trecho & $\begin{array}{c}\mathbf{L} \\
(\mathbf{m})\end{array}$ & $\begin{array}{c}\mathrm{S} \\
(\mathrm{m} / \mathbf{m})\end{array}$ & $\begin{array}{c}\text { Altura } \\
(\mathbf{m})\end{array}$ & $\begin{array}{c}\text { Canal } \\
\text { Largura } \\
(\mathbf{m}) \\
\end{array}$ & $\mathbf{n}$ & $\begin{array}{c}\text { Planíci } \\
\text { Altura } \\
(\mathbf{m}) \\
\end{array}$ & $\begin{array}{l}\text { ie de Inund } \\
\text { Largura } \\
\text { (m) }\end{array}$ & $\begin{array}{c}\text { lação } \\
\mathbf{n}\end{array}$ \\
\hline \multirow{20}{*}{ Monjolinho } & 1.2 .1 & 918,3 & 0,015 & 1,0 & 1,2 & 0,40 & & & \\
\hline & 1.3 .1 & 944,6 & 0,003 & 1,0 & 1,2 & 0,39 & & & \\
\hline & 1.4 .1 & 373,5 & 0,013 & 1,0 & 2,0 & 0,39 & & & \\
\hline & 1.5 .1 & 436,3 & 0,023 & 1,0 & 2,0 & 0,38 & & & \\
\hline & 1.6 .1 & 585,4 & 0,002 & 1,0 & 3,0 & 0,37 & & & \\
\hline & 1.7 .1 & 747,1 & 0,001 & 1,0 & 3,5 & 0,37 & & & \\
\hline & 1.8 .1 & 754,5 & 0,001 & 1,0 & 3,5 & 0,37 & & & \\
\hline & 1.9 .1 & 902,2 & 0,001 & 1,0 & 4,0 & 0,35 & & & \\
\hline & 1.10 .1 & 323,4 & 0,003 & 1,0 & 5,0 & 0,35 & 1,0 & 40,0 & 0,30 \\
\hline & 1.11 .1 & 416,7 & 0,002 & 1,0 & 5,0 & 0,33 & 1,0 & 40,0 & 0,30 \\
\hline & 1.12 .1 & 1575,0 & 0,006 & 1,0 & 5,0 & 0,25 & 1,0 & 50,0 & 0,30 \\
\hline & 1.13 .1 & 621,5 & 0,008 & 1,0 & 5,0 & 0,25 & 1,0 & 50,0 & 0,35 \\
\hline & 1.14 .1 & 1248,1 & 0,008 & 2,5 & 8,0 & 0,15 & 1,0 & 50,0 & 0,35 \\
\hline & 3.2 .1 & 229,2 & 0,022 & 2,5 & 10,0 & 0,15 & 1,0 & 55,0 & 0,35 \\
\hline & 5.2 .1 & 223,0 & 0,022 & 3,0 & 10,0 & 0,15 & 1,0 & 55,0 & 0,35 \\
\hline & 5.3 .1 & 490,4 & 0,031 & 3,5 & 15,0 & 0,15 & 1,0 & 55,0 & 0,35 \\
\hline & 5.4.1_a & 406,1 & 0,007 & 3,5 & 16,0 & 0,16 & 1,0 & 55,0 & 0,35 \\
\hline & 5.4.1_b & 1231,4 & 0,002 & 3,5 & 16,0 & 0,15 & 1,0 & 55,0 & 0,35 \\
\hline & 10.2 .1 & 259,5 & 0,019 & 3,5 & 18,0 & 0,15 & 1,0 & 60,0 & 0,35 \\
\hline & 11.2.1 & 454,9 & 0,033 & 3,5 & 18,0 & 0,11 & 1,0 & 60,0 & 0,35 \\
\hline Tijuco Preto & 4.2 .1 & 1457,5 & 0,007 & 1,5 & 3,5 & 0,11 & & & \\
\hline \multirow{3}{*}{$\begin{array}{l}\text { Sta Maria } \\
\text { Madalena }\end{array}$} & 2.2 .1 & 626,9 & 0,013 & 1,4 & 1,9 & 0,07 & & & \\
\hline & 2.3 .1 & 1328,5 & 0,010 & 1,5 & 3,0 & 0,37 & & & \\
\hline & 2.4 .1 & 1184,4 & 0,005 & 1,5 & 3,0 & 0,35 & & & \\
\hline Mineirinho & 6.2 .1 & 2149,2 & 0,020 & 0,6 & 3,8 & 0,33 & & & \\
\hline \multirow{7}{*}{ Gregório } & 7.2 .1 & 1433,6 & 0,003 & 2,5 & 5,0 & 0,11 & & & \\
\hline & 7.3 .1 & 546,6 & 0,009 & 3,0 & 10,0 & 0,25 & & & \\
\hline & 7.4 .1 & 812,0 & 0,031 & 3,2 & 20,0 & 0,15 & & & \\
\hline & 9.2 .1 & 1489,4 & 0,010 & 3,0 & 10,0 & 0,15 & & & \\
\hline & 9.3 .1 & 664,1 & 0,030 & 3,0 & 10,0 & 0,07 & \multirow{3}{*}{1,0} & \multirow{3}{*}{60,0} & \multirow{3}{*}{0,30} \\
\hline & 9.4 .1 & 1816,9 & 0,003 & 2,5 & 8,0 & 0,08 & & & \\
\hline & 8.2 .1 & 1350,4 & 0,032 & 2,5 & 5,0 & 0,25 & & & \\
\hline
\end{tabular}


Tabela D29: Dados de entrada do modelo para o cenário TG 2050 - Módulo Bacia.

\begin{tabular}{|c|c|c|c|c|c|c|c|c|}
\hline & $\begin{array}{l}\text { Sub- } \\
\text { bacia }\end{array}$ & $\begin{array}{c}\text { Área } \\
\left(\mathbf{k m}^{2}\right)\end{array}$ & $\mathrm{CN}$ & $\begin{array}{c}\mathbf{L} \\
(\mathbf{m})\end{array}$ & $\begin{array}{l}\mathbf{C M} \\
(\mathbf{m})\end{array}$ & $\begin{array}{l}\mathbf{C J} \\
(\mathbf{m})\end{array}$ & $\begin{array}{c}\mathbf{S} \\
(\mathbf{m} / \mathbf{m})\end{array}$ & $\begin{array}{c}\text { Tc } \\
\text { (min) }\end{array}$ \\
\hline \multirow{27}{*}{ Monjolinho } & 1 & 2,40 & 58 & 1350,2 & 910,0 & 871,6 & 0,028 & 114,0 \\
\hline & 2 & 0,51 & 58 & 918,3 & 871,6 & 858,0 & 0,015 & 116,0 \\
\hline & 3 & 0,74 & 58 & 1193,3 & 890,0 & 858,0 & 0,027 & 106,3 \\
\hline & 4 & 0,76 & 58 & 944,6 & 858,0 & 855,0 & 0,003 & 256,3 \\
\hline & 5 & 1,85 & 58 & 2209,3 & 895,0 & 855,0 & 0,018 & 211,8 \\
\hline & 6 & 0,06 & 65 & 373,5 & 855,0 & 850,0 & 0,013 & 49,7 \\
\hline & 7 & 1,37 & 72 & 2018,8 & 898,0 & 850,0 & 0,024 & 118,1 \\
\hline & 8 & 1,31 & 65 & 1440,9 & 898,0 & 850,0 & 0,033 & 92,8 \\
\hline & 9 & 0,22 & 65 & 436,3 & 850,0 & 840,0 & 0,023 & 43,0 \\
\hline & 10 & 1,80 & 65 & 1316,2 & 877,0 & 840,0 & 0,028 & 94,0 \\
\hline & 11 & 0,36 & 72 & 585,4 & 840,0 & 839,0 & 0,002 & 163,6 \\
\hline & 12 & 1,95 & 80 & 2168,6 & 898,0 & 839,0 & 0,027 & 92,9 \\
\hline & 13 & 0,52 & 72 & 747,1 & 839,0 & 837,0 & 0,003 & 158,9 \\
\hline & 14 & 1,99 & 58 & 2116,7 & 898,0 & 837,0 & 0,029 & 162,2 \\
\hline & 15 & 0,70 & 80 & 754,5 & 837,0 & 836,0 & 0,001 & 180,9 \\
\hline & 16 & 2,22 & 88 & 2189,1 & 879,0 & 836,0 & 0,020 & 82,8 \\
\hline & 17 & 0,98 & 80 & 902,2 & 836,0 & 835,0 & 0,001 & 228,2 \\
\hline & 18 & 2,33 & 65 & 2463,2 & 876,0 & 835,0 & 0,017 & 201,7 \\
\hline & 19 & 0,18 & 80 & 323,4 & 835,0 & 834,0 & 0,003 & 60,1 \\
\hline & 20 & 1,06 & 80 & 1540,7 & 859,0 & 834,0 & 0,016 & 91,5 \\
\hline & 21 & 0,26 & 88 & 416,7 & 834,0 & 833,0 & 0,002 & 62,9 \\
\hline & 22 & 3,64 & 65 & 2434,6 & 862,0 & 833,0 & 0,012 & 236,2 \\
\hline & 23 & 2,68 & 93 & 1575,0 & 833,0 & 825,0 & 0,005 & 100,5 \\
\hline & 24 & 3,64 & 72 & 2619,8 & 879,0 & 825,0 & 0,021 & 156,2 \\
\hline & 25 & 0,66 & 93 & 621,5 & 825,0 & 821,0 & 0,006 & 42,4 \\
\hline & 26 & 1,12 & 93 & 1166,4 & 858,0 & 821,0 & 0,032 & 31,6 \\
\hline & 27 & 1,06 & 93 & 1248,1 & 821,0 & 817,0 & 0,003 & 105,1 \\
\hline \multirow{6}{*}{$\begin{array}{l}\text { Sta Maria } \\
\text { Madalena }\end{array}$} & 28 & 5,24 & 65 & 1691,2 & 858,0 & 837,0 & 0,012 & 172,8 \\
\hline & 29 & 0,47 & 65 & 626,9 & 837,0 & 829,0 & 0,012 & 77,1 \\
\hline & 30 & 2,18 & 65 & 1257,5 & 857,0 & 829,0 & 0,022 & 101,8 \\
\hline & 31 & 1,29 & 72 & 1411,7 & 829,0 & 820,0 & 0,006 & 171,3 \\
\hline & 32 & 1,54 & 65 & 1212,4 & 855,0 & 820,0 & 0,029 & 86,9 \\
\hline & 33 & 1,22 & 88 & 1233,2 & 820,0 & 817,0 & 0,002 & 148,7 \\
\hline Outras & 34 & 0,14 & 93 & 229,2 & 817,0 & 814,0 & 0,013 & 13,4 \\
\hline \multirow{2}{*}{ Tijuco Preto } & 35 & 2,01 & 93 & 1385,0 & 860,0 & 815,0 & 0,032 & 35,9 \\
\hline & 36 & 1,39 & 93 & 1519,5 & 815,0 & 814,0 & 0,001 & 271,4 \\
\hline \multirow{5}{*}{ Outras } & 37 & 0,31 & 93 & 223,0 & 814,0 & 804,0 & 0,045 & 7,1 \\
\hline & 38 & 0,32 & 80 & 490,4 & 804,0 & 793,0 & 0,022 & 31,2 \\
\hline & 39 & 0,66 & 88 & 879,2 & 800,0 & 793,0 & 0,008 & 62,7 \\
\hline & $40-a$ & 0,24 & 80 & 406,1 & 793,0 & 786,0 & 0,017 & 30,6 \\
\hline & $40-b$ & 0,84 & 80 & 1231,4 & 786,0 & 781,0 & 0,004 & 152,9 \\
\hline \multirow{2}{*}{ Mineirinho } & 41 & 3,14 & 80 & 1758,6 & 858,0 & 823,0 & 0,020 & 88,7 \\
\hline & 42 & 2,56 & 80 & 2253,5 & 823,0 & 781,0 & 0,021 & 108,2 \\
\hline
\end{tabular}


Continuação da Tabela D29: Dados de entrada do modelo para o cenário TG 2050 - Módulo Bacia.

\begin{tabular}{lcccccccc}
\hline & $\begin{array}{c}\text { Sub- } \\
\text { bacia }\end{array}$ & $\begin{array}{c}\text { Área } \\
\left(\mathbf{k m}^{2}\right)\end{array}$ & $\mathbf{C N}$ & $\begin{array}{c}\mathbf{L} \\
(\mathbf{m})\end{array}$ & $\begin{array}{c}\mathbf{C M} \\
(\mathbf{m})\end{array}$ & $\begin{array}{c}\mathbf{C J} \\
(\mathbf{m})\end{array}$ & $\begin{array}{c}\mathbf{S} \\
(\mathbf{m} / \mathbf{m})\end{array}$ & $\begin{array}{c}\mathbf{T c} \\
(\mathbf{m i n})\end{array}$ \\
\hline \multirow{6}{*}{ Gregório } & 43 & 1,55 & 83 & 1831,7 & 912,0 & 850,0 & 0,034 & 65,5 \\
& 44 & 1,19 & 85 & 1688,4 & 899,0 & 850,0 & 0,029 & 62,6 \\
& 45 & 1,65 & 86 & 1444,6 & 850,0 & 846,0 & 0,003 & 168,6 \\
& 46 & 0,68 & 86 & 858,9 & 880,0 & 846,0 & 0,040 & 29,4 \\
& 47 & 0,63 & 90 & 583,4 & 846,0 & 842,0 & 0,007 & 45,5 \\
& 48 & 1,22 & 86 & 1853,5 & 900,0 & 842,0 & 0,031 & 61,2 \\
& 59 & 0,72 & 90 & 858,5 & 842,0 & 817,0 & 0,029 & 30,1 \\
& 51 & 0,94 & 86 & 482,4 & 877,0 & 858,0 & 0,039 & 18,6 \\
& 52 & 2,27 & 92 & 1129,8 & 817,0 & 804,0 & 0,012 & 55,4 \\
Exutório & 53 & 3,74 & 93 & 1746,7 & 838,0 & 804,0 & 0,019 & 55,8 \\
& 54 & 1,28 & 95 & 730,3 & 804,0 & 780,0 & 0,033 & 19,6 \\
& 55 & 0,62 & 95 & 1853,2 & 780,0 & 778,0 & 0,001 & 227,9 \\
\hline
\end{tabular}


Tabela D30: Dados de entrada do modelo para o cenário TG 2050 - Módulo Rio.

\begin{tabular}{|c|c|c|c|c|c|c|c|c|c|}
\hline & \multirow[b]{2}{*}{ Trecho } & \multirow[b]{2}{*}{$\begin{array}{l}\mathbf{L} \\
(\mathbf{m})\end{array}$} & \multirow[b]{2}{*}{$\begin{array}{c}\mathbf{S} \\
(\mathbf{m} / \mathbf{m})\end{array}$} & \multicolumn{3}{|c|}{ Canal } & \multicolumn{3}{|c|}{ Planície de Inundação } \\
\hline & & & & $\begin{array}{c}\text { Altura } \\
(\mathbf{m})\end{array}$ & $\begin{array}{c}\text { Largura } \\
\text { (m) }\end{array}$ & $\mathbf{n}$ & $\begin{array}{c}\text { Altura } \\
\text { (m) }\end{array}$ & $\begin{array}{c}\text { Largura } \\
\text { (m) }\end{array}$ & $\mathbf{n}$ \\
\hline \multirow{20}{*}{ Monjolinho } & 1.2 .1 & 918,3 & 0,015 & 1,0 & 1,2 & 0,47 & & & \\
\hline & 1.3 .1 & 944,6 & 0,003 & 1,0 & 1,2 & 0,46 & & & \\
\hline & 1.4 .1 & 373,5 & 0,013 & 1,0 & 2,0 & 0,46 & & & \\
\hline & 1.5 .1 & 436,3 & 0,023 & 1,0 & 2,0 & 0,45 & & & \\
\hline & 1.6 .1 & 585,4 & 0,002 & 1,0 & 3,0 & 0,44 & & & \\
\hline & 1.7 .1 & 747,1 & 0,003 & 1,0 & 3,5 & 0,44 & & & \\
\hline & 1.8 .1 & 754,5 & 0,001 & 1,0 & 3,5 & 0,44 & & & \\
\hline & 1.9 .1 & 902,2 & 0,001 & 1,0 & 4,0 & 0,42 & & & \\
\hline & 1.10 .1 & 323,4 & 0,003 & 1,0 & 5,0 & 0,42 & 1,0 & 40,0 & 0,38 \\
\hline & 1.11 .1 & 416,7 & 0,002 & 1,0 & 5,0 & 0,40 & 1,0 & 40,0 & 0,38 \\
\hline & 1.12 .1 & 1575,0 & 0,005 & 1,0 & 5,0 & 0,32 & 1,0 & 50,0 & 0,38 \\
\hline & 1.13 .1 & 621,5 & 0,006 & 1,0 & 5,0 & 0,32 & 1,0 & 50,0 & 0,43 \\
\hline & 1.14 .1 & 1248,1 & 0,003 & 2,5 & 8,0 & 0,22 & 1,0 & 50,0 & 0,43 \\
\hline & 3.2 .1 & 229,2 & 0,013 & 2,5 & 10,0 & 0,22 & 1,0 & 55,0 & 0,43 \\
\hline & 5.2 .1 & 223,0 & 0,045 & 3,0 & 10,0 & 0,22 & 1,0 & 55,0 & 0,43 \\
\hline & 5.3 .1 & 490,4 & 0,022 & 3,5 & 10,0 & 0,22 & 1,0 & 55,0 & 0,43 \\
\hline & 5.4.1_a & 406,1 & 0,017 & 3,5 & 10,0 & 0,23 & 1,0 & 55,0 & 0,43 \\
\hline & 5.4.1_b & 1231,4 & 0,004 & 3,5 & 10,0 & 0,22 & 1,0 & 55,0 & 0,43 \\
\hline & 10.2 .1 & 259,5 & 0,012 & 3,5 & 10,0 & 0,22 & 1,0 & 60,0 & 0,43 \\
\hline & 11.2.1 & 454,9 & 0,004 & 3,5 & 10,0 & 0,18 & 1,0 & 60,0 & 0,43 \\
\hline Tijuco Preto & 4.2 .1 & 1519,5 & 0,001 & 1,5 & 3,5 & 0,18 & & & \\
\hline \multirow{3}{*}{$\begin{array}{l}\text { Sta Maria } \\
\text { Madalena }\end{array}$} & 2.2 .1 & 626,9 & 0,013 & 1,4 & 1,9 & 0,14 & & & \\
\hline & 2.3 .1 & 1411,7 & 0,006 & 1,5 & 3,0 & 0,44 & & & \\
\hline & 2.4 .1 & 1233,2 & 0,002 & 1,5 & 3,0 & 0,42 & & & \\
\hline Mineirinho & 6.2 .1 & 2253,5 & 0,021 & 0,6 & 3,8 & 0,40 & & & \\
\hline \multirow{7}{*}{ Gregório } & 7.2 .1 & 1444,6 & 0,003 & 2,5 & 5,0 & 0,18 & & & \\
\hline & 7.3 .1 & 583,4 & 0,007 & 3,0 & 10,0 & 0,32 & & & \\
\hline & 7.4 .1 & 858,5 & 0,029 & 3,2 & 10,0 & 0,22 & & & \\
\hline & 9.2 .1 & 1129,8 & 0,012 & 3,0 & 10,0 & 0,22 & & & \\
\hline & 9.3 .1 & 730,3 & 0,033 & 3,0 & 10,0 & 0,14 & \multirow{3}{*}{1,0} & \multirow{3}{*}{60,0} & \multirow{3}{*}{0,35} \\
\hline & 9.4 .1 & 1853,2 & 0,001 & 2,5 & 10,0 & 0,15 & & & \\
\hline & 8.2 .1 & 1350,4 & 0,030 & 2,5 & 5,0 & 0,32 & & & \\
\hline
\end{tabular}


Tabela D31: Dados de entrada do modelo para o cenário TG 2075 - Módulo Bacia.

\begin{tabular}{|c|c|c|c|c|c|c|c|c|}
\hline & $\begin{array}{c}\text { Sub- } \\
\text { bacia }\end{array}$ & $\begin{array}{c}\text { Área } \\
\left(\mathbf{k m}^{2}\right)\end{array}$ & $\mathrm{CN}$ & $\begin{array}{c}\mathbf{L} \\
(\mathbf{m})\end{array}$ & $\begin{array}{l}\text { CM } \\
(\mathbf{m})\end{array}$ & $\begin{array}{l}\mathbf{C J} \\
(\mathbf{m})\end{array}$ & $\begin{array}{c}\mathbf{S} \\
(\mathbf{m} / \mathbf{m})\end{array}$ & $\begin{array}{c}\text { Tc } \\
(\mathbf{m i n})\end{array}$ \\
\hline \multirow{27}{*}{ Monjolinho } & 1 & 2,40 & 58 & 1350,2 & 910,0 & 871,6 & 0,028 & 114,0 \\
\hline & 2 & 0,51 & 58 & 918,3 & 871,6 & 858,0 & 0,015 & 116,0 \\
\hline & 3 & 0,74 & 58 & 1193,3 & 890,0 & 858,0 & 0,027 & 106,3 \\
\hline & 4 & 0,76 & 60 & 944,6 & 858,0 & 855,0 & 0,003 & 241,3 \\
\hline & 5 & 1,85 & 59 & 2209,3 & 895,0 & 855,0 & 0,018 & 204,5 \\
\hline & 6 & 0,06 & 60 & 373,5 & 855,0 & 850,0 & 0,013 & 55,9 \\
\hline & 7 & 1,37 & 70 & 2018,8 & 898,0 & 850,0 & 0,024 & 124,8 \\
\hline & 8 & 1,31 & 63 & 1440,9 & 898,0 & 850,0 & 0,033 & 96,7 \\
\hline & 9 & 0,22 & 63 & 436,3 & 850,0 & 840,0 & 0,023 & 44,9 \\
\hline & 10 & 1,80 & 63 & 1316,2 & 877,0 & 840,0 & 0,028 & 98,0 \\
\hline & 11 & 0,36 & 70 & 585,4 & 840,0 & 839,0 & 0,002 & 172,9 \\
\hline & 12 & 1,95 & 78 & 2168,6 & 898,0 & 839,0 & 0,027 & 98,4 \\
\hline & 13 & 0,52 & 70 & 747,1 & 839,0 & 837,0 & 0,003 & 167,9 \\
\hline & 14 & 1,99 & 56 & 2116,7 & 898,0 & 837,0 & 0,029 & 169,0 \\
\hline & 15 & 0,70 & 78 & 754,5 & 837,0 & 836,0 & 0,001 & 191,6 \\
\hline & 16 & 2,22 & 86 & 2189,1 & 879,0 & 836,0 & 0,020 & 89,8 \\
\hline & 17 & 0,98 & 78 & 902,2 & 836,0 & 835,0 & 0,001 & 241,8 \\
\hline & 18 & 2,33 & 63 & 2463,2 & 876,0 & 835,0 & 0,017 & 210,2 \\
\hline & 19 & 0,18 & 78 & 323,4 & 835,0 & 834,0 & 0,003 & 63,7 \\
\hline & 20 & 1,06 & 78 & 1540,7 & 859,0 & 834,0 & 0,016 & 97,0 \\
\hline & 21 & 0,26 & 86 & 416,7 & 834,0 & 833,0 & 0,002 & 68,2 \\
\hline & 22 & 3,64 & 63 & 2434,6 & 862,0 & 833,0 & 0,012 & 246,1 \\
\hline & 23 & 2,68 & 91 & 1575,0 & 833,0 & 825,0 & 0,005 & 111,7 \\
\hline & 24 & 3,64 & 70 & 2619,8 & 879,0 & 825,0 & 0,021 & 165,1 \\
\hline & 25 & 0,66 & 91 & 621,5 & 825,0 & 821,0 & 0,006 & 47,2 \\
\hline & 26 & 1,12 & 91 & 1166,4 & 858,0 & 821,0 & 0,032 & 35,1 \\
\hline & 27 & 1,06 & 91 & 1248,1 & 821,0 & 817,0 & 0,003 & 116,7 \\
\hline \multirow{6}{*}{$\begin{array}{l}\text { Sta Maria } \\
\text { Madalena }\end{array}$} & 28 & 5,24 & 63 & 1691,2 & 858,0 & 837,0 & 0,012 & 180,1 \\
\hline & 29 & 0,47 & 63 & 626,9 & 837,0 & 829,0 & 0,012 & 80,3 \\
\hline & 30 & 2,18 & 63 & 1257,5 & 857,0 & 829,0 & 0,022 & 106,1 \\
\hline & 31 & 1,29 & 70 & 1411,7 & 829,0 & 820,0 & 0,006 & 181,0 \\
\hline & 32 & 1,54 & 63 & 1235,1 & 855,0 & 820,0 & 0,028 & 92,7 \\
\hline & 33 & 1,22 & 86 & 1233,2 & 820,0 & 817,0 & 0,002 & 161,3 \\
\hline Outras & 34 & 0,14 & 90 & 229,2 & 817,0 & 814,0 & 0,013 & 15,5 \\
\hline \multirow{2}{*}{ Tijuco Preto } & 35 & 2,01 & 90 & 1508,5 & 860,0 & 815,0 & 0,030 & 46,4 \\
\hline & 36 & 1,39 & 90 & 1519,5 & 815,0 & 814,0 & 0,001 & 314,3 \\
\hline \multirow{5}{*}{ Outras } & 37 & 0,31 & 90 & 223,0 & 814,0 & 804,0 & 0,045 & 8,2 \\
\hline & 38 & 0,32 & 78 & 490,4 & 804,0 & 793,0 & 0,022 & 33,0 \\
\hline & 39 & 0,66 & 86 & 911,0 & 800,0 & 793,0 & 0,008 & 71,2 \\
\hline & $40-\mathrm{a}$ & 0,24 & 78 & 406,1 & 793,0 & 786,0 & 0,017 & 32,4 \\
\hline & $40-b$ & 0,84 & 78 & 1231,4 & 786,0 & 781,0 & 0,004 & 162,0 \\
\hline \multirow{2}{*}{ Mineirinho } & 41 & 3,14 & 80 & 1758,6 & 858,0 & 823,0 & 0,020 & 91,5 \\
\hline & 42 & 2,56 & 81 & 2253,5 & 823,0 & 781,0 & 0,021 & 111,8 \\
\hline
\end{tabular}


Continuação da Tabela D31: Dados de entrada do modelo para o cenário TG 2075 - Módulo Bacia.

\begin{tabular}{lcccccccc}
\hline & $\begin{array}{c}\text { Sub- } \\
\text { bacia }\end{array}$ & $\begin{array}{c}\text { Área } \\
\left(\mathbf{k m}^{2}\right)\end{array}$ & $\mathbf{C N}$ & $\begin{array}{c}\mathbf{L} \\
(\mathbf{m})\end{array}$ & $\begin{array}{c}\mathbf{C M} \\
(\mathbf{m})\end{array}$ & $\begin{array}{c}\mathbf{C J} \\
(\mathbf{m})\end{array}$ & $\begin{array}{c}\mathbf{S} \\
(\mathbf{m} / \mathbf{m})\end{array}$ & $\begin{array}{c}\text { Tc } \\
(\mathbf{m i n})\end{array}$ \\
\hline \multirow{6}{*}{ Gregório } & 43 & 1,55 & 80 & 1831,7 & 912,0 & 850,0 & 0,034 & 72,5 \\
& 44 & 1,19 & 83 & 1688,4 & 899,0 & 850,0 & 0,029 & 66,6 \\
& 45 & 1,65 & 84 & 1444,6 & 850,0 & 846,0 & 0,003 & 184,0 \\
& 46 & 0,68 & 84 & 858,9 & 880,0 & 846,0 & 0,040 & 32,1 \\
& 47 & 0,63 & 88 & 583,4 & 846,0 & 842,0 & 0,007 & 49,0 \\
& 48 & 1,22 & 84 & 1853,5 & 900,0 & 842,0 & 0,031 & 66,8 \\
& 50 & 0,72 & 88 & 858,5 & 842,0 & 817,0 & 0,029 & 32,4 \\
& 51 & 0,94 & 84 & 482,4 & 877,0 & 858,0 & 0,039 & 20,3 \\
& 52 & 2,27 & 90 & 1129,8 & 817,0 & 804,0 & 0,012 & 59,3 \\
Exutório & 53 & 3,74 & 91 & 1839,8 & 838,0 & 804,0 & 0,018 & 66,3 \\
& 54 & 1,28 & 93 & 730,3 & 804,0 & 780,0 & 0,033 & 21,7 \\
& 55 & 0,62 & 93 & 1853,2 & 780,0 & 778,0 & 0,001 & 252,6 \\
\hline
\end{tabular}


Tabela D32: Dados de entrada do modelo para o cenário TG 2075 - Módulo Rio.

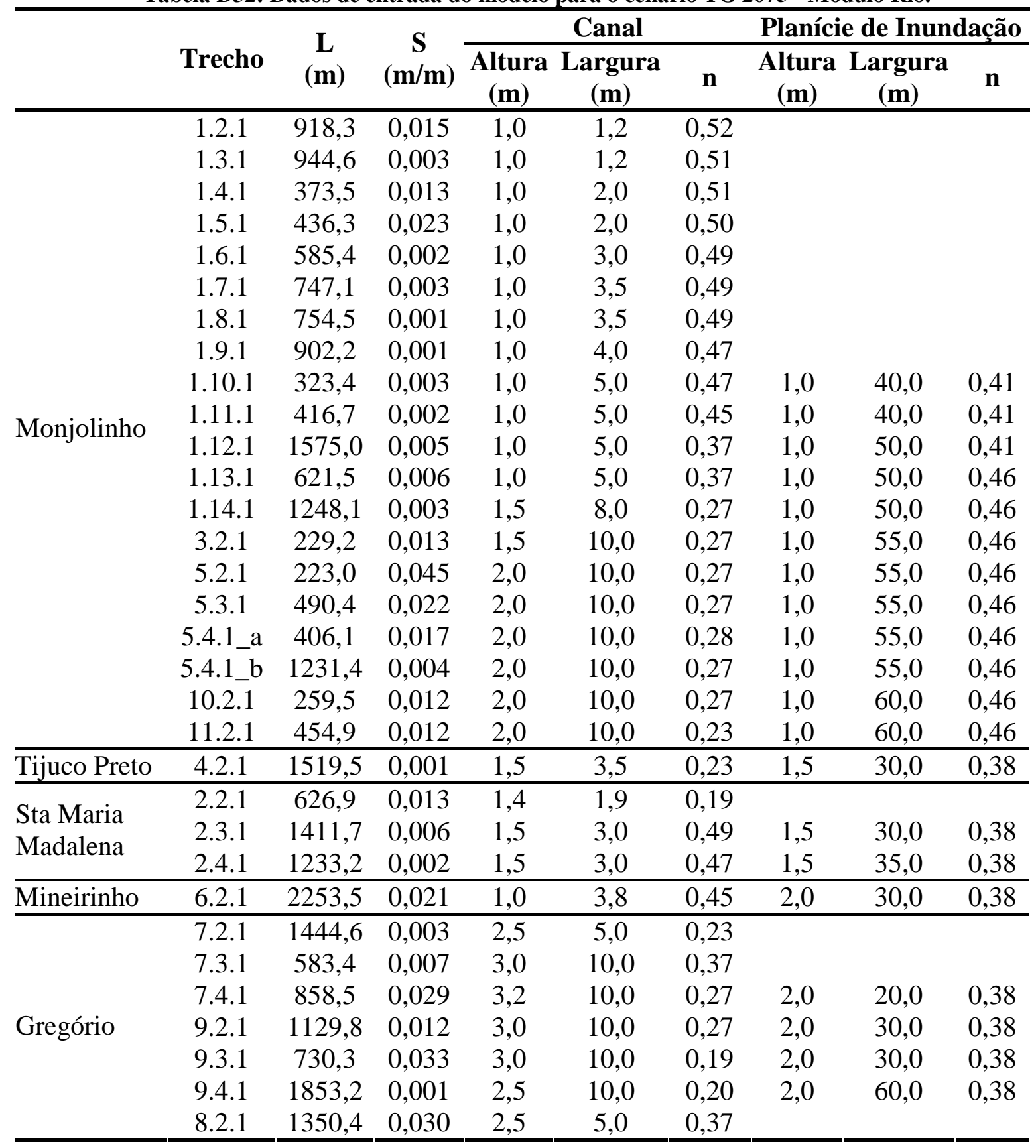


Tabela D33: Dados de entrada do modelo para o cenário TG 2100 - Módulo Bacia.

\begin{tabular}{|c|c|c|c|c|c|c|c|c|}
\hline & $\begin{array}{l}\text { Sub- } \\
\text { bacia }\end{array}$ & $\begin{array}{c}\text { Área } \\
\left(\mathbf{k m}^{2}\right)\end{array}$ & $\mathrm{CN}$ & $\begin{array}{c}\mathbf{L} \\
(\mathbf{m})\end{array}$ & $\begin{array}{l}\mathbf{C M} \\
(\mathbf{m})\end{array}$ & $\begin{array}{l}\text { CJ } \\
\text { (m) }\end{array}$ & $\begin{array}{c}\mathbf{S} \\
(\mathbf{m} / \mathbf{m})\end{array}$ & $\begin{array}{c}\text { Tc } \\
\text { (min) }\end{array}$ \\
\hline \multirow{27}{*}{ Monjolinho } & 1 & 2,40 & 58 & 1350,2 & 910,0 & 871,6 & 0,028 & 114,0 \\
\hline & 2 & 0,51 & 58 & 918,3 & 871,6 & 858,0 & 0,015 & 116,0 \\
\hline & 3 & 0,74 & 58 & 1193,3 & 890,0 & 858,0 & 0,027 & 106,3 \\
\hline & 4 & 0,76 & 57 & 944,6 & 858,0 & 855,0 & 0,003 & 260,3 \\
\hline & 5 & 1,85 & 57 & 2209,3 & 895,0 & 855,0 & 0,018 & 215,1 \\
\hline & 6 & 0,06 & 57 & 373,5 & 855,0 & 850,0 & 0,013 & 60,3 \\
\hline & 7 & 1,37 & 67 & 2018,8 & 898,0 & 850,0 & 0,024 & 135,2 \\
\hline & 8 & 1,31 & 60 & 1440,9 & 898,0 & 850,0 & 0,033 & 104,4 \\
\hline & 9 & 0,22 & 60 & 436,3 & 850,0 & 840,0 & 0,023 & 48,4 \\
\hline & 10 & 1,80 & 60 & 1316,2 & 877,0 & 840,0 & 0,028 & 105,7 \\
\hline & 11 & 0,36 & 67 & 585,4 & 840,0 & 839,0 & 0,002 & 187,3 \\
\hline & 12 & 1,95 & 75 & 2168,6 & 898,0 & 839,0 & 0,027 & 107,5 \\
\hline & 13 & 0,52 & 67 & 747,1 & 839,0 & 837,0 & 0,003 & 181,9 \\
\hline & 14 & 1,99 & 53 & 2116,7 & 898,0 & 837,0 & 0,029 & 182,2 \\
\hline & 15 & 0,70 & 75 & 754,5 & 837,0 & 836,0 & 0,001 & 209,3 \\
\hline & 16 & 2,22 & 83 & 2189,1 & 879,0 & 836,0 & 0,020 & 99,6 \\
\hline & 17 & 0,98 & 75 & 902,2 & 836,0 & 835,0 & 0,001 & 264,1 \\
\hline & 18 & 2,33 & 60 & 2463,2 & 876,0 & 835,0 & 0,017 & 226,9 \\
\hline & 19 & 0,18 & 75 & 323,4 & 835,0 & 834,0 & 0,003 & 69,6 \\
\hline & 20 & 1,06 & 75 & 1540,7 & 859,0 & 834,0 & 0,016 & 105,9 \\
\hline & 21 & 0,26 & 83 & 416,7 & 834,0 & 833,0 & 0,002 & 75,6 \\
\hline & 22 & 3,64 & 60 & 2434,6 & 862,0 & 833,0 & 0,012 & 265,7 \\
\hline & 23 & 2,68 & 88 & 1575,0 & 833,0 & 825,0 & 0,005 & 126,0 \\
\hline & 24 & 3,64 & 67 & 2619,8 & 879,0 & 825,0 & 0,021 & 178,8 \\
\hline & 25 & 0,66 & 88 & 621,5 & 825,0 & 821,0 & 0,006 & 53,2 \\
\hline & 26 & 1,12 & 88 & 1166,4 & 858,0 & 821,0 & 0,032 & 39,7 \\
\hline & 27 & 1,06 & 88 & 1248,1 & 821,0 & 817,0 & 0,003 & 131,7 \\
\hline \multirow{6}{*}{$\begin{array}{l}\text { Sta Maria } \\
\text { Madalena }\end{array}$} & 28 & 5,24 & 60 & 1691,2 & 858,0 & 837,0 & 0,012 & 194,4 \\
\hline & 29 & 0,47 & 60 & 642,4 & 837,0 & 829,0 & 0,012 & 89,5 \\
\hline & 30 & 2,18 & 60 & 1257,5 & 857,0 & 829,0 & 0,022 & 114,6 \\
\hline & 31 & 1,29 & 77 & 1411,7 & 829,0 & 820,0 & 0,006 & 148,6 \\
\hline & 32 & 1,54 & 60 & 1235,1 & 855,0 & 820,0 & 0,028 & 100,1 \\
\hline & 33 & 1,22 & 83 & 1233,2 & 820,0 & 817,0 & 0,002 & 178,9 \\
\hline Outras & 34 & 0,14 & 77 & 229,2 & 817,0 & 814,0 & 0,013 & 24,2 \\
\hline \multirow{2}{*}{ Tijuco Preto } & 35 & 2,01 & 88 & 1508,5 & 860,0 & 815,0 & 0,030 & 50,2 \\
\hline & 36 & 1,39 & 88 & 1519,5 & 815,0 & 814,0 & 0,001 & 340,2 \\
\hline \multirow{5}{*}{ Outras } & 37 & 0,31 & 77 & 223,0 & 814,0 & 804,0 & 0,045 & 12,8 \\
\hline & 38 & 0,32 & 75 & 490,4 & 804,0 & 793,0 & 0,022 & 36,0 \\
\hline & 39 & 0,66 & 83 & 911,0 & 800,0 & 793,0 & 0,008 & 79,0 \\
\hline & $40-\mathrm{a}$ & 0,24 & 75 & 406,1 & 793,0 & 786,0 & 0,017 & 35,4 \\
\hline & $40-\mathrm{b}$ & 0,84 & 75 & 1231,4 & 786,0 & 781,0 & 0,004 & 176,9 \\
\hline \multirow{2}{*}{ Mineirinho } & 41 & 3,14 & 75 & 1758,6 & 858,0 & 823,0 & 0,020 & 106,3 \\
\hline & 42 & 2,56 & 75 & 2253,5 & 823,0 & 781,0 & 0,021 & 133,9 \\
\hline
\end{tabular}


Continuação da Tabela D33: Dados de entrada do modelo para o cenário TG 2100 - Módulo Bacia.

\begin{tabular}{lcccccccc}
\hline & $\begin{array}{c}\text { Sub- } \\
\text { bacia }\end{array}$ & $\begin{array}{c}\text { Área } \\
\left(\mathbf{k m}^{2}\right)\end{array}$ & $\mathbf{C N}$ & $\begin{array}{c}\mathbf{L} \\
(\mathbf{m})\end{array}$ & $\begin{array}{c}\mathbf{C M} \\
(\mathbf{m})\end{array}$ & $\begin{array}{c}\mathbf{C J} \\
(\mathbf{m})\end{array}$ & $\begin{array}{c}\mathbf{S} \\
(\mathbf{m} / \mathbf{m})\end{array}$ & $\begin{array}{c}\mathbf{T c} \\
(\mathbf{m i n})\end{array}$ \\
\hline \multirow{6}{*}{ Gregório } & 43 & 1,55 & 80 & 1831,7 & 912,0 & 850,0 & 0,034 & 72,5 \\
& 44 & 1,19 & 83 & 1688,4 & 899,0 & 850,0 & 0,029 & 66,6 \\
& 45 & 1,65 & 84 & 1444,6 & 850,0 & 846,0 & 0,003 & 184,0 \\
& 46 & 0,68 & 84 & 858,9 & 880,0 & 846,0 & 0,040 & 32,1 \\
& 47 & 0,63 & 85 & 583,4 & 846,0 & 842,0 & 0,007 & 54,7 \\
& 48 & 1,22 & 81 & 1853,5 & 900,0 & 842,0 & 0,031 & 73,8 \\
& 59 & 0,72 & 85 & 858,5 & 842,0 & 817,0 & 0,029 & 36,1 \\
& 51 & 0,94 & 81 & 482,4 & 877,0 & 858,0 & 0,039 & 22,4 \\
& 52 & 2,27 & 97 & 1129,8 & 817,0 & 804,0 & 0,012 & 42,5 \\
Exutório & 53 & 3,74 & 88 & 1839,8 & 838,0 & 804,0 & 0,018 & 74,8 \\
& 54 & 1,28 & 90 & 730,3 & 804,0 & 780,0 & 0,033 & 24,8 \\
& 55 & 0,62 & 90 & 1853,2 & 780,0 & 778,0 & 0,001 & 287,7 \\
\hline
\end{tabular}


Tabela D34: Dados de entrada do modelo para o cenário TG 2100 - Módulo Rio.

\begin{tabular}{|c|c|c|c|c|c|c|c|c|c|}
\hline & \multirow[b]{2}{*}{ Trecho } & \multirow{2}{*}{$\begin{array}{c}\mathbf{L} \\
(\mathbf{m})\end{array}$} & \multirow{2}{*}{$\underset{(\mathbf{m} / \mathbf{m})}{\mathbf{S}}$} & \multicolumn{3}{|c|}{ Canal } & \multicolumn{3}{|c|}{ Planície de Inundacão } \\
\hline & & & & $\begin{array}{c}\text { Altura } \\
(\mathbf{m})\end{array}$ & $\begin{array}{l}\text { Largura } \\
\text { (m) }\end{array}$ & n & $\begin{array}{c}\text { Altura } \\
\text { (m) }\end{array}$ & $\begin{array}{l}\text { Largura } \\
\text { (m) }\end{array}$ & n \\
\hline \multirow{20}{*}{ Monjolinho } & 1.2 .1 & 918,3 & 0,015 & 1,0 & 1,2 & 0,52 & & & \\
\hline & 1.3 .1 & 944,6 & 0,003 & 1,0 & 1,2 & 0,51 & & & \\
\hline & 1.4 .1 & 373,5 & 0,013 & 1,0 & 2,0 & 0,51 & & & \\
\hline & 1.5 .1 & 436,3 & 0,023 & 1,0 & 2,0 & 0,50 & & & \\
\hline & 1.6 .1 & 585,4 & 0,002 & 1,0 & 3,0 & 0,49 & & & \\
\hline & 1.7 .1 & 747,1 & 0,003 & 1,0 & 3,5 & 0,49 & & & \\
\hline & 1.8 .1 & 754,5 & 0,001 & 1,0 & 3,5 & 0,49 & & & \\
\hline & 1.9 .1 & 902,2 & 0,001 & 1,0 & 4,0 & 0,47 & & & \\
\hline & 1.10 .1 & 323,4 & 0,003 & 1,0 & 5,0 & 0,47 & 1,0 & 40,0 & 0,41 \\
\hline & 1.11 .1 & 416,7 & 0,002 & 1,0 & 5,0 & 0,45 & 1,0 & 40,0 & 0,41 \\
\hline & 1.12 .1 & 1575,0 & 0,005 & 1,0 & 5,0 & 0,37 & 1,0 & 50,0 & 0,41 \\
\hline & 1.13 .1 & 621,5 & 0,006 & 1,0 & 5,0 & 0,37 & 1,0 & 50,0 & 0,46 \\
\hline & 1.14 .1 & 1248,1 & 0,003 & 1,5 & 8,0 & 0,27 & 1,0 & 50,0 & 0,46 \\
\hline & 3.2 .1 & 229,2 & 0,013 & 1,5 & 10,0 & 0,27 & 1,0 & 55,0 & 0,46 \\
\hline & 5.2 .1 & 223,0 & 0,045 & 2,0 & 10,0 & 0,27 & 1,0 & 55,0 & 0,46 \\
\hline & 5.3 .1 & 490,4 & 0,022 & 2,0 & 10,0 & 0,27 & 1,0 & 55,0 & 0,46 \\
\hline & 5.4.1_a & 406,1 & 0,017 & 2,0 & 10,0 & 0,28 & 1,0 & 55,0 & 0,46 \\
\hline & 5.4.1_b & 1231,4 & 0,004 & 2,0 & 10,0 & 0,27 & 1,0 & 55,0 & 0,46 \\
\hline & 10.2 .1 & 259,5 & 0,012 & 2,0 & 10,0 & 0,27 & 1,0 & 60,0 & 0,46 \\
\hline & 11.2 .1 & 454,9 & 0,004 & 2,0 & 10,0 & 0,23 & 1,0 & 60,0 & 0,46 \\
\hline Tijuco Preto & 4.2 .1 & 1519,5 & 0,001 & 1,5 & 3,5 & 0,23 & 1,5 & 30,0 & 0,38 \\
\hline \multirow{3}{*}{$\begin{array}{l}\text { Sta Maria } \\
\text { Madalena }\end{array}$} & 2.2 .1 & 642,4 & 0,012 & 1,4 & 1,9 & 0,19 & & & \\
\hline & 2.3.1 & 1411,7 & 0,006 & 1,5 & 3,0 & 0,49 & 1,5 & 30,0 & 0,38 \\
\hline & 2.4 .1 & 1233,2 & 0,002 & 1,5 & 3,0 & 0,47 & 1,5 & 35,0 & 0,38 \\
\hline \multirow[t]{3}{*}{ Mineirinho } & 6.2 .1 & 2253,5 & 0,021 & 1,0 & 3,8 & 0,45 & 2,0 & 30,0 & 0,38 \\
\hline & 7.2 .1 & 1444,6 & 0,003 & 2,5 & 5,0 & 0,23 & & & \\
\hline & 7.3.1 & 583,4 & 0,007 & 3,0 & 10,0 & 0,37 & & & \\
\hline & 7.4.1 & 858,5 & 0,029 & 3,2 & 10,0 & 0,27 & 2,0 & 20,0 & 0,38 \\
\hline \multirow[t]{4}{*}{ Gregório } & 9.2 .1 & 1129,8 & 0,012 & 3,0 & 10,0 & 0,27 & 2,0 & 30,0 & 0,38 \\
\hline & 9.3 .1 & 730,3 & 0,033 & 3,0 & 10,0 & 0,19 & 2,0 & 30,0 & 0,38 \\
\hline & 9.4 .1 & 1853,2 & 0,001 & 2,5 & 10,0 & 0,20 & 2,0 & 60,0 & 0,38 \\
\hline & 8.2 .1 & 1350,4 & 0,030 & 2,5 & 5,0 & 0,37 & & & \\
\hline
\end{tabular}




\section{APÊNDICE E}

- Tabelas de pesos de cada componente do incentivo ambiental, da estimativa dos valores de IPTU e do incentivo ambiental, para cada cenário estudado.

Tabela E1 - Pesos (w) relativos a cada componente da expressão do incentivo ambiental: lote micro e macrodrenagem, para todos os cenários.

\begin{tabular}{|c|c|c|c|c|c|}
\hline Cenários & $\operatorname{Peso}(w)$ & 2025 & 2050 & 2075 & 2100 \\
\hline \multirow{7}{*}{ GO } & w lote $-\mathrm{S}$ & 0 & 0 & 0 & 0 \\
\hline & w micro $-\mathrm{S}$ & 0 & 0 & 0 & 0 \\
\hline & W macro - S & 0 & 0 & 0 & 0 \\
\hline & w lote - Q & 0 & 0 & 0 & 0 \\
\hline & w micro - Q & 0 & 0 & 0 & 0 \\
\hline & w macro - Q & 1 & 1 & 1 & 1 \\
\hline & soma & 1 & 1 & 1 & 1 \\
\hline \multirow{7}{*}{ OS } & w lote $-\mathrm{S}$ & 0 & 0 & 0 & 0 \\
\hline & $\mathrm{W}$ micro - S & 0 & 0 & 0 & 0 \\
\hline & W macro - S & 0 & 0 & 0 & 0 \\
\hline & w lote - Q & 0 & 0 & 0 & 0 \\
\hline & w micro - Q & 0 & 0 & 0 & 0 \\
\hline & w macro - Q & 0 & 0 & 0 & 0 \\
\hline & soma & 0 & 0 & 0 & 0 \\
\hline \multirow{7}{*}{$\mathrm{AM}$} & w lote $-\mathrm{S}$ & 0,80 & 0,65 & 0,60 & 0,60 \\
\hline & w micro - S & 0 & 0 & 0 & 0 \\
\hline & W macro - S & 0 & 0 & 0 & 0 \\
\hline & w lote - Q & 0,20 & 0,35 & 0,40 & 0,40 \\
\hline & w micro - Q & 0 & 0 & 0 & 0 \\
\hline & w macro - Q & 0 & 0 & 0 & 0 \\
\hline & soma & 1,00 & 1,00 & 1,00 & 1,00 \\
\hline \multirow{7}{*}{ TG } & w lote - S & 0,1 & 0,2 & 0,2 & 0,2 \\
\hline & w micro - S & 0 & 0 & 0 & 0 \\
\hline & W macro - S & 0 & 0 & 0 & 0 \\
\hline & w lote - Q & 0,15 & 0,2 & 0,3 & 0,3 \\
\hline & w micro - Q & 0 & 0 & 0 & 0 \\
\hline & w macro - Q & 0,75 & 0,6 & 0,5 & 0,5 \\
\hline & soma & 1,00 & 1,00 & 1,00 & 1,00 \\
\hline
\end{tabular}

Tabela E2 - Área construída (dada pela soma da área impermeável e impermeável diretamente conectada), para todos os cenários.

\begin{tabular}{ccccc}
\hline Cenários & GO & OS & AM & TG \\
\hline 2025 & 128,0 & 136,0 & 122,0 & 122,0 \\
2050 & 140,0 & 146,0 & 94,2 & 100,0 \\
2075 & 136,8 & 150,0 & 87,0 & 78,0 \\
2100 & 136,8 & 150,0 & 81,0 & 72,8 \\
\hline
\end{tabular}


Tabela E3 - Valor do IPTU a ser cobrado em cada cenário (R\$).

\begin{tabular}{ccccc}
\hline Cenários & GO & OS & AM & TG \\
\hline 2025 & 562,0 & 575,4 & 551,9 & 551,9 \\
2050 & 582,2 & 592,2 & 505,2 & 514,9 \\
2075 & 576,8 & 598,9 & 493,1 & 478,0 \\
2100 & 576,8 & 598,9 & 483,0 & 469,3 \\
\hline
\end{tabular}

Tabela E4 - Valor do Incentivo a ser aplicado sobre o IPTU em cada cenário (valores positivos implicam em uma taxação e valores negativos em incentivos/desconto).

\begin{tabular}{ccccc}
\hline Cenários & GO & OS & AM & TG \\
\hline 2025 & 1,85 & 0,00 & 0,12 & 0,69 \\
2050 & 2,39 & 0,00 & $-0,80$ & $-0,35$ \\
2075 & 1,26 & 0,00 & $-1,40$ & $-1,27$ \\
2100 & 0,81 & 0,00 & $-1,45$ & $-1,41$ \\
\hline
\end{tabular}

Tabela E5 - Valor do IPTU final, com Incentivo aplicado em cada cenário.

\begin{tabular}{rcccc}
\hline Cenários & GO & OS & AM & TG \\
\hline 2025 & 1038,14 & 575,43 & 68,09 & 383,14 \\
2050 & 1391,31 & 592,23 & $-402,86$ & $-178,35$ \\
2075 & 726,71 & 598,95 & $-692,69$ & $-608,13$ \\
2100 & 469,52 & 598,95 & $-701,60$ & $-661,14$ \\
\hline
\end{tabular}




\section{APÊNDICE F}

- Fotos Ilustrativas dos Cenários Estudados.

\section{Galeria Perceptual de Imagens de Possíveis de Drenagem Urbana}

\section{Global Orchestration}
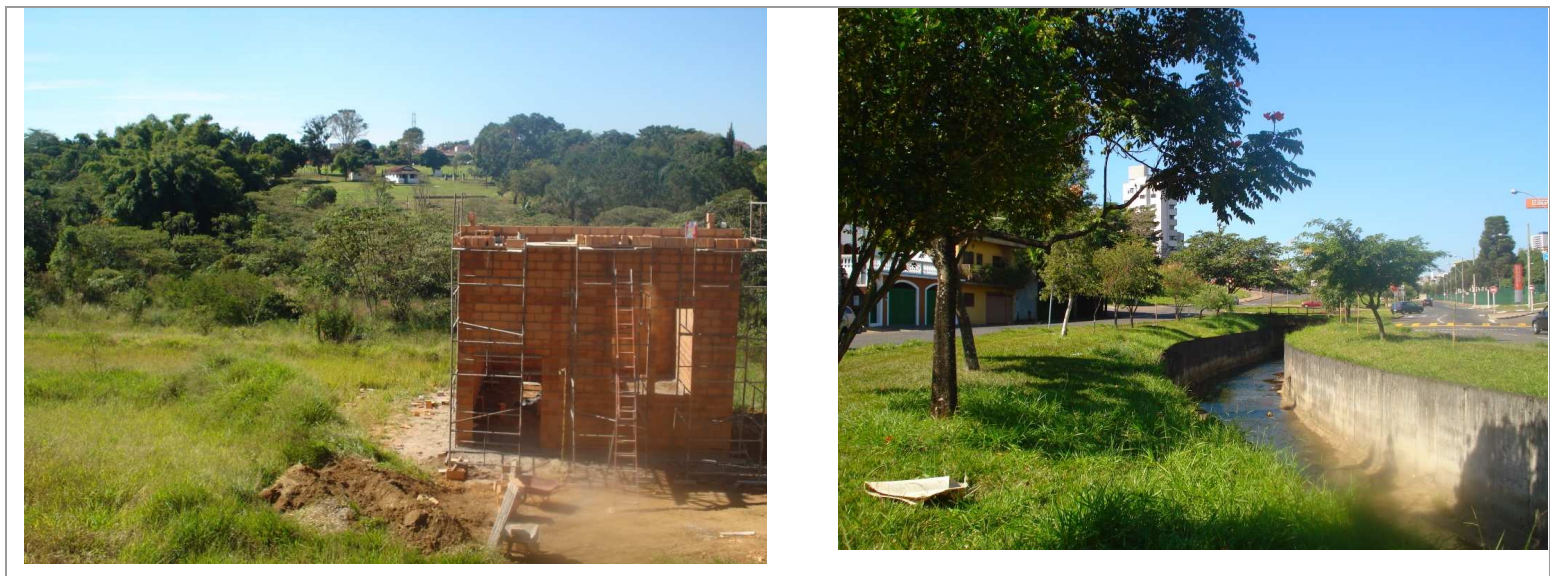

Order from Strength

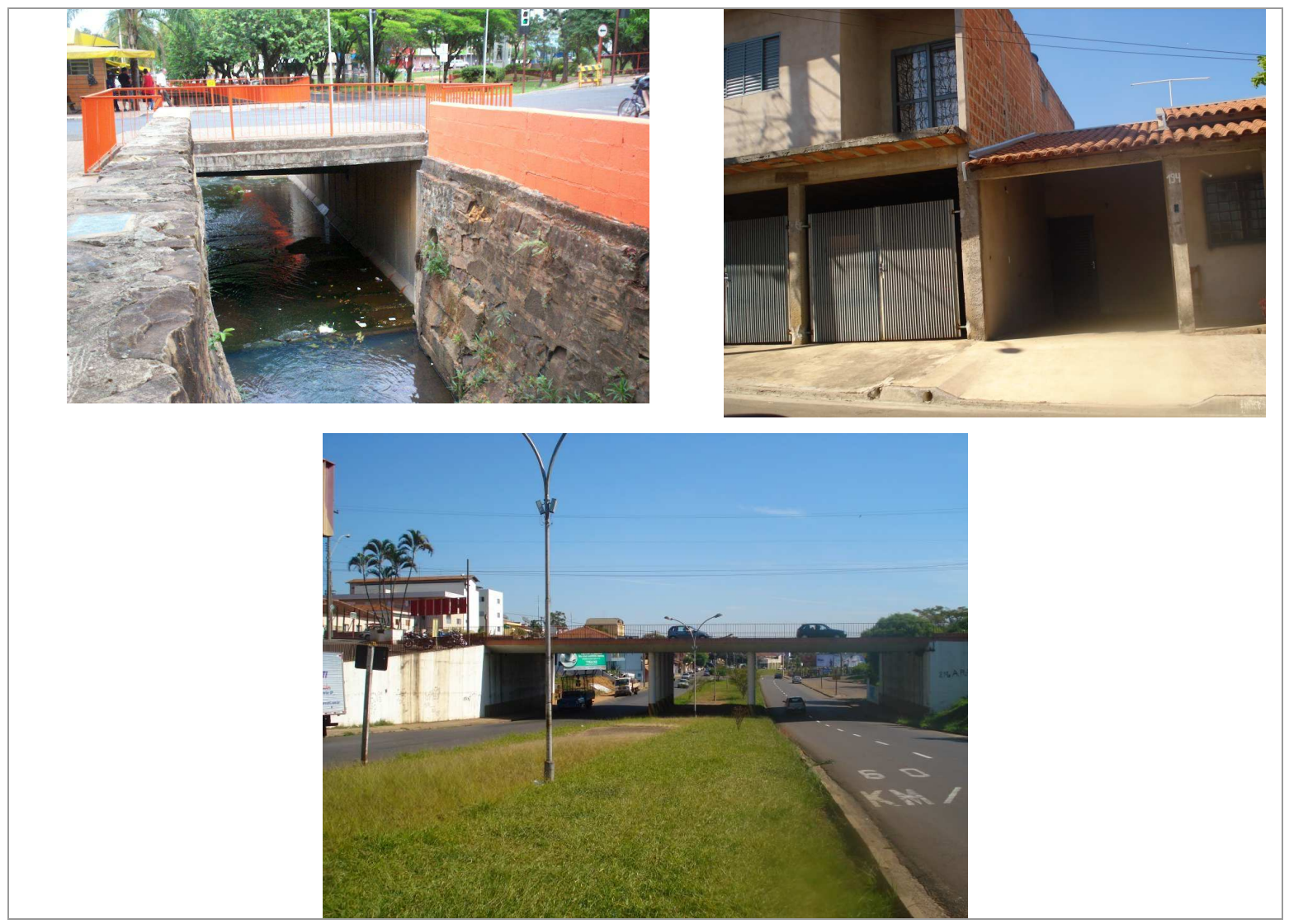




\section{Adapting Mosaic}

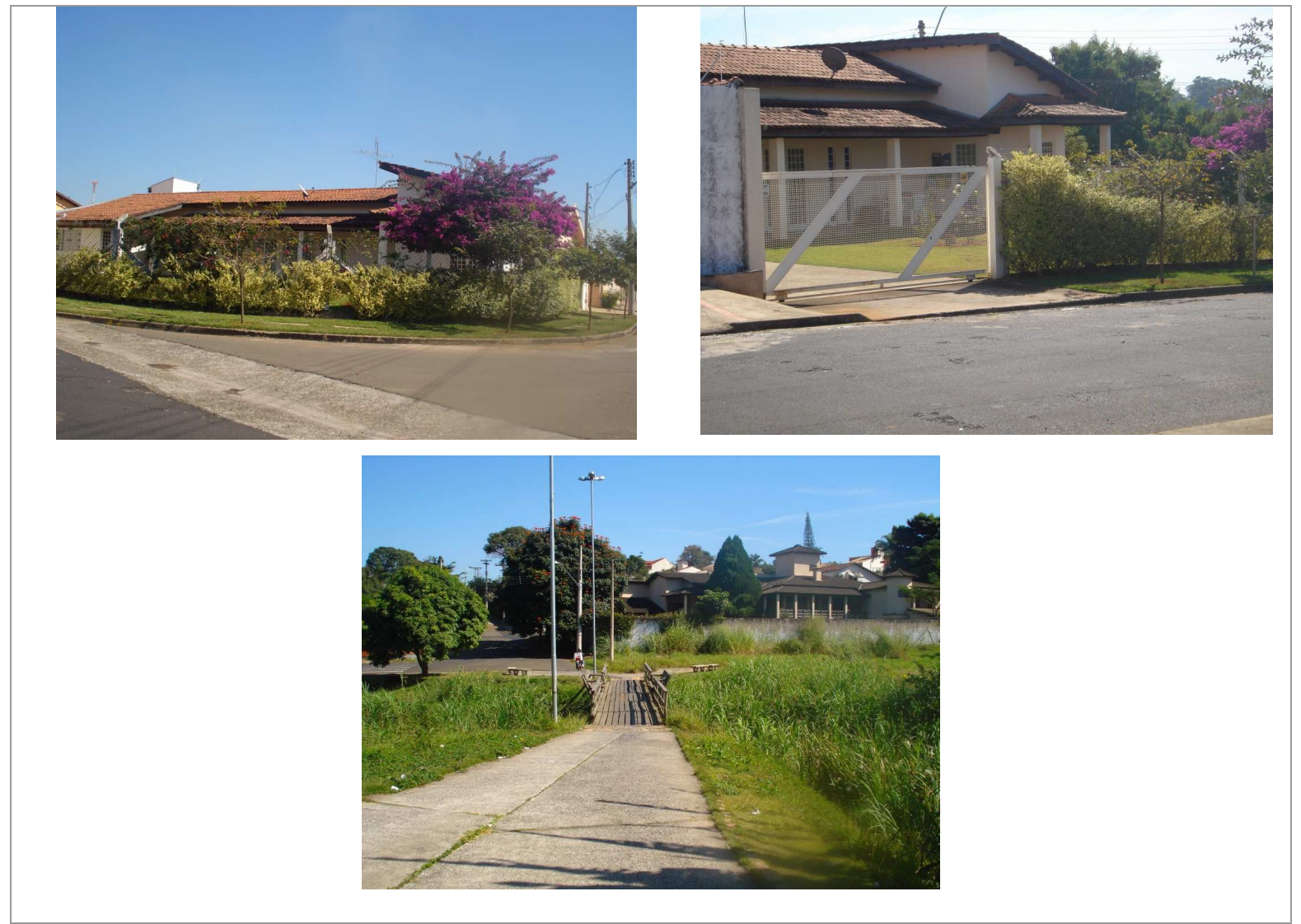

\section{Technogarden}
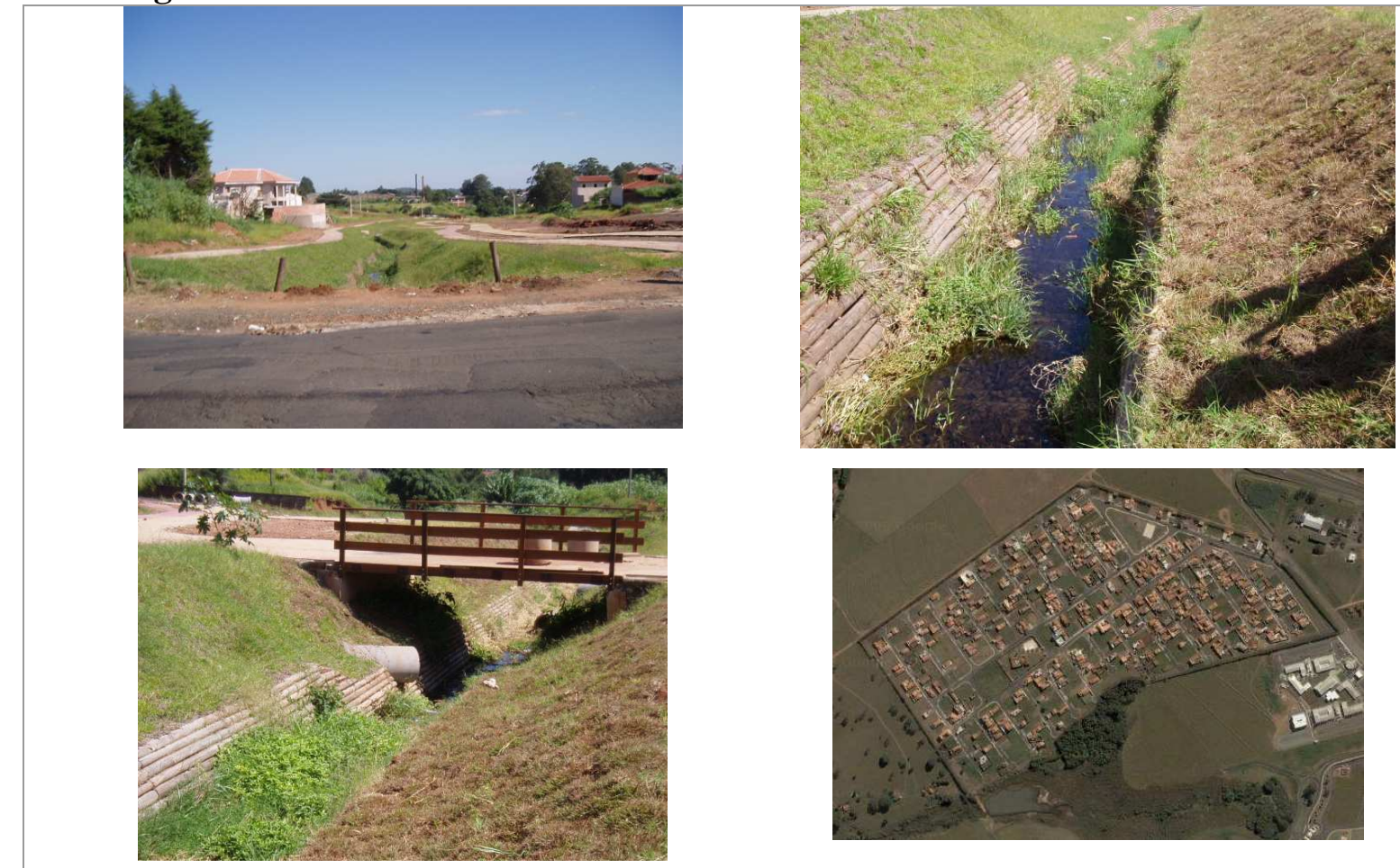
${ }^{1}$ PRONK e HAQ (1992). Desarrollo Sostenible, del concepto a la acción. El Informe de La Haya, UNESCO.

${ }^{2}$ GODET, M. (1993) - Manual de Prospectiva Estratégica: da antecipação à ação. Lisboa.

${ }^{3}$ MACROPLAN (2004) - Caderno de Exercício de Planejamento Estratégico. Rio de Janeiro.

${ }^{4}$ ROOKWOOD, D.M. (1958). Columbia Basin Stream Flow Routing by Computer, Journal of the Waterways and Harbor Division ASCE V.84 NWM-5.

${ }^{5}$ CRAWFORD, M.; LINSLEY, R. (1966). Digital Simulation in Hydrology. Technical Report n.39, Departamento f Civil Engineer, Starford University.

${ }^{6}$ JAMES, L.D. (1970). Hydrologic Modelling parameters estimation and watershed characteristics, Journal of Hydrology.

${ }^{7}$ CLABORN, B.J.: MOORE, W. (1970). Numerical Simulation in Watershed Hydrology. Hydraulic Engineering Lab. Technical Report HYDI4-7001, University of Texas.

${ }^{8}$ HARLEY, B.M.; PERKINS, F.E.; EAGLESON, P.S. (1970). A modular Distributed model of catchment dynamic, MIT, Technical Reprint n.133, December.

${ }^{9}$ U.S.Army (1973). HEC-1 Flood Hydrograph Package. Hydrologic Engineering Center Davis.

${ }^{10}$ CLARKE, R.T. (1973). Mathematical Models n Hydrology. Irrigation and Drainage Paper n.19 FAO. Roma.

${ }^{11}$ USACE (1990). U.S. Army Corps of Engineers. HEC-2 Water Surface Profiles User's Manual, Hydrologic Engineering Center, CPD-2 Davis, CA.

${ }^{12}$ HAESTAD METHODS (2003). PondPack User's Manual. Waterbury, Connecticut.

${ }^{13}$ DHI (2003). MIKE 11 - A Modelling Systems for Rivers and Channels. User Guide. DHI Water \& Environment, Software.

${ }^{14}$ MACHADO, E.S. (1981). Modelo Hidrológico Determinístico para Bacias Urbanas. Tese. EESCUSP, Departamento de Hidráulica e Saneamento. São Carlos. p286.

${ }^{15}$ JONES, S. B. (1981). Choice of space and time steps in the Muskingum-Cunge flood routing method. Proceedings Institution of Civil Engineers, v.71, n.2, p. 758-772.

${ }^{16}$ MILLER W. A., CUNGE, J. A. (1975). "Simplified equations of unsteady flow", cap. 8 de "Unsteady flow in open channelo", edit. MAHMOOD K e V.

${ }^{17}$ Sant'Anna Neto, J. L. (1995). As Chuvas no Estado de São Paulo: Contribuição ao Estudo da Variabilidade e Tendência da Pluviosidade na Perspectiva da Análise Geográfica. São Paulo. Tese apresentada ao departamento de Geografia/ FFLCH/ USP.

${ }^{18}$ SETZER, J. (1966). Atlas Climático e Ecológico do Estado de São Paulo. São Paulo: Comissão Internacional da Bacia do rio Paraná - Uruguai. 